Fort Bliss Standards for the Treatment of Historic Buildings

An Illustrated Maintenance and Repair Manual

Sunny Stone, Adam Smith, and Ryan Murphy

May 2008
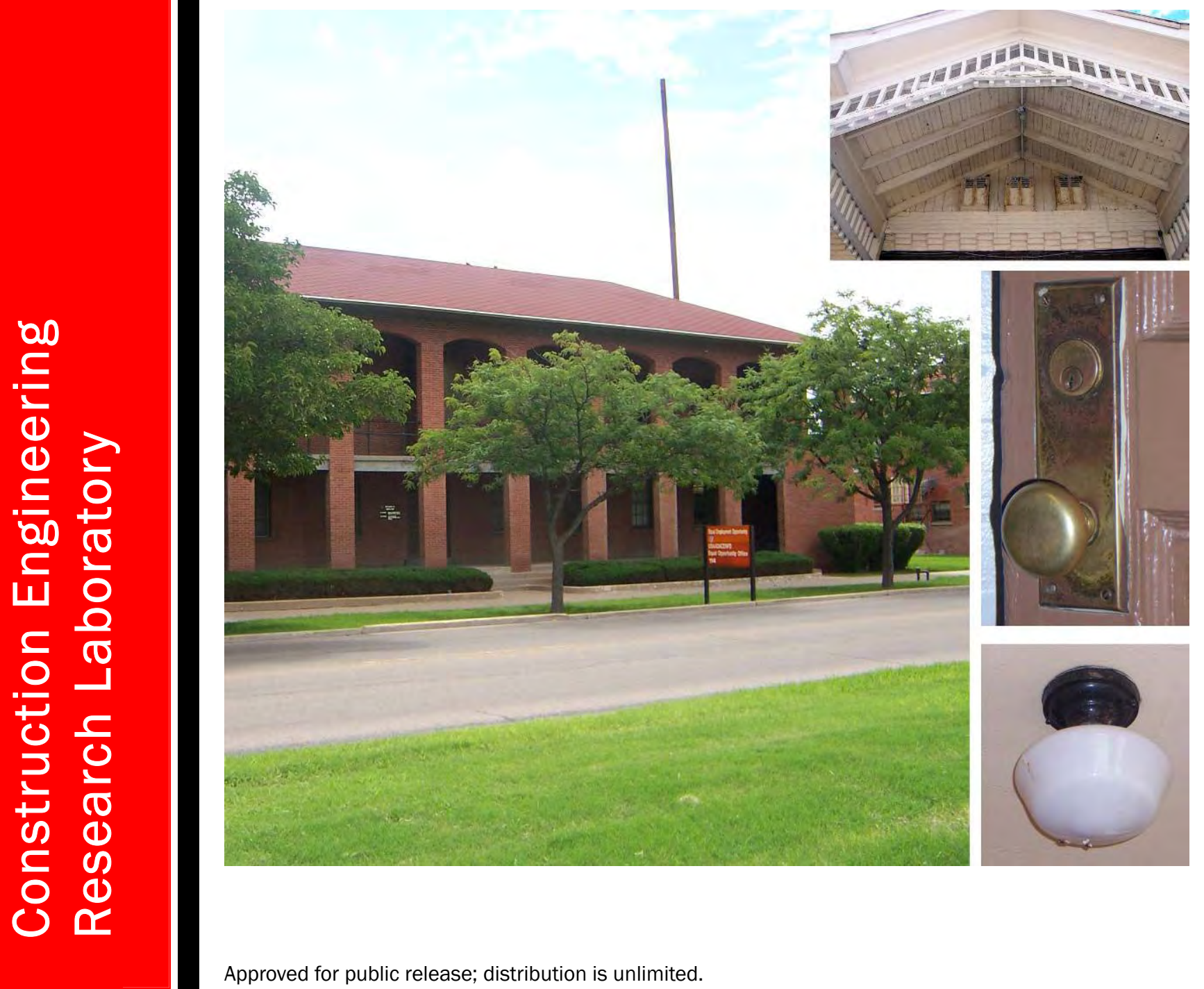
May 2008

\section{Fort Bliss Standards for the Treatment of Historic Buildings}

An Illustrated Maintenance and Repair Manual

Sunny Stone, Adam Smith, and Ryan Murphy

Construction Engineering Research Laboratory

U.S. Army Engineer Research and Development Center

P.O. Box 9005

Champaign, IL 61826-9005

Final report

Approved for public release; distribution is unlimited.

Prepared for Conservation Division

Directorate of Environment

Fort Bliss, Texas 79916 


\begin{abstract}
This report satisfies Section 110 of the National Historic Preservation Act (NHPA) of 1966 as amended and will help the Fort Bliss Cultural Resources Office and Directorate of Public Works in managing their historic building.
\end{abstract}

All buildings, especially historic ones, require regular planned maintenance and repair. The most notable cause of historic building element failure and/ or decay is not due to the fact that the historic building is old, but rather is caused by an incorrect or inappropriate repair and/ or basic neglect of the historic building fabric.

Maintaining historic buildings and keeping a log of completed repairs and maintenance can help in:

Reducing the cost of maintenance in the long run

Increasing the life of the building and its elements

The efficient use of the building and its elements

Safety and security

Compliance with Federal and DoD historic preservation regulations.

DISCLAIMER: The contents of this report are not to be used for advertising, publication, or promotional purposes. Citation of trade names does not constitute an official endorsement or approval of the use of such commercial products. All product names and trademarks cited are the property of their respective owners. The findings of this report are not to be construed as an official Department of the Army position unless so designated by other authorized documents. 


\section{Contents}

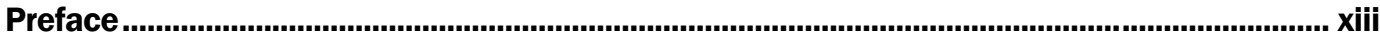

Unit Conversion Factors................................................................................................................

1 Maintenance Guides for Brick ....................................................................................................

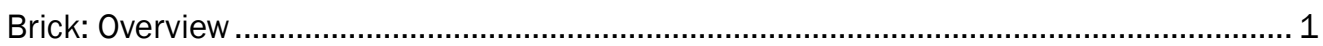

Identify, Retain, and Preserve .................................................................................... 1

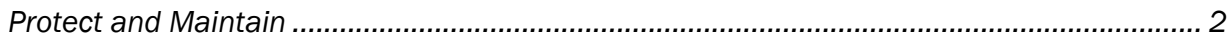

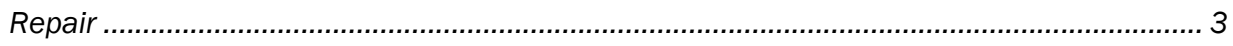

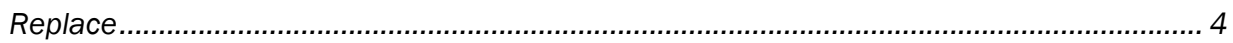

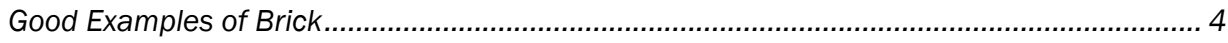

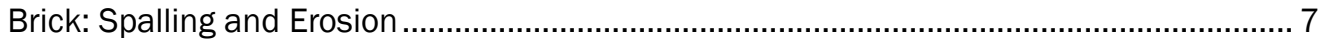

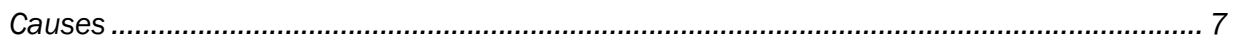

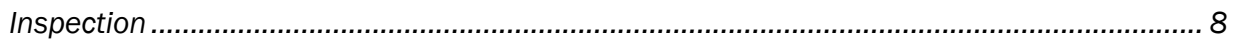

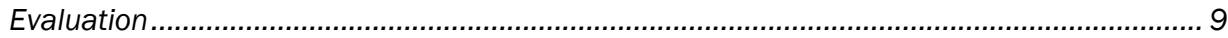

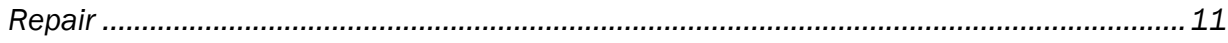

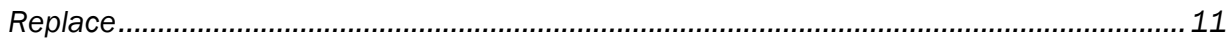

Brick: Cracking.................................................................................................... 13

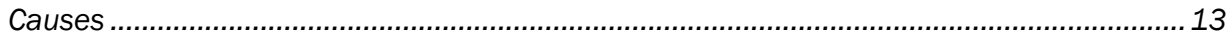

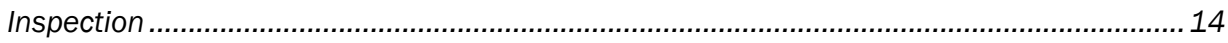

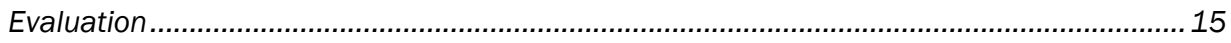

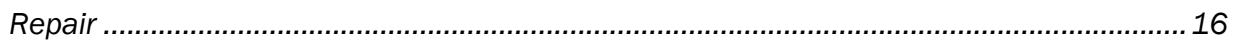

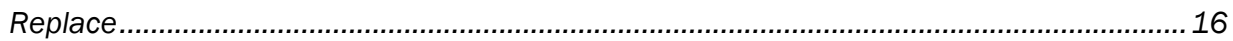

Brick: Mortar Deterioration ............................................................................................. 19

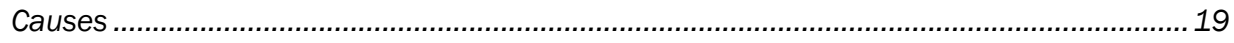

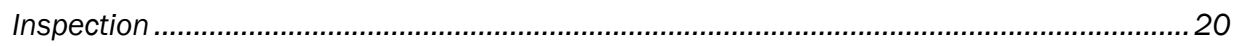

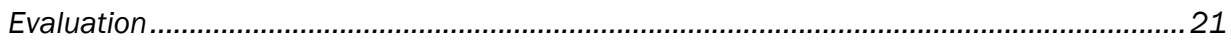

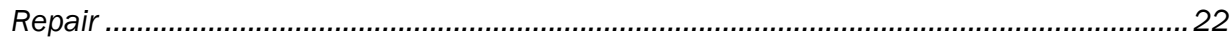

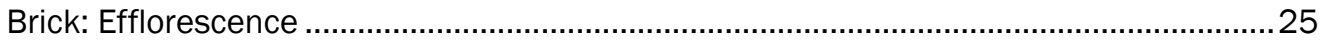

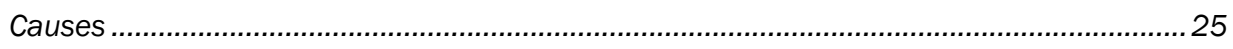

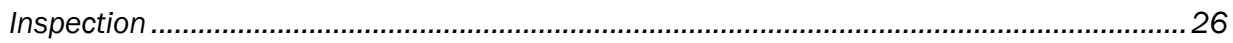

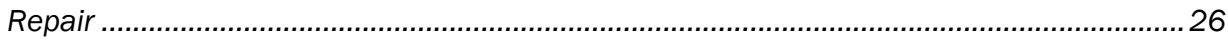

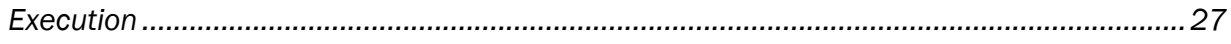

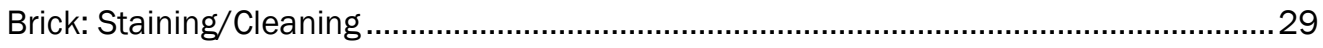

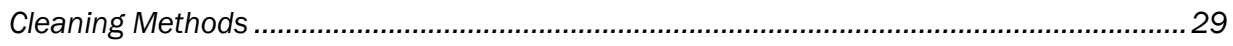

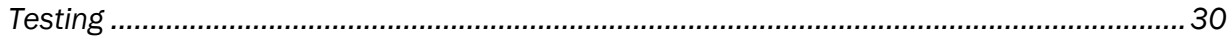

Environmental and Safety Considerations ................................................................... 30

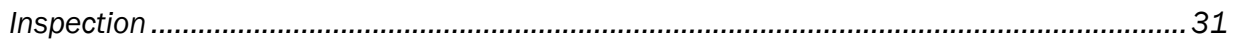

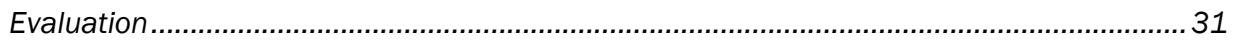

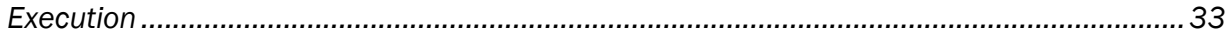

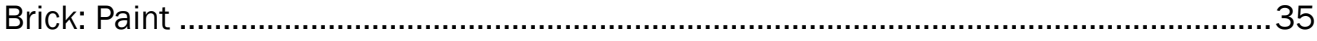

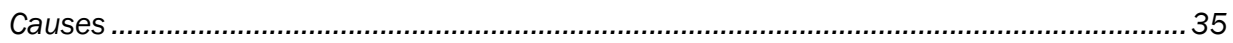


Inspection

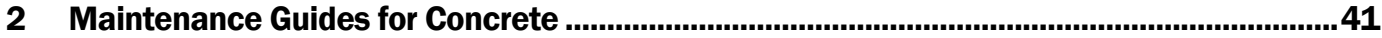

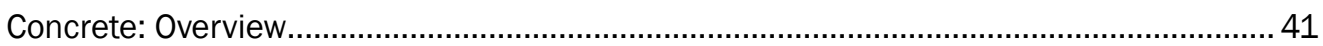

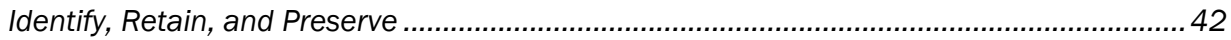

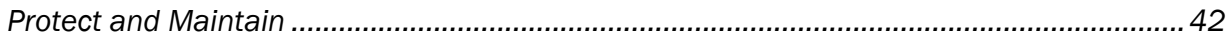

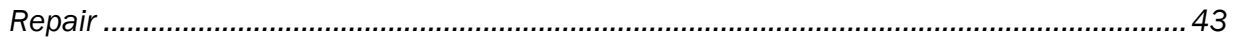

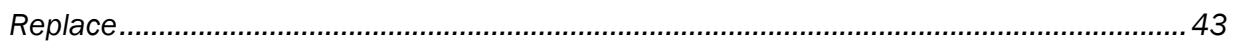

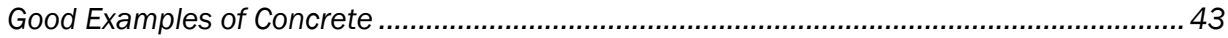

Concrete: Spalling/Corrosion/Erosion ..................................................................... 47

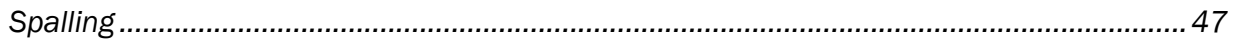

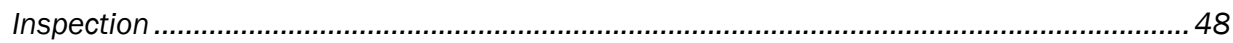

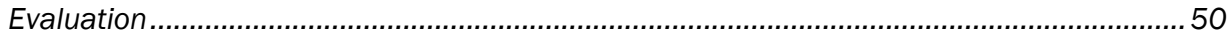

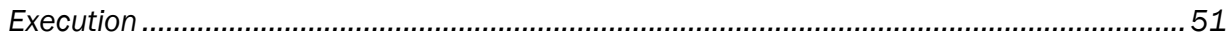

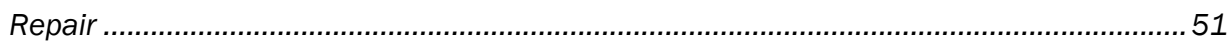

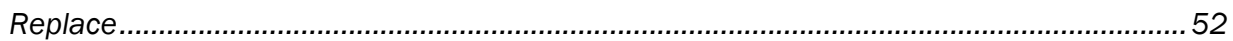

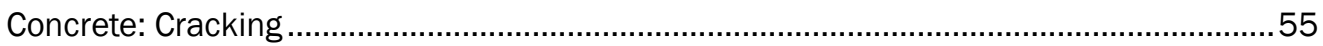

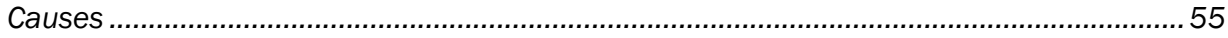

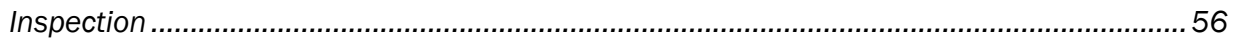

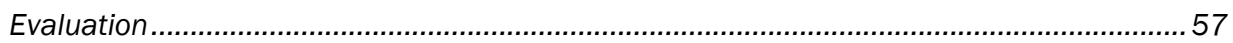

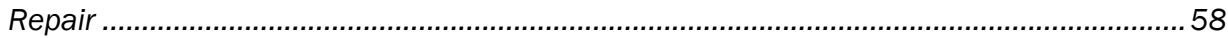

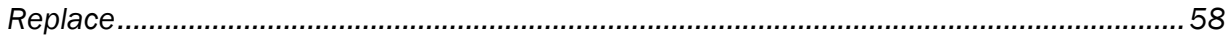

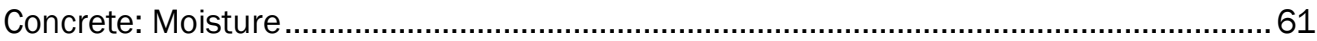

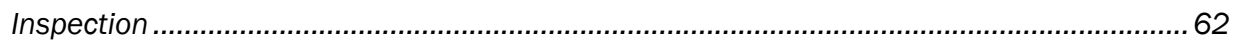

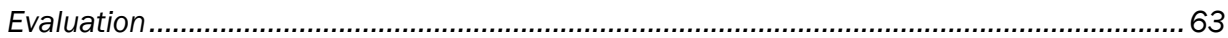

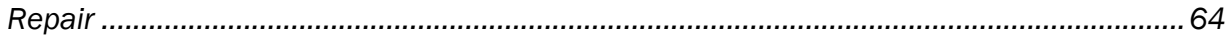

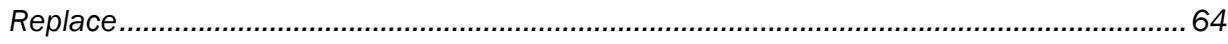

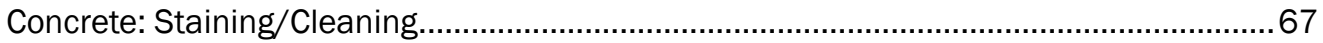

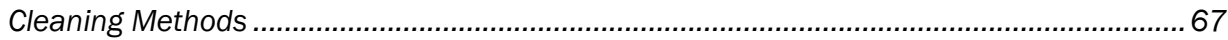

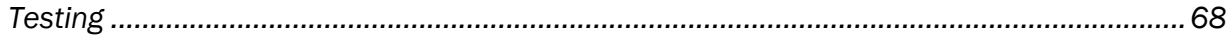

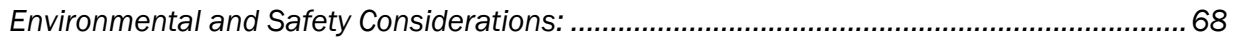

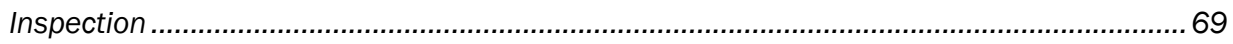

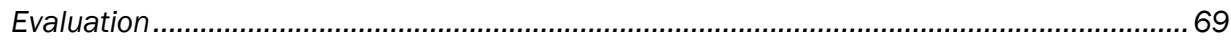

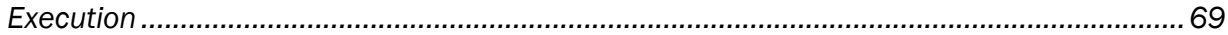

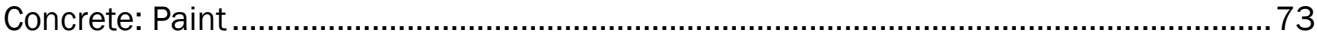

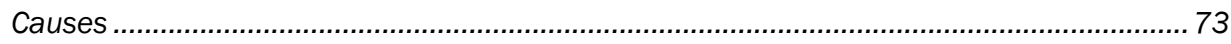

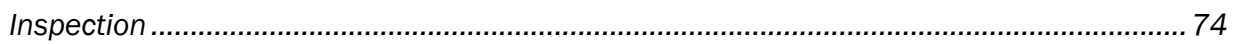

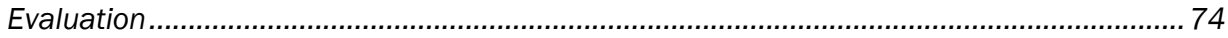

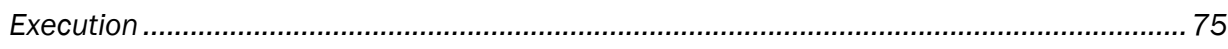

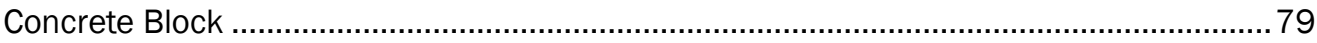

Natural or Inherent Problems................................................................................................ 79

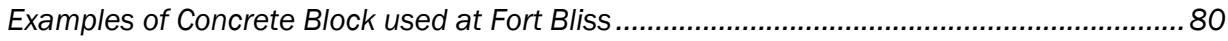

Current technique used on concrete block buildings at Fort Bliss....................................... 81 


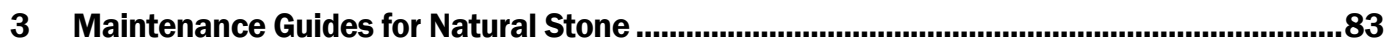

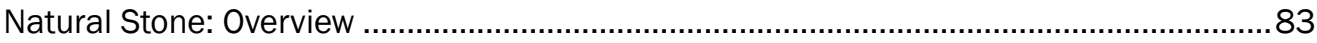

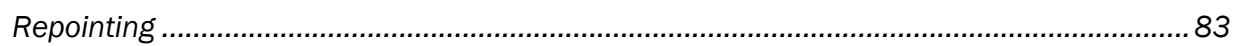

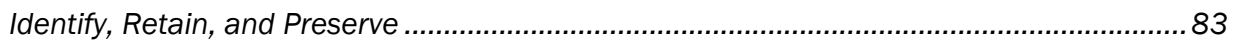

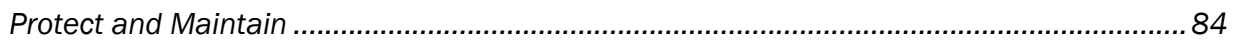

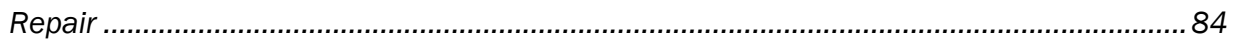

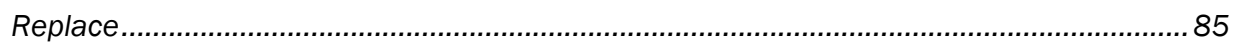

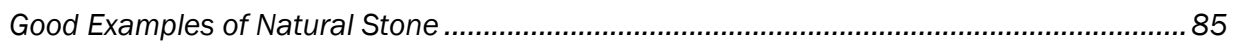

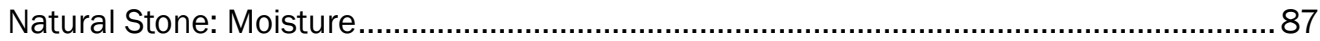

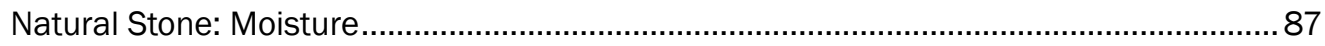

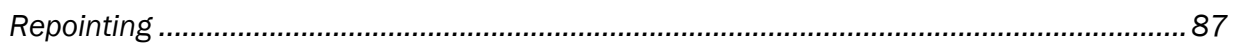

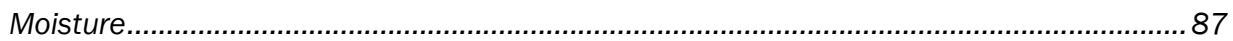

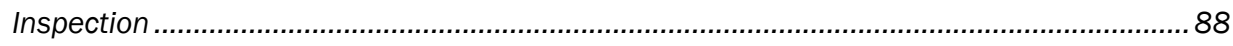

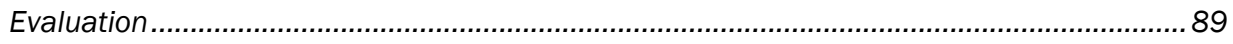

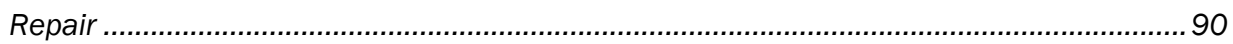

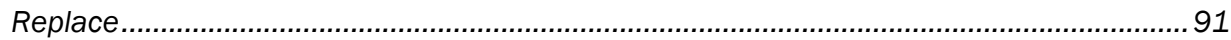

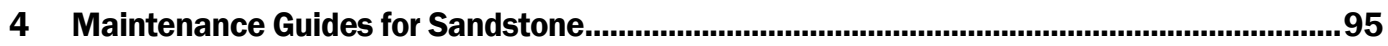

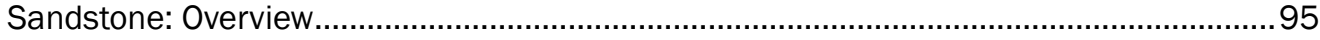

Natural or Inherent Problems........................................................................................... 95

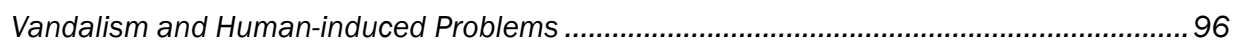

Typical historical uses for sandstone included ................................................................. 96

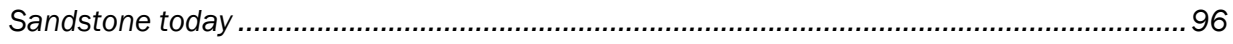

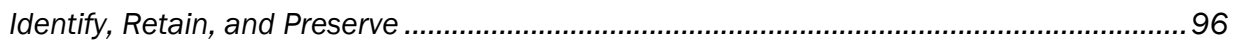

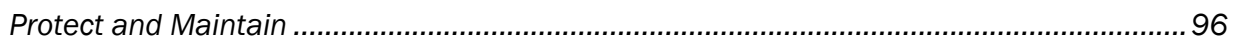

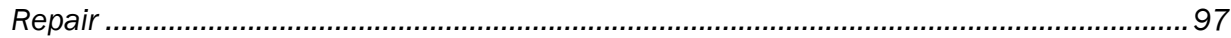

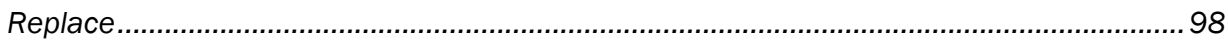

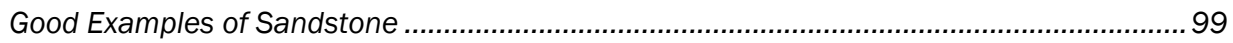

Sandstone: Moisture-Related Problems .................................................................. 101

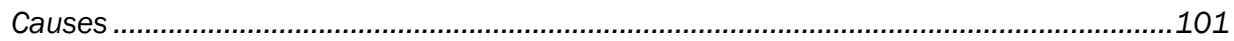

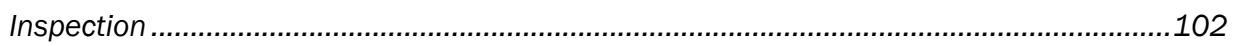

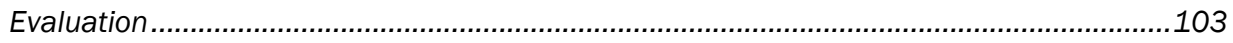

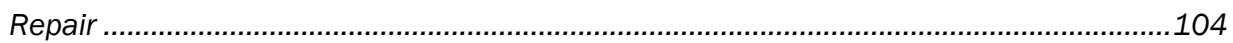

Sandstone: Weathering....................................................................................... 107

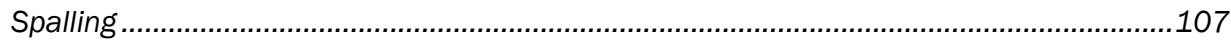

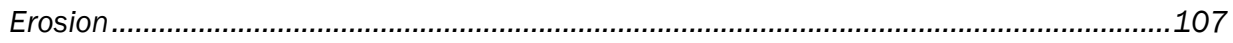

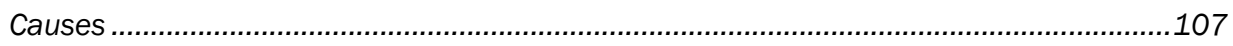

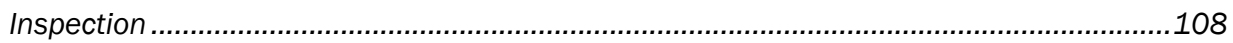

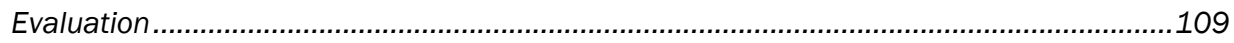

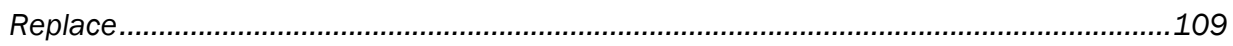

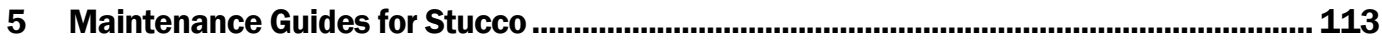

Stucco: Overview .................................................................................................... 113

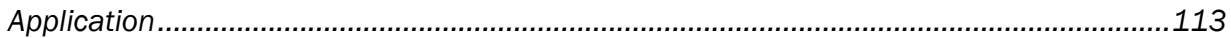

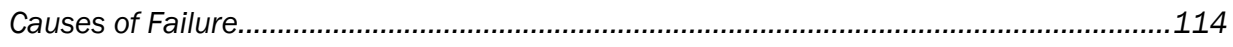

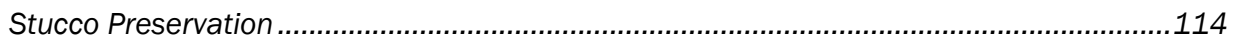


Identify, Retain, and Preserve ........................................................................................... 114

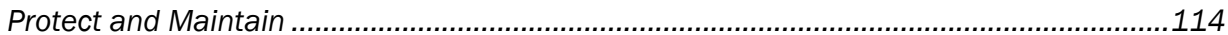

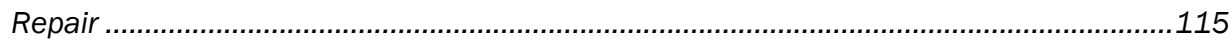

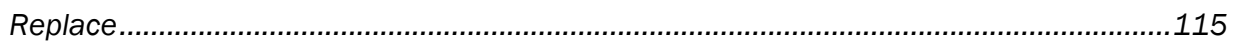

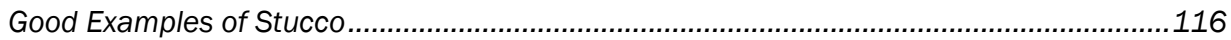

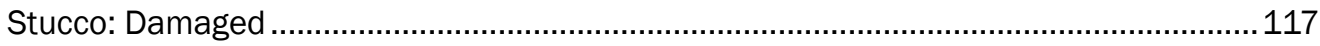

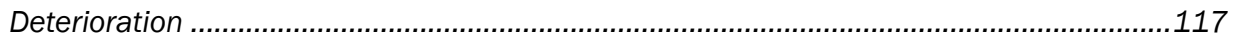

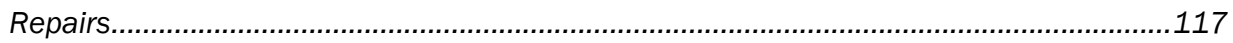

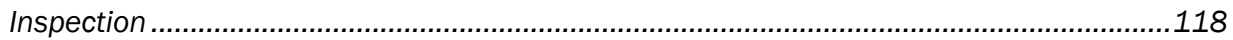

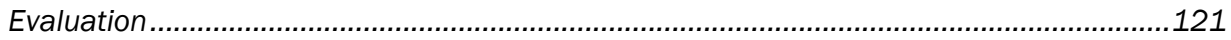

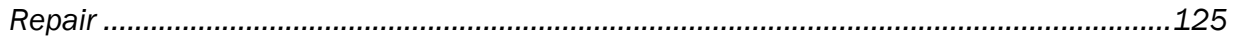

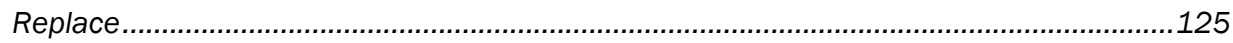

6 Maintenance Guides for Wood ..................................................................................... 129

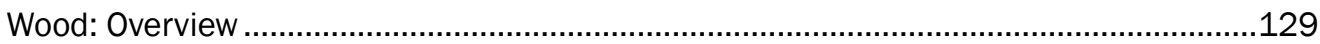

Identify, Retain, and Preserve ...................................................................................... 129

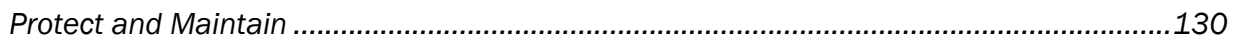

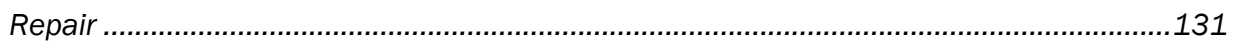

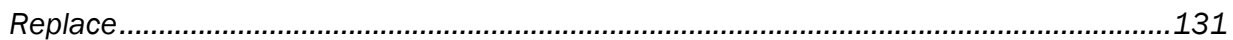

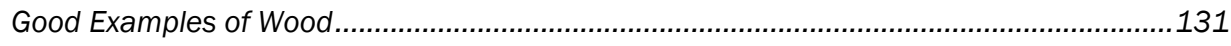

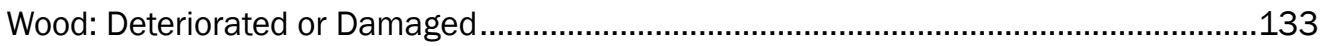

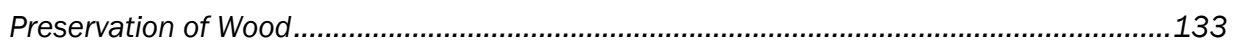

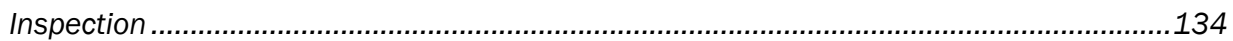

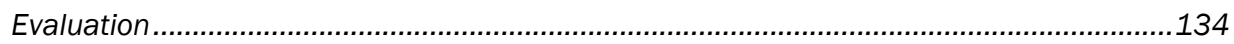

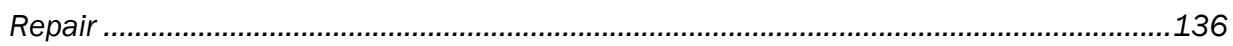

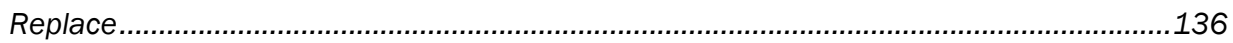

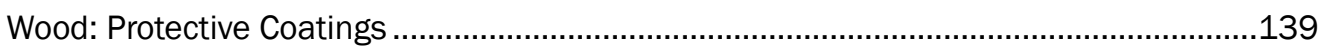

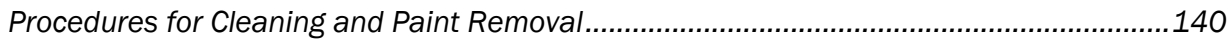

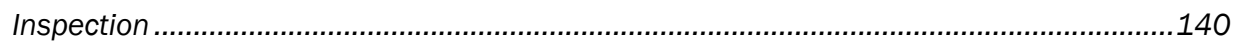

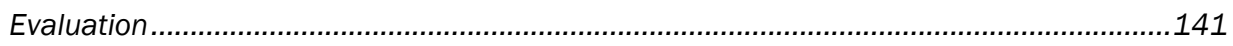

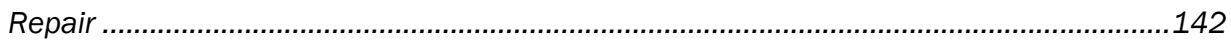

7 Maintenance Guides for Roofing.....................................................................................147

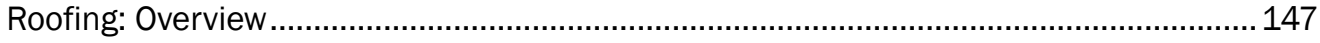

Preservation of Roofing Systems ............................................................................147

Identify, Retain, and Preserve .......................................................................................... 148

Protect and Maintain ....................................................................................................... 148

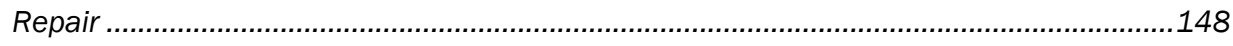

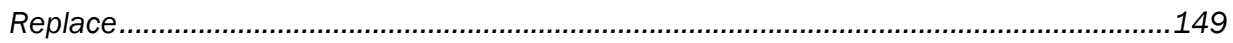

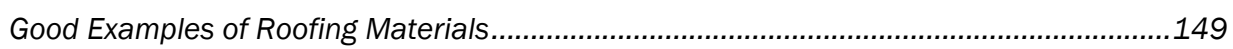

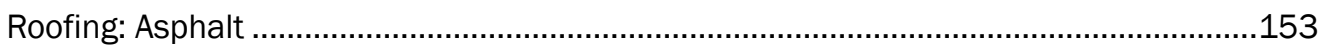

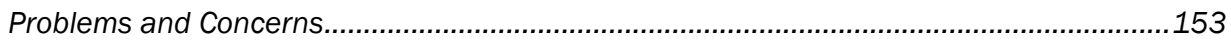

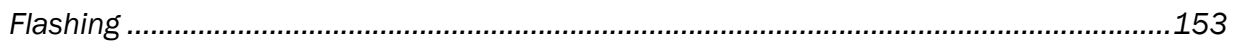

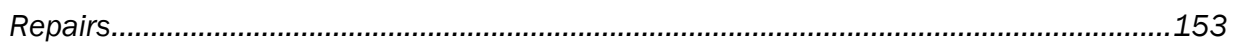

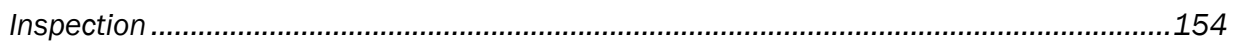

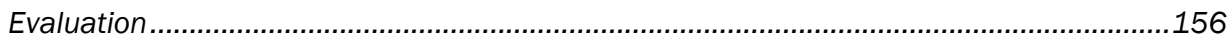




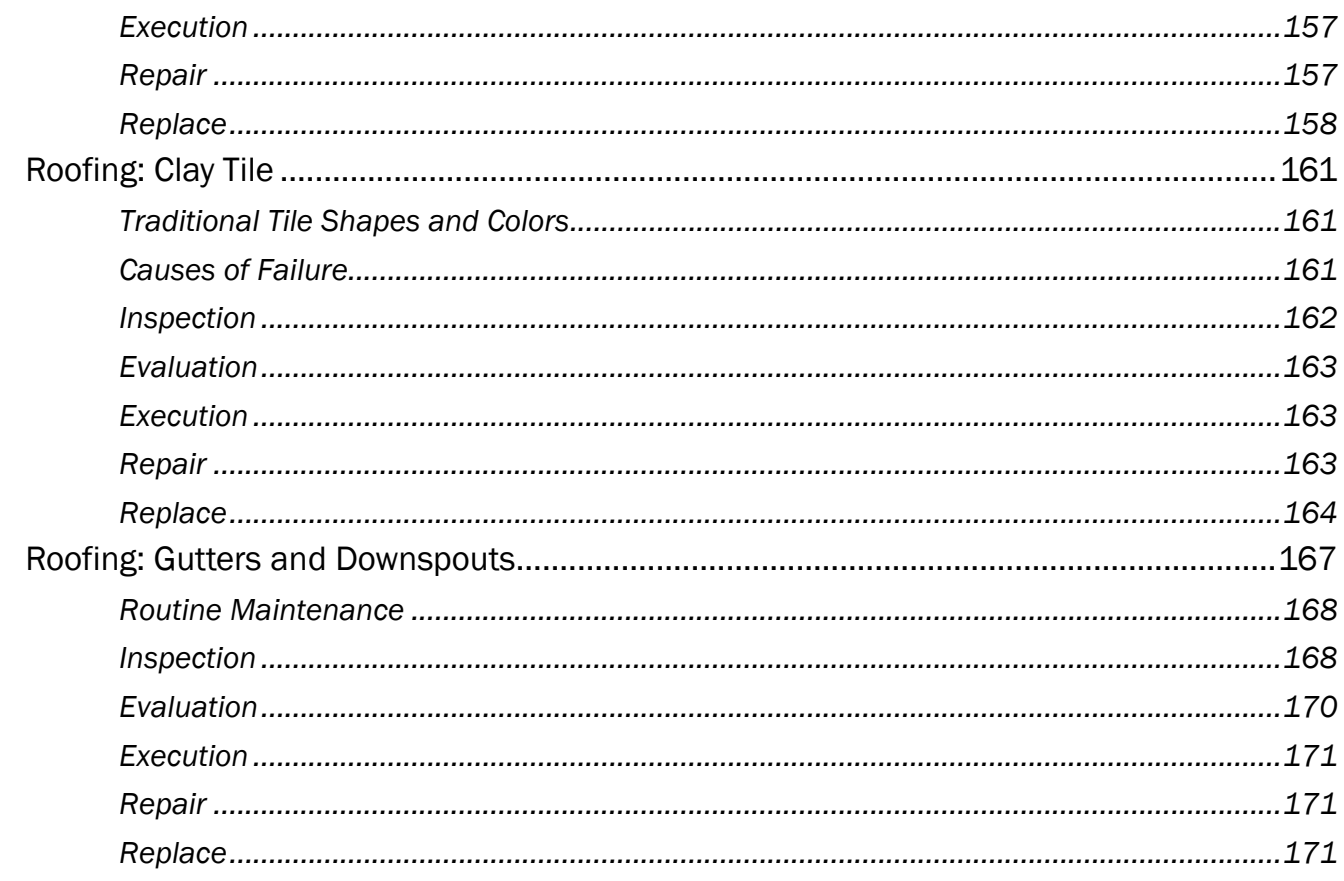

8 Maintenance Guides for Doors ........................................................................................175

Doors: Overview................................................................................................ 175

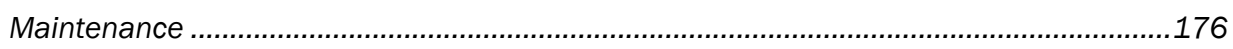

Identify, Retain, and Preserve .................................................................................176

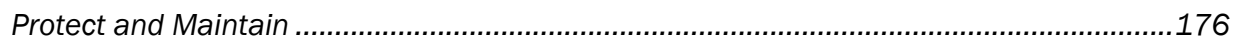

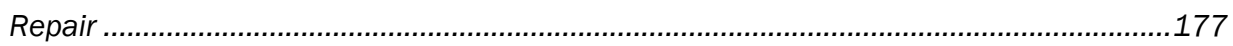

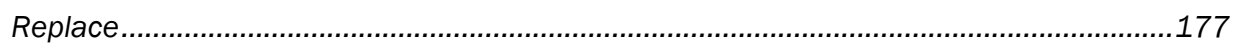

Good Examples of Exterior Doors.................................................................................. 178

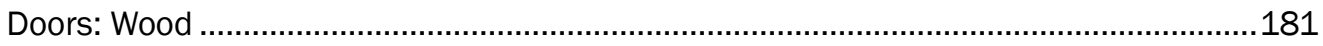

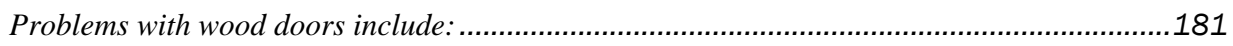

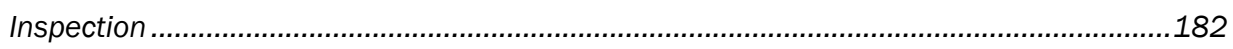

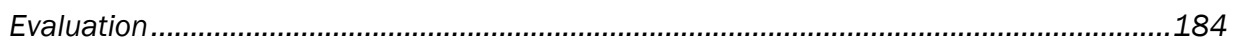

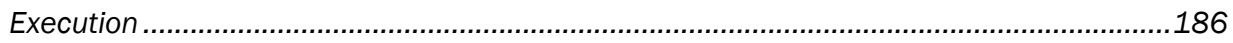

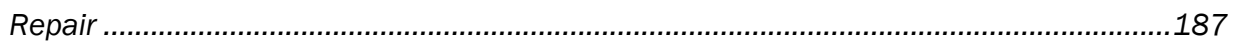

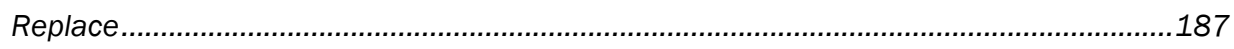

Doors: Metal ..................................................................................................... 193

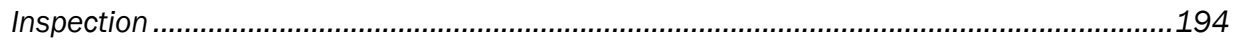

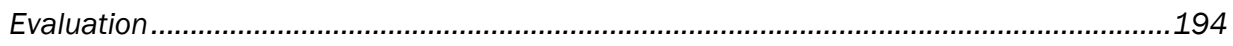

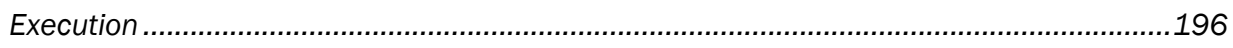

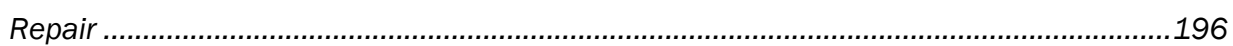

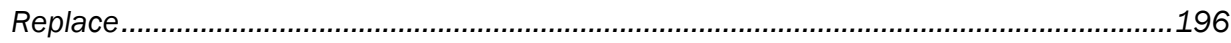

9 Maintenance Guides for Windows ................................................................................ 201

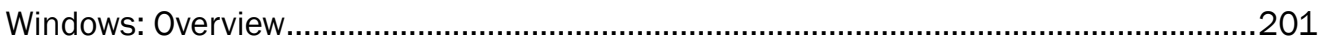

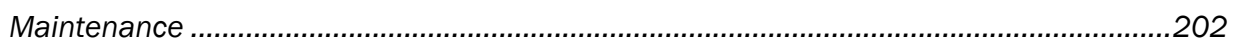

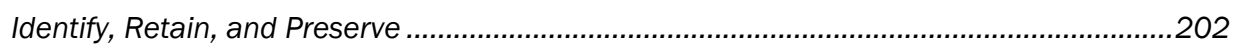

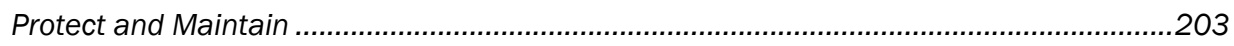




Repair
Replace Example of Windows

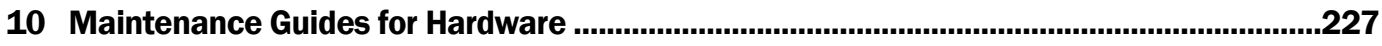

Hardware: Overview ................................................................................................... 227

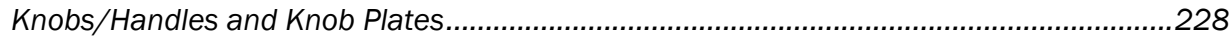

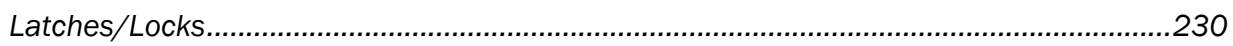

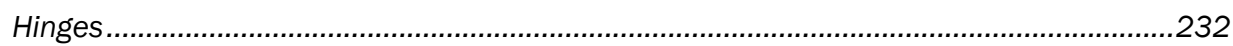

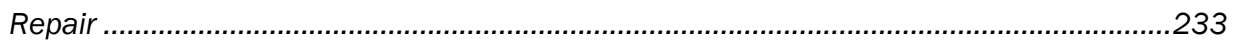

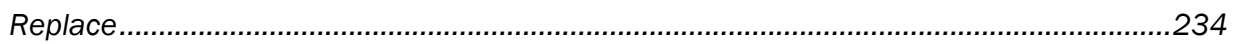

11 Maintenance Guides for Metal ............................................................................................ 241

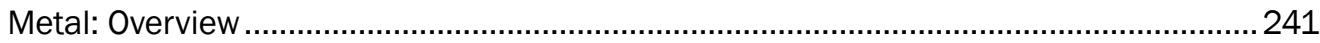

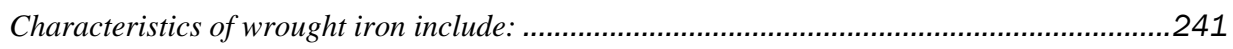

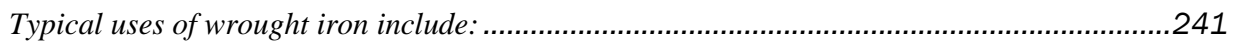

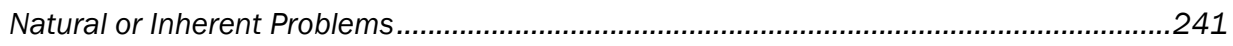

Vandalism or Human-Induced Problems .........................................................................242

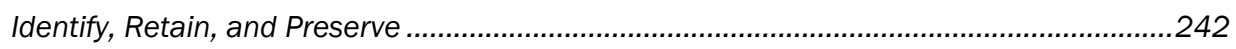

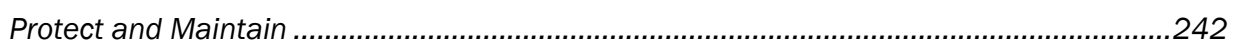

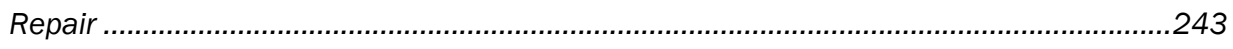

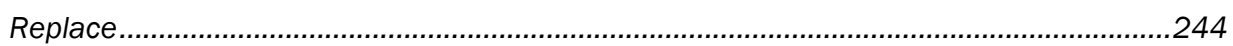

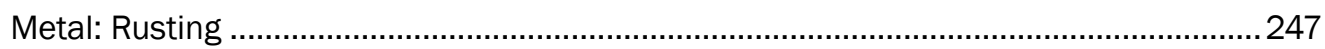

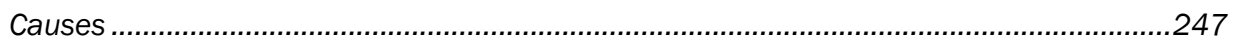

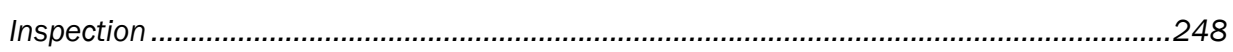

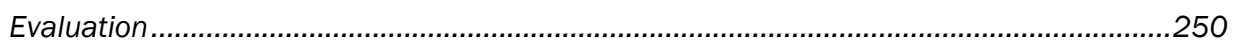

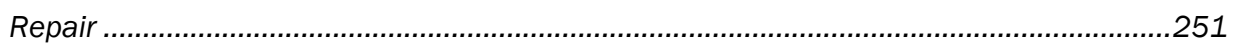

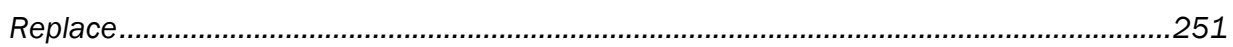

Metal: Protective Coatings ..............................................................................................25

Procedures for Cleaning and Paint Removal....................................................................25

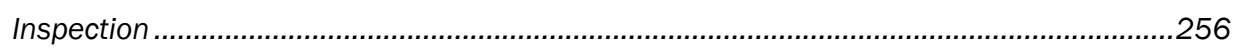

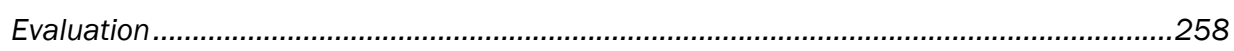

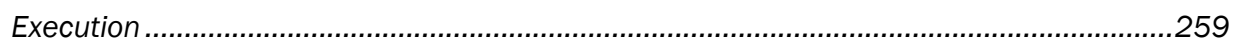




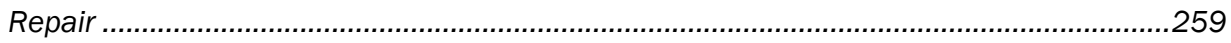

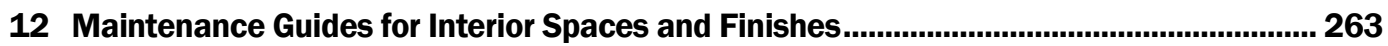

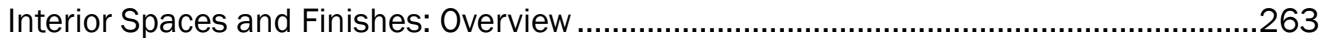

Identify and Evaluate the Importance of Interior Elements Prior to Rehabilitation .............263

Recommended Approaches for Rehabilitating Historic Interiors.........................................264

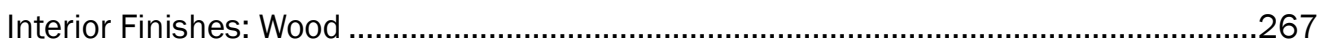

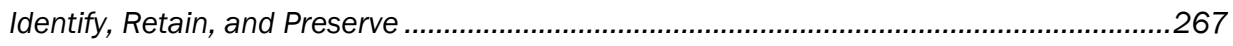

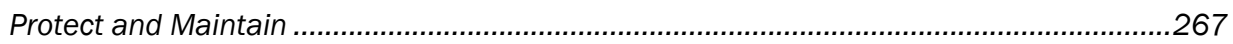

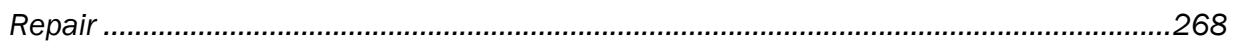

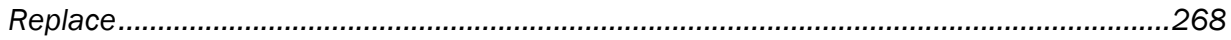

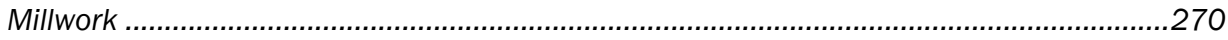

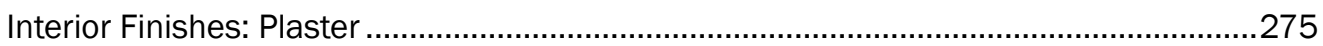

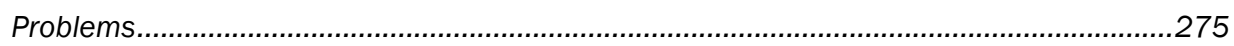

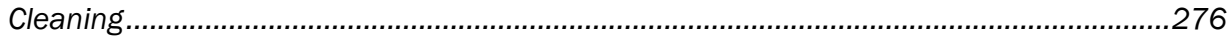

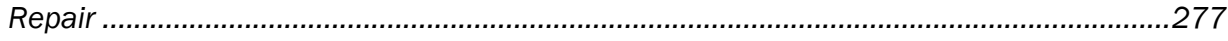

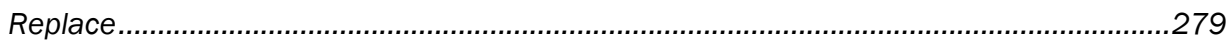

13 Maintenance Guides for Mechanical and Electrical Systems ...................................... 281

Mechanical and Electrical Systems: Overview ...........................................................281

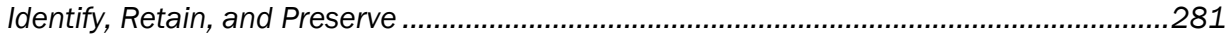

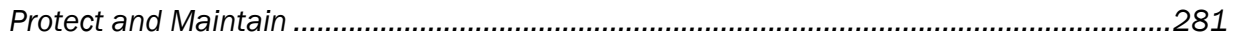

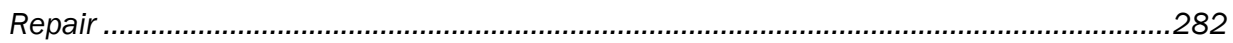

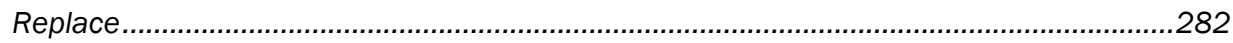

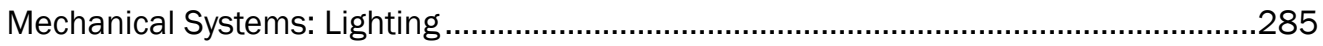

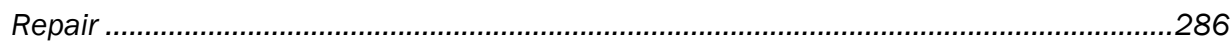

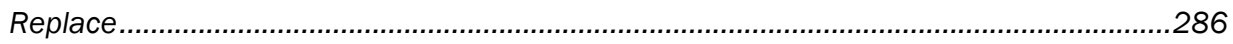

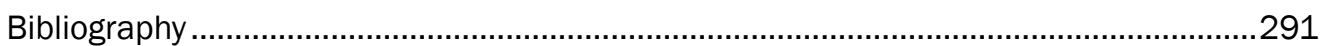

\section{Report Documentation Page}




\section{Preface}

This study was conducted for the U.S. Army Garrison Fort Bliss, Directorate of Environment, Conservation Division, Fort Bliss, Texas. Funding was provided by Military Interdepartmental Purchase Request 21/2020/ 220/ A/ MIPRF6090CM007/ PO, dated 31 March 2006. The Fort Bliss technical monitor was Hugo Gardea, Historical Architect.

The work was performed by the Land and Heritage Conservation Branch (CN-C) of the Installations Division (CN), Construction Engineering Research Laboratory (CERL). The CERL Project Manager was Adam Smith. Dr. Christopher White is Chief, CN-C, and Dr. J ohn T. Bandy is Chief, CN. The Deputy Director of CERL is Dr. Kirankumar V. Topudurti. The Director of CERL is Dr. Ilker R. Adiguzel.

CERL is an element of the U.S. Army Engineer Research and Development Center (ERDC), U.S. Army Corps of Engineers. The Commander and Executive Director of ERDC is COLJ ames R. Rowan and the Director of ERDC is Dr. James R. Houston. 


\section{Unit Conversion Factors}

\begin{tabular}{|l|c|l|}
\hline Multiply & By & To Obtain \\
\hline Acres & $4,046.873$ & square meters \\
\hline cubic feet & 0.02831685 & cubic meters \\
\hline cubic inches & $1.6387064 \mathrm{E}-05$ & cubic meters \\
\hline cubic yards & 0.7645549 & cubic meters \\
\hline feet & 0.3048 & meters \\
\hline hectares & $1.0 \mathrm{E}+04$ & square meters \\
\hline inches & 0.0254 & meters \\
\hline miles (U.S. statute) & $1,609.347$ & meters \\
\hline ounces (U.S. fluid) & $2.957353 \mathrm{E}-05$ & cubic meters \\
\hline pints (U.S. liquid) & $4.73176 \mathrm{E}-04$ & cubic meters \\
\hline pints (U.S. liquid) & 0.473176 & liters \\
\hline square feet & 0.09290304 & square meters \\
\hline square inches & $6.4516 \mathrm{E}-04$ & square meters \\
\hline square miles & $2.589998 \mathrm{E}+06$ & square meters \\
\hline yards & 0.9144 & meters \\
\hline
\end{tabular}




\section{Maintenance Guides for Brick}

\section{Brick: Overview}

Masonry is among the most durable of historic building materials, but it is also very susceptible to damage by improper maintenance or repair, and by harsh or abrasive cleaning methods. Problems that affect brick may be classified into two broad categories: 1) Natural or inherent problems based on the characteristics of the material and the conditions of the exposure, and 2) Vandalism and human-induced problems.

Typical historical and current uses for brick include:

- $\quad$ structural uses such as foundations, walls, and floors and/or

- $\quad$ decorative/ornamental uses, which may be cast to form moldings and other decorative features; may be carved; may be used in a variety of colors, textures, bonds, and joints and/or

- $\quad$ may be concealed by other finish materials such as stucco, plaster or paint, or may be exposed both on the interior and exterior.

All exposed masonry should be inspected for cracking, spalling, bowing (bulges vertically), sweeping (bulges horizontally), leaning, and mortar deterioration. It is important to know whether the walls are masonry or masonry cavity, or whether they are non-structural brick or stone veneer. The overall quality of the building's construction and often that of its neighbors is a good indicator of the condition of the masonry. Masonry features (such as brick cornices, door pediments, stone window architraves, brackets, and railings) as well as masonry surfaces (modeling, tooling, bonding pattern, joint size, and color) may be important in defining the historic character of the building.

\section{Identify, Retain, and Preserve}

Recommended...

- Identifying, retaining, and preserving masonry features that are important in defining the overall historic character of the building such as walls, brackets, railings, cornices, window architraves, door pediments, steps, and columns; and details such as tooling and bonding patterns, coatings, and color.

\section{Maintenance/ Management Guidelines for Brick}

- Cyclical maintenance has always been a key to successful brick building survival. As soon as rehabilitation or restoration has been completed, some program of continuing maintenance should be initiated. Changes in the building should particularly be noted. The early stages of cracking, bulging, or spalling in brick walls should be monitored regularly. All water damage should be noted and remedied at its earliest possible stages. Plant, animal, and insect damage should be halted before it becomes substantial. The roof should be inspected periodically. Surface coatings must be inspected frequently and repaired or replaced as the need indicates.

- According to The Secretary of the Interior's Standards for Rehabilitation, the proper procedure is to respect the significance of the original materials and features, repair and retain wherever possible, and replace them only when absolutely necessary.

- The following recommendations for care of the historic building are to be thoroughly read and understood before a treatment is specified. The Secretary of the Interior's Standards for Rehabilitation should also be consulted to determine the appropriateness of any treatment.

Full documentation can be found at http://www.cr.nps.gov/tps/tax/rhb/stand.htm.

Construction Documents \& Specifications: Preservation \& Rehabilitation of Historic Masonry, Fort Bliss Manual 
Not Recommended...

- Removing or radically changing masonry features that are important in defining the overall historic character of the building so that, as a result, the character is diminished.

- Replacing or rebuilding a major portion of exterior masonry walls that could be repaired so that, as a result, the building is no longer historic and is essentially new construction.

- Applying paint or other coatings such as stucco to masonry that has been historically unpainted or uncoated to create a new appearance.

- Removing paint from historically painted masonry.

- Radically changing the type of paint or coating or its color.

\section{Protect and Maintain}

Recommended...

- Protecting and maintaining masonry by providing proper drainage so that water does not stand on flat, horizontal surfaces or accumulate in curved decorative features.

- Cleaning masonry only when necessary to halt deterioration or remove heavy soiling.

- Carrying out masonry surface cleaning tests after it has been determined that such cleaning is appropriate. Tests should be observed over a sufficient period so that both the immediate and the long range effects are known to enable selection of the gentlest method possible.

- Cleaning masonry surfaces with the gentlest method possible, such as low pressure water and detergents, using natural bristle brushes.

- Inspecting painted masonry surfaces to determine whether repainting is necessary.

- Removing damaged or deteriorated paint only to the next sound layer using the gentlest method possible (e.g., hand-scraping) prior to repainting.

- Applying compatible paint coating systems following proper surface preparation.

- Repainting with colors that are historically appropriate to the building and district.

- Evaluating the overall condition of the masonry to determine whether more than protection and maintenance are required, that is, if repairs to the masonry features will be necessary.

Not Recommended...

- Failing to evaluate and treat the various causes of mortar joint deterioration such as leaking roofs or gutters, differential settlement of the building, capillary action, or extreme weather exposure.

- Cleaning masonry surfaces when they are not heavily soiled to create a new appearance, thus needlessly introducing chemicals or moisture into historic materials.

- Cleaning masonry surfaces without testing or without sufficient time for the testing results to be of value.

- Sandblasting brick or stone surfaces using dry or wet grit or other abrasives. These methods of cleaning permanently erode the surface of the material and accelerate deterioration.

- Using a cleaning method that involves water or liquid chemical solutions when there is any possibility of freezing temperatures.

- Cleaning with chemical products that will damage masonry, such as using acid on limestone or marble, or leaving chemicals on masonry surfaces. 
- Applying high-pressure water cleaning methods that will damage historic masonry and mortar joints.

- Removing paint that is firmly adhering to, and thus protecting, masonry surfaces.

- Using methods of removing paint that are destructive to masonry, such as sandblasting, application of caustic solutions, or high pressure water blasting.

- Failing to follow manufacturers' product and application instructions when repainting masonry.

- Using new paint colors that are inappropriate to the historic building and district.

- Failing to undertake adequate measures to assure the protection of masonry features.

\section{Repair}

Recommended...

- Repairing masonry walls and other masonry features by repointing the mortar joints where there is evidence of deterioration such as disintegrating mortar, cracks in mortar joints, loose bricks, damp walls, or damaged plasterwork.

- Removing deteriorated mortar by carefully hand raking the joints to avoid damaging the masonry.

- Duplicating old mortar in strength, composition, color, and texture.

- Duplicating old mortar joints in width and in joint profile.

- Repairing masonry features by patching, piecing-in, or consolidating the masonry using recognized preservation methods. Repair may also include the limited replacement inkind —or with compatible substitute material—of those extensively deteriorated or missing parts of masonry features when there are surviving prototypes such as terra cotta brackets or stone balusters.

- Applying new or non-historic surface treatments such as water-repellent coatings to masonry only after repointing and only if masonry repairs have failed to arrest water penetration problems.

Not Recommended...

- Removing non-deteriorated mortar from sound joints, and then repointing the entire building to achieve a uniform appearance.

- Using electric saws and hammers rather than hand tools to remove deteriorated mortar from joints prior to repointing.

- Repointing with mortar of high Portland cement content (unless it is the content of the historic mortar). This can often create a bond that is stronger than the historic material and can cause damage as a result of the differing coefficient of expansion and the differing porosity of the material and the mortar.

- Repointing with a synthetic caulking compound.

- $\quad$ Using a "scrub" coating technique to repoint instead of traditional repointing methods.

- Changing the width or joint profile when repointing.

- Using a substitute material for the replacement part that does not convey the visual appearance of the surviving parts of the masonry feature or that is physically or chemically incompatible.

- Applying waterproof, water repellent, or non-historic coatings such as stucco to masonry as a substitute for repointing and masonry repairs. Coatings are frequently unnecessary, 
expensive, and may change the appearance of historic masonry as well as accelerate its deterioration.

\section{Replace}

Recommended...

- Replacing in-kind an entire masonry feature that is too deteriorated to repair-if the overall form and detailing are still evident-using the physical evidence as a model to reproduce the feature. Examples can include large sections of a wall, a cornice, balustrade, column, or stairway. If using the same kind of material is not technically or economically feasible, then a compatible substitute material may be considered.

Not Recommended...

- Removing a masonry feature that is unrepairable and not replacing it; or replacing it with a new feature that does not convey the same visual appearance.

\section{Good Examples of Brick}

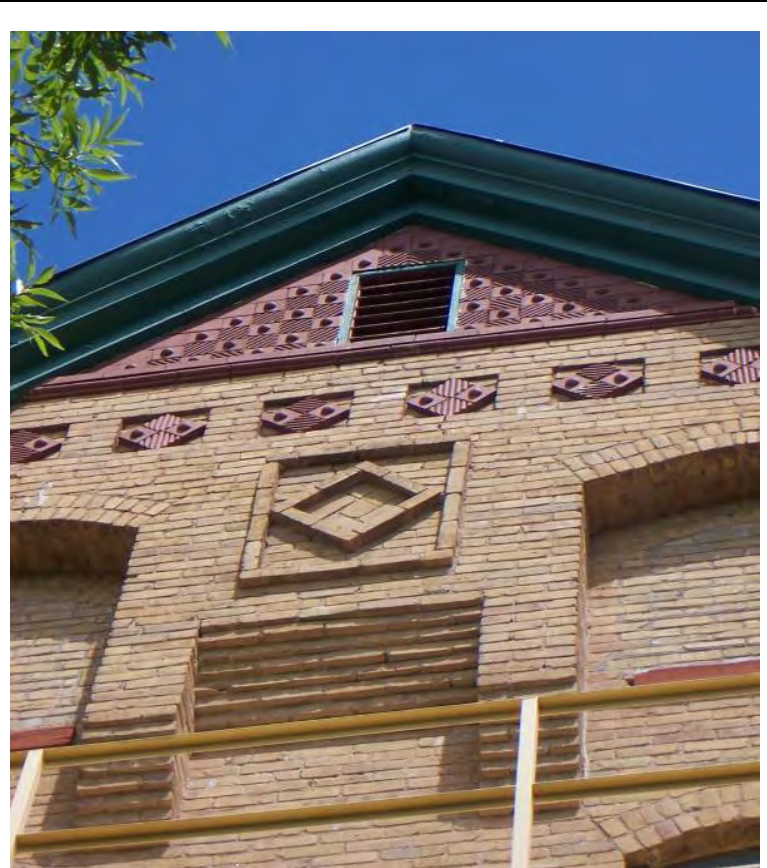

Building 13 - Decorative brick on a building should be protected and maintained by following proper Secretary of Interior Standards guidelines.

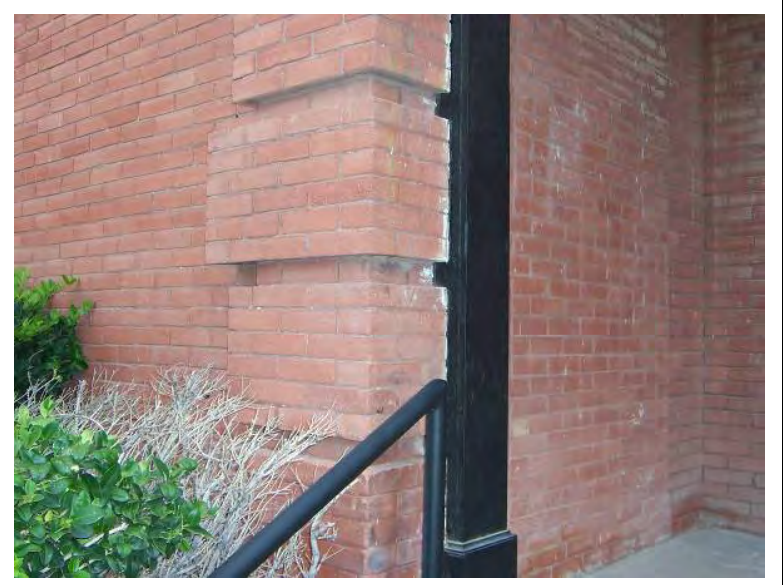

Building 51 - The brick and mortar should be maintained and connections between brick and other building materials should be inspected. Here is an example of a connection between brick and wood. 


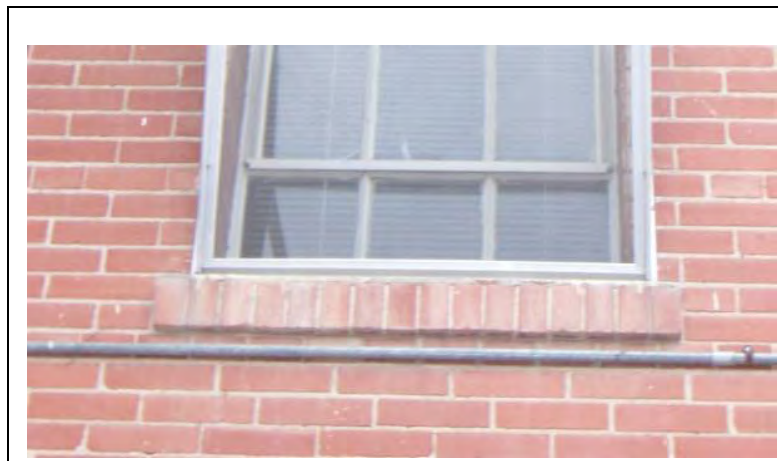

Building 54 - Make sure that water does not stand on brick surfaces like a windowsill.

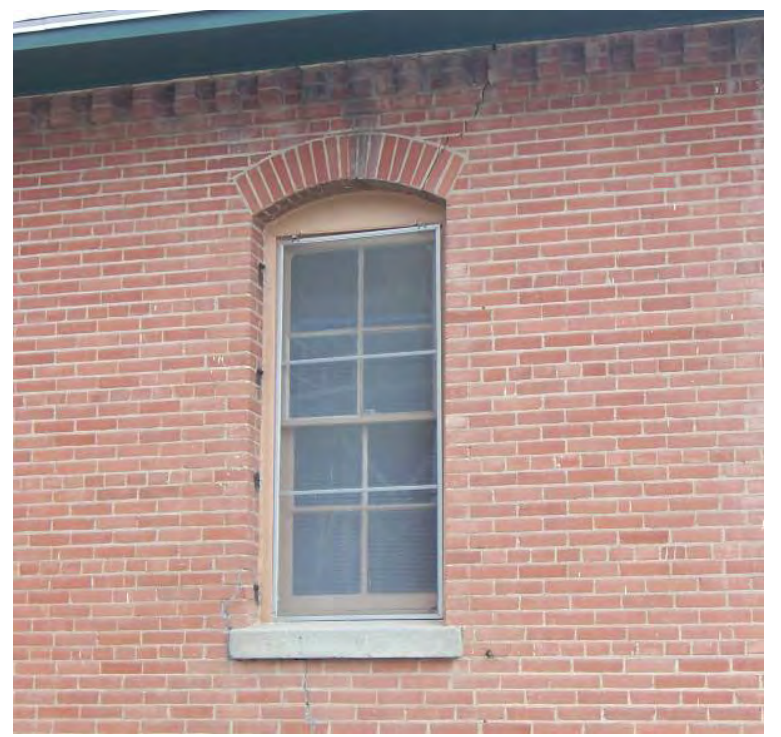

Building 55 - Evaluate the overall condition of all brick features including windowsills, walls, lintels, and details. 


\section{Brick: Spalling and Erosion}

\section{Spalling}

All exposed masonry should be inspected for spalling. The spalling, dusting, or flaking of brick masonry units may be due to either mechanical or chemical damage. Mechanical damage is caused by moisture entering the brick and freezing. The expansion of the ice will break off the brick's face if the brick has not been fired at a high enough temperature, resulting in spalling of the brick's outer layers. Spalling may continue or may stop of its own accord after the outer layers that trapped the interior moisture have broken off. Chemical damage is due to the leaching of chemicals from the ground into the brick, resulting in internal deterioration. External signs of such deterioration are a dusting or flaking of the brick. The loss of the surface material may vary in size. Spalling can also result from cracked and open mortar joints between the bricks.

Very little can be done to correct existing mechanical and chemical damage except to replace the brick. Mechanical deterioration can be slowed or stopped by directing water away from the masonry surface and by pointing mortar joints to slow water entry into the wall. Surface sealants (damp proofing coatings) are rarely effective and may hasten deterioration by trapping moisture or soluble salts that inevitably penetrate the wall and in turn cause further spalling. Chemical deterioration can be slowed or stopped by adding a damp proof course (or injecting a damp proofing material) into the brick wall just above the ground line. Consult a masonry specialist for this type of repair.

\section{Erosion}

Erosion is the weathering of the brick surface by wind, rain, and salt air. Erosion can also be caused by inadequate drainage of water. Rainwater that has accumulated at the base of brick walls should be diverted away from the building. This may be done by regrading or by building gravel-filled trenches or stone drip gutters. Regrading is perhaps the best solution because defective gutters and trenches may in effect collect and hold water at the base of the wall or foundation.

\section{Causes}

- $\quad$ Another common problem in the El Paso area and especially at Fort Bliss is the inappropriate placement of window air conditioning units and evaporative coolers. Due to the dry 
climate of the southwest, evaporative coolers are used in abundance as an efficient and effective machine to cool structures. However, the water supply used to cool the structures ultimately poses a problem for the structures' building materials, such as brick. Many of these evaporative coolers penetrate an exterior wall or are located on the structure's roof. The water that circulates through the cooler is constantly dripping onto building surfaces.

- $\quad$ Bricks located near the foundation of a structure are susceptible to spalling. Water that is not properly drained away from the structure causes deterioration of both the brick and the mortar. El Paso is known for its summer rain showers, which produce an ample amount of rainfall in a short period of time. If gutters are not properly installed or if rainwater is continually bouncing off of the ground surface back onto the face of the brick and mortar located at the base of the wall, mortar deterioration will continually progress.

\section{Inspection}

Recommended...

- $\quad$ Identifying, retaining, and preserving masonry features that are important in defining the overall historic character of the building such as walls, brackets, railings, cornices, window architraves, door pediments, steps, and columns; and joint and unit size, tooling and bonding patterns, coatings, and color.

Not Recommended...

- $\quad$ Removing or radically changing masonry features that are important in defining the overall historic character of the building so that, as a result, the character is diminished.

- $\quad$ Replacing or rebuilding a major portion of exterior masonry walls that could be repaired so that, as a result, the building is no longer historic and is essentially new construction.

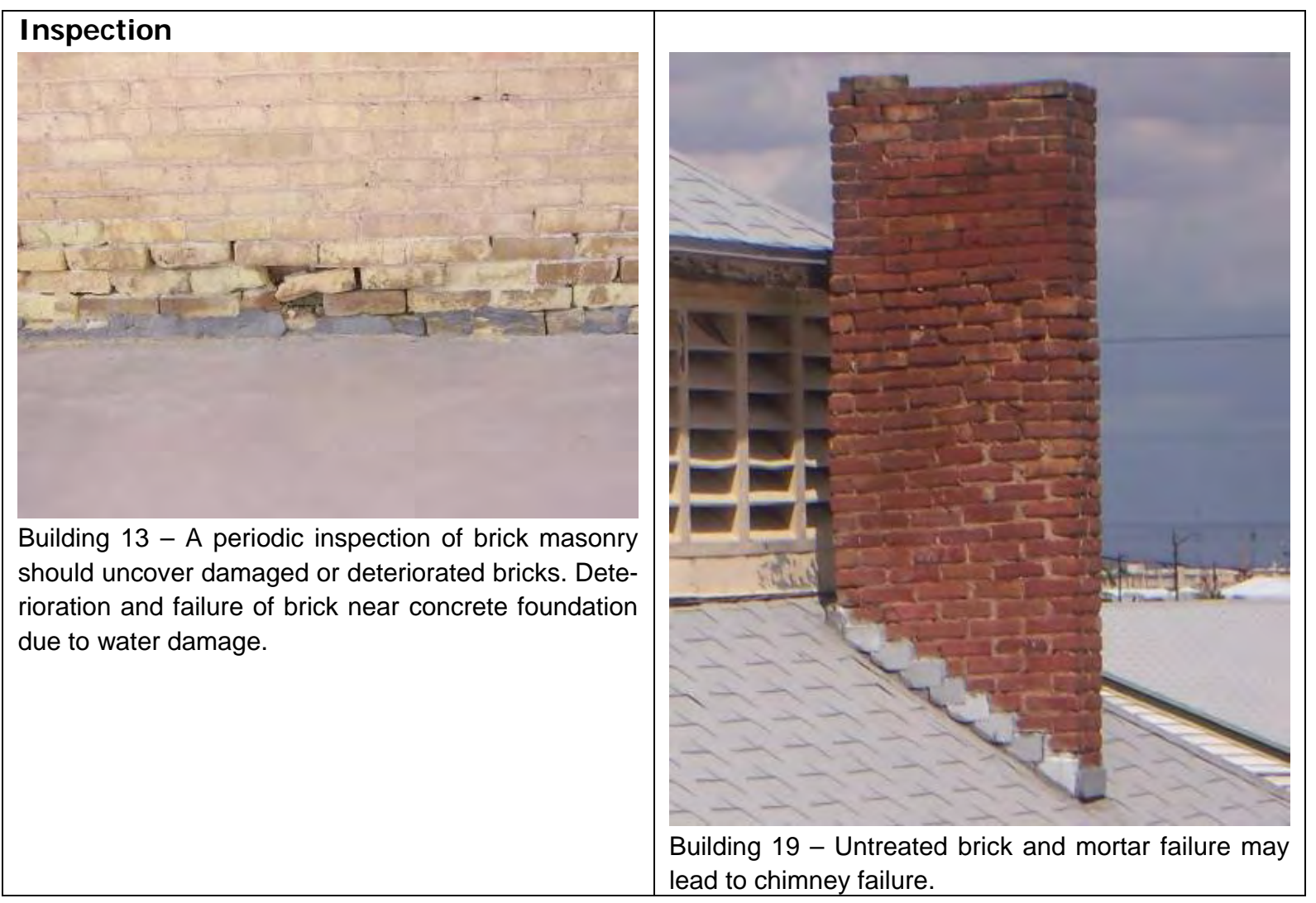




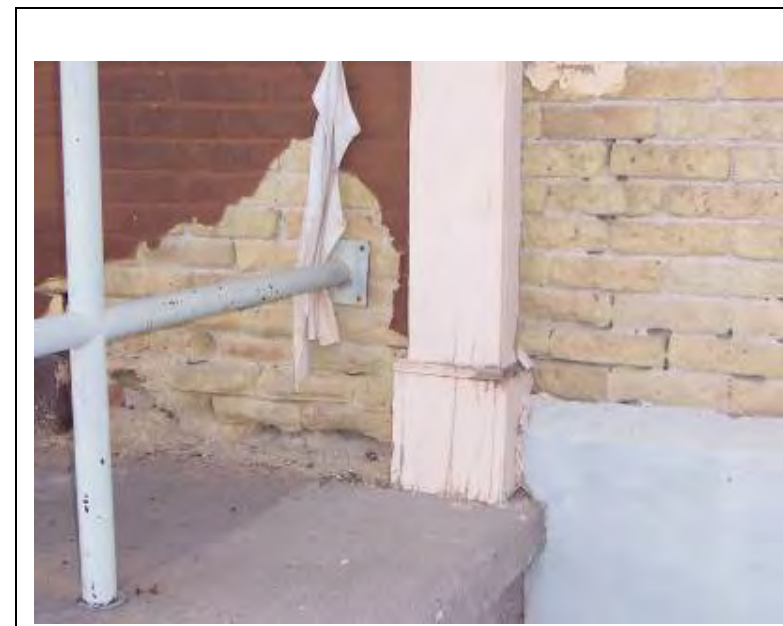

Building 21 - Bricks located near the foundation of a structure are suseptible to spalling. Water that is not properly drained away from the structure causes deterioration of both the brick and the mortar. Here standing water on the concrete porch caused the brick, mortar, and paint to fail.

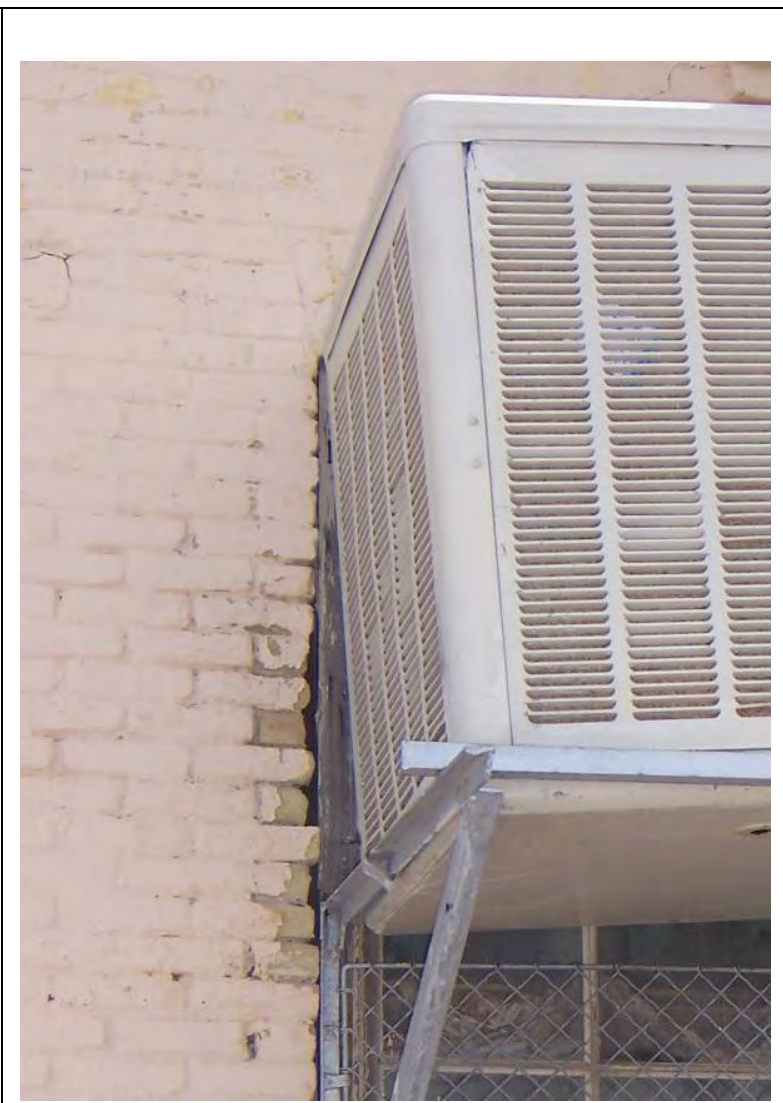

Building 21 - Example of damage to painted brick near a window opening caused by moisture produced by the evaporative cooler.

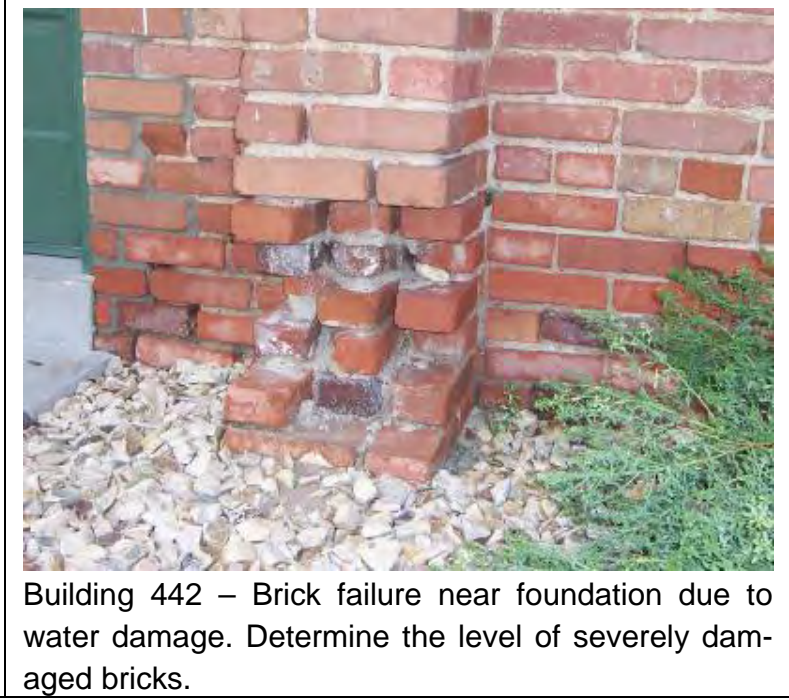

\section{Evaluation}

- A masonry sealant can help prevent the problem as long as it allows the brick to breathe.

- $\quad$ Keep moisture away from brick foundations by providing proper drainage away from the structure. 
- If spalling is confined to just a few bricks, leave them alone. They will not compromise the stability of a wall or a chimney.

- $\quad$ Determine the level of repair for severely damaged bricks.

- $\quad$ Determine the size, color, texture of the appropriate replacement brick.

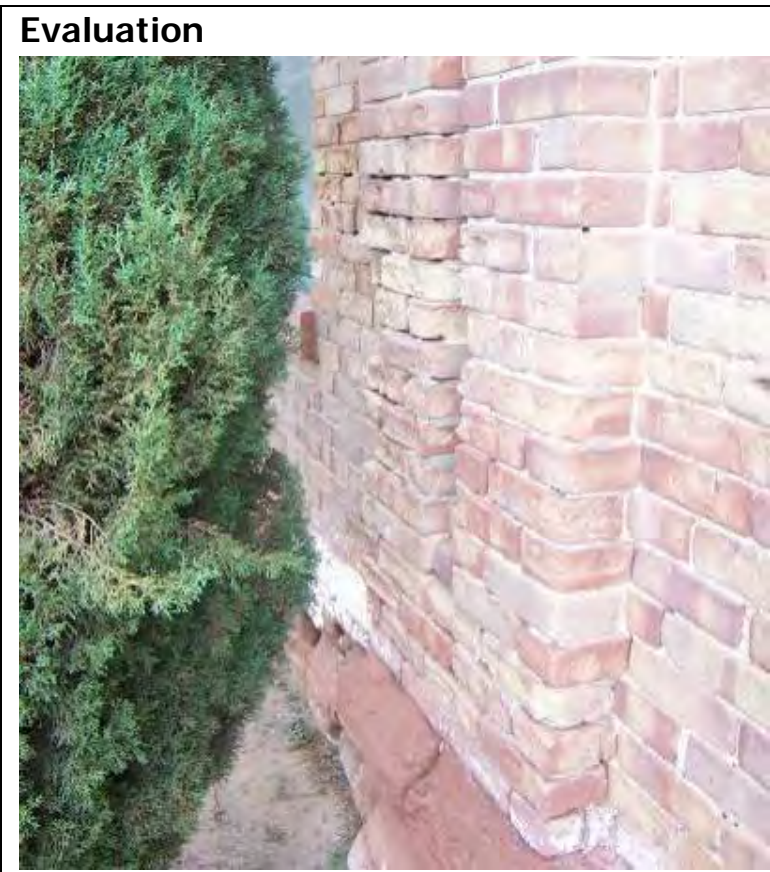

Building 128 - Brick deterioration due to the proximity of vegetation to the brick exterior wall.
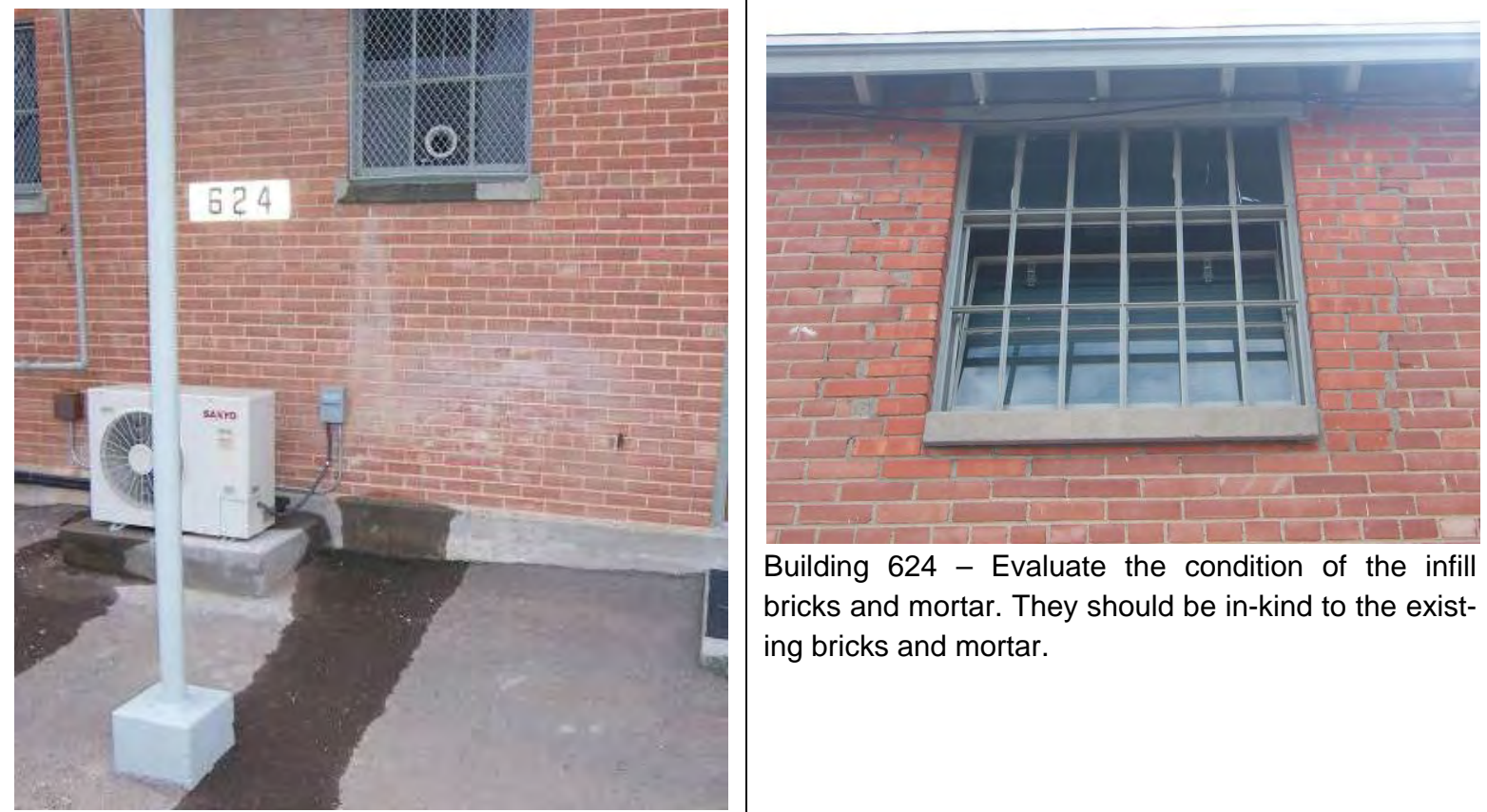

Building 624 - Evaluate the condition of the infill bricks and mortar. They should be in-kind to the exist-

Building 624 - Identify the source of damage. Water is constantly running down the surface of the brick exterior wall from the evaporative cooler located above the window.

Building 128 - Evaluate the overall condition of all brick features to determine whether more than protection and maintenance are required.

\author{
ing bricks and mortar.
}




\section{Repair}

Recommended...

- $\quad$ Repairing the source of the damage before repairing or repointing proceeds.

- When an individual brick has partially disintegrated, it may be patched in place using recognized preservation methods.

\section{Replace}

Recommended...

- $\quad$ Spalled brick is almost impossible to repair. Damaged bricks have to be cut out and replaced.

- $\quad$ Limited replacement in-kind or with compatible substitute material of those extensively deteriorated or missing parts of masonry feature. In replacing damaged brick, every reasonable effort should be made to find brick with a texture and color similar to the original fabric.

- $\quad$ Replacing in-kind an entire feature that is too deteriorated to repair. Examples can include large sections of a wall, a cornice, balustrade, column, or stairway. If using the same kind of material is not technically or economically feasible, then a compatible substitute material may be considered.

Not Recommended...

- $\quad$ Brick replacement under adverse weather conditions, or when temperatures are below or above manufacturer's recommended limitations for installation.

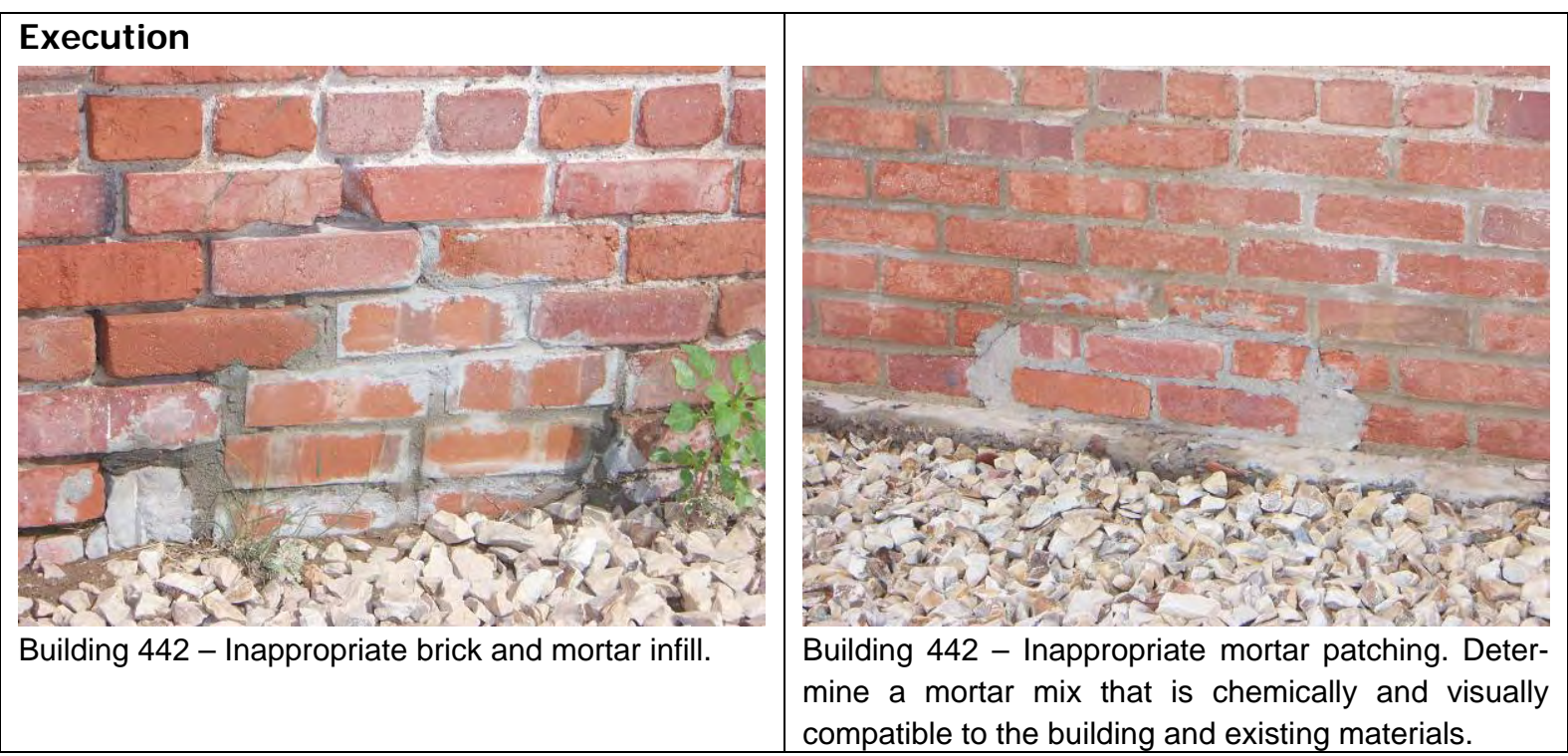


Notes

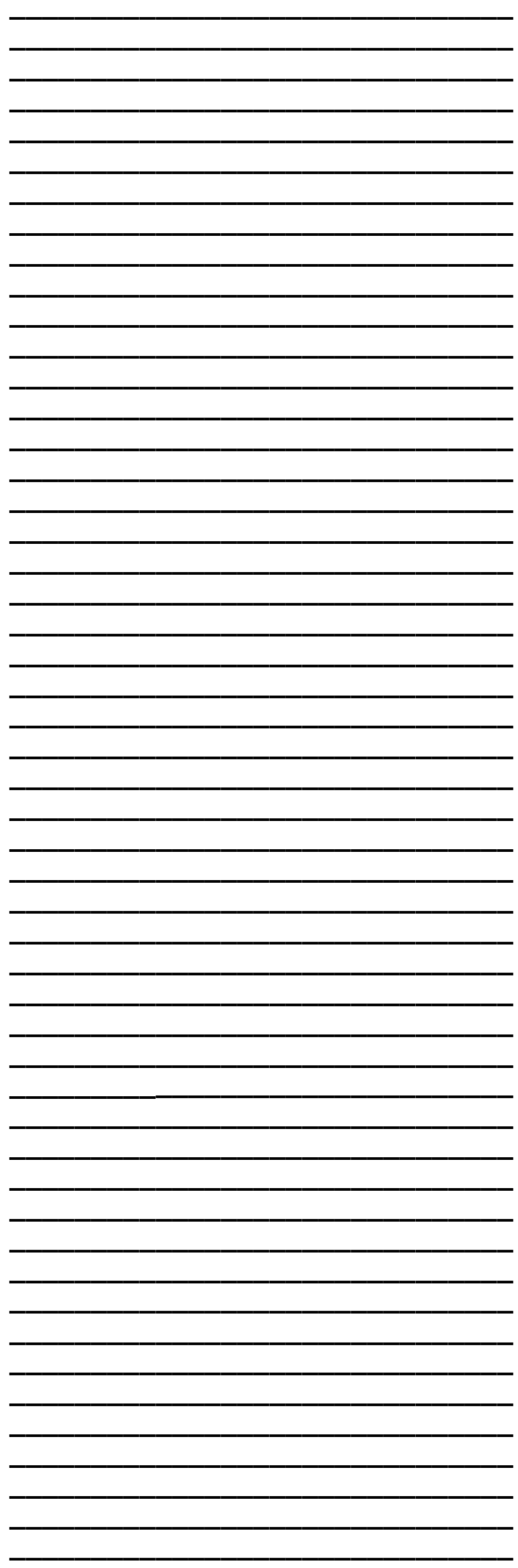




\section{Brick: Cracking}

All exposed masonry should be inspected for cracking. Although masonry can deform elastically over long periods of time to accommodate small amounts of movement, large movements normally cause cracking. Cracks may appear along the mortar joints or through the masonry units. Cracking may result in a variety of problems: differential settlement of foundations, drying shrinkage, expansion and contraction due to ambient thermal and moisture variations, improper support over openings, the effects of freeze-thaw cycles, the corrosion of iron and steel wall reinforcement, differential movement between building materials, expansion of salts, and the bulging or leaning of walls. Cracking in brick is a natural and inherent problem.

\section{Causes}

- Wall cracking associated with thermal and moisture movement: Above ground brick walls expand in warm weather and contract in cool weather.

- $\quad$ Cracking around sills, cornices, eaves, chimneys, parapets, and other elements subject to water penetration: The water expands upon freezing, breaking the bond of the mortar and the masonry and eventually displacing the masonry itself.

- $\quad$ Cracking around iron or steel lintels: The corrosion that builds up on the surface of the metal exerts great pressure surrounding the masonry and displaces it. Rust stains usually indicate that corrosion is the cause of the problem.

- $\quad$ Cracking or displacement of masonry over openings: The deflection or failure of lintels or arches that span the opening cause the brick and mortar bond to separate. In older walls with wood lintels, cracking will occur as the wood sags or decays. Iron and steel lintels also cause cracking as they deflect over time. Concrete and stone lintels occasionally bow and sometimes crack. Masonry arches of brick or stone may crack or fail when there is wall movement or when their mortar joints deteriorate.

- $\quad$ Cracking or outward displacement under the eaves of a pitched roof: The failure in the horizontal roof ties cause a lateral thrust of the roof on the masonry wall, which will cause the brick wall to crack horizontally just below the eaves or to move outward with the roof.

- $\quad$ Bulging of walls: Masonry walls sometimes show signs of bulging as they age. In very old buildings, small wall bulges may result from the decay and collapse of internal wood lintel or wood-bonding course, which can cause the inner course to settle and the outer course to 
bulge outward. When wall bulges occur in solid masonry walls, the walls may be insufficiently tied back to the structure; the star-shaped anchors on the exterior of the masonry walls of many older buildings are examples of such ties.

\section{Inspection}

Recommended...

- Hairline, nonstructural cracks that show no sign of worsening normally need not be repaired.

- $\quad$ Cracks larger than hairline cracks, but less than approximately 1/16-inch, can be repaired with a mix of cement and water.

- If the crack is wider than $1 / 16$-inch, fine sand should be added to the mix to allow for greater compactibility, and to reduce shrinkage during drying.

- $\quad$ For larger cracks, field trials will determine whether the crack should be routed (widened and deepened) minimally before patching to allow sufficient penetration of the patching material.

- $\quad$ Protecting and maintaining masonry by providing proper drainage so that water does not stand on flat, horizontal surfaces or accumulate in curved decorative features.

Not Recommended...

- $\quad$ Failing to undertake adequate measures to assure the protection of masonry features.

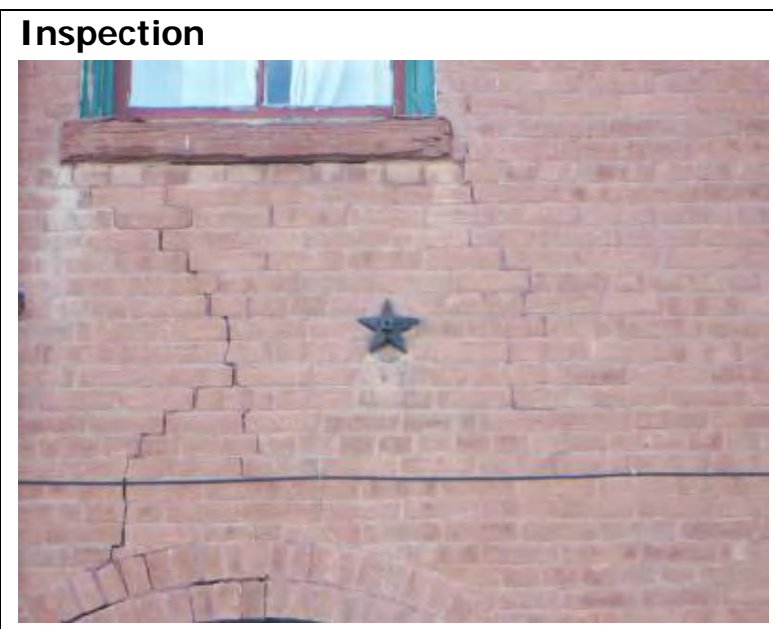

Building 13 - Inspect for cracks and damaged bricks. Vertical crack in brick exterior wall that extends from the top of the arched lintel to the bottom of the sandstone windowsill.

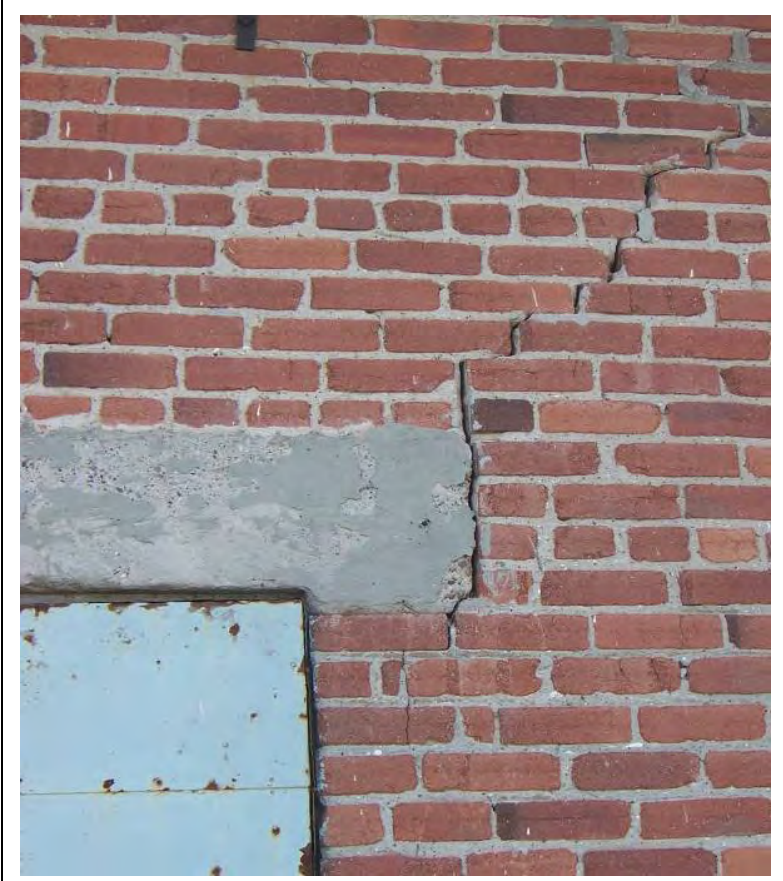

Building 890 - Crack extending up the brick wall from the corner of the concrete door lintel. Notice that the crack follows the mortar joints up the wall. 


\section{Evaluation}

Recommended...

- $\quad$ Evaluating the overall condition of the masonry to determine whether more than protection and maintenance are required, that is, if repairs to the masonry features will be necessary.

- $\quad$ To ensure a long-term repair, the patching materials should be carefully selected to be compatible with the existing concrete as well as with subsequent surface treatments such as paint or stucco.

- When it is desirable to reestablish the structural integrity of a brick structure involving dormant cracks, epoxy injection repair should be considered. An epoxy injection repair is made by sealing the crack on both sides of a wall or a structural member with an epoxy mortar, leaving small holes, or "ports" to receive the epoxy resin. After the surface mortar has hardened, epoxy is pumped into the ports. Once the epoxy in the crack has hardened, the surface mortar can be ground off, but the repair may be visually noticeable.

Not Recommended...

- $\quad$ Failing to evaluate and treat the various causes of mortar joint deterioration such as leaking roofs or gutters, differential settlement of the building, capillary action, or extreme weather exposure.

- $\quad$ Patching masonry without removing the source of deterioration.

- $\quad$ Patching with a substitute material that is physically or chemically incompatible with the original masonry.

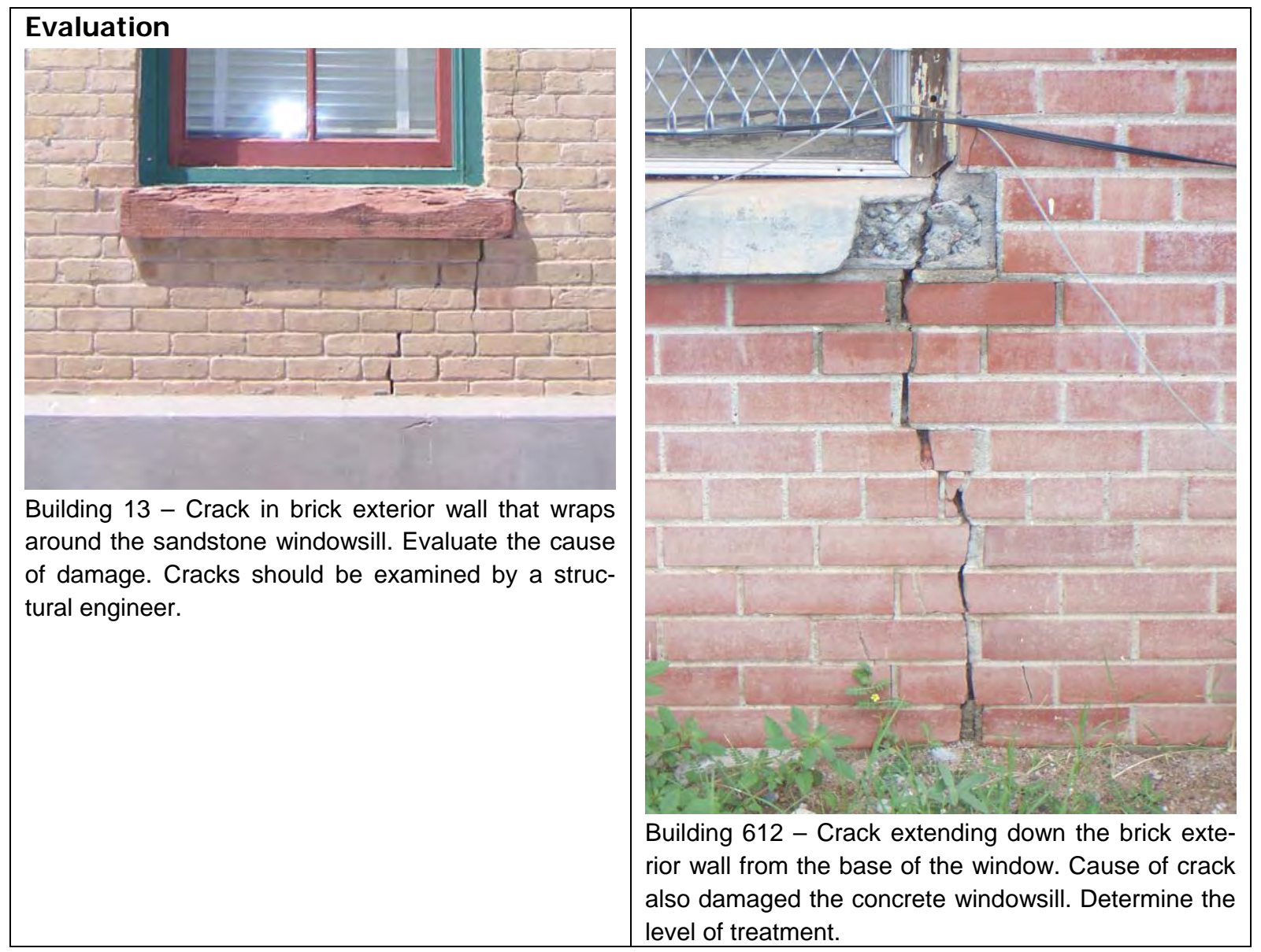




\section{Repair}

Cracks in brick are usually active, which widen or migrate, or dormant/inactive, which remain unchanged. Cracking may be caused by structural movement or settlement of the building, use of too hard of a repointing mortar, or differing rates of expansion and contraction between adjacent materials. Cracks should be evaluated to determine their cause and whether corrective action is required. Look for signs of movement. A clean crack indicates recent movement; a dirty or previously filled crack may be inactive. Correlate the width of larger cracks to the age of the building. A one-half-inch crack in a new building may be a sign of rapid settlement, in a 50 year old building, it may indicated a very slow movement of only 1/100 inch per year. In each case the cause and treatment may differ.

Recommended...

- $\quad$ Some cracks are active, changing their width and length. Active structural cracks will move as loads are added or removed. Thermal cracks will move as temperatures fluctuate. Thus, expansion-contraction joints may have to be introduced before repair is undertaken. Active cracks should be filled with sealants that will adhere to the sides of the cracks and will compress or expand during crack movement. The design, detailing, and execution of sealant-filled cracks require considerable attention, or else they will detract from the appearance of the historic building.

- $\quad$ Repairing masonry features by patching, piecing-in, or consolidating the masonry using recognized preservation methods. Repair may also include the limited replacement inkind — or with compatible substitute material—of those extensively deteriorated or missing parts of masonry features when there are surviving prototypes.

- $\quad$ Applying new or non-historic surface treatments such as water-repellent coatings to masonry only after repointing and only if masonry repairs have failed to arrest water penetration problems.

Not Recommended...

- Replacing or rebuilding a major portion of exterior masonry walls that could be repaired so that, as a result, the building is no longer historic and is essentially new construction.

- Using a substitute material for the replacement part that does not convey the visual appearance of the surviving parts of the masonry feature or that is physically or chemically incompatible.

- Applying waterproof, water repellent, or non-historic coatings such as stucco to masonry as a substitute for repointing and masonry repairs. Coatings are frequently unnecessary, expensive, and may change the appearance of historic masonry as well as accelerate its deterioration.

\section{Replace}

Recommended...

- If a crack is has developed from the corrosion of iron or steel lintels or sills, the corroded components should either be repaired or replaced and the cracked brick should be repaired and repointed. Where cracking is severe, portions of the wall may have to be reconstructed. Cracks should be examined by a structural engineer.

- When cracking or displacement of masonry over openings is caused from lintel deflections or arch failures, the masonry above may be supporting itself and will exhibit step cracks beginning at the edges of the opening joining in an inverted $\mathrm{V}$ above the openings midpoint. Correcting such problems means replacing failed components and rebuilding the area above the opening.

- $\quad$ Replacing sections too deteriorated to repair using materials compatible with the original materials. 
Not Recommended....

- $\quad$ Removing a masonry feature that is unrepairable and not replacing it; or replacing it with a new feature that does not convey the same visual appearance.

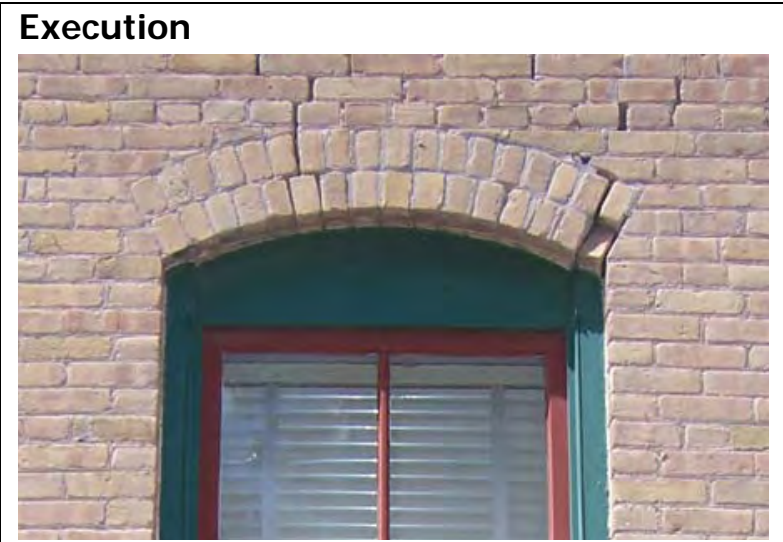

Building 13 - When cracking or displacement of masonry over openings is caused from lintel deflections or arch failures, the masonry above may be supporting itself and will exhibit step cracks beginning at the edges of the opening and joining in an inverted $V$ above the opening's midpoint. Correcting such problems means replacing failed components and rebuilding the area above the opening.

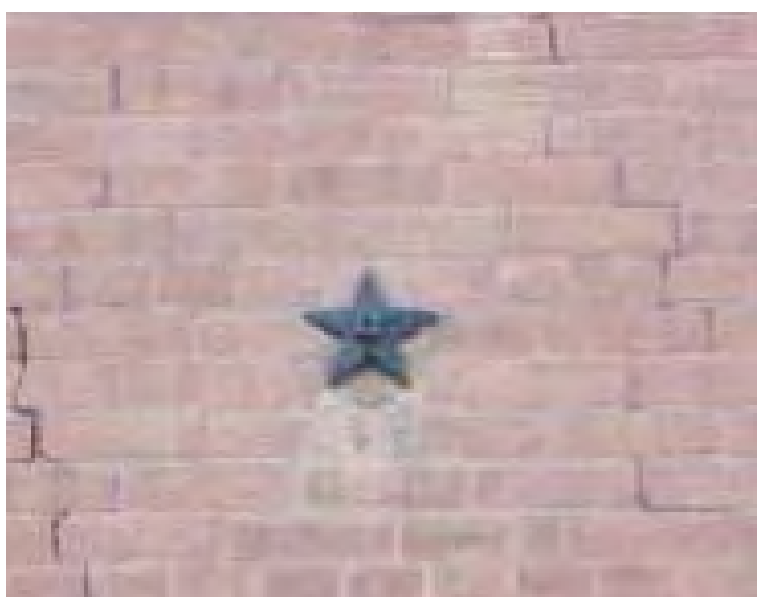

Building 13 - Example of a masonry tie used to help control cracking in bowing in brick walls. 


\section{Notes}

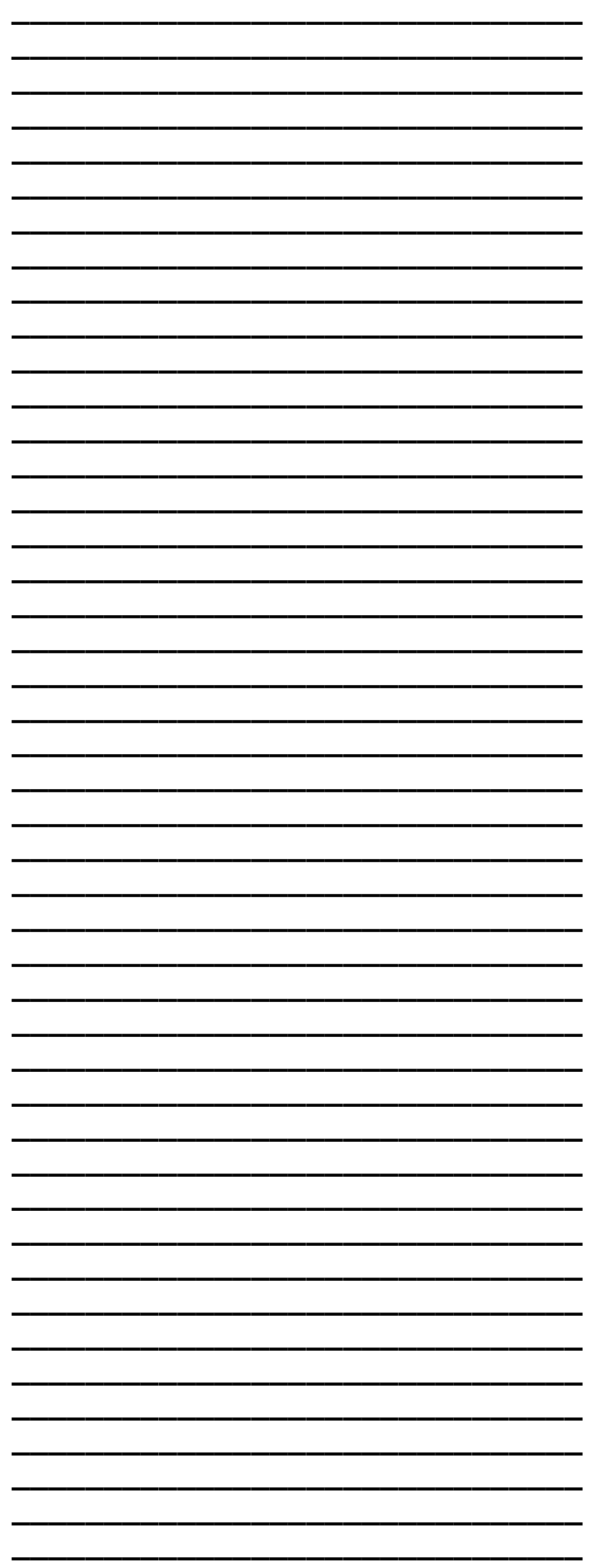




\section{Brick: Mortar Deterioration}

The two important qualities of mortar are its ability to bond to masonry and its internal strength. A sign of poorly made mortar may be random cracking at the bond joint. Until about the 19th century, the standard mortar for masonry was a mixture of sand and pure lime or lime-possolan-sand. These low-strength mortars gave masonry the ability to absorb considerable strain. Accordingly, the tendency to crack was reduced and when cracks did appear in the mortar joints, they were to a great extent capable of chemical reconstitution or self healing. Thus, the age of the building may be a good clue in evaluating its mortar problems. Older mortar (or mortar of any that uses hydrated lime) will be softer and may require pointing, but otherwise may be responsible for a sound wall.

Most often, mortar deterioration is found in areas of excessive moisture, such as near leaky downspouts, below windows, and at tops of walls. In such cases the remedy is to redirect the water flow and point the joints. Pointing should be performed with mortar of a composition similar to or compatible with the original mortar. The use of highstrength mortar to point mortar of lower strength can do serious damage to the masonry since pointing cannot flex with or act in a similar way to the rest of the joint. It is useful to remember that mortar acts as a drainage system to equalize hydrostatic pressure within the masonry. Nothing should be done to reduce its porosity and thereby block water flow to the exterior surface.

\section{Causes}

- $\quad$ Another common problem in the El Paso area and especially at Fort Bliss is the inappropriate placement of window air conditioning units and evaporative coolers. Due to the dry climate of the southwest, evaporative coolers are used in abundance as an efficient and effective machine used to cool the structures. However, the water supply that is used to cool the structures ultimately poses a problem for the structures' building materials, such as brick. Many of these evaporative coolers penetrate an exterior wall or are located on the structure's roof. The water that circulates through the cooler is constantly dripping onto building surfaces.

- $\quad$ Bricks located near the foundation of a structure are susceptible to deterioration. Water that is not properly drained away from the structure causes the deterioration of both the

\author{
Inspection \\ - Identify missing or deteriorated mortar. \\ - Identify missing or loose brick. \\ - Identify areas where inappropriate mortar type \\ was used during repointing. \\ - Identify root cause of damage, including stand- \\ ing water.

\section{Evaluation} \\ - Determine level of treatment necessary to re- \\ pair severely damaged mortar. \\ - Determine a mortar mix that is chemically and \\ visually compatible with the building.

\section{Execution} \\ - $\quad$ Repair the source of the damage before repair- \\ ing or repointing proceeds. \\ - $\quad$ Replace in-kind to the historic materials.
}

\section{Further Readings}

GSA has developed technical procedures to be used in specialized historic preservation work, as well as general evaluation, maintenance and repair of older building materials. For more detailed descriptions of repair procedures for mortar deterioration refer to the following, which can be found at http://w3.gsa.gov/web/p/hptp.nsf

- Guidelines for Rehabilitating Historic Buildings: Masonry

- Guidelines for Evaluating the Condition of Brick Masonry and Mortar

- $\quad$ Preservation Briefs: \#2 Repointing Mortar Joints in Historic Brick Buildings

- $\quad$ Preparing Lime Mortar for Repointing Masonry

- Waterproofing Masonry Joints Using Molten Lead, Lead Wool, or a Proprietary Lead Cap System

- $\quad$ Removing Lime Mortar Deposits from Brick Masonry 
brick and mortar. El Paso is known for its summer rain showers, which produce an ample amount of rainfall in a short period of time. If gutters are not properly installed or if rainwater is continually bouncing off of the ground surface back onto the face of the brick and mortar located at the base of the wall, mortar deterioration will continually progress.

\section{Inspection}

Recommended...

- $\quad$ Repairing masonry walls and other masonry features by repointing the mortar where there is evidence of deterioration such as disintegrating mortar, cracks in mortar joints, loose bricks, damp walls, or damaged plasterwork.
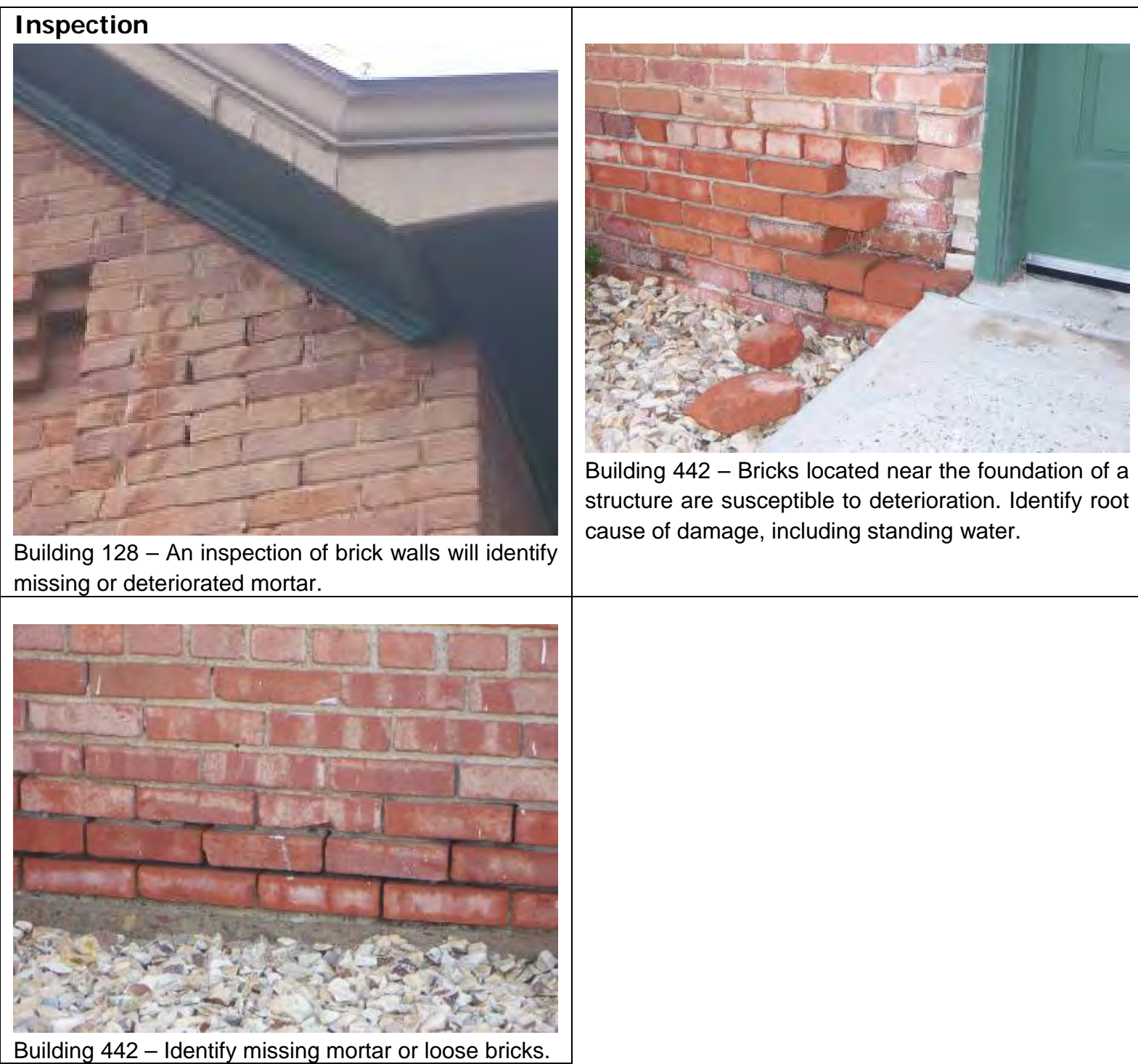

Building 442 - Bricks located near the foundation of a structure are susceptible to deterioration. Identify root cause of damage, including standing water. 


\section{Evaluation}

Recommended...

- Determining level of treatment necessary to repair severely damaged mortar.

- Determining a mortar mix that is chemically and visually compatible with the building.

Not Recommended...

- $\quad$ Removing non-deteriorated mortar from sound joints, and then repointing the entire building to achieve a uniform appearance.

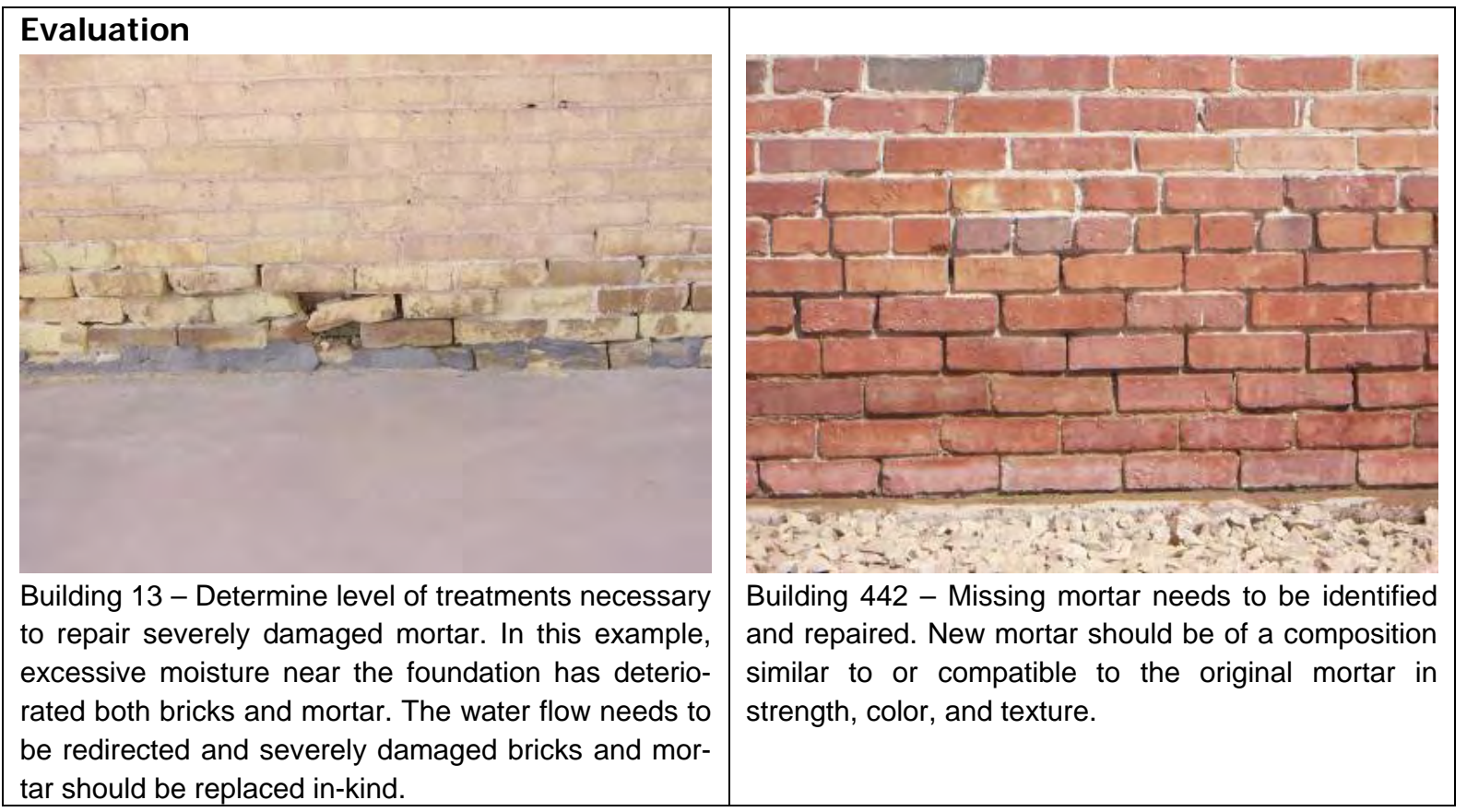




\section{Repair}

Repointing is the process of removing deteriorated mortar from the joints of a masonry wall and replacing it with new mortar. Properly done, repointing restores the visual and physical integrity of the masonry. Improperly done, repointing not only detracts from the appearance of the building, but may, in fact, cause physical damage to the masonry units themselves. The true cause of the deterioration should be determined before beginning any repointing work. Leaking roofs or gutters, differential settlement of the building, capillary action causing rising damp, or extreme weather exposure should all be dealt with immediately. Without such action, mortar deterioration will continue and any repointing work will have been a waste of time and money.

A good repointing job is meant to last, often in the range of 50-100 years. Shortcuts and poor craftsmanship not only result in a job that looks bad, but also in one that will require future repointing more frequently than if the job had been done correctly in the first place. The mortar joint in a historic brick building has often been called the wall's "first line of defense." Good repointing practices guarantee the long life of the mortar joint, the wall, and the historic structure.

Recommended...

- $\quad$ Removing deteriorated mortar by carefully hand-raking the joints to avoid damaging the masonry.

- $\quad$ Duplicating old mortar in strength, composition, color, and texture.

- $\quad$ Duplicating old mortar joints in width and in joint profile.

Not Recommended...

- $\quad$ Using electric saws and hammers rather than hand tools to remove deteriorated mortar from joints prior to repointing.

- $\quad$ Repointing mortar of high Portland cement content (unless it is the content of the historic mortar). This can often create a bond that is stronger than the historic material and can cause damage as a result of the differing coefficient of expansion and the differing porosity of the material and the mortar.

- $\quad$ Repointing with a synthetic caulking compound.

- Using a "scrub" coating technique to repoint instead of traditional repointing methods.

- $\quad$ Changing the width or joint profile when repointing. 


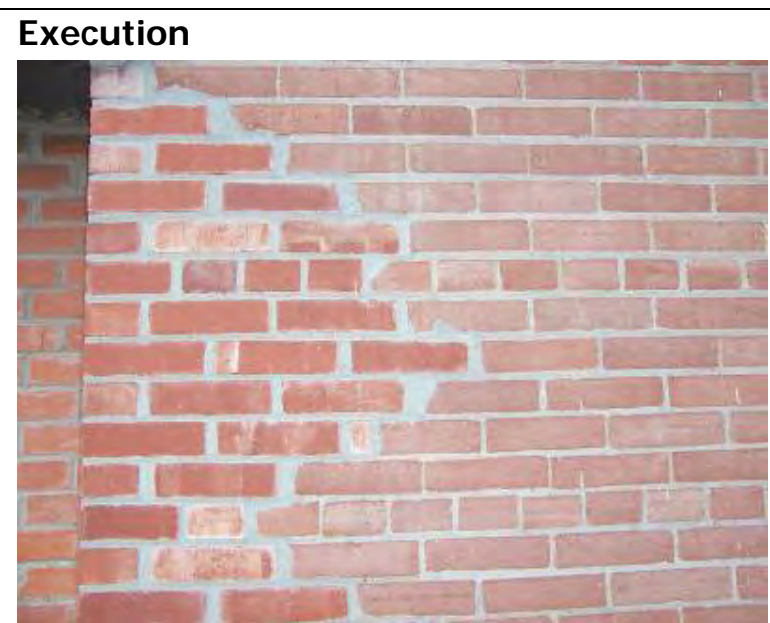

Building 55 - Improper repointing detracts from the appearance of the building

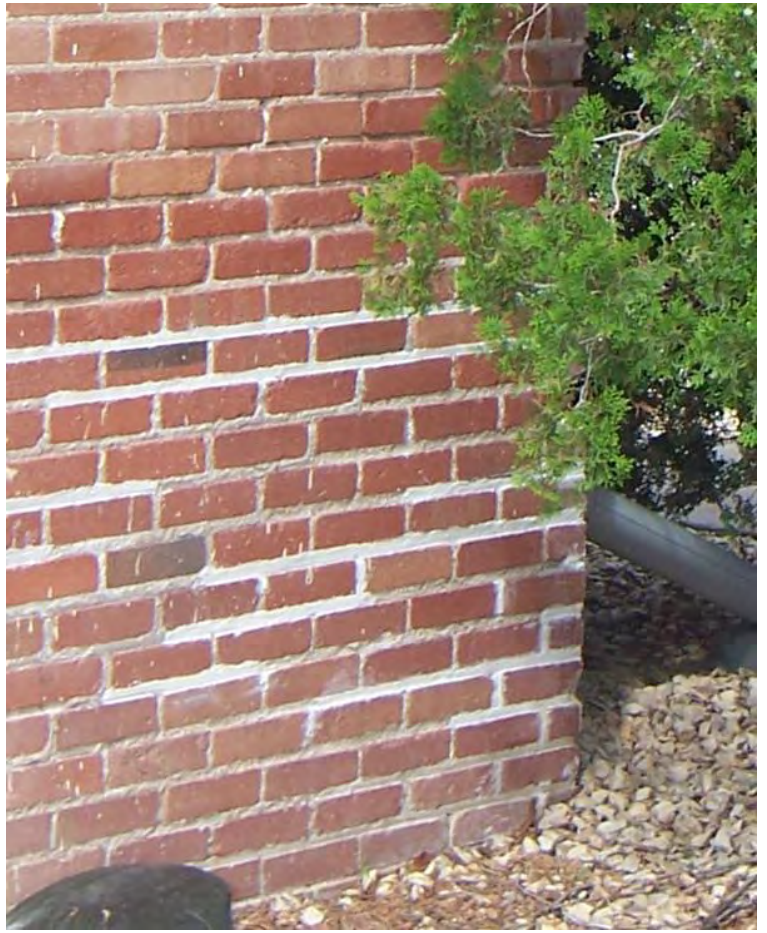

Building 440 - Removing deteriorated mortar by carefully hand-raking the joints to avoid damaging the masonry. This is a poor example of repointing. It is not recommended to apply a new coat of mortar over existing mortar.

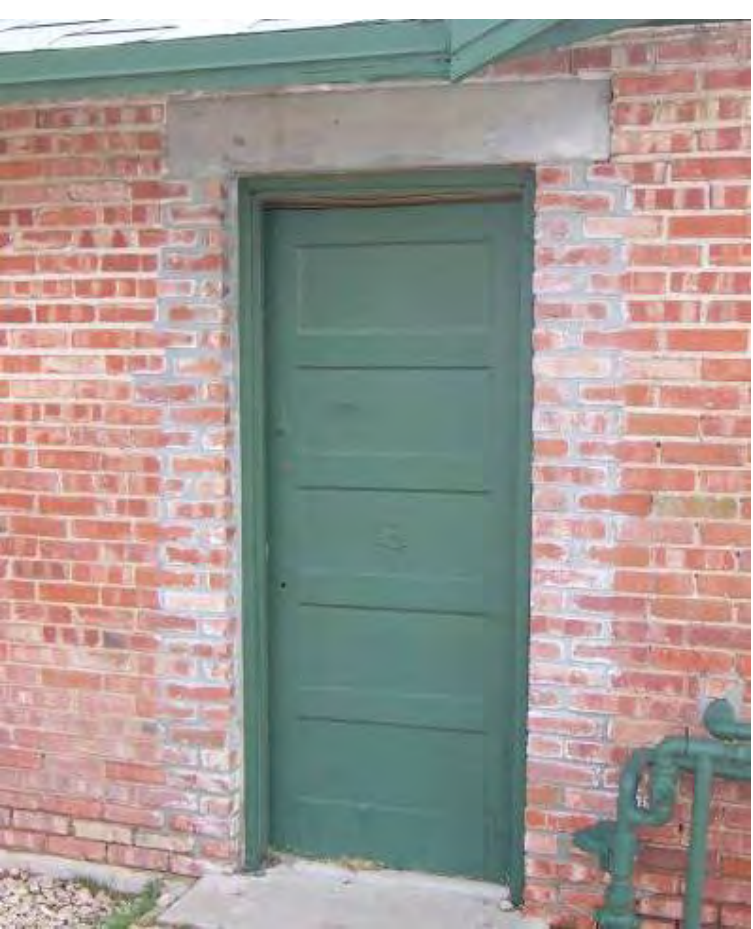

Building 442 - It is not recommended to repoint mortar with high Portland cement content. This can often create a bond that is stronger than the historic material and can cause damage. 
Notes

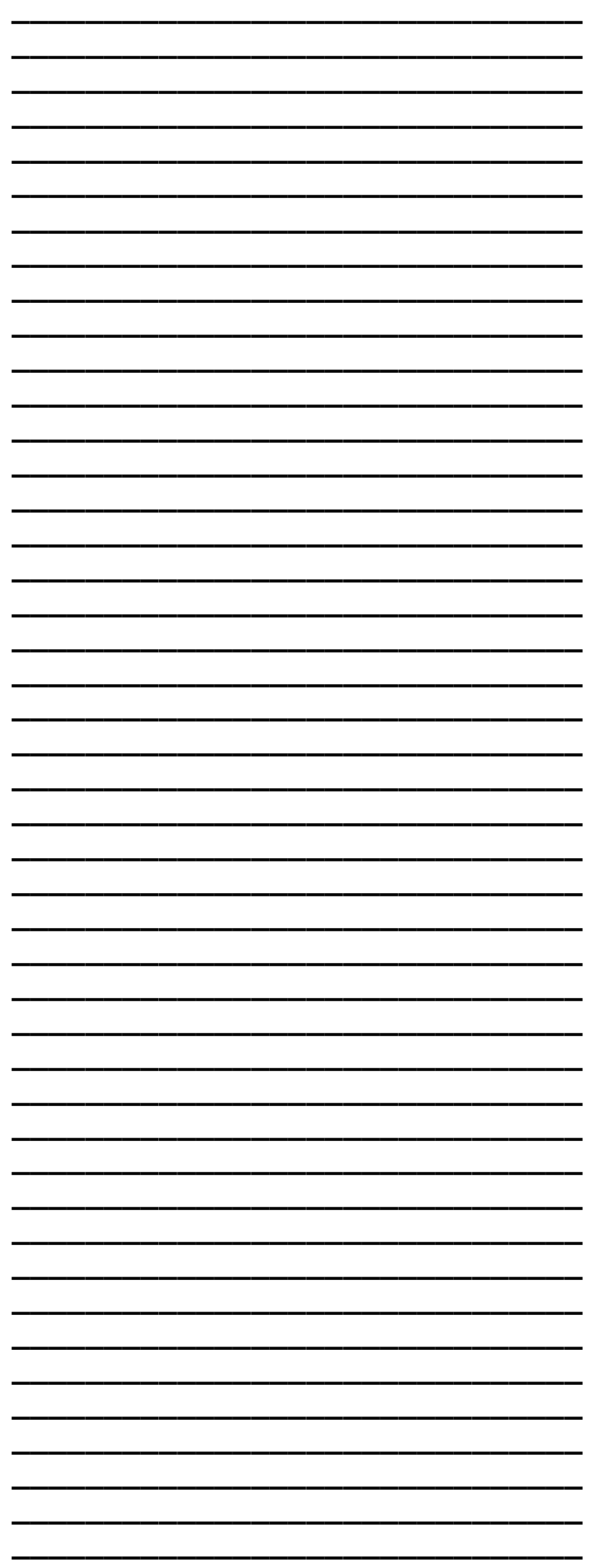




\section{Brick: Efflorescence}

Efflorescence is the white salty deposit found on masonry. It is formed by water within the construction material reacting with the natural salts contained within them and the mortar. These salts dissolve in the water and are carried to, and deposited on, the surface by the natural evaporation that occurs when air comes in contact with the surface of the wall or floor. These deposits are generally not harmful to the building, just unattractive. However, they should be washed from the surface as soon as possible.

Brick should be cleaned only when it is necessary to halt deterioration, as most cleaning methods have adverse effects on the brick and on the environment. Inappropriate cleaning of masonry buildings is a major cause of deterioration of the Nation's historic resources.

\section{Causes}

- $\quad$ Salts enter the wall from various sources. Ground waters that are naturally salt-bearing can be drawn into base brickwork. A faulty damp-proof course or a damp course bridged by mortar will allow the salts to migrate up the wall.

\section{Inspection}

- Identify if the substance on the brick surface is efflorescence or a stain.

\section{Evaluation}

- Determine if the amount of efflorescence is a result of a larger moisture problem within the building walls, such as a leak or faulty flashing.

\section{Execution}

- Bricks should be cleaned only when it is necessary to halt deterioration.

- Brush off deposits with a stiff dry bristle brush when wall is completely dried out.

- $\quad$ Do NOT use abrasive cleaning techniques to remove the efflorescence, such as highpressure washing or sandblasting.

\section{Further Readings}

GSA has developed technical procedures to be used in specialized historic preservation work, as well as general evaluation, maintenance and repair of older building materials. For more detailed descriptions of repair procedures for efflorescence on brick refer to the following, which can be found at http://w3.gsa.gov/web/p/hptp.nsf

- Removing Salt/Efflorescence from Brick and Stone Masonry

- $\quad$ Brick: Characteristics, Uses, and Problems

- The amount of efflorescence that occurs is directly related to the amount of water in the bricks and their drying time. The more water in the bricks, and the longer it is there, the more chance salts will have to dissolve in it and be brought to the surface as the bricks dry out.

- $\quad$ Persistent efflorescence should be taken as a warning that water is entering the wall through faulty copings, flashings, or pipe leakage. If allowed to continue unchecked, the salts carried to the face of the wall may eventually attack and cause deterioration of some bricks. 


\section{Inspection}

Recommended...

- Identifying if the substance on the brick surface is efflorescence or a stain.

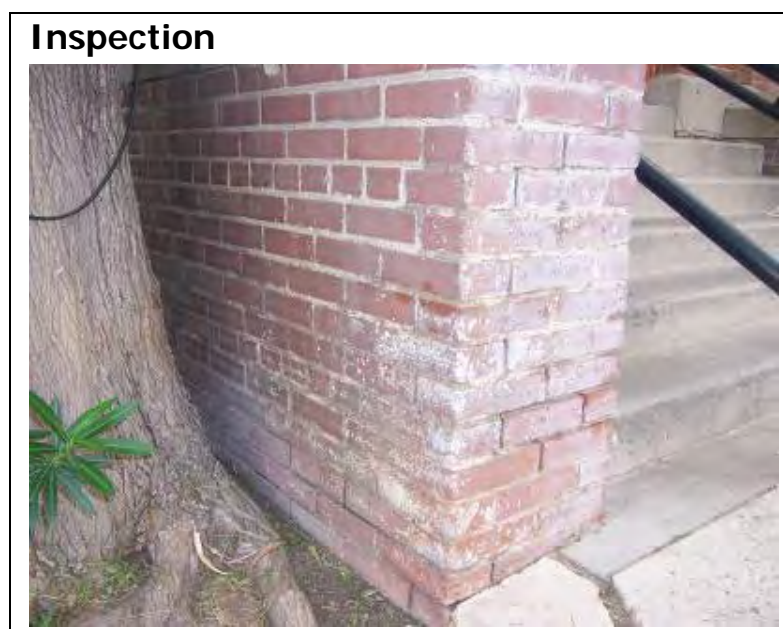

Building 55 - Identify if the substance on the brick is efflorescence or a stain. Identify the location of the efflorescence on the brick and its surroundings.

\section{Repair}

The most effective treatment for efflorescence is time. The natural weathering of the surface, if maintained, will remove it. The salts that cause efflorescence are soluble in water. Hosing with water will cause the salts to dissolve and be re-absorbed into the brickwork, then reappear when the brick wall dries out again. Treatments, such as acid etc, generally involve getting the surface, and the salts, wet.

Recommended...

- Determining if the amount efflorescence is a result of a larger moisture problem within the building walls, such as a leak or faulty flashing.

\section{Evaluation}

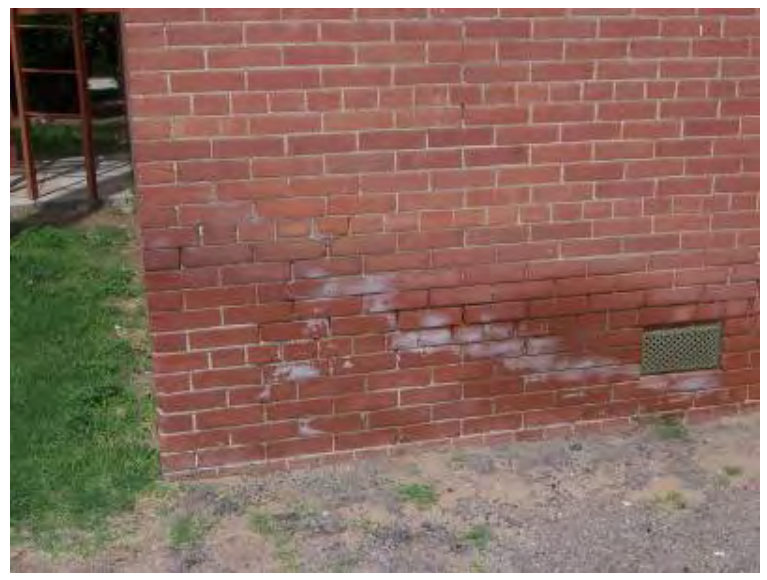

Building 114 - Determine if the amount of efflorescence is a larger moisture problem, such as standing water near the foundation. 


\section{Execution}

Recommended...

- $\quad$ The best method for a build-up of deposits on a wall is simply brush off the deposit with a stiff dry bristle brush after the wall has dried out. Then sponge the surface with a damp synthetic chamois or high suction sponge to move the salts away from the wall entirely. Use very little water and rinse the sponge frequently in fresh water.

Not Recommended...

Note: Sandblasting is NOT recommended by The Secretary of the Interior's Standards for Rehabilitation and shall not be used. High-pressure water blasting is also NOT recommended without adequate testing or experience as it may erode concrete and drive moisture into the wall.

- $\quad$ Sandblasting using dry or wet grit or other abrasive agents, high-pressure water blasting, or caustic solutions. These methods of cleaning may permanently erode wall surface and accelerate deterioration.

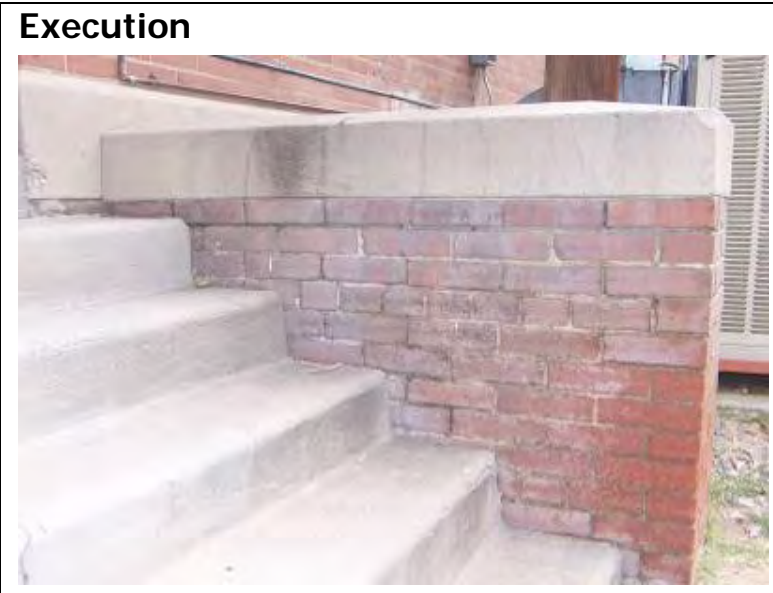

Building 55 - Brush off deposits with a stiff dry bristle brush when wall is completely dried out.

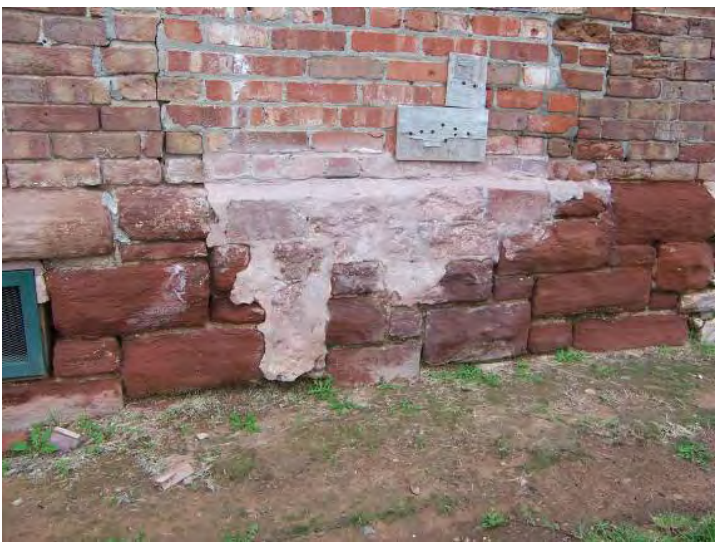

Building 128 - High-pressure water blasting or sandblasting is NOT recommended to clean efflorescence off of brick. 


\section{Notes}

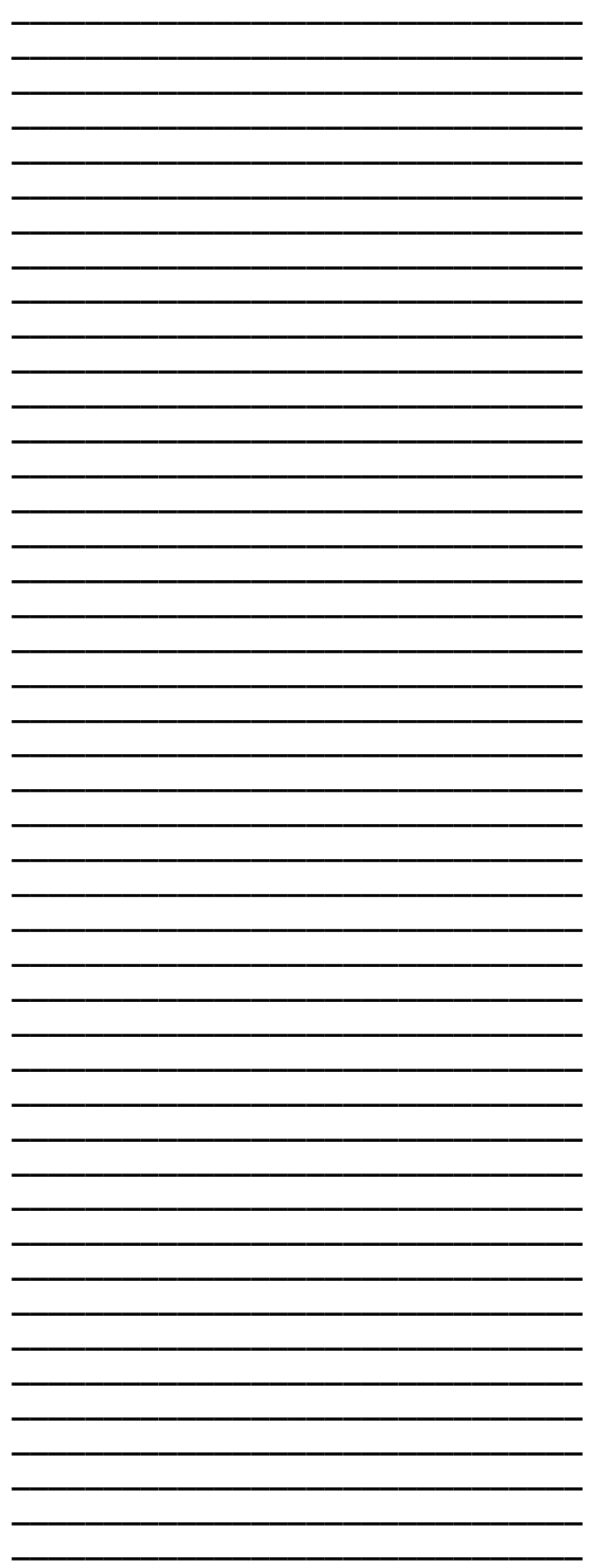




\section{Brick: Staining/Cleaning}

Brick should be cleaned only when it is necessary to halt deterioration, as most cleaning methods have adverse effects on the brick and on the environment. Inappropriate cleaning of masonry buildings is a major cause of deterioration of the Nation's historic resources. Cleaning with water should be done only when there are no major cracks or deterioration in the brick. Do not use high pressure water cleaning methods. Always start with the mildest method of cleaning and proceed to stronger methods. However, it is highly recommended NOT to resort to ABRASIVE CLEANING on masonry surfaces!

The general nature and source of dirt on a building must be determined in order to remove it in the most effective, yet least harmful manner. Common cleaning problems include metal stains such as rust and organic matter such as the tendrils left on the masonry after the removal of ivy.

The construction of the building must be considered in developing a cleaning program because inappropriate cleaning can have a corrosive effect on both the masonry and the other building materials.

Previous treatments of the building and its surroundings also should be evaluated, if known. Earlier waterproofing applications may make cleaning difficult.

\section{Cleaning Methods}

The following list is a brief breakdown of the steps needed when cleaning is considered necessary to prolong the life of a building. For a more in-depth description of each step please refer to Preservation Brief 1, The Cleaning and Waterproof Coatings of Masonry Buildings found at http://www.w3.gsa.gov/web/p/hptp/nsf.

- Water methods - soften the dirt and rinse the deposits from the surface. There are four kinds of waterbased methods.

- Soaking

- Water washing

- Water washing with detergents

\section{Inspection}

- Cleaning brick only when necessary to halt deterioration or heavy soiling.

- Is the cleaning being done to improve the appearance of the building or to make it look new? The so-called "dirt" actually may be weathered brick, not accumulated deposits; a portion of the brick itself thus will be removed if a "clean" appearance is desired.

\section{Evaluation}

- $\quad$ Carrying out brick surface cleaning tests after it has been determined that such cleaning is appropriate. Tests should be observed over a sufficient period of time so that both the immediate and long range effects are known to enable the selection of the gentlest method possible.

\section{Execution}

- $\quad$ Cleaning brick surfaces with the gentlest method possible, such as low-pressure water and detergents, using natural bristle brushes.

- Do NOT use abrasive cleaning techniques to remove the efflorescence or stains, such as high-pressure washing or sandblasting.

\section{Further Readings}

GSA has developed technical procedures to be used in specialized historic preservation work, as well as general evaluation, maintenance and repair of older building materials. For more detailed descriptions of repair procedures for cleaning brick refer to the following, which can be found at http://w3.gsa.gov/web/p/hptp.nsf

- $\quad$ Preservation Briefs: \#1 The Cleaning and Waterproof Coating of Masonry Buildings

- $\quad$ Preservation Briefs: \#6 Dangers of Abrasive Cleaning to Historic Buildings

- General Cleaning of Exterior Brick Masonry

- Removal of Adhesive Residue from Brick, Granite and Limestone

- Removal of Copper-Based Stains from Brick, Concrete, and Limestone

- $\quad$ Removing Smoke Stains from Brick Masonry

- $\quad$ Removing Oil and Tar Stains from Brick Masonry

- $\quad$ Removing Dirt from Brick Masonry 
- Steam/hot-pressurized water cleaning

- $\quad$ Chemical cleaners - react with the dirt and/or masonry to hasten the removal process; the deposits, reaction products and excess chemicals then are rinsed away with water. There are two kinds of chemical cleaners:

- Alkaline cleaners

- Acidic cleaners

- $\quad$ Mechanical methods - include grit blasting (and usually sand blasting), grinders, and sanding discs, which remove the dirt by abrasion and usually are followed by a water rinse. (Note: Generally abrasive/mechanical methods are NOT appropriate for use on historic masonry buildings.)

\section{Testing}

Several potentially useful methods should be tested prior to selecting the one for use on the building. The test patch should be at least one square yard and, with large stones, should include several stones and mortar joints. Test should be observed over a sufficient period of time (preferably a year but, if not feasible, at least a month or two) so that both the immediate and long-term effects are known. Use materials in the following sequence:

- $\quad$ water with natural bristle brushes

- $\quad$ water and non-ionic detergent with natural bristle brushes (Note: Non-ionic detergents are not the same as soaps. They are synthetic organic compounds that are especially effective in removing oily soil.)

- $\quad$ water with stronger soap

- $\quad$ water with stronger soap plus ammonia

- $\quad$ water with stronger soap plus vinegar

\section{Environmental and Safety Considerations}

- $\quad$ Authorities from the local regulatory agency, usually under jurisdiction of the Federal or state Environmental Protection Agency (EPA), should be consulted prior to beginning a cleaning project, especially if it involves anything more than plain water washing.

- $\quad$ Cleaning can also cause damage to non-masonry materials on a building, including glass, metal, and wood. Thus, it is usually necessary to cover windows and doors, and other features that may be vulnerable to chemical cleaners.

- $\quad$ The precautions listed in Material Safety Data Sheets (MSDS) that are provided with chemical products should always be followed.

A well-planned cleaning project is an essential step in preserving, rehabilitating, and restoring a historic masonry building. Proper cleaning methods, when determined necessary for the preservation of the masonry, can enhance the aesthetic character as well as the structural stability of a historic building. Cleaning that is carelessly or insensitively prescribed or carried out by inexperienced workers can have the opposite of the intended effect. It may scar the masonry permanently and eventually causing surface loss in the masonry, which can result in serious damage both physically and aesthetically to a historic masonry building. 


\section{Inspection}

Points to consider before cleaning when inspecting stained or dirt covered masonry.

- $\quad$ Is the cleaning being done to improve the appearance of the building or to make it look new? The so-called "dirt" actually may be weathered masonry, not accumulated deposits; a portion of the masonry itself thus will be removed if a "clean" appearance is desired.

- Is there any evidence that dirt and pollutants are having a harmful effect on the masonry? Improper cleaning can accelerate the deteriorating effect of pollutants.

- Many historic buildings that show only a slight amount of soil or discoloration are much better left as they are.

Recommended...

- $\quad$ Cleaning brick only when necessary to halt deterioration or heavy soiling.

Not Recommended...

- Cleaning masonry surfaces when they are not heavily soiled to create a new appearance, thus needlessly introducing chemicals or moisture into historic materials.

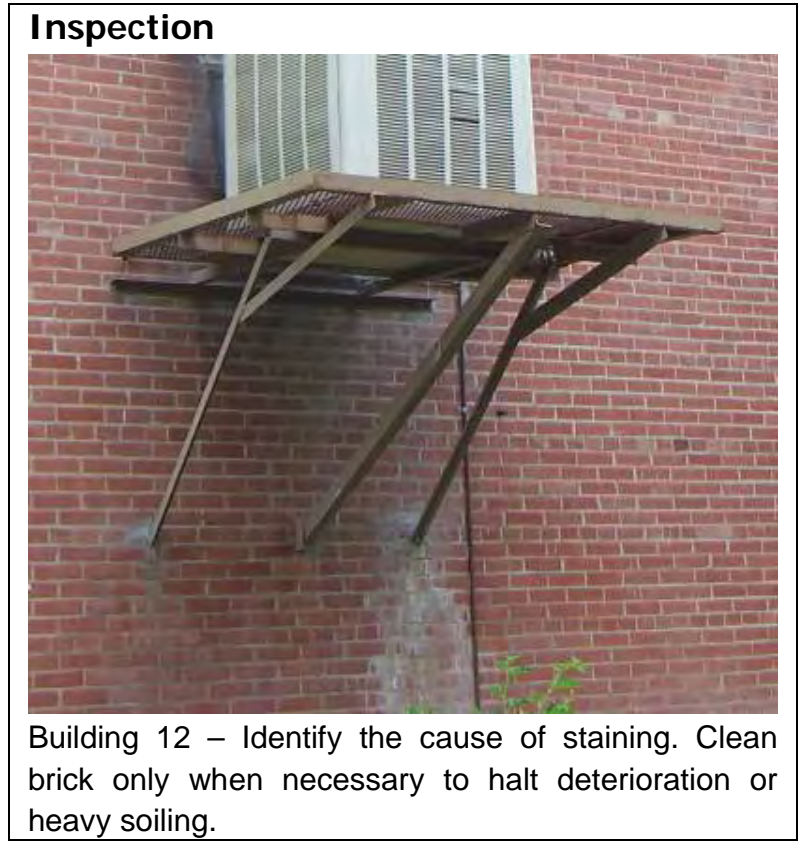

\section{Evaluation}

Recommended...

- $\quad$ Carrying out masonry surface cleaning tests after it has been determined that such cleaning is appropriate. Tests should be observed over a sufficient period of time so that both the immediate and the long range effects are known to enable selection of the gentlest method possible.

Not Recommended...

- $\quad$ Cleaning masonry surfaces without testing or without sufficient time for testing results to be of value. 


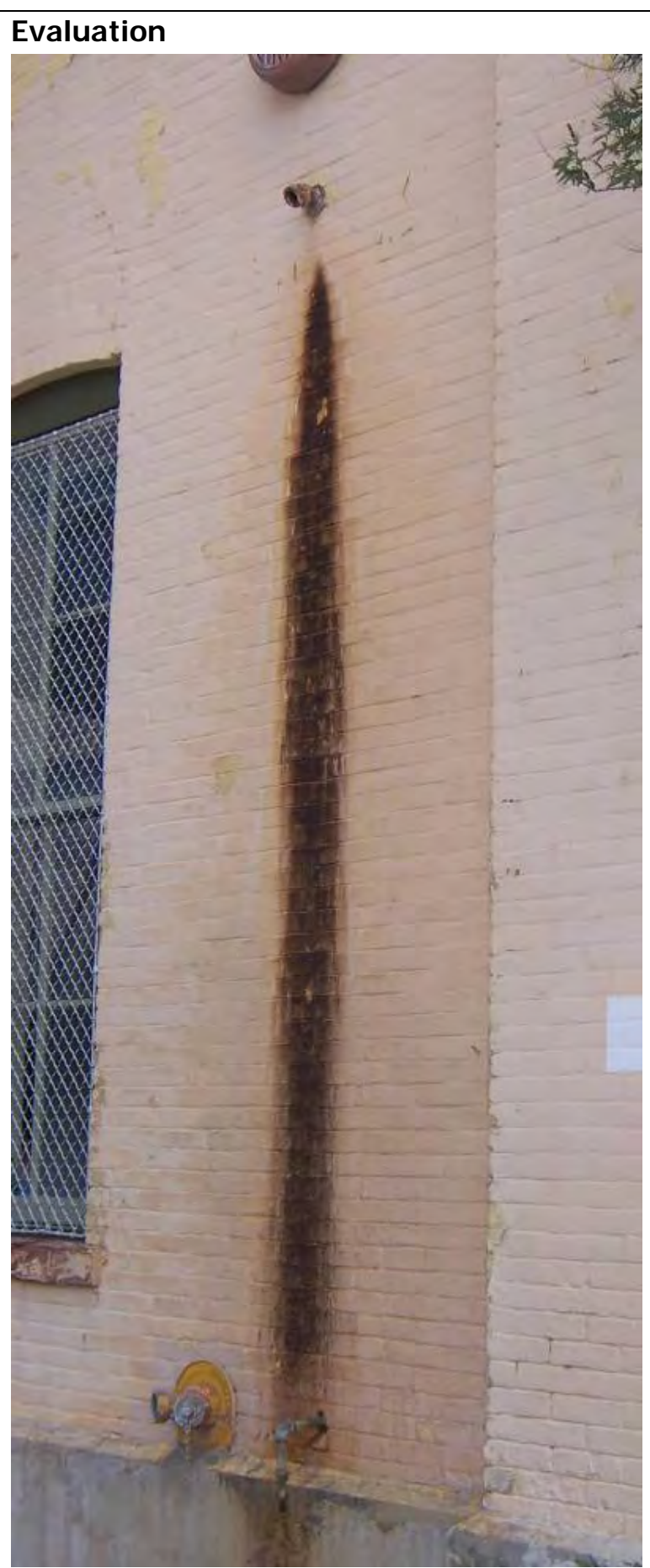

Building 21 - Clean brick surfaces with the gentlest method possible, such as low-pressure water and detergents, using natural bristle brushes. Do NOT use abrasive cleaning techniques, such as high-pressure washing or sandblasting, to remove the efflorescence or stains. 


\section{Execution}

Note: When cleaning, avoid over cleaning. Aim for achieving $85 \%$ clean. Most damage occurs when attempting to clean the last $15 \%$.

Recommended...

- $\quad$ Cleaning masonry surfaces with the gentlest method possible, such as low-pressure water and detergents, using natural bristle brushes.

Not Recommended...

Note: Sandblasting is NOT recommended by The Secretary of the Interior's Standards for Rehabilitation and shall not be used. High-pressure water blasting is also NOT recommended without adequate testing or experience as it may erode soft brick and drive moisture into the wall.

- $\quad$ Sandblasting brick surfaces using dry or wet grit or other abrasives. These methods of cleaning permanently erode the surface of the material and accelerate deterioration.

- $\quad$ Using a cleaning method that involves water or liquid chemical solutions when there is a possibility of freezing temperatures.

- $\quad$ Cleaning with chemical products that will damage masonry.

- $\quad$ Applying high-pressure water cleaning methods that will damage historic brick and the mortar joints.

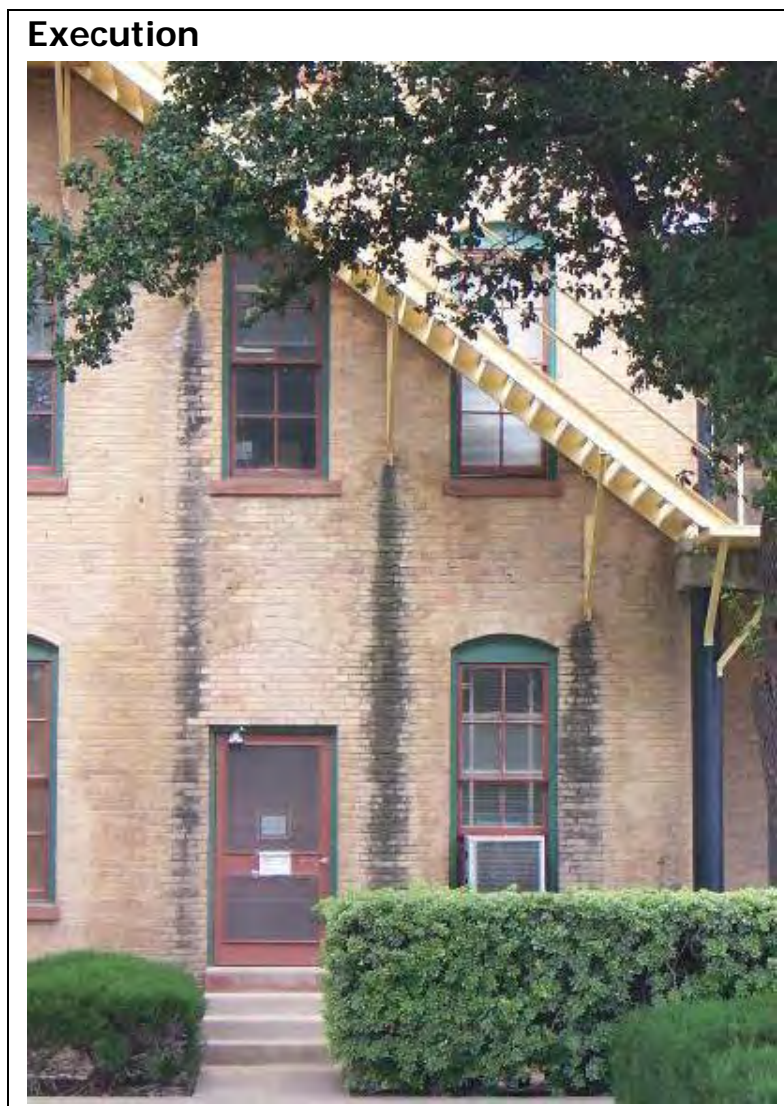

Building 21 - Authorities from the local regulatory agency, usually under jurisdiction of the Federal or State Environmental Protection Agency (EPA), should be consulted prior to beginning a cleaning project, especially if it involves anything more than plain water washing. 
Notes

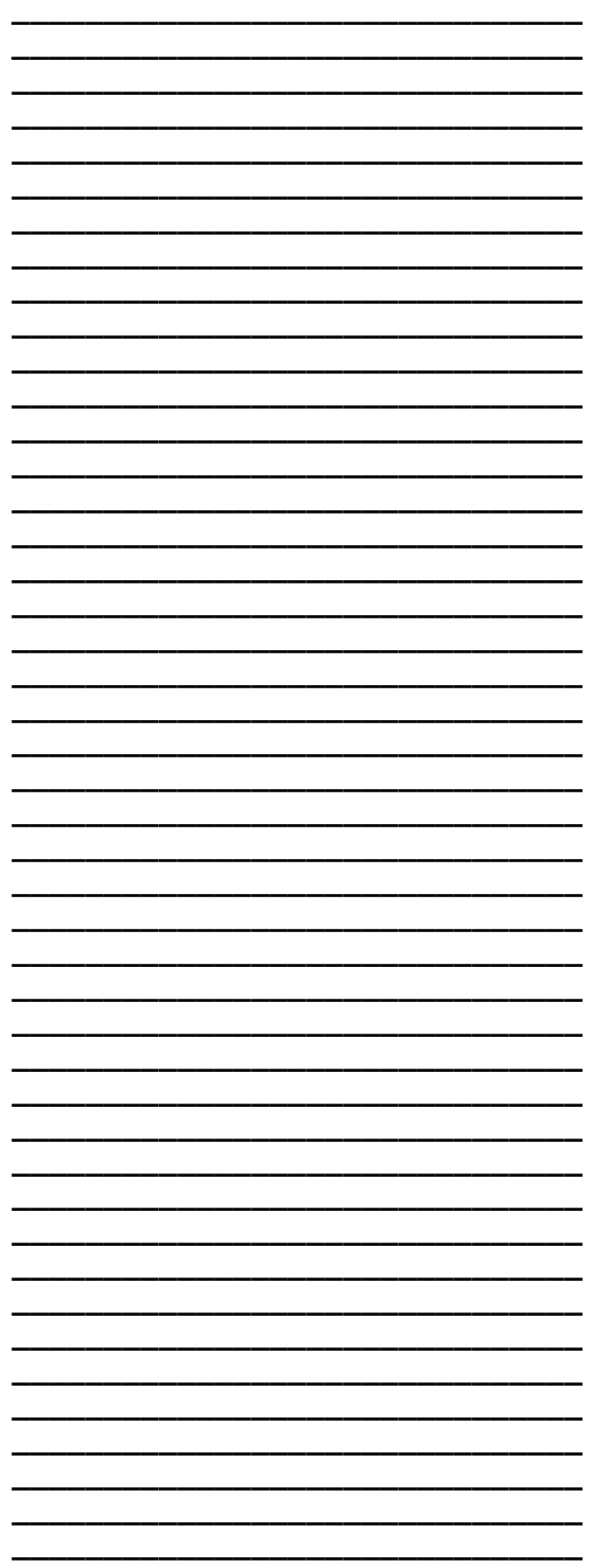




\section{Brick: Paint}

Brick properly fired, is a durable surface that does not need a sacrificial coating such as paint, to protect it. Painting often creates long-term maintenance problems. However, brick that has been painted is usually not properly fired and needs the protection provided by the application of paint. Furthermore, brick which has been damaged by abrasive cleaning may require painting in order to seal the masonry from excessive water penetration which, if not protected, can lead to further deterioration of the masonry. However, if a brick building at Fort Bliss was not originally painted, it should not be painted.

It is a common 20th-century misconception that all historic masonry buildings were initially unpainted. If the intent of a modern restoration is to return a building to its original appearance, removal of the paint not only may be historically inaccurate, but also harmful. Many older buildings were painted at some point to correct recurring maintenance problems caused by faulty construction techniques, to hide alterations, or in an attempt to solve moisture problems. If this is the case, removal of paint or stucco may cause these problems to reoccur.

\section{Causes}

The cause of paint failure often stems from poor paint, inadequate preparation, or faulty workmanship. Sometimes peeling paint is caused by moisture build-up in the wall. Cracking is often caused by poor adhesion, which comes from incompatible types of paint layered over each other or from the build-up of many layers of old paint. Careful scraping to remove the layers often results in improved performance.

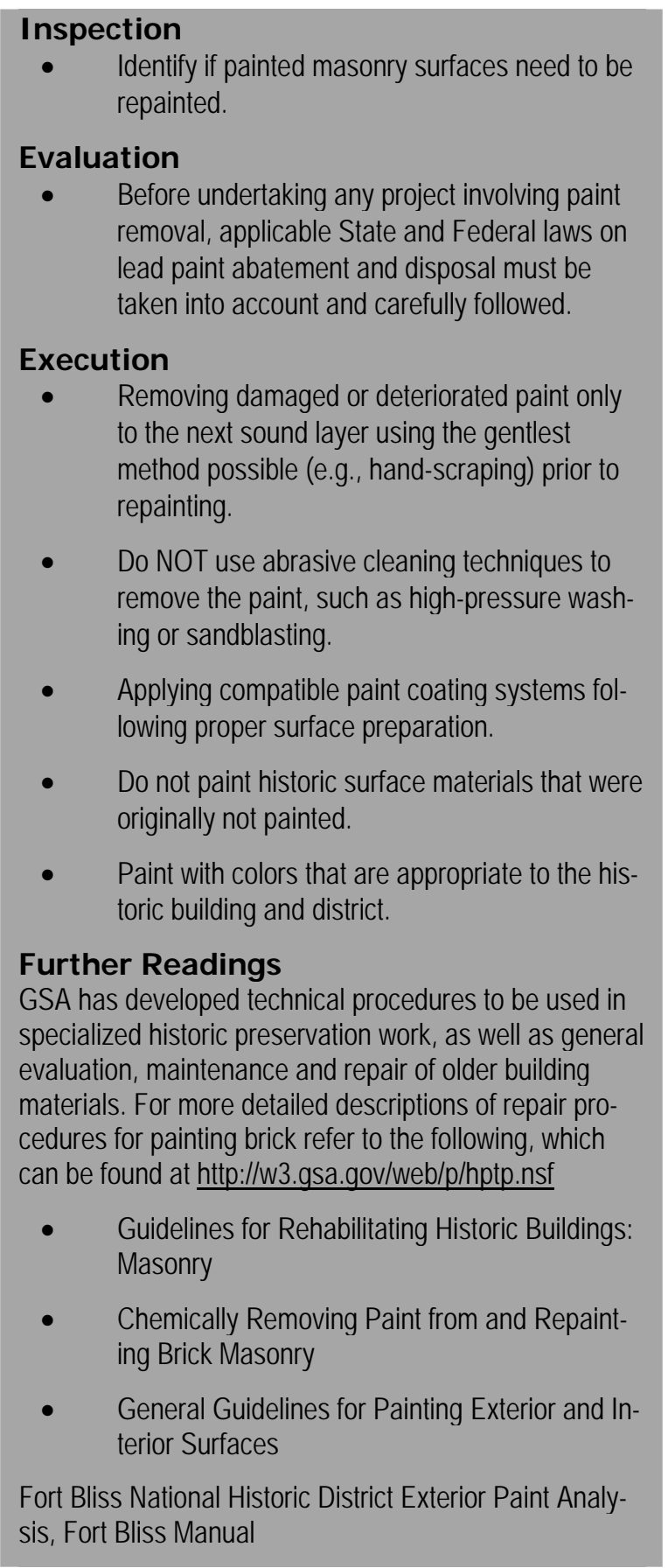




\section{Inspection}

Recommended...

- Inspecting painted masonry surfaces to determine whether repainting is necessary.

Not Recommended...

- $\quad$ Removing paint that is firmly adhering to, and thus protecting, masonry surfaces.

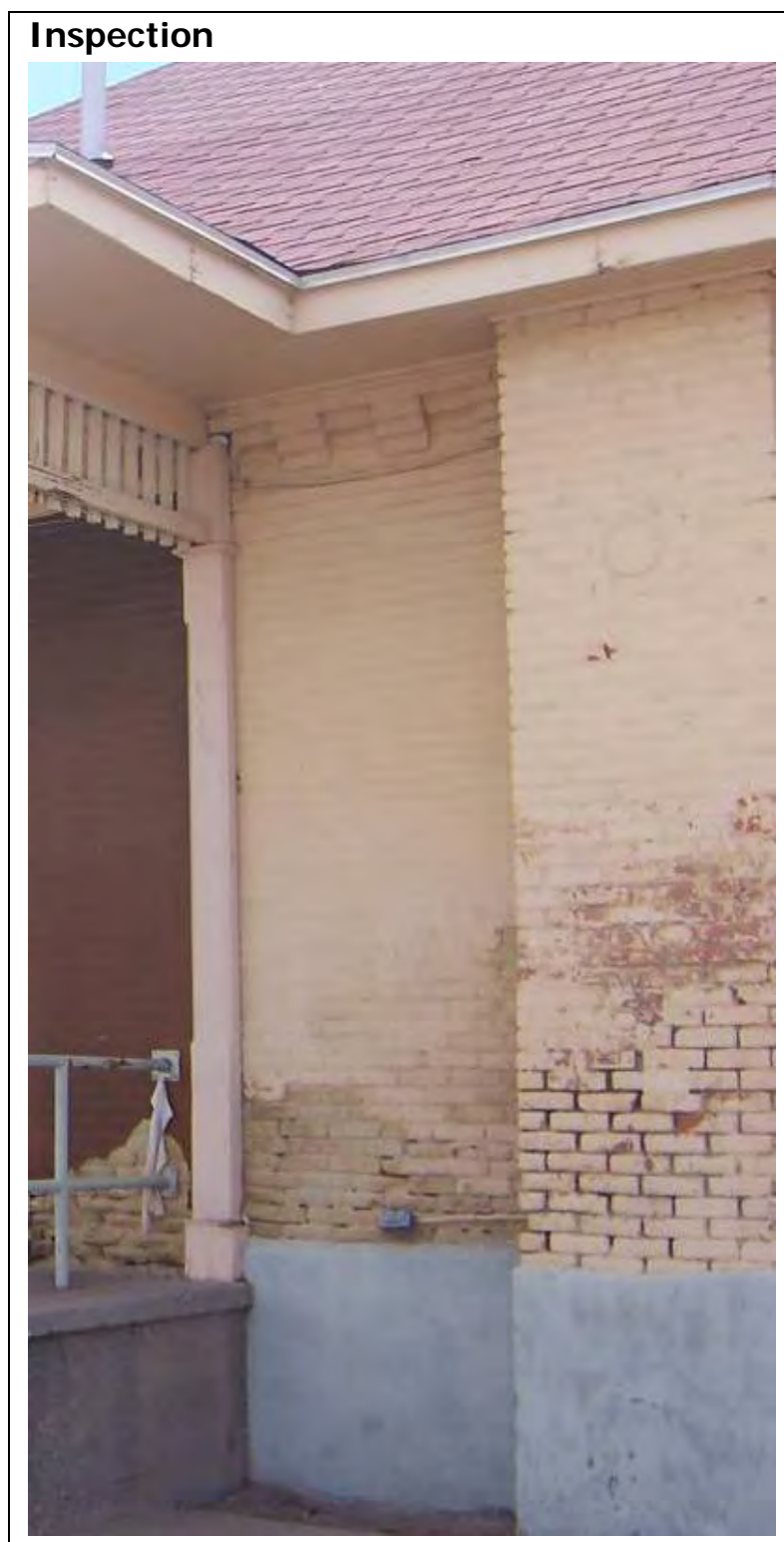

Building 122 - Identify the root cause of paint failure and if the bricks need to be cleaned and repainted. 


\section{Evaluation}

Recommended...

- A study of all the paint layers should be conducted to determine what were the original colors and if any special treatments were used.

- $\quad$ Under the supervision of the historic architect, test panels using the appropriate cleaning methods, shall be done to determine the best method to remove paint.

- $\quad$ Testing shall include the evaluation of the materials and techniques proposed for the protection of surrounding areas from the chemicals used to strip the paint.

- $\quad$ Removing damaged or deteriorated paint only to the next sound layer using the gentlest method possible (e.g., hand-scraping) prior to repainting.

Not Recommended...

- Using methods of removing paint which are destructive to masonry, such as sandblasting, application of caustic solutions, or high-pressure water-blasting. These methods of cleaning may permanently erode the wall surface and accelerate deterioration.

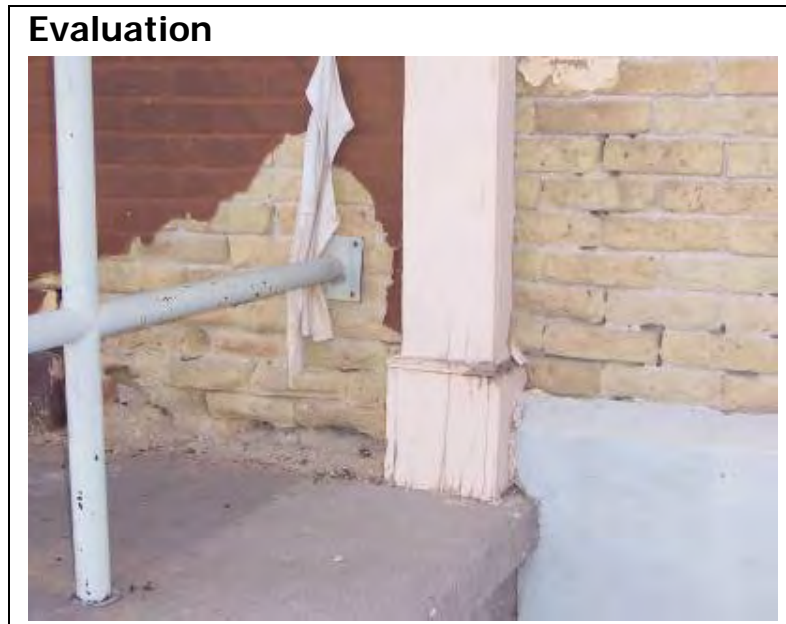

Building 21 - Before undertaking any project involving paint removal, applicable State and Federal laws on lead paint abatement and disposal must be taken into account and carefully followed. 


\section{Execution}

\section{Recommended...}

- $\quad$ Manually scraping away all loose paint and efflorescence using paint scrapers, putty knifes, or stiff bristle brushes. If the mortar and bricks are quite crumbly, use a softer brush.

- $\quad$ Applying compatible paint coating systems following proper surface preparation.

- $\quad$ Repainting with colors that are historically appropriate to the building and district.

Not Recommended...

Note: Sandblasting is NOT recommended by The Secretary of the Interior's Standards for Rehabilitation and shall not be used. High-pressure water blasting is also NOT recommended without adequate testing or experience as it may erode soft brick and drive moisture into the wall.

- $\quad$ Failing to follow manufacturers' product and application instructions when repainting masonry.

- $\quad$ Using new paint colors that are inappropriate to the historic building and district.

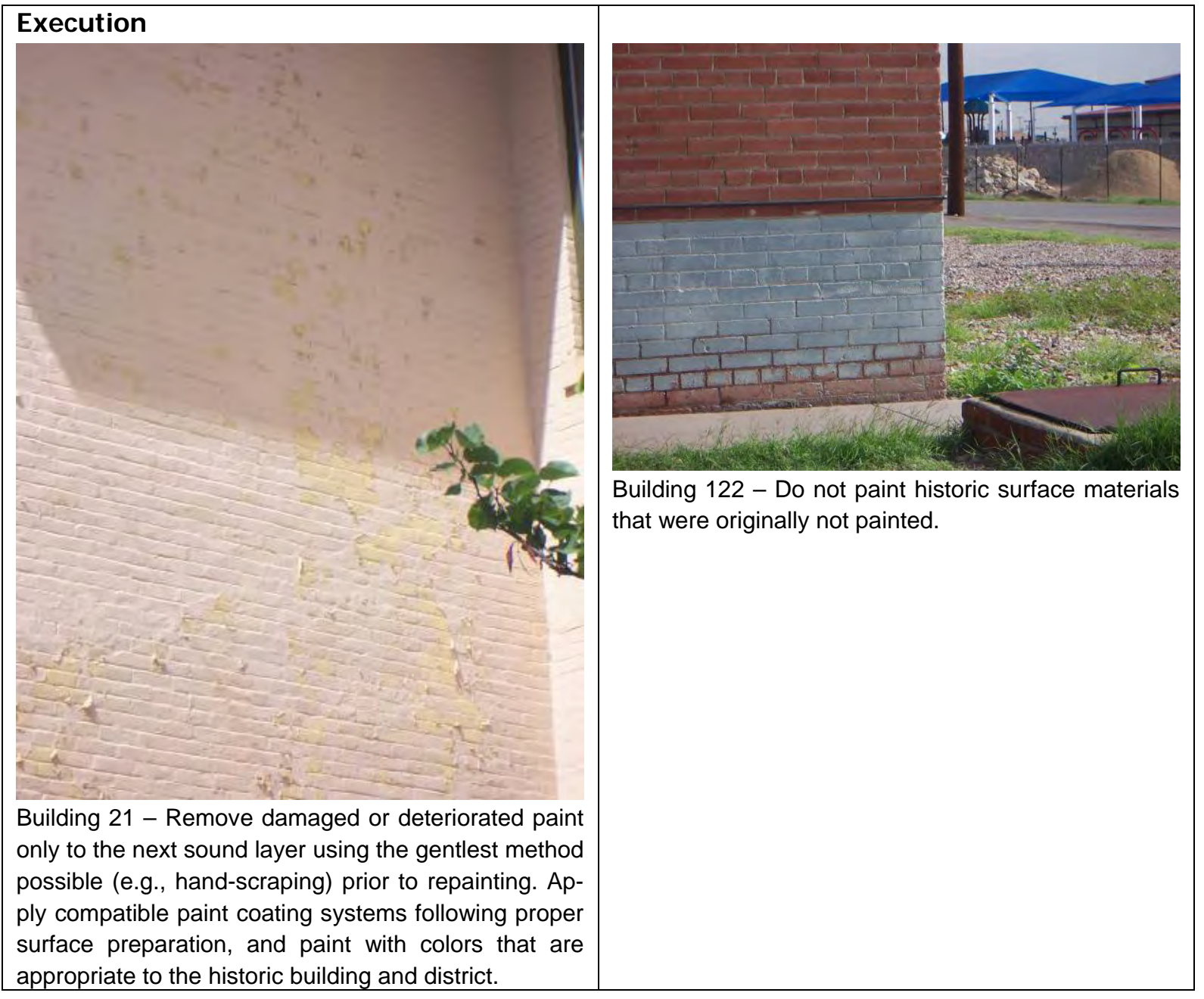


Notes

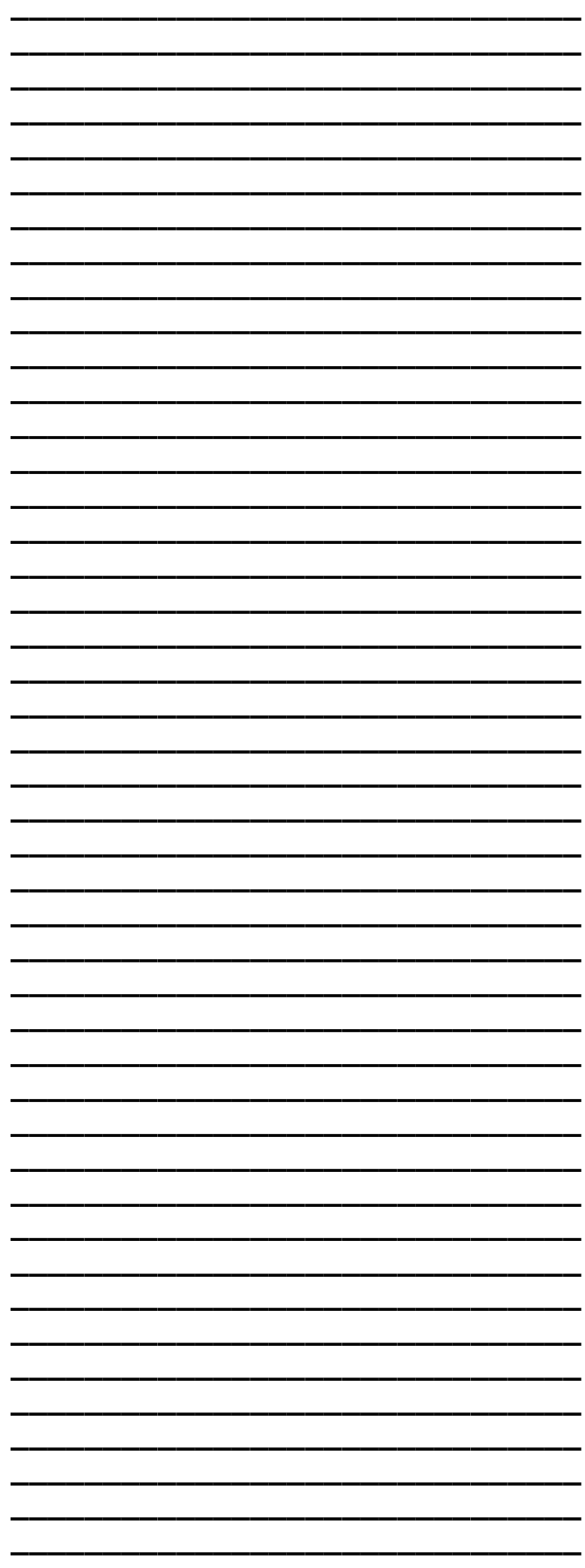




\section{Maintenance Guides for Concrete}

\section{Concrete: Overview}

Concrete is a name applied to any of a number of compositions consisting of sand, gravel, crushed stone, or other coarse material, bound together with various kinds of cementitious materials, such as lime or cements. It is among the most durable of historic building materials, but it is also very susceptible to damage by improper maintenance or repair, and by harsh or abrasive cleaning methods. Deterioration in concrete can be caused by environmental factors, inferior materials, poor workmanship, inherent structural design defects, and inadequate maintenance.

Types of concrete include:

- $\quad$ unreinforced concrete

- $\quad$ reinforced concrete

- $\quad$ cast-in place concrete.

Typical historical and current uses for concrete include:

- $\quad$ structural uses such as foundations, walls, and floors and/or

- decorative/ornamental uses, which may be cast to form moldings and other decorative features; may be carved; may be used in a variety of colors, textures, bonds, and joints and/or

- $\quad$ may be concealed by other finish materials such as stucco, plaster, or paint, or may be exposed both on the interior and exterior.

All exposed masonry should be inspected for cracking, spalling, deflection, erosion, and corrosion. The overall quality of the building's construction and often that of its neighbors is a good indicator of the condition of the masonry. Masonry features (such as concrete cornices and door pediments, stone window architraves, brackets and railings) as well as masonry surfaces (modeling, tooling, bonding pattern, joint size, and color) may be important in defining the historic character of the building.

\author{
Maintenance/ Management Guidelines \\ for Concrete \\ - Effective protection and maintenance are the \\ keys to the durability of concrete. Improper \\ maintenance of historic buildings can cause \\ long-term deterioration of concrete. Water is a \\ principal source of damage to historic concrete \\ and prolonged exposure to it can cause serious \\ problems. Even when historic concrete struc- \\ tures are deteriorated, many can be saved \\ through preservation projects involving sensi- \\ tive repair or replacement of deteriorated con- \\ crete with carefully selected matching material. \\ As soon as rehabilitation or restoration has \\ been completed, some program of continuing \\ maintenance should be initiated. Changes in \\ the building should particularly be noted. The \\ early stages of cracking, deflection, or spalling \\ in concrete should be monitored regularly. All \\ water damage should be noted and remedied \\ at its earliest possible stages. Plant, animal, \\ and insect damage should be halted before it \\ becomes substantial. Surface coatings must be \\ inspected frequently and repaired or replaced \\ as the need indicates.
}

- According to The Secretary of the Interior's Standards for Rehabilitation, the proper procedure is to respect the significance of the original materials and features, repair and retain wherever possible, and replace them only when absolutely necessary.

- The following recommendations for care of the historic site are to be thoroughly read and understood before a treatment is specified. The Secretary of the Interior's Standards for Rehabilitation should also be consulted to determine the appropriateness of any treatment.

Full documentation can be found at http://www.cr.nps.gov/hps/tps/tax/rhb/stand.htm

Structural Condition Assessment Report: Structural Concrete- Fort Bliss Main Post Historic District, Fort Bliss Report 


\section{Identify, Retain, and Preserve}

Recommended...

- Identifying, retaining, and preserving concrete features that are important in defining the overall historic character of the building.

Not Recommended...

- $\quad$ Removing or radically changing concrete features that are important in defining the overall historic character of the building so that, as a result, the character is diminished.

- $\quad$ Replacing or rebuilding a major portion of exterior concrete walls that could be repaired so that, as a result, the building is no longer historic and is essentially new construction.

- Applying paint or other coatings such as stucco to concrete that has been historically unpainted or uncoated to create a new appearance.

- $\quad$ Removing paint from historically painted concrete.

- $\quad$ Radically changing the type of paint or coating or its color.

\section{Protect and Maintain}

Recommended...

- $\quad$ Providing proper drainage so water does not stand or accumulate.

- $\quad$ Cleaning concrete only when necessary to halt deterioration or remove heavy soiling.

- Carrying out masonry surface cleaning tests after it has been determined that such cleaning is appropriate. Tests should be observed over a sufficient period so that both the immediate and the long range effects are known to enable selection of the gentlest method possible.

- $\quad$ Cleaning masonry surfaces with the gentlest method possible, such as low-pressure water and detergents, using natural bristle brushes.

- Inspecting painted concrete surfaces to determine whether repainting is necessary.

- $\quad$ Removing damaged or deteriorated paint only to the next sound layer using the gentlest method possible (e.g., hand-scraping) prior to repainting.

- $\quad$ Applying compatible paint coating systems following proper surface preparation.

- $\quad$ Repainting with colors that are historically appropriate to the building and district.

- $\quad$ Evaluating the overall condition of the masonry to determine whether more than protection and maintenance are required, that is, if repairs to the concrete features will be necessary.

Not Recommended...

- $\quad$ Cleaning masonry surfaces when they are not heavily soiled.

- $\quad$ Cleaning concrete surfaces without testing or without sufficient time for the testing results to be of value.

- $\quad$ Sandblasting using dry or wet grit or other abrasive agents; high-pressure water-blasting, or caustic solutions. These methods of cleaning and paint removal may permanently erode concrete surfaces and accelerate deterioration.

- $\quad$ Failing to undertake adequate measures to assure the protection of concrete features. 


\section{Repair}

Recommended...

- $\quad$ Repairing any cracks in concrete by sealing with specification-approved sealant.

- $\quad$ Patching damaged sections with in-kind material finished to match the existing.

Not Recommended...

- $\quad$ Using a substitute material for the replacement part that does not convey the visual appearance of the surviving parts of the concrete feature or that is physically or chemically incompatible.

- Applying waterproof, water repellent, or non-historic coatings such as stucco to concrete as a substitute for repairs.

\section{Replace}

Recommended...

- $\quad$ Repairing damaged concrete too deteriorated to patch by cutting damaged material back to remove the source of deterioration (often corrosion of metal reinforcement bars).

- $\quad$ Applying new patch with in-kind material finish to match the existing.

Not Recommended

- $\quad$ Removing a concrete feature that is unrepairable and not replacing it; or replacing it with a new feature that does not convey the same visual appearance.

\section{Good Examples of Concrete}
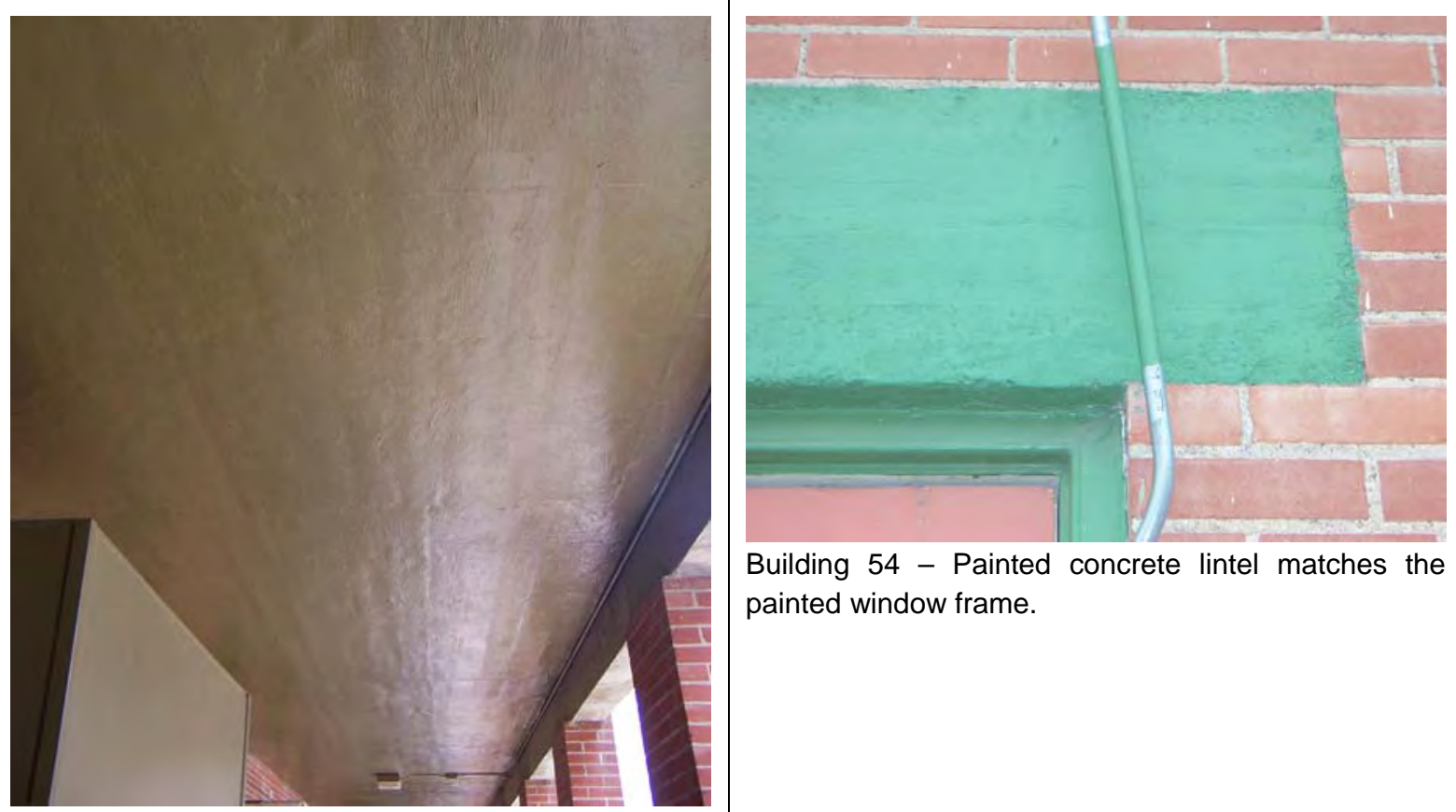

Building 54 - Painted concrete lintel matches the painted window frame.

Building 11 - Painted concrete ceiling, which is the underside of the exterior balcony. 


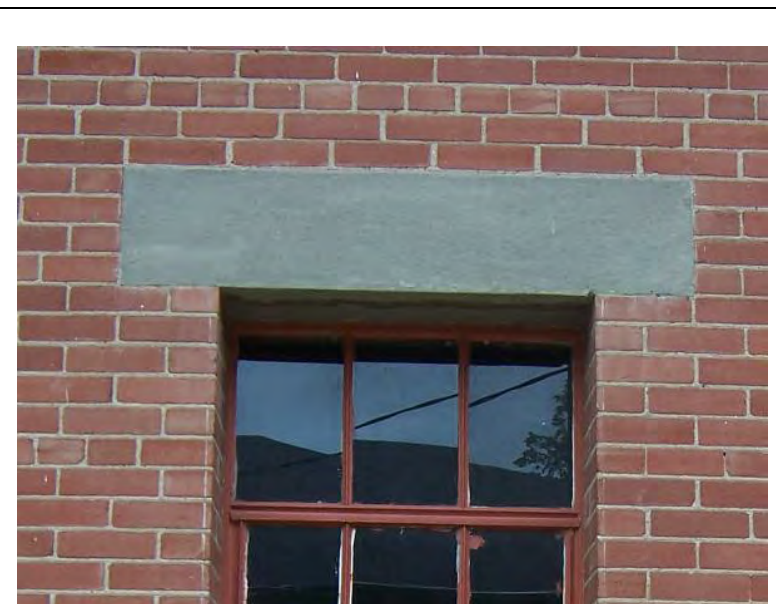

Building 54 - Unpainted concrete window lintel.

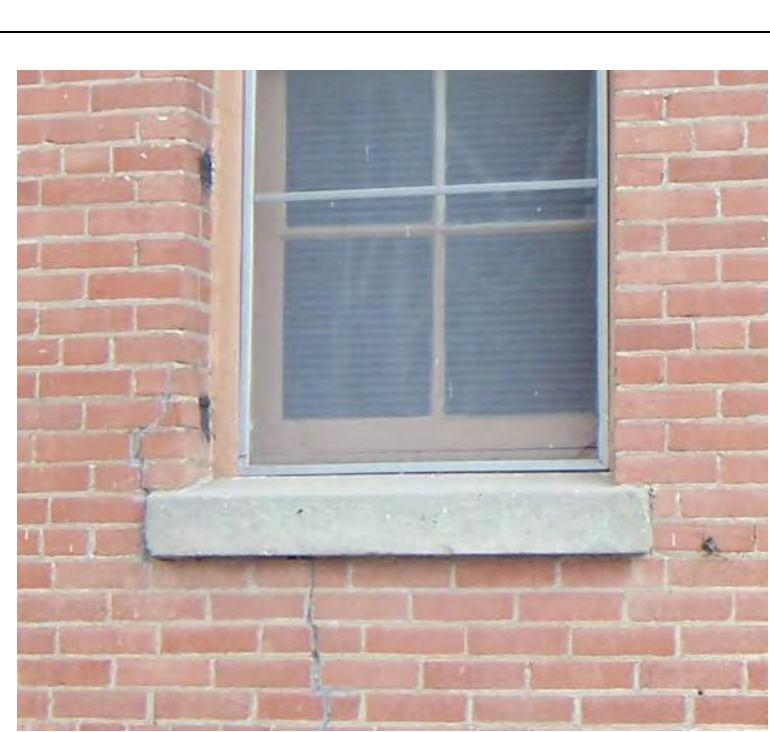

Building 55 - Unpainted concrete windowsill

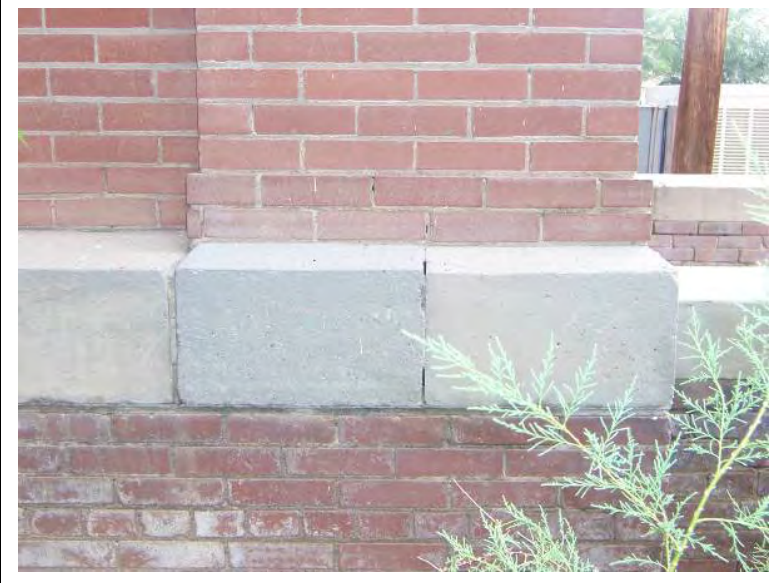

Building 55 - Exposed concrete water table detail.

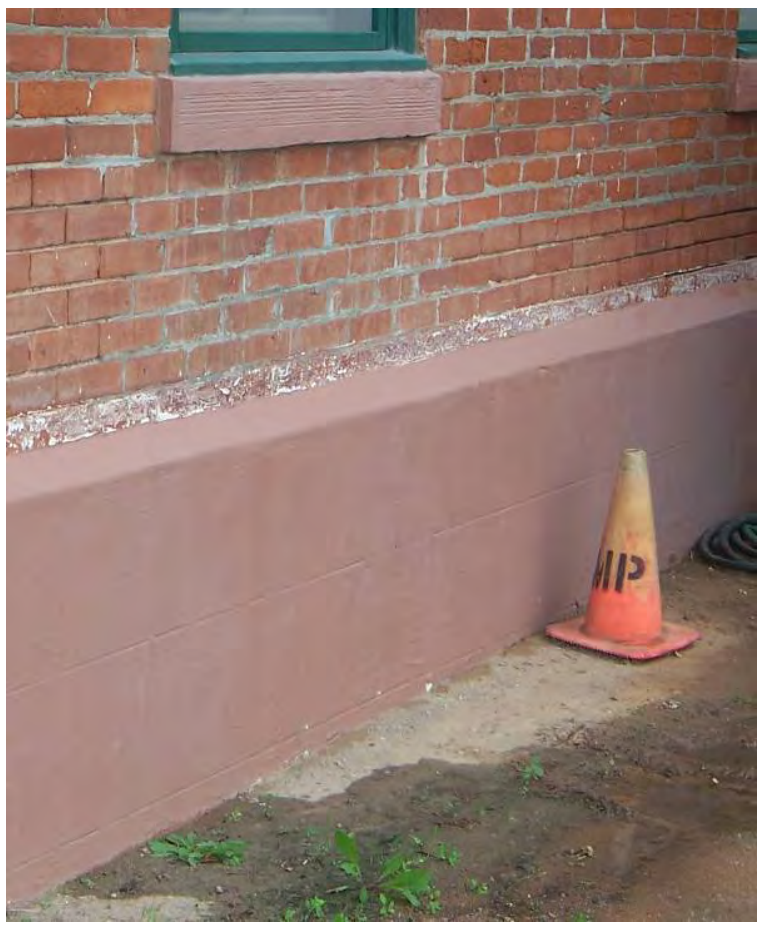

Building 128 - Painted and scored concrete foundation wall. 


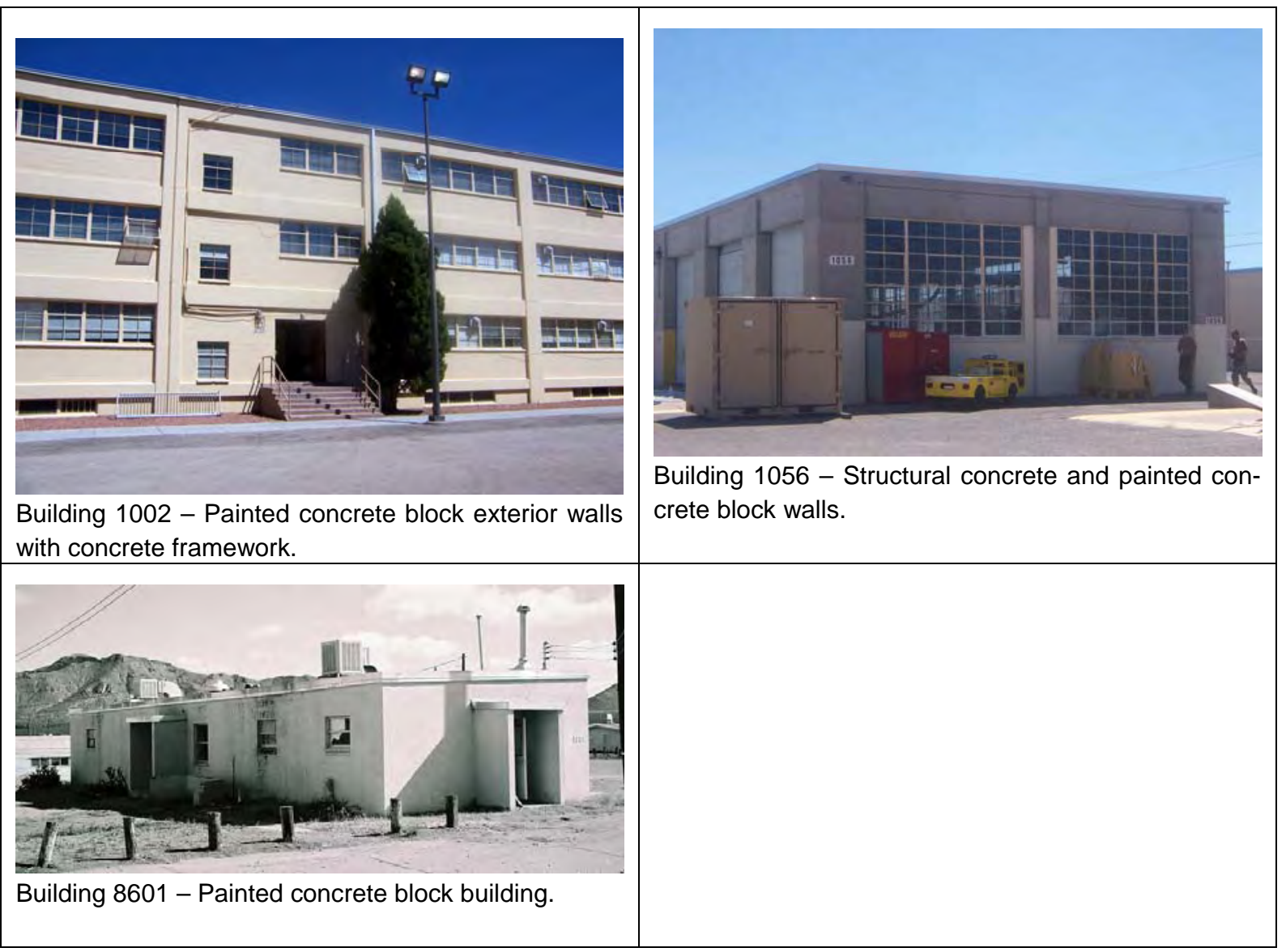




\section{Concrete: Spalling/Corrosion/Erosion}

\section{Spalling}

All exposed masonry should be inspected for spalling. The spalling, dusting, or flaking of concrete may be due to either mechanical or chemical damage. Spalling concrete is largely due to a natural deterioration process called carbonation. Carbon dioxide in the air diffuses into the concrete and reacts with the alkalis in it. The concrete becomes carbonated, which allows the embedded steel bars to corrode. These steel bars expand and exert a force on the surrounding concrete causing the concrete to bulge and crack. The early stages of spalling concrete will not affect the safety of the building. However, the spalling concrete should be repaired as soon as possible before the steel bars corrode further and damage larger areas. Mechanical damage is caused by moisture entering the concrete and freezing. The expansion of the ice will break off the concrete's surface. The loss of the surface material may vary in size.

Vapor-proof paints or sealants, which trap moisture beneath the surface of the impermeable barrier, also can cause spalling. Spalling may also result from the improper consolidation of concrete during construction. In this case, water-rich cement paste rises to the surface. The surface weakness encourages scaling, which is spalling in thin layers. Spalling is a common maintenance problem when buildings get older.

\section{Corrosion}

Corrosion is the rusting of reinforcing bars in concrete and can be a most serious problem. Normally, embedded reinforcing bars are protected against corrosion by being buried within the mass of the concrete and by the high alkalinity of the concrete itself. This protection, however, can be destroyed in two ways. First, by carbonation, which occurs when carbon dioxide in the air reacts chemically with cement paste at the surface and reduces the alkalinity of the concrete. Second, chloride ions from salts combine with moisture to produce an electrolyte that effectively corrodes the reinforcing bars. Chlorides may come from seawater additives in the original mix, or from prolonged contact with salt spray or deicing salts.

Regardless of the cause, corrosion of reinforcing bars produces rust, which occupies significantly more space than the original metal and causes expansive forces within the concrete. Cracking and spalling are frequent results. In addition, the load-carrying capacity of the structure can be diminished by the loss of concrete, by the loss of bond between reinforcing bars and concrete, and by the decrease in thickness of the reinforcing bars themselves. Rust stains on the surface of the concrete area an indication that internal corrosion is taking place. 


\section{Erosion}

Erosion is the weathering of the concrete surface by wind, rain, and salt air. Erosion can also be caused by inadequate drainage of water. Rainwater that has accumulated at the base of concrete walls should be diverted away from the building. This may be done by regrading or by building gravel-filled trenches or stone drip gutters. Regrading is perhaps the best solution because defective gutters and trenches may in effect collect and hold water at the base of the wall or foundation.

\section{Inspection}

Recommended...

- Identifying, retaining, and preserving concrete features that are important in defining the overall historic character of the building.

- A concrete sealant can help prevent the problem as long as it allows the concrete to breathe.

- $\quad$ Keeping moisture away from concrete foundations by providing proper drainage away from the structure.

- $\quad$ Slight rust stains coming out of an otherwise innocent looking concrete surface are often the first symptom of spalling. Such areas must be repaired immediately.

Not Recommended...

- $\quad$ Failing to identify the root cause of concrete damage.

- $\quad$ Not conducting a routine maintenance check on concrete elements.

- $\quad$ Removing or radically changing concrete features which are important in defining the overall historic character of the building so that, as a result, the character is diminished. 


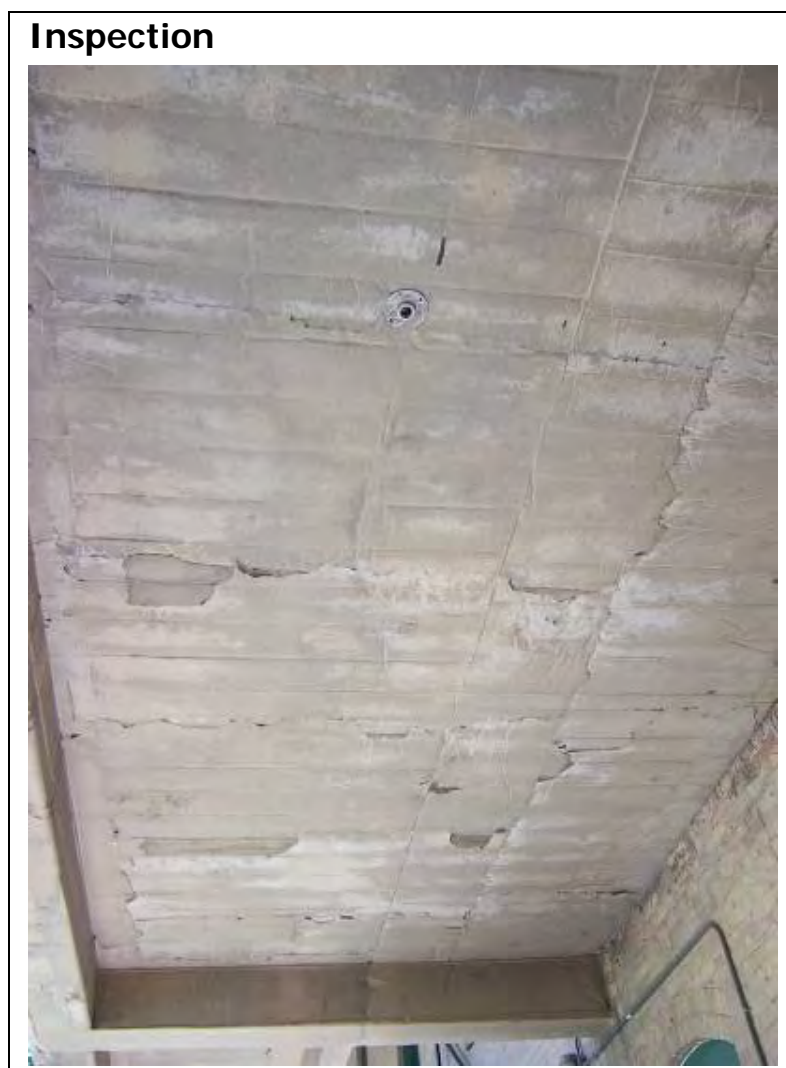

Building 13 - A periodic inspection of concrete surfaces is essential in maintaining and preserving concrete features that are important in defining the overall historic character of the building.

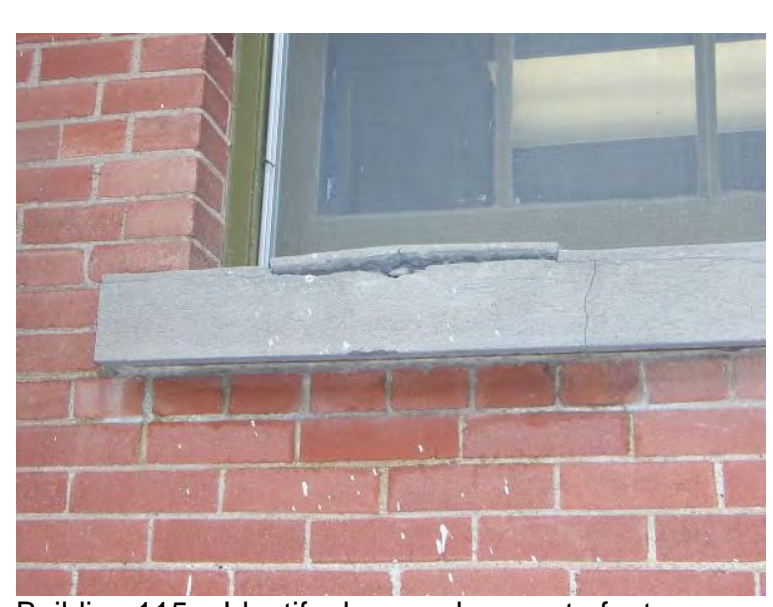

Building 115 - Identify damaged concrete features such as windowsills and note the root cause of damage.

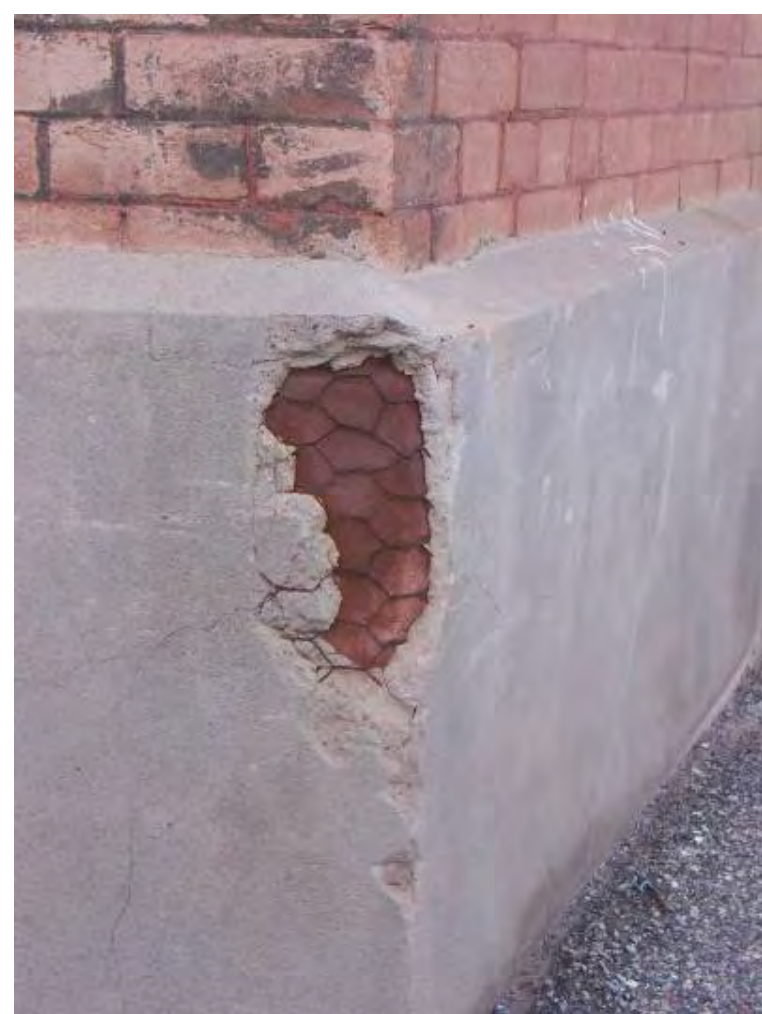

Building 13 - It is not recommended to replace an entire concrete feature that could be repaired. It is not recommended to use a substitute material for the replacement part that does not convey the visual appearance of the surviving parts of the concrete feature.

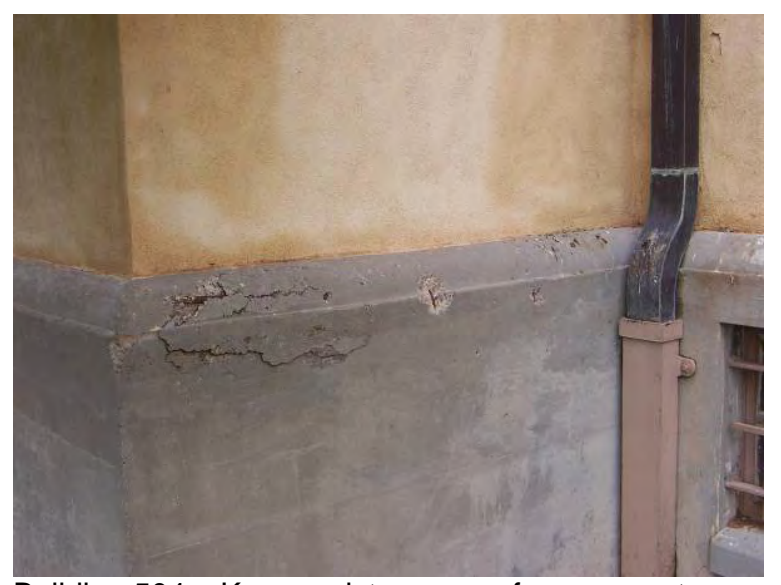

Building 504 - Keep moisture away from concrete foundations. Direct water flow away from the building in order to preserve concrete foundations. 


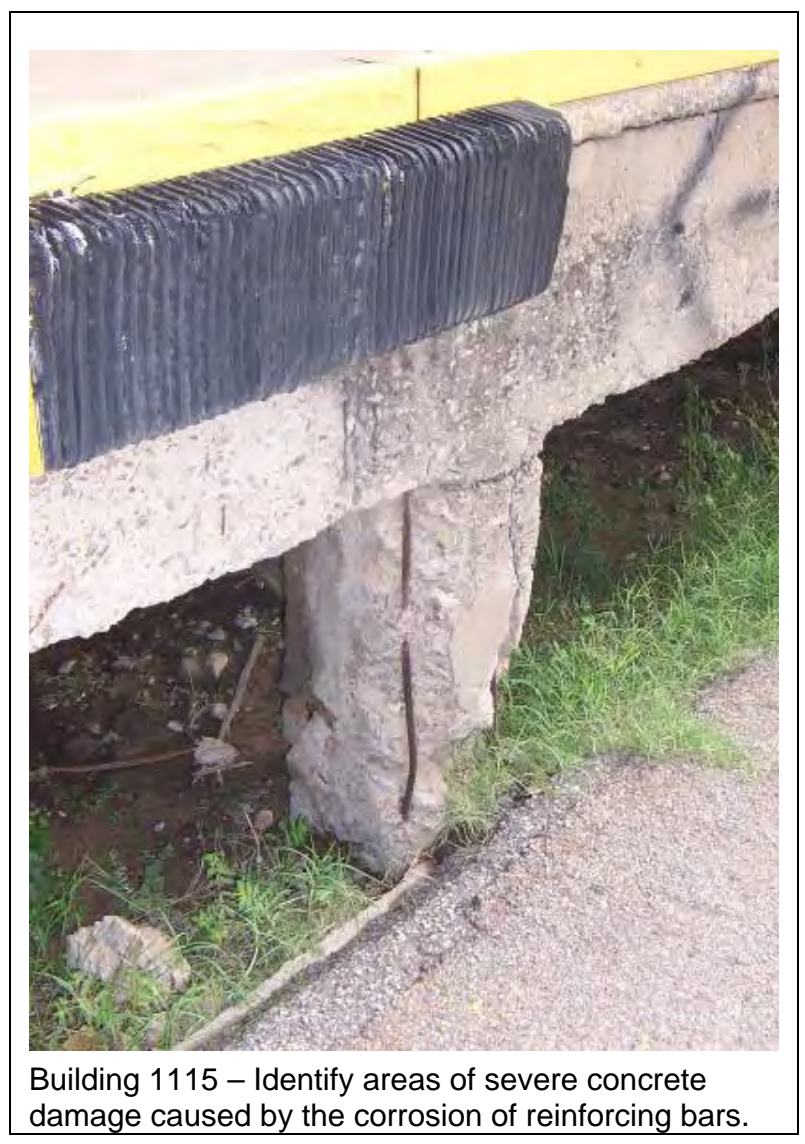

\section{Evaluation}

- $\quad$ Determine the level of repair for damaged concrete.

- $\quad$ Provide proper drainage so that water does not accumulate on concrete features.

In order to prevent future crack development after the spall has been patched and to ensure that the patch matches the historic concrete, great attention must be paid to the:

- $\quad$ existing treatment of rebars,

- $\quad$ the preparation of the existing concrete substrate,

- $\quad$ the selection of compatible patch material,

- $\quad$ the development of good contact between patch and substrate, and

- $\quad$ the curing of the patch. 


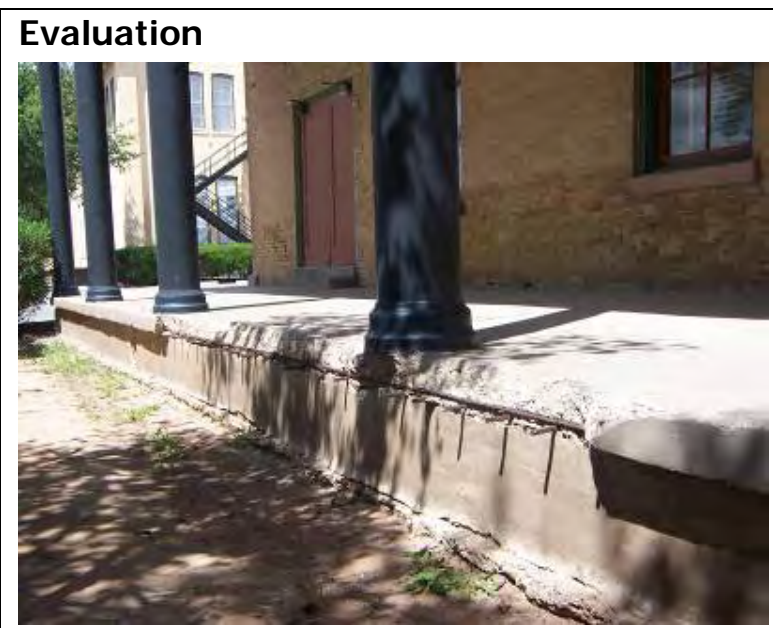

Building 13 - Repair the source of damage before repairing the concrete.

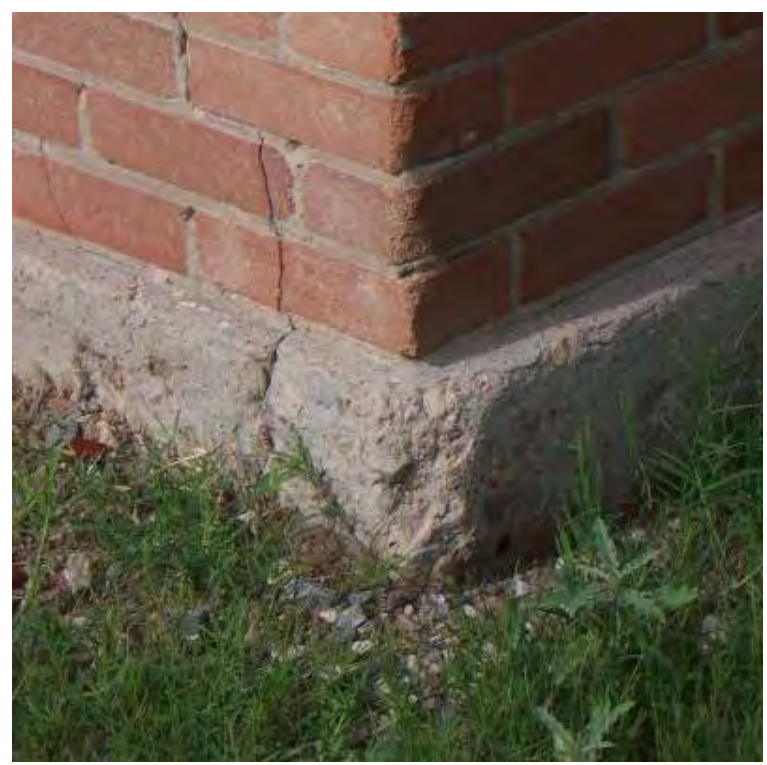

Building 889 - Provide proper water drainage away from concrete foundations so that water does not accelerate concrete deterioration.

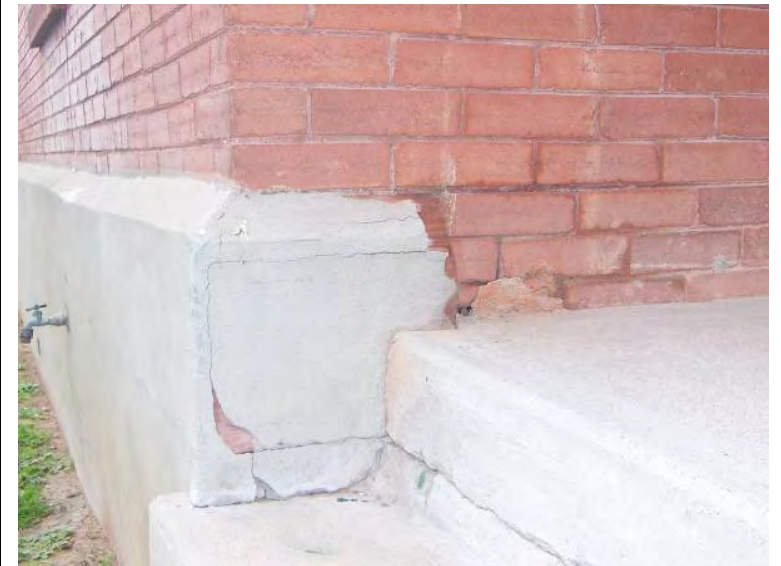

Building 111 - Patch and repair damaged concrete with a material similar or compatible to the original material in color and texture.

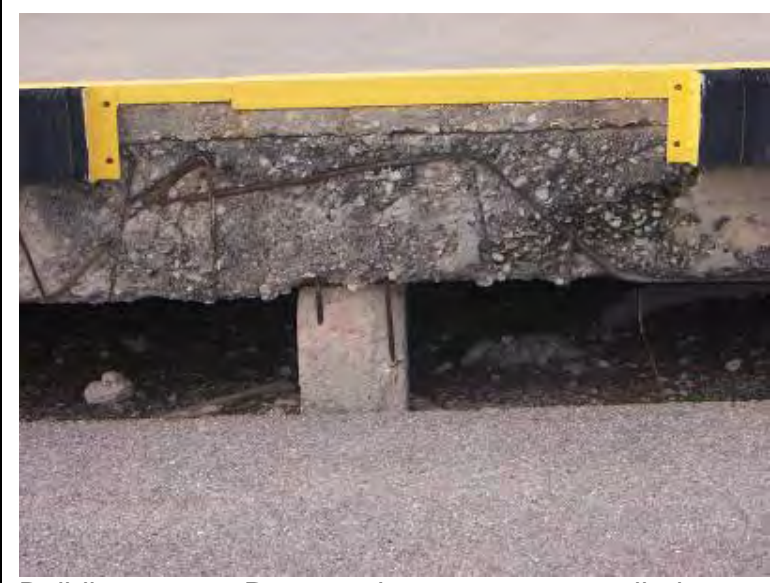

Building 1119 - Remove the concrete at spalled areas to expose the corroded steel bars. Once the deteriorated concrete has been removed, rust on the exposed rebars must be removed by wire brush. Note: If the rebars are so corroded that a structural engineer determines they should be replaced, new supplemental rebars will normally be required.

\section{Execution}

Repair of historic concrete may consist of either patching the historic material or filling in with new material worked to match the historic material. If replacement is necessary, duplication of historic materials and detailing should be as exact as possible to assure a repair that is functionally and aesthetically acceptable. The correction and elimination of concrete problems can be difficult, time-consuming, and costly. Yet the temptation to resort to temporary solutions should be avoided, since their failure can expose a building to further and more serious deterioration, and in some cases can mask underlying structural problems that could lead to serious safety hazards.

\section{Repair}

Recommended...

- $\quad$ Removing the concrete at the spalled areas to expose the corroded steel bars. 
- $\quad$ Once the deteriorated concrete in a spalled area has been removed, rust on the exposed rebars must be removed by wire brush. Note: If the rebars are so corroded that a structural engineer determines they should be replaced, new supplemental reinforcing bars will normally be required, assuming that the rebar is important to the strength of the concrete. If not, it is possible to cut away the rebar.

- $\quad$ Applying an epoxy coating immediately over the cleaned bars will help diminish the possibility of further corrosion.

- $\quad$ Properly preparing the substrate to ensure a good bond between the patch and the existing concrete.

- $\quad$ The substrate should be kept moist with wet rags, sponges, or running water for at least an hour before placement of the patch.

- $\quad$ Bonding between the patch and substrate can be encouraged by scrubbing the substrate with cement paste, or by applying a liquid bonding agent to the surface of the substrate. Note: admixtures such as epoxy resins, latexes, and acrylics in the patch may also be used to increase the bonding, but this may cause problems with color matching if the surfaces are to be left unpainted.

- $\quad$ Compatible matching of patch material to the existing concrete is critical for both appearance and durability. It should match as closely as possible so that the properties of the two materials, such as coefficient of thermal expansion and strength, are compatible.

- $\quad$ Repairing material should match the composition of the original material.

- $\quad$ Applying the proper depth/thickness of concrete to cover the reinforcing bars.

Not Recommended...

- $\quad$ Replacing or rebuilding a major portion of foundation, wall, or detail that could be repaired.

- Patching concrete without removing the source of deterioration.

- $\quad$ Patching with substitute material that is physically or chemically incompatible with the original concrete.

\section{Replace}

Recommended...

- $\quad$ Repairing damaged concrete too deteriorated to patch by cutting damaged material back to remove the source of deterioration (often corrosion of metal reinforcement bars).

- $\quad$ Limited replacement in-kind or with compatible substitute material of those extensively deteriorated or missing parts of masonry feature. In replacing damaged concrete, every reasonable effort should be made to match the patch material in a texture and color similar to the original fabric.

- $\quad$ Replacing in-kind an entire feature that is too deteriorated to repair. Examples can include large sections of a wall, a cornice, balustrade, column, or stairway. If using the same kind of material is not technically or economically feasible, then a compatible substitute material may be considered.

Not Recommended...

- $\quad$ Removing a concrete feature that is unrepairable and not replacing it; or replacing it with a new feature that does not convey the same visual appearance. 


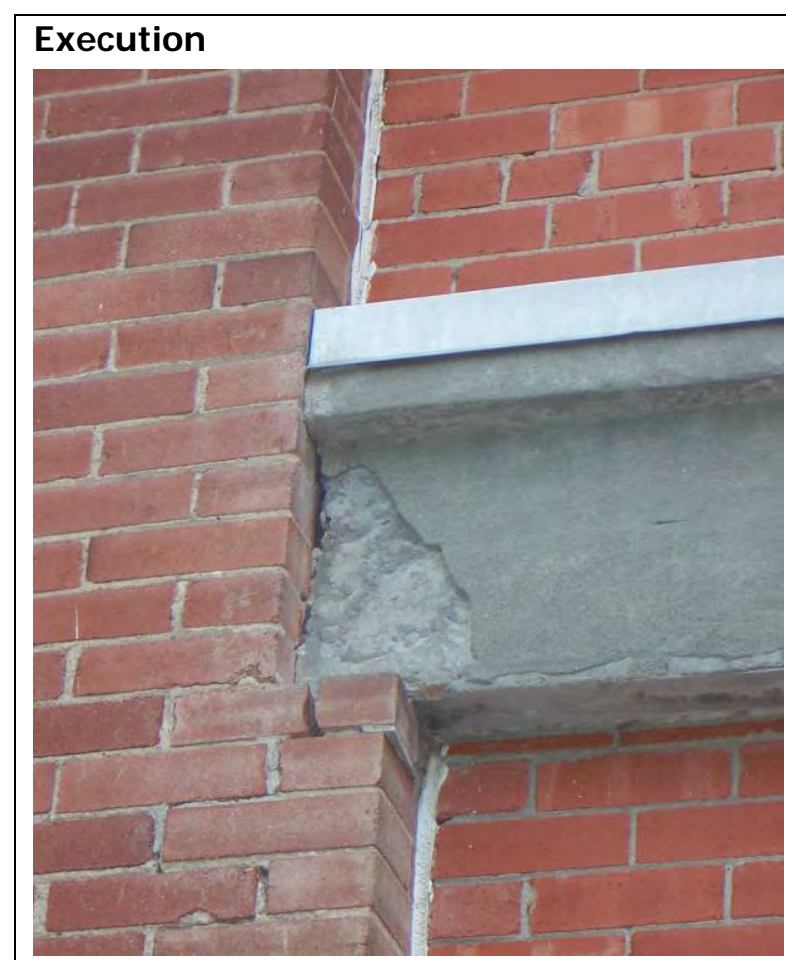

Building 113 - Properly prepare the substrate to ensure a good bond between the patch and the existing concrete. Compatible matching of patch material to the existing concrete is critical for both appearance and durability.

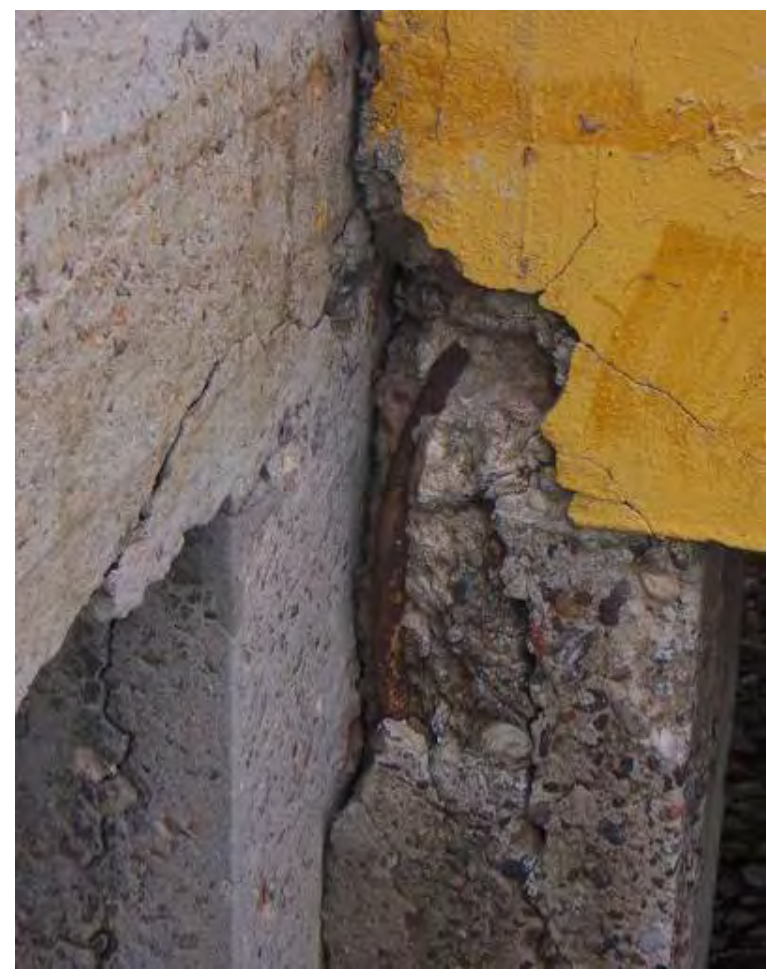

Building 1113 - Remove the concrete at the spalled areas to expose corroded steel bars.

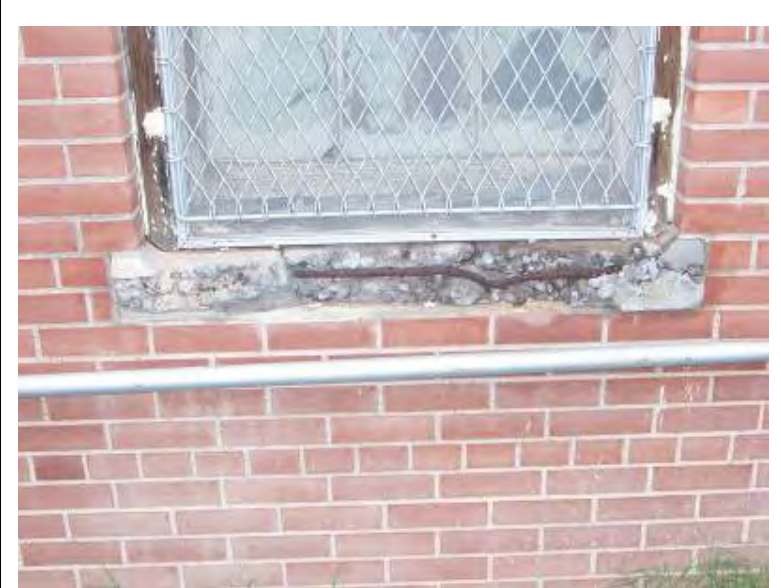

Building 612 - Appropriate thickness of concrete over reinforcing bars is recommended so that the concrete does not fail.

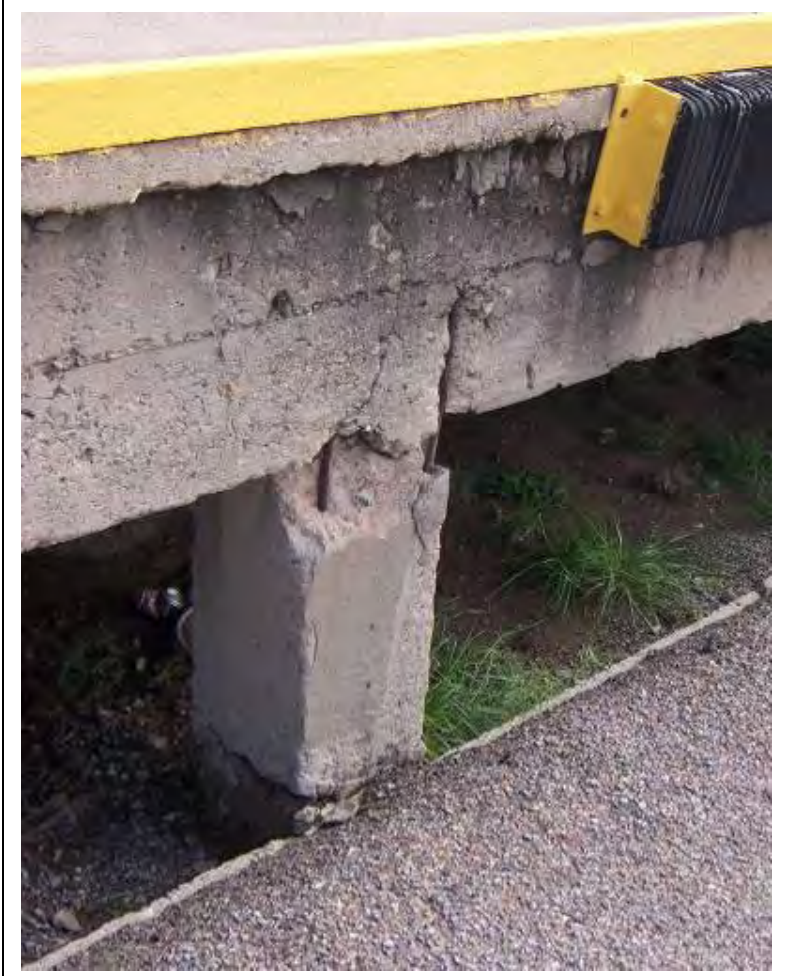

Building 1114 - Repair concrete too deteriorated to patch by cutting damaged material back to remove the source of deterioration. 
Notes

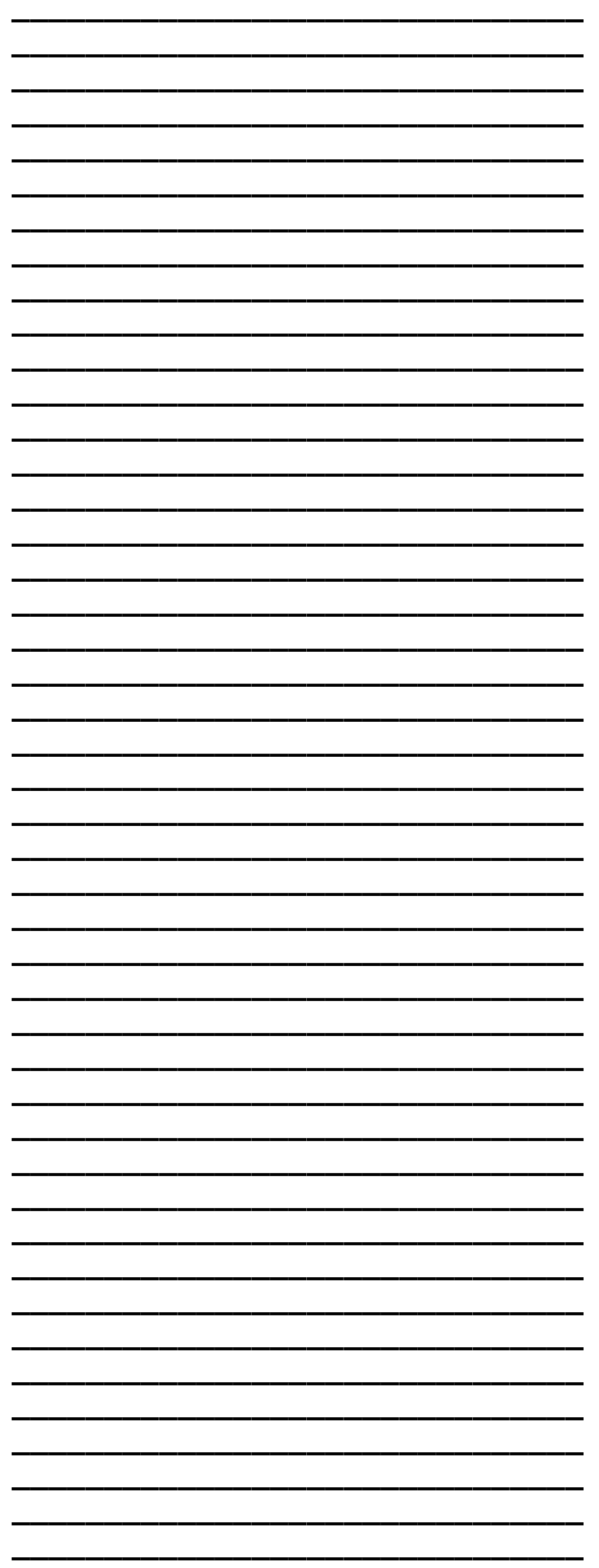




\section{Concrete: Cracking}

All exposed masonry should be inspected for cracking. Although masonry can deform elastically over long periods of time to accommodate small amounts of movement, large movements normally cause cracking. Cracks vary in depth, width, direction, pattern, location, and cause. Cracks can be either active or dormant (inactive). Dormant cracks, such as those formed during the curing process, pose no danger, but if left unrepaired, they can allow moisture penetration into the concrete, which usually causes damage. Cracking may result in a variety of problems: differential settlement of foundations, drying shrinkage, expansion and contraction due to ambient thermal and moisture variations, improper support over openings, the effects of freezethaw cycles, the corrosion of iron and steel wall reinforcement, and differential movement between building materials. Cracking can originate within concrete due to a number of mechanisms.

\section{Causes}

- $\quad$ Plastic shrinkage cracking: are most common in slabs and are relatively short cracks that occur in unhardened concrete. The cracks appear in the surface of fresh concrete soon after it is placed and while it is still plastic. The cracks appear mostly on horizontal surfaces. They typically run diagonally and parallel to each other, are relatively shallow, and highly likely to occur when high evaporation rates cause the concrete surface to dry out before it is set. These cracks are unsightly but rarely impair the strength and durability of the concrete. Any factor that delays the setting increases the possibility of plastic cracking.

\author{
Inspection \\ - Identify cracked or damaged masonry. \\ - Identify size and type of crack. \\ - Identify root cause of damage.

\section{Evaluation} \\ - Determine level of treatment necessary to re- \\ pair severely damaged concrete. \\ - $\quad$ Determine a patching material that is chemi- \\ cally and visually compatible with the building.

\section{Execution \\ - $\quad$ Repair the source of the damage before repair- ing proceeds. \\ - If the crack is too severe, remove the damaged concrete and replace in-kind to the historic ma- terials.}

\section{Further Readings}

GSA has developed technical procedures to be used in specialized historic preservation work, as well as general evaluation, maintenance and repair of older building materials. For more detailed descriptions of repair procedures for cracked concrete refer to the following, which can be found at http://w3.gsa.gov/web/p/hptp.nsf

- $\quad$ Guidelines for Rehabilitating Historic Buildings: Masonry

- $\quad$ Preservation Briefs: \#15 Preservation of Historic Concrete: Problems and General Approaches

- $\quad$ Repairing Cracks in Concrete by Injecting Epoxy Resin

- $\quad$ Patching Scaling Concrete Masonry

- Removing and Replacing Deteriorated Concrete Paving

- Types of Cracks in Concrete and Typical Causes

- $\quad$ Settlement cracking: happens during placement when the concrete experiences settlement and the concrete has insufficient strength to withstand the resulting stresses. Settlement cracks may develop over embedded items, such as reinforcing steel, or adjacent to forms or hardened concrete as the concrete settles or subsides. Settlement cracking results from insufficient consolidation (vibration), high slumps (overly wet concrete), or a lack of adequate cover over embedded items. 
- Drying shrinkage cracking: is the most common cause of cracking. Drying shrinkage is not a problem if the concrete is free to move. If the concrete is restrained in any way, drying shrinkage will introduce tensile stresses which, if they exceed the tensile strength of the concrete, will cause the concrete to crack. Reducing drying shrinkage will not necessarily prevent cracking, which is also influenced by the restraint and the design and detailing of the concrete element. Shrinkage cracks are parallel sided and in the case of slabs usually extend right through the slab thickness. Such cracks can cause water penetration/ leakage and ultimately impair the durability of the concrete element. Therefore, control of cracking due to drying shrinkage is important and requires appropriate design and detailing of the concrete element.

- $\quad$ Structural cracking: usually results from settlement or horizontal loading. Most (but not all) structural cracks resulting from applied loads are nearly horizontal (parallel to the floor) and occur 16" to 48” from the top of the wall. Diagonal cracks that extend nearly the full height of the wall are often an indication of settlement. Diagonal cracks emanating from the corner of windows and other openings are called reentrant cracks and are usually the result of stress build-up at the corner. Diagonal reinforcement at the corner of openings can reduce the instance of crack formation and will keep the cracks narrow.

- $\quad$ Thermal cracking: results in a difference between concrete temperature and ambient temperature. The cracks frequently occur at the ends or corners of older concrete structures built without expansion joints capable of relieving such stress. The width and depth of cracks depends upon the temperature differential, physical properties of the concrete, and the reinforcing steel.

- Crazing: is a pattern of fine cracks that do not penetrate much below the surface and are usually a cosmetic problem only. They are barely visible, except when the concrete is drying after the surface has been wet.

- $\quad$ Rust cracking: Rusting of embedded steel in masonry may result in a build up of rust and scale on lintels, arch bars, wall ties, and bolts to displace surrounding masonry creating stepped or horizontal cracking that originates from the point of embedment. Corrosion of reinforcing steel and other embedded metals is one of the leading causes of deterioration of concrete. When steel corrodes, the resulting rust occupies a greater volume than steel. The expansion creates tensile stresses in the concrete, which can eventually cause cracking.

- Tension cracking: only occurs in reinforced concrete and is caused be elongation of the reinforcement in tension zones. Concrete members may be put into tension by applied loads. This is most common in concrete beams, where a transversely applied load will put one surface into compression and the opposite surface into tension. The portion of the beam that is in tension will crack - the size and length of cracks depends on the degree of curvature of the beam.

\section{Inspection}

Recommended...

- Identifying cracked or damaged masonry.

- $\quad$ Identifying size and type of crack.

- Identifying root cause of damage.

- Hairline, nonstructural cracks that show no sign of worsening normally need not be repaired.

- $\quad$ Cracks larger than hairline cracks, but less than approximately 1/16 inch, can be repaired with a mix of cement and water.

- If the crack is wider than $1 / 16$ inch, fine sand should be added to the mix to allow for greater compactibility, and to reduce shrinkage during drying. 
- $\quad$ For larger cracks, field trials will determine whether the crack should be routed (widened and deepened) minimally before patching to allow sufficient penetration of the patching material.

Not Recommended...

- $\quad$ Ignoring the crack and the cause for the damaged concrete, allowing for further deterioration of the concrete material.

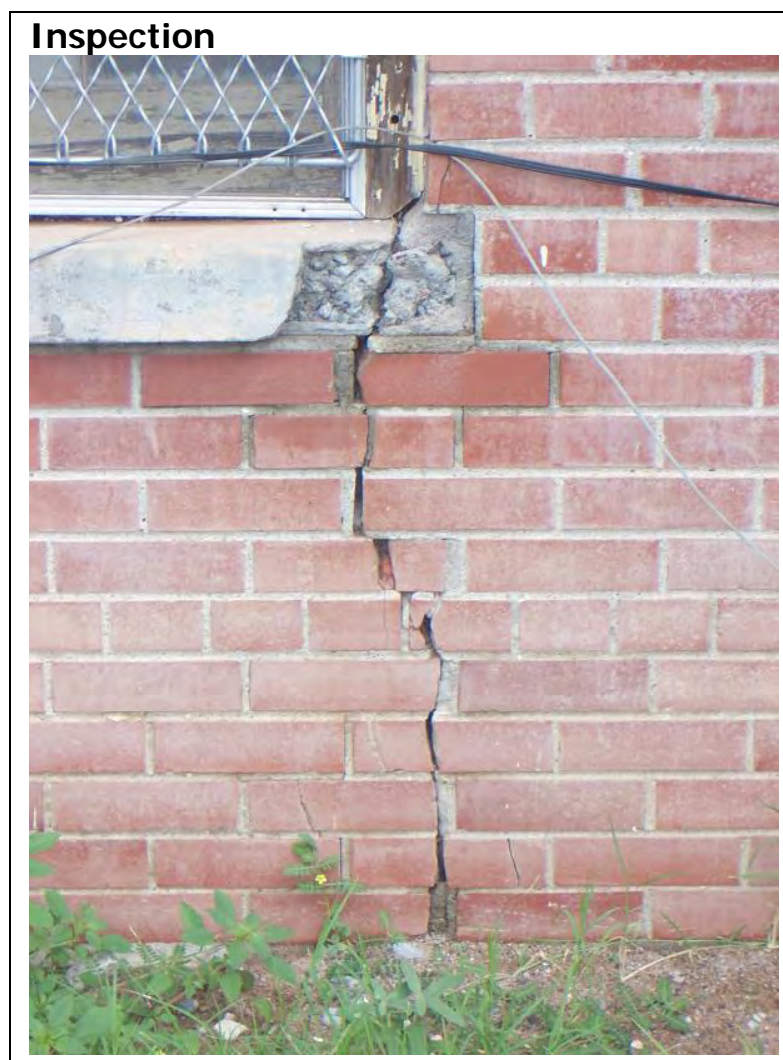

Building 612 - Identify cracked or damaged concrete. Identify the size and type of crack.

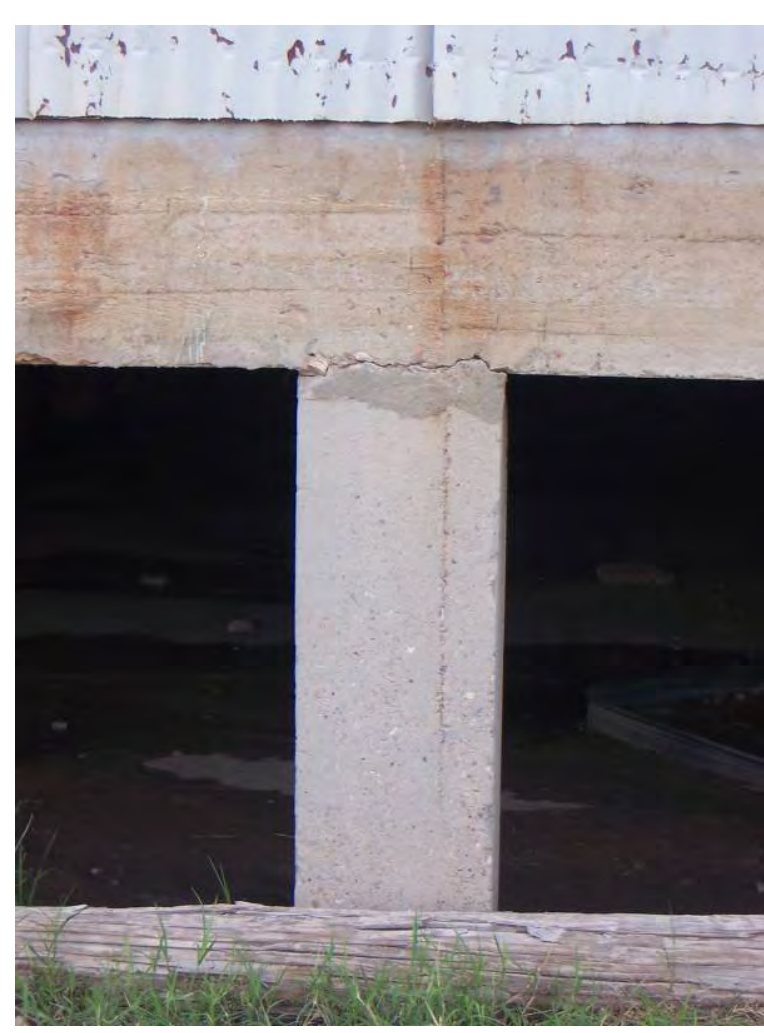

Building 1113 - Identify root cause of damage. Hairline, nonstructural cracks that show no signs of worsening normally need not be repaired. Cracks larger than hairline cracks, but less than approximately $1 / 16$ inch, can be repaired with a mix of cement and water.

\section{Evaluation}

Recommended...

- $\quad$ Determining the level of treatment necessary to repair damaged concrete.

- Determining a patching material that is chemically and visually compatible with the building and the existing material.

- $\quad$ To ensure a long-term repair, the patching materials should be carefully selected to be compatible with the existing concrete as well as with subsequent surface treatments such as paint or stucco.

Not Recommended...

- $\quad$ Patching with a substitute material that is physically or chemically incompatible with the original concrete. 


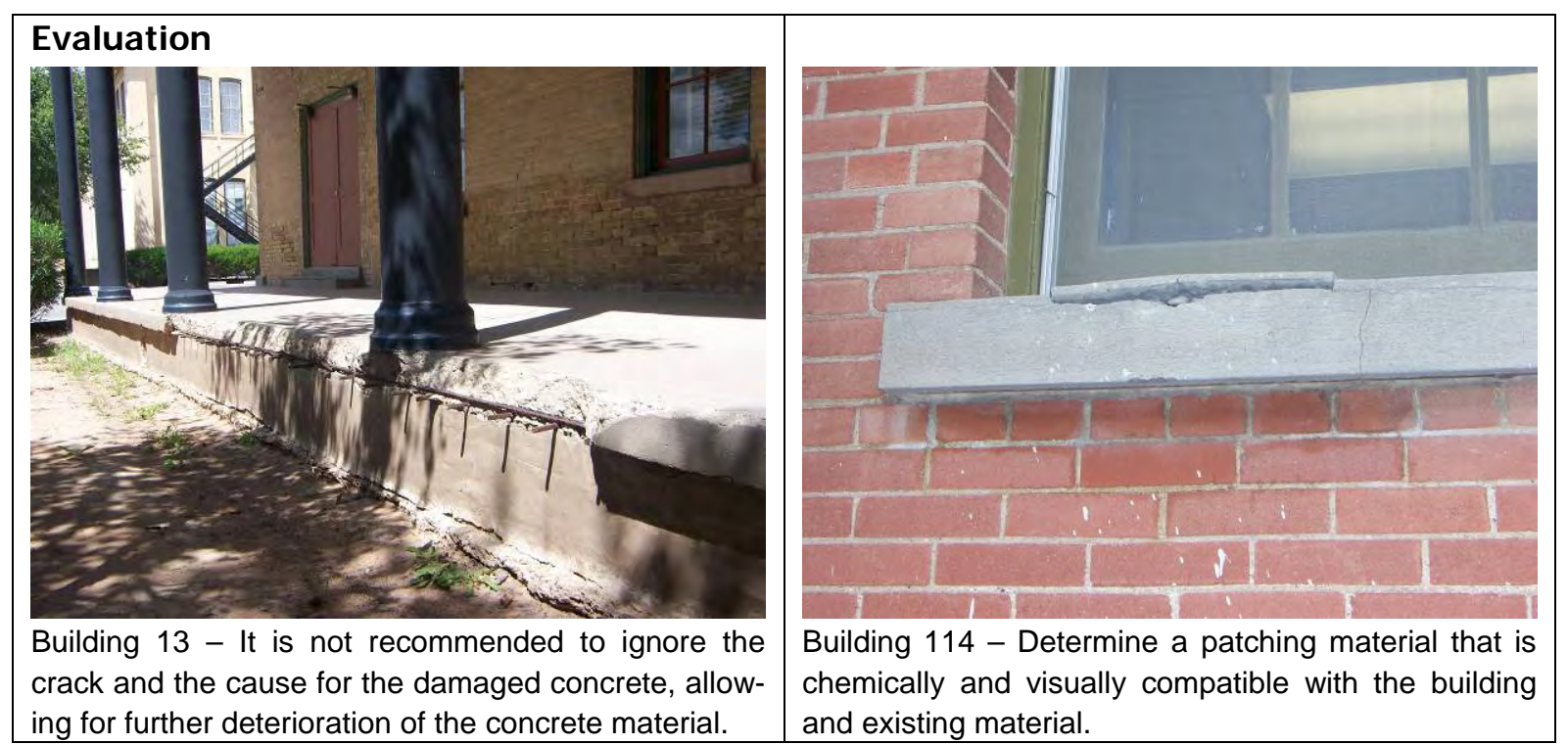

\section{Repair}

Repairs of historic concrete may consist of either patching the historic material or filling in with new material worked to match the historic material. If replacement is necessary, duplication of historic materials and detailing should be as exact as possible to assure a repair that is functionally and aesthetically acceptable.

Recommended...

- $\quad$ To ensure a long-term repair, the patching materials should be carefully selected to be compatible with the existing concrete as well as with subsequent surface treatments such as paint or stucco.

- $\quad$ Repairing any cracks in concrete by sealing with specification-approved sealant.

- Expansion-contraction joints may have to be introduced before repair is undertaken. Active cracks should be filled with sealants that will adhere to the sides of the cracks and will compress or expand during crack movement. The design, detailing, and execution of sealant-filled cracks require considerable attention, or else they will detract from the appearance of the historic building.

Not Recommended...

- $\quad$ Patching concrete without removing the source of deterioration.

- $\quad$ Patching with a substitute material that is physically or chemically incompatible with the original concrete.

\section{Replace}

Recommended...

- When cracking or displacement of masonry over openings is caused from lintel deflections or arch failures, the concrete above may be supporting itself and will exhibit step cracks beginning at the edges of the opening joining in an inverted $\mathrm{V}$ above the openings midpoint. Correcting such problems means replacing failed components and rebuilding the area above the opening.

- $\quad$ Replacing sections too deteriorated to repair using materials compatible with the original materials. 
- If a crack has developed from the corrosion of iron or steel lintels or sills, the corroded components should either be repaired or replaced and the cracked concrete should be repaired. Where cracking is severe, portions of the wall may have to be reconstructed. Cracks should be examined by a structural engineer.

Not Recommended....

- $\quad$ Removing a concrete feature that is unrepairable and not replacing it; or replacing it with a new feature that does not convey the same visual appearance.

\begin{tabular}{|l|l|}
\hline Execution \\
$\begin{array}{l}\text { Building } 115 \text { - Patching is most recommended for the } \\
\text { repair of damaged concrete. If too deteriorated to } \\
\text { repair, it is NOT recommended to remove a concrete } \\
\text { feature that is unrepairable and not replace it or to } \\
\text { replace it with a new feature that does not convey the } \\
\text { same visual appearance. }\end{array}$ & $\begin{array}{l}\text { Building } 1113 \text { - Where cracking is severe or reinforc- } \\
\text { ing bars are visible, portions of the wall or feature may } \\
\text { have to be reconstructed. Cracks of this magnitude } \\
\text { should be examined by a structural engineer. }\end{array}$ \\
\hline
\end{tabular}


Notes

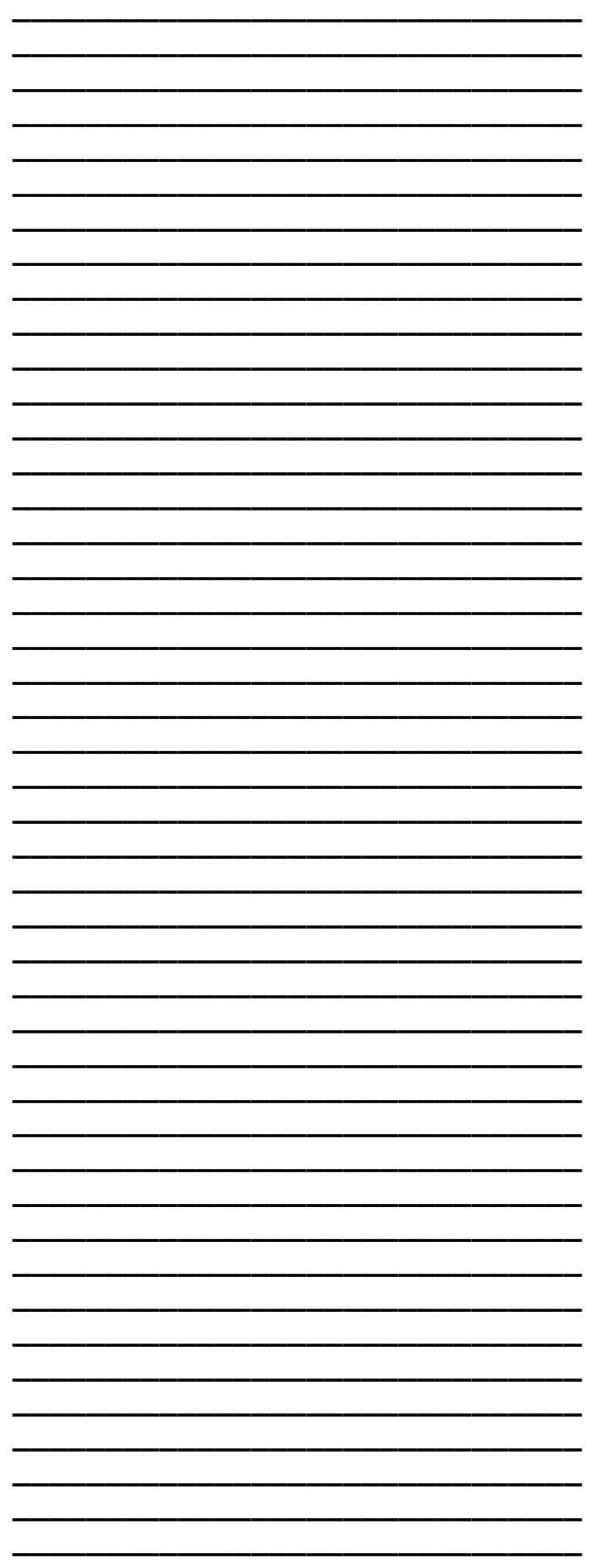




\section{Concrete: Moisture}

Uncontrolled moisture is the most prevalent cause of deterioration in older and historic buildings. It leads to erosion, corrosion, rot, and ultimately the destruction of materials, finishes, and eventually structural components. Some of the more common signs of visible as well as hidden moisture damage include:

- $\quad$ presence of standing water, mold, mildew, or fungus,

- $\quad$ wet stains, eroding surfaces, or efflorescence on interior and exterior surfaces,

- $\quad$ flaking paint or moisture blisters on finished surfaces,

- $\quad$ dank musty smells in high humidity or poorly ventilated areas,

- $\quad$ rust and corrosion stains on metal elements,

- $\quad$ spalled, cracked concrete,

- $\quad$ faulty roofs and gutters including missing roof slates, tiles, or shingles and poor condition of flashing or gutters, and/or

- $\quad$ condensation of window and wall surfaces.

Above-grade moisture generally results from weather related moisture entering through deteriorating materials as a result of deferred maintenance, structural settlement cracks, or damage from high winds or storms. Such sources as faulty roofs, cracks in walls, and open joints around door and window openings can be corrected through either repair or limited replacement. In some cases, materials become saturated from rain or gutter overflows, or in Fort Bliss' case, improper placement of evaporative coolers and air conditioning units.

Vines or other vegetation materials allowed to grow directly on the building without trellis or framework can cause damage from roots eroding foundations as well as dampness being held against surfaces. In most cases, keeping vegetation off of buildings, repairing damaged materials, replacing flashing, rehanging gutters, repairing downspouts, repointing mortar, caulking perimeter joints around door and window openings, and repainting surfaces can alleviate most sources of unwanted exterior moisture.

\section{Inspection}

- Identify root cause of damage, including standing water.

\section{Evaluation}

- Determine the level of treatment necessary to repair severely damaged concrete.

- Evaluating the overall condition of the concrete to determine whether more than protection and maintenance are required, that is, if repairs to the concrete features will be necessary.

\section{Execution}

- If moisture cannot be managed by maintenance alone, it is important to reduce it by mitigating problems before deterioration materials are replaced.

- $\quad$ Repair the source of damage before repairing proceeds.

- $\quad$ Replace in-kind to the historic materials.

- Do not coat buildings with waterproof sealers that can accelerate an existing problem.

\section{Further Readings}

GSA has developed technical procedures to be used in specialized historic preservation work, as well as general evaluation, maintenance and repair of older building materials. For more detailed descriptions of repair procedures for moisture-related problems refer to the following, which can be found at http://w3.gsa.gov/web/p/hptp.nsf

- Guidelines for Rehabilitating Historic Buildings: Masonry

Removing Climbing Plants and Creepers from Masonry 
Appropriate Level of Treatment:

- $\quad$ Level I - preservation and maintenance

- $\quad$ Level II - repair using historically compatible materials and essentially mitigating damaging moisture conditions

- $\quad$ Level III - replacement and alteration of materials that permit continued use in a chronically moist environment

Note: It is important to keep record of moisture problems within a building and to protect the historic or old building through cyclical maintenance.

\section{Inspection}

Recommended...

- Inspecting for the root cause of damage, including standing water.

- $\quad$ Providing proper drainage so water does not stand or accumulate.

Not Recommended...

- $\quad$ Failing to undertake adequate measures to assure the protection of concrete features.

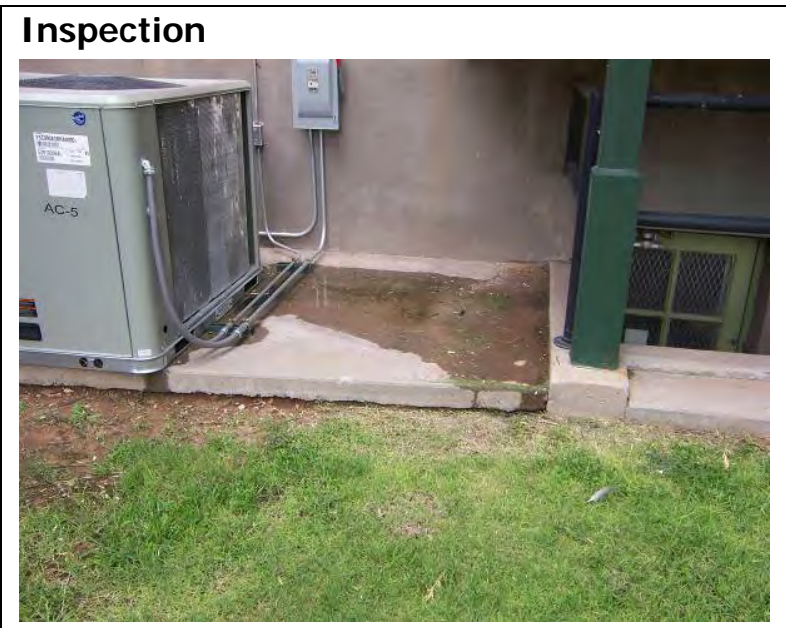

Building 1 - A periodic inspection will reveal areas of concern such as standing water on concrete.

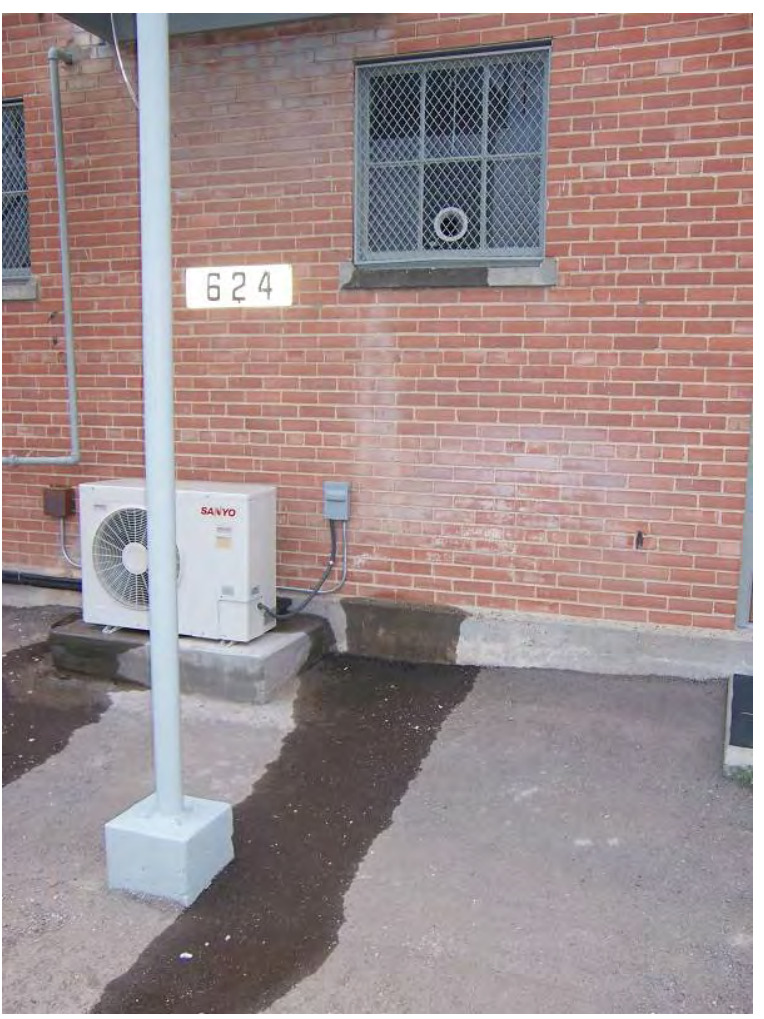

Building $624-$ The water is constantly dripping onto the concrete foundation and windowsill from the air conditioning units. 


\section{Evaluation}

Recommended...

- $\quad$ Evaluating the overall condition of the concrete to determine whether more than protection and maintenance are required, that is, if repairs to the concrete features will be necessary.

- A concrete sealant can help prevent the problem as long as it allows the concrete to breathe.

- $\quad$ Keeping moisture away from concrete foundations by providing proper drainage away from the structure.

- If spalling is minimal, no repair is needed. They will not compromise the stability of a concrete feature.

- $\quad$ Determining the level of repair for severely damaged concrete.

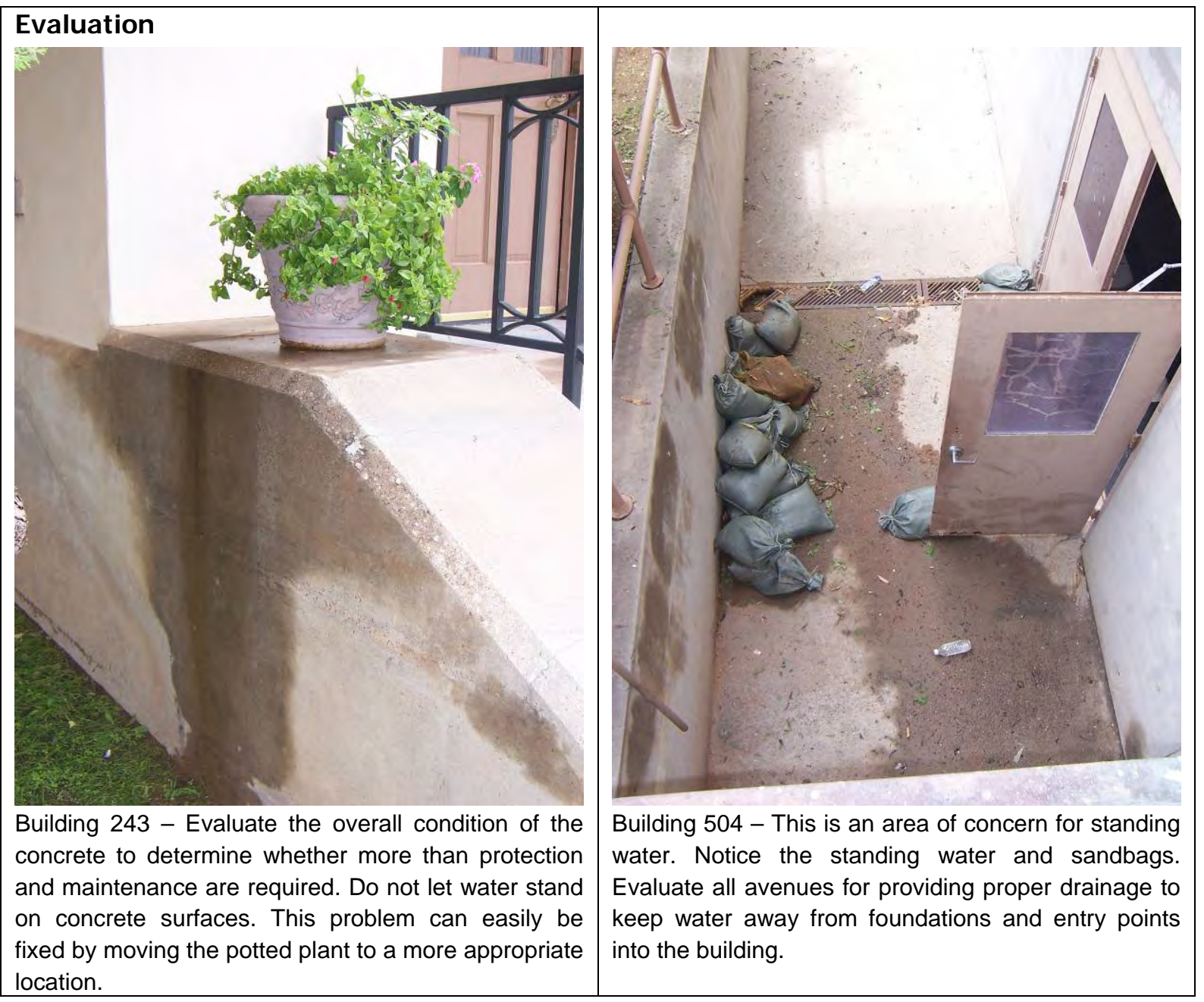




\section{Repair}

Start with the repair of any obvious deficiencies using sound preservation maintenance. If moisture cannot be managed by maintenance alone, it is important to reduce it by mitigating problems before deteriorated materials are replaced. Treatments should not remove any materials that can be preserved, should not involve extensive evacuation unless there is a documented need, and should not include coating buildings with waterproof sealers that can accelerate an existing problem.

Recommended...

- $\quad$ Repairing any cracks in concrete by sealing with specification-approved sealant.

- $\quad$ Patching damaged sections with in-kind material finished to match the existing.

Not Recommended...

- $\quad$ Using a substitute material for the replacement part that does not convey the visual appearance of the surviving parts of the concrete feature or that is physically or chemically incompatible.

- Applying waterproof, water repellent, or non-historic coatings such as stucco to concrete as a substitute for repairs.

\section{Replace}

Recommended...

- $\quad$ Repairing damaged concrete too deteriorated to patch by cutting damaged material back to remove the source of deterioration (often corrosion of metal reinforcement bars).

- $\quad$ Applying new patch with in-kind material finish to match the existing.

Not Recommended

- $\quad$ Removing a concrete feature that is unrepairable and not replacing it; or replacing it with a new feature that does not convey the same visual appearance.

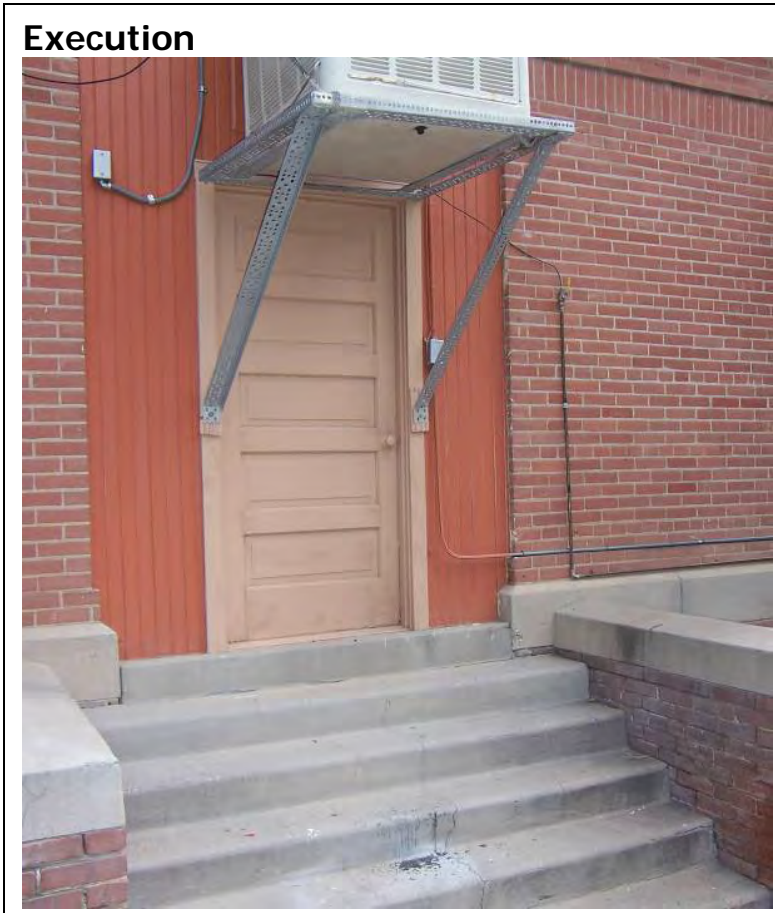

Building 55 - This is an inappropriate placement of an evaporative cooler.

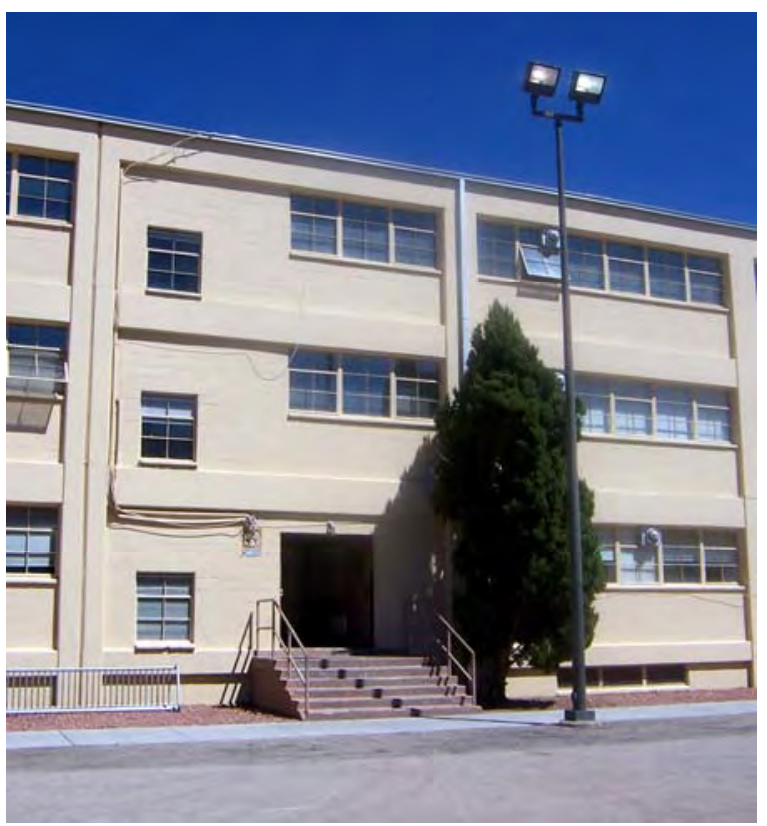

Building 1002 - The tree is too close to the building, which can cause damage from roots eroding the foundation as well as dampness being held against the surface. 
Notes

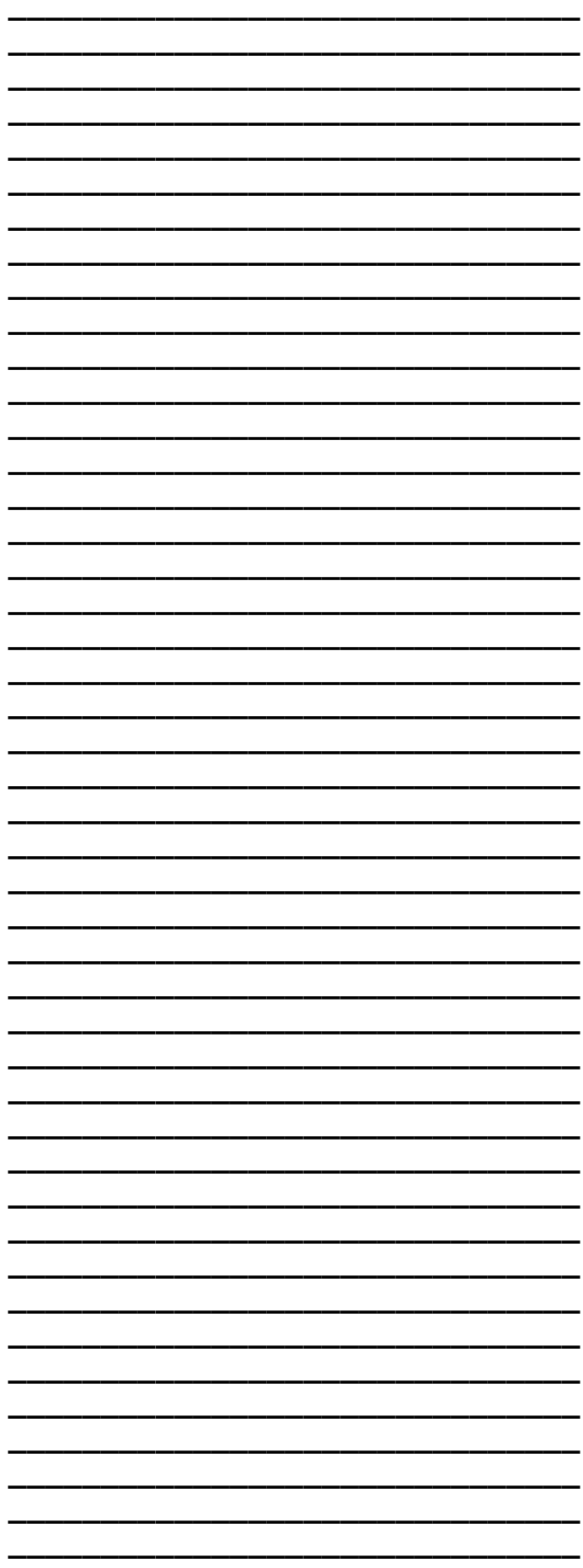




\section{Concrete: Staining/Cleaning}

Stains can be produced by alkali-aggregate reaction, which forms a white gel exuding through cracks and hardening as a white stain on the surface. Efflorescence is a white, powdery stain produced by the leaching of lime from Portland cement, or by the pre-World War II practice of adding lime to whiten the concrete. Discoloration can also result from metals inserted into the concrete, or from corrosion products dripping onto the surface. Concrete should be cleaned only when it is necessary to halt deterioration, as most cleaning methods have adverse effects on the concrete and on the environment. Inappropriate cleaning of concrete is a major cause of deterioration of the Nation's historic resources. Cleaning with water should be done only when there are no major cracks or deterioration in the brick. Do not use high-pressure water cleaning methods. Always start with the mildest method of cleaning and proceed to stronger methods. However, it is highly recommended NOT to resort to ABRASIVE CLEANING on masonry surfaces!

The general nature and source of dirt on a building must be determined in order to remove it in the most effective, yet least harmful, manner. A common cleaning problem includes metal stains such as rust.

If the proposed cleaning is to remove paint, it is important in each case to learn whether or not exposed concrete is historically appropriate.

The construction of the building must be considered in developing a cleaning program because inappropriate cleaning can have a corrosive effect on both the masonry and the other building materials.

Previous treatments of the building and its surroundings also should be evaluated, if known. Earlier waterproofing applications may make cleaning difficult.

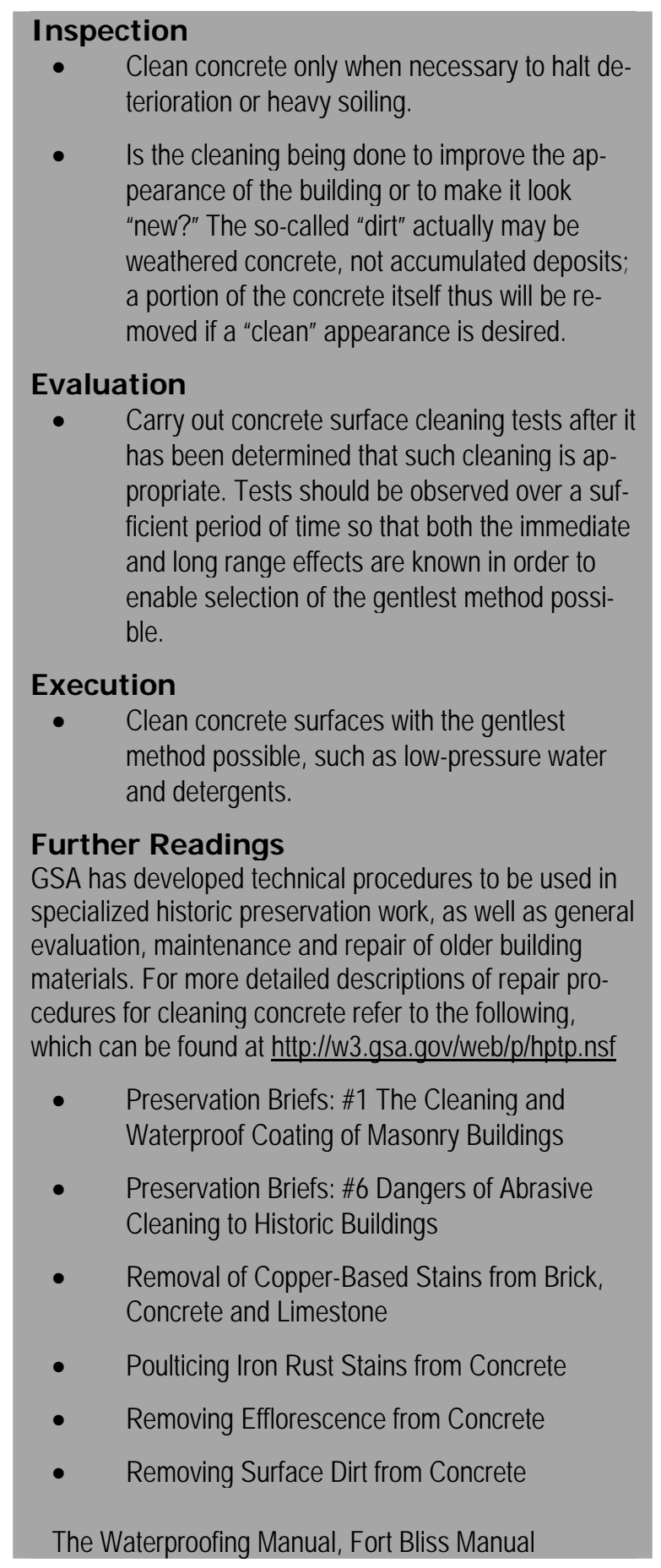

\section{Cleaning Methods}

The following list is a brief breakdown of the steps needed when cleaning is considered necessary to prolong the life of a building. For a more in-depth description of each step please refer to Preservation Brief 1, The Cleaning and Waterproof Coatings of Masonry Buildings. 
- Water methods - soften the dirt and rinse the deposits from the surface. There are four kinds of water-based methods:

- Soaking

- Water washing

- Water washing with detergents

- Steam/hot-pressurized water cleaning

- $\quad$ Chemical cleaners - react with the dirt and/or masonry to hasten the removal process; the deposits, reaction products and excess chemicals then are rinsed away with water. There are two kinds of chemical cleaners:

- Alkaline cleaners

- Acidic cleaners

- $\quad$ Mechanical methods - include grit blasting (and usually sand blasting), grinders, and sanding discs, which remove the dirt by abrasion and usually are followed by a water rinse. (Note: Generally abrasive/mechanical methods are not appropriate for use on historic masonry buildings.)

\section{Testing}

Several potentially useful methods should be tested prior to selecting the one for use on the building. The test patch should include at least one square yard and, with large stones, should include several stones and mortar joints. Test should be observed over a sufficient period of time (preferably a year but, if not feasible, at least a month or two) so that both the immediate and long-term effects are known. Use materials in the following sequence:

- $\quad$ water with natural bristle brushes

- $\quad$ water and non-ionic detergent with natural bristle brushes (Note: Non-ionic detergents are not the same as soaps. They are synthetic organic compounds that are especially effective in removing oily soil.)

- $\quad$ water with stronger soap

- $\quad$ water with stronger soap plus ammonia

- $\quad$ water with stronger soap plus vinegar.

\section{Environmental and Safety Considerations:}

- $\quad$ Authorities from the local regulatory agency, usually under jurisdiction of the Federal or State Environmental Protection Agency (EPA), including DOE Compliance Division and other regulatory agencies, should be consulted prior to beginning a cleaning project, especially if it involves anything more than plain water washing.

- $\quad$ Cleaning can also cause damage to non-masonry materials on a building, including glass, metal, and wood. Thus, it is usually necessary to cover windows and doors, landscape, and other features that may be vulnerable to chemical cleaners.

- $\quad$ The precautions listed in Material Safety Data Sheets (MSDS) provided with chemical products should always be followed.

A well-planned cleaning project is an essential step in preserving, rehabilitating, and restoring a historic masonry building. Proper cleaning methods, when determined necessary for the preservation of the masonry, can enhance the aesthetic character as well as the structural stability of a historic building. Cleaning that is carelessly or insensitively prescribed or carried out by inexperienced workers can have the opposite of the intended effect. It may scar the concrete permanently 
and eventually causing surface loss in the concrete, which can result in serious damage both physically and aesthetically to a historic masonry building.

\section{Inspection}

Points to consider before cleaning when inspecting stained or dirt covered concrete.

- Is the cleaning being done to improve the appearance of the building or to make it look new? The so-called "dirt" actually may be weathered concrete, not accumulated deposits; a portion of the concrete itself thus will be removed if a "clean" appearance is desired.

- $\quad$ Is there any evidence that dirt and pollutants are having a harmful effect on the concrete? Improper cleaning can accelerate the deteriorating effect of pollutants.

- Many historic buildings that show only a slight amount of soil or discoloration are much better left as they are.

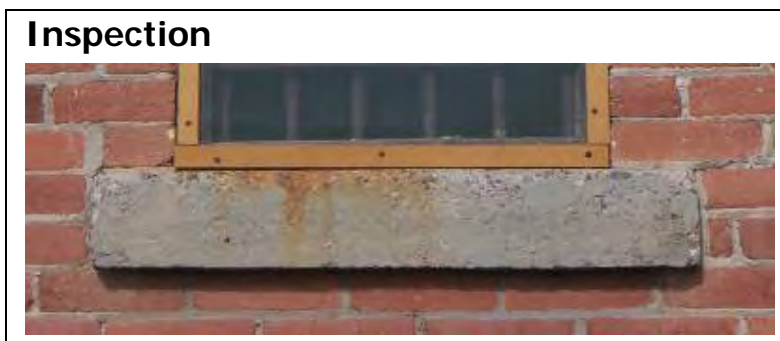

Building 889 - Inspect concrete surfaces to determine the cause of the staining. Determine if cleaning is necessary to preserve the concrete feature. Clean concrete only when necessary to halt deterioration or heavy soiling.

\section{Evaluation}

Recommended...

- $\quad$ Carrying out concrete surface cleaning tests after it has been determined that such cleaning is appropriate. Tests should be observed over a sufficient period of time so that both the immediate and the long range effects are known in order to enable selection of the gentlest method possible.

- $\quad$ Cleaning concrete only when necessary to halt deterioration or heavy soiling.

Not Recommended...

- Cleaning masonry surfaces without testing or without sufficient time for testing results to be of value.

- Cleaning concrete surfaces when they are not heavily soiled to create a new appearance, thus needlessly introducing chemicals or moisture into historic materials.

\section{Execution}

Note: When cleaning, avoid over cleaning. Aim for achieving 85\% clean. Most damage occurs when attempting to clean the last $15 \%$.

Recommended...

- $\quad$ Cleaning concrete surfaces with the gentlest method possible, such as low-pressure water and detergents, using natural bristle brushes. 
Not Recommended...

Note: Sandblasting is NOT recommended by The Secretary of the Interior's Standards for Rehabilitation and shall not be used. High-pressure water blasting is also NOT recommended without adequate testing or experience as it may erode soft concrete and drive moisture into the wall.

- Using a cleaning method that involves water or liquid chemical solutions when there is a possibility of freezing temperatures.

- $\quad$ Cleaning with chemical products that will damage concrete.

- $\quad$ Cleaning concrete surfaces without testing or without sufficient time for testing results to be of value.

\section{Execution}

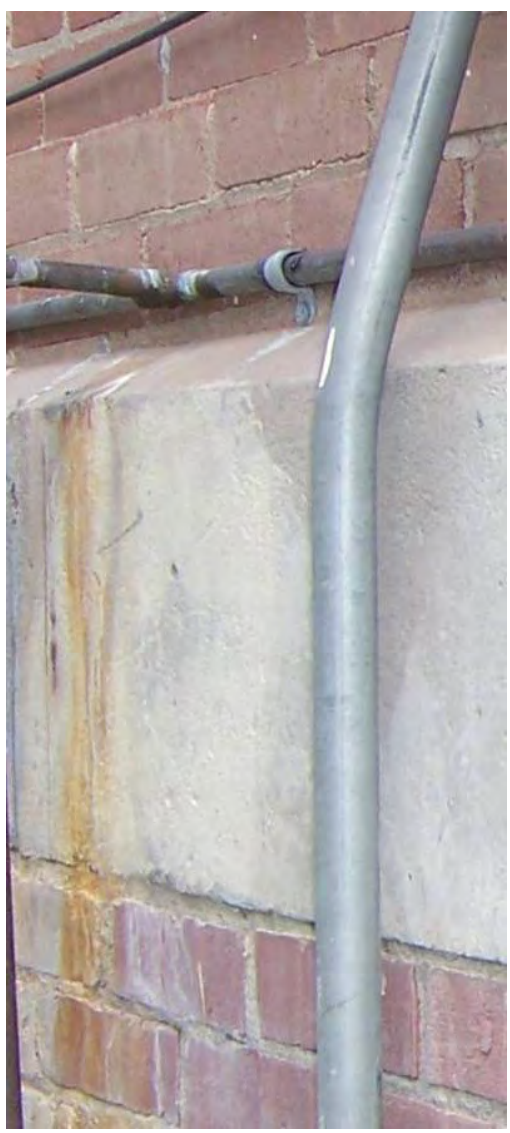

Building 55 - Cleaning concrete surfaces with the gentlest method possible, such as low-pressure water and detergents, is recommended to remove stains. 
Notes

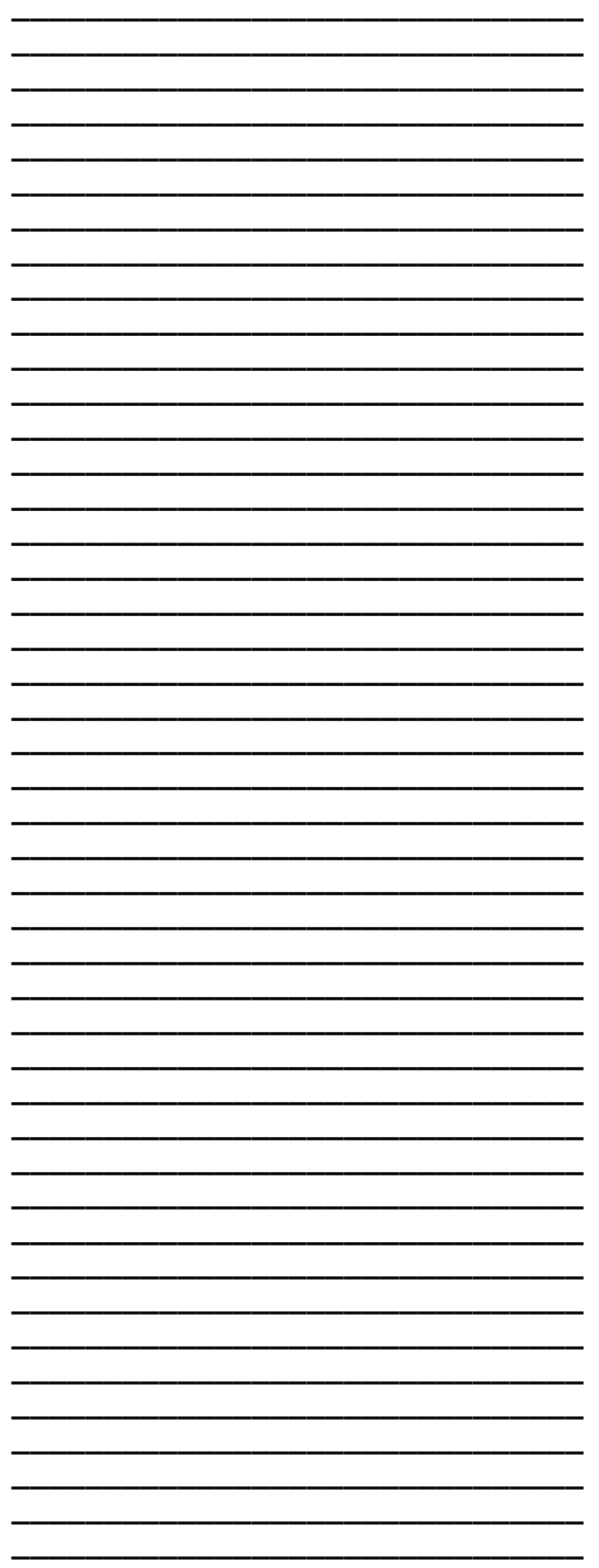




\section{Concrete: Paint}

Many older buildings were painted at some point to correct recurring maintenance problems caused by faulty construction techniques, to hide alterations, or in an attempt to solve moisture problems. If this is the case, removal of paint may cause these problems to reoccur.

Furthermore, concrete which has been damaged by abrasive cleaning may require painting in order to seal the concrete from excessive water penetration which, if not protected, can lead to further deterioration of the concrete.

\section{Causes}

The cause of paint failure often stems from poor paint, inadequate preparation, or faulty workmanship. Sometimes peeling paint is caused by moisture build-up in the wall. Cracking is often caused by poor adhesion, which comes from incompatible types of paint layered over each other, or from the build-up of many layers of old paint. Careful scraping to remove the layers often results in improved performance.

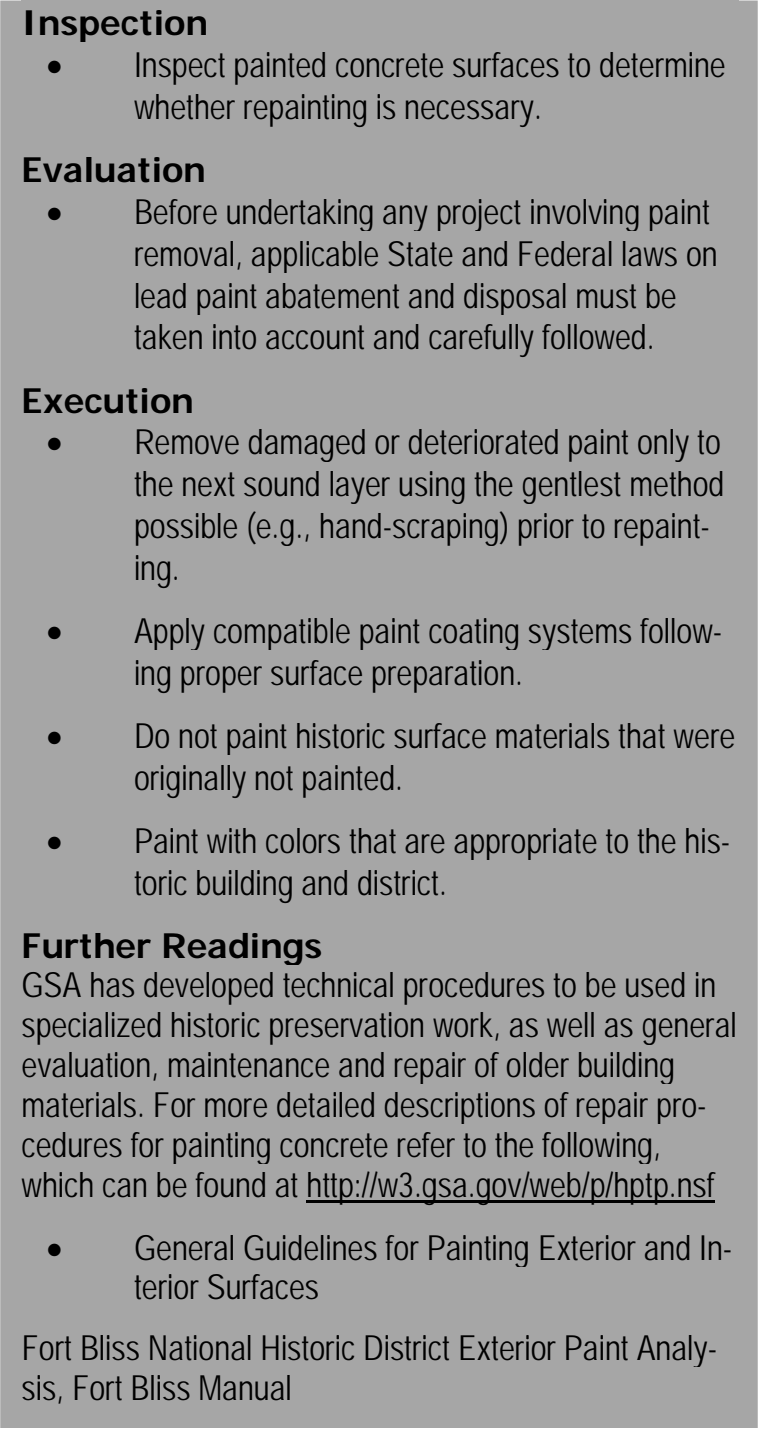




\section{Inspection}

Recommended...

- Inspecting painted concrete surfaces to determine whether repainting is necessary.

Not Recommended...

- $\quad$ Removing paint that is firmly adhering to, and thus protecting, concrete surfaces.

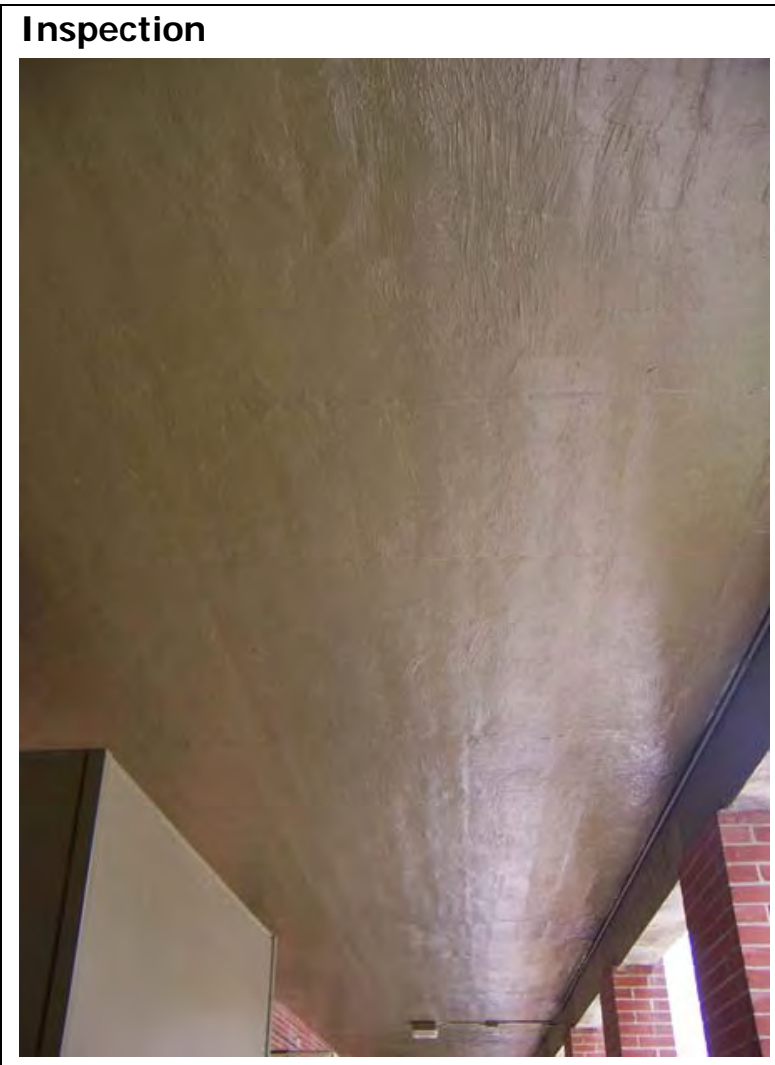

Building 11 - A good example of maintenance and preservation on painted concrete surface. Identify the correct paint color used on historic buildings.

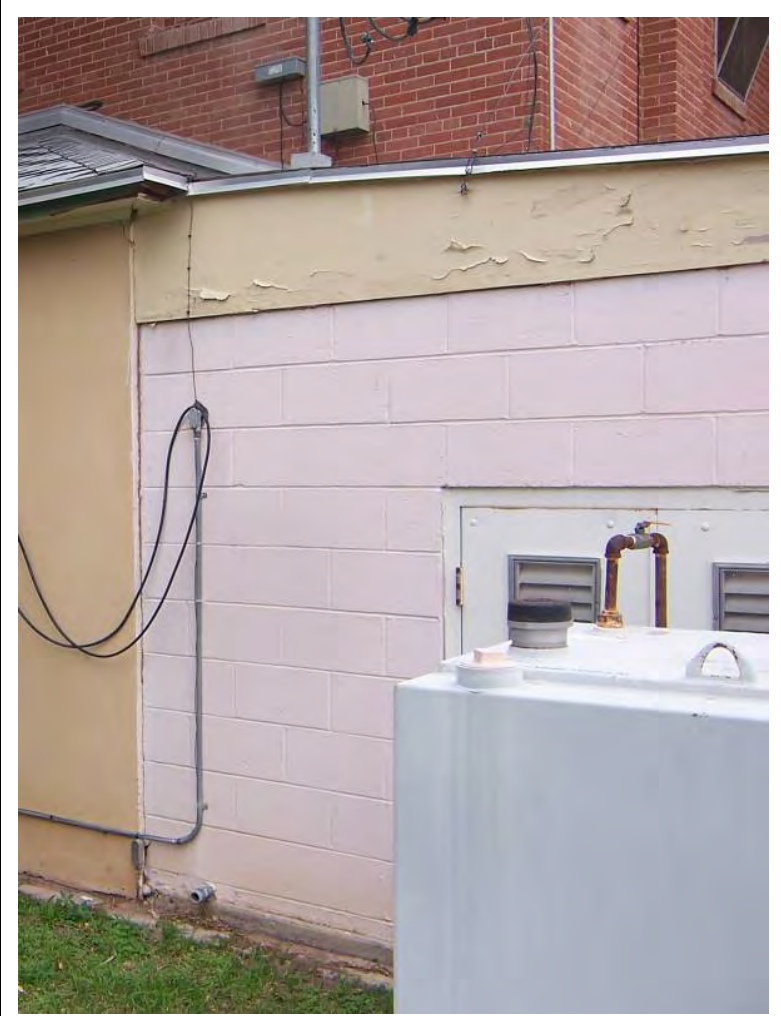

Building 54 - A periodic inspection of painted concrete surfaces would determine if the concrete needs to be repainted.

\section{Evaluation}

Recommended...

- $\quad$ Conducting a study of all the paint layers to determine what the original colors were and if any special treatments were used.

- Under the supervision of the historic architect, test panels using the appropriate cleaning methods, shall be done to determine the best method to remove paint.

- $\quad$ Testing shall include evaluation of the materials and techniques proposed for the protection of surrounding areas from the chemicals used to strip the paint.

Not Recommended...

- $\quad$ Using methods of removing paint that are destructive to concrete, such as sandblasting, application of caustic solutions, or high-pressure water-blasting. These methods of cleaning may permanently erode wall surface and accelerate deterioration. 


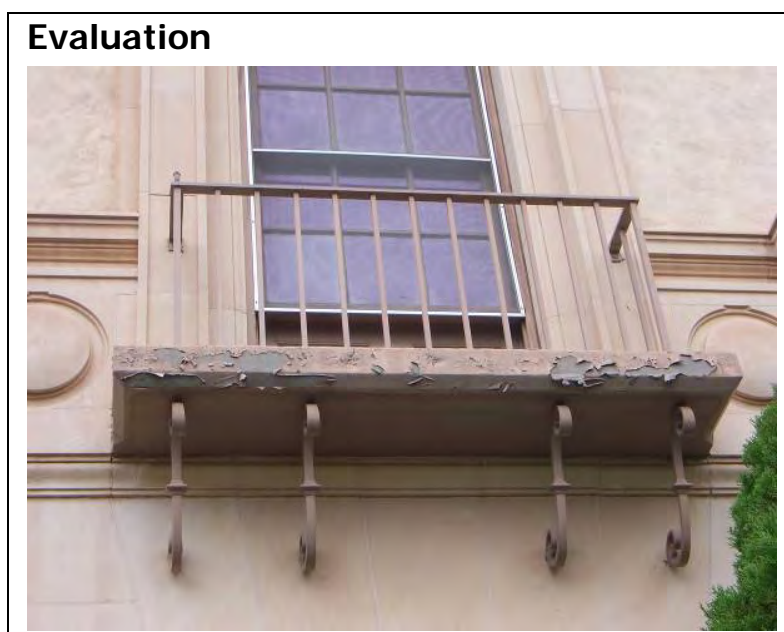

Building 504 - Under the supervision of the historic architect, test panels using the appropriate cleaning method, shall be done to determine the best method to remove the paint. It is recommended to remove damaged paint to the next sound layer using the gentlest methods possible (e.g., hand-scraping) prior to repainting.

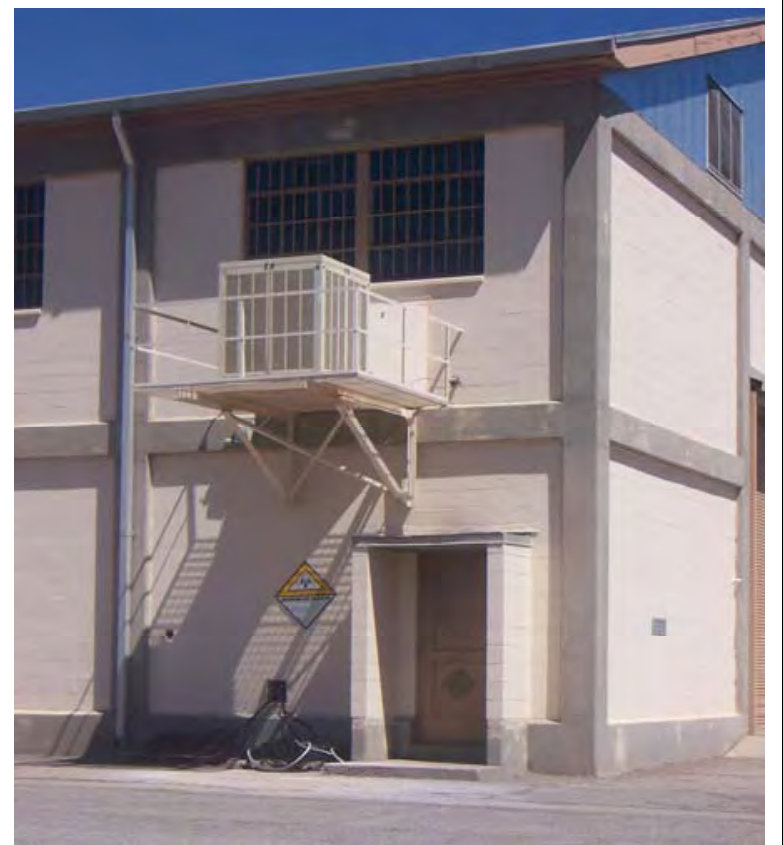

Building 739 - It is recommended to repaint with colors that are historically appropriate to the building and district. It is not recommended to paint concrete surfaces that were historically left unpainted and exposed.

\section{Execution}

\section{Recommended...}

- $\quad$ Scraping away all loose paint manually using paint scrapers, putty knifes, or stiff bristle brushes.

- $\quad$ Removing damaged or deteriorated paint only to the next sound layer using the gentlest method possible (e.g., hand-scraping) prior to repainting.

- $\quad$ Applying compatible paint coating systems following proper surface preparation.

- $\quad$ Repainting with colors that are historically appropriate to the building and district.

Not Recommended...

Note: Sandblasting is NOT recommended by The Secretary of the Interior's Standards for Rehabilitation and shall not be used. High-pressure water blasting is also NOT recommended without adequate testing or experience as it may erode concrete and drive moisture into the wall.

- $\quad$ Removing paint that is firmly adhering to, and thus protecting, concrete surfaces.

- $\quad$ Failing to follow manufactures' product and application instructions when repainting masonry.

- $\quad$ Using new paint colors that are inappropriate to the historic building and district.

- Applying paint or other coatings such as stucco to concrete that has been historically unpainted or uncoated to create a new appearance.

- $\quad$ Removing paint from historically painted concrete.

- $\quad$ Radically changing the type of paint or coating or its color. 


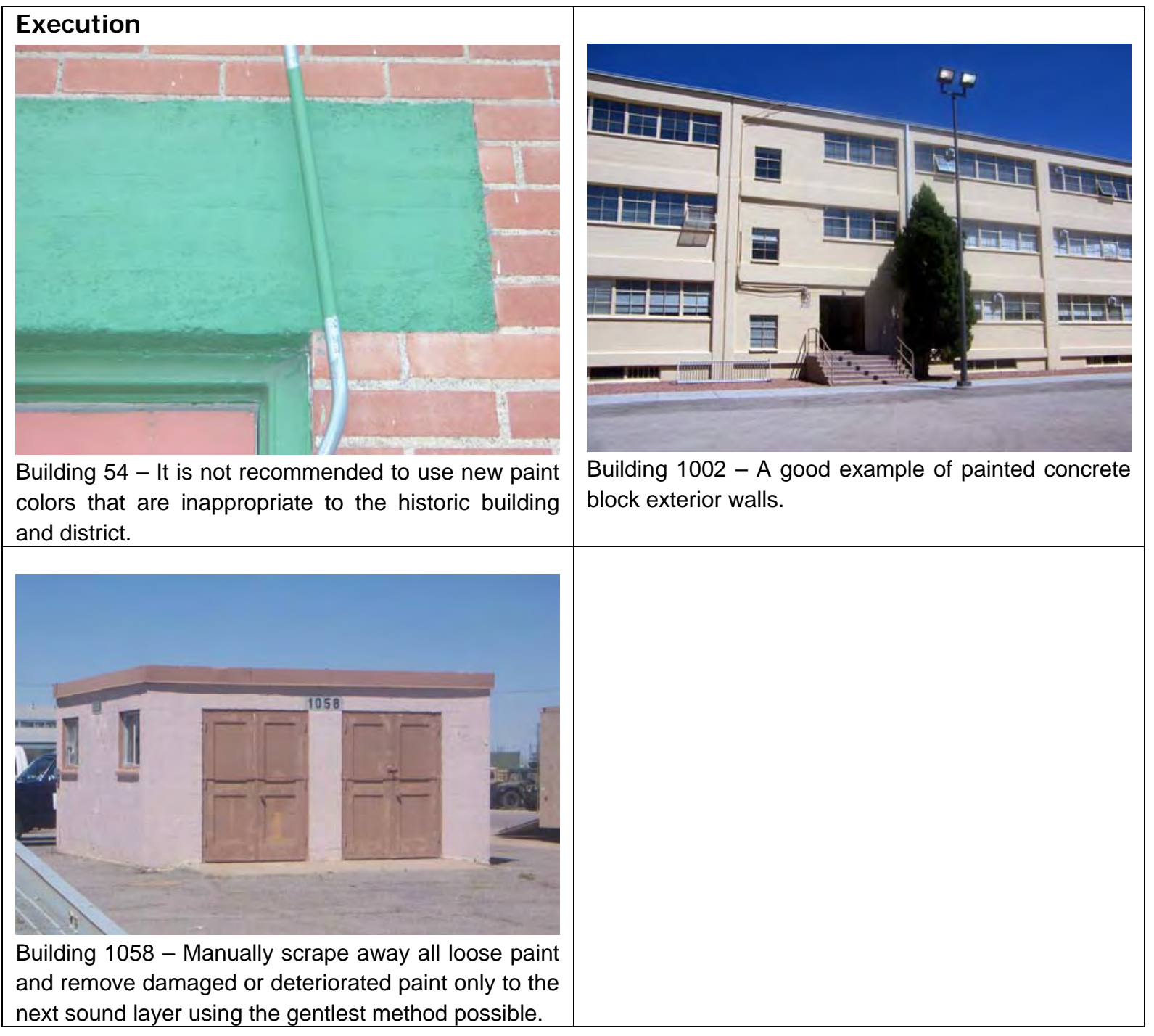


Notes

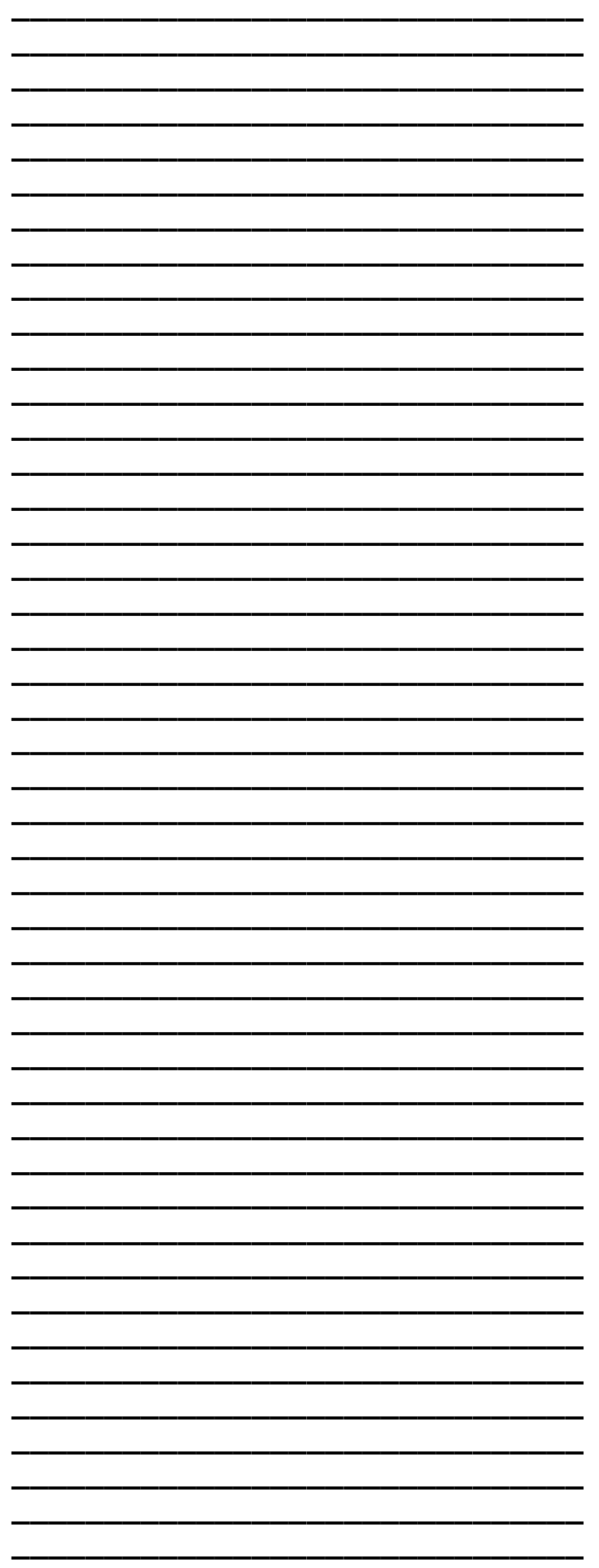




\section{Concrete Block}

Many of the buildings constructed at Fort Bliss during the Cold War were constructed of concrete block. Concrete block is a molded concrete masonry unit (CMU) with vertical hollow core holes; made with water, cement, aggregate, and sometimes coloring. Concrete block, when reinforced with concrete columns and tie beams, is very common building material for load bearing walls of buildings.

The concrete block finish used at Fort Bliss was usually plainface. Typically the concrete block buildings at Fort Bliss were painted. Currently, synthetic stucco has been and is being placed over existing concrete block in order to give the building a more "current day" appearance. However, synthetic should NOT be placed on any historic building constructed of concrete block.

Typical historical uses of concrete block include:

- foundation walls

- basement walls

- partition walls

- exterior walls.

Most concrete block was used as a back-up material or for cavity wall construction. Coatings are often applied to concrete block in order to prevent water penetration; some of these include Portland cement paints, latex paints, oil- and rubber-based paints, epoxy coatings, and alkyd paints. A single type may be selected for a specific function including its water resistance; other factors to consider might also include its resistance to ultraviolet rays, its breathability, its resistance to alkalis, and its coloration or visual appearance when applied to the block.

\section{Natural or Inherent Problems}

Concrete block is subject to the same types of problems as poured concrete.

\section{Inspection \\ - Inspect painted concrete surfaces to determine whether repainting is necessary. \\ - Changes in the building should particularly be noted. The early stages of cracking or deflec- tion in concrete should be monitored regularly. \\ Evaluation \\ - $\quad$ All water damage should be noted and reme- died at its earliest possible stages. \\ - $\quad$ Surface coatings must be inspected frequently and repaired or replaced as the need indicates. \\ - $\quad$ Before undertaking any project involving paint removal, applicable State and Federal laws on lead paint abatement and disposal must be taken into account and carefully followed. \\ - Determine the level of treatment necessary 0 repair severely damaged concrete. \\ - $\quad$ Determine a patching material that is chemi- cally and visually compatible with the building. \\ Execution \\ - $\quad$ Remove damaged or deteriorated paint only to the next sound layer. \\ - Apply compatible paint coating systems follow- ing proper surface preparation. \\ - Do not paint historic surface materials that were originally not painted. \\ - $\quad$ Paint with colors that are appropriate to the his- toric building and district. \\ - Repair the source of damage before repairing proceeds.}

\section{Further Readings}

GSA has developed technical procedures to be used in specialized historic preservation work, as well as general evaluation, maintenance and repair of older building materials. For more detailed descriptions of repair procedures for concrete block refer to the following, which can be found at http://w3.gsa.gov/web/p/hptp.nsf

- $\quad$ Concrete Block: Characteristics, Uses, and Problems

Cracking: Often due to shrinkage of the concrete or movement of the wall. All exposed masonry should be inspected for cracking. 
Efflorescence: Occurs when accumulations of salt are carried to the surface by water migrating through the masonry.

Moisture: Above-grade moisture generally results from weather-related moisture entering through deteriorating materials as a result of deferred maintenance, or cracks. Vegetation materials allowed to grow directly on the building can cause damage from roots eroding foundations as well as dampness being held against the surface.

Staining: Staining may appear in many forms, including dirt build-up, metallic staining, or painted graffiti. Concrete should be cleaned only when it is necessary to halt deterioration.

\section{Examples of Concrete Block used at Fort Bliss}

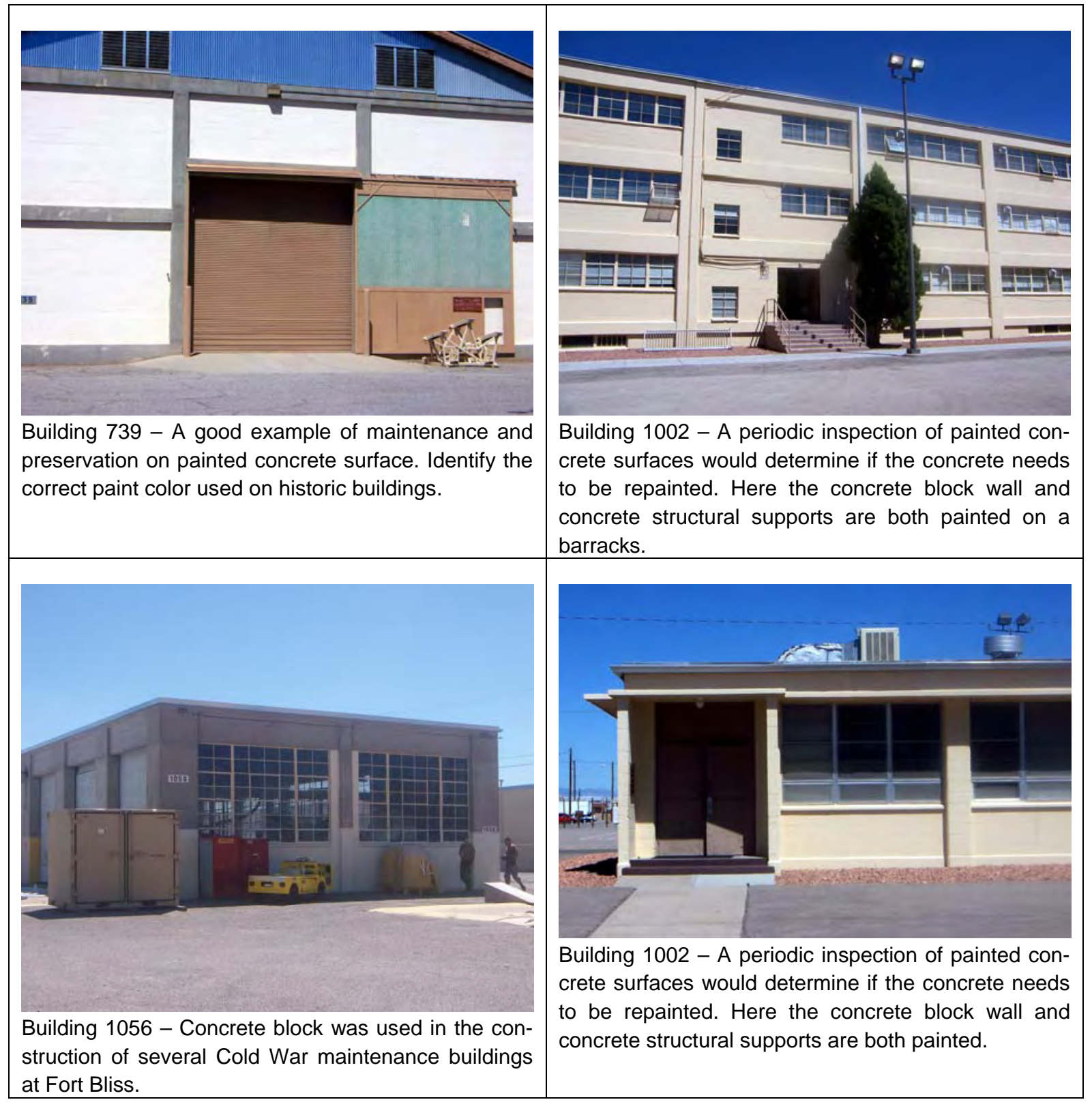


Current technique used on concrete block buildings at Fort Bliss

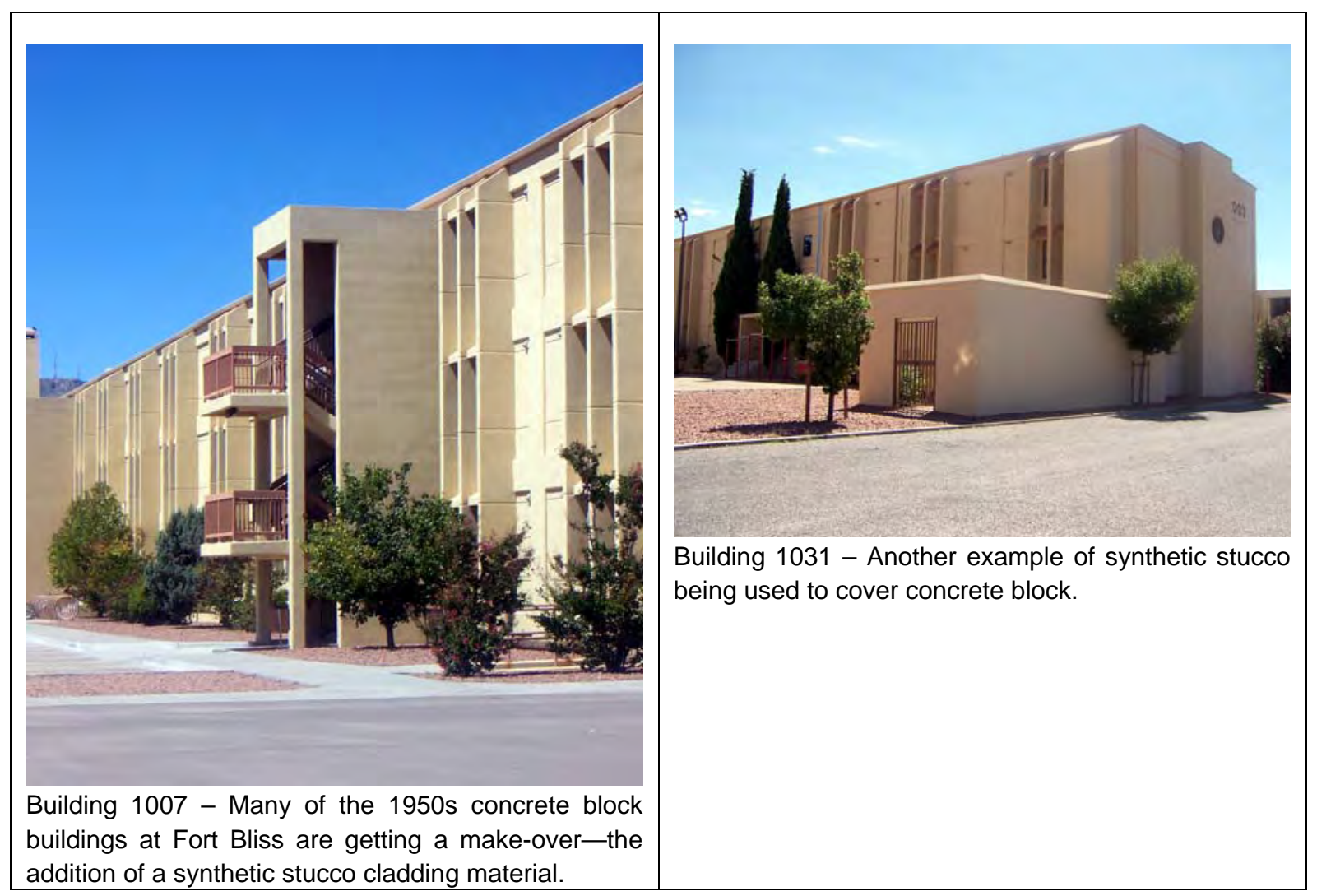




\section{Notes}

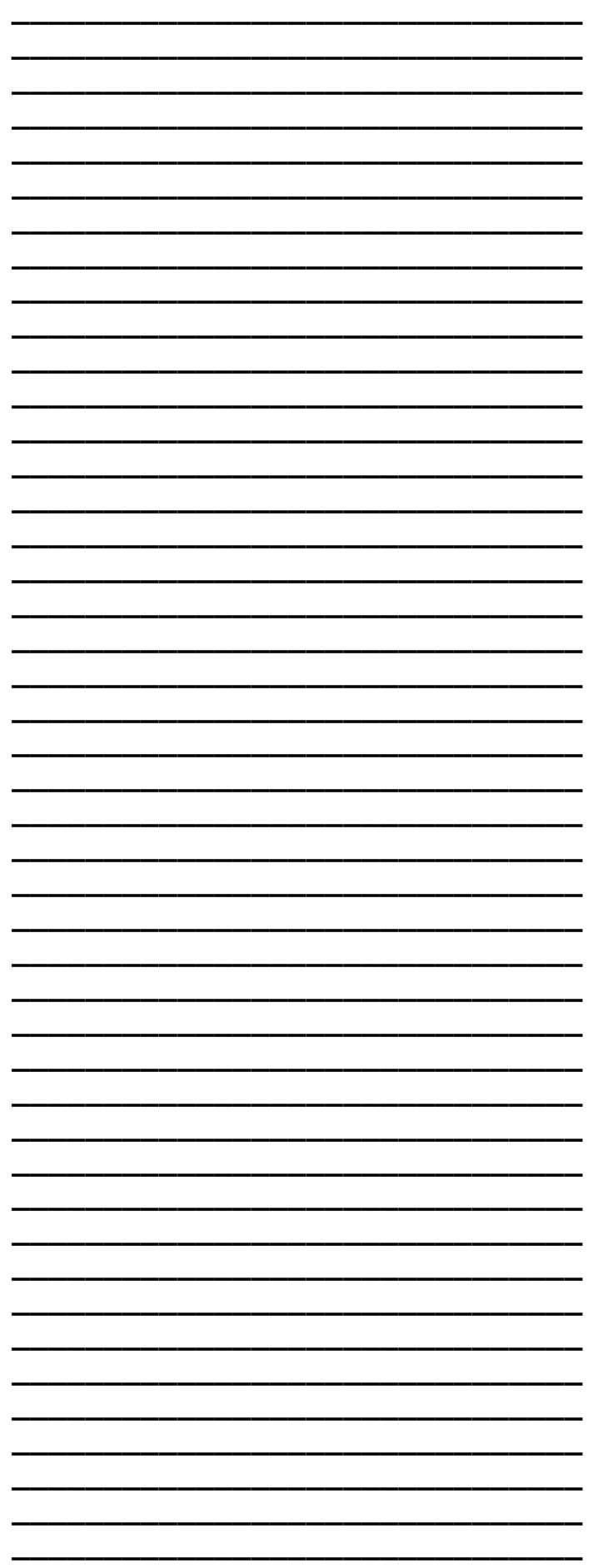




\section{Maintenance Guides for Natural Stone}

\section{Natural Stone: Overview}

All exposed stone should be inspected for bulging, bowing (bulges vertically), shifting, or settlement of a stone foundation. The overall quality of the buildings construction and often that of its neighbors is a good indicator of the condition of the foundation.

\section{Repointing}

Most stone foundations have, or had at some point, a mortar coating on their interior. The purpose of this coating was to hold the stones in place. This mortar coating will eventually flake off due to moisture migration, revealing the surface of the stones. As this coating continues to erode, the soft sandy mortar in between the stones will begin to fall out. When this occurs, repointing is needed as soon as possible to refill the voids where the old mortar fell out.

\section{Identify, Retain, and Preserve}

Recommended...

- Identifying, retaining, and preserving stone features that are important in defining the overall historic character of the building such as walls, brackets, railings, cornices, window architraves, door pediments, steps, and columns; and details such as tooling and bonding patterns, coatings, and color.

Not Recommended...

- Removing or radically changing stone features that are important in defining the overall historic character of the building so that, as a result, the character is diminished.

- Replacing or rebuilding a major portion of exterior stone walls that could be repaired so that, as a result, the building is no longer historic and is essentially new construction.

- Applying paint or other coatings such as stucco to stone that has been historically unpainted or uncoated to create a new appearance.

\section{Maintenance/ Management Guidelines for Natural Stone}

- Cyclical maintenance of stone foundations and walls is a key to the successful survival of a building. As soon as rehabilitation or restoration has been completed, some program of continuing maintenance should be initiated. Changes in the building should particularly be noted. All water damage should be noted and remedied at its earliest possible stages. Gutter and downspouts should be kept clean and working properly. Plant, animal, and insect damage should be halted before it becomes substantial.

- $\quad$ According to The Secretary of the Interior's Standards for Rehabilitation, the proper procedure is to respect the significance of the original materials and features, repair and retain wherever possible, and replace them only when absolutely necessary.

- The following recommendations for care of the historic site are to be thoroughly read and understood before a treatment is specified. The Secretary of the Interior's Standards for Rehabilitation should also be consulted to determine the appropriateness of any treatment.

Full documentation can be found at http://www.cr.nps.gov/hps/tps/tax/rhb/stand.htm

Guidelines for Rehabilitating Historic Buildings: Masonry 


\section{Protect and Maintain}

Recommended...

- Protecting and maintaining stone by providing proper drainage so that water does not stand on flat, horizontal surfaces or accumulate in curved decorative features.

- Cleaning stone only when necessary to halt deterioration or remove heavy soiling.

- Carrying out stone surface cleaning tests after it has been determined that such cleaning is appropriate. Tests should be observed over a sufficient period so that both the immediate and the long range effects are known in order to enable selection of the gentlest method possible.

- Cleaning stone surfaces with the gentlest method possible, such as low-pressure water and detergents, using natural bristle brushes.

- Evaluating the overall condition of the stone to determine whether more than protection and maintenance are required, that is, if repairs to the stone features will be necessary.

Not Recommended...

- Failing to evaluate and treat the various causes of mortar joint deterioration such as leaking roofs or gutters, differential settlement of the building, capillary action, or extreme weather exposure.

- Cleaning stone surfaces when they are not heavily soiled to create a new appearance, thus needlessly introducing chemicals or moisture into historic materials.

- Cleaning stone surfaces without testing or without sufficient time for the testing results to be of value.

- Sandblasting stone surfaces using dry or wet grit or other abrasives. These methods of cleaning permanently erode the surface of the material and accelerate deterioration.

- Using a cleaning method that involves water or liquid chemical solutions when there is any possibility of freezing temperatures.

- Cleaning with chemical products that will damage stone, such as using acid on limestone or marble, or leaving chemicals on masonry surfaces.

- Applying high-pressure water cleaning methods that will damage historic stone and the mortar joints.

- Failing to undertake adequate measures to assure the protection of stone features.

\section{Repair}

Recommended...

- Repairing stone walls and other stone features by repointing the mortar joints where there is evidence of deterioration such as disintegrating mortar, cracks in mortar joints, loose bricks, damp walls, or damaged plasterwork.

- Removing deteriorated mortar by carefully hand raking the joints to avoid damaging the stone.

- Repairing stone features by patching, piecing-in, or consolidating the stone using recognized preservation methods. Repair may also include the limited replacement in-kind—or with compatible substitute material—of those extensively deteriorated or missing parts of stone features when there are surviving prototypes.

- Duplicating mortar in strength, composition, color, and texture by performing tests on existing mortar. 
Not Recommended...

- Removing non-deteriorated mortar from sound joints, and then repointing the entire building to achieve a uniform appearance.

- Using electric saws and hammers rather than hand tools to remove deteriorated mortar from joints prior to repointing.

- Repointing with a synthetic caulking compound.

- Using a substitute material for the replacement part that does not convey the visual appearance of the surviving parts of the stone feature or that is physically or chemically incompatible.

- Applying waterproof, water repellent, or non-historic coatings such as stucco to stone as a substitute for repointing and stone repairs. Coatings are frequently unnecessary, expensive, and may change the appearance of historic stone as well as accelerate its deterioration.

\section{Replace}

Recommended...

- Replacing in-kind an entire stone feature that is too deteriorated to repair-if the overall form and detailing are still evident—using the physical evidence as a model to reproduce the feature. Examples can include large sections of a wall, a cornice, balustrade, column, or stairway. If using the same kind of material is not technically or economically feasible, then a compatible substitute material may be considered.

Not Recommended...

- Removing a stone feature that is unrepairable and not replacing it; or replacing it with a new feature that does not convey the same visual appearance.

\section{Good Examples of Natural Stone}

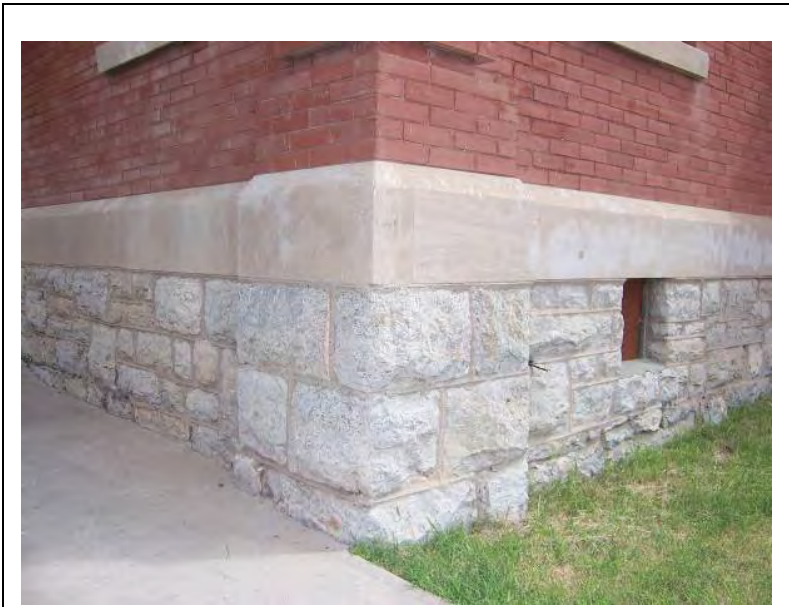

Building 51 - Natural stone was typically used in foundation walls.

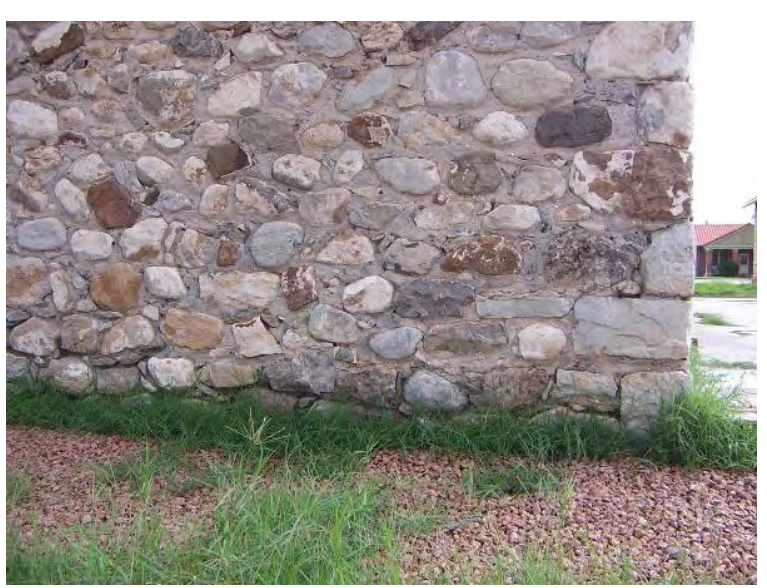

Building 2014 - This is a good example of a natural stone and mortar wall; however, the base of the wall needs to be inspected. Determine the repairs needed for the damaged stones and mortar at the base of the wall caused by water. 


\section{Natural Stone: Moisture}

\section{Repointing}

When the sandy mortar between the stones begins to deteriorate, repointing is needed to fill in the voids of the missing mortar between the stones. When repointing the exterior surface of a historic building, the mortar needs to be softer than the surrounding stones. For this reason, avoid prepackaged mortar mixes, which contain a heavy dose of "hard" Portland cement. To avoid perpetual repointing, a complete repointing needs to be applied over the mortar and stone. This repointing does not have to look like the artisan's creation; it merely has to serve the purpose of keeping the old mortar in place.

\section{Moisture}

Most stone foundation and stone wall deterioration is the result of water infiltration into the building structure. Potential causes of deterioration include: ground settlement, inadequate or leaking gutters and downspouts, intrusive vegetation, and poor drainage around the foundation. Repair and correct the source of damage and underlying moisture problem before any repair methods, such as repointing, are carried out.

Above-grade moisture generally results from weather-related moisture entering through deteriorating materials as a result of deferred maintenance, structural settlement cracks, or damage from high winds or storms. Such sources as faulty roofs, cracks in walls, and open joints around door and window openings can be corrected through either repair or limited replacement. In some cases, excessively absorbent materials, such as soft sandstone, become saturated from rain or gutter overflows, or in Fort Bliss' case, improper installation of evaporative coolers and air conditioning units.

- $\quad$ To avoid these conditions proper drainage around the structure needs to be maintained.

- $\quad$ Soils and surfaces of patios and walkways adjacent to the foundation should have a positive slope away from the structure.

- $\quad$ Roof run-off should be collected in a well-maintained gutter system and extensions should be provided on the downspouts.

\section{Inspection}

- Identify root cause of damage, including standing water.

\section{Evaluation}

- Determine the level of treatment necessary to repair severely damaged stone.

- Evaluate the overall condition of the stone to determine whether more than protection and maintenance are required, that is, if repairs to the stone features will be necessary.

\section{Execution}

- If moisture cannot be managed by maintenance alone, it is important to reduce it by mitigating problems before deteriorated materials are replaced.

- Repair the source of the damage before repairing proceeds.

- $\quad$ Replace in-kind to the historic materials.

- $\quad$ Do not coat buildings with waterproof sealers that can accelerate an existing problem.

\section{Further Readings}

GSA has developed technical procedures to be used in specialized historic preservation work, as well as general evaluation, maintenance and repair of older building materials. For more detailed descriptions of repair procedures for moisture-related problems refer to the following, which can be found at http://w3.gsa.gov/web/p/hptp.nsf

- $\quad$ Guidelines for Rehabilitating Historic Buildings: Masonry

- $\quad$ Removing Climbing Plants and Creepers from Masonry 


\section{Inspection}

Recommended...

- $\quad$ Identifying root cause of damage, including standing water.

- $\quad$ Protecting and maintaining stone by providing proper drainage so that water does not stand on flat, horizontal surfaces or accumulate in curved decorative features.

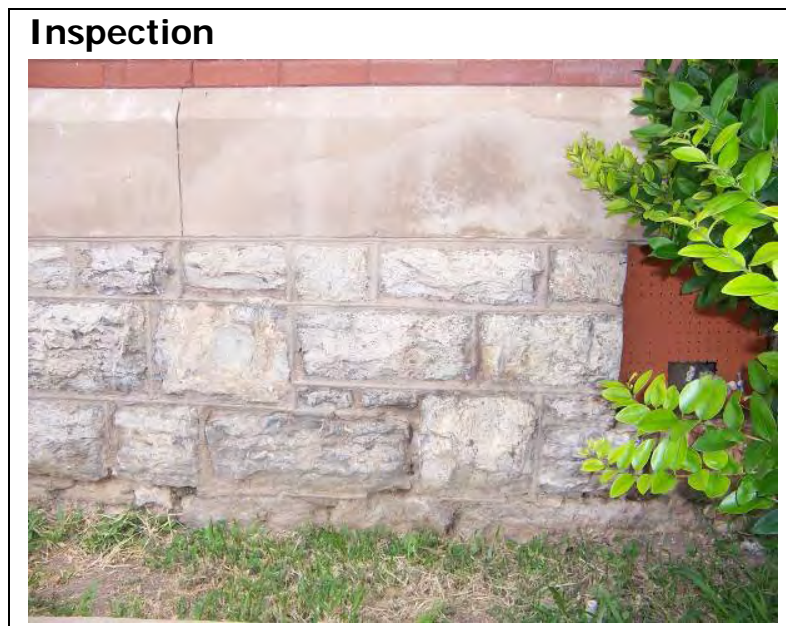

Building 51 - A periodic inspection of stones and mortar will reveal any maintenance or repair concerns.

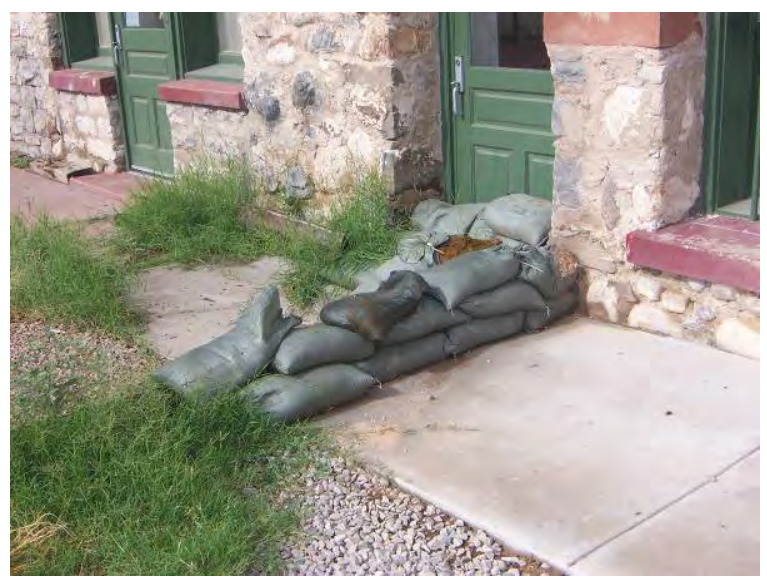

Building 2011 - Proper drainage is a key to maintaining stone and mortar foundation walls. An inspection found standing water near the foundation and door. Sandbags are not a permanent solution to the problem.

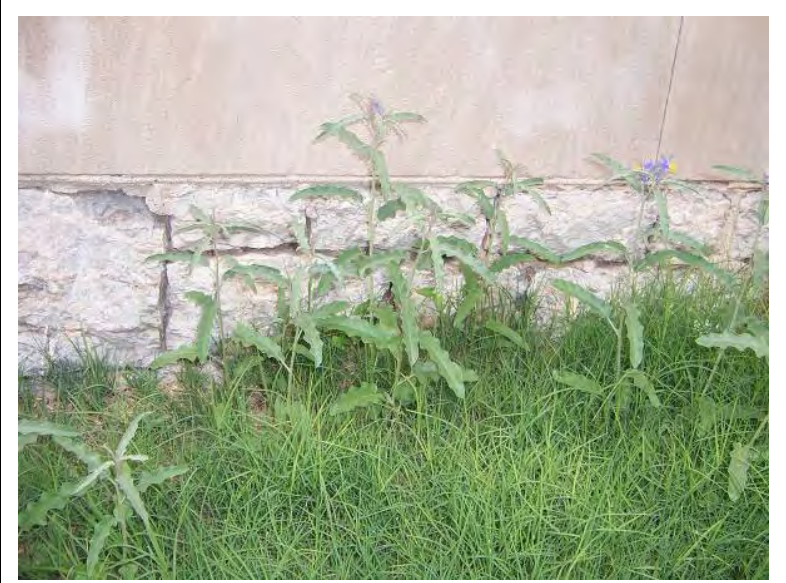

Building 51 - Keep vegetation away from stone foundations. The vegetation draws moisture closer to the building's foundation.

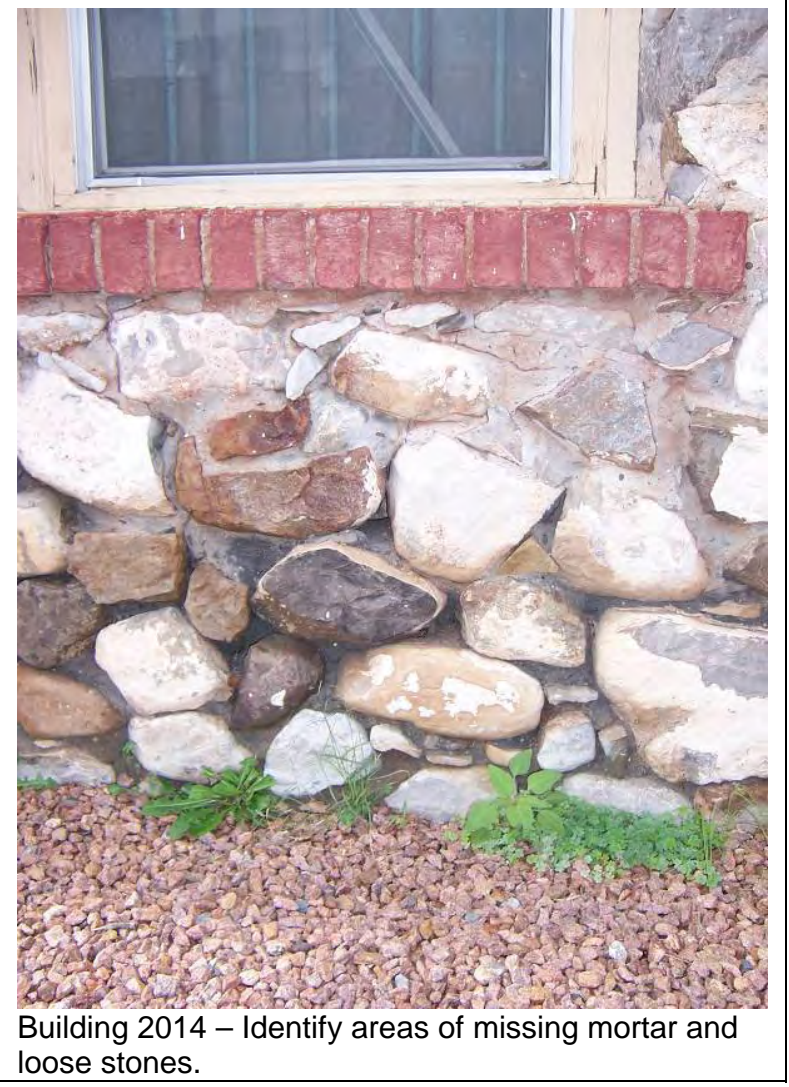




\section{Evaluation}

Recommended...

- $\quad$ Evaluating the overall condition of the stone to determine whether more than protection and maintenance are required.

- Determining the level of treatment necessary to repair severely damaged stone.

Not Recommended...

- $\quad$ Failing to evaluate and treat the various causes of mortar joint deterioration such as leaking roofs or gutters, differential settlement of the building, or extreme weather exposure.

\section{Evaluation}

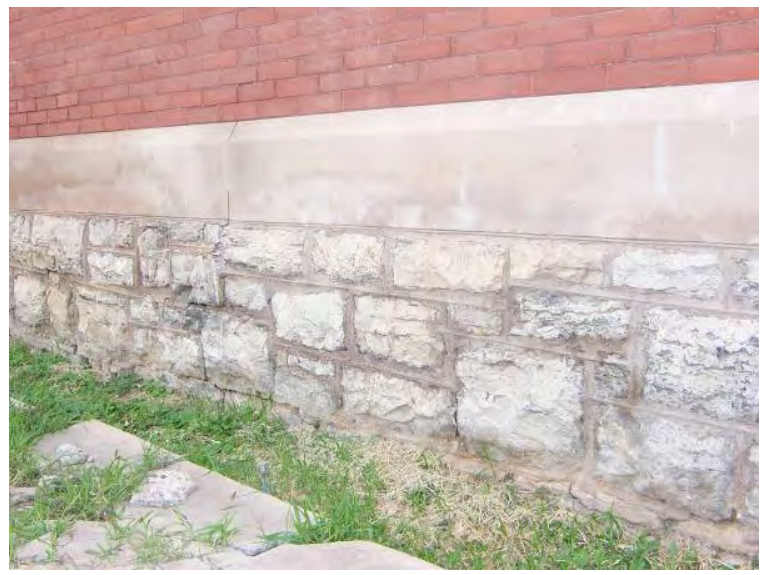

Building 51 - Evaluate the overall condition of the stone to determine whether more than protection and maintenance are required.

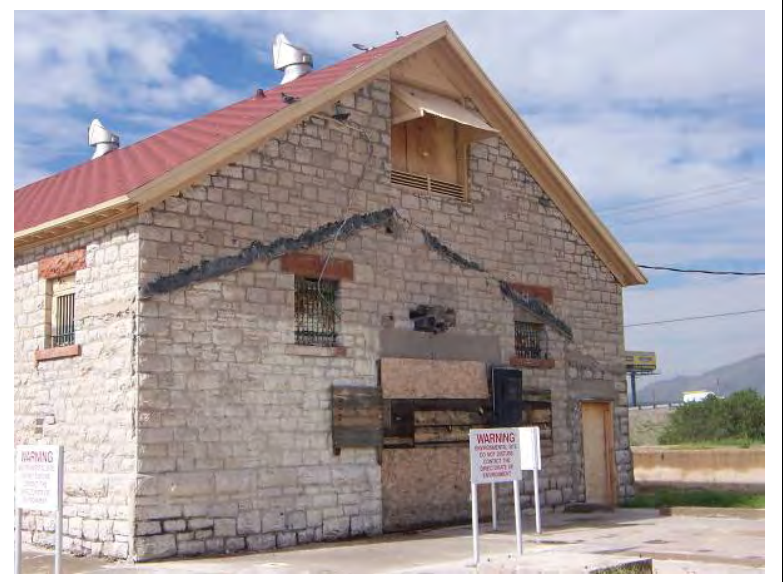

Building 2031 - It is important to note all previous work performed on stone exterior walls in order to develop a maintenance schedule. 


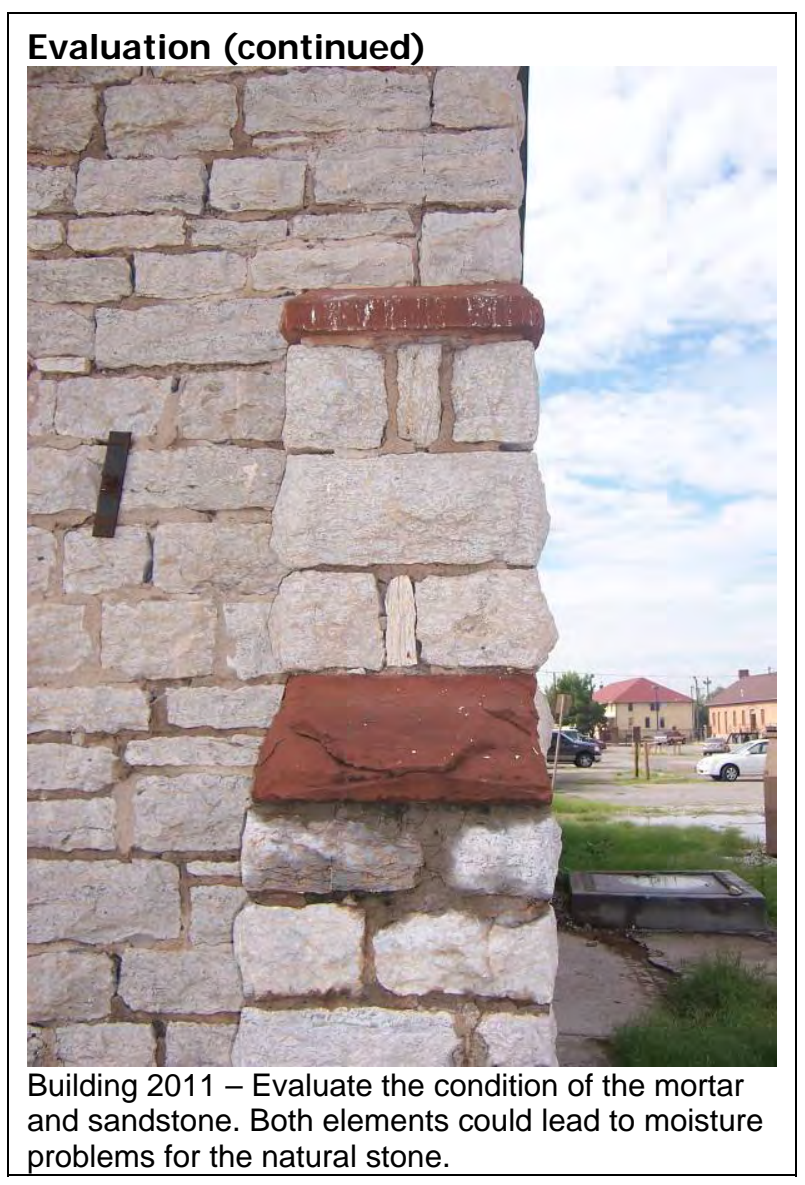

\section{Repair}

Recommended...

- $\quad$ Applying new or non-historic surface treatments such as water-repellent coatings to stone only after repointing and only if stone repairs have failed to arrest water penetration problems.

- If applying a new coat of paint, it must be compatible with any coating already on the surface. In preparation for repainting, all loose or peeling paint or other coating materials not firmly adhered to the stone must be removed by hand-scraping or natural bristle brushes. The surface should then be cleaned.

Not Recommended...

- $\quad$ Removing or radically changing stone features that are important in defining the overall historic character of the building so that, as a result, the character is diminished.

- $\quad$ Coating buildings with waterproof sealers that can accelerate an existing problem.

- Applying paint or other coatings such as stucco to stone that has been historically unpainted or uncoated to create a new appearance.

- $\quad$ Replacing or rebuilding a major portion of exterior stone walls that could be repaired so that, as a result, the building is no longer historic and is essentially new construction. 


\section{Replace}

Recommended...

- $\quad$ Patching rather than wholesale replacement is preferred.

- $\quad$ Replace in-kind to the historic materials.

Not Recommended...

- $\quad$ Removing a stone feature that is unrepairable and not replacing it.

- $\quad$ Using a substitute material for the replacement part that does not convey the visual appearance of the surviving parts of the stone feature or that is physically or chemically incompatible.

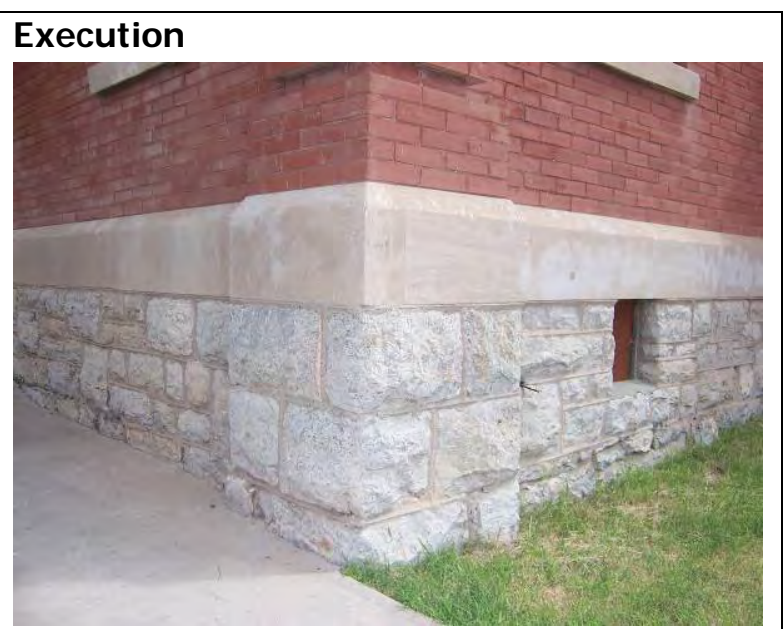

Building 51 - Maintain proper mortar joints in stone foundations to ensure the highest protection against water penetration and stone deterioration.

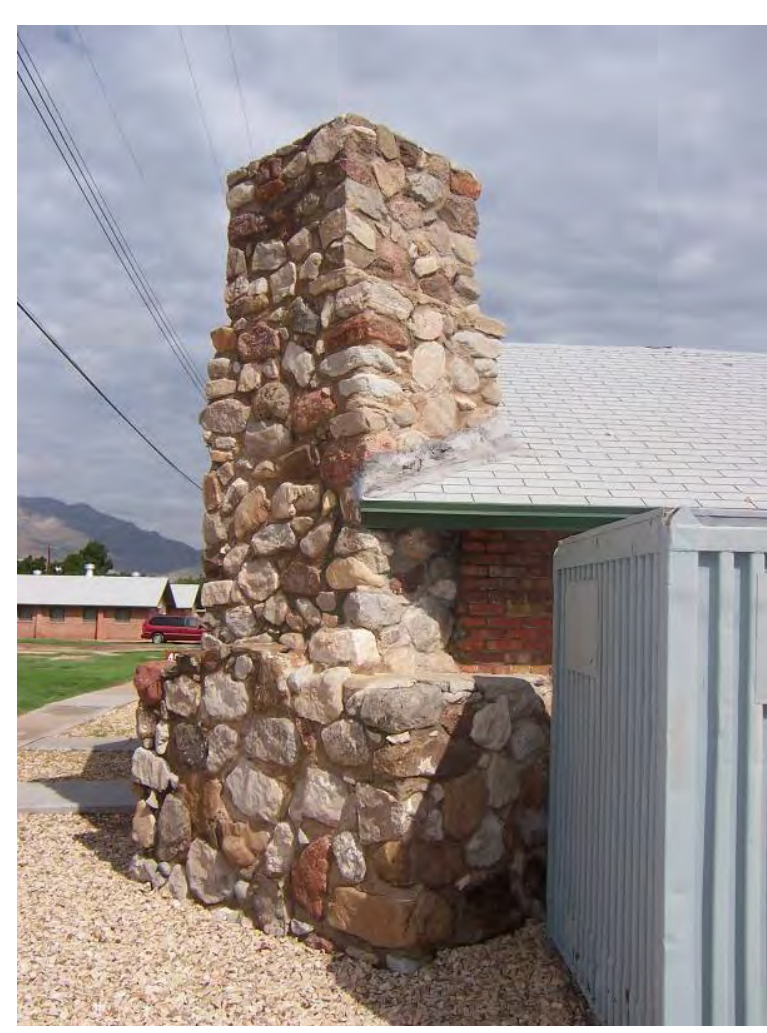

Building 451 - This stone chimney is in good condition; however, it is not recommended to remove an entire stone feature that is unrepairable and not replace it. 


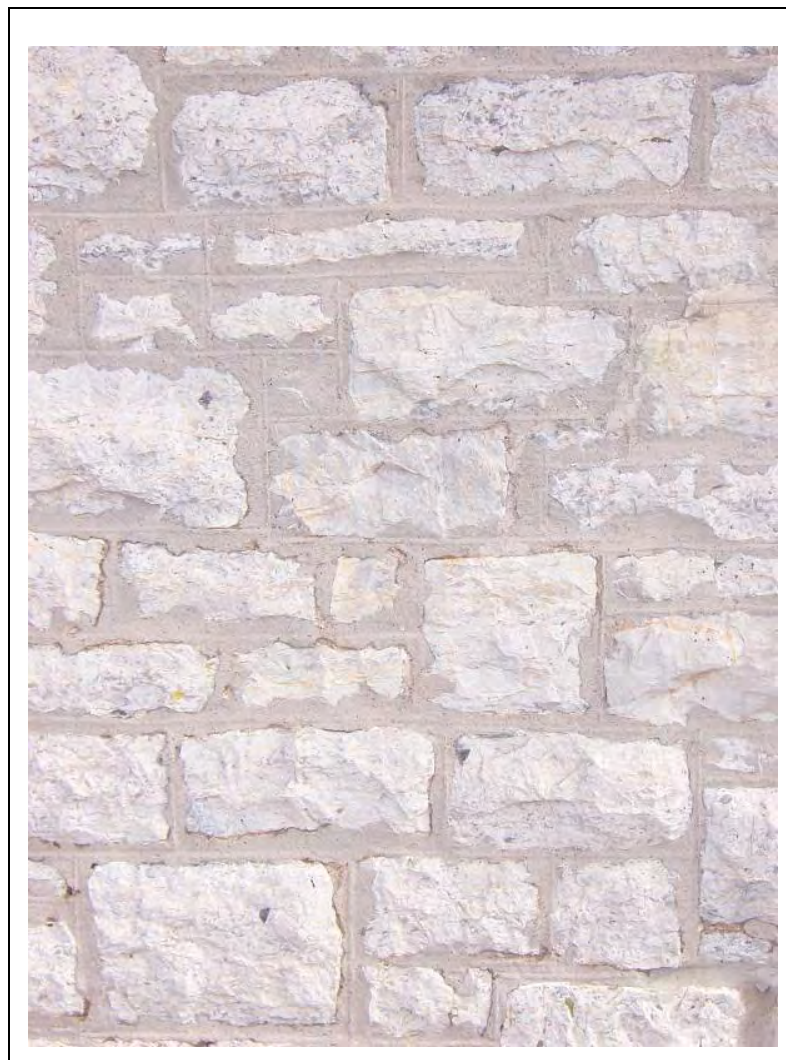

Building 2009 - Removing non-deteriorated mortar from sound joints, and then repointing the entire building to achieve a uniform appearance is not recommended. 
Notes

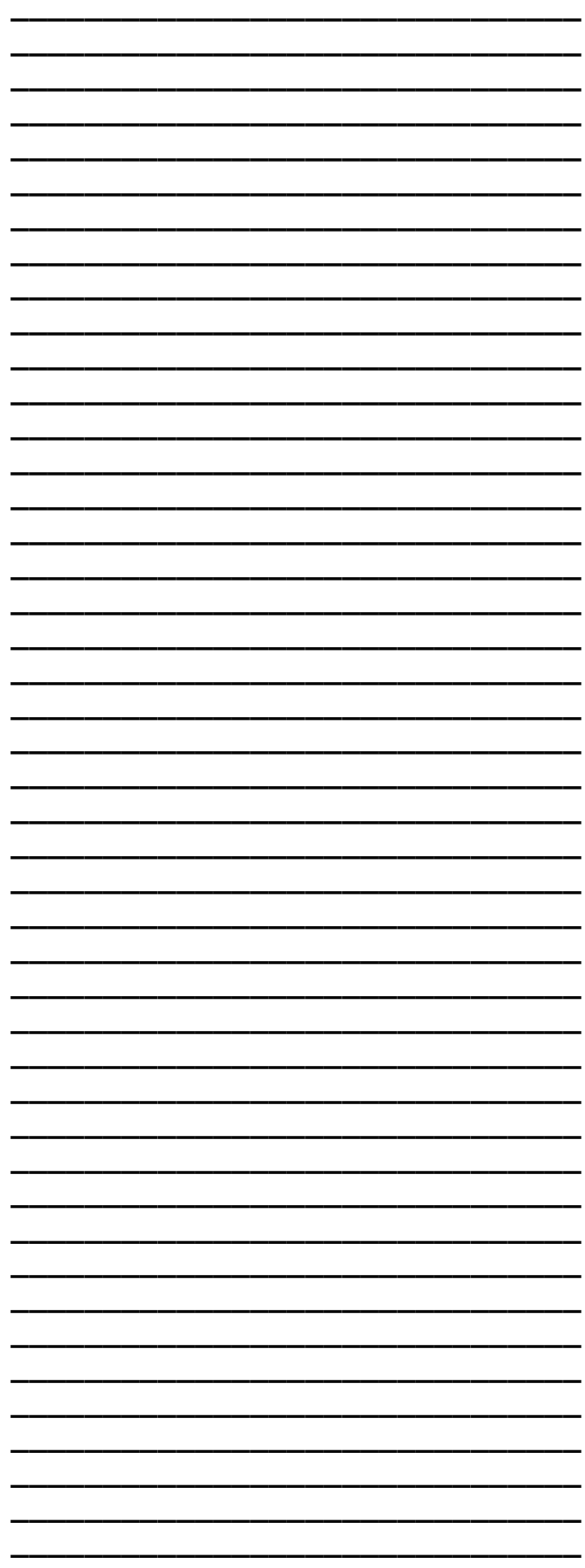




\section{Maintenance Guides for Sandstone}

\section{Sandstone: Overview}

Sandstone is a soft and porous material and can often be difficult to repair. It is also very susceptible to damage by improper maintenance or repair and by harsh or abrasive cleaning methods. The maintenance issues for sandstone are primarily focused on its decay and on how it can be repaired and preserved, since it is difficult to find compatible sandstone to match the historic sandstone. The typical uses for sandstone for buildings located at Fort Bliss are windowsills, lintels, and water tables. A majority of the sandstone elements at Fort Bliss are damaged or are showing signs of deterioration. Problems that affect sandstone may be classified into two broad categories: 1) Natural or inherent problems based on the characteristics of the material and the conditions of the exposure, and 2) Vandalism and human-induced problems.

\section{Natural or Inherent Problems}

Based on the characteristics of the material and the conditions of the exposure

- $\quad$ Moisture-related problems: May be evident in sandstone as spalling, erosion, cracking, flaking, and deteriorated mortar joints.

- Weathering: Disintegration of the stone's surface usually caused by erosion, chemical action, and moisture freezing in the stone.

- $\quad$ Exfoliation: Separation and loss of large areas of stone along the bedding planes usually caused by the stone having been face-bedded.

- $\quad$ Blind Exfoliation: Separation of stone along bedding planes, but where layers are still loosely attached behind the surface. It is often caused by having laid the stone with the bedding planes running parallel with the surface of the wall (face-bedding). Blind exfoliated stone will sound hollow when lightly tapped with a rubber mallet.

- $\quad$ Blistering: Swelling and rupturing of a thin uniform skin caused by air-borne chemicals reacting with the stone's surface, forming a hard, brittle skin. The blisters will often pop when touched.

- $\quad$ Cracking: Narrow fractures in the stone from 1/16 to 1/2-inch wide.

\section{Maintenance/ Management Guidelines} for Sandstone

- Cyclical maintenance has always been a key to successful sandstone survival. As soon as rehabilitation or restoration has been completed, some program of continuing maintenance should be initiated. Changes in the building should particularly be noted. The early stages of cracking, spalling, erosion, flaking, or detachment in sandstone elements should be monitored regularly. All water damage should be noted and remedied at its earliest possible stages. Plant, animal, and insect damage should be halted before it becomes substantial. The roof should be inspected periodically. Surface coatings must be inspected frequently and repaired or replaced as the need indicates.

- According to The Secretary of the Interior's Standards for Rehabilitation, the proper procedure is to respect the significance of the original materials and features, repair and retain wherever possible, and replace them only when absolutely necessary.

- The following recommendations for care of the historic site are to be thoroughly read and understood before a treatment is specified. The Secretary of the Interior's Standards for Rehabilitation should also be consulted to determine the appropriateness of any treatment.

Full documentation can be found at http://www.cr.nps.gov/hps/tps/tax/rhb/stand.htm 
- Detachment: A clean break in the stone often resulting from a sharp impact, or from stresses concentrated in a small area of stone due to structural settlement.

\section{Vandalism and Human-induced Problems}

- $\quad$ Stone laid with its layers parallel to the wall plane (face-bedded) rather than perpendicular to the wall plane (naturally-bedded): Face-bedded stone is more prone to deterioration by weathering as entire sheets of stone tend to flake off.

- $\quad$ Painting over a deteriorated stone surface: This only leads to more serious moisturerelated problems.

- $\quad$ Applying a cement patch over deteriorated surface areas: If an inappropriate patching mix is used, it may be necessary to paint the entire stone surface to lessen the visual disparity between the two materials.

\section{Typical historical uses for sandstone included}

- $\quad$ Urban row houses, commercial buildings and churches built from the 1840s through the early 20th century (this was usually brownstone).

- $\quad$ Lighter-colored sandstones were used more frequently by the end of the 19th century.

- $\quad$ Sandstone found at Fort Bliss was historically used for windowsills and foundations.

\section{Sandstone today}

- New sandstone is not widely available for use today.

- The popularity of sandstone today is focused primarily on its decay and on how it can be repaired and preserved.

\section{Identify, Retain, and Preserve}

Recommended...

- $\quad$ Identifying, retaining, and preserving masonry features that are important in defining the overall historic character of the building such as walls, brackets, railings, cornices, window architraves, door pediments, steps, and columns; and details such as tooling and bonding patterns, coatings, and color.

Not Recommended...

- $\quad$ Removing or radically changing masonry features that are important in defining the overall historic character of the building so that, as a result, the character is diminished.

- $\quad$ Replacing or rebuilding a major portion of exterior masonry walls that could be repaired so that, as a result, the building is no longer historic and is essentially new construction.

- Applying paint or other coatings such as stucco to stone that has been historically unpainted or uncoated to create a new appearance.

- $\quad$ Removing paint from historically painted stone.

- $\quad$ Radically changing the type of paint or coating or its color.

\section{Protect and Maintain}

Recommended...

- $\quad$ Protecting and maintaining masonry by providing proper drainage so that water does not stand on flat, horizontal surfaces or accumulate in curved decorative features. 
- $\quad$ Cleaning stone only when necessary to halt deterioration or remove heavy soiling.

- Carrying out stone surface cleaning tests after it has been determined that such cleaning is appropriate. Tests should be observed over a sufficient period so that both the immediate and the long range effects are known in order to enable selection of the gentlest method possible.

- $\quad$ Cleaning stone surfaces with the gentlest method possible, such as low-pressure water and detergents, using natural bristle brushes.

- Inspecting painted stone surfaces to determine whether repainting is necessary.

- $\quad$ Removing damaged or deteriorated paint only to the next sound layer using the gentlest method possible (e.g., hand-scraping) prior to repainting.

- $\quad$ Applying compatible paint coating systems following proper surface preparation.

- $\quad$ Repainting with colors that are historically appropriate to the building and district.

- $\quad$ Evaluating the overall condition of the masonry to determine whether more than protection and maintenance are required, that is, if repairs to the masonry features will be necessary.

Not Recommended...

- Failing to evaluate and treat the various causes of mortar joint deterioration such as leaking roofs or gutters, differential settlement of the building, capillary action, or extreme weather exposure.

- Cleaning stone surfaces when they are not heavily soiled to create a new appearance, thus needlessly introducing chemicals or moisture into historic materials.

- $\quad$ Cleaning stone surfaces without testing or without sufficient time for the testing results to be of value.

- $\quad$ Sandblasting stone surfaces using dry or wet grit or other abrasives. These methods of cleaning permanently erode the surface of the material and accelerate deterioration.

- $\quad$ Using a cleaning method that involves water or liquid chemical solutions when there is any possibility of freezing temperatures.

- Cleaning with chemical products that will damage masonry, such as using acid on limestone or marble, or leaving chemicals on masonry surfaces.

- Applying high-pressure water cleaning methods that will damage historic stone and the mortar joints.

- $\quad$ Removing paint that is firmly adhering to, and thus protecting, stone surfaces.

- Using methods of removing paint that are destructive to stone, such as sandblasting, application of caustic solutions, or high-pressure water blasting.

- $\quad$ Failing to follow manufacturers' product and application instructions when repainting stone.

- $\quad$ Using new paint colors that are inappropriate to the historic building and district.

- $\quad$ Failing to undertake adequate measures to assure the protection of stone features.

\section{Repair}

Recommended...

- $\quad$ Removing deteriorated mortar by carefully hand-raking the joints to avoid damaging the stone.

- $\quad$ Duplicating old mortar in strength, composition, color, and texture. 
- $\quad$ Duplicating old mortar joints in width and in joint profile.

- $\quad$ Repairing stone features by patching, piecing-in, or consolidating the masonry using recognized preservation methods. Repair may also include the limited replacement in-kindor with compatible substitute material—of those extensively deteriorated or missing parts of stone features when there are surviving prototypes.

Not Recommended...

- $\quad$ Removing non-deteriorated mortar from sound joints, and then repointing the entire building to achieve a uniform appearance.

- $\quad$ Using electric saws and hammers rather than hand tools to remove deteriorated mortar from joints prior to repointing.

- $\quad$ Repointing with mortar of high Portland cement content (unless it is the content of the historic mortar). This can often create a bond that is stronger than the historic material and can cause damage as a result of the differing coefficient of expansion and the differing porosity of the material and the mortar.

- $\quad$ Repointing with a synthetic caulking compound.

- Changing the width or joint profile when repointing.

- $\quad$ Using a substitute material for the replacement part that does not convey the visual appearance of the surviving parts of the masonry feature or that is physically or chemically incompatible.

- $\quad$ Applying waterproof, water repellent, or non-historic coatings such as stucco to masonry as a substitute for repointing and masonry repairs. Coatings are frequently unnecessary, expensive, and may change the appearance of historic masonry as well as accelerate its deterioration.

\section{Replace}

Recommended...

- $\quad$ Replacing in-kind an entire masonry feature that is too deteriorated to repair-if the overall form and detailing are still evident—using the physical evidence as a model to reproduce the feature. If using the same kind of material is not technically or economically feasible, then a compatible substitute material may be considered.

Not Recommended...

- $\quad$ Removing a masonry feature that is unrepairable and not replacing it; or replacing it with a new feature that does not convey the same visual appearance. 


\section{Good Examples of Sandstone}

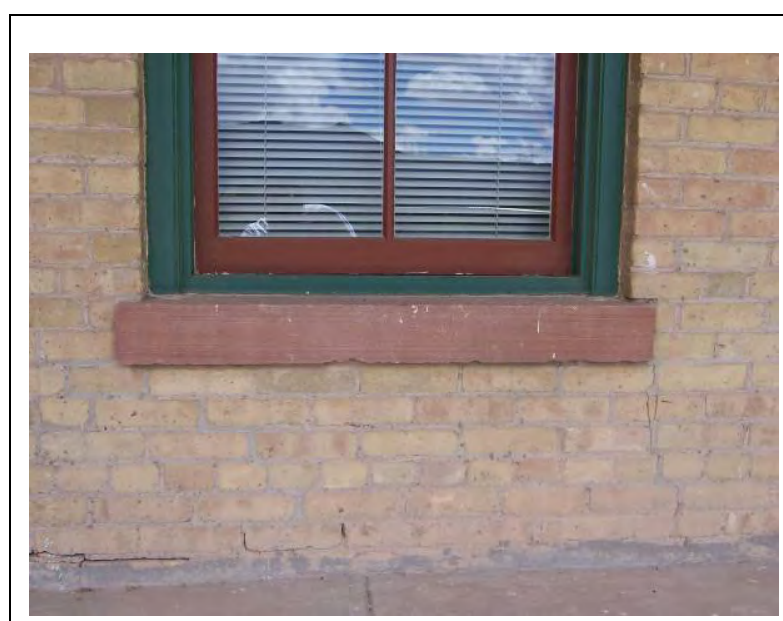

Building 13 - Most historic sandstone at Fort Bliss was used for windowsills and foundations.

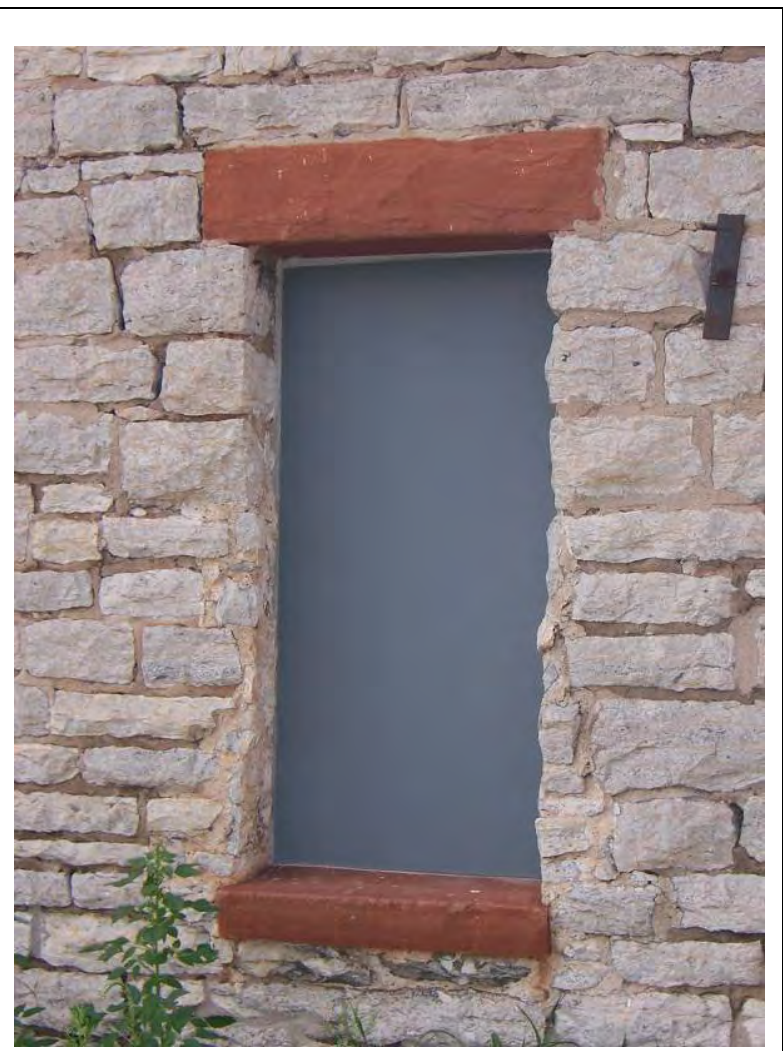

Building 2011 - Sandstone is used as a lintel and windowsill. 


\section{Sandstone: Moisture-Related Problems}

One of the most important elements to monitor on a masonry building is the deterioration of the stone. Damage to masonry that is detected before it becomes too severe can often be repaired. If the damaged area continues to deteriorate, more costly repairs may become necessary.

Uncontrolled moisture is the most prevalent cause of deterioration in older and historic buildings. It leads to erosion, corrosion, rot, and ultimately the destruction of materials, finishes, and eventually structural components. Some of the more common signs of visible as well as hidden moisture damage include:

- $\quad$ presence of standing water, mold, mildew, or fungus,

- $\quad$ wet stains, eroding surfaces, or efflorescence on interior and exterior surfaces,

- $\quad$ spalled cracked masonry or eroded mortar joints, and/or

- $\quad$ condensation on window and wall surfaces.

\section{Causes}

- $\quad$ Above-grade moisture generally results from weather related moisture entering through deteriorating materials as a result of deferred maintenance, structural settlement cracks, damage from high winds or storms, or lawn sprinklers hitting the building. Such sources as faulty roofs, cracks in walls, and open joints around door and window openings can be corrected through either repair or limited replacement. In some cases, excessively absorbent materials, such as soft sandstone, become saturated from rain or gutter overflows.

- A common problem in the El Paso area and especially at Fort Bliss is the inappropriate placement of window air conditioning units and evaporative coolers. Due to the dry climate of the southwest, evaporative coolers are used in abundance as an efficient and effective machine used to cool the structures. However, the water supply used to cool the structures ultimately poses a problem for the structures' building materials, such as sandstone. Many of these evaporative coolers penetrate an exterior wall or are located on the structure's roof. The water that circulates through the cooler is causing moisture-related problems to the building materials that are in contact with them.

\author{
Inspection \\ - It is important to keep record of moisture prob- \\ lems within a building and to protect the historic \\ or old building through cyclical maintenance. \\ - Identify areas of soft sandstone that are spalled \\ and may need to be redressed. \\ - Identify root cause of damage, including stand- \\ ing water.

\section{Evaluation} \\ - Determine level of treatment necessary to re- \\ pair severely damaged sandstone. \\ - Evaluate the overall condition of the sandstone \\ to determine whether more than protection and \\ maintenance are required, that is, if repairs to \\ the sandstone features will be necessary.

\section{Execution} \\ - If moisture cannot be managed by mainte- \\ nance alone, it is important to reduce it by miti- \\ gating problems before deteriorated materials \\ are replaced. \\ - $\quad$ Repair the source of the damage before repair- \\ ing proceeds. \\ - $\quad$ Do not coat buildings with waterproof sealers \\ that can accelerate an existing problem.
}

\section{Further Readings}

GSA has developed technical procedures to be used in specialized historic preservation work, as well as general evaluation, maintenance and repair of older building materials. For more detailed descriptions of repair procedures for moisture-related problems with sandstone refer to the following, which can be found at http://w3.gsa.gov/web/p/hptp.nsf

- $\quad$ Sandstone: Characteristics, Uses, and Problems

- $\quad$ Repairing Sandstone by Through Surface Repair

- $\quad$ Composite Patching Weathered, Exfoliated, or Blistering Sandstone 
- $\quad$ Sandstone located near the foundation of a structure is susceptible to spalling. Water that is not properly drained away from the structure causes the deterioration of both the stone and mortar. El Paso is known for its summer rain showers, which produce an ample amount of rainfall in a short period of time. If gutters are not properly installed or if rainwater is continually bouncing off of the ground surface back onto the face of the sandstone and mortar located at the base of the wall, mortar deterioration will continually progress.

- Vines or other vegetation materials allowed to grow directly on the building without trellis or framework can cause damage from roots eroding mortar joints and foundations as well as dampness being held against surfaces. In most cases, keeping vegetation off of buildings, repairing damaged materials, replacing flashing, rehanging gutters, repairing downspouts, repointing mortar, caulking perimeter joints around door and window openings, and repainting surfaces can alleviate most sources of unwanted exterior moisture.

\section{Inspection}

When inspecting for damaged sandstone elements look closely at the following:

- $\quad$ Color: What color is the stone? Is there variation in color within individual stones? Is there variation between stones?

- $\quad$ Pattern: Are there swirls, bands, or veins of color within the individual stones?

- Texture: Is the stone surface rough or smooth? Is it hard or crumbly? Is the texture uniform or varied?

- $\quad$ Surface Tooling: Is the face of the stone rough or smooth? Are there any chiseled grooves? Are there any decorative surface patterns? Are any parts damaged or missing?

- $\quad$ Sand Grains: is the grain size large or small? Does the grain structure appear densely or loosely packed together?

- $\quad$ Decay and Old Repairs: Is there evidence of erosion, crumbling, spalling, or other types of deterioration? Is there evidence of previous patching or repairs?

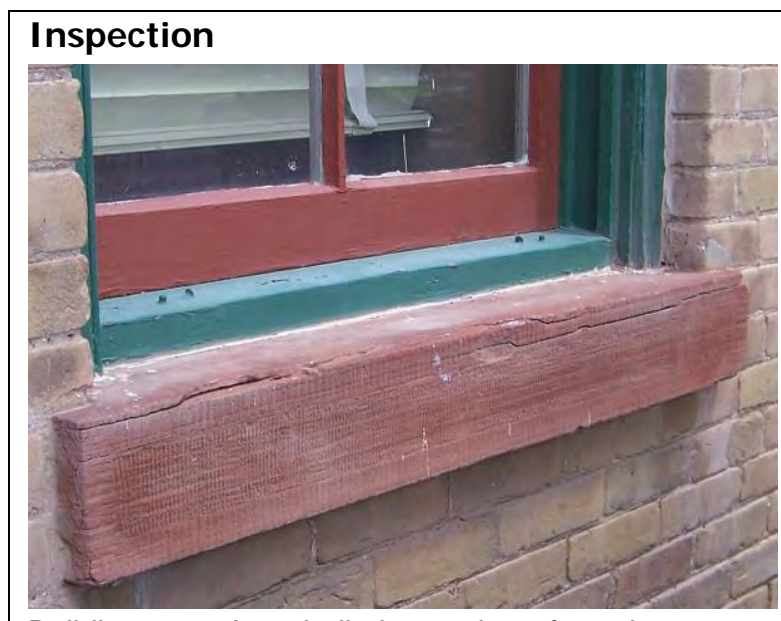

Building 13 - A periodic inspection of sandstone masonry should uncover cracking or spalling issues. The top of the sandstone windowsill is damaged from rain water standing on the flat surface.

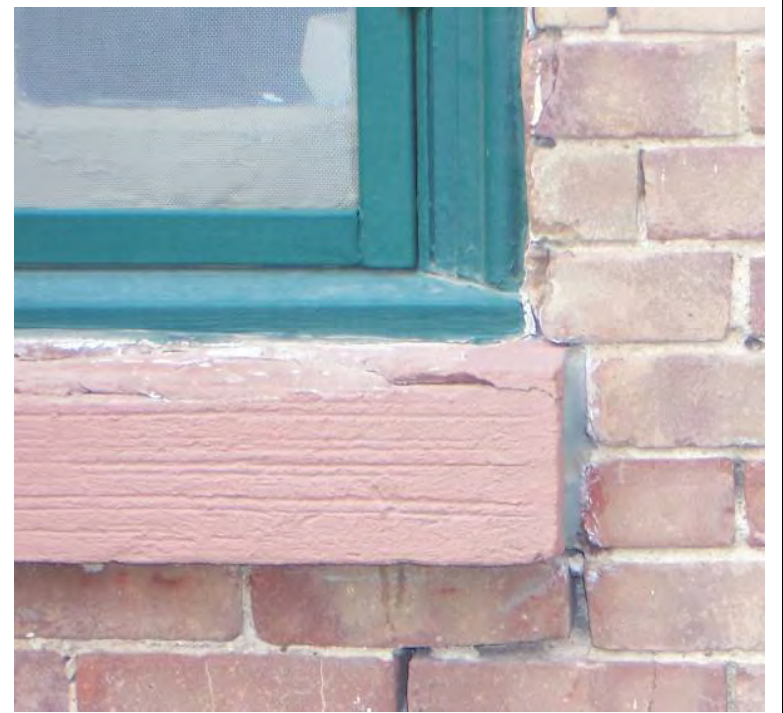

Building 128 - When inspecting for damaged sandstone look closely at the color, pattern, texture, sand grains, surface tooling, decay, and old repairs. 


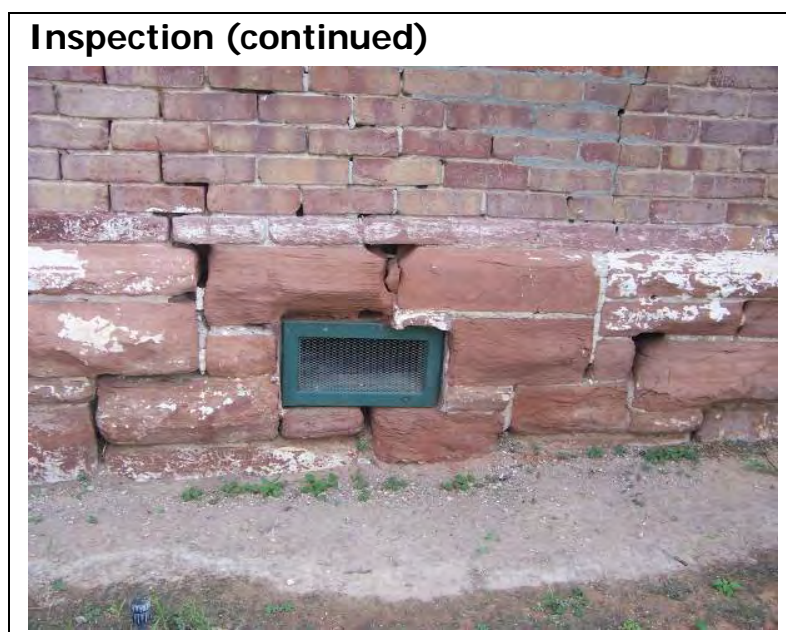

Building 128 - Inspect key areas of the building where sandstone could be located, like the foundation. Examine the overall condition of the sandstone and mortar joints.

\section{Evaluation}

- Determine the level of damage to the sandstone element and the extent of cause of damage.

- Compare undamaged stone with areas of suspected decay.

- Determine whether the sandstone piece can be repaired through patching or if the piece needs to be replaced.

- If patching is the appropriate treatment, then proceed with a composite patch, which is the process whereby cement and sand mixtures are applied as a series of stucco-like coats to reconstruct missing stone surfaces. Three types of stone deterioration that warrant composite patching include weathering, exfoliation, and blistering.

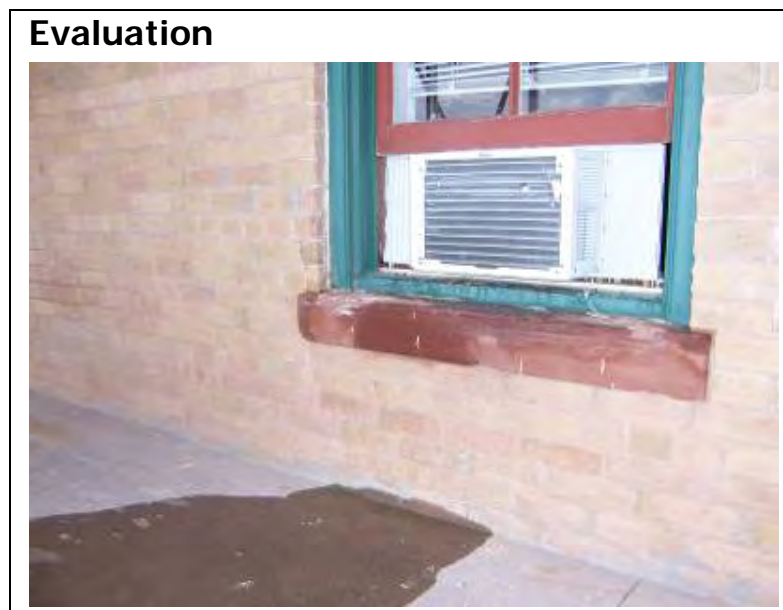

Building 13 - Areas of spalled sandstone caused by water damage should be identified. Water dripping from the window air conditioning unit is damaging the sandstone windowsill. Determine whether the sandstone piece can be repaired through patching or if the piece needs to be replaced.

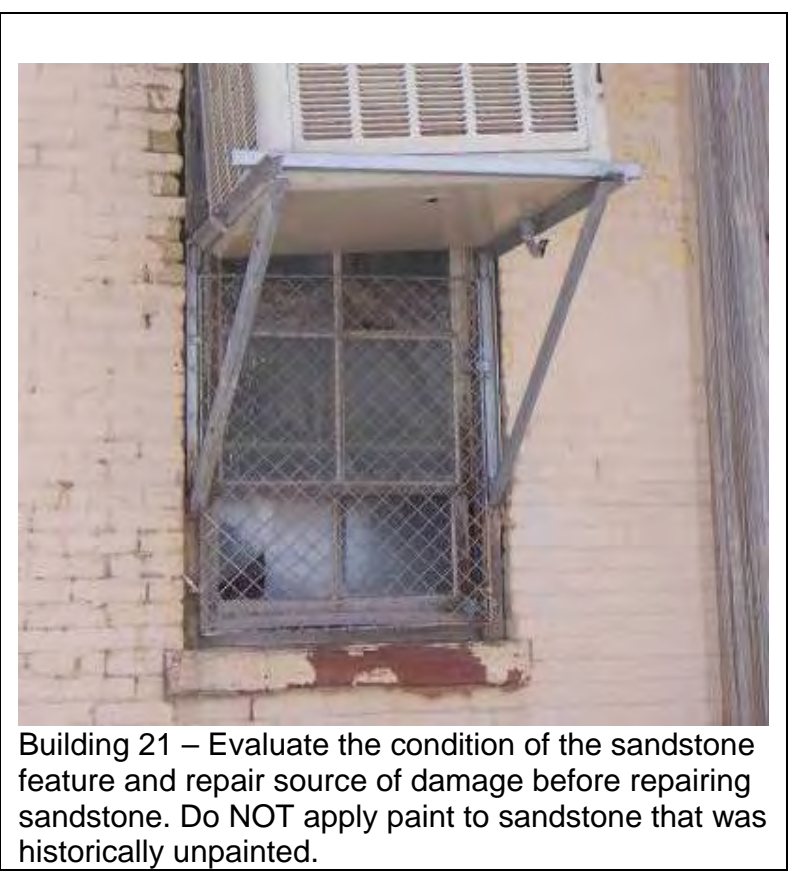




\section{Repair}

Start with the repair of any obvious deficiencies using sound preservation maintenance. If moisture cannot be managed by maintenance alone, it is important to reduce it by mitigating problems before deteriorated materials are replaced. Treatments should not remove any materials that can be preserved, should not involve extensive evacuation unless there is a documented need, and should not include coating buildings with waterproof sealers that can accelerate an existing problem.

Appropriate Level of Treatment:

- $\quad$ Level I - preservation and maintenance

- $\quad$ Level II - repair using historically compatible materials and essentially mitigating damaging moisture conditions

- $\quad$ Level III - replacement and alteration of materials that permit continued use in a chronically moist environment

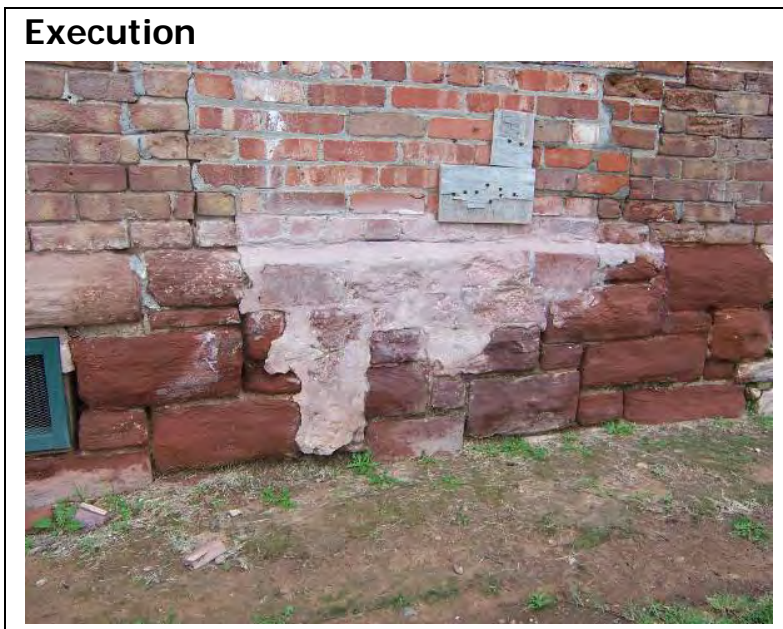

Building 128 - Sandblasting is NOT recommended as a cleaning method for sandstone. Sandstone is a soft porous material and needs to be maintained by the gentlest methods possible, such as using natural bristle brushes with low-pressure water and detergents. 
Notes

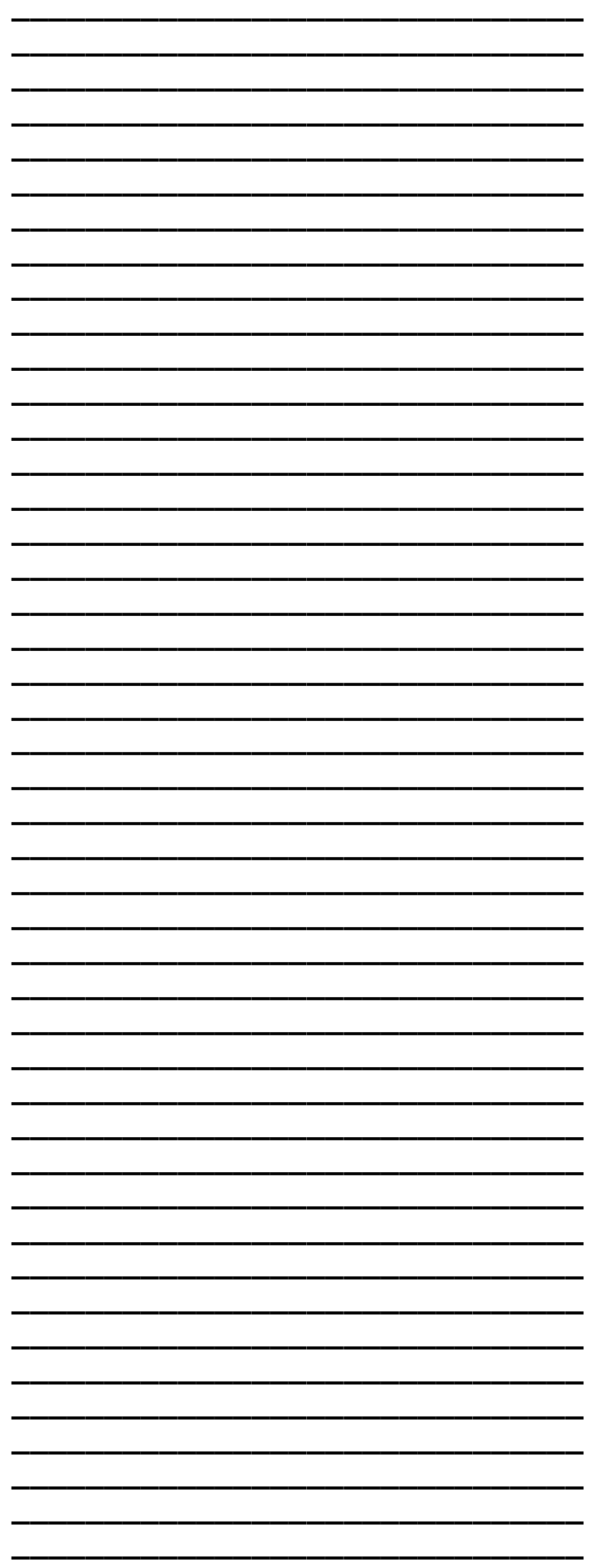




\section{Sandstone: Weathering}

\section{Spalling}

All exposed masonry should be inspected for spalling. The spalling, dusting, or flaking of sandstone may be due to either mechanical or chemical damage. Mechanical damage is caused by moisture entering the stone and freezing. The expansion of the ice will break off the stone's face. Spalling may continue or may stop on its own after the outer layers that trapped the interior moisture have broken off. Chemical damage is due to the leaching of chemicals from the ground into the sandstone, resulting in internal deterioration. External signs of such deterioration are a dusting or flaking of the sandstone. The loss of the surface material may vary in size.

\section{Erosion}

Erosion is the weathering of the stone's surface by wind, rain, and salt air. Erosion can also be caused by inadequate drainage of water. Rainwater that has accumulated at the base of stone walls should be diverted away from the building. This may be done by regrading or by building gravel-filled trenches or stone drip gutters. Regrading is perhaps the best solution because defective gutters and trenches may in effect collect and hold water at the base of the wall or foundation.

\section{Causes}

- $\quad$ A common problem in the El Paso area and especially at Fort Bliss is the inappropriate placement of window air conditioning units and evaporative coolers. Due to the dry climate of the southwest, evaporative coolers are used in abundance as an efficient and effective machine used to cool the structures. However, the water supply used to cool the structures ultimately poses a problem for the structures' building materials, such as sandstone. Many of these evaporative coolers penetrate an exterior wall or are located on the structure's roof. The water that circulates through the cooler is constantly dripping onto building surfaces.

\section{Inspection}

- Identify loose or missing masonry.

- Identify areas of soft sandstone that are weathered and may need to be redressed.

\section{Evaluation}

- Determine level of treatment necessary to repair severely damaged sandstone.

- Determine whether the sandstone can be repaired or if it needs to be patched.

\section{Execution}

- Repair the source of the damage before repairing or repointing proceeds.

- If a patch is the appropriate treatment, make sure the patch is compatible in color, texture, and pattern to the original historic sandstone.

\section{Further Readings}

GSA has developed technical procedures to be used in specialized historic preservation work, as well as general evaluation, maintenance and repair of older building materials. For more detailed descriptions of repair procedures for weathering problems to sandstone refer to the following, which can be found at http://w3.gsa.gov/web/p/hptp.nsf

- $\quad$ Sandstone: Characteristics, Uses, and Problems

- Repairing Sandstone by Through Surface Repair

- $\quad$ Composite Patching Weathered, Exfoliated, or Blistering Sandstone 


\section{Inspection}

- Identify areas of soft sandstone that are weathered and may need to be redressed.

- Keep moisture away from sandstone foundations by providing proper drainage away from the structure.

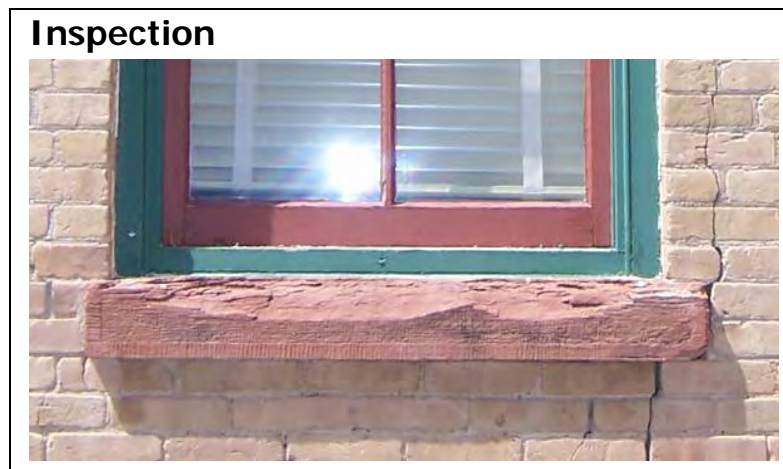

Building 13 - A periodic inspection of sandstone will reveal areas of damage. Identify areas of soft sandstone that are weathered and may need to be addressed.

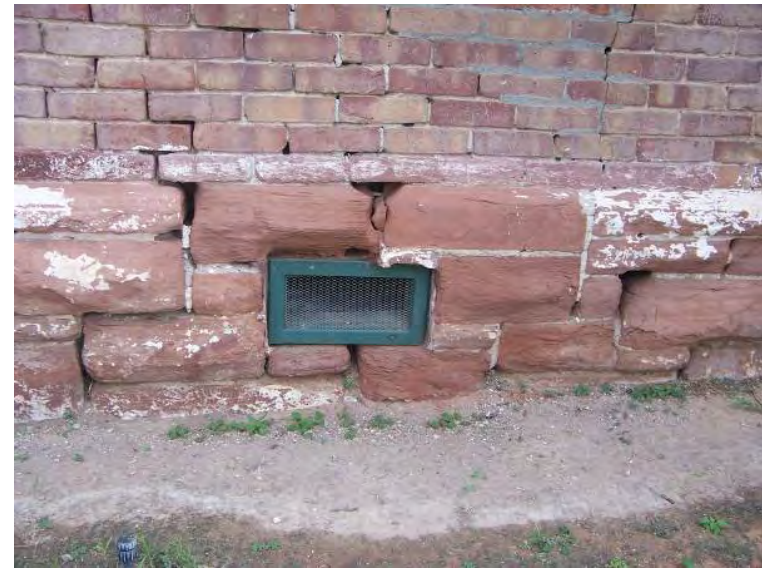

Building 128 - It is important to keep moisture away from sandstone foundations. Note areas where there is missing mortar or loose stones. 


\section{Evaluation}

Recommended...

- $\quad$ Determining the level of damage to the sandstone element.

- Comparing undamaged stone with areas of suspected decay.

- Determining whether the sandstone piece can be repaired through patching or if the piece needs to be replaced.

- If patching is the appropriate treatment, then proceed with a composite patch, which is the process whereby cement and sand mixtures are applied as a series of stucco-like coats to reconstruct missing stone surfaces. Three types of stone deterioration that warrant composite patching include weathering, exfoliation, and blistering.

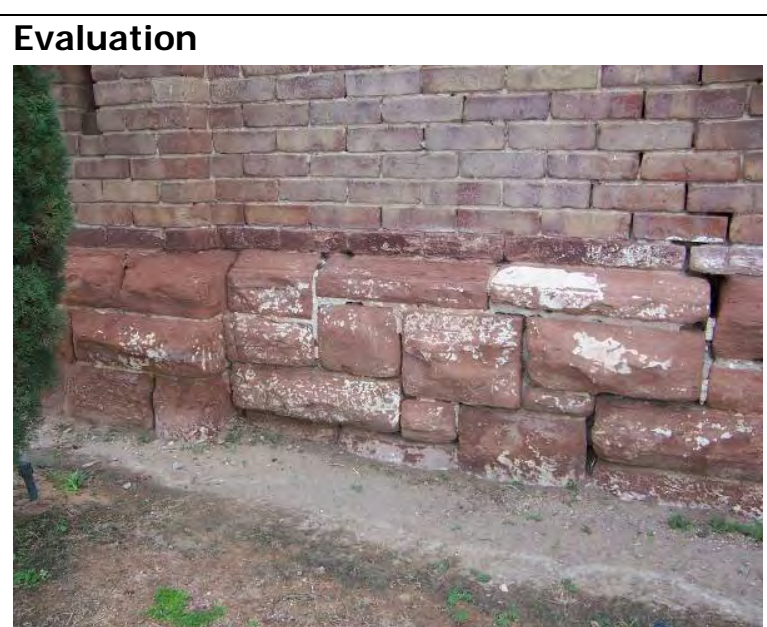

Building 128 - Evaluate the condition of the stone foundation. Test the type of mortar used for the foundation and determine the appropriate mixture for new mortar. Remove deteriorated mortar by carefully hand-raking the joints to avoid damaging the sandstone.

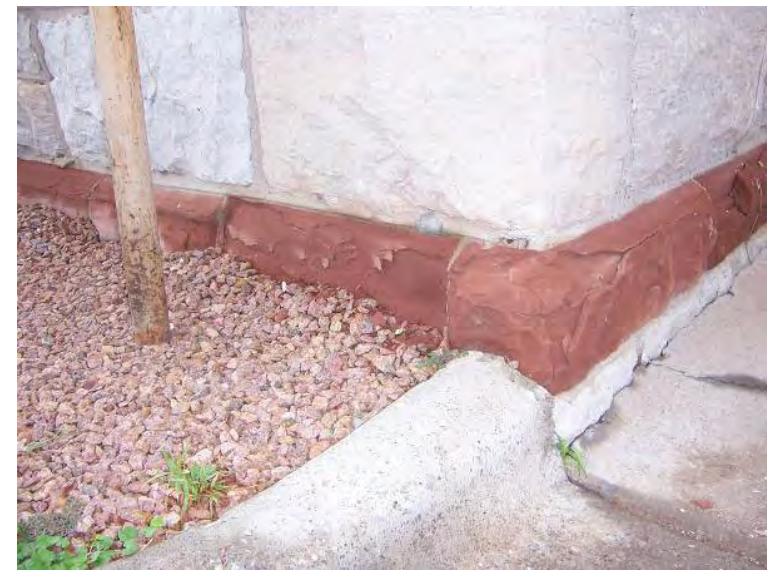

Building 2014 - Determine whether the sandstone piece can be repaired through patching or if the piece needs to be replaced. If patching is the appropriate treatment then proceed with a composite patch. Here the stone foundation is deteriorated because of excessive moisture.

\section{Replace}

Recommended...

- $\quad$ Repairing the source of the damage before repair of the element proceeds.

- $\quad$ Limited replacement in-kind or with compatible substitute material of those extensively deteriorated or missing parts of sandstone feature. In replacing damaged sandstone, every reasonable effort should be made to find stone with a texture and color similar to the original fabric.

- $\quad$ Replacing in-kind an entire feature that is too deteriorated to repair. If using the same kind of material is not technically or economically feasible, then a compatible substitute material may be considered.

- If a patch is the appropriate treatment, make sure the patch is compatible in color, texture, and pattern to the original historic sandstone. 
Not Recommended...

- $\quad$ Proceeding with sandstone replacement under adverse weather conditions, or when temperatures are below or above manufacturer's recommended limitations for installation.

- $\quad$ Removing a sandstone feature that is unrepairable and not replacing; or replacing it with a new feature that does not convey the same visual appearance.

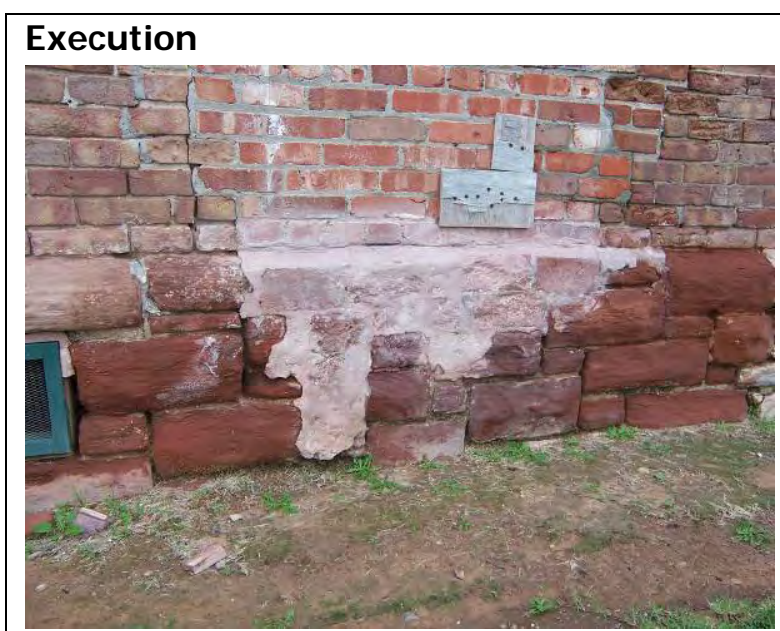

Building 128 - Repair the source of the damage before repair of the element proceeds. It is unclear what the substance is covering the sandstone foundation, but it needs to be removed by the gentlest methods possible (e.g., low-pressure water and detergent with a natural bristle brush). 
Notes

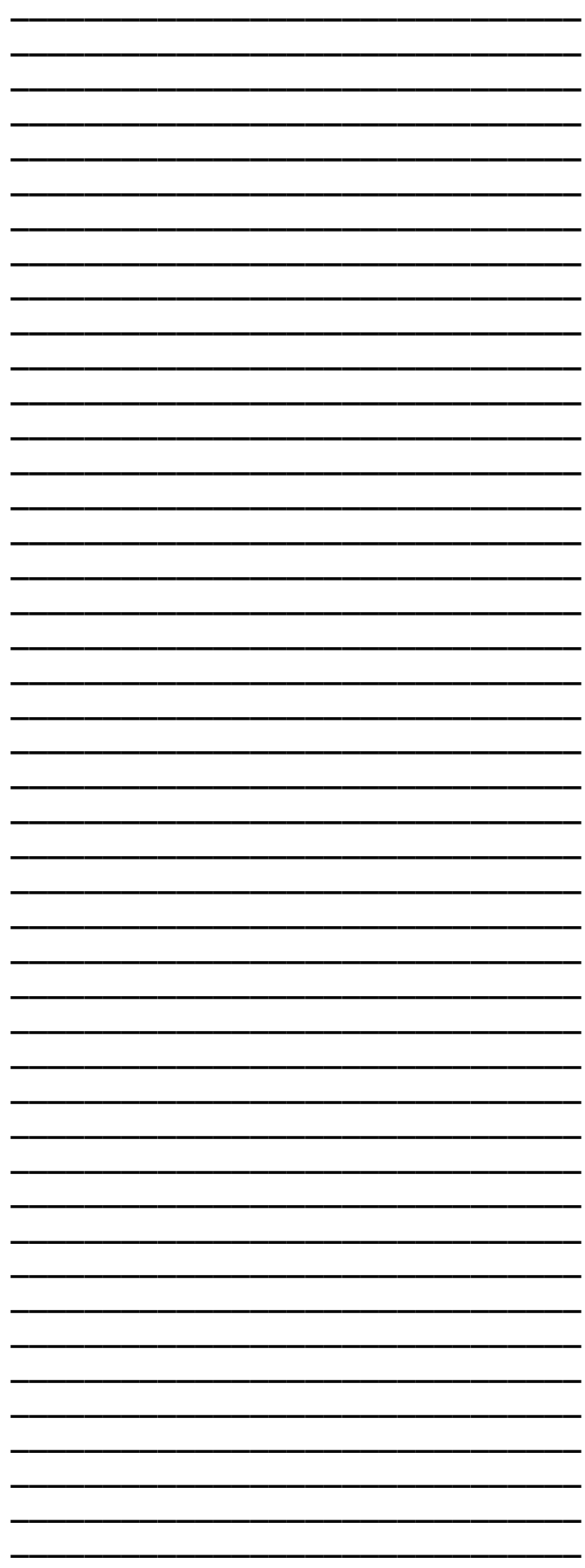




\section{Maintenance Guides for Stucco}

\section{Stucco: Overview}

The term "stucco" is used to describe a type of exterior plaster applied as a two- or three-part coating directly onto masonry or reinforced concrete. Stucco is found in many forms on historic structures throughout the United States. It is so common, in fact, that it frequently goes unnoticed, and is often disguised or used to imitate another material. Historic stucco is also sometimes incorrectly viewed as a sacrificial coating and consequently is removed to reveal stone, brick, or logs that historically were never intended to be exposed. Age and lack of maintenance hasten the deterioration of many historic stucco buildings. Like most historic building materials, stucco is at the mercy of the elements, and even though it is a protective coating, it is particularly susceptible to water damage.

\section{Application}

Stucco is applied directly, without lath, to masonry substrates such as brick, stone, concrete or hollow tile. On wood structures, however, stucco, like its interior counterpart plaster, must be applied over lath in order to obtain an adequate key to hold the stucco. When stuccoing over a stone or brick substrate, it was customary to cut back or rake out the mortar joints if they were not already recessed by natural weathering or erosion, and sometimes the bricks themselves were gouged to provide a key for the stucco. This helped provide the necessary bond for the stucco to remain attached to the masonry, much like the key provided by wood or metal lath on frame buildings.

Stucco is a material of deceptive simplicity: in most cases its repair should NOT be undertaken by a property owner unfamiliar with the art of plastering. Successful stucco repair requires the skill and experience of a professional plasterer.

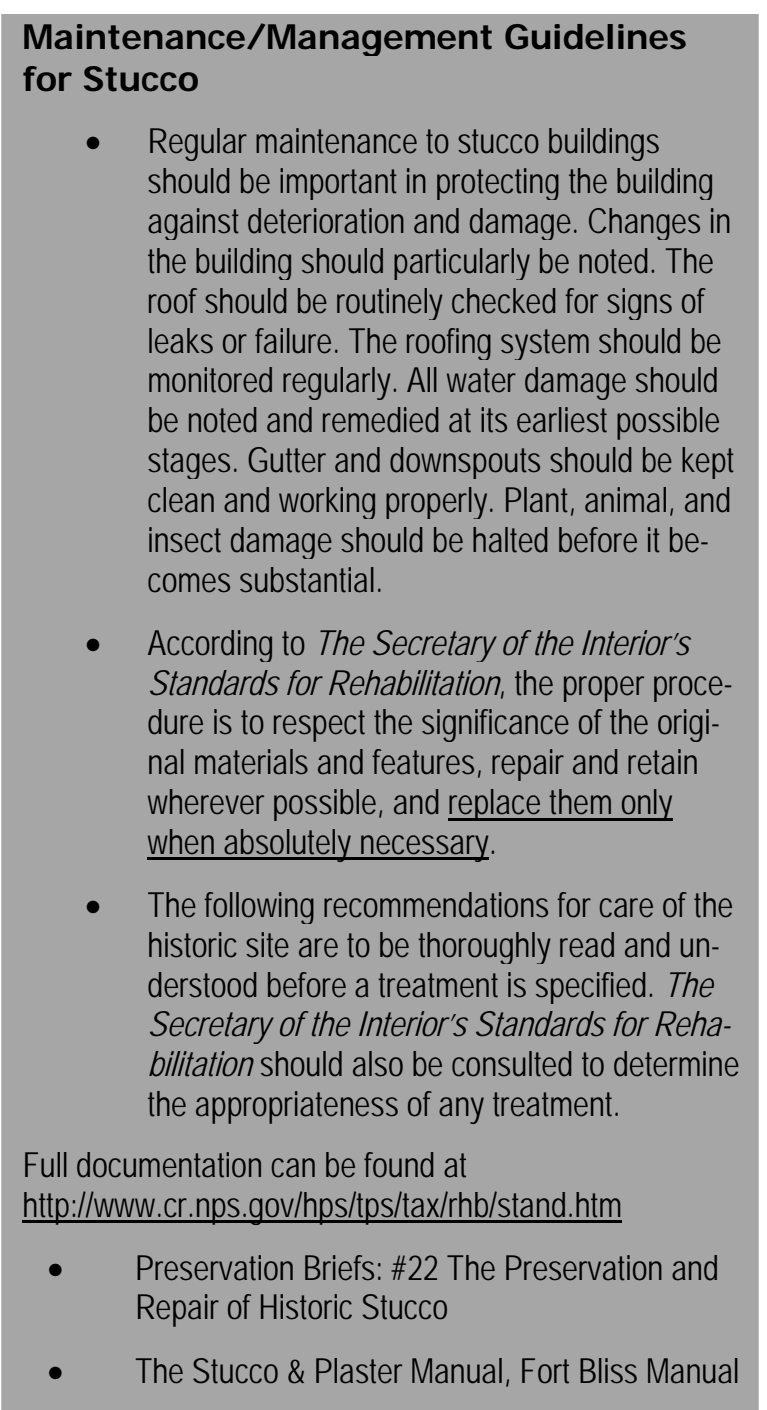

Full documentation can be found at

- $\quad$ Preservation Briefs: \#22 The Preservation and Repair of Historic Stucco

- The Stucco \& Plaster Manual, Fort Bliss Manual 


\section{Causes of Failure}

- $\quad$ Poor original materials and techniques

- $\quad$ Incompatible building materials with different expansion rates

- $\quad$ Structural settlement

- $\quad$ Biological growth

- $\quad$ Corrosion of metal anchors

These conditions can cause cracking or adhesion failure between the stucco and its backing or between individual stucco layers. Lack of proper maintenance increases the likelihood of problems that can lead to the breakdown of the stucco skin.

\section{Stucco Preservation}

- Survey stuccoed surfaces for conditions such as biological growth, water or metallic staining, or leaching deposit, which may indicate active water penetration or damage that is masked by the stucco coat.

- $\quad$ Maintain roofs, gutters, and downspouts to prevent moisture from penetrating walls.

- $\quad$ Remove all plant materials from the base of stuccoed walls.

- $\quad$ Clean stucco only when necessary to halt deterioration or remove heavy soiling. Test cleaning methods in a discreet location before full-scale treatment. The gentlest method should be selected and tested to avoid unnecessary damage.

- $\quad$ Remove dirt and biological growth such as mold, using a low-pressure water rinse and mild detergent applied with natural fiber brushes. Poultice-applied solvents are probably the most appropriate for removing metallic stains.

- $\quad$ Maintain paint coatings by applying vapor-permeable coating matched to existing color.

\section{Identify, Retain, and Preserve}

Recommended...

- Identifying, retaining, and preserving stucco features that are important in defining the overall historic character of the building such as walls, brackets, railings, cornices, window architraves, door pediments, steps, and columns; and joint and unit size, tooling and bonding patterns, coatings, and color.

Not Recommended...

- $\quad$ Removing or radically changing stucco features which are important in defining the overall historic character of the building so that, as a result, the character is diminished.

- $\quad$ Replacing or rebuilding a major portion of exterior stucco walls that could be repaired so that, as a result, the building is no longer historic and is essentially new construction.

- $\quad$ Radically changing the type of paint or coating or its color.

\section{Protect and Maintain}

Recommended...

- $\quad$ Protecting and maintaining stucco by providing proper drainage so that water does not stand on flat, horizontal surfaces or accumulate in curved decorative features.

- $\quad$ Cleaning stucco only when necessary to halt deterioration or remove heavy soiling. 
- $\quad$ Carrying out stucco surface cleaning tests after it has been determined that such cleaning is necessary. Tests should be observed over a sufficient period of time so that both the immediate effects and the long-range effects are known in order to enable selection of the gentlest method possible.

- $\quad$ Cleaning masonry surfaces with the gentlest method possible, such as low-pressure water and detergents, using natural bristle brushes.

- Inspecting painted stuccoed surfaces to determine whether repainting is necessary.

- $\quad$ Removing damaged or deteriorated paint only to the next sound layer using the gentlest method possible (e.g., hand-scraping) prior to repainting.

- $\quad$ Applying compatible paint coating systems following proper surface preparation.

- $\quad$ Repainting with colors that are historically appropriate to the building and district.

Not Recommended...

- $\quad$ Failing to evaluate and treat the various causes of stucco deterioration such as leaking roofs or gutters, differential settlement of the building, vegetation, or extreme weather exposure.

- $\quad$ Cleaning stucco surfaces when they are not heavily soiled to create a new appearance, thus needlessly introducing chemicals or moisture into historic materials.

- $\quad$ Cleaning masonry surfaces without testing or without efficient time for the testing results to be of value.

- $\quad$ Removing paint that is firmly adhering to, and thus protecting, stuccoed surfaces.

- $\quad$ Failing to follow manufacturers' product and application instructions when repainting masonry.

- $\quad$ Using new paint colors that are inappropriate to the historic building and district.

- $\quad$ Failing to undertake adequate measures to assure the preservation of stuccoed features.

\section{Repair}

Recommended...

- $\quad$ Repairing stuccoed walls by patching where there is evidence of deterioration such as cracks in the walls or damp walls.

- $\quad$ Repairing stucco by removing the damaged material and patching with new stucco to match original stucco in strength, composition, color, and texture.

Not Recommended...

- $\quad$ Removing sound stucco; or repairing with new stucco that is stronger than the historic material or does not convey the same visual appearance.

- $\quad$ Patching small hairline cracks with a synthetic caulking compound.

\section{Replace}

Recommended...

- $\quad$ Replacing in-kind an entire stucco feature that is too deteriorated to repair-if the overall form and detailing are still evident—using the physical evidence to guide the new work. Examples can include large sections of a wall, a cornice, balustrade, column, or stairway. If using the same kind of material is not technically or economically feasible, then a compatible substitute material may be considered. 
Not Recommended...

- $\quad$ Removing a stucco feature that is unrepairable and not replacing it; or replacing it with a new feature that does not convey the same visual appearance.

\section{Good Examples of Stucco}

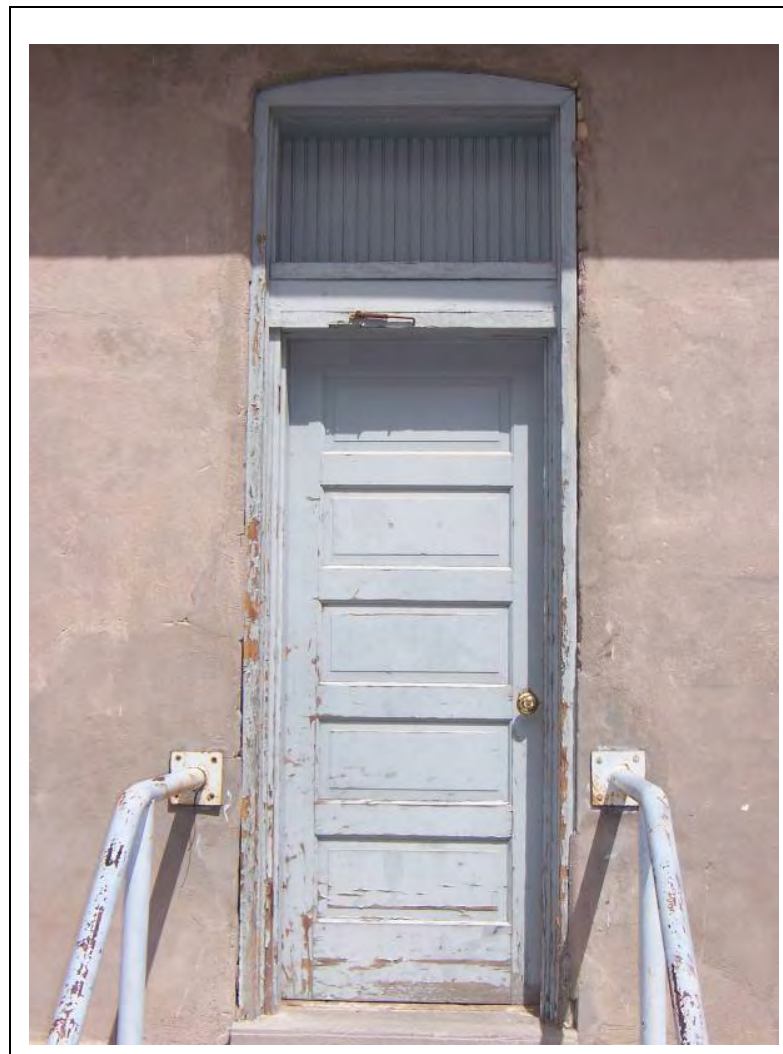

Building 19 - Stucco over a brick building. Historic stucco is sometimes incorrectly viewed as a sacrificial coating, and consequently is removed to reveal stone, brick, or logs that historically were never intended to be exposed.

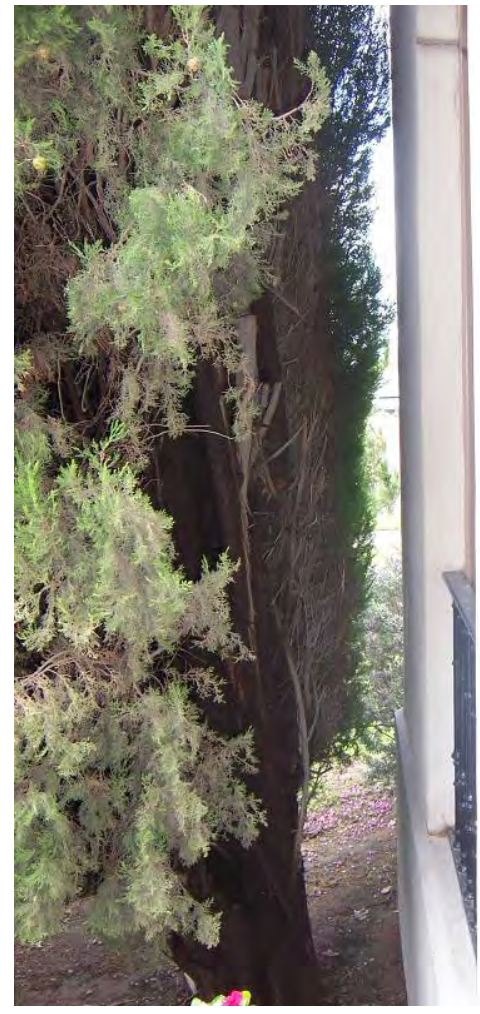

Building 243 - This is an appropriate distance for vegetation to be from a stucco wall or feature. Do NOT let vegetation touch or rest on stucco material, which could just accelerate deterioration. 


\section{Stucco: Damaged}

In most cases, parging is an appropriate fix for damaged or deteriorated masonry. At Fort Bliss, historic sandstone is most commonly parged. Since sandstone is a soft and porous material, it can often be difficult to repair. Also replacing sandstone is a difficult process since historic sandstone is hard to replace because it is not widely available. Parging is a technique used to waterproof and repair damaged or deteriorated sandstone, to give it a protective coverage, and prevent further deterioration. Parging uses a Portland cement and lime/sand mix.

\section{Deterioration}

Most stucco deterioration is the result of water infiltration into the building structure, either through the roof, around chimneys, window and door openings, or from excessive ground water or moisture penetrating through or splashing up from the foundation. Potential causes of deterioration include: ground settlement, lintel and door frame settlement, inadequate or leaking gutters and downspouts, intrusive vegetation, moisture migration within walls due to interior condensation and humidity, vapor drive problems caused by furnace, bathroom and kitchen vents, and rising damp resulting from excessive ground water and poor drainage around the foundation. Water infiltration will cause wood lath to rot, and metal lath and nails to rust, which eventually will cause stucco to lose its bond and pull away from its substrate.

\section{Repairs}

Before beginning any stucco repair, an assessment of the stucco should be undertaken to determine the extent of the damage, and how much stucco must be replaced or repaired. Testing should be carried out systematically on all elevations of the building to determine the overall condition of the stucco. Some areas in need of repair will be clearly evidenced by missing sections of stucco or stucco layers. Bulging or cracked areas are obvious places to begin.

After the cause of deterioration has been identified, any necessary repairs to the building should be made first before repairing the stucco. Such work is likely to include repairs designed to keep excessive water away from the stucco, such as roof, gutter, downspout and flashing repairs, improving drainage, and redirecting rainwater runoff and splash-back away from the building. Horizontal areas such as the tops of parapet walls or chimneys are particularly vulnerable to water infiltration,

\section{I nspection \\ - Inspect stucco surfaces for any damage or de- terioration. \\ - Inspect painted stuccoed surfaces to determine whether repainting is necessary. \\ - Inspect deteriorated sandstone that has been parged to see if the parging material is adher- ing to the sandstone and providing protection. \\ - $\quad$ Protect and maintain stucco by providing proper drainage so that water does not stand on flat, horizontal surfaces or accumulate in curved decorative features. \\ Evaluation \\ - $\quad$ Determine the level of repair needed for dam- aged stucco. \\ - Determine if the stucco can be repaired or if it needs to be replaced. \\ - Clean stucco only when necessary to halt dete- rioration or remove heavy soiling. \\ Execution \\ - $\quad$ Repair the source of the damage before repair- ing proceeds. \\ - $\quad$ Repair stucco by removing the damaged mate- rial and patching with new stucco to match original stucco in strength, composition, color, and texture.}

\section{Further Readings}

GSA has developed technical procedures to be used in specialized historic preservation work, as well as general evaluation, maintenance and repair of older building materials. For more detailed descriptions of repair procedures for stucco maintenance refer to the following, which can be found at http://w3.gsa.gov/web/p/hptp.nsf

- $\quad$ Preservation Briefs: \#22 The Preservation and Repair of Historic Stucco

- $\quad$ Removing Loose Stucco and Patching

- $\quad$ Painting Exterior Stucco 
and may require modifications to their original design, such as the addition of flashing to correct the problem.

Previous repairs inexpertly carried out may have caused additional deterioration, particularly if executed in Portland cement, which tends to be very rigid, and therefore incompatible with early, mostly soft lime-based stucco that is more "flexible." Incompatible repairs, external vibration caused by traffic or construction, or building settlement can also result in cracks that permit the entrance of water and cause the stucco to fail.

\section{Inspection}

\section{Recommended...}

- Inspecting deteriorated sandstone that has been parged to see if the parging material is adhering to the sandstone and providing protection.

- $\quad$ Protecting and maintaining stucco by providing proper drainage so that water does not stand on flat, horizontal surfaces or accumulate in curved decorative features.

Not Recommended...

- $\quad$ Failing to evaluate and treat the various causes of stucco deterioration such as leaking roofs or gutters, differential settlement of the building, vegetation, or extreme weather exposure.

- $\quad$ Failing to undertake adequate measures to assure the preservation of stuccoed features.

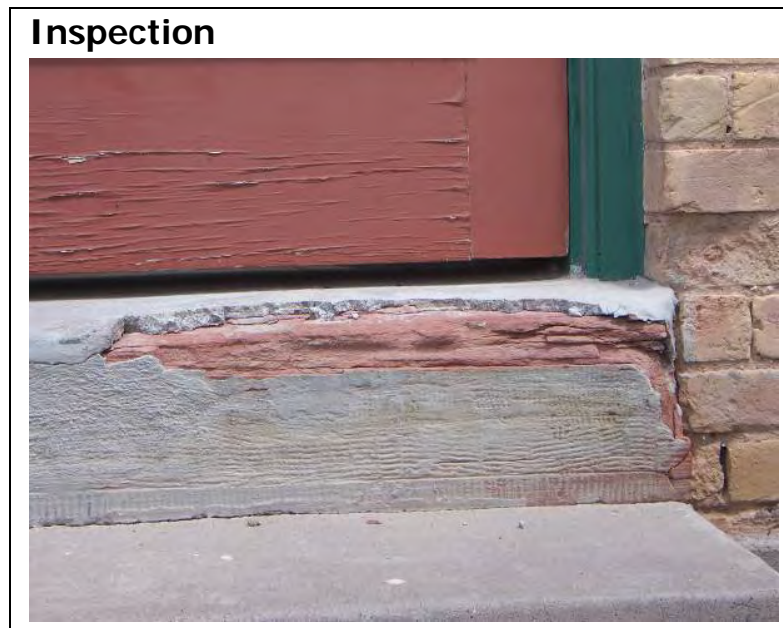

Building 13 - Here a stucco-like application (parge) was applied over a sandstone threshold to protect the sandstone. However, the parged material is failing and no longer protecting the sandstone. A periodic inspection would identify such areas of concern.

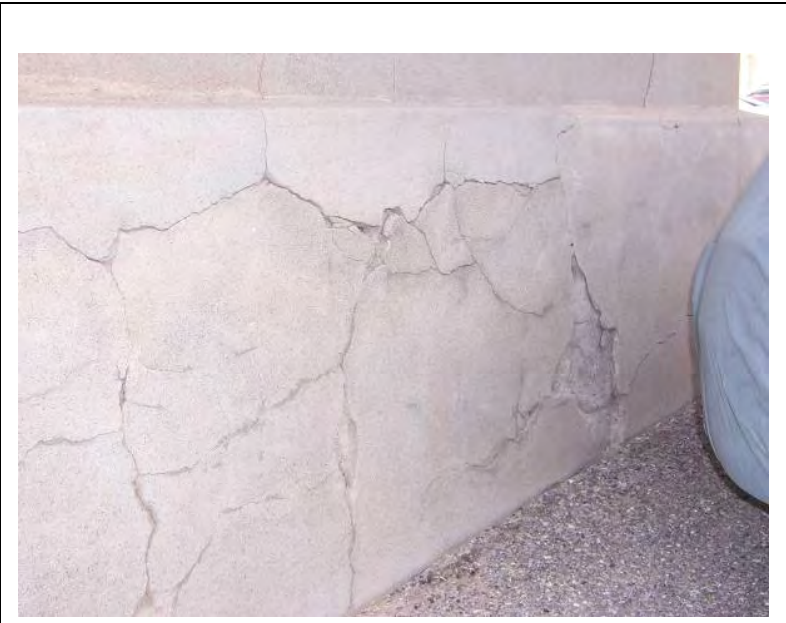

Building 19 - Determine the extent of damage and how much stucco must be replaced or repaired. 


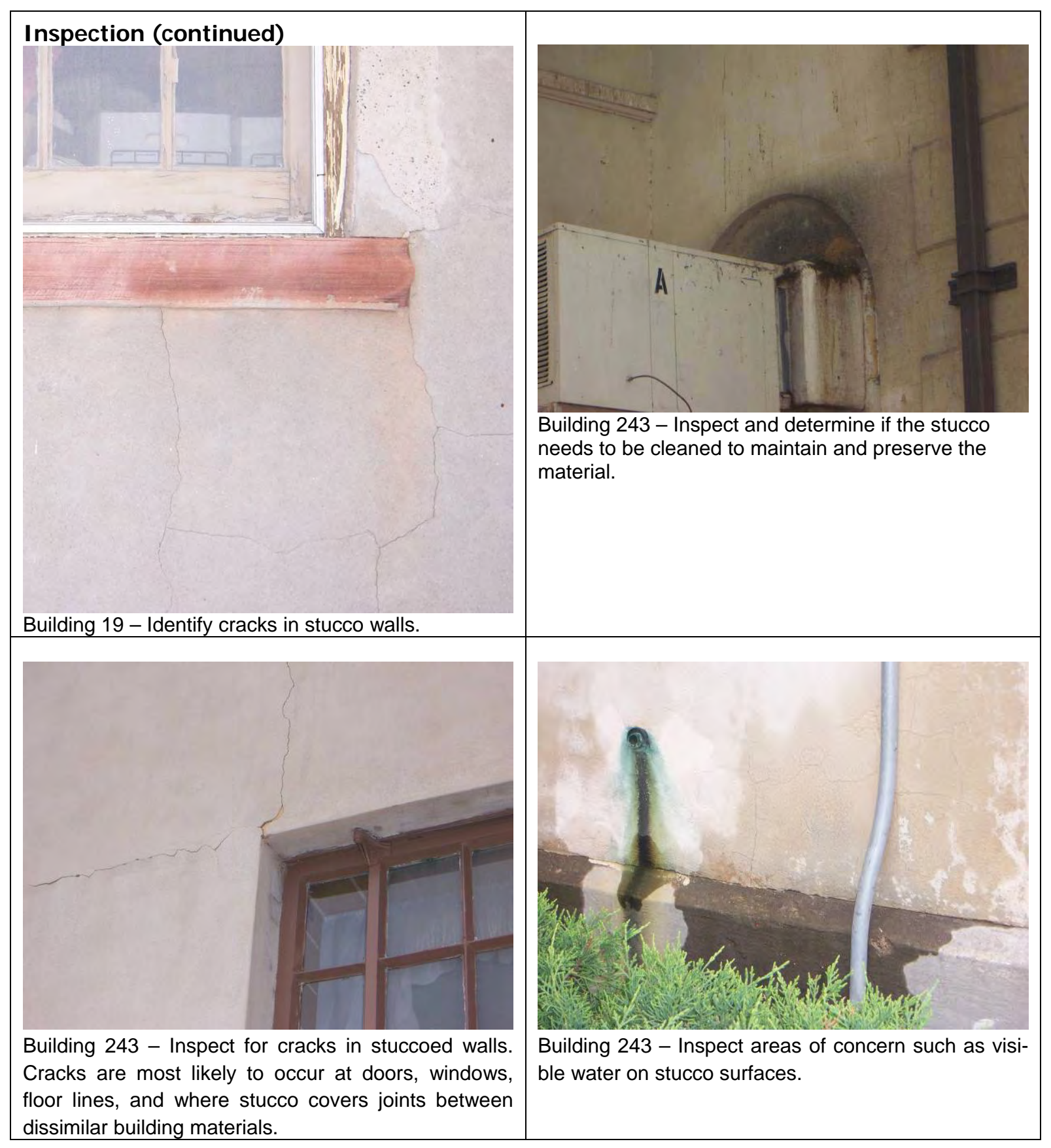




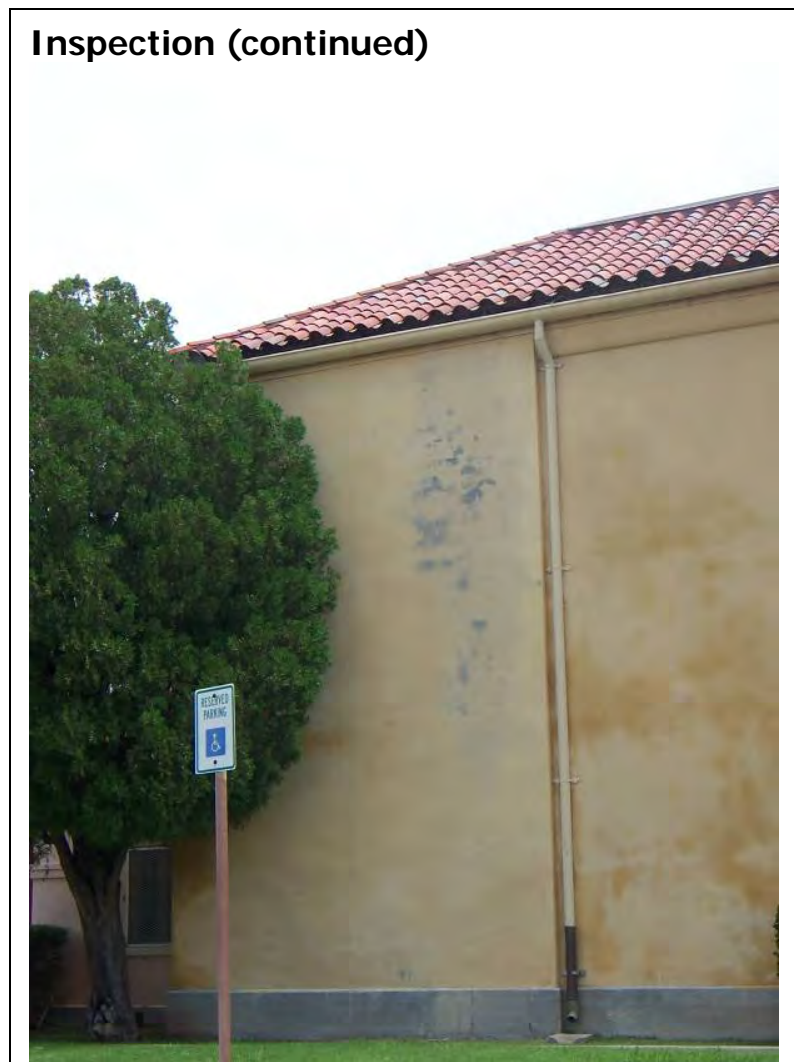

Building 243 - Determine if repainting stucco is necessary for the preservation of the material. Consult paint analysis for correct color.

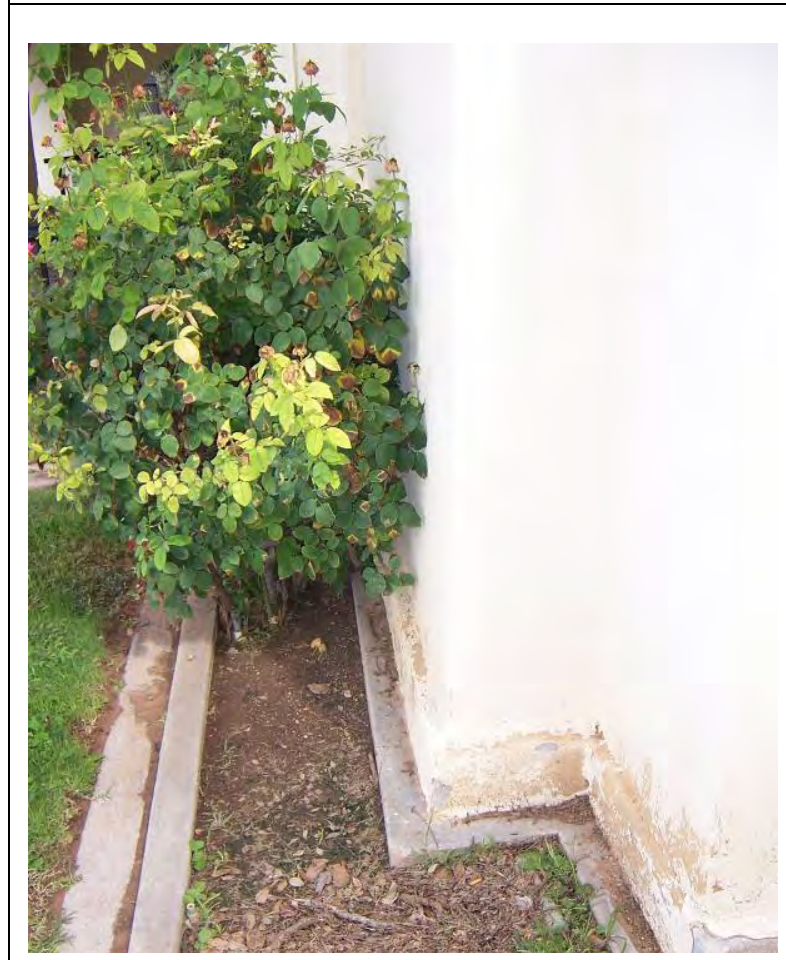

Building 315 - Inspect the proximity of vegetation to stucco walls. Vegetation should be approximately 3 feet from exterior wall or stucco feature.

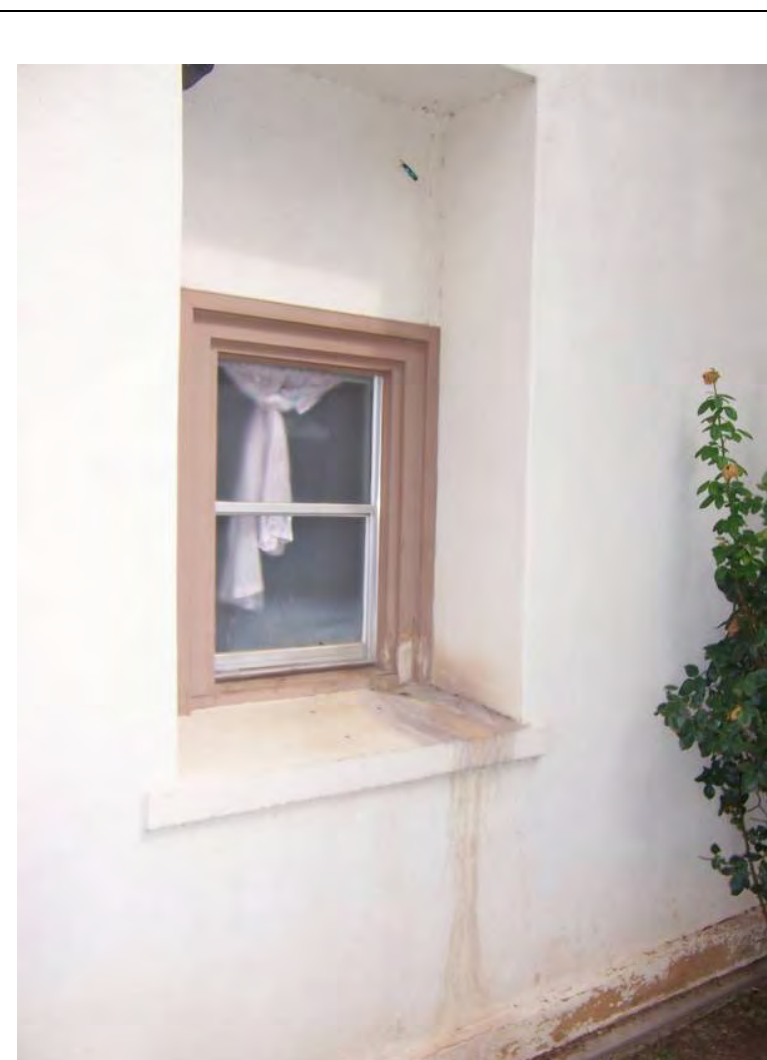

Building 311 - Clean stucco only when necessary to halt deterioration or remove heavy soiling. Carry out stucco surface cleaning tests after it has been determined that such cleaning is necessary.

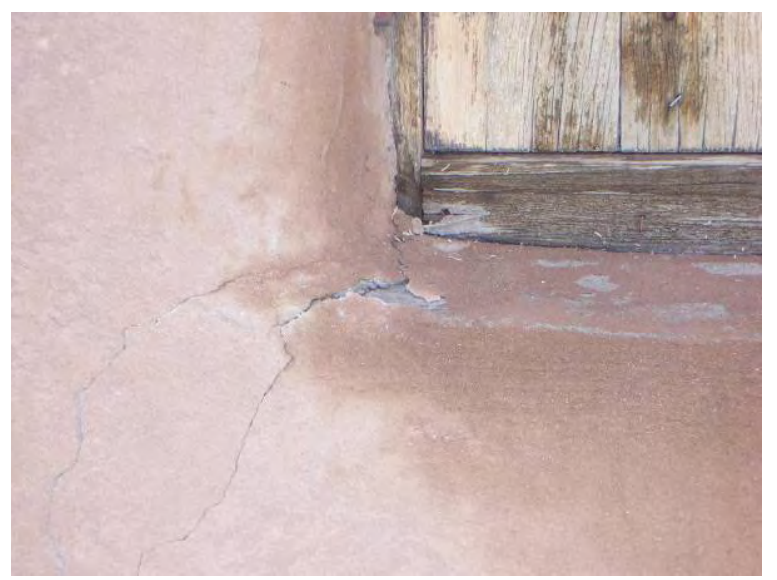

Building 5041 - Protect and maintain stucco by providing proper drainage so that water does not stand on flat, horizontal surfaces or accumulate in curved decorative features. 


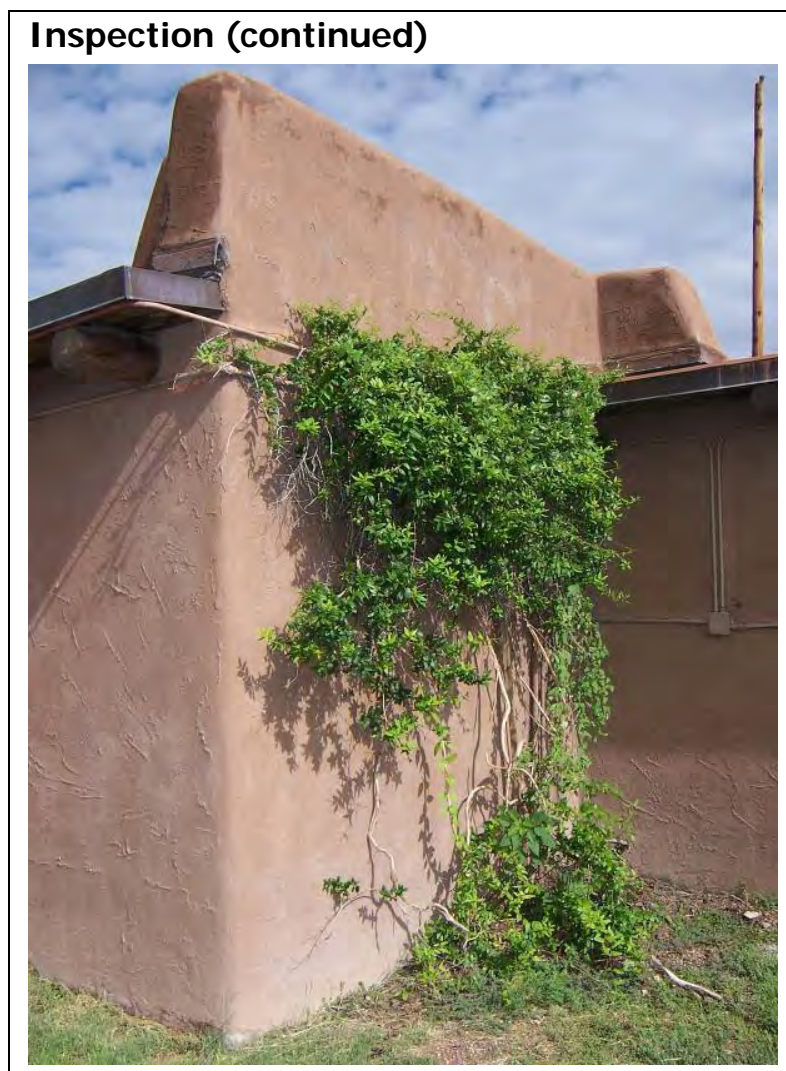

Building 5041 - Vegetation should not be allowed to grow on the stucco wall. Lack of proper maintenance increases the likelihood of problems that can lead to the breakdown of the stucco skin.

\section{Evaluation}

- Small hairline cracks usually are not serious and may be sealed with a thin slurry coat consisting of the finish coat ingredients.

- $\quad$ Larger cracks will have to be cut out in preparation for more extensive repair.

- $\quad$ Many stucco buildings have been painted over the years and will require repainting after the stucco repairs have been made. Limewash or cement-based paint, latex paint, or oilbased paint are appropriate coatings for stucco buildings.

Recommended...

- $\quad$ Analyzing the existing stucco and identifying its type for repair purposes.

- $\quad$ Determining the level of repair needed for damaged stucco.

- Determining if the stucco can be repaired or if it needs to be replaced.

- Cleaning stucco only when necessary to halt deterioration or remove heavy soiling.

- $\quad$ Carrying out stucco surface cleaning tests after it has been determined that such cleaning is necessary. Tests should be observed over a sufficient period of time so that both the immediate effects and the long-range effects are known in order to enable selection of the gentlest method possible. 
- $\quad$ Cleaning stucco surfaces with the gentlest method possible, such as low-pressure water and detergents, using natural bristle brushes.

Not Recommended...

- $\quad$ Cleaning stucco surfaces when they are not heavily soiled to create a new appearance, thus needlessly introducing chemicals or moisture into historic materials.

- $\quad$ Cleaning stucco surfaces without testing or without efficient time for the testing results to be of value.

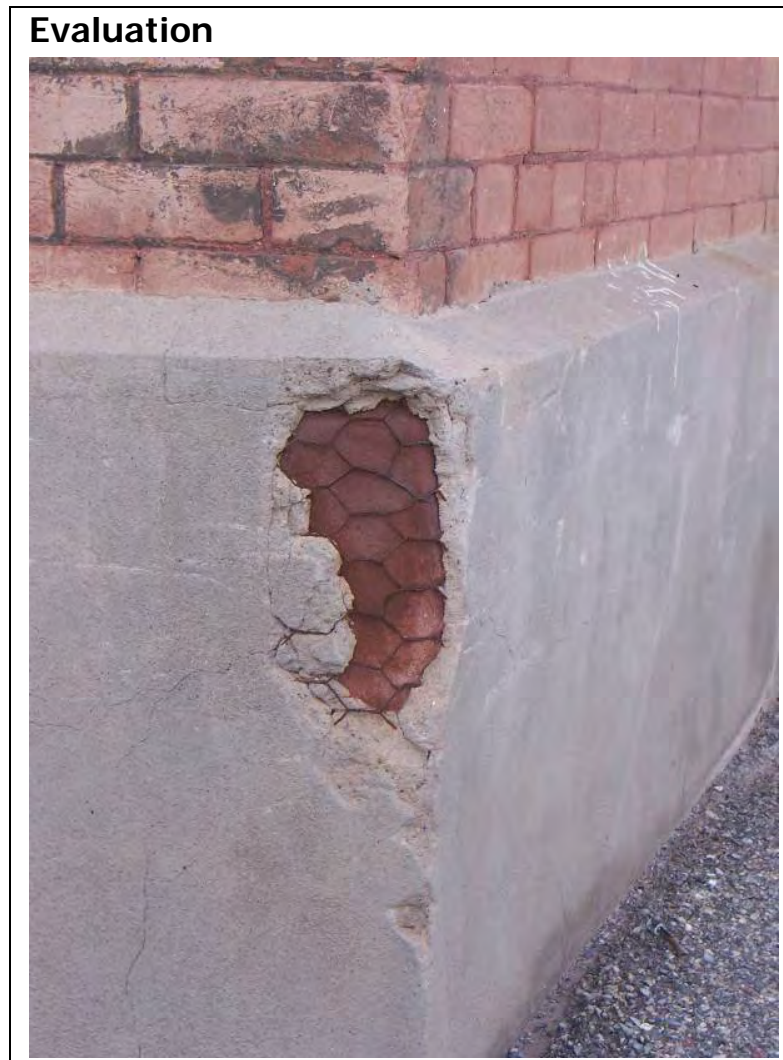

Building 13 - Evaluate the condition of the sandstone foundation that has been parged to see if the parging material is adhering and providing protection. If the stucco parging is failing, determine the level of repair needed for the damaged stucco.

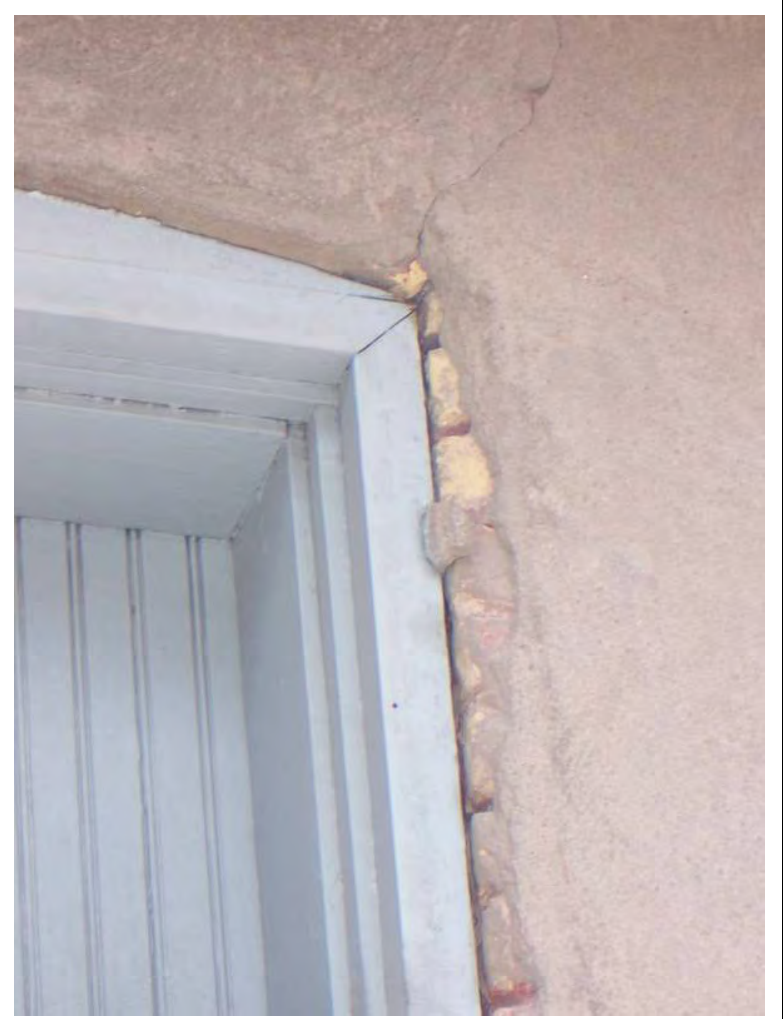

Building 19 - Here the stucco is not completely covering the brick wall underneath. Determine if this is affecting the brick or allowing moisture penetration. 


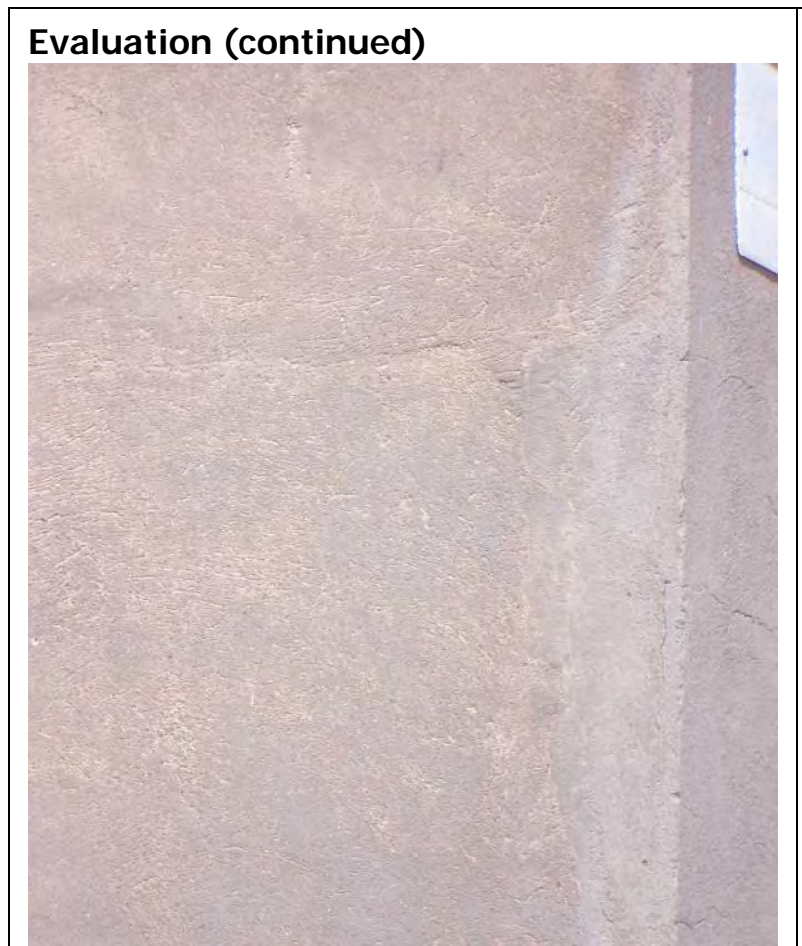

Building 19 - Small hairline cracks usually are not serious and may be sealed with a thin slurry coat consisting of the finish coat ingredients.

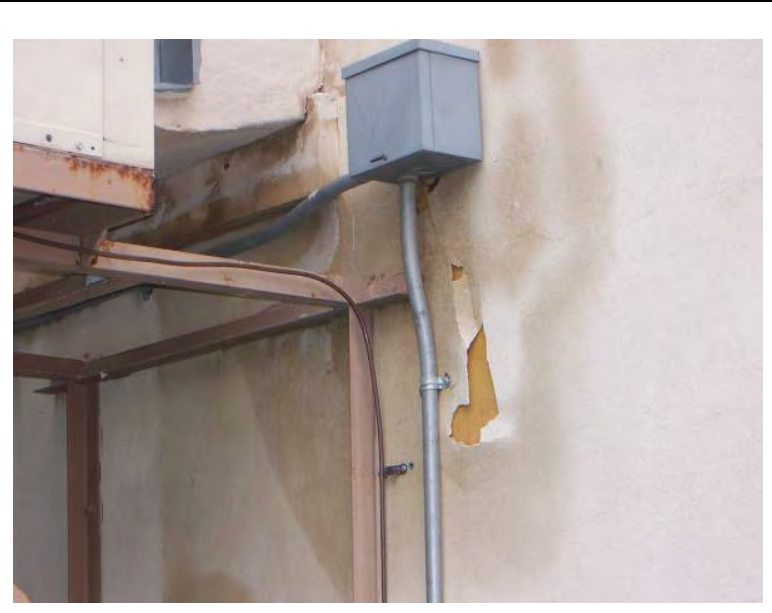

Building 243 - Here water damage is causing paint deterioration on a stucco wall. Remove damaged or deteriorated paint only to the next sound layer using the gentlest method possible (e.g., hand-scraping) prior to repainting.

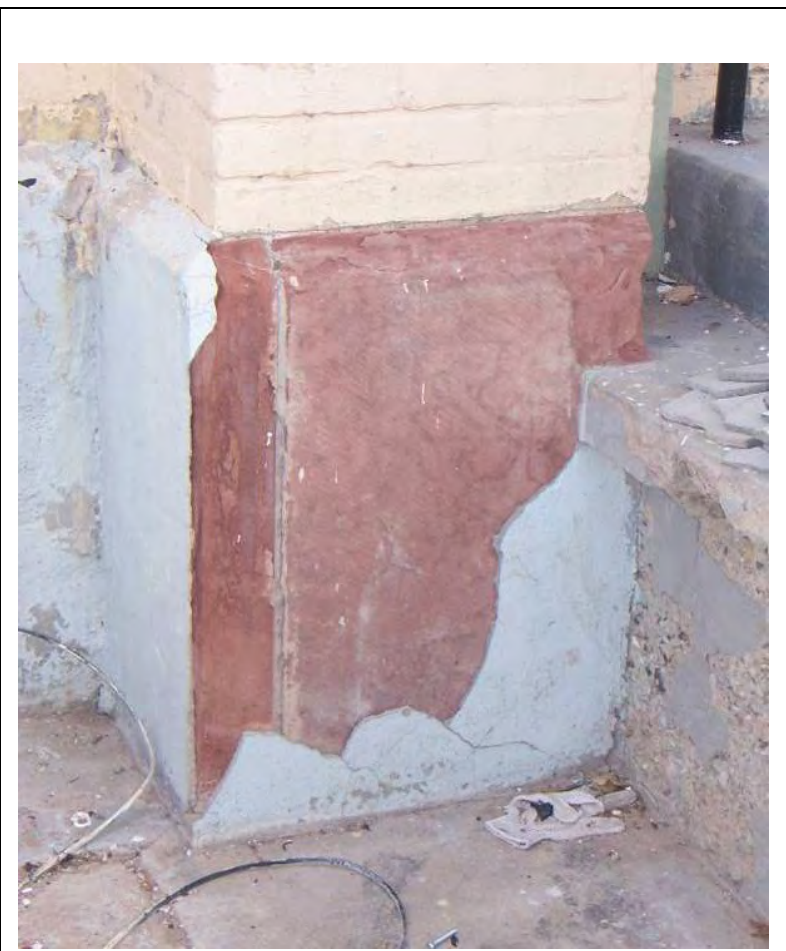

Building 21 - A thin layer of stucco is used over some sandstone features like foundations found at Fort Bliss. Evaluate the condition of the stucco and determine the appropriate repair method needed to protect and maintain the sandstone feature.

Remember patching should be in-kind to the existing material.

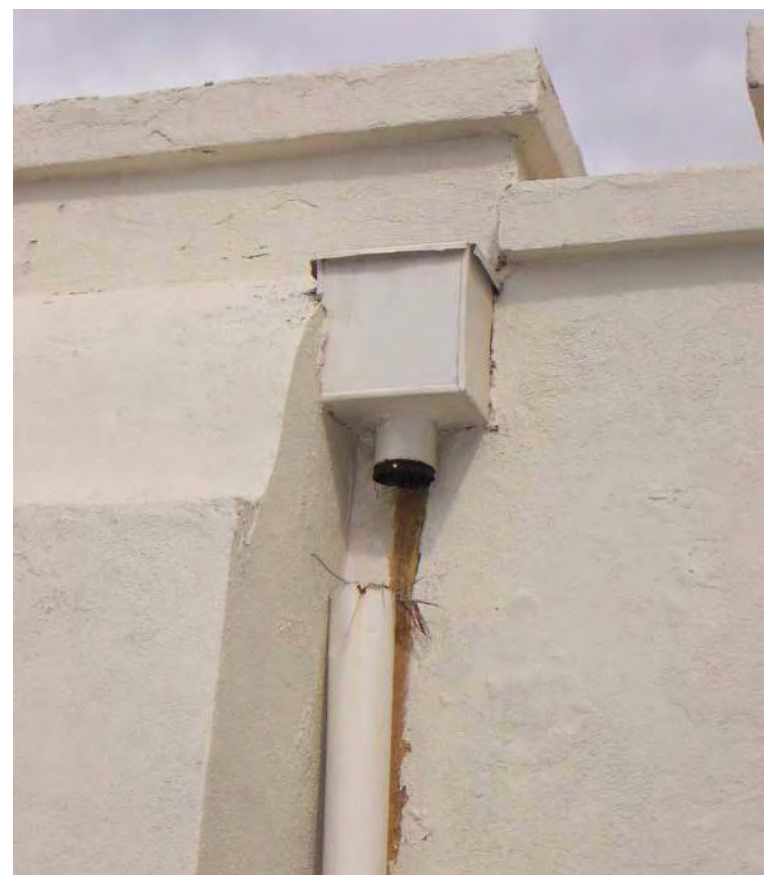

Building 243 - An evaluation of this building would reveal that this is an inappropriate placement for an evaporative cooler. 


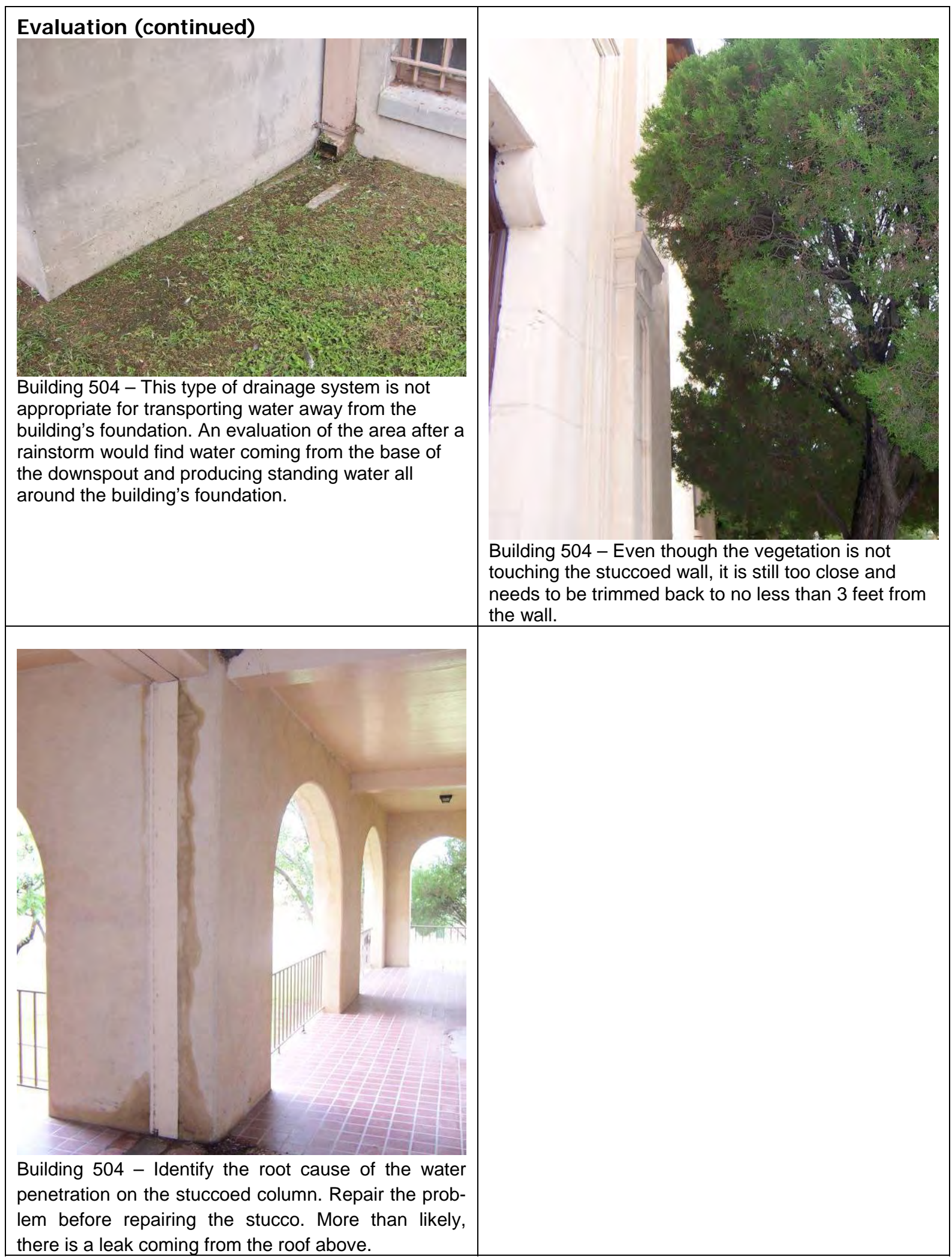




\section{Repair}

Recommended...

- $\quad$ Repairing stuccoed walls by patching where there is evidence of deterioration such as cracks in the walls or damp walls.

- $\quad$ All deteriorated, severely cracked, and loose stucco should be removed down to the lath or down to the masonry if the stucco is directly applied to the masonry.

- It is important that the new stucco match the existing stucco in strength, composition, texture, and color.

- A clean surface is necessary to obtain a good bond between the stucco and the substrate.

- If necessary, brick or stone mortar joints should be raked out to a depth of approximately $5 / 8$ inch to ensure a good bond between the substrate and the new stucco.

- $\quad$ To obtain a neat repair, the area to be patched should be squared-off with a butt joint.

- $\quad$ To ensure a good bond, the new patch must not overlap the old stucco.

- When patching over masonry, cutting out the old stucco at a diagonal angle may also help secure the bond between the new and the old stucco.

- $\quad$ A stucco mix compatible with the historic stucco should be selected after analyzing and testing the existing stucco. Test patches can be done to check the compatibility of the new mix with the existing stucco. The number and thickness of stucco coats used in repair should match the original.

- If applying a new coat of paint, it must be compatible with any coating already on the surface. In preparation for repainting, all loose or peeling paint or other coating materials not firmly adhered to the stucco must be removed by hand-scraping or natural bristle brushes. The surface should then be cleaned.

- $\quad$ Repairing stucco by removing the damaged material and patching with new stucco to match original stucco in strength, composition, color, and texture.

Not Recommended...

- $\quad$ Patching with a non-compatible material that does not match the existing material.

- $\quad$ Removing sound stucco; or repairing with new stucco that is stronger than the historic material or does not convey the same visual appearance.

- $\quad$ Patching small hairline cracks with a synthetic caulking compound.

\section{Replace}

Recommended...

- $\quad$ Patching rather than wholesale replacement is preferred.

- $\quad$ Replacing in-kind an entire stucco feature that is too deteriorated to repair-if the overall form and detailing are still evident—using the physical evidence to guide the new work. If using the same kind of material is not technically or economically feasible, then a compatible substitute material may be considered.

Not Recommended...

- Removing a stucco feature that is unrepairable and not replacing it; or replacing it with a new feature that does not convey the same visual appearance. 


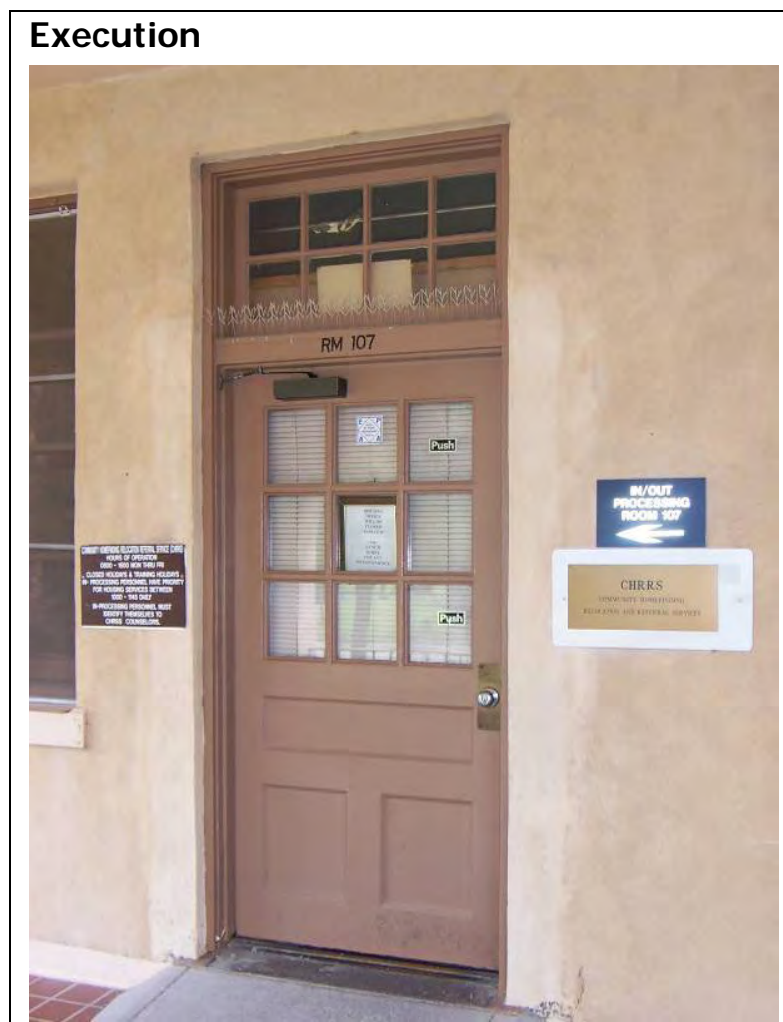

Building 504 - Here some minor maintenance work has been done on the stucco around the door frame; however, the new paint is slightly different in color and does not match the existing. It is recommended to repaint with colors that are historically appropriate to the building and district.

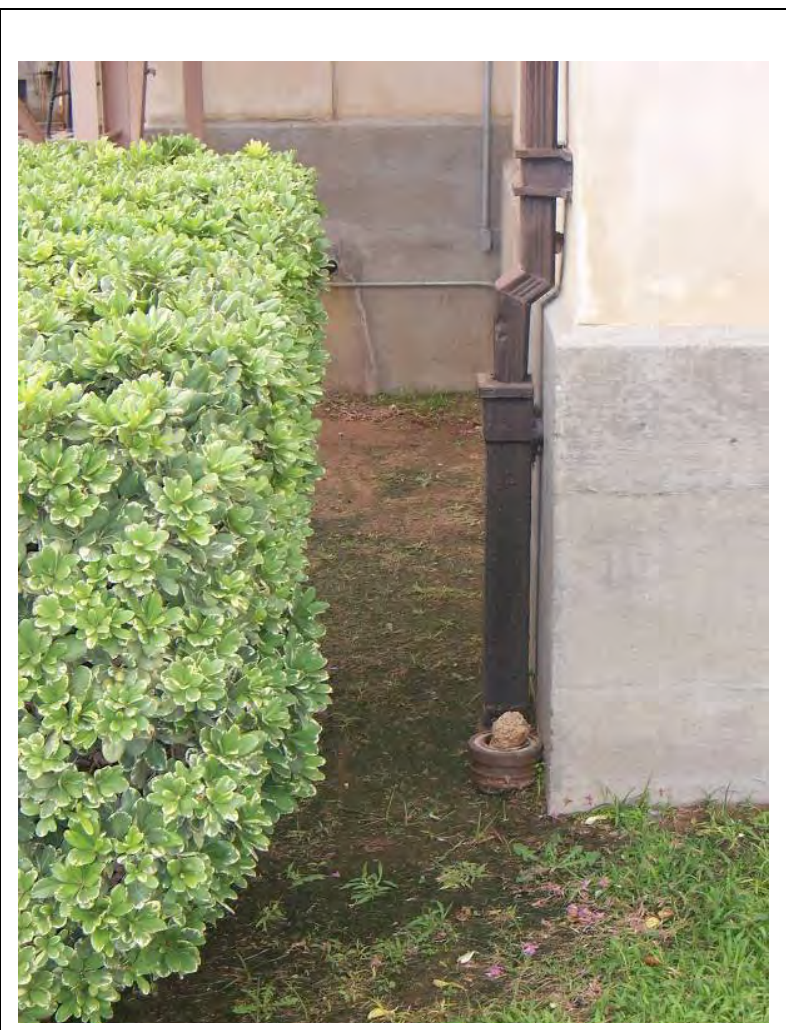

Building 243 - Here are two good examples of adequate measures taken to assure the preservation of stuccoed features: 1) proper drainage is provided with downspout and drain to transport water away from the building's foundation, and 2) vegetation is trimmed back far enough to where it is not near or touching any stuccoed feature or foundation. 
Notes

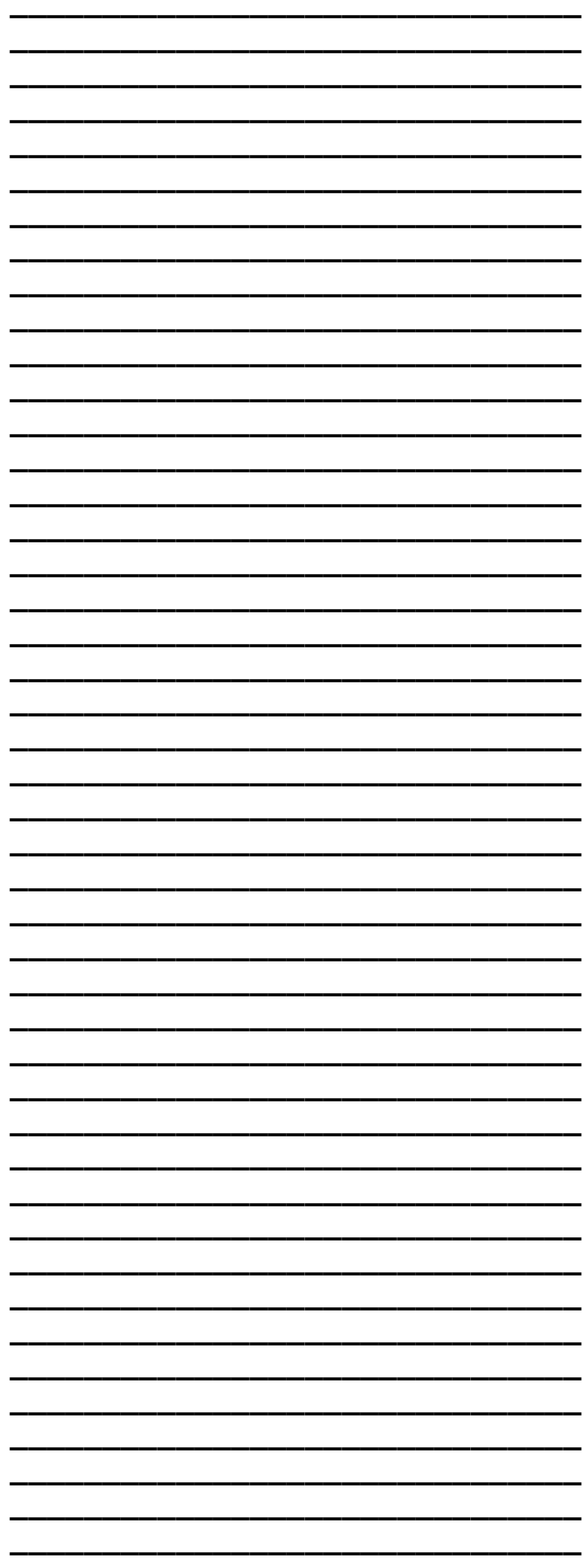




\section{Maintenance Guides for Wood}

\section{Wood: Overview}

Wood is the most common material used for architectural features such as siding, trim, cornices, brackets, entablatures, shutters, columns, and balustrades. Due to its ease of being shaped by carving, sawing, planning, and gouging, the wood features on a building are both functional and decorative, which may be important in defining the historic character of the building. Their retention, protection, and repair are of particular importance in rehabilitation projects.

\section{Identify, Retain, and Preserve}

Recommended...

- Identifying, retaining, and preserving wood features that are important in defining the overall historic character of the building such as siding, cornices, brackets, window architraves, and doorway pediments; and their paints, finishes, and colors.

Not Recommended...

- $\quad$ Removing or radically changing wood features that are important in defining the overall historic character of the building so that, as a result, the character is diminished.

- $\quad$ Removing a major portion of the historic wood from a facade instead of repairing or replacing only the deteriorated wood, then reconstructing the facade with new material in order to achieve a uniform or "improved" appearance.

- $\quad$ Radically changing the type of finish or its color or accent scheme so that the historic character of the exterior is diminished.

- $\quad$ Stripping historically painted surfaces to bare wood, then applying clear finishes or stains in order to create a "natural look."

- $\quad$ Stripping paint or varnish to bare wood rather than repairing or reapplying a special finish, i.e., a grained finish to an exterior wood feature such as a front door.

\author{
Maintenance/ Management Guidelines \\ for Wood
}

- Cyclical maintenance has always been a key to successful wood structural members and wood details. As soon as rehabilitation or restoration has been completed, some program of continuing maintenance should be initiated. Changes in the building should particularly be noted. The early stages of paint deterioration, rot, or cracking in wood elements should be monitored regularly. All water damage should be noted and remedied at its earliest possible stages. Plant, animal, and insect damage should be halted before it becomes substantial. The roof should be inspected periodically. Surface coatings must be inspected frequently and repaired or replaced as the need indicates.

- According to The Secretary of the Interior's Standards for Rehabilitation, the proper procedure is to respect the significance of the original materials and features, repair and retain wherever possible, and replace them only when absolutely necessary.

- The following recommendations for care of the historic site are to be thoroughly read and understood before a treatment is specified. The Secretary of the Interior's Standards for Rehabilitation should also be consulted to determine the appropriateness of any treatment.

Full documentation can be found at http://www.cr.nps.gov/hps/tps/tax/rhb/stand.htm

The Wood \& Carpentry Manual, Fort Bliss Manual

Fort Bliss National Historic District Exterior Paint Analysis, Fort Bliss Manual 


\section{Protect and Maintain}

Recommended...

- $\quad$ Protecting and maintaining wood features by providing proper drainage so that water is not allowed to stand on flat, horizontal surfaces or accumulate in decorative finishes.

- $\quad$ Before any work on historic painted surfaces takes place, making sure the paint has been properly tested for lead.

- $\quad$ Applying chemical preservatives to wood features such as beam ends or outriggers that are exposed to decay hazards and are traditionally unpainted.

- $\quad$ Retaining coatings such as paint that help protect the wood from moisture and ultraviolet light. Paint removal should be considered only where there is paint surface deterioration and as part of an overall maintenance program that involves repainting or applying other appropriate protective coatings.

- Inspecting painted wood surfaces to determine whether repainting is necessary or if cleaning is all that is required.

- $\quad$ Removing damaged or deteriorated paint to the next sound layer using the gentlest method possible (hand-scraping and hand-sanding), then repainting.

- $\quad$ Using with care electric hot-air guns on decorative wood features and electric heat plates on flat wood surfaces when paint is so deteriorated that total removal is necessary prior to repainting.

- Using chemical strippers primarily to supplement other methods such as hand-scraping, hand-sanding and the above- recommended thermal devices. Detachable wooden elements such as shutters, doors, and columns may — with the proper safeguards—be chemically dip-stripped.

- $\quad$ Applying compatible paint coating systems following proper surface preparation.

- $\quad$ Repainting with colors that are appropriate to the historic building and district.

- $\quad$ Evaluating the overall condition of the wood to determine whether more than protection and maintenance are required, that is, if repairs to wood features will be necessary.

Not Recommended...

- $\quad$ Failing to identify, evaluate, and treat the causes of wood deterioration, including faulty flashing, leaking gutters, cracks and holes in siding, deteriorated caulking in joints and seams, plant material growing too close to wood surfaces, or insect or fungus infestation.

- $\quad$ Using chemical preservatives such as creosote, which can change the appearance of wood features unless they were used historically.

- $\quad$ Stripping paint or other coatings to reveal bare wood, thus exposing historically coated surfaces to the effects of accelerated weathering.

- $\quad$ Removing paint that is firmly adhering to and, thus, protecting wood surfaces.

- Using destructive paint removal methods such as propane or butane torches, sandblasting, or water blasting. These methods can irreversibly damage historic woodwork.

- $\quad$ Using thermal devices improperly so that the historic woodwork is scorched.

- $\quad$ Failing to neutralize the wood thoroughly after using chemicals so that new paint does not adhere.

- $\quad$ Allowing detachable wood features to soak too long in a caustic solution so that the wood grain is raised and the surface roughened. 
- $\quad$ Failing to follow manufacturers' product and application instructions when repainting exterior woodwork.

- Using new colors that are inappropriate to the historic building or district.

- $\quad$ Failing to undertake adequate measures to assure the preservation of wood features.

\section{Repair}

Recommended...

- $\quad$ Repairing wood features by patching, piecing-in, consolidating, or otherwise reinforcing the wood using recognized preservation methods. Repair may also include the limited replacement in-kind —or with compatible substitute material—of those extensively deteriorated or missing parts of features where there are surviving prototypes such as brackets, moldings, or sections of siding.

Not Recommended...

- $\quad$ Replacing an entire wood feature such as a cornice or wall when repair of the wood and limited replacement of deteriorated or missing parts are appropriate.

- $\quad$ Using substitute materials for the replacement part that does not convey the visual appearance of the surviving parts of the wood feature or that is physically or chemically incomparable.

\section{Replace}

Recommended...

- $\quad$ Replacing in-kind an entire wood feature that is too deteriorated to repair-if the overall form and detailing are still evident—using the physical evidence to guide the new work. Examples of wood features include a cornice, entablature, or balustrade. If using the same kind of material is not technically or economically feasible, then a compatible substitute material may be considered.

Not Recommended...

- $\quad$ Removing an entire wood feature that is unrepairable and not replacing it; or replacing it with a new feature that does not convey the same visual appearance.

\section{Good Examples of Wood}

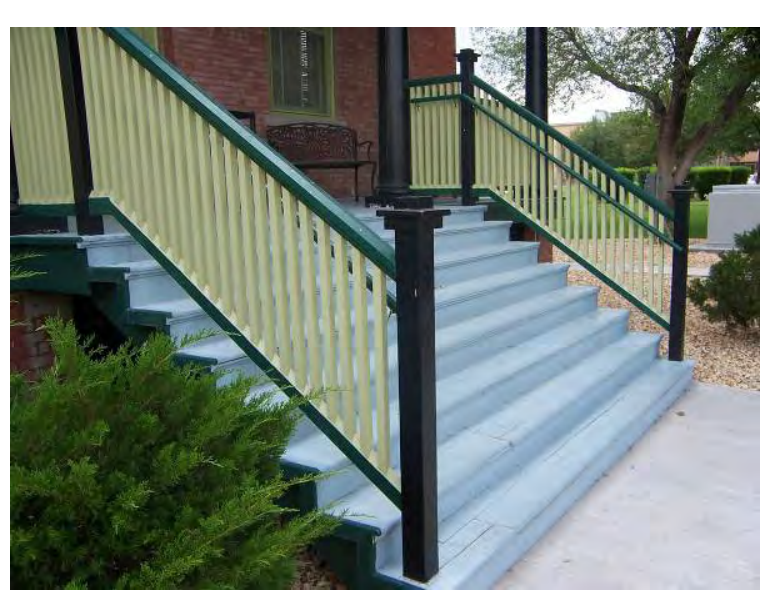

Building 4 - The wood balustrade and newel posts are appropriate examples of replacing in-kind an entire wood feature too deteriorated to repair.

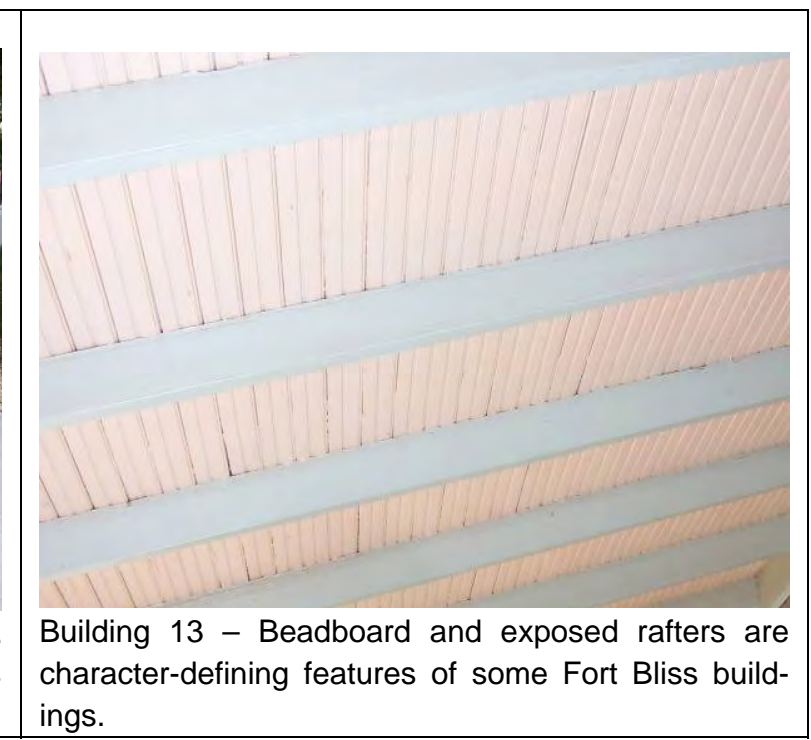




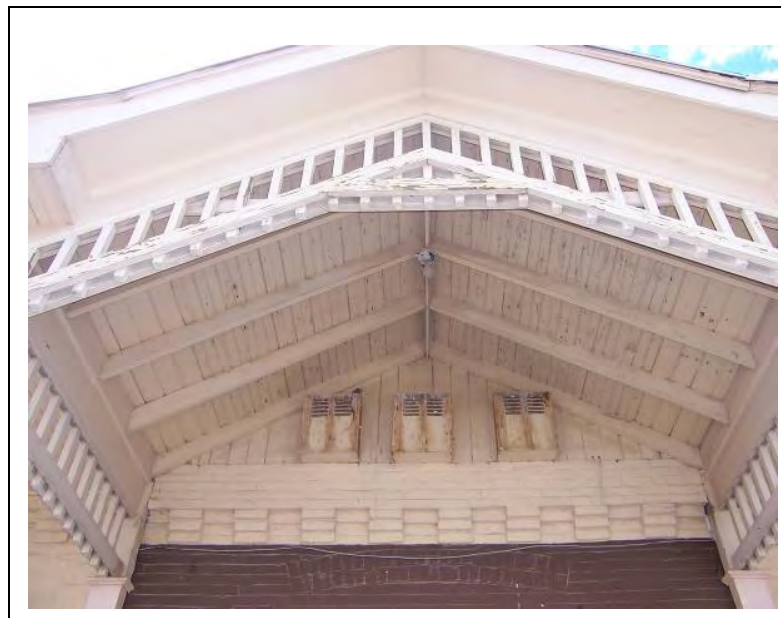

Building 21 - It is recommended to identify, retain, and preserve wood features that are important in defining the overall historic character of the building.

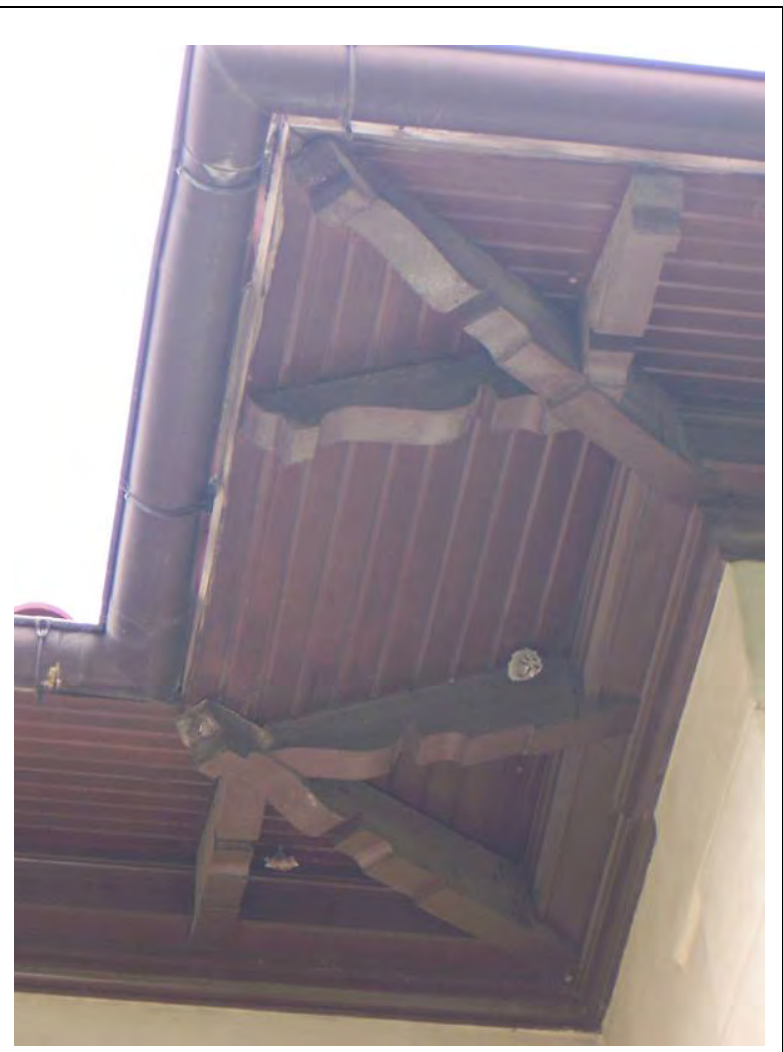

Bulding 243 - Decorative wood features such as the overhang and braces should be preserved and maintained. 


\section{Wood: Deteriorated or Damaged}

The two major causes of wood deterioration are termites and rot. Maintaining a watertight roof and good paint film are two of the best ways to eliminate causes of rot. Keeping water away from wood and keeping wood from contact with the ground are important ways of controlling termite infestation.

Pests can be numerous and include squirrels, raccoons, bats, mice, rats, snakes, termites, moths, beetles, ants, bees and wasps, pigeons, and other birds. Termites, beetles, and carpenter ants destroy wood. Mice, too, gnaw wood as well as plaster, insulation, and electrical wires. Pigeon and bat droppings not only damage wood finishes but create a serious and sometimes deadly health hazard.

\section{Preservation of Wood}

- Verify that all gutters and downspouts are operating well and that rainwater is being drained properly away from the building so that water is not allowed to stand on flat surfaces or accumulate in decorative features. Peeling paint, spongy wood, discoloration, staining, and the presence of fungi are signs of wood rot and should be taken care of immediately.

- $\quad$ Keep dense plant growth away from wood members. Prune overhanging branches of trees so they are not resting or touching any wood members, especially roof eaves.

- $\quad$ Paint is one of the most effective means of waterproofing a wood surface and protecting it from ultraviolet light. Keep paint films and sealant joints in good condition.

\section{Inspection}

- $\quad$ Protect and maintain architectural woods from decay and rot by providing proper drainage so that water does not stand on flat, horizontal surfaces or accumulate in curved, decorative features.

- Identify root cause of damage, including standing water.

\section{Evaluation}

- $\quad$ Evaluate the overall condition of the architectural wood to determine whether more than protection and maintenance are required, that is, if repairs to features will be necessary.

- Determine if the wood element needs to be replaced if too deteriorated to repair.

\section{Execution}

- The new wood should duplicate the original in dimensions, configuration, and texture.

- Repair deteriorated or damaged wood by carefully patching, piecing-in, or otherwise reinforcing the wood using recognized preservation methods.

- Missing elements should be replaced in-kind to the historic materials.

- $\quad$ Any repairs to the wood should be made after cleaning the surface gently if necessary.

- $\quad$ Replace in-kind to the historic material.

\section{Further Readings}

GSA has developed technical procedures to be used in specialized historic preservation work, as well as general evaluation, maintenance and repair of older building materials. For more detailed descriptions of repair procedures for damaged or deteriorated wood refer to the following, which can be found at http://w3.gsa.gov/web/p/hptp.nsf

- $\quad$ Epoxy Repair for Deterioration and Decay in Wooden Members

- $\quad$ Patching Cracks and Holes in Woodwork

- $\quad$ Repairing Water-Damaged Woodwork

- Replacing Deteriorated Woodwork

- $\quad$ Historic Exteriors: Preserving Wood

- $\quad$ Preservation Brief \#31: Mothballing Historic Buildings 


\section{Inspection}

\section{Recommended...}

- $\quad$ Regular inspection of architectural woods for protection from decay and rot by ensuring proper drainage so that water does not stand on flat, horizontal surfaces or accumulate in curved, decorative features.

- If the building is in a southern or humid climate and termites or other insects are a particular problem, the foundation and floor framing should be inspected to ensure that there are no major structural weaknesses. This can usually be done by observation from the crawl space or basement. For those structures where this is not possible, it may be advisable to lift selective floor boards to expose the floor framing. If there is evidence of pest damage, particularly termites, active colonies should be treated and the structural members reinforced or replaced, if necessary.

Not Recommended...

- $\quad$ Failing to identify, evaluate, and treat the causes of wood deterioration, including faulty flashing, leaking gutters, cracks and holes in siding, deteriorated caulking in joints and seams, plant material growing too close to wood surfaces or insect or fungus infestation.

- $\quad$ Failing to undertake adequate measures to assure the preservation of wood features.

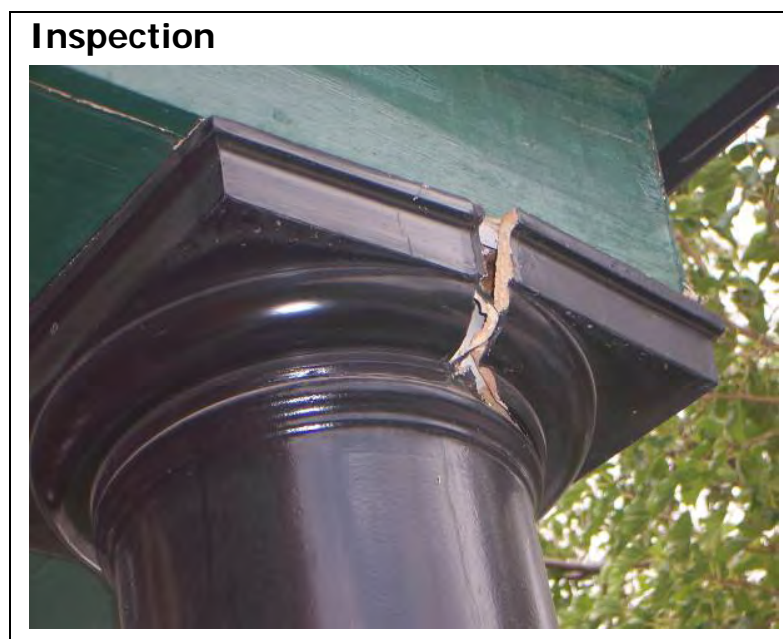

Building 4 - A periodic inspection of buildings would reveal damaged features such as this wood capital.

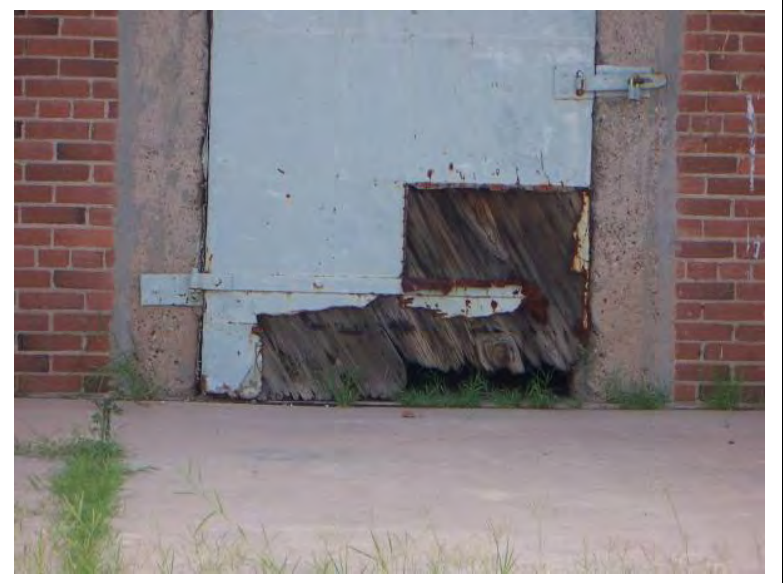

Building 888 - Need to inspect and evaluate the overall condition of the wood feature to determine whether more than protection and maintenance are required.

\section{Evaluation}

Recommended...

- Determining level of treatment necessary to repair damaged wood.

- $\quad$ Determining if the wood element needs to be replaced if too deteriorated to repair.

- $\quad$ Evaluating the overall condition of the architectural wood to determine whether more than protection and maintenance are required, that is, if repairs to features will be necessary.

- $\quad$ Keeping dense plant growth away from wood exteriors and features. Allow at least 5 feet distance between the wood and the hedge. Prune overhanging branches of trees so they are kept 5 feet away from roof eaves. 
- If the property is infested with animals or insects, it is important to get them out and to seal off their access to the building. If necessary, exterminate and remove any nests or hatching colonies. It may be advantageous to have damp or infected wood treated with insecticides (as permitted by each state) or preservatives, such as borate, to slow the rate of deterioration during the time that the building is not in use.

Not Recommended...

- Ignoring signs of insect infestation.

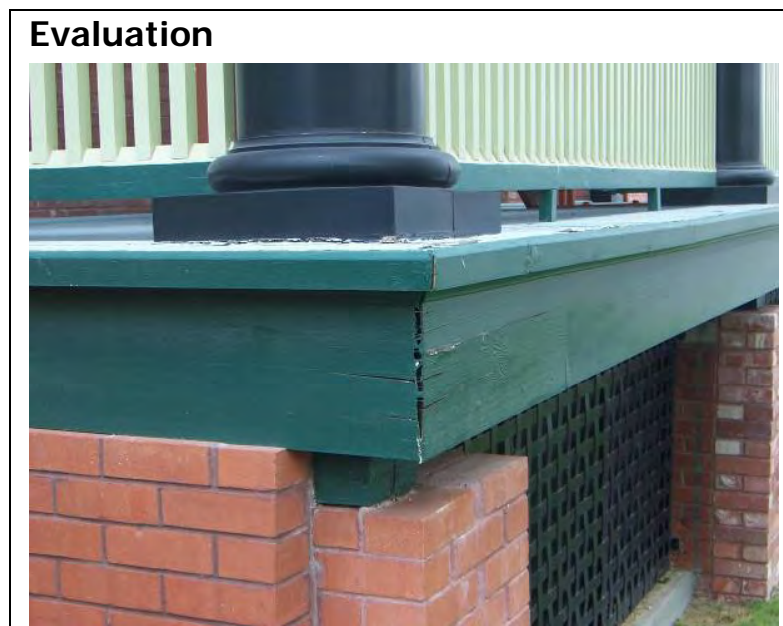

Building 4 - An inspection of building materials would find areas of concern like the damaged joint bond of the wood pieces. An evaluation of the materials would find the cause of the damage. The bond needs to be repaired so that water does not penetrate into the building or further damage the material.

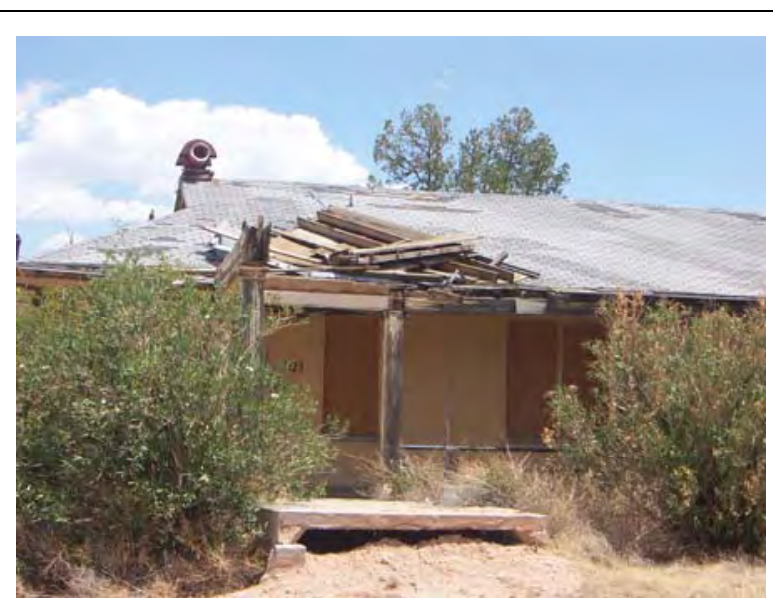

Building 7125 - The wood porch is too deteriorated to repair. The feature needs to be replaced in-kind to the original in design and material.

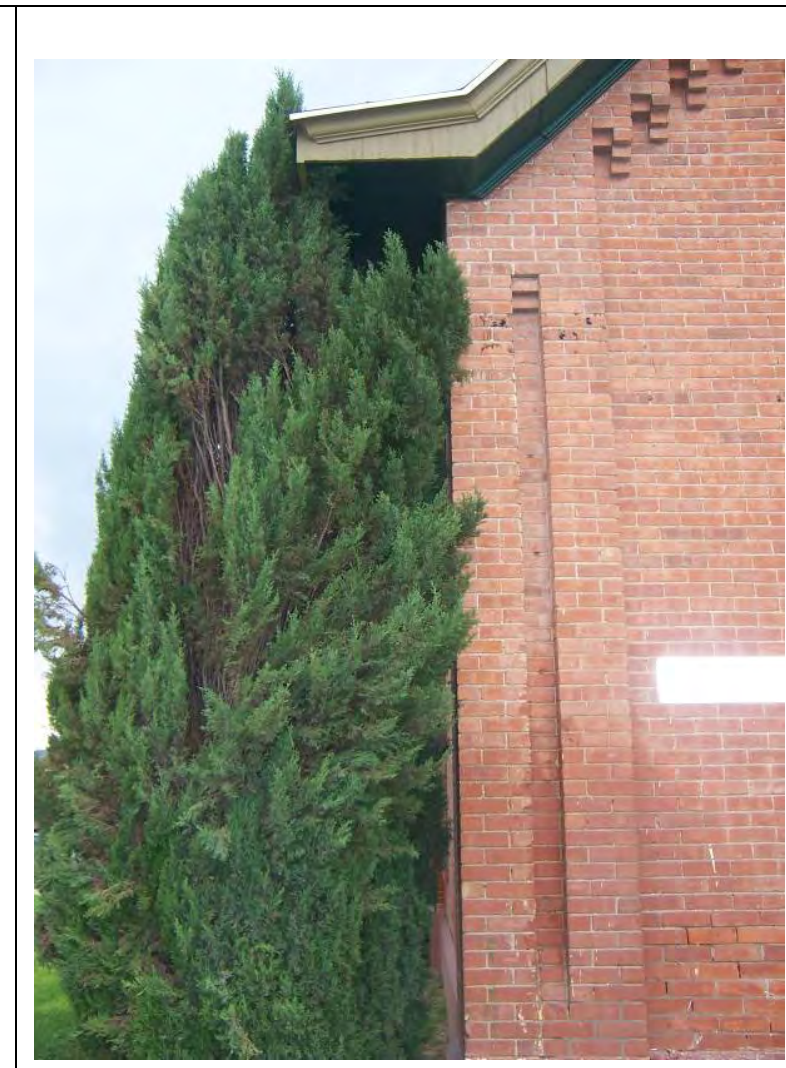

Building 128 - Vegetation should not be allowed to rest on or touch wood features. This enables further problems within the building and the building's materials such as water penetration. 


\section{Repair}

Recommended...

- $\quad$ Repairing the source of the damage before repairing wood parts and components proceeds.

- $\quad$ Repairing architectural wood features by patching, splicing, or otherwise reinforcing the wood following recognized preservation methods. Repairs may also include the limited replacement in-kind —or with a compatible substitute material—of those extensively deteriorated or missing parts of features when there are surviving prototypes such as porch balusters, column capitals or bases; or porch cresting.

- Applying an environmentally safe chemical preservative to wood features, such as post ends at foundations that are exposed to decay and are traditionally unpainted.

- $\quad$ The normal checking and splitting of wood with age results in minor cracks, holes, and voids in wood. These, and holes caused by abandoned nail or screw holes, can usually be filled with common wood putty and repainted. Larger voids may require the use of epoxy consolidants and fillers.

- $\quad$ As epoxies cure, heat is produced. For this reason, epoxies should be used in small quantities to deter extensive heat build-up. Care should be taken when using epoxy on a hot day.

- $\quad$ After the wood has been fixed with epoxy, applying a wood preservative to surround wood surfaces and priming and painting the entire surface.

- $\quad$ Using predrilling and screws in old brittle wood rather than nails to minimize cracking. On buildings where the nails were originally set below the surface with the heads puttied, the new repair work should be similar.

Not Recommended...

- $\quad$ Replacing an entire architectural wood features such as a cornice, column, or balustrade when repair of the wood and limited replacement of deteriorated or missing parts are appropriate.

- Using latex wood fillers to fill larger holes in wood.

- $\quad$ Epoxy repair may not be appropriate if the wood piece is a structural member or the wood to be repaired is to remain unpainted since the epoxy is quite different in appearance then wood.

- Using chemical preservatives (such as creosote), which can change the appearance of wood features.

- $\quad$ Using substitute materials for the replacement part that does not convey the visual appearance of the surviving parts of the wood feature or that is physically or chemically incomparable.

\section{Replace}

Recommended...

- $\quad$ Rather than removing the entire wood member, remove damaged or decayed sections only. Deteriorated wood can often be repaired with wood fillers or consolidants. This is most often justifiable when dealing with finished carpentry items such as doors and windows.

- $\quad$ Replacing in-kind an entire wood feature only if deemed too deteriorated to repair. If the overall form and detailing are still evident, using the physical evidence to guide the new work. Examples of wood features include a cornice, entablature, or balustrade. If using the same kind of material is not technically or economically feasible, then a compatible substitute material may be considered. 
- If damage is too extensive, replacing individual wood members is appropriate. The new wood should duplicate the original in dimensions, configuration, and texture.

- $\quad$ The replacement should be limited to only those parts of a historic item or system and should not be used as an excuse for wholesale replacement.

Not Recommended...

- $\quad$ Removing or radically changing wood features that are important in defining the overall historic character of the building so that, as a result, the character is diminished.

- $\quad$ Removing a major portion of the historic wood from a facade instead of repairing or replacing only the deteriorated wood, then reconstructing the facade with new material in order to achieve a uniform or "improved" appearance.

- $\quad$ Removing an entire wood feature that is unrepairable and not replacing it; or replacing it with a new feature that does not convey the same visual appearance.

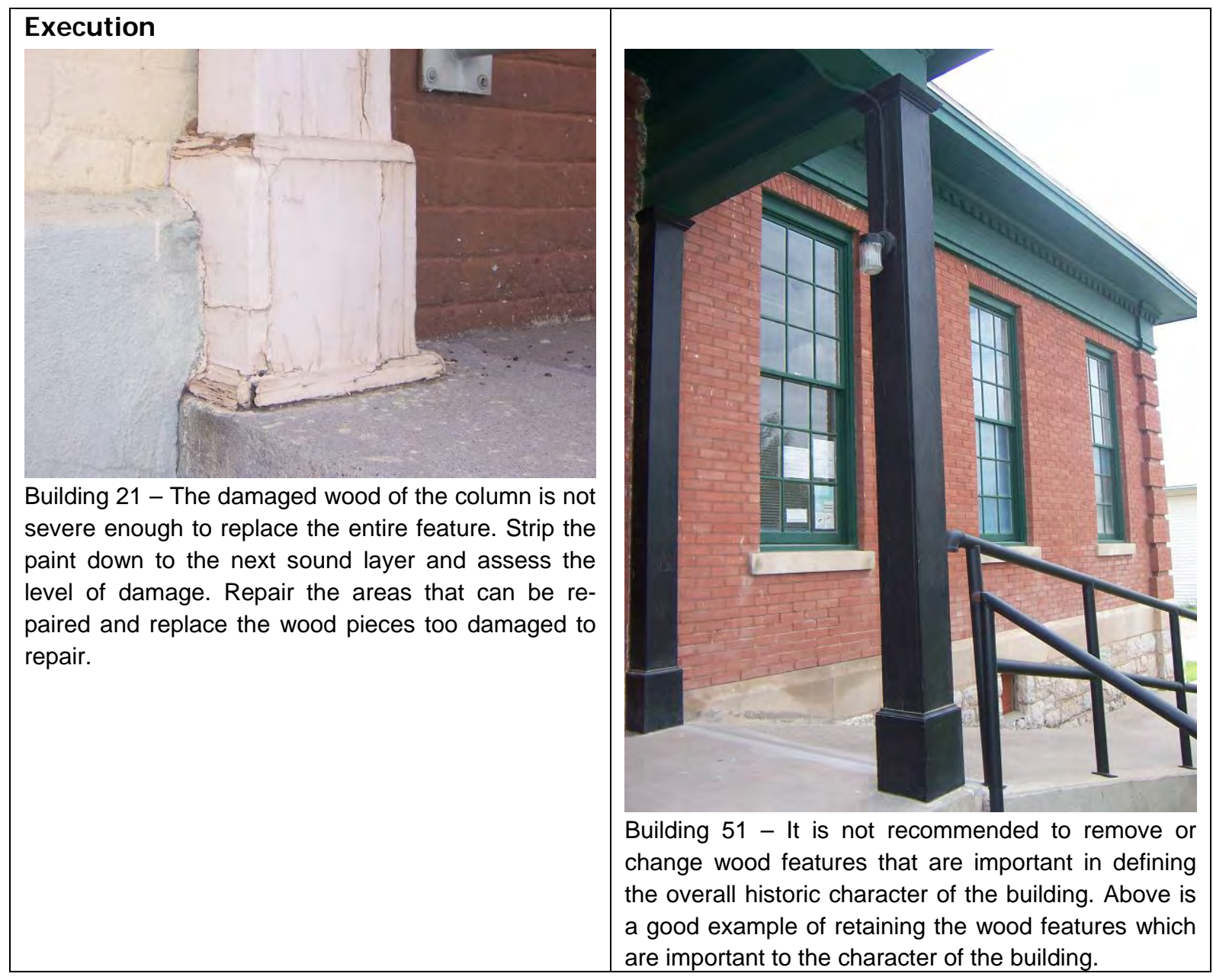




\section{Notes}

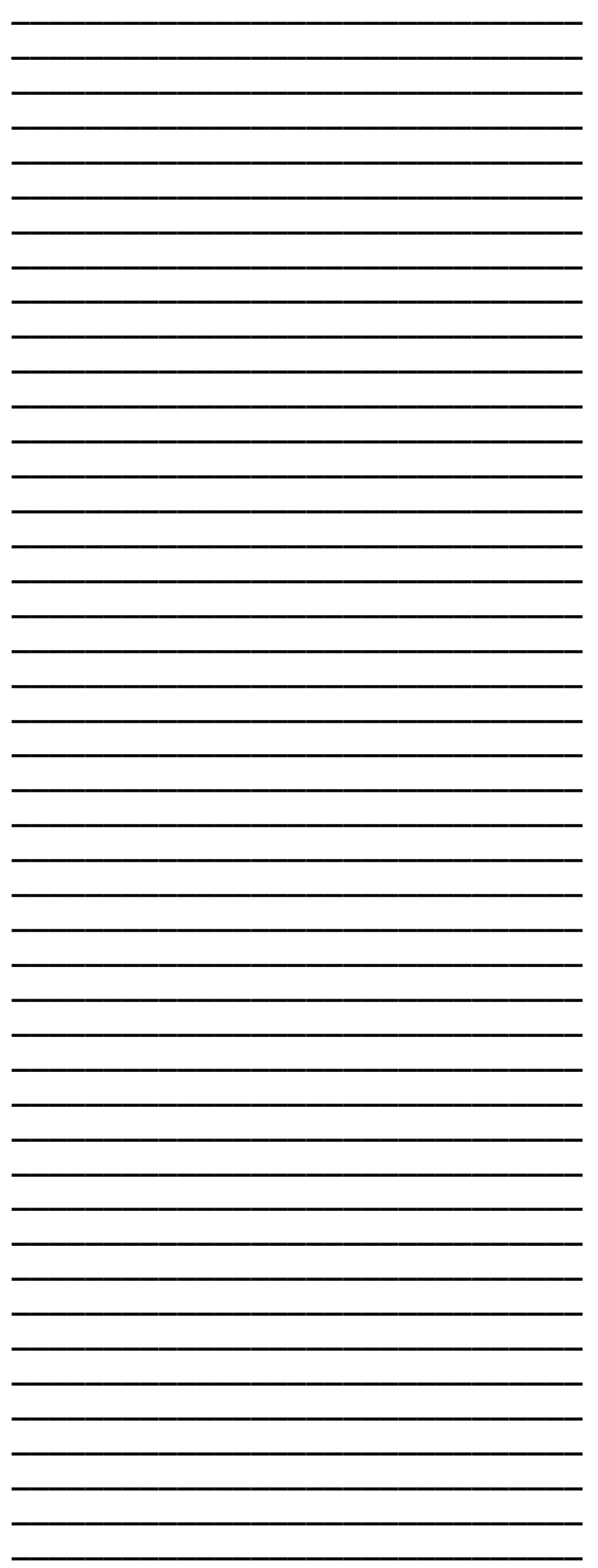




\section{Wood: Protective Coatings}

Barrier coatings are the most commonly used protective mechanism for wood. Some type of coating should probably be considered an integral feature of wood maintenance. The absence of such a coating, or a failure in an existing coating, should be corrected. Inspection should include a visual examination of all surfaces to determine if a coating exists. Surfaces having the peeling, wet-looking, discolored, or stained look should be carefully examined for signs of rot. Absence of a coating should be considered a major problem and corrective action should be undertaken.

Wood should be examined for general material failure and construction technique. More so than any other material, wood is susceptible to deterioration when exposed to moisture. Moisture damage in wood is evidenced by rot and/or decay. Failure of a coating should also be identified and corrected. Coatings can wear away, crack, flake, blister, or peel away, indicating that the coating has failed and is no longer protecting the wood from moisture. Rotting or decaying wood is indicated by unusually soft or brittle areas that easily flake or crumble when prodded by a blunt tool. Wood should be checked for signs of deflection, cracking, weathering, and rot at regular inspection intervals. Fortunately wood does not hide its deterioration like other materials and in most cases problems can easily be detected by visual examination. Because wood features and details are made up of many individual pieces of lumber, only those pieces that are damaged should be repaired or replaced in-kind. Wholesale replacement or materials in a historic building is not recommended. Inspection of the surface should include a careful check for all of the types of coating failures. A record should be made of any coating failures observed so that corrective action can be taken.

Many of the maintenance and repair techniques, particularly those relating to cleaning and painting, are potentially dangerous and should be carried out only by experienced and qualified workman using protective equipment suitable to the task.

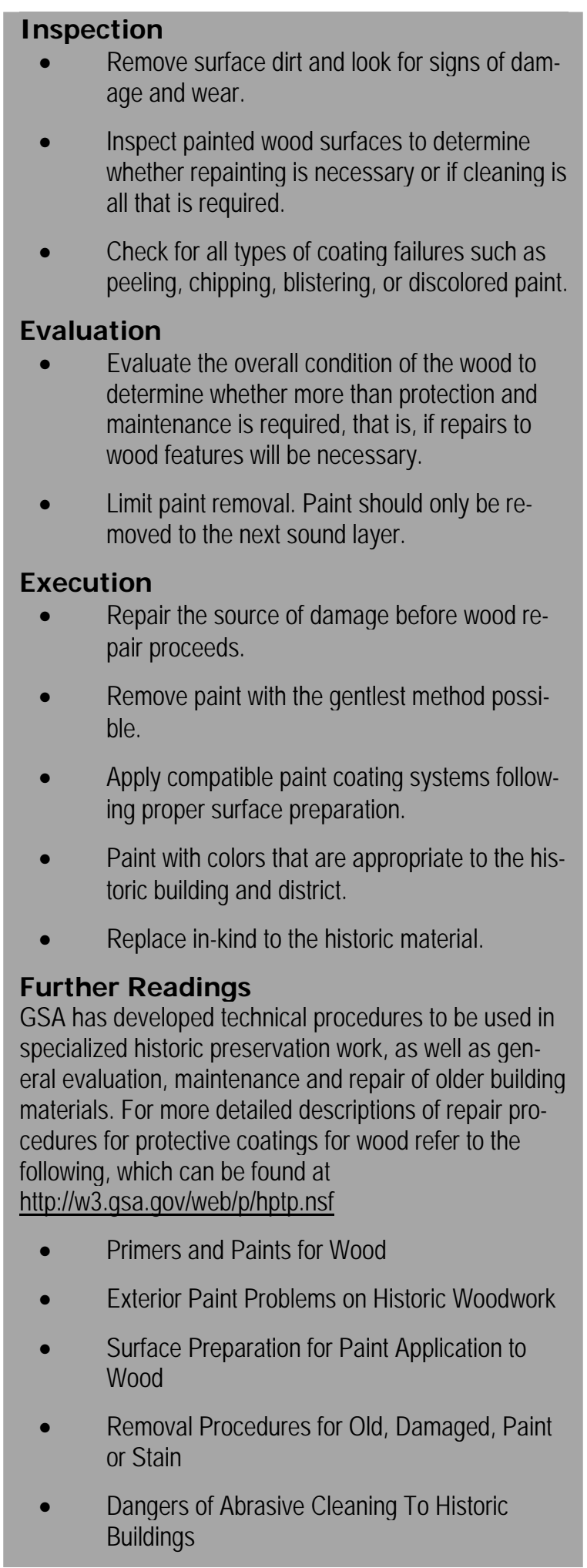

\section{nspection} age and wear whether repainting is necessary or if cleaning is all that is required.

Check for all types of coating failures such as tion

- Evaluate the overall condition of the wood to determine whether more than protection and maintenance is required, that is, if repairs to wood features will be necessary.

Limit paint removal. Paint should only be retion

Repair the source of damage before wood repair proceeds.

Remove paint with the gentlest method possiing proper surface preparation.

Paint with colors that are appropriate to the historic building and district.

Replace in-kind to the historic materia.

\section{Further Readings}

GSA has developed technical procedures to be used in specialized historic preservation work, as well as general evaluation, maintenance and repair of older building materials. For more detailed descriptions of repair procedures for protective coatings for wood refer to the following, which can be found at

- Surface Preparation for Paint Application to Wood

Removal Procedures for Old, Damaged, Paint Buildings 


\section{Procedures for Cleaning and Paint Removal}

When there is extensive failure of the protective coating, most or all of the paint must be removed to prepare the surfaces for new protective coatings. Before selecting a process, test panels should be prepared on the wood to be cleaned to determine the relative effectiveness of various techniques. A number of techniques can be used to remove paint from wood, including:

- $\quad$ Hand-scraping, Chipping, and Wire Brushing - the most common and least expensive methods of removing paint. However, they do not remove all paint as effectively as other methods.

- $\quad$ Low-Pressure Grit Blasting - commonly called abrasive cleaning. It is often the most effective approach to removing excessive paint build-up.

- $\quad$ Air-abrasive Paint Removal - while air-abrasive cleaning (commonly known as sandblasting) is destructive for softer building materials. Do not use air-abrasive cleaning methods in the following situations: 1) On thin sections or fine, intricate details of wood features.

2) On features for which the original surface texture is an integral part of the design.

Thorough surface preparation is necessary for the adhesion of new protective coatings. All loose, flaking, and deteriorated paint must be removed from the wood, as well as dirt. For paint to adhere properly, the wood surfaces must be absolutely dry before painting. Poorly prepared surfaces will cause the failure of even the best paints.

\section{Inspection}

Recommended...

- Identifying, retaining, and preserving wood features that are important in defining the overall historic character of the building such as siding, cornices, brackets, window architraves, and doorway pediments; and their paints, finishes, and colors.

- $\quad$ Paint is one of the most effective means of waterproofing a wood surface and protecting it from ultraviolet light. Keep paint films and sealant joints in good condition.

- Inspecting painted wood surfaces to determine whether repainting is necessary or if cleaning is all that is required.

- $\quad$ Removing surface dirt and grime and look for signs of damage and wear.

Not Recommended...

- $\quad$ Failing to identify, evaluate, and treat the causes of paint deterioration, such as moisture from leaking roofs or gutters.

- $\quad$ Failing to undertake adequate measures to assure the preservation of architectural wood features. 


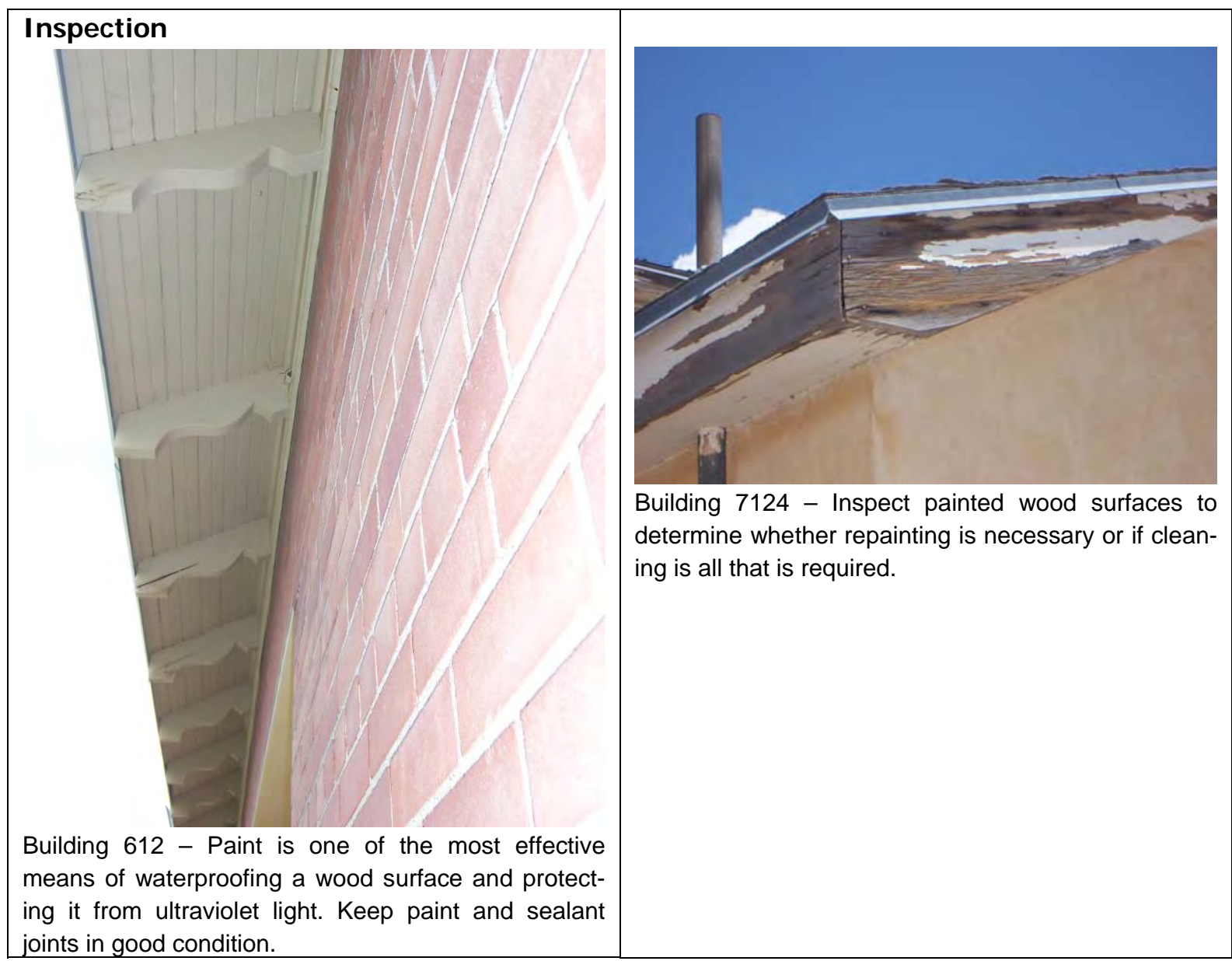

\section{Evaluation}

Recommended...

- $\quad$ Determining level of treatment necessary to repair damaged wood.

- Determining if the wood element needs to be replaced if too deteriorated to repair.

- $\quad$ Evaluating the overall condition of the wood to determine whether more than protection and maintenance are required, that is, if repairs to wood features will be necessary.

- $\quad$ Retaining coatings such as paint that help protect the wood from moisture and ultraviolet light. Paint removal should be considered only where there is paint surface deterioration and as part of an overall maintenance program that involves repainting or applying other appropriate protective coatings. 


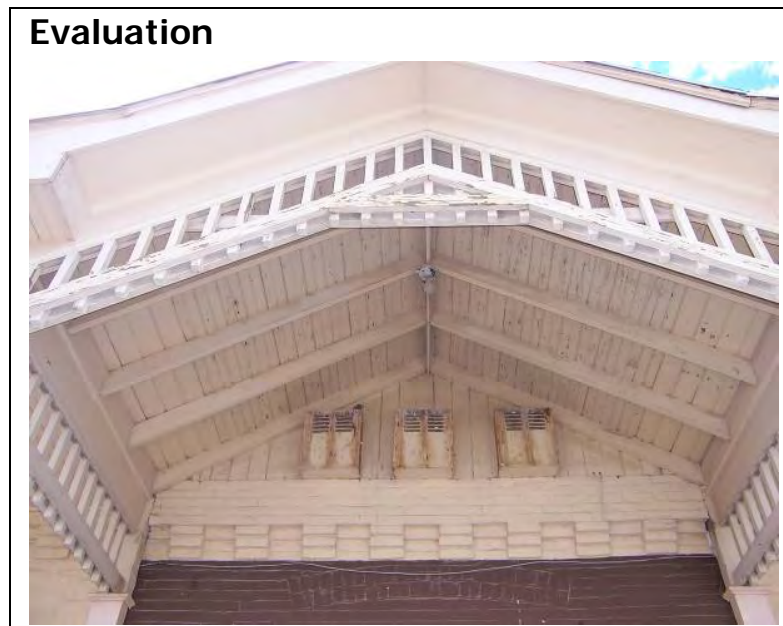

Building 21 - Paint removal should be considered only where there is surface deterioration and as part of an overall maintenance program which involves repainting or applying other appropriate protective coatings.

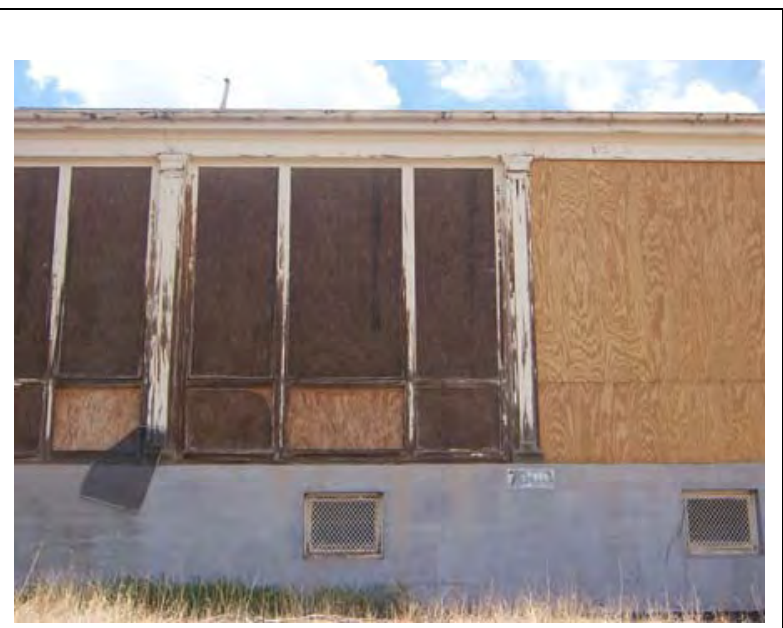

Building 7000 - Evaluate the overall condition of he wood to determine whether more than protection and maintenance are required.

\section{Repair}

Note: Sandblasting is NOT recommended by The Secretary of the Interior's Standards for Rehabilitation and shall not be used. High-pressure water blasting is also NOT recommended without adequate testing or experience as it may damage wood and drive moisture into the wall.

Recommended...

- $\quad$ Repairing the source of the damage before repair proceeds.

- $\quad$ Repairing wood features by patching, piecing-in, consolidating, or otherwise reinforcing the wood using recognized preservation methods. Repair may also include the limited replacement in-kind—or with compatible substitute material—of those extensively deteriorated or missing parts of features where there are surviving prototypes.

- $\quad$ Removing damaged or deteriorated paint to the next sound layer using the gentlest method possible (hand-scraping and hand-sanding), then repainting.

- $\quad$ Using with care electric hot-air guns on decorative wood features and electric heat plates on flat wood surfaces when paint is so deteriorated that total removal is necessary prior to repainting.

- $\quad$ Using chemical strippers primarily to supplement other methods such as hand-scraping, hand-sanding and the above-recommended thermal devices. Detachable wooden elements such as shutters, doors, and columns may — with the proper safeguards—be chemically dip-stripped.

- $\quad$ Cleaning architectural wood, when necessary, to remove deteriorated paint prior to repainting or applying other appropriate protective coatings.

- $\quad$ Applying compatible paint coating systems following proper surface preparation.

- $\quad$ Repainting with colors that are appropriate to the historic building and district.

Not Recommended...

- $\quad$ Stripping historically painted surfaces to bare wood, then applying clear finishes or stains in order to create a "natural look." 
- $\quad$ Stripping paint or varnish to bare wood rather than repairing or reapplying a special finish, i.e., a grained finish to an exterior wood feature such as a front door.

- $\quad$ Using chemical preservatives such as creosote that can change the appearance of wood features unless they were used historically.

- $\quad$ Stripping paint or other coatings to reveal bare wood, thus exposing historically coated surfaces to the effects of accelerated weathering.

- $\quad$ Removing paint that is firmly adhering to and thus protecting wood surfaces.

- Using destructive paint removal methods such as propane or butane torches, sandblasting, or water blasting. These methods can irreversibly damage historic woodwork.

- Using thermal devices improperly so that the historic woodwork is scorched.

- $\quad$ Failing to neutralize the wood thoroughly after using chemicals so that new paint does not adhere.

- $\quad$ Allowing detachable wood features to soak too long in a caustic solution so that the wood grain is raised and the surface roughened.

- $\quad$ Failing to follow manufacturers' product and application instructions when repainting exterior woodwork.

- $\quad$ Using new colors that are inappropriate to the historic building or district.

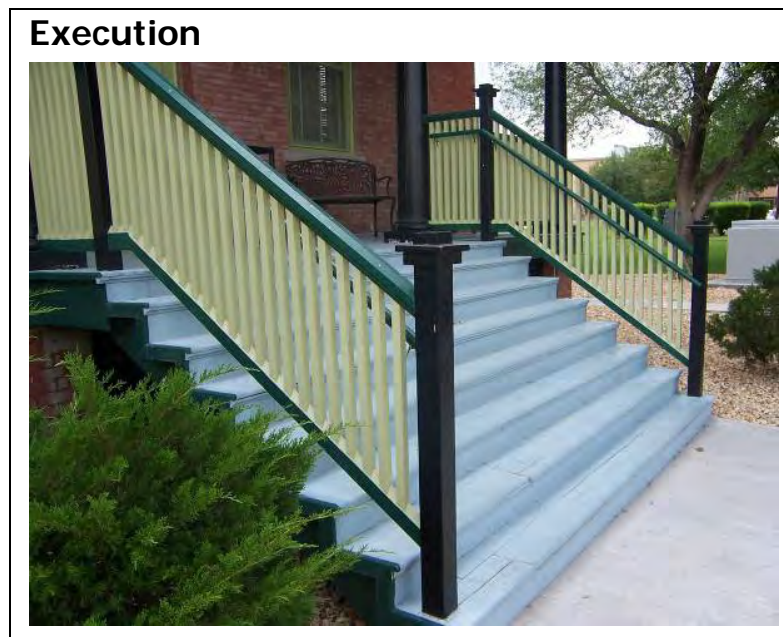

Building 4 - Repaint with colors that are appropriate to the historic building and district.

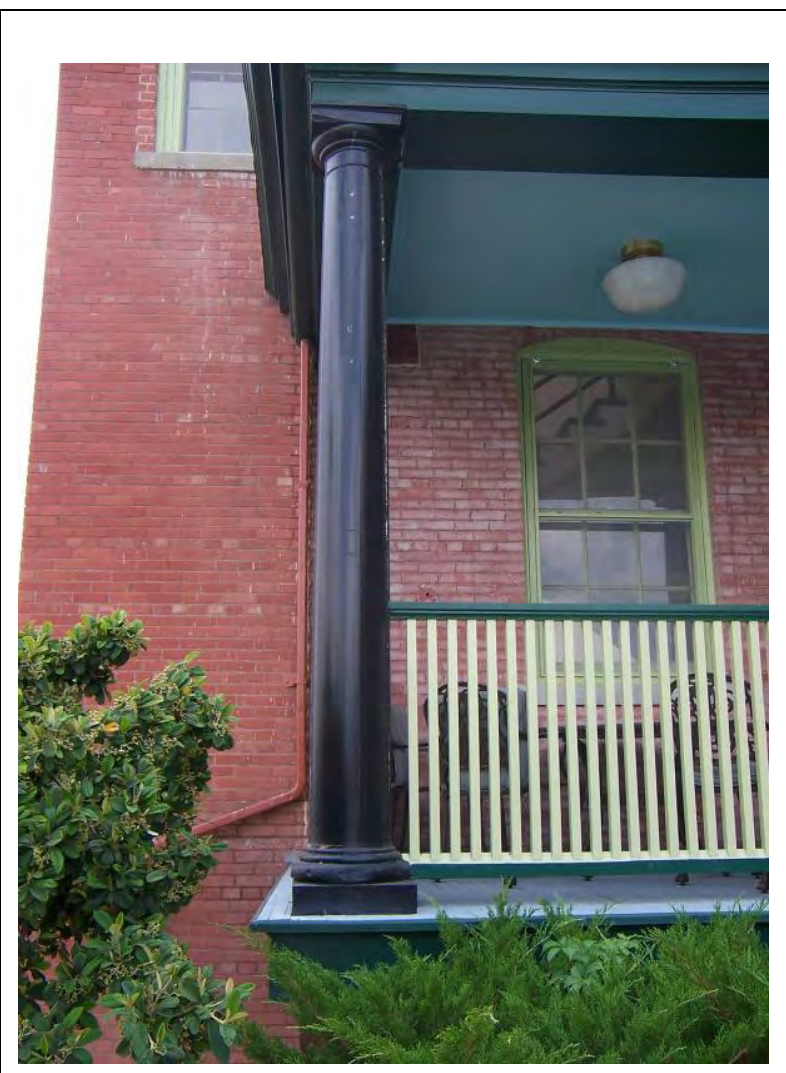

Building 4 - Apply compatible paint coating systems following proper surface preparation. 


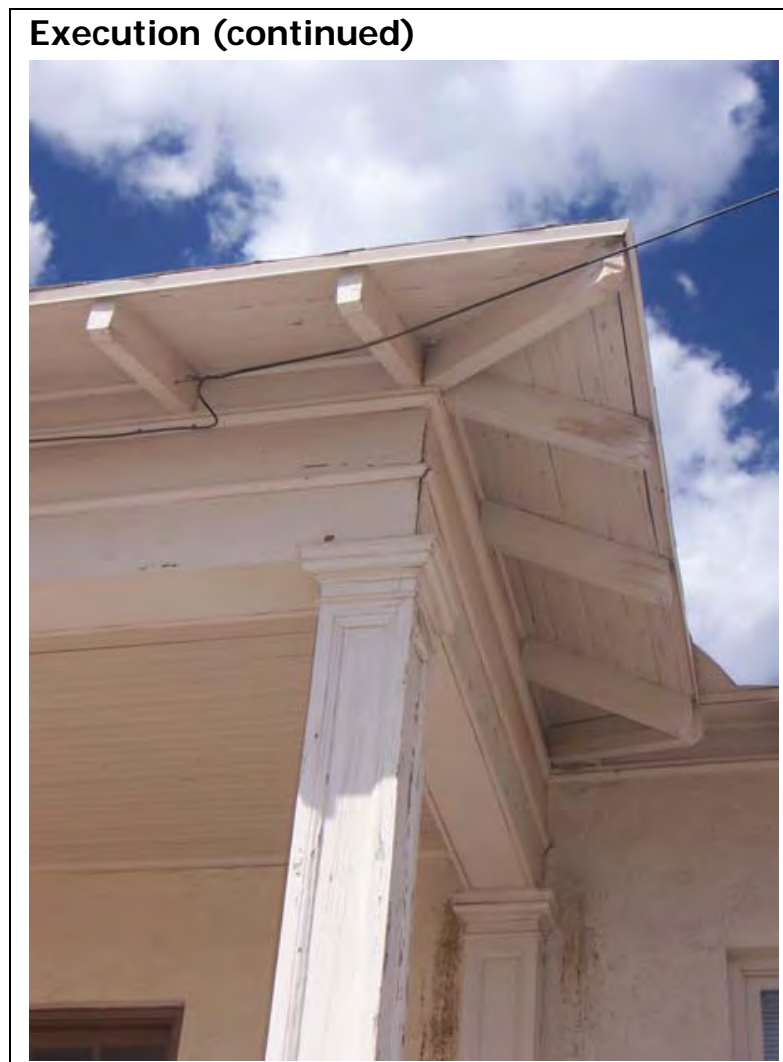

Building 7167 - Stripping historically painted wood surfaces to bare wood, then applying clear finishes or stains in order to create a "natural look" is not recommended.

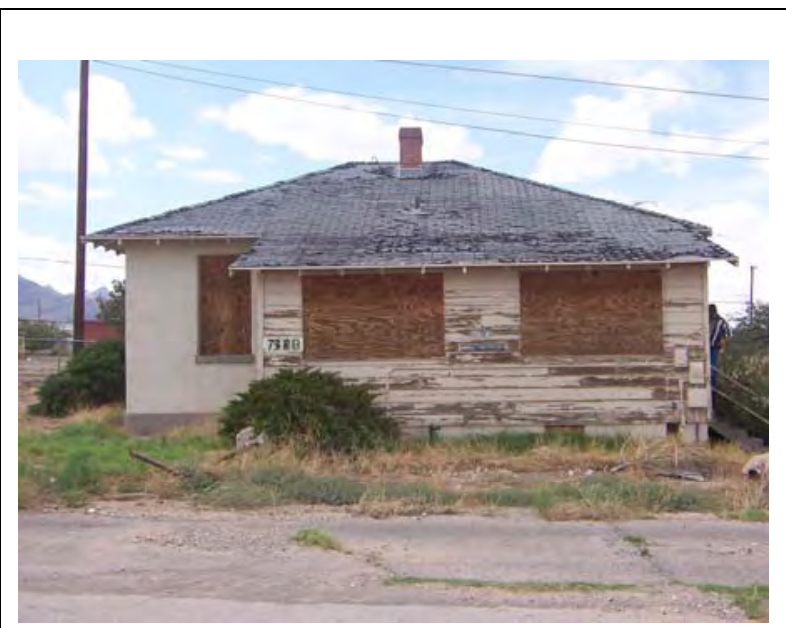

Building 7183 - Remove paint to the next sound layer by using the gentlest method possible (e.g., handscraping). DO NOT sandblast the wood to remove paint, which could damage the wood and drive moisture into the building. 
Notes

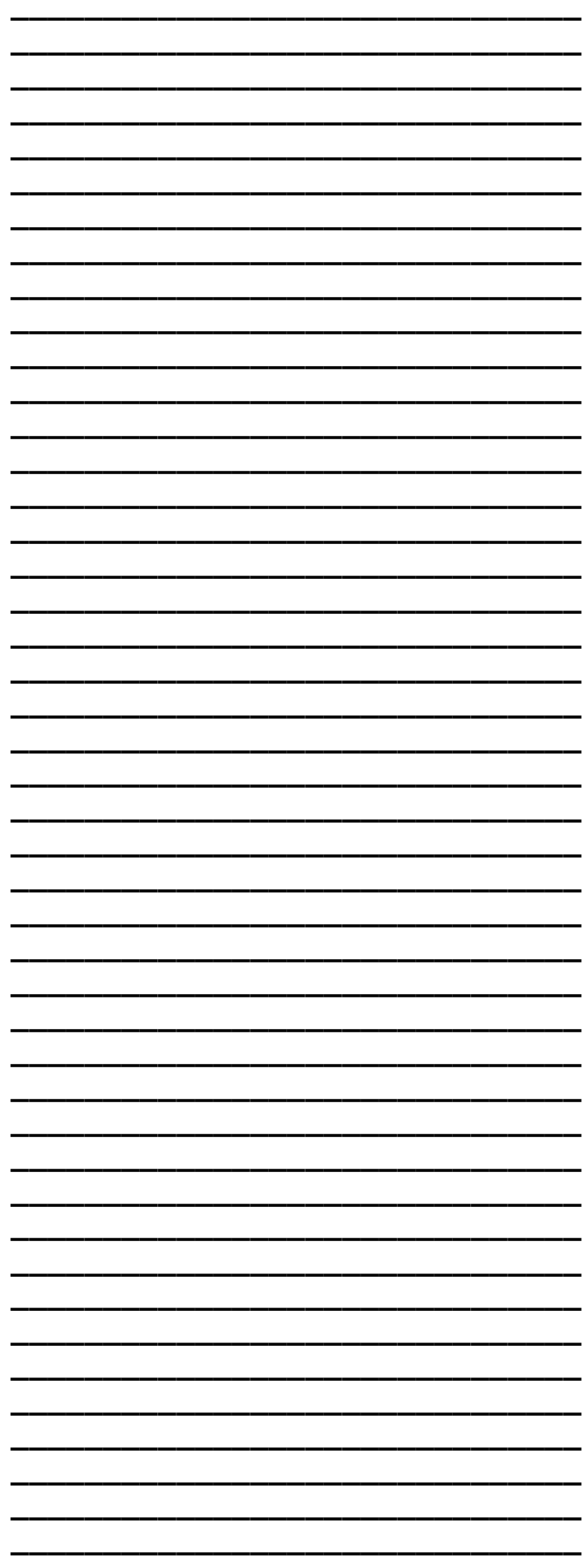




\section{Maintenance Guides for Roofing}

\section{Roofing: Overview}

A weather-tight roof is basic in the preservation of a structure, regardless of its age, size, or design. In addition to providing protection from the elements, the roof can be one of the most important historic design features of a building. Its shape, features (such as dormers and chimneys), and the size, color, and patterning of the roofing material are all character-defining elements that must be preserved. A complete internal and external inspection of the roof structure and the roof covering is recommended to determine the condition, potential causes of failure, or source of leaks, and will help in developing a program for the preservation and repair of roofs.

\section{Preservation of Roofing Systems}

- $\quad$ At least twice a year, inspect the roof against a checklist. Record and report all changes. Check the eaves for leaks or damage to the drainage system.

- $\quad$ Preserve historic roofing materials and repair in-kind when possible. Use replacement materials that are identical to the originals in color, size, finish, and pattern.

- $\quad$ Provide adequate anchorage for roofing material to guard against wind damage and moisture penetration. Protect a leaking roof with plywood and building paper until it can be properly repaired.

- $\quad$ Protect and maintain a roof by cleaning the gutters and downspouts and replacing deteriorated flashing. Roof sheathing should also be checked for proper venting to prevent moisture condensation and water penetration and to ensure those materials are free from insect infestation.

- $\quad$ Do not change roof shapes or add features such as skylights, especially if they will be visible from the street. Avoid installing mechanical and service equipment on the roof, especially if it will be visible. An installation should be done in a way that maximizes protection of the roofing systems.

- $\quad$ Repair historic flashing in-kind where possible. Flashing failure is a frequent cause of leaks and damage to the roof structure and the building interior, as well as exterior masonry.

\author{
Maintenance/ Management Guidelines \\ for Roofing
}

- Cyclical maintenance of roofing systems is a key to the successful survival of a building. As soon as rehabilitation or restoration has been completed, some program of continuing maintenance should be initiated. Changes in the building should particularly be noted. The roof should be routinely checked for signs of leaks or failure. The roofing system should be monitored regularly. All water damage should be noted and remedied at its earliest possible stages. Gutter and downspouts should be kept clean and working properly. Plant, animal, and insect damage should be halted before it becomes substantial.

- According to The Secretary of the Interior's Standards for Rehabilitation, the proper procedure is to respect the significance of the original materials and features, repair and retain wherever possible, and replace them only when absolutely necessary.

- The following recommendations for care of the historic site are to be thoroughly read and understood before a treatment is specified. The Secretary of the Interior's Standards for Rehabilitation should also be consulted to determine the appropriateness of any treatment.

Full documentation can be found at http://www.cr.nps.gov/hps/tps/tax/rhb/stand.htm

Construction Documents and Specifications for Rehabilitation and Replacement of Historic Roofing, Fort Bliss Manual 
- $\quad$ Do not remove original eaves, overhangs, and cornices. They are usually important design features. Repair if possible, or replace with exact replicas.

\section{Identify, Retain, and Preserve}

Recommended...

- Identifying, retaining, and preserving roofs — and their functional and decorative features

- that are important in defining the overall historic character of the building. This includes the roof's shape, such as hipped, gambrel, and mansard; decorative features such as cupolas, cresting, chimneys, and weathervanes; and roofing materials such as slate, wood, clay tile, and metal, as well as its size, color, and patterning.

Not Recommended...

- $\quad$ Radically changing, damaging, or destroying roofs that are important in defining the overall historic character of the building so that, as a result, the character is diminished.

- $\quad$ Removing a major portion of the roof or roofing material that is repairable, then reconstructing it with new material in order to create a uniform, or "improved" appearance.

- $\quad$ Changing the configuration of a roof by adding new features such as dormer windows, vents, or skylights so that the historic character is diminished.

- $\quad$ Stripping the roof of sound historic material such as slate, clay tile, wood, and architectural metal.

- $\quad$ Applying paint or other coatings to roofing material that has been historically uncoated.

\section{Protect and Maintain}

Recommended...

- $\quad$ Protecting and maintaining a roof by cleaning the gutters and downspouts and replacing deteriorated flashing. Roof sheathing should also be checked for proper venting to prevent moisture condensation and water penetration; and to ensure that materials are free from insect infestation.

- $\quad$ Providing adequate anchorage for roofing material to guard against wind damage and moisture penetration.

- $\quad$ Protecting a leaking roof with plywood and building paper until it can be properly repaired.

Not Recommended...

- $\quad$ Failing to clean and maintain gutters and downspouts properly so that water and debris collect and cause damage to roof fasteners, sheathing, and the underlying structure.

- $\quad$ Allowing roof fasteners, such as mails and clips, to corrode so that roofing material is subject to accelerated deterioration.

- $\quad$ Permitting a leaking roof to remain unprotected so that accelerated deterioration of historic building materials—-masonry, wood, plaster, paint and structural members—occurs.

\section{Repair}

Recommended...

- $\quad$ Repairing a roof by reinforcing the historic materials of which roof features are made. Repairs will also generally include the limited replacement in-kind — or with compatible substitute material —of those extensively deteriorated or missing parts of features when there are surviving prototypes such as cupola louvers, dentils, dormer roofing; or slates, tiles, or wood shingles on a main roof. 
Not Recommended...

- $\quad$ Replacing an entire roof feature such as a cupola or dormer when repair of the historic materials and limited replacement of deteriorated or missing parts are appropriate.

- $\quad$ Using a substitute material for the replacement part that does not convey the visual appearance of the surviving parts of the roof or that is physically or chemically incompatible.

\section{Replace}

Recommended...

- $\quad$ Replacing in-kind an entire feature of the roof that is too deteriorated to repair-if the overall form and detailing are still evident—using the physical evidence to guide the new work. Examples can include a large section of roofing, or a dormer or chimney. If using the same kind of material is not technically or economically feasible, then a compatible substitute material may be considered.

Not Recommended...

- $\quad$ Removing a feature of the roof that is unrepairable, such as a chimney or dormer, and not replacing it; or replacing it with a new feature that does not convey the same visual appearance.

\section{Good Examples of Roofing Materials}

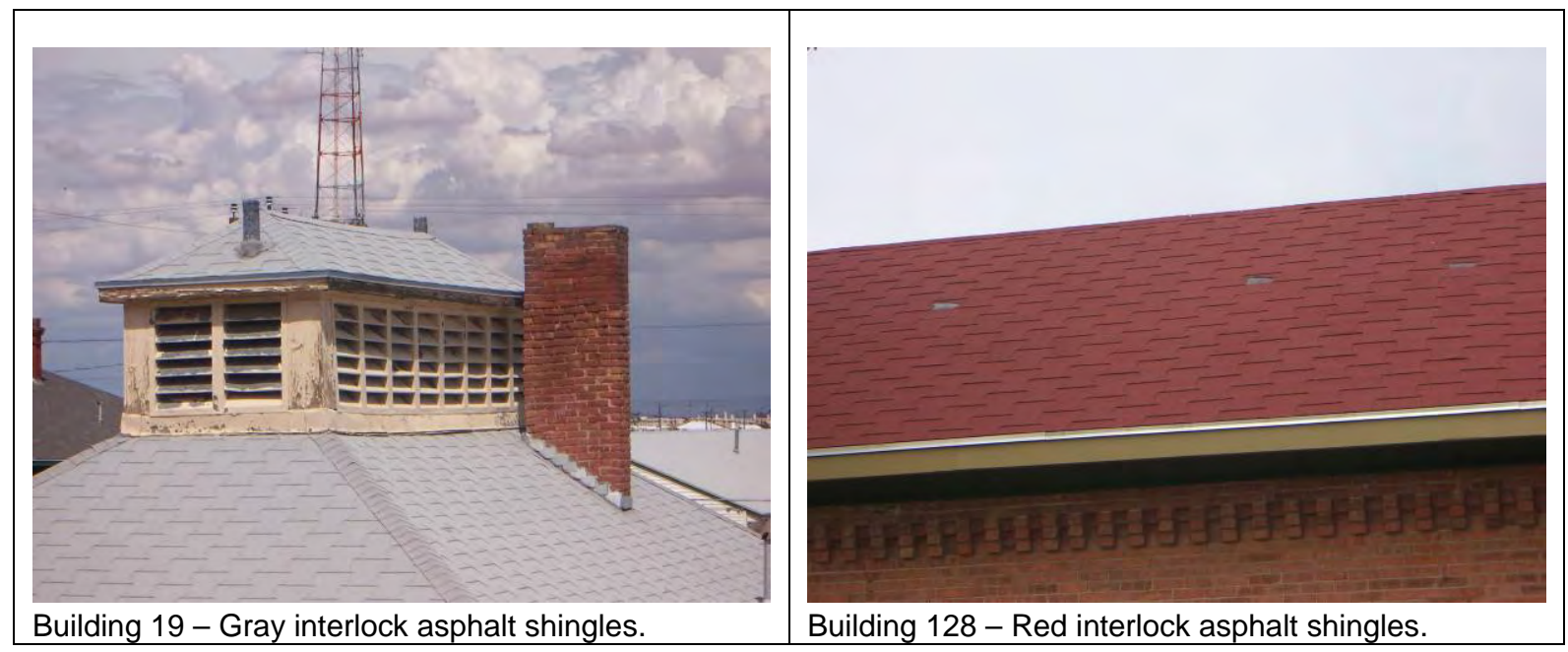



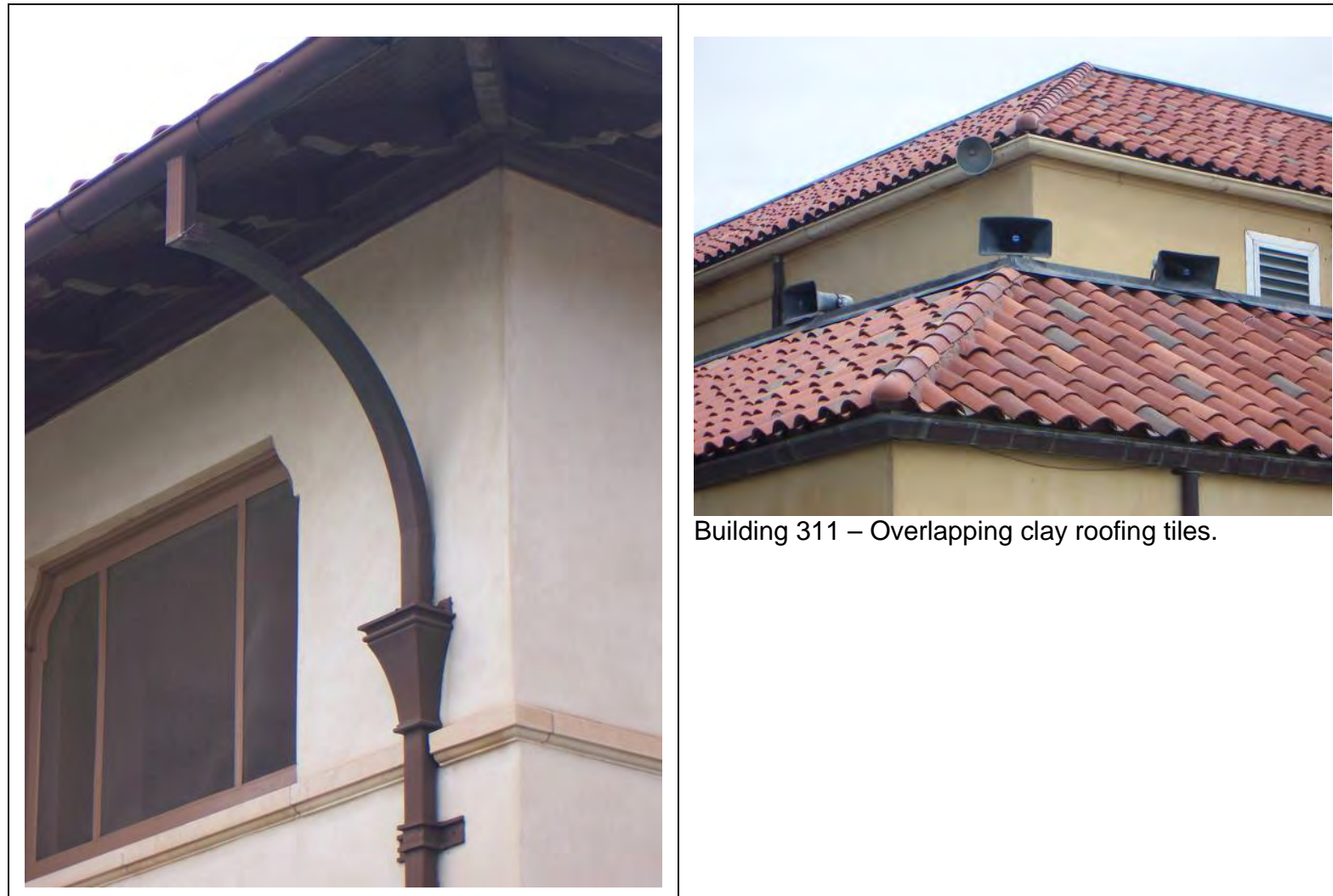

Building 311 - Overlapping clay roofing tiles.

Building 243 - Decorative gutter and downspout.

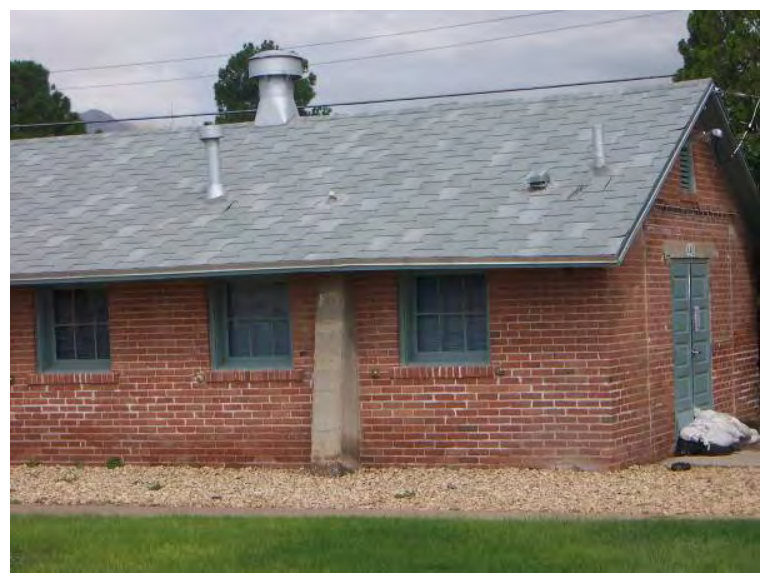

Building 440 - Gray interlock asphalt shingles.

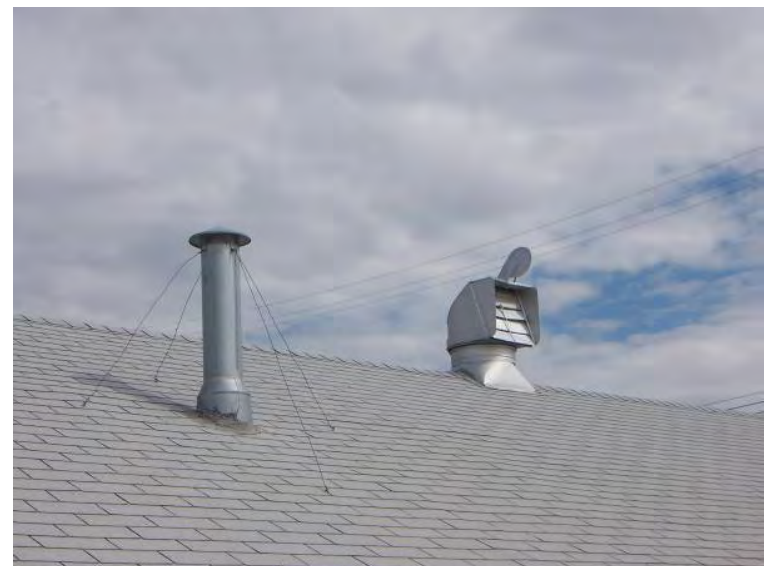

Building 444 - Gray three-tab asphalt shingles. 


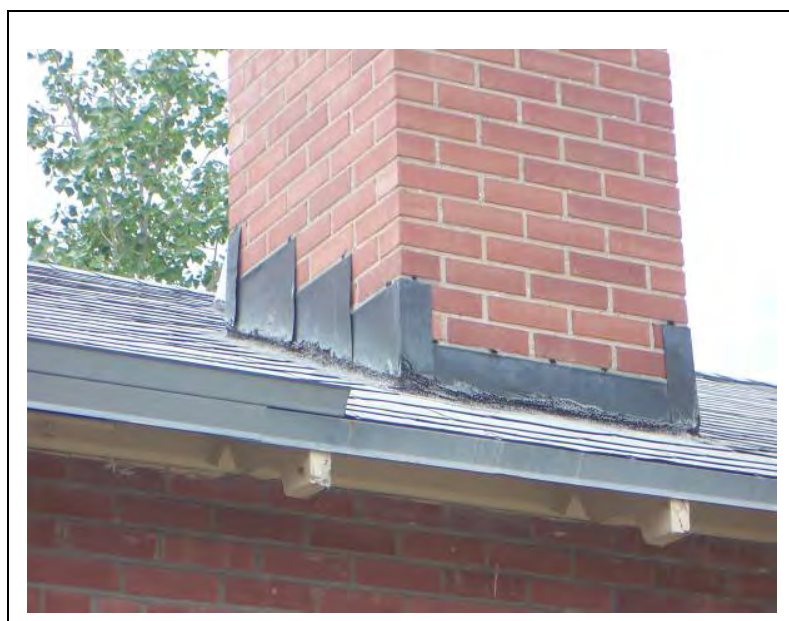

Building 612 - Correctly installed flashing detail around chimney base.

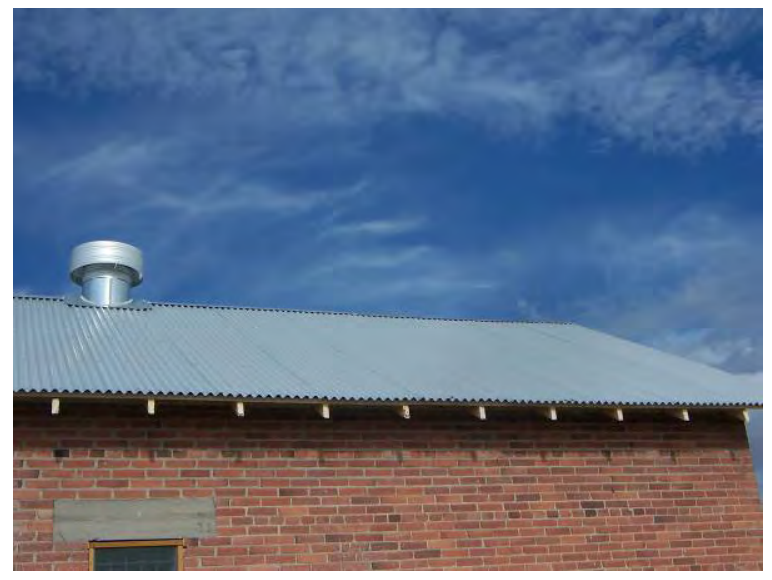

Building 889 - Crimped metal roof.

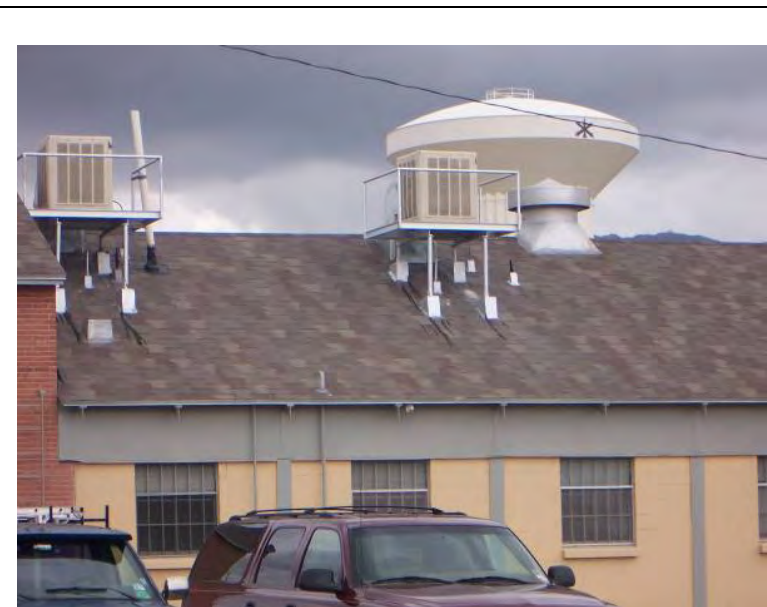

Building 641 - Multi-color interlock asphalt shingles.

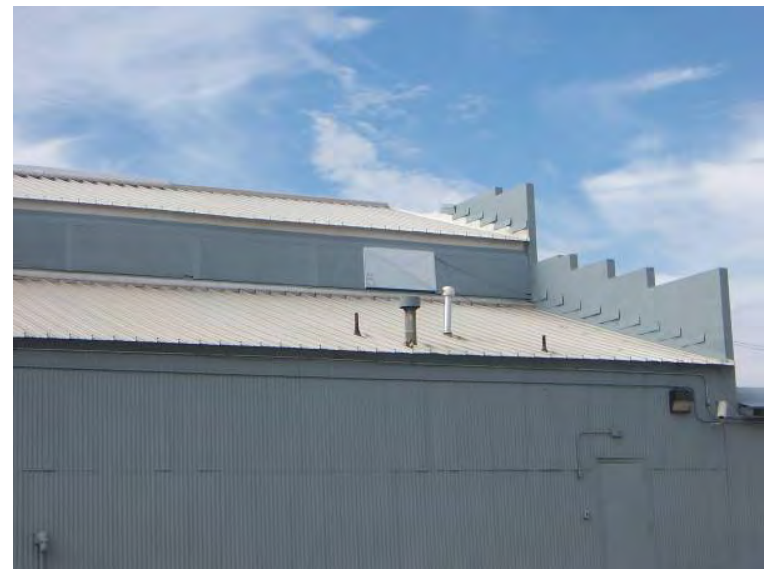

Building 1008 - Metal channel roof. 


\section{Roofing: Asphalt}

Asphalt shingles and rolled asphalt have a service life of about 20 years for the first layer and 15 years for the second layer added over the first layer depending on their weight, quality, and exposure. Available in a wide range of types, colors, and patterns, asphalt shingles are by far the most popular type of roofing system used due to its cost effectiveness and easy installation. Rolled asphalt roofing material is commonly found on buildings with flat roofs. Some asphalt shingles and rolled asphalt may perform unsatisfactorily, especially in hot, arid climates where thermal shock condition (high heat with rapid cooling from thunderstorms) occurs. Being a product of nonrenewable fossil materials, asphalt shingles and rolled asphalt are not the best choice from a sustainability standpoint.

\section{Problems and Concerns}

The deterioration of asphalt shingles and rolled asphalt can be seen in the following:

- $\quad$ loose or missing shingles,

- $\quad$ cracks or holes in the shingles or rolled asphalt,

- $\quad$ curling of the shingles or rolled asphalt,

- $\quad$ drying out of the shingles or rolled asphalt,

- $\quad$ cracking of the shingles or rolled asphalt, and/or

- $\quad$ loss of protective granules.

\section{Flashing}

Failure of the flashing system is a major cause of roof deterioration/leaks. Flashing should be carefully inspected for failure caused by either poor workmanship, thermal stress, or metal deterioration (both of flashing material itself and of the fasteners). With many roofing materials, the replacement of flashing on an existing roof is a major operation, which may require taking up large sections of the roof surface. Therefore, the installation of top quality flashing material on a new or replaced roof should be a primary consideration. Remember, some roofing and flashing materials are not compatible and some dissimilar metals may cause galvanic corrosion.

\section{Repairs}

Isolated small holes or cracks in shingles and rolled asphalt can be temporarily repaired by troweling on plastic roofing cement. Curled shingles and rolled asphalt can often be cemented back in 
place. Individual shingles that are badly damaged can be replaced by slipping a pry bar under the damaged shingle, removing the nails, sliding the shingle out, replacing the shingle, and applying roofing cement to the new nail heads and the bottom edge of new shingle, and the one above.

If large number of shingles exhibit excess drying out, curling, loss of protective granules, cracking, or other deterioration, or if there is evidence of significant leaks that are not due to faulty flashing, then a complete shingle or rolled asphalt material replacement is likely to be required.

A critical decision will be whether or not to remove the existing shingles or rolled asphalt material or apply the new layer of shingles or rolled material over the existing layer. In many cases, it is not necessary to tear off the old shingles or rolled material if the roof has only one layer of shingles, is laying flat, and the roof decking is in good condition. The existing shingles or rolled asphalt will probably have to be removed, however, if an inspection of the roof sheathing/substrate reveals significant rotting or warping of the sheathing members, if there is more than one existing layer of asphalt shingles on the roof or two layers of rolled asphalt on the roof, or if the condition of the existing shingles or rolled asphalt is so rough and distorted that new shingles or rolled material would not lay flat.

\section{Inspection}

Recommended...

- $\quad$ Periodically inspecting roofs for signs of damage, including cracked, curled, or missing asphalt shingles or rolled asphalt.

- Inspecting the condition of the flashing.

- Inspecting gutters and valleys for debris and making sure they are functionally correctly.

- $\quad$ Checking the proximity of vegetation to the roofing system. Making sure that it is not resting on or causing damage to the asphalt shingles or rolled material.

- $\quad$ Protecting and maintaining a roof by cleaning the gutters and downspouts and replacing deteriorated flashing. Roof sheathing should also be checked for proper venting to prevent moisture condensation and water penetration.

Not Recommended...

- $\quad$ Failing to clean and maintain gutters and downspouts properly so that water and debris collect and cause damage to roof fasteners, sheathing, and the underlying structure.

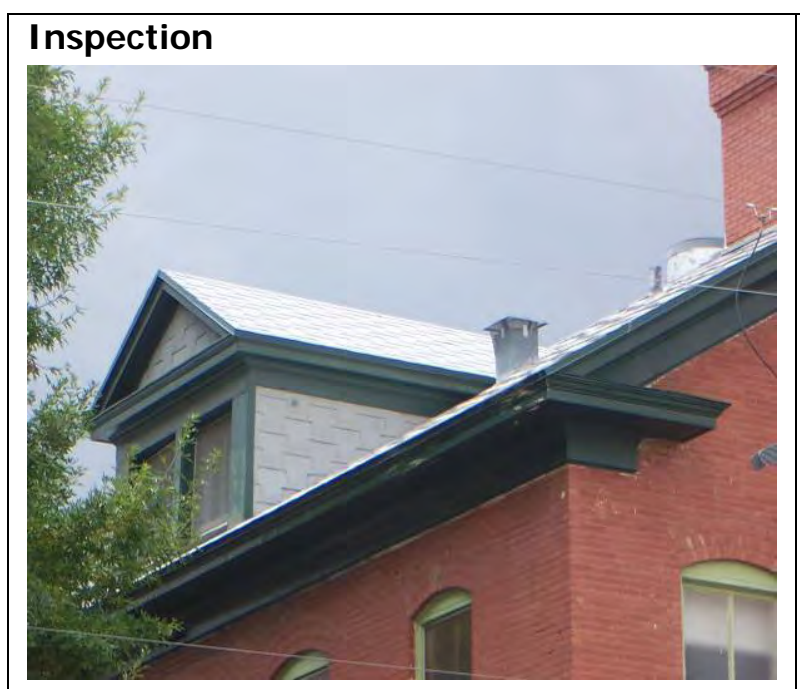

Building 1 - A periodic inspection of roof features such as a dormer or chimney is needed to maintain the roof system and to monitor any damage or deterioration below the roofing material.

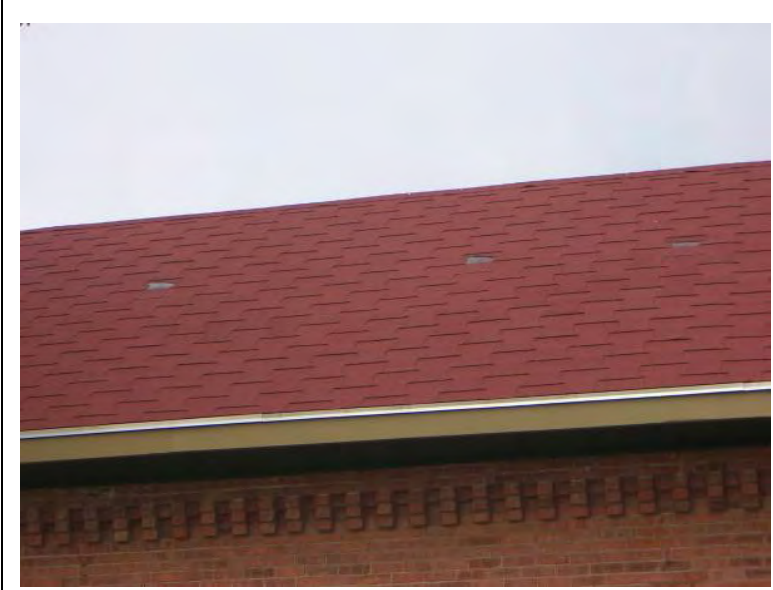

Building 128 - Inspect asphalt shingle roofs and rolled asphalt roofs for signs of damage, including cracked, curled, or missing asphalt shingles or rolled material. 


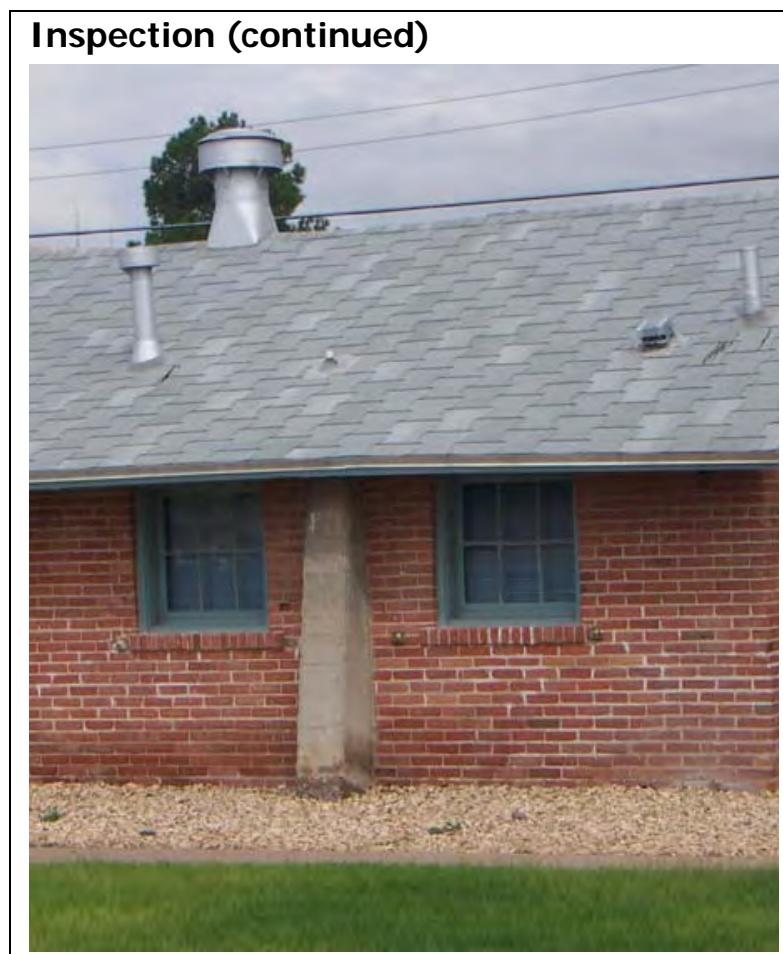

Building 440 - Inspect roofs near penetrations points into the roof structure, such as vent stacks, to make sure the flashing is working properly.

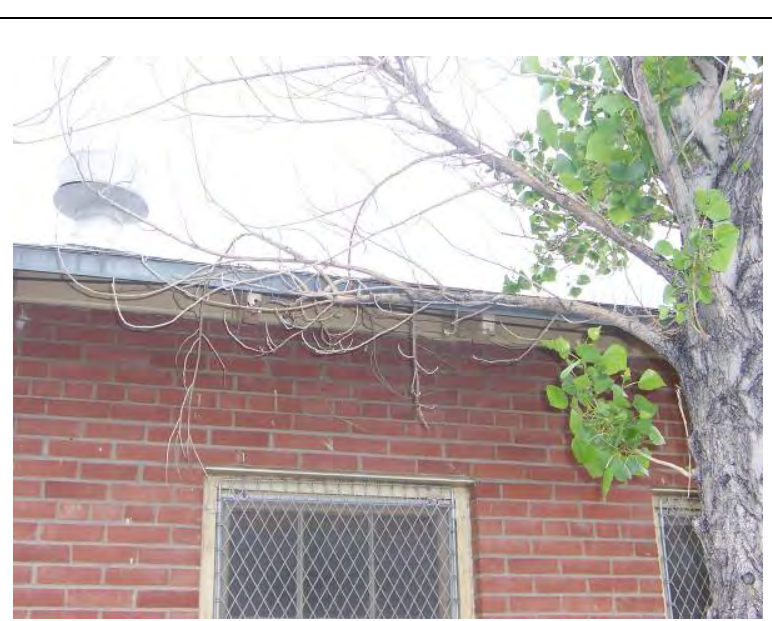

Building 612 - Tree branches laying on and in the gutter can cause damage to the roofing system by filling it with debris and causing the gutter not to function properly.

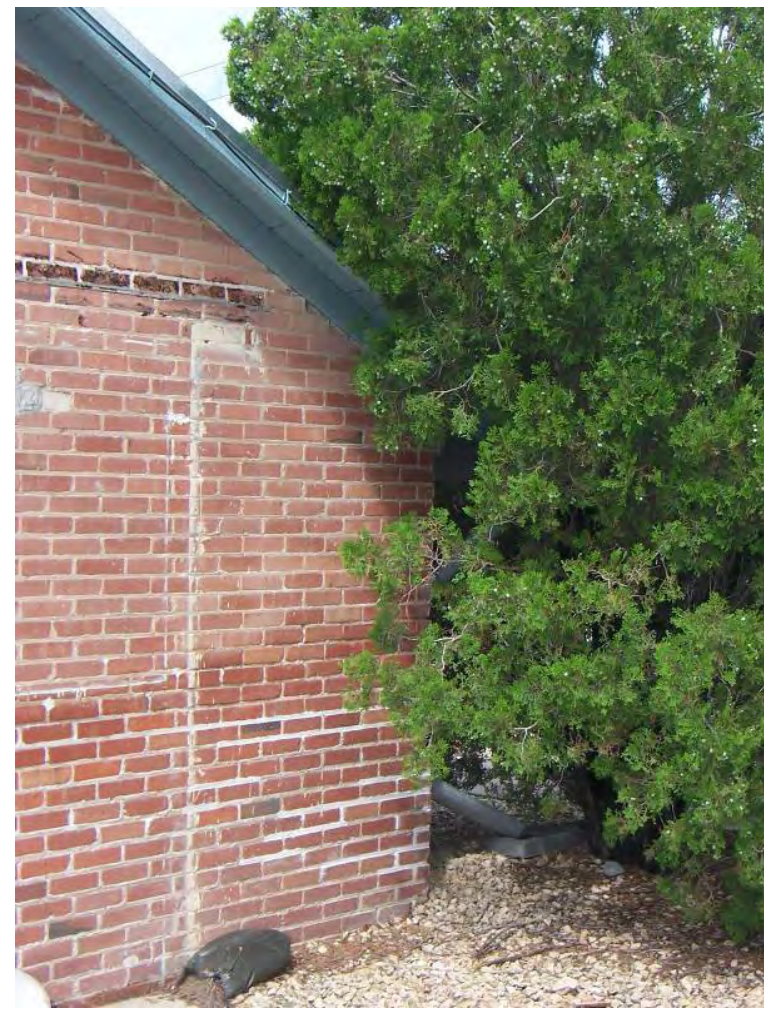

Building 440 - Vegetation is too close to a roofing system, gutter, and downspout. Make sure that tree branches are not resting on or causing damage to the roof.

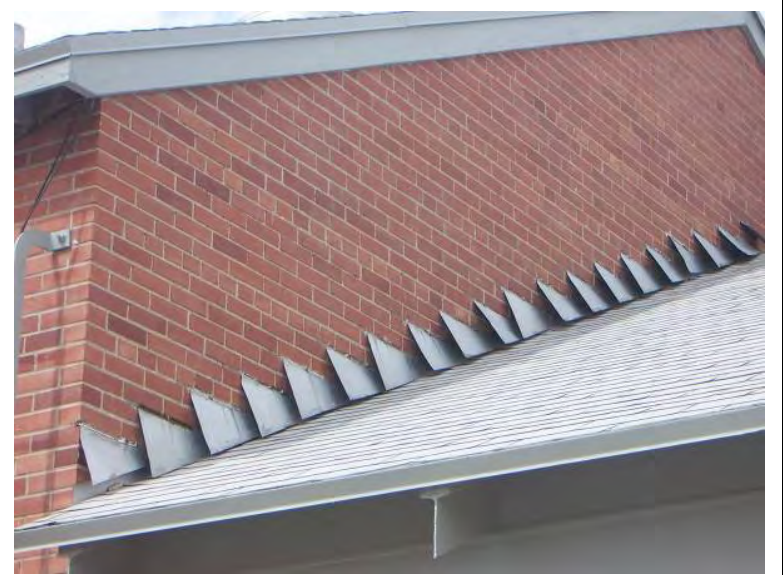

Building 620 - Inspect condition of the flashing. 


\section{Evaluation}

Recommended...

- $\quad$ Determining level of treatment necessary to repair severely damaged asphalt shingles.

- $\quad$ Determining how many layers of shingles are covering the sheathing. Using no more than two layers of asphalt shingles is recommended.

- $\quad$ Providing adequate anchorage for roofing material to guard against wind damage and moisture penetration.

- $\quad$ Protecting a leaking roof with plywood and building paper until it can be properly repaired.

\section{Not Recommended...}

- $\quad$ Allowing roof fasteners, such as nails and clips, to corrode so that roofing material is subject to accelerated deterioration.

- $\quad$ Permitting a leaking roof to remain unprotected so that accelerated deterioration of historic building materials—masonry, wood, plaster, paint, and structural members—occurs.

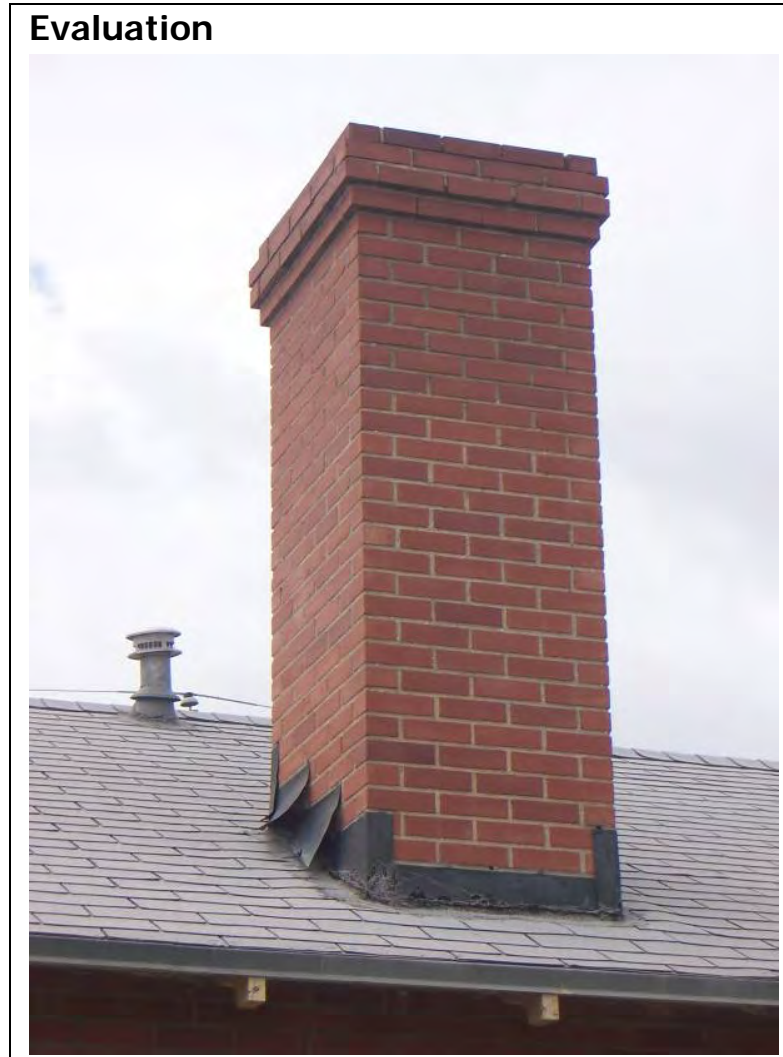

Building 612 - Example of improper use of step flashing. Be careful not to damage adjacent surfaces and materials such as chimneys and dormers when repairing the roof and flashing.

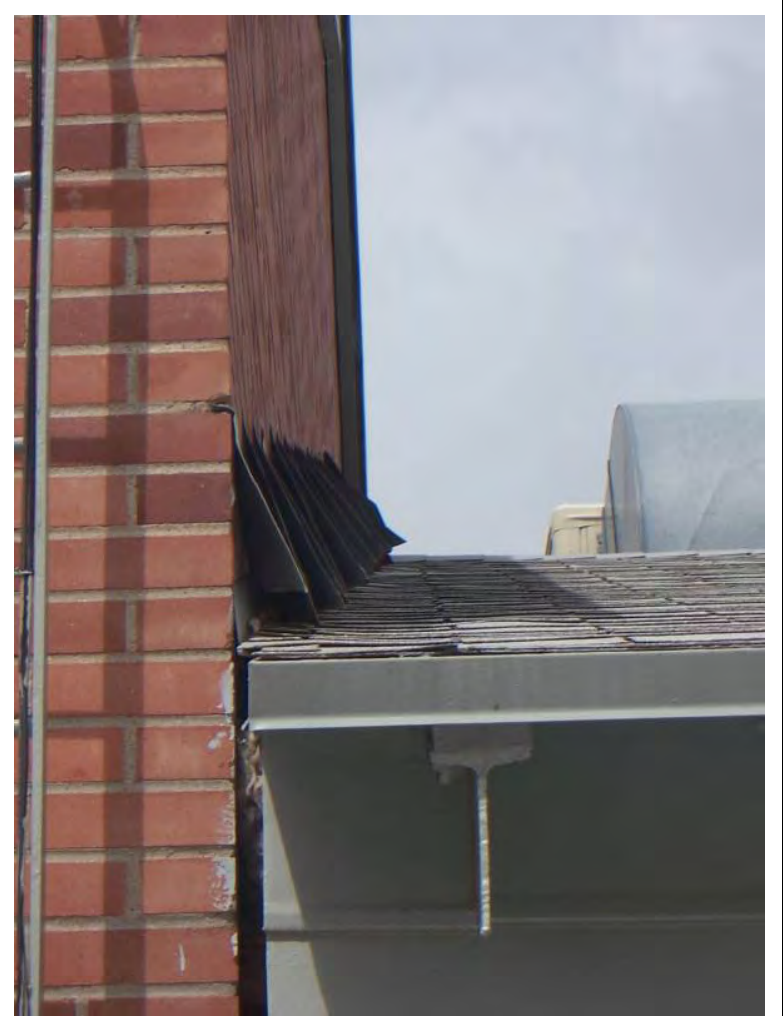

Building 620 - Stepped flashing that has become detached. Also there is no gutter installed to help transport water away from the building, especially the large gap in between the two walls and roof. 


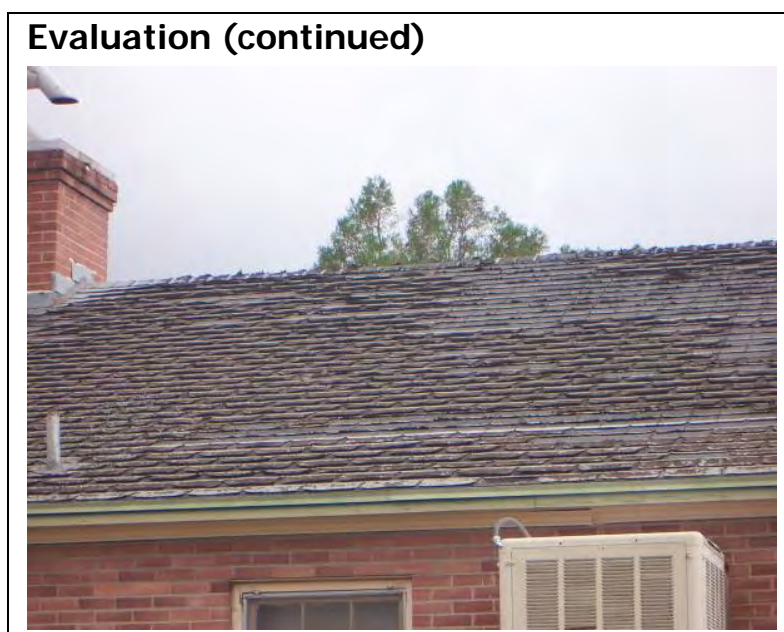

Building 628 - The majority of asphalt shingles exhibit excessive drying out and curling. A complete shingle replacement is likely to be required.

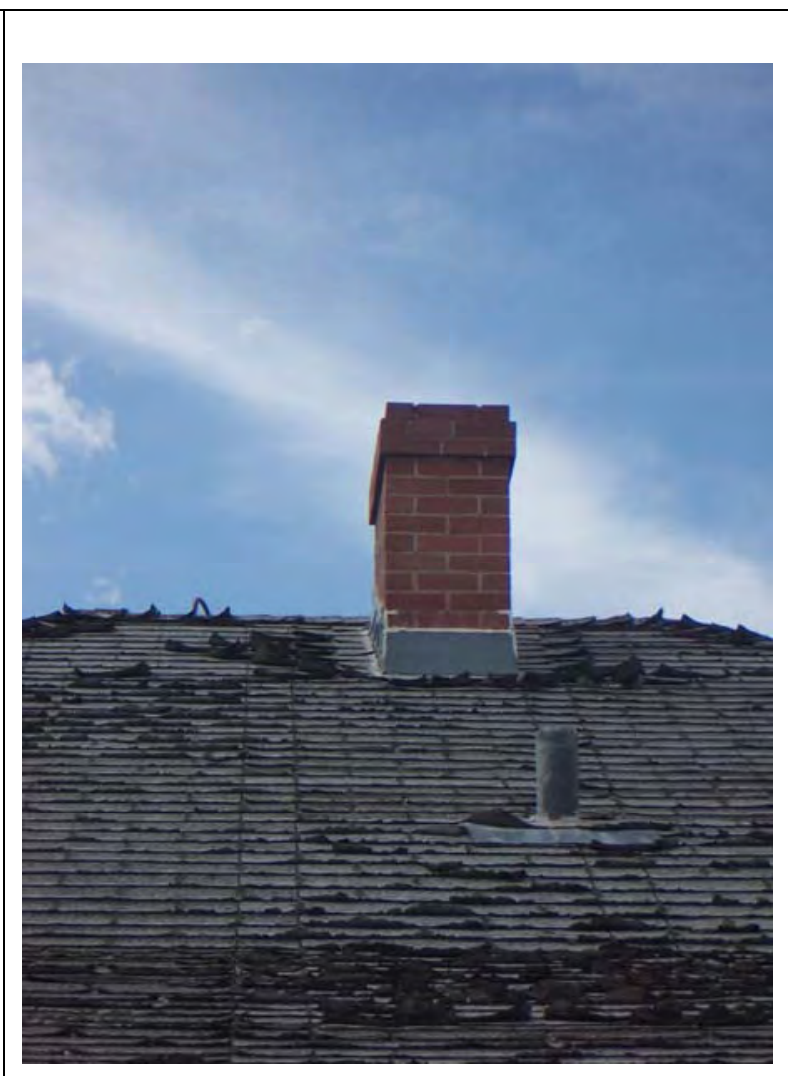

Building 7183 - Another example of curled asphalt shingles.

\section{Execution}

- Consult manufacturer's recommendations before attempting to repair a damaged roof system.

- $\quad$ Be careful not to damage adjacent surfaces and materials when repairing the roof, including chimneys, dormers, and flashings.

- $\quad$ Repair the source of the damage before repairing proceeds.

\section{Repair}

Recommended...

- $\quad$ Repairing a roof by reinforcing the historic materials of which roof features are made.

- Temporarily repairing isolated small holes or cracks in shingles or rolled asphalt by troweling on plastic roofing cement.

- When installing new flashing, work should be done comparable to the historical methods or as recommended by the Sheet Metal and Air Conditioning Contractors' National Association (SMACNA).

- Installing a new layer of asphalt shingles over one layer of existing shingles or a new layer of rolled asphalt over two layers of existing rolled material if the existing layer of shingles are laying flat and the roof decking is in good condition.

- $\quad$ Replacing flashing in-kind. 
Not Recommended...

- $\quad$ Replacing an entire roof feature such as a cupola or dormer when repair of the historic materials and limited replacement of deteriorated or missing parts are appropriate.

- $\quad$ Using a substitute material for the replacement part that does not convey the visual appearance of the surviving parts of the roof or that is physically or chemically incompatible.

- Installing a new layer of asphalt shingles over more than one layer of existing shingles or installing a new layer of rolled asphalt over more than two layers of existing rolled material.

- Using roofing cement for flashing in favor of stepped flashing

\section{Replace}

\section{Recommended...}

- Replacing in-kind an entire feature of the roof that is too deteriorated to repair. If using the same kind of material is not technically or economically feasible, then a compatible substitute material may be considered.

- Using red asphalt interlock shingles to keep the uniformity of the existing appearance of the building.

Not Recommended...

- $\quad$ Removing a feature of the roof that is unrepairable, such as a chimney or dormer, and not replacing it; or replacing it with a new feature that does not convey the same visual appearance.

- Installing a new layer of asphalt shingles over more than two layers of existing shingles or if the condition of the existing shingles is so rough and distorted that new shingles would not lay flat.

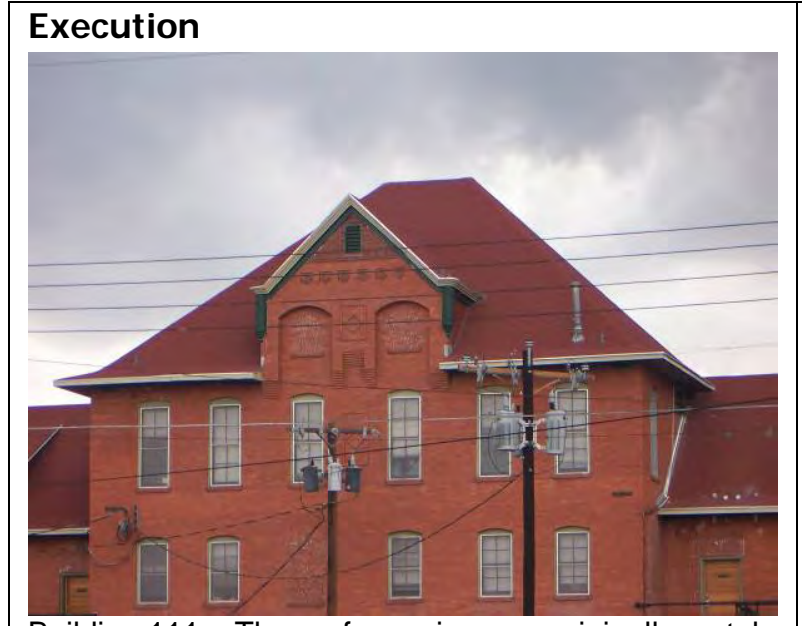

Building 111 - The roof covering was originally metal shingles and was re-roofed with the current red covering. The red color, as a contractor error, was never replaced but was compatible to the red color of the clay tile roof structures constructed at Fort Bliss

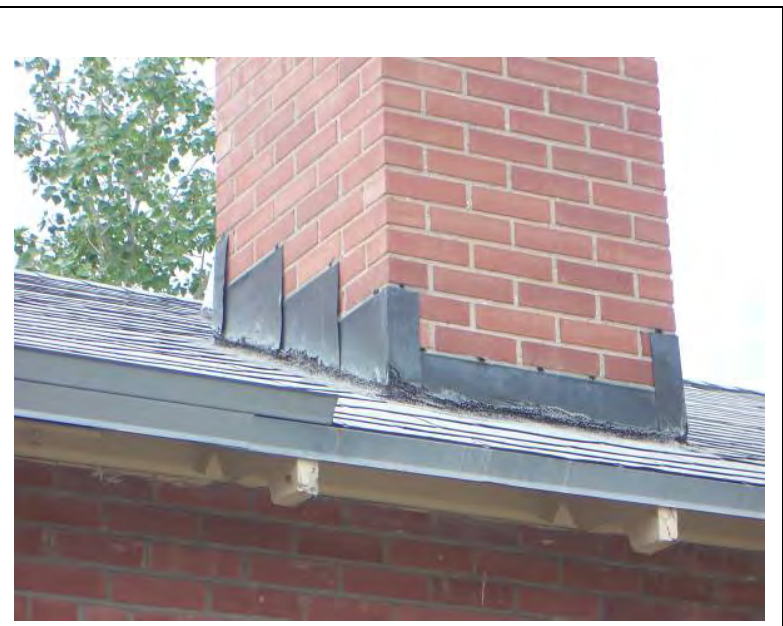

Building 612 - Stepped flashing reinstalled correctly (see photo on page 152) 


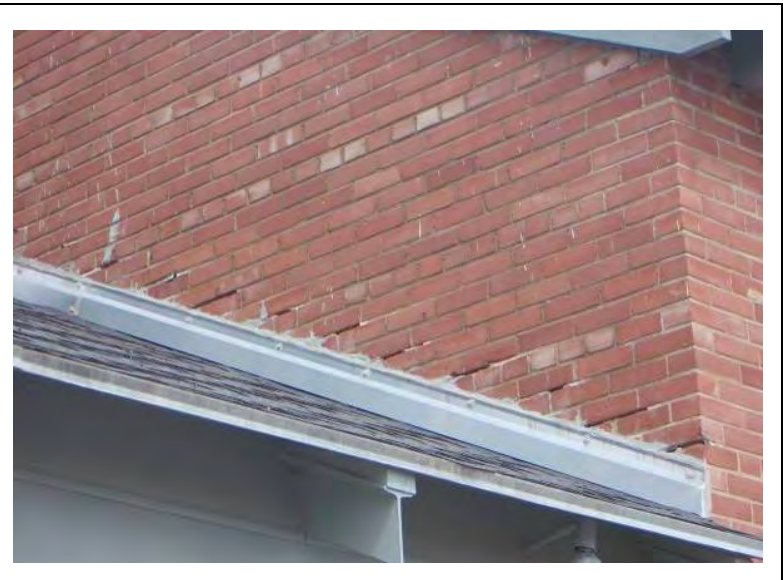

Building 624 - Flashing should be replaced in-kind. Here the original stepped flashing was removed and replaced with straight metal flashing. 
Notes

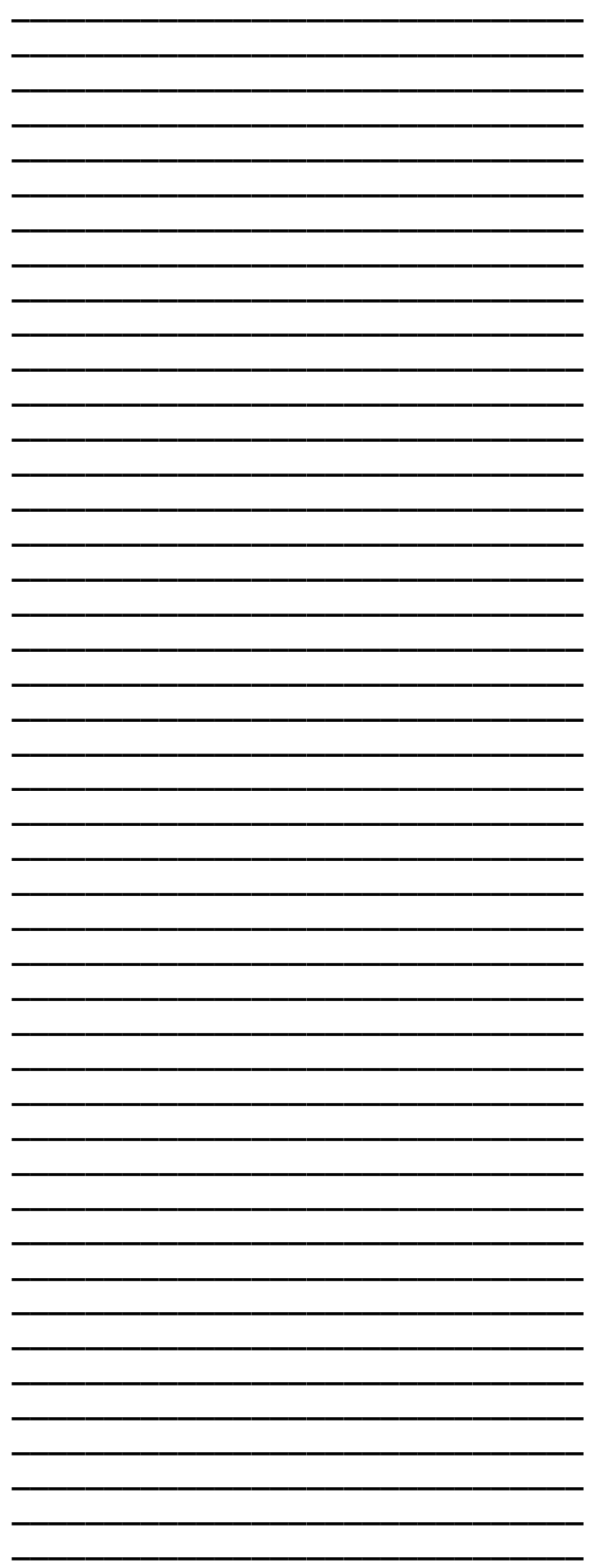




\section{Roofing: Clay Tile}

Clay tiles are one of the most distinctive and decorative historic roofing materials because of their great variety of shapes, colors, profiles, patterns, and textures. Traditionally, clay tiles were formed by hand and later by machine extrusion of natural clay, textured or glazed with color, and fired in high-temperature kilns. The unique visual qualities of a clay tile roof often make it a prominent feature in defining the overall character of a historic building. The significance and inherently fragile nature of the historic tile roofs dictate that special care and precaution be taken to preserve and repair them.

Clay tile has one of the longest life expectancies among historic roofing materialsgenerally about 100 years. A regularly scheduled maintenance program is necessary to prolong the life of any roofing system. A complete internal and external inspection of the roof structure and the roof covering is recommended to determine the condition, potential causes of failure, or source of leaks, and will help in developing a program for the preservation and repair of clay tile roofs.

\section{Traditional Tile Shapes and Colors}

There are two types of clay roofing tiles: interlocking and overlapping. Interlocking tiles are designed in pairs so that an extrusion or "lip" on one of the tiles "hooks" over the other tile thereby "locking" or securing the two together; they are also usually nailed to the roof structure. Overlapping tiles, which can also function in pairs, generally do not have any sort of "lip" and must be nailed in place. Both types of clay tiles can be found at Fort Bliss. There is a wide range of shapes of historic clay roofing tiles, and many, sometimes with slight variations, are still produced today. There are many variations, and the country of origin of some of them may be revealed in their names, but there are essentially only two kinds of shapes: pan tiles and flat tiles. Both pan tiles and flat tiles may be either interlocking or overlapping.

\section{Causes of Failure}

- A clay tile roof system most commonly fails due to the breakdown of the fastening system. The deterioration of metal flashing, valleys, and gutters can also lead to the failure of a clay tile roof.

\author{
Inspection \\ - $\quad$ Periodically inspect roofs for signs of damage, \\ including missing tiles. \\ - Inspect the condition of the flashing. \\ - Inspect gutters and valleys for debris and make \\ sure they are functionally correctly. \\ - Identify root cause of damage.

\section{Evaluation} \\ - Determine level of treatment necessary to re- \\ pair severely damaged clay tiles.

\section{Execution} \\ - $\quad$ Consult manufacturer's recommendations be- \\ fore attempting to repair a damaged roof sys- \\ tem. \\ - $\quad$ Be careful not to damage adjacent surfaces \\ and materials when repairing the roof, including \\ chimneys, dormers, and flashings. \\ - $\quad$ Repair source of the damage before repairing \\ proceeds. \\ - $\quad$ Replace in-kind to the historic materials.
}

\section{Further Readings}

GSA has developed technical procedures to be used in specialized historic preservation work, as well as general evaluation, maintenance and repair of older building materials. For more detailed descriptions of repair procedures for clay tile roofing refer to the following, which can be found at http://w3.gsa.gov/web/p/hptp.nsf

- $\quad$ Preservation Briefs: \#30 The Preservation and Repair of Historic Clay Tile Roof

- $\quad$ Removing and Replacing a Clay Tile Roof

- $\quad$ Replacing Loose, Broken or Missing Clay Roof Tiles

- Cleaning Blackened Clay Roofing Tiles 
- $\quad$ Another area of potential failure of historic clay tile roof is the support system. Clay tiles are heavy and it is important that the roof structure is sound. If gutters and downspouts are allowed to fill with debris, water can back up and seep under roofing tiles, causing the eventual deterioration of roofing battens, the sheathing and fastening system, or even the roof's structural members.

- $\quad$ Efflorescence of soluble salts on the surface may indicate that a tile has excessive porosity which results from underburning during manufacturing. Poor quality porous tiles are particularly susceptible to breaking and exterior surface spalling during freeze-thaw cycles. By letting in moisture, porous tiles can permit the roof battens and roof structure to rot. The problem may be compounded by waterproof building paper or building felt laid underneath which can, in some instances, prevent adequate ventilation.

- $\quad$ Clay roofing tiles can also be damaged by roofers walking carelessly on an unprotected roof while making repairs, or by overhanging tree branches, falling tree limbs, or heavy hail. Broken tiles may no longer provide a continuous waterproof surface, thereby allowing water to penetrate the roofing structure, and may eventually result in its deterioration if the broken tiles are not replaced in a timely manner.

\section{Inspection}

Recommended...

- $\quad$ Periodically inspecting roofs for signs of damage, including broken or missing tiles.

- Inspecting the condition of the flashing.

- Inspecting gutters and valleys for debris and make sure they are functionally correctly.

- $\quad$ Checking the proximity of vegetation to the roofing system. Make sure that it is not resting on or causing damage to the clay tiles.

- $\quad$ Protecting and maintaining a roof by cleaning the gutters and downspouts and replacing deteriorated flashing. Roof sheathing should also be checked for proper venting to prevent moisture condensation and water penetration; and to ensure that materials are free from insect infestation.

Not Recommended...

- $\quad$ Failing to clean and maintain gutters and downspouts properly so that water and debris collect and cause damage to roof fasteners, sheathing, and the underlying structure.

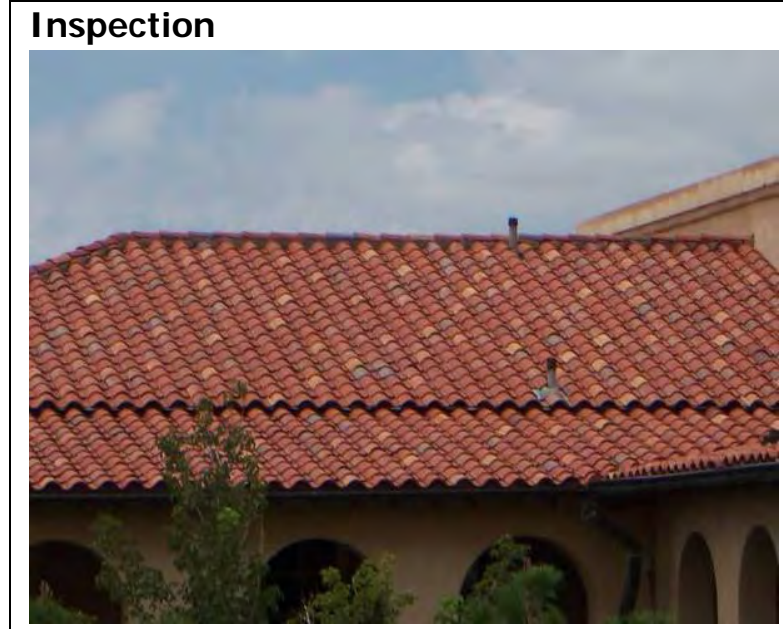

Building 503 - A periodic inspection of a roof finds any damages including broken or missing tiles.

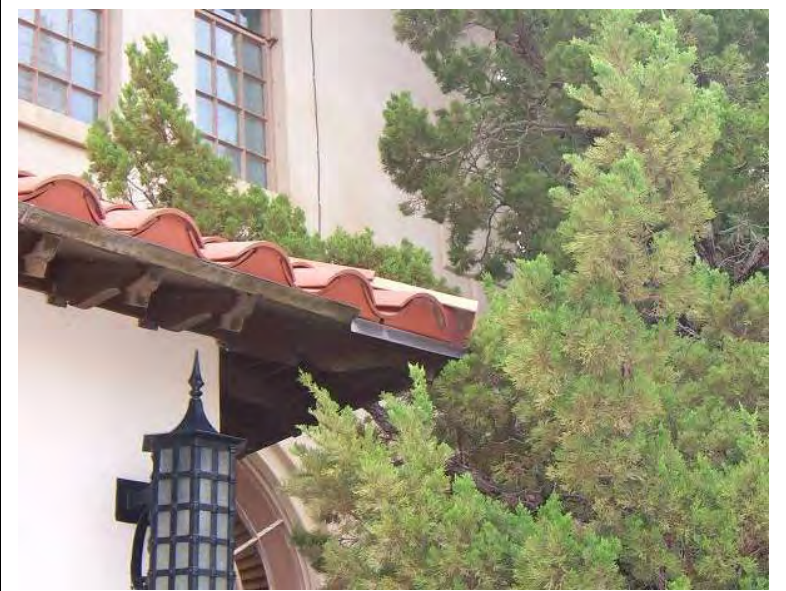

Building 243 - Check the proximity of vegetation to the roofing system. Make sure it is not resting on or causing damage to the clay tiles. 


\section{Evaluation}

Recommended...

- Determining level of treatment necessary to repair severely damaged clay tiles.

- Considering potential sources for replacement material early in a project to allow for delivery time.

- Using salvaged material for replacement whenever possible.

Not Recommended...

- $\quad$ Allowing roof fasteners, such as nails and clips, to corrode so that roofing material is subject to accelerated deterioration.

- $\quad$ Permitting a leaking roof to remain unprotected so that accelerated deterioration of historic building materials occurs.

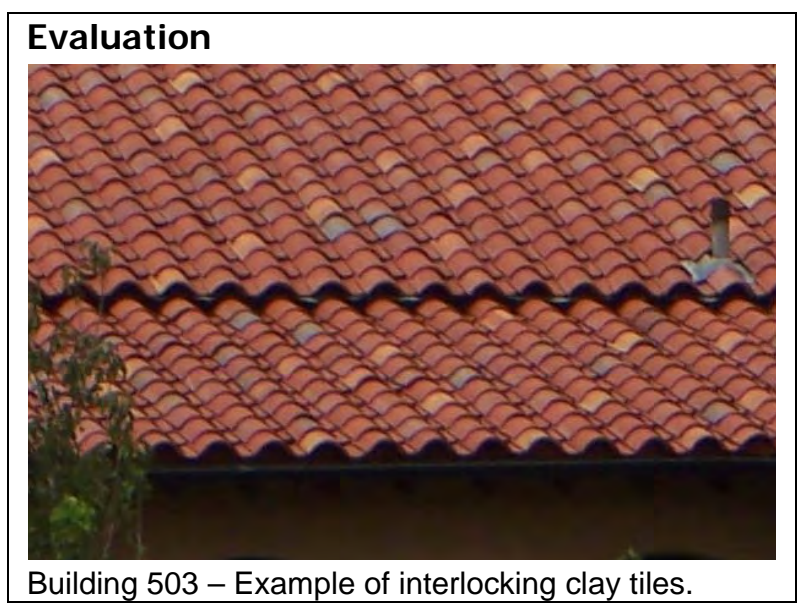

\section{Execution}

- Consult manufacture’s recommendations before attempting to repair a damaged roof system.

- $\quad$ Be careful not to damage adjacent surfaces and materials when repairing the roof, including chimneys, dormers, and flashings.

- $\quad$ Repair the source of the damage before repair proceeds.

- $\quad$ Replace in-kind to the historic materials.

\section{Repair}

Recommended...

- $\quad$ Repairing a roof by reinforcing the historic materials of which roof features are made. Repairs will also generally include the limited replacement in-kind —or with compatible substitute material—of those extensively deteriorated or missing parts of features when there are surviving prototypes.

Not Recommended...

- $\quad$ Replacing an entire roof feature such as a cupola or dormer when repair of the historic materials and limited replacement of deteriorated or missing parts are appropriate. 
- $\quad$ Using a substitute material for the replacement part that does not convey the visual appearance of the surviving parts of the roof or that is physically or chemically incompatible.

\section{Replace}

Recommended...

- Replacing in-kind an entire feature of the roof that is too deteriorated to repair-if the overall form and detailing are still evidence-using the physical evidence to guide the new work. Examples can include a large section of roofing, or a dormer or chimney. If using the same kind of material is not technically or economically feasible, then a compatible substitute material may be considered.

Not Recommended...

- $\quad$ Removing a feature of the roof that is unrepairable, such as a chimney or dormer, and not replacing it; or replacing it with a new feature that does not convey the same visual appearance.

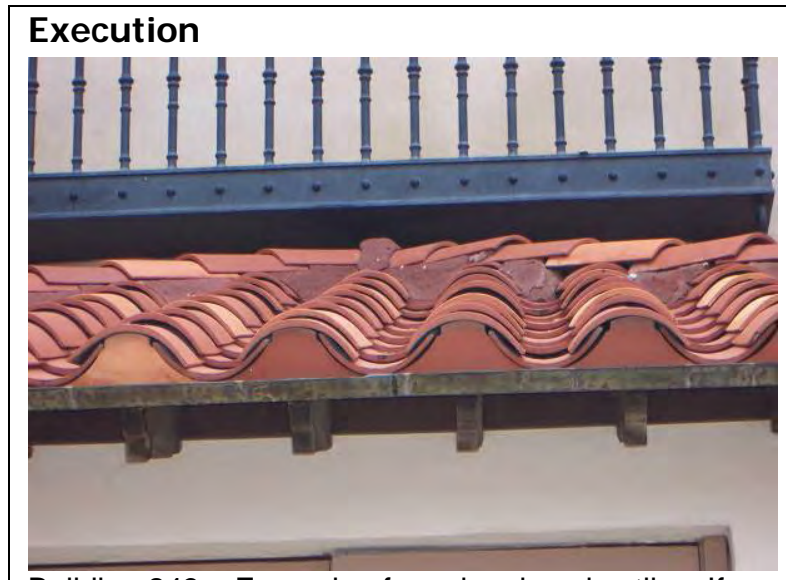

Building 243 - Example of overlapping clay tiles. If a clay tile roof needs to be repaired, generally limited replacement in-kind is required. Salvaged material should be used for replacement whenever possible. 
Notes

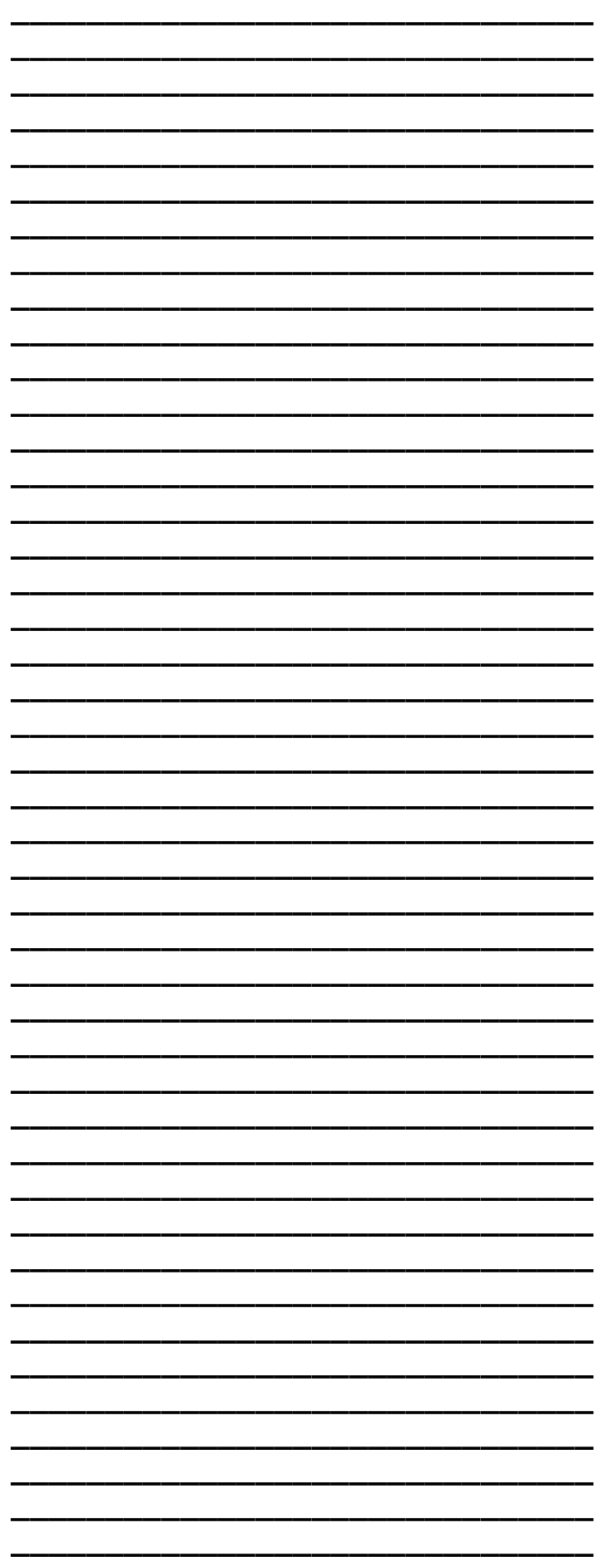




\section{Roofing: Gutters and Downspouts}

The purpose of gutter and leader (downspout) systems is to collect rainwater from the roof and direct it away from the building foundation by means of downspout systems, splash blocks, or underground drain lines. An improperly functioning gutter and downspout system can contribute to water and ice backing up against fascias and under roof shingles, can damage soffits, and can discolor and deteriorate siding material. Faulty gutters and downspouts can also lead to soil erosion adjacent to buildings and serious water and foundation displacement problems in basements and crawl spaces.

Gutter systems take more abuse from extreme weather conditions than any other component of the building envelope. They are also subject to damage from ladders and being stepped on, as well as from falling tree limbs and debris.

Wider gutters may be required for certain hard surface roofing material, such as slate and tile, to prevent water from shooting over the gutter. Gutters should be positioned tight against the roofing material and the fascia. Downspouts are typically rectangular and are made of the same material as the gutter to prevent destructive galvanic actions. Connection between gutters and downspouts and downspouts and storm drains requires continuing maintenance to assure the drain is free of leaves and debris and the connection has not become loose. Other maintenance points include the connection between the downspout and the building.

Other than keeping gutters clean of leaves and debris, gutter maintenance usually involves refastening hangers that have come unfastened, repairing broken hangers, or adding new hangers where hanger spacing was excessive.

At some point, usually when new roofing is required, the gutters may have weathered to the point where they are not functioning, are unsightly, or have significantly deteriorated. The choice of replacement will be decided upon based on the appearance, value, physical characteristics, and age of the existing building. Other maintenance and repair items include keeping gutter and downspout screens in place, refastening downspouts, and maintaining splash blocks or connections to underground drains.

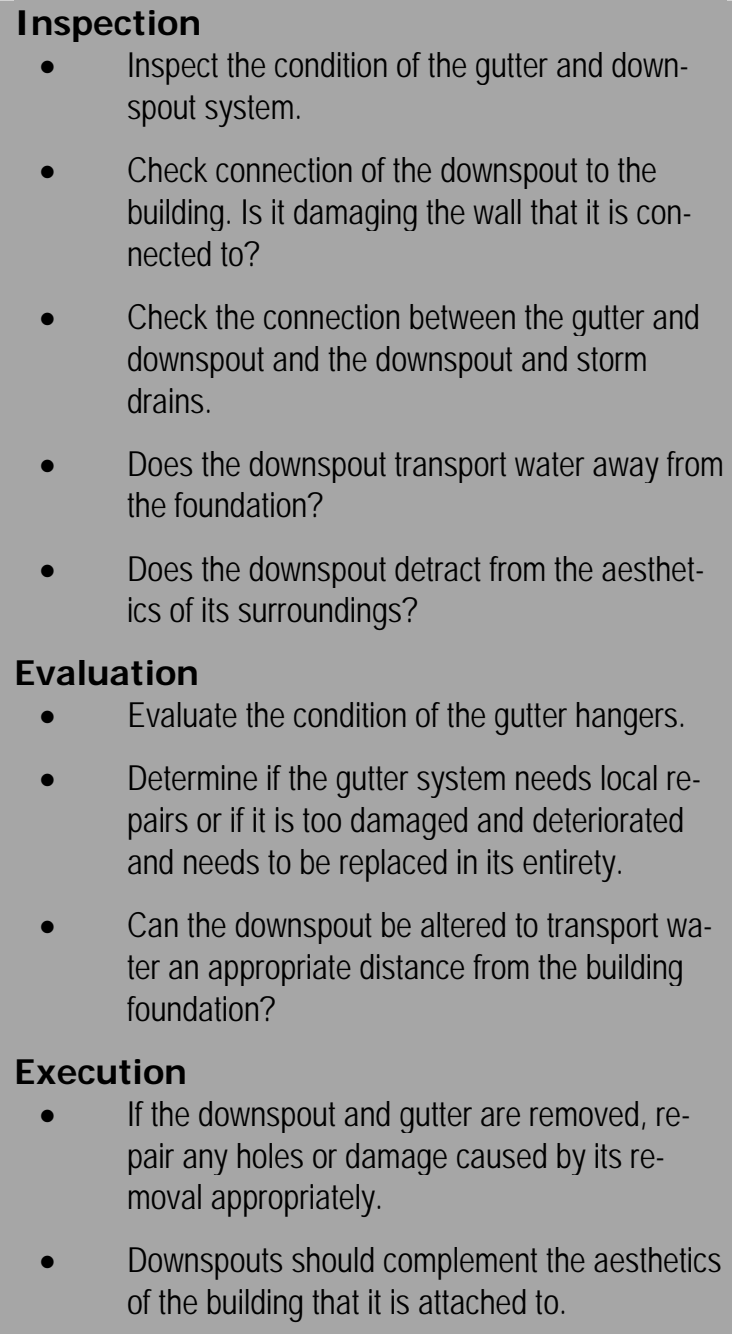

- Inspect the condition of the gutter and downspout system.

- Check connection of the downspout to the building. Is it damaging the wall that it is connected to?

- Check the connection between the gutter and downspout and the downspout and storm drains.

- Does the downspout transport water away from the foundation?

- Does the downspout detract from the aesthetics of its surroundings?

\section{Evaluation}

- $\quad$ Evaluate the condition of the gutter hangers.

- Determine if the gutter system needs local repairs or if it is too damaged and deteriorated and needs to be replaced in its entirety.

- $\quad$ Can the downspout be altered to transport water an appropriate distance from the building foundation?

\section{Execution}

- If the downspout and gutter are removed, repair any holes or damage caused by its removal appropriately.

- Downspouts should complement the aesthetics of the building that it is attached to.

\section{Further Readings}

GSA has developed technical procedures to be used in specialized historic preservation work, as well as general evaluation, maintenance and repair of older building materials. For more detailed descriptions of repair procedures for gutter and downspout maintenance refer to the following, which can be found at http://w3.gsa.gov/web/p/hptp.nsf

- Guidelines for Rehabilitating Historic Buildings: Roofs

- $\quad$ General Inspection and Maintenance of Gutters and Downspouts 


\section{Routine Maintenance}

- Examine gutters as part of the annual roof inspection and repair defects immediately.

- $\quad$ Carry out a professional survey every five years.

- In the fall, check gutters and clean as necessary from the time the leaves begin to fall until they have all fallen.

- Monthly inspections are recommended in the winter months to make sure that nothing impedes the flow of water, which could result in an ice dam.

\section{Inspection}

Recommended...

- $\quad$ Downspouts, flashing, conductor heads, leaders, roof drains, and scuppers are all part of the drainage system, and should be included in the work list when maintenance or repairs are being inspected, evaluated, and scheduled for gutters.

- $\quad$ Checking connection between the gutter and the building.

- $\quad$ Checking for interior deterioration that might point to gutter and/or roof problems.

- Inspecting for build-up of debris and vegetation such as moss or lichen. Biological material excretes corrosive acids. This is apt to occur with improper gutter sloping.

- Inspecting for gutters that are split or cracked with loose, broken, or out of place hangers, corners or slopes, or pulling of fasteners, broken joints or seams; excessive staining or punctures of gutter fabric.

- $\quad$ Checking for deterioration of adjacent roof and soffit areas, and behind downspouts. Look for peeling paint or stains, or eroded mortar joints on adjacent surfaces.

- $\quad$ Several buildings have a drainage system that takes roof water through the downspouts into the building and to a sump pump/well that removes it from the building. Recommend inspecting buildings with these occurrences.

Not Recommended...

- $\quad$ Failing to conduct routine maintenance of gutter and downspout systems.

- $\quad$ Resting ladders on gutters. 


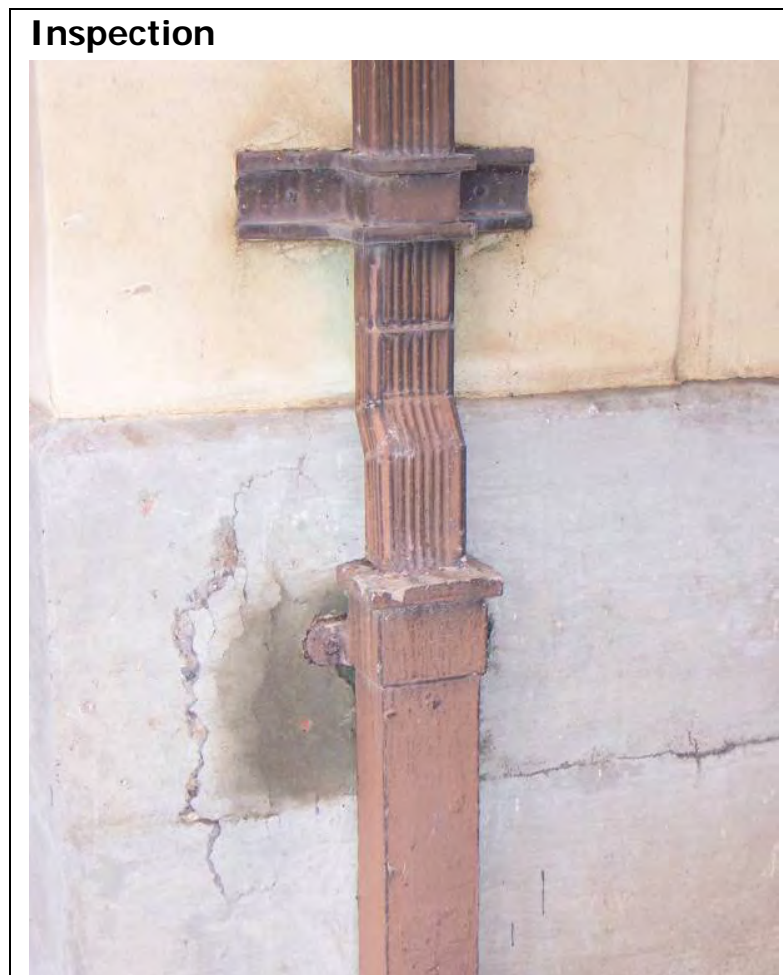

Building 243 - Check the connection of the downspout to the building. Is it damaging the wall to which it is connected? In this example, evidence of water damage and cracks can be seen near the connection.

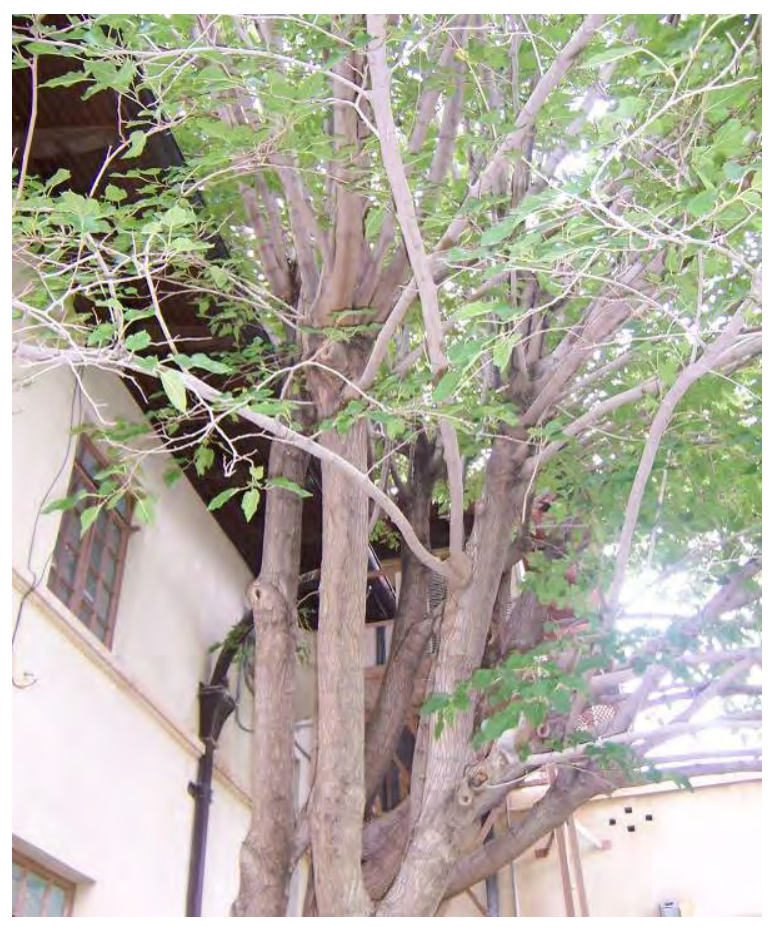

Building 243 - Vegetation is too close to the building; branches are laying on top of the gutter, which can contribute to water damage of the fascia, soffits, and roofing material.

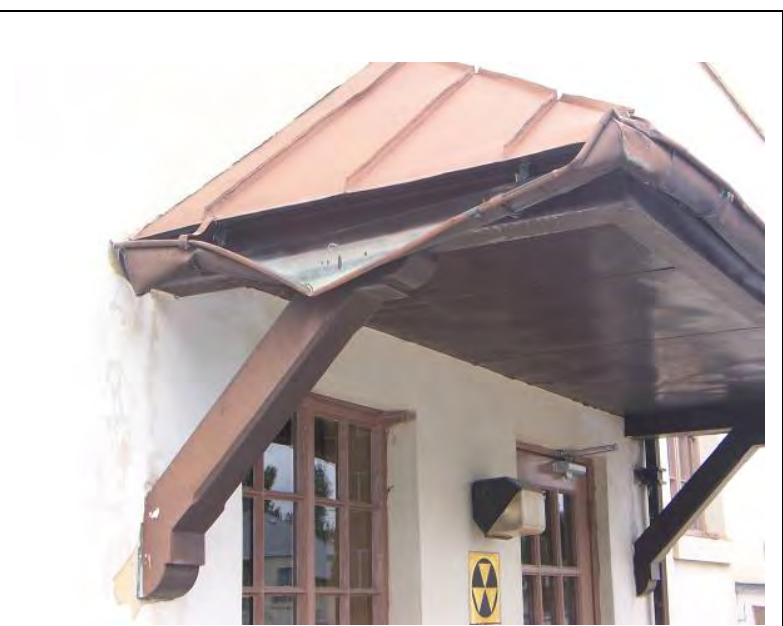

Building 243 - Failing to conduct routine maintenance of gutter and downspout systems is NOT recommended. Do not rest ladders on gutters.

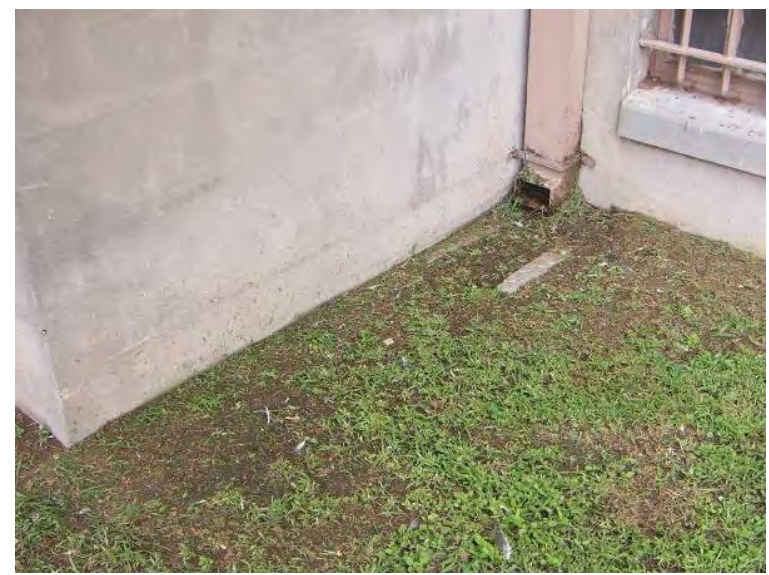

Building 504 - Inspection should find such examples of improper drainage from a downspout. 


\section{Evaluation}

Recommended...

- $\quad$ Looking for corrosion around nails. Roof cement on gutters may hide leaks that have not been corrected.

- Determining if the gutter system needs local repairs or if it is too damaged and deteriorated and needs to be replaced in its entirety.

- $\quad$ Keeping gutters and downspouts clean so they will not collect debris and cause further deterioration.

- $\quad$ Evaluating the condition of the gutter hangers and anchoring systems.

- $\quad$ Providing proper drainage away from the building's foundation.

Not Recommended...

- $\quad$ Failing to clean and maintain gutters and downspouts properly so that water and debris collect and cause damage to roof fasteners, sheathing, and the underlying structure.

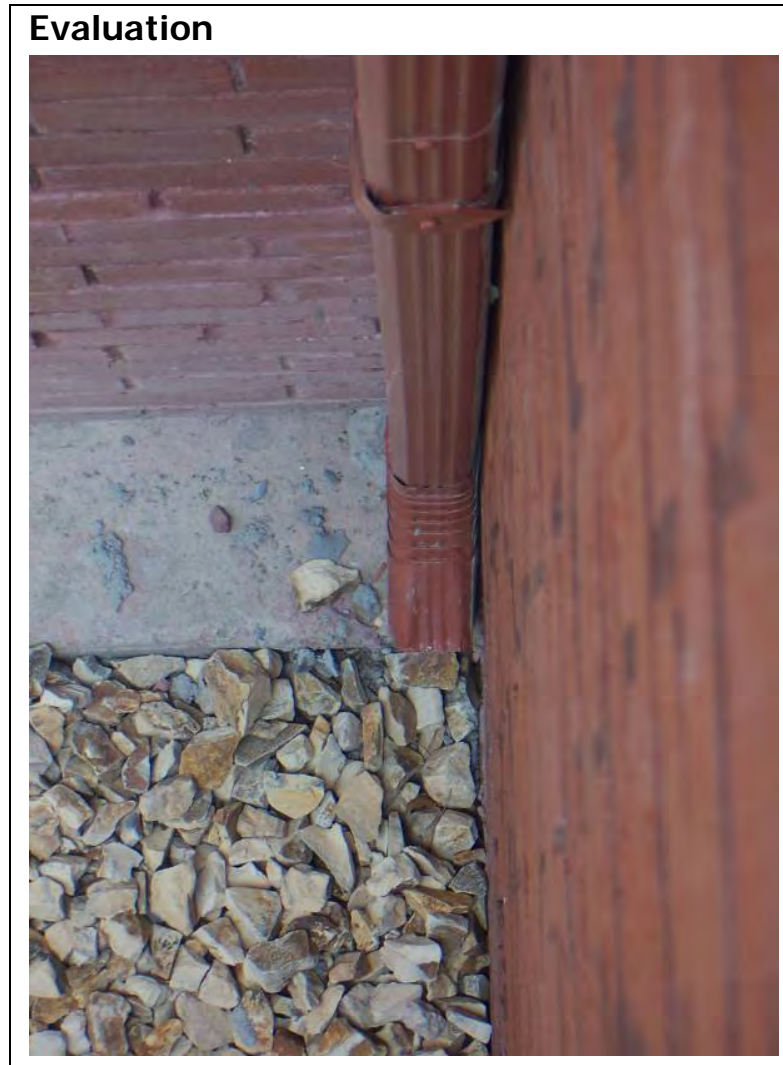

Building 4 - Stones are a good example of erosion control; however, the water from a downspout should flow into a downspout extender that transports water at least 3 feet from the foundation.

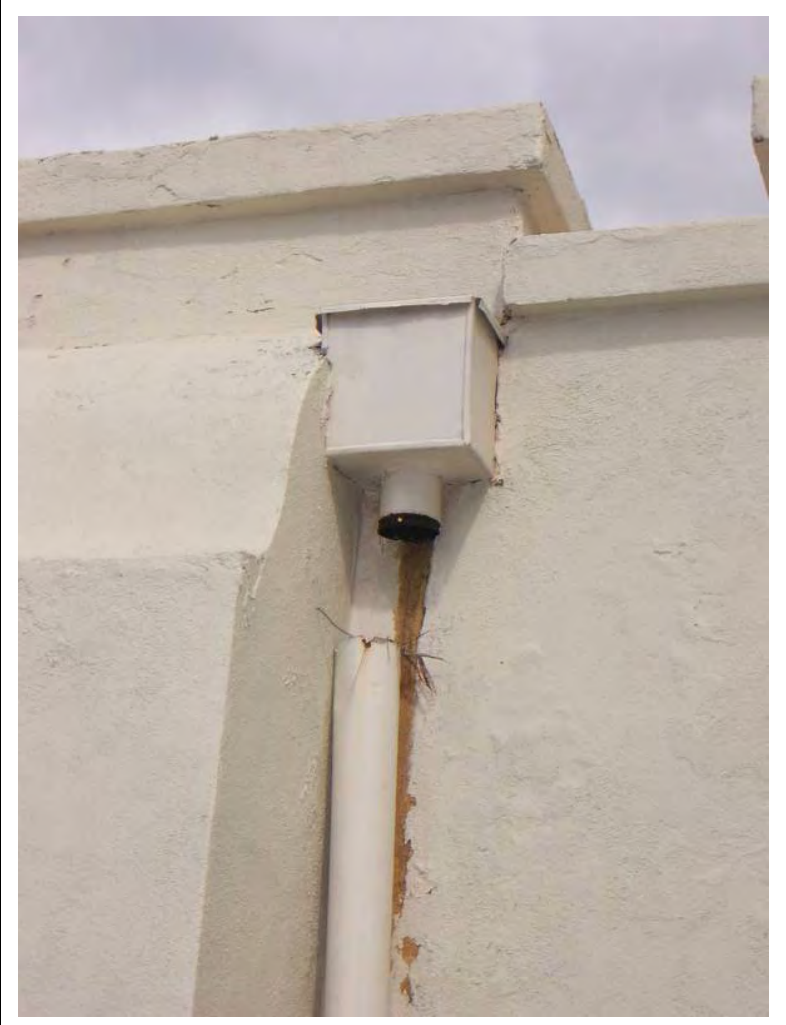

Building 315 - Downspouts, flashing, leaders, roof drains, and scuppers are all part of the drainage system, and should be included in the work list when maintenance or repairs are being inspected and evaluated. 


\section{Execution}

- $\quad$ Check for adequate slope and drainage towards downspouts during cleaning.

- $\quad$ Any gutter liners made of tin, galvanized iron, or terne metal should be kept clean.

- $\quad$ Clean gutters of debris at least twice a year.

- If debris is blocking a downspout, remove a lower section and flush. Do not allow clog to be forced into sewer or drainfield systems. Realign the gutters and downspouts.

\section{Repair}

Recommended...

- If the downspout and gutter are removed, repair any holes or damage caused by its removal appropriately.

Not Recommended...

- $\quad$ Using bleach on bird droppings.

\section{Replace}

Recommended...

- When gutters show widespread deterioration and become unsightly, they should be replaced in their entirety.

- Replacement gutter and downspout systems should be sympathetic to the building's design and construction.

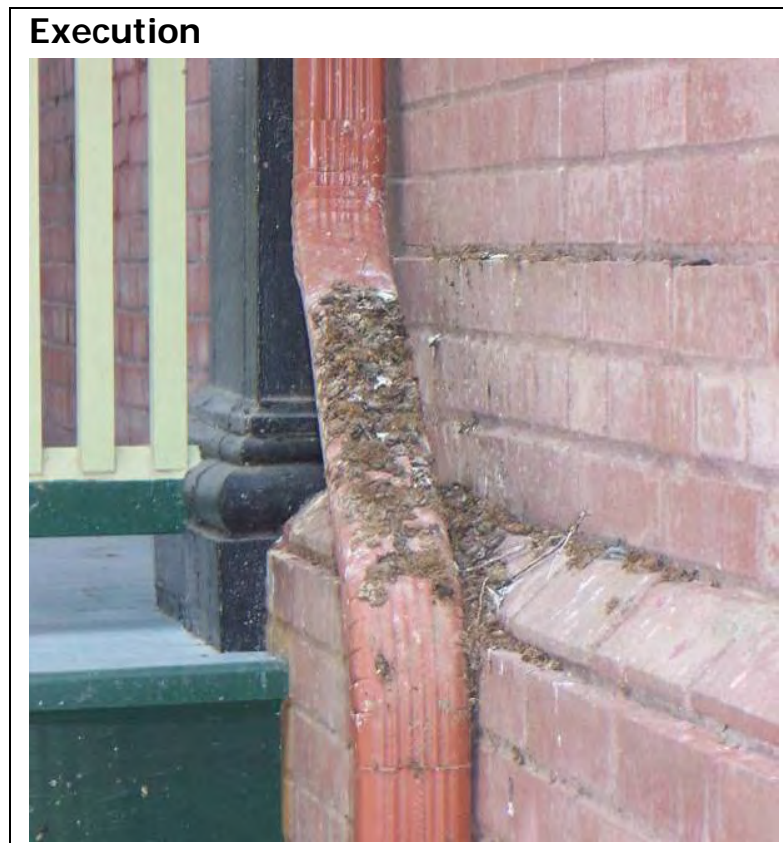

Building 4 - Although the gutter is not historic, proper removal of pigeon guano should be maintained since the gutter is part of a historic building. Do not use bleach on bird guano.

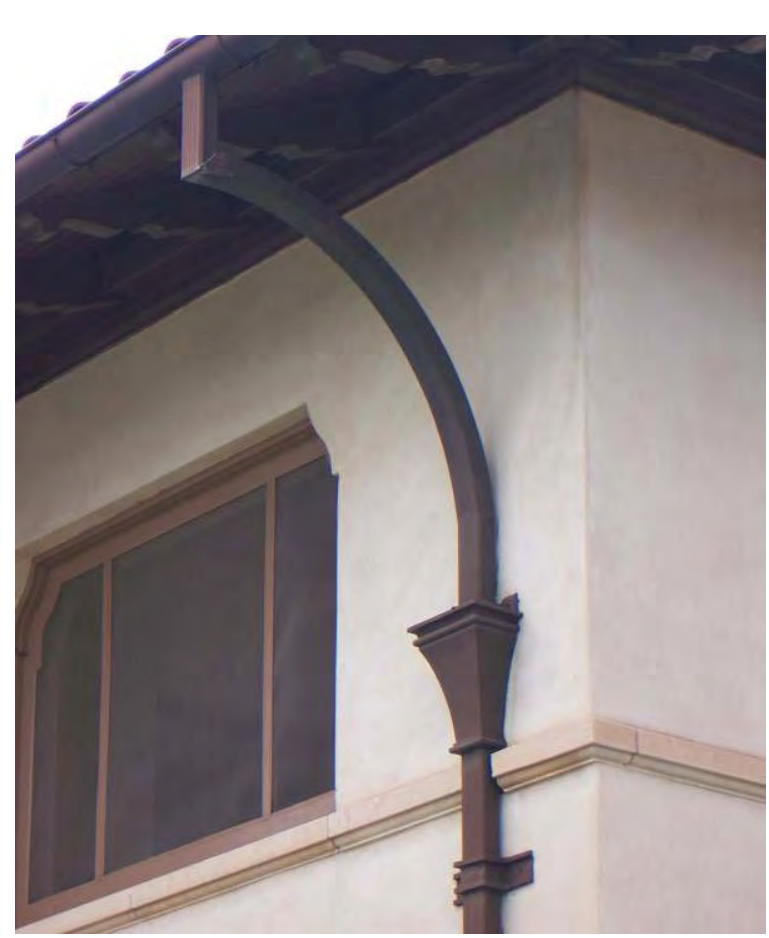

Building 243 - decorative downspout. Downspouts should complement the aesthetics of the building. 


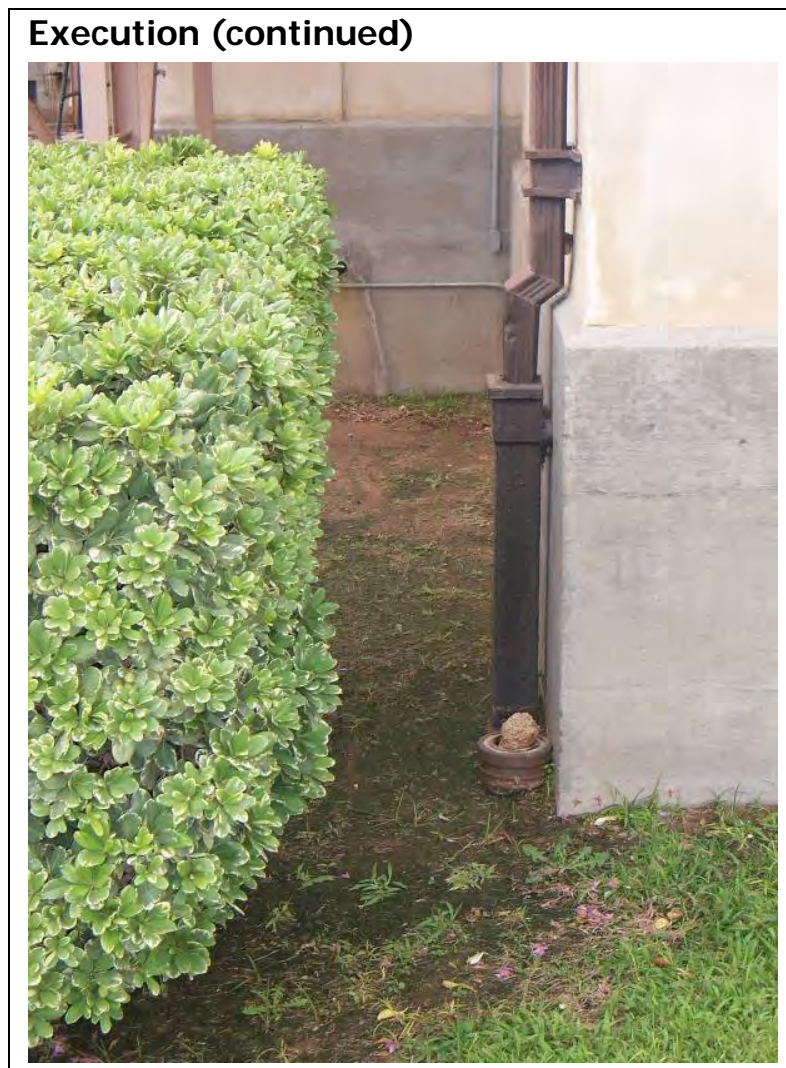

Building 243 - Example of proper distance for vegetation to be from the building and drainage systems.

Also the old downspout extender is no longer used. Make sure the new drain system is compatible to the old one in order to carry water away from the building. 
Notes

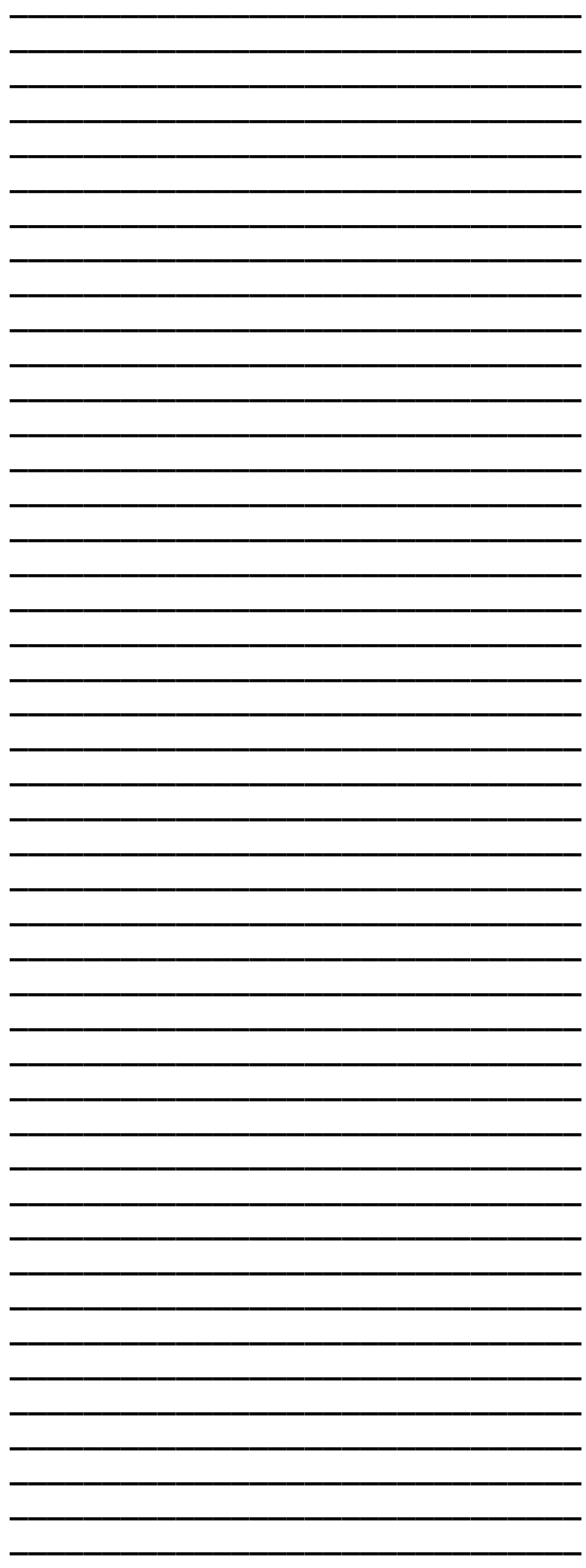




\section{Maintenance Guides for Doors}

\section{Doors: Overview}

Original doors are important features on historic buildings. Their spacing contributes to the visual rhythm of the facade, while providing insight into interior spaces and the uses of the building. Their design, craftsmanship, and materials contribute to a property's historic value. Because there are so many design choices such as number, location, size, and arrangement of panels on the doors, these architectural elements are key indicators of the historical style and date of construction.

Historic materials for doors include wood and metal (most often steel). Wood is easily worked for design effects, including the addition of decorative trim for door surrounds. Most of the historic doors were made from old growth wood and have a natural resistance to weather and insect decay. Metal doors were originally made to imitate wood doors.

Exterior doors should be examined for their condition, overall operation and fit, and for the functionality of their hardware. Door types include hinged, single, and double doors of wood, steel, and aluminum, with and without glazing. Check wood and plastic doors that are not protected from the weather. These doors should be rated for exterior use.

Doors should also be inspected for the exterior condition of their frames and sills. Check doors that are not protected from the weather for the presence of essential flashing at the head.

The glazing compound or putty around glass panels in older doors should be examined especially carefully since this is often the most vulnerable part of the door and its repair is time consuming. Examine glazing tapes or strips around glass panels in steel and aluminum doors for signs of deterioration such as hardened sealant or poor fit.

Door weather stripping is generally of three types; metal, foam plastic, or plastic stripping. Check each type for fit. Check metal for dents, bends, or straightness. Check foam plastic for resiliency. Check plastic stripping for brittleness and cracks. Make sure that weather stripping is held in place.

Storm doors should be checked for operation, weather-tightness, overall condition, and fit.

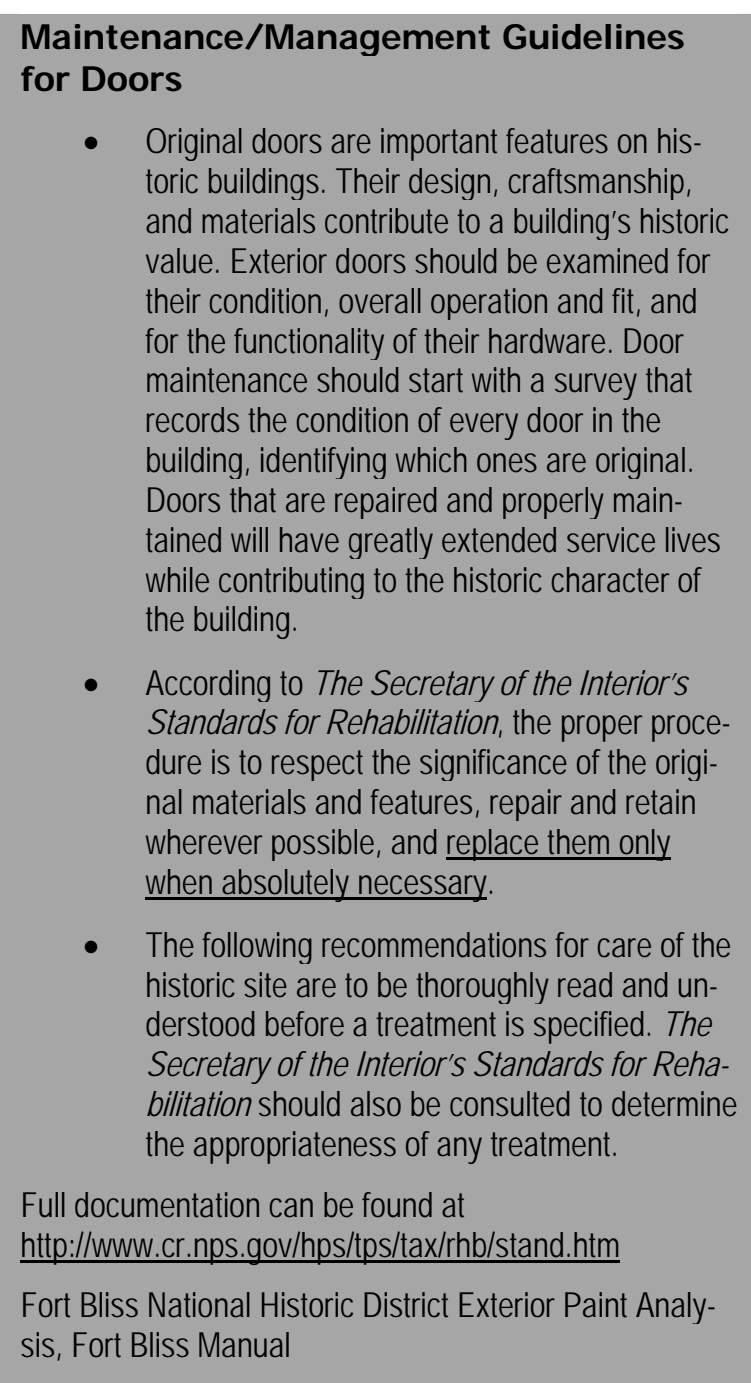

Full documentation can be found at

Fort Bliss National Historic District Exterior Paint Analy(1) 


\section{Maintenance}

Door maintenance should start with a survey that records the condition of every door in the building, identifying which ones are original. Door schedules should be prepared, listing all parts of each door unit. Perform simple maintenance first, repair as needed, replace damaged or missing parts in-kind, and replace the entire unit in-kind only if it cannot be repaired. Maintaining protective paint coatings is important to prevent decay of wood and rolled steel doors. The exterior of the doors should be checked periodically. Appropriate surface treatments such as cleaning, rust removal, limited paint removal, and reapplication of protective coating systems are necessary.

The replacement of doors is often proposed because of condition or poor functioning. However, peeling paint, broken glass, damaged hardware, and high air infiltration are no indication that doors are beyond their useful lives. These concerns can be addressed through repair and repainting and, replacement is not recommended. Doors that are repaired and properly maintained will have greatly extended service lives while contributing to the historic character of the building. When energy conservation is a concern, weatherization and/or the addition of storm doors will reduce heating and cooling costs, while helping to preserve the original materials and the paint finish.

\section{Identify, Retain, and Preserve}

Recommended...

- Identifying, retaining, and preserving doors—and their functional and decorative features - that are important in defining the overall historic character of the building. Such features can include frames, glazing, heads, and paneled or decorated jambs and moldings.

- $\quad$ Conducting an in-depth survey of the conditions of existing doors early in rehabilitation planning so that repair and upgrading methods and possible replacement options can be fully explored.

Not Recommended...

- $\quad$ Removing or radically changing doors that are important in defining the historic character of the building so that, as a result, the character is diminished.

- Changing the number, location, or size, through cutting new openings, blocking-in doors, and installing replacement doors that do not fit the historic opening.

- $\quad$ Obscuring historic door trim with metal or other material.

- $\quad$ Stripping doors of historic material such as wood, cast iron, and bronze.

- $\quad$ Replacing doors solely because of peeling paint, broken glass, and high air filtration. These conditions, in themselves, are no indication that doors are beyond repair.

\section{Protect and Maintain}

Recommended...

- $\quad$ Protecting and maintaining the wood and architectural metal which the door, door frame, and surrounds are composed of through appropriate surface treatments such as cleaning, rust removal, limited paint removal, and reapplication of protective coatings.

- $\quad$ Evaluating the overall condition of materials to determine whether more than protection and maintenance are required, i.e., if repairs to doors and door features will be required.

Not Recommended...

- $\quad$ Failing to provide adequate protection of material on a cyclical basis so that deterioration of the door material is accelerated.

- $\quad$ Retrofitting or replacing doors rather than maintaining the door, frame, and glazing.

- $\quad$ Failing to undertake adequate measures to assure protection of historic doors. 


\section{Repair}

Recommended...

- $\quad$ Repairing door frames by patching, splicing, consolidating or otherwise reinforcing. Such repair may also include replacement in-kind —or with compatible substitute material—of those parts that are either extensively deteriorated or are missing when there are surviving prototypes.

Not Recommended...

- $\quad$ Replacing an entire door when repair of materials and limited replacement of deteriorated or missing parts are appropriate.

- $\quad$ Failing to reuse serviceable door hardware such as brass hinges, handles, and locks.

- Using substitute material for the replacement part that does not convey the visual appearance of the surviving parts of the door or that is physically or chemically incompatible.

\section{Replace}

Recommended...

- $\quad$ Replacing in-kind an entire door that is too deteriorated to repair using the same design details such as number of divided lights, panels, and hardware. If using the same kind of material is not technically or economically feasible when replacing doors deteriorated beyond repair; then a compatible substitute material may be considered.

Not Recommended...

- $\quad$ Removing a character-defining door that is unrepairable and blocking it in, or replacing it with a new door that does not convey the same visual appearance. 


\section{Good Examples of Exterior Doors}

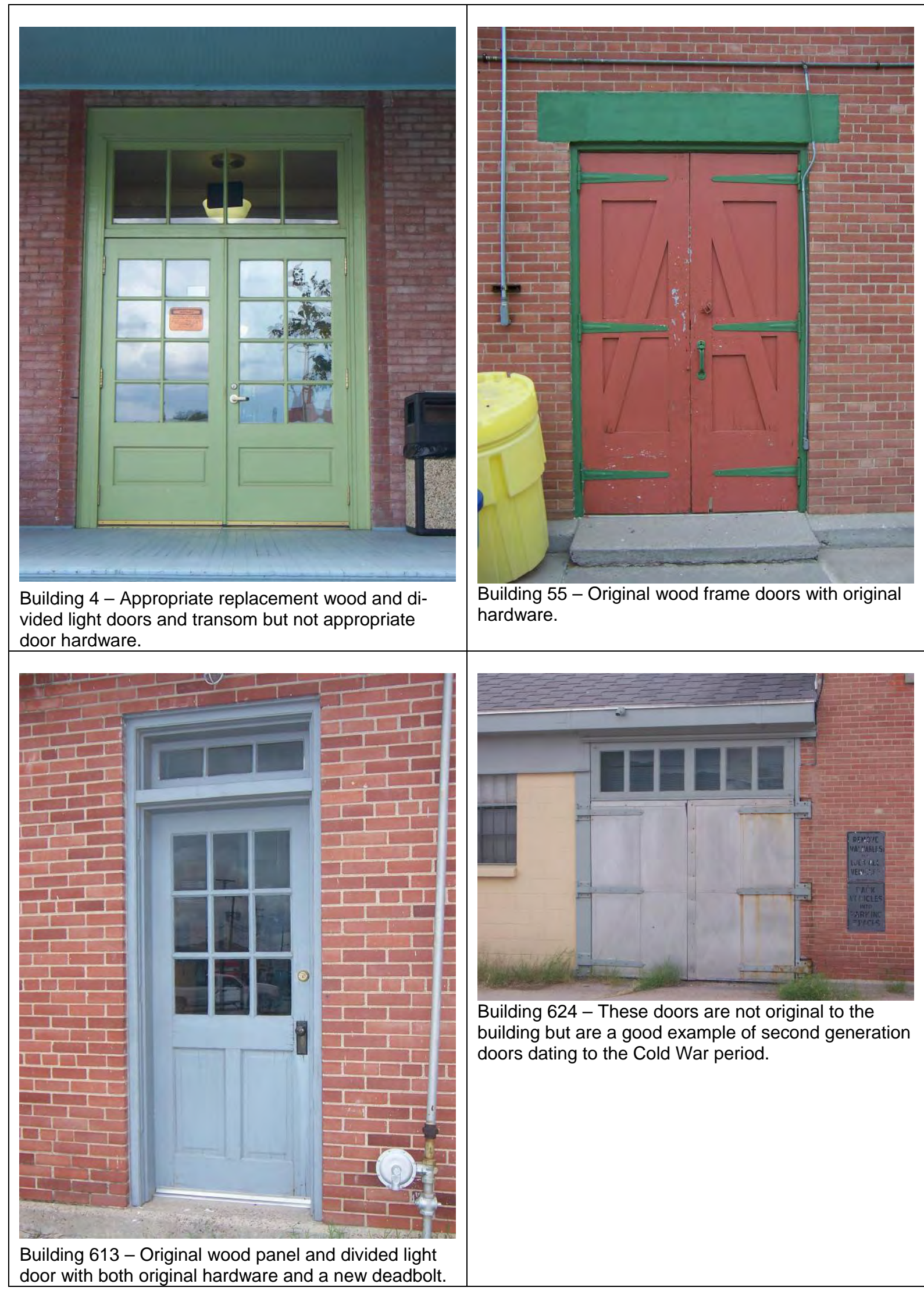




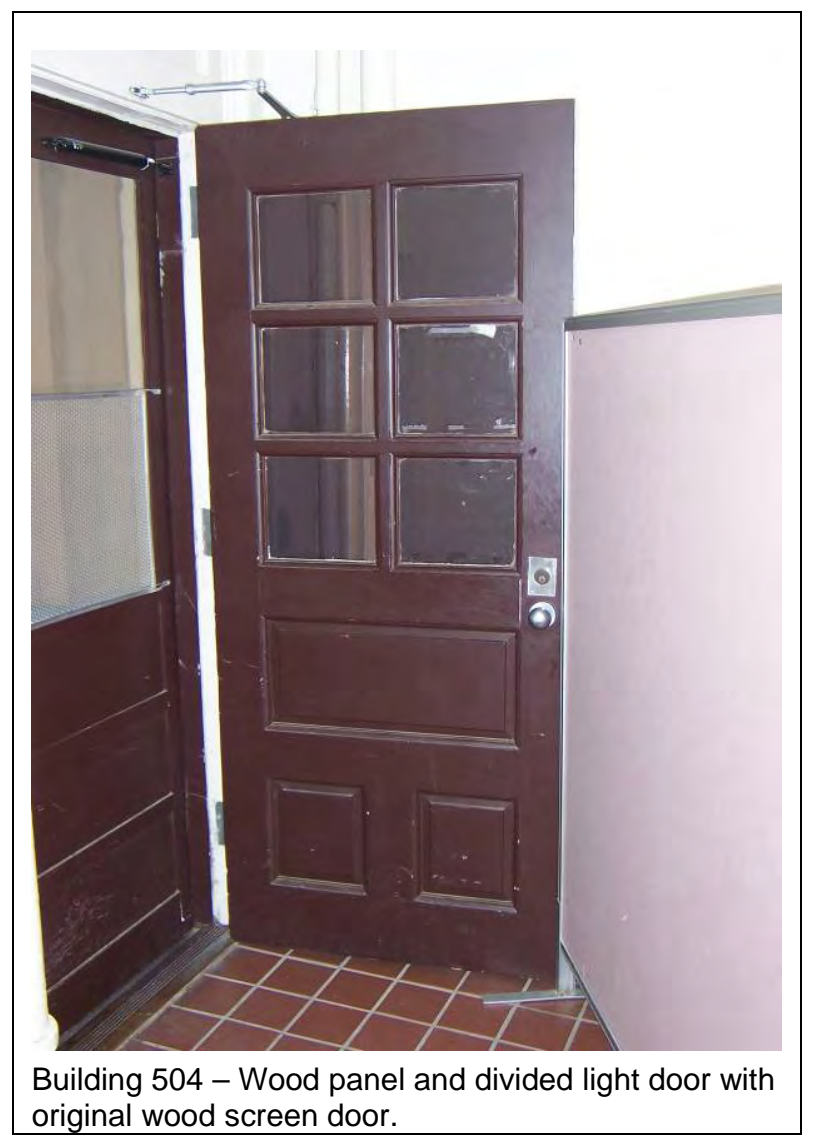




\section{Doors: Wood}

Original doors shall be retained unless they are damaged beyond reasonable repair. The frame and trim shall be retained, or replicated, when damaged beyond repair. If a door must be replaced due to rot, dry rot, insect or other damage, the new door shall replicate the original door (if known) in size, proportion, material, shape, glazing pattern, and number of panels, including the use of true-divided lights. If the design of the original door is unknown, staff will work with the applicant to help determine a compatible replacement door.

When a prominent historic door is too deteriorated, or the existing door is not historic, it may make sense to re-use a similar exterior door from a less prominent location such as side or rear entrance.

Problems with wood doors include:

- termite infestation,

- $\quad$ water infiltration,

- $\quad$ misalignment and difficulty in opening or closing due to uneven settlement of the wood frame and building,

- $\quad$ peeling paint and deteriorated weather stripping, and/or

- $\quad$ sticky or rotten jambs.

In most cases, except for where misalignment is due to uneven settlement of the building, damage can be easily repaired.

Generally the actions necessary to repair a door to "like new" condition will fall into three broad categories:

- $\quad$ Routine maintenance: paint removal, cleaning, repair of weather stripping, and repainting.

- $\quad$ Structural stabilization: dry the wood, treat decayed areas with fungicide, waterproof with two or three applications of boiled linseed oil, fill cracks and holes with putty or wood filler, and paint the surface.

- $\quad$ Replacement or refurbishment of parts including hardware.

\section{Inspection}

- $\quad$ Are the doors historic? Are they solid wood panel doors?

- If the door being replaced is not historic, note features of any other doors that are historic.

- Note materials and their condition at door jambs, sill, and head.

- $\quad$ Does the door match other doors used for similar purposes on the building?

\section{Evaluation}

- If the door is historic can it be repaired?

- If the door is not aesthetically appropriate, will replacing the hardware be sufficient or will the entire door need to be replaced?

\section{Execution}

- Doors that are inappropriate aesthetically should be replaced with doors that match the original door in design and material as closely as possible.

- $\quad$ Use appropriate door hardware.

- Reuse historic doors and door frames.

\section{Further Readings}

GSA has developed technical procedures to be used in specialized historic preservation work, as well as general evaluation, maintenance and repair of older building materials. For more detailed descriptions of repair procedures for wooden door maintenance refer to the following, which can be found at http://w3.gsa.gov/web/p/hptp.nsf

- $\quad$ Replacement of Damaged Wood Doors

- Repair of Bows or Undulations in a Wood Door Frame

- $\quad$ Repair of Binding Door

- $\quad$ Preservation Briefs: \#3 Conserving Energy in Historic Buildings

- $\quad$ Preservation Briefs: \#10 Exterior Paint Problems on Historic Woodwork

- $\quad$ Preservation Briefs:\#16 The Use of Substitute Materials on Historic Building Exteriors

- General Guidelines for Painting Exterior and Interior Surfaces 


\section{Inspection}

Recommended...

- Identifying, retaining, and preserving doors - and their functional and decorative features - those are important in defining the overall historic character of the building.

- $\quad$ Conducting an in-depth survey of the condition of existing doors early in rehabilitation planning so that repair and upgrading methods and possible replacement options can be fully explored.

- $\quad$ Protecting and maintaining the wood and architectural metal which comprises the door, door frame, and surrounds through appropriate surface treatments such as cleaning, rust removal, limited paint removal, and reapplication of protective coatings.

Not Recommended...

- $\quad$ Failing to provide adequate protection of material on a cyclical basis so that deterioration of the door material is accelerated.

- $\quad$ Failing to undertake adequate measures to assure protection of historic doors.

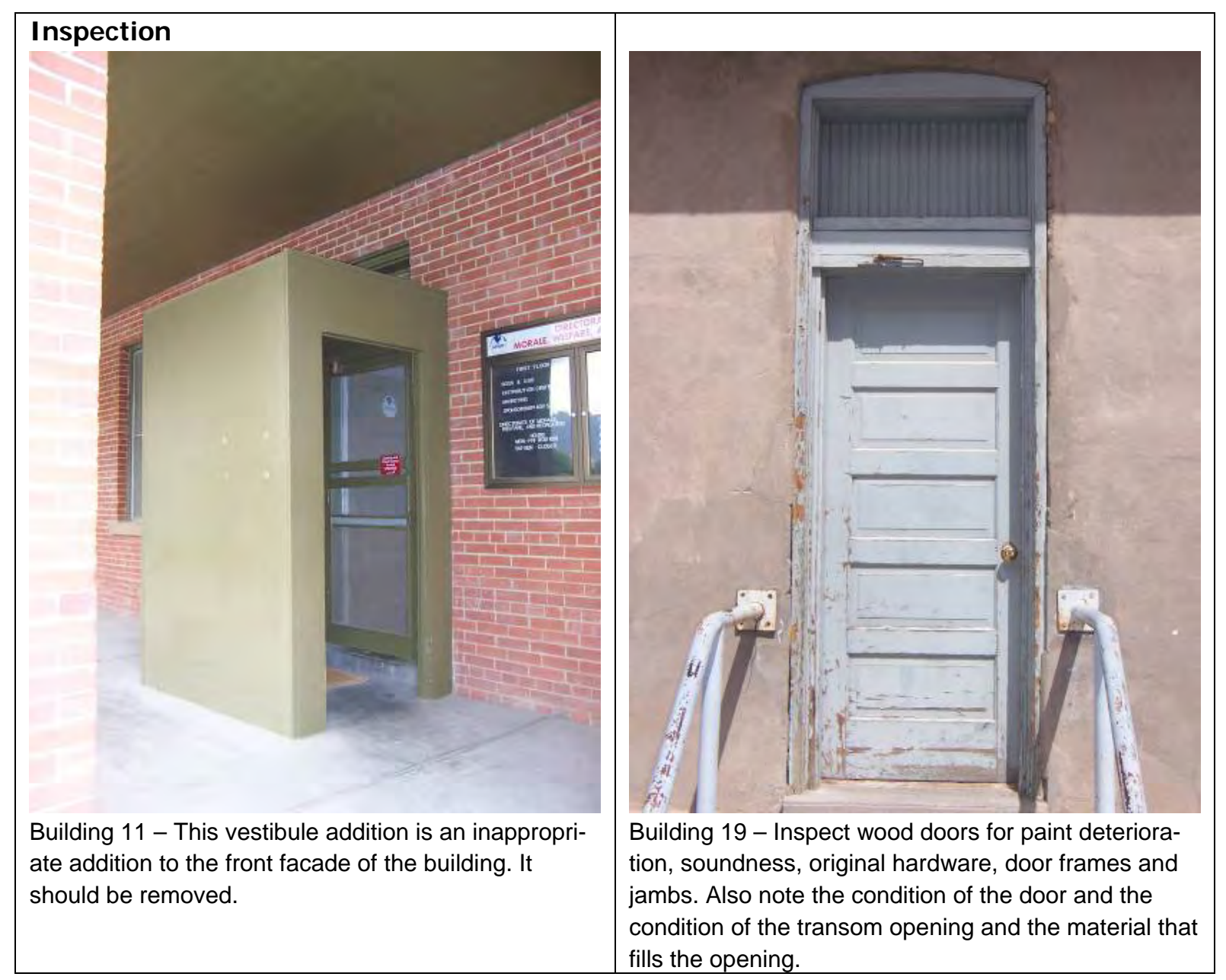



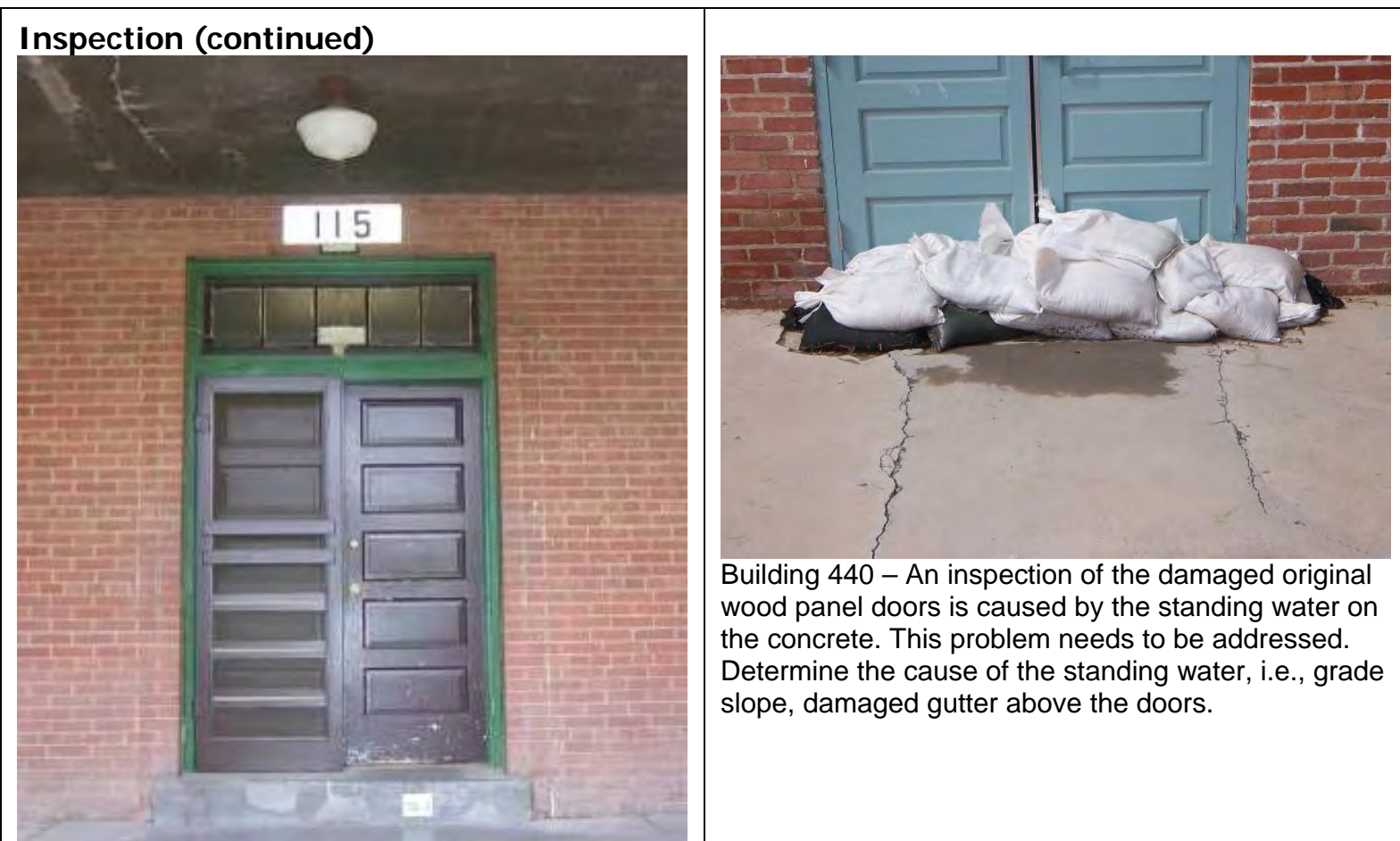

Building 440 - An inspection of the damaged original wood panel doors is caused by the standing water on the concrete. This problem needs to be addressed. Determine the cause of the standing water, i.e., grade slope, damaged gutter above the doors.

Building 115 - The inspection of the wood doors and screens should note that one of the screen doors on the front elevation is missing.

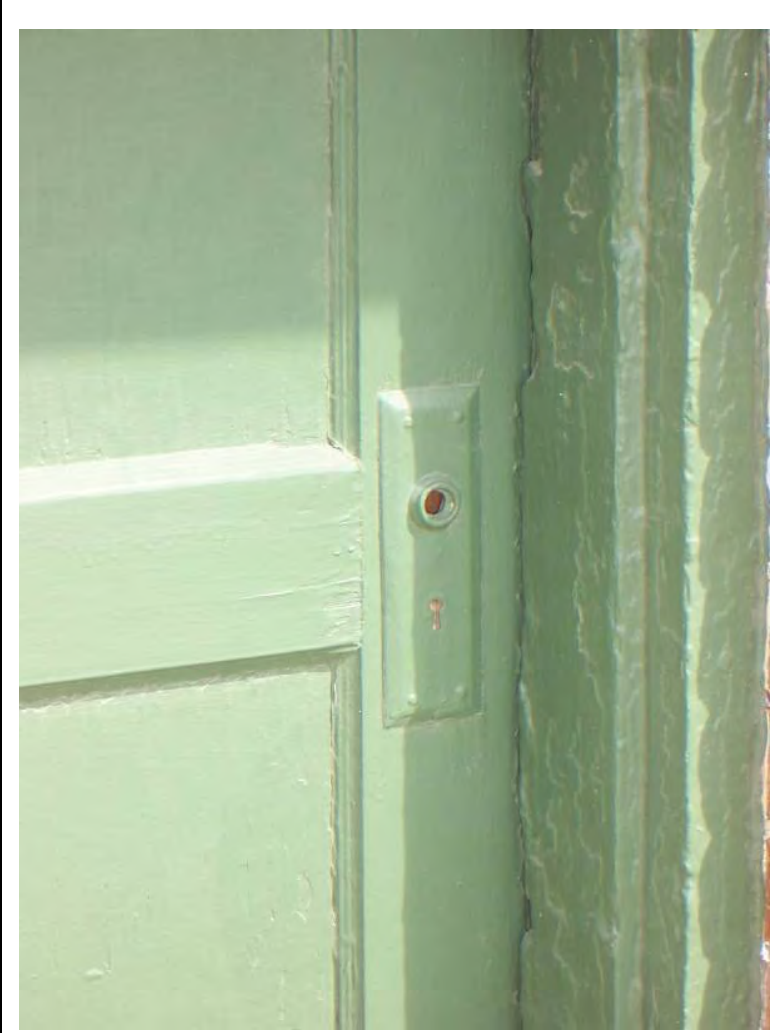

Building 442 - An in-depth survey of all of the doors on the buildings will uncover missing hardware.

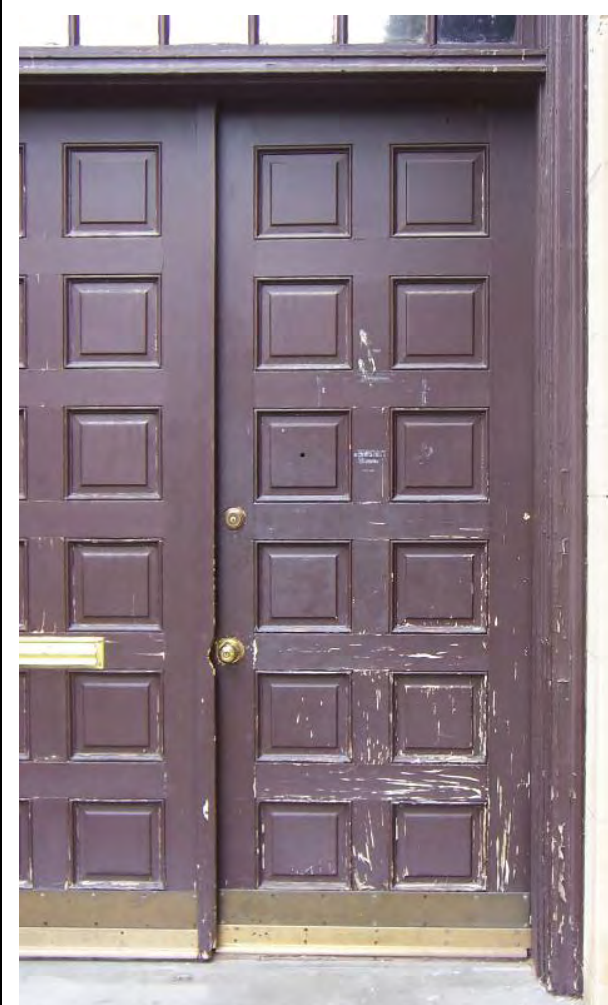

Building 504 - Inspection of wood doors should include any notes regarding damaged painted surfaces. 


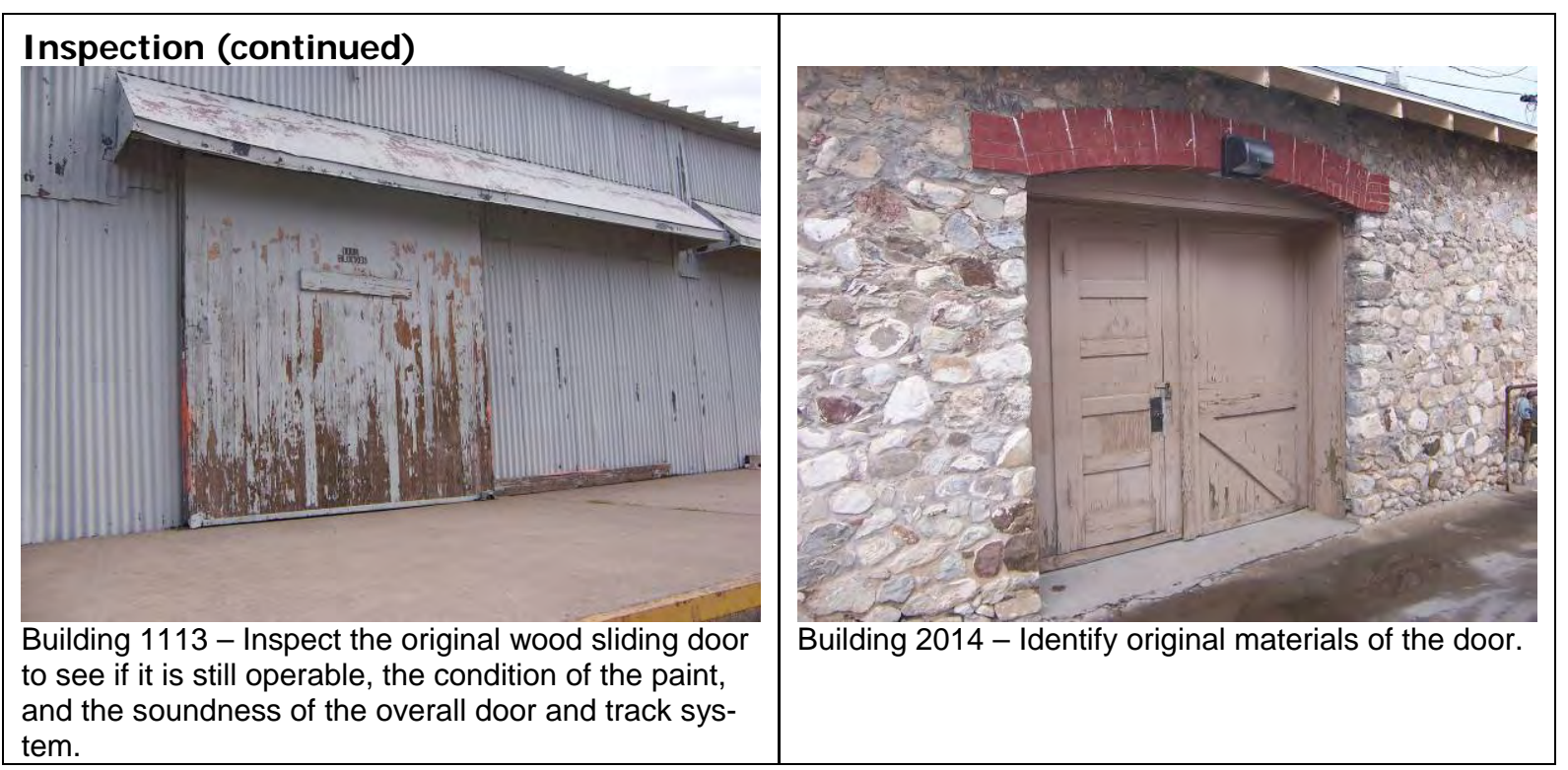

\section{Evaluation}

The following is a checklist of items to be covered when evaluating the condition of a wood door:

- $\quad$ Condition of the paint: One clue to the areas suffering from excessive moisture is the condition of the paint; therefore, each door should be examined for areas of paint failure.

Paint blistering, cracking, flaking, and peeling usually indicate points of water penetration, moisture saturation, and potential deterioration. Failure of the paint should NOT, however, be mistakenly interpreted as a sign that the wood is unrepairable.

- $\quad$ Condition of the frame: Poor design of the frame and threshold causes deterioration of the doors if water is allowed to continuously come in contact with the door.

- $\quad$ Condition of the door: Cracks or any signs of wood swelling and splitting are serious problems.

- $\quad$ Glazing problems: Inspect and evaluate the divided lights in doors.

- $\quad$ Hardware: Check hardware frequently for signs of disrepair.

Recommended...

- $\quad$ Evaluating the overall condition of materials to determine whether more than protection and maintenance are required, i.e., if repairs to doors and door features will be required.

Not Recommended...

- $\quad$ Removing or radically changing doors that are important in defining the historic character of the building so that, as a result, the character is diminished.

- Changing the number, location, or size, through cutting new openings, blocking-in doors, and installing replacement doors that do not fit the historic opening.

- $\quad$ Obscuring historic door trim with metal or other material. 


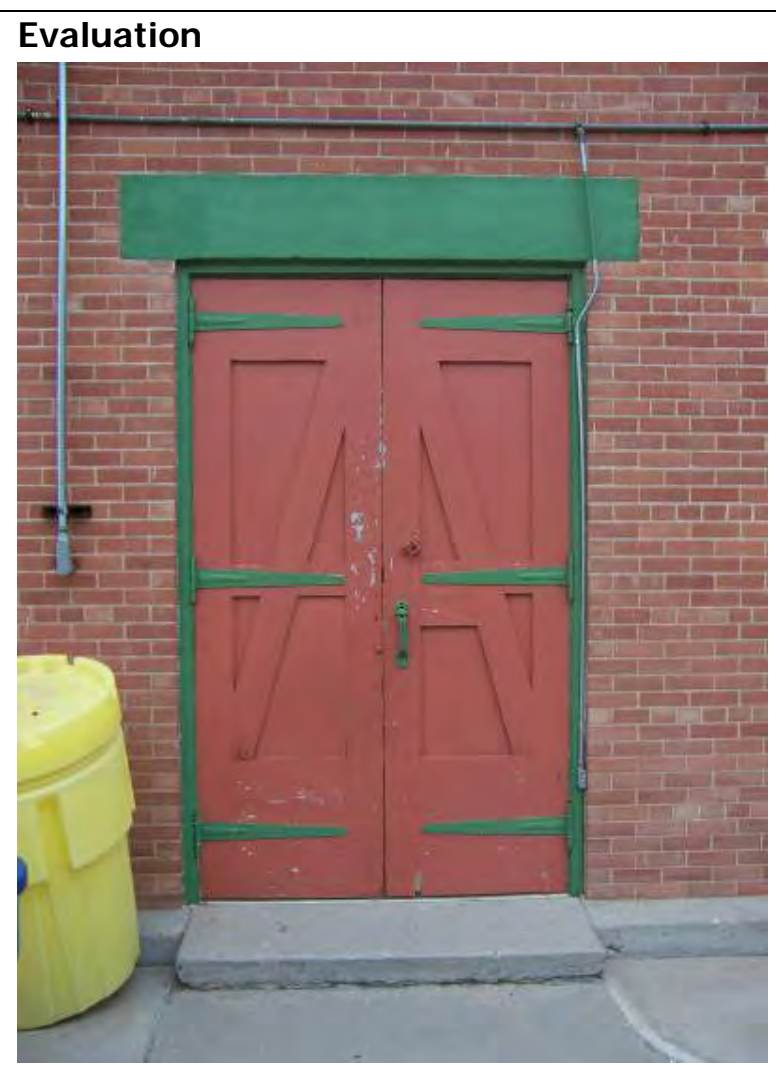

Building 54 - Evaluate the condition of the materials of the wood door and all the hardware to determine whether more than protection and maintenance are required.

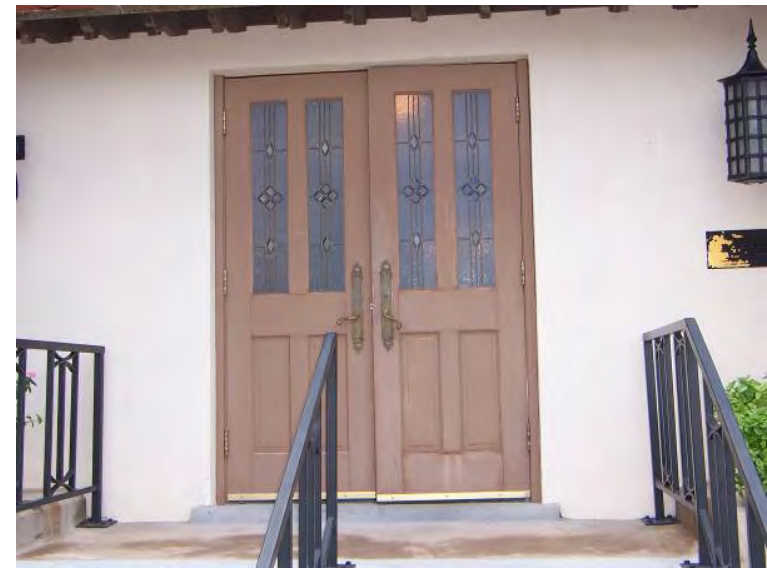

Building 243 - Original wood door with original etched glass panes and hardware.

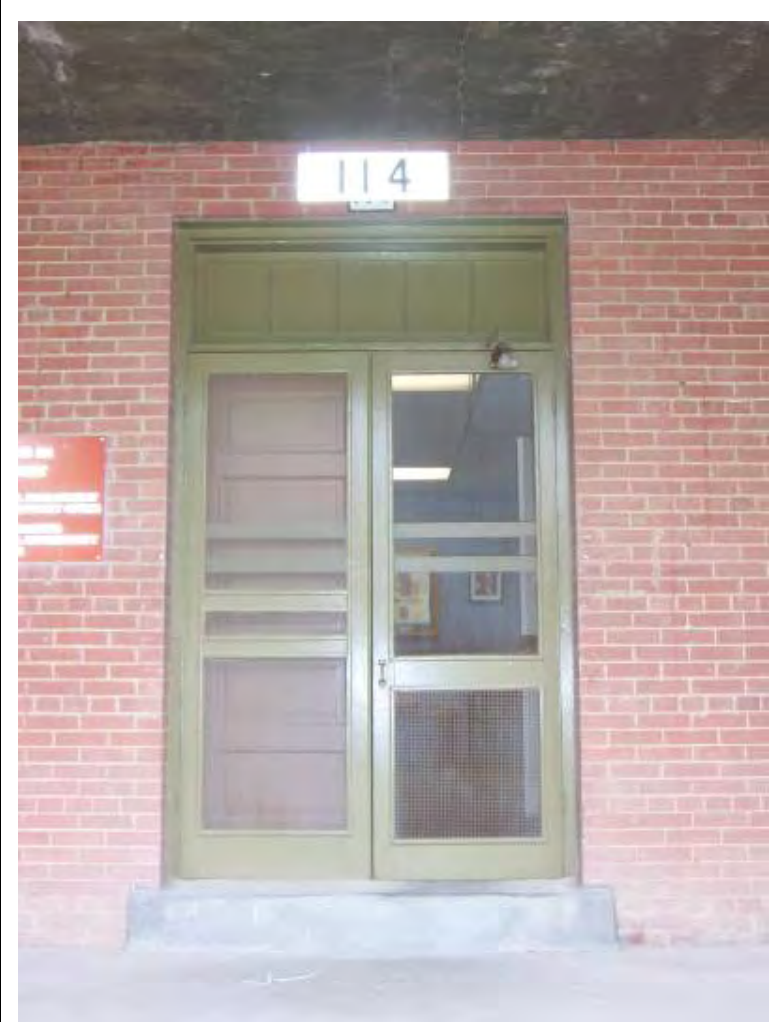

Building 114 - Determine original screen door style before replacing. Replacement wooden screen doors should match those original to the building.

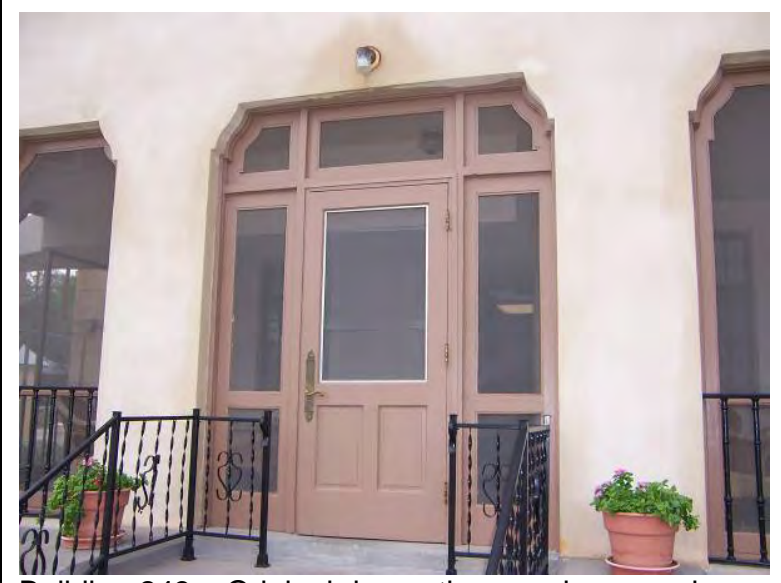

Building 243 - Original decorative wood screen door and side lights. 


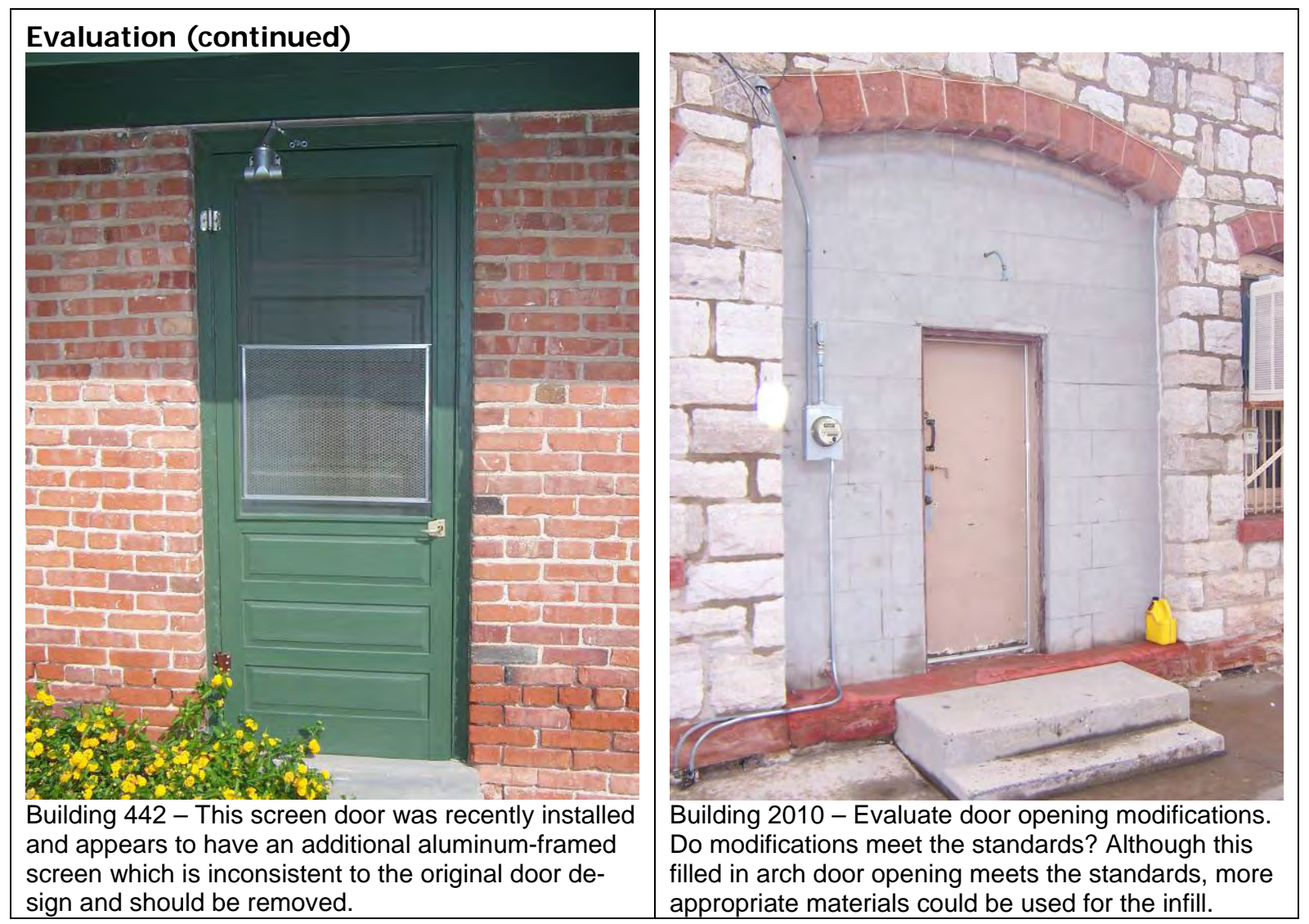

\section{Execution}

- If doors will be repainted in the historic colors, do an analysis to determine the original colors before beginning to remove paint.

- $\quad$ Remove excessive or deteriorated paint as needed to the next sound layer.

- $\quad$ Strip the paint using an appropriate method. Avoid using mechanical abrasive scraping techniques that may damage the wood and its profiles.

- $\quad$ Use care not to damage the profile of the moldings with scraping.

- $\quad$ Sand carefully so as not to blunt the edges of the moldings.

- If using a heat gun, either remove the divided lights in the door or protect them from sudden temperature changes with gypsum board covered with aluminum foil.

- $\quad$ Correct any conditions, including poor design, which permit water to come in contact with the wood or to puddle near the base of the door or the threshold.

- $\quad$ Prime dried-out wood with linseed oil before repainting.

- $\quad$ Caulk gaps between joints and seams.

- $\quad$ Check glazing putty for cracked, loose, or missing sections around divided lights. 


\section{Repair}

Recommended...

- Immediately repairing gaps in sealant joints between the door frame and walls of the structure that might let moisture into the wood.

- $\quad$ Repairing or, if too deteriorated, replacing decayed wood using epoxies or by splicing new wood.

- $\quad$ Repairing glazing putty where necessary.

- $\quad$ Repairing door frames by patching, splicing, consolidating or otherwise reinforcing. Such repair may also include replacement in-kind —or with compatible substitute material—of those parts that are either extensively deteriorated or are missing when there are surviving prototypes.

Not Recommended...

- $\quad$ Stripping doors of historic material such as wood, cast iron, and bronze.

- $\quad$ Failing to reuse serviceable door hardware such as brass hinges, handles, and locks.

\section{Replace}

\section{Recommended...}

- $\quad$ Replacing in-kind an entire door that is too deteriorated to repair using the same design details such as number of divided lights, panels, and hardware. If using the same kind of material is not technically or economically feasible when replacing doors deteriorated beyond repair; then a compatible substitute material may be considered.

- If removing the door entirely, the door opening should be filled in with appropriate materials to the building's exterior materials in accordance to the Secretary of Interior Standards.

- Hallway doors that are proposed to be filled in with walls should be left in place, if visually and reasonable feasible, with a wall constructed behind it so as to leave the original door on the hallway side.

Not Recommended...

- $\quad$ Using aluminum thresholds. Original thresholds were often natural finished or painted pieces of hardwood. If refurbishment is not possible, replace in-kind with a similar styled threshold.

- $\quad$ Replacing doors solely because of peeling paint, broken glass, and high air filtration. These conditions, in themselves, are not indication that doors are beyond repair.

- $\quad$ Retrofitting or replacing doors rather than maintaining the door, frame, and glazing.

- $\quad$ Replacing an entire door when repair of materials and limited replacement of deteriorated or missing parts are appropriate.

- $\quad$ Using substitute material for the replacement part that does not convey the visual appearance of the surviving parts of the door or that is physically or chemically incompatible.

- $\quad$ Removing a character-defining door that is unrepairable and blocking it in, or replacing it with a new door that does not convey the same visual appearance.

- $\quad$ Filling in a door opening with inappropriate material or making the opening flush to the exterior walls, giving the illusion that an opening was never there. 


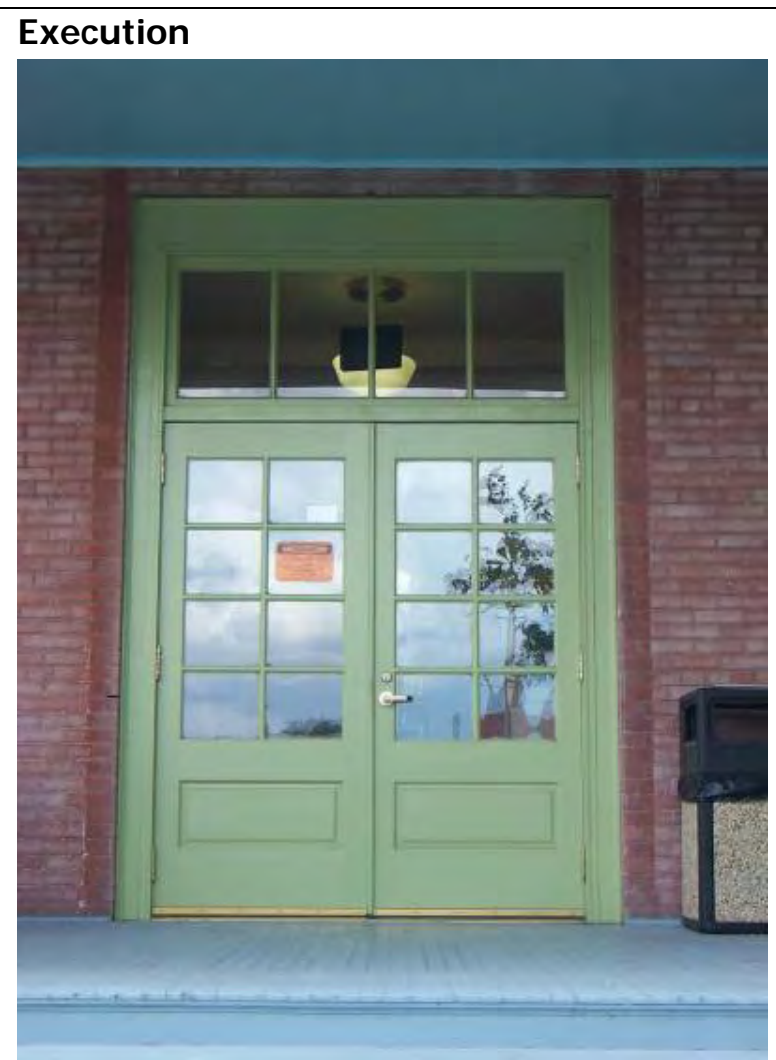

Building 4 - These are appropriate wood doors, wood transom, and door frame replacement types for this building.

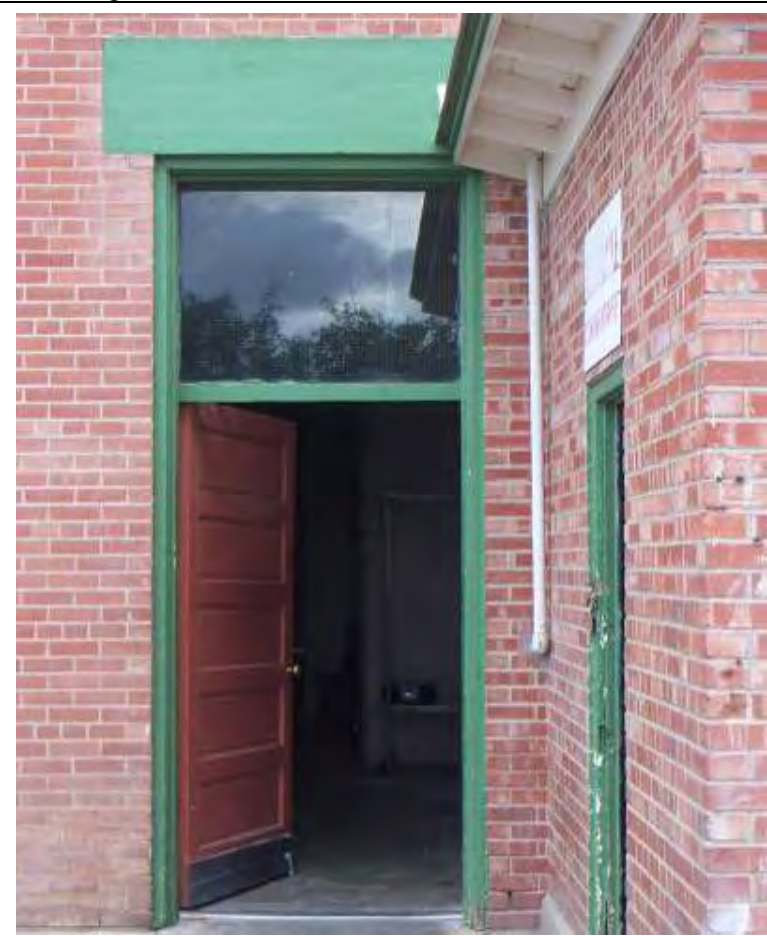

Building 54 - The replacement single-pane fixed transom above the door is not in-kind to the historic material of the building.

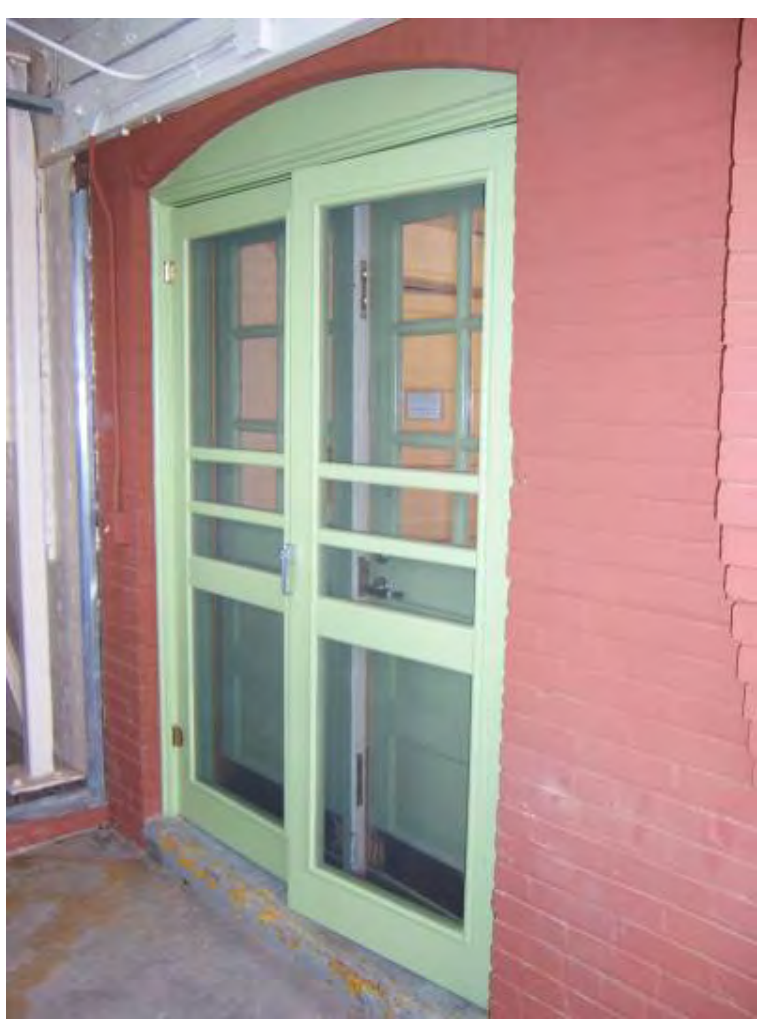

Building 4 - These wood screen doors are appropriate replacement types for this building.

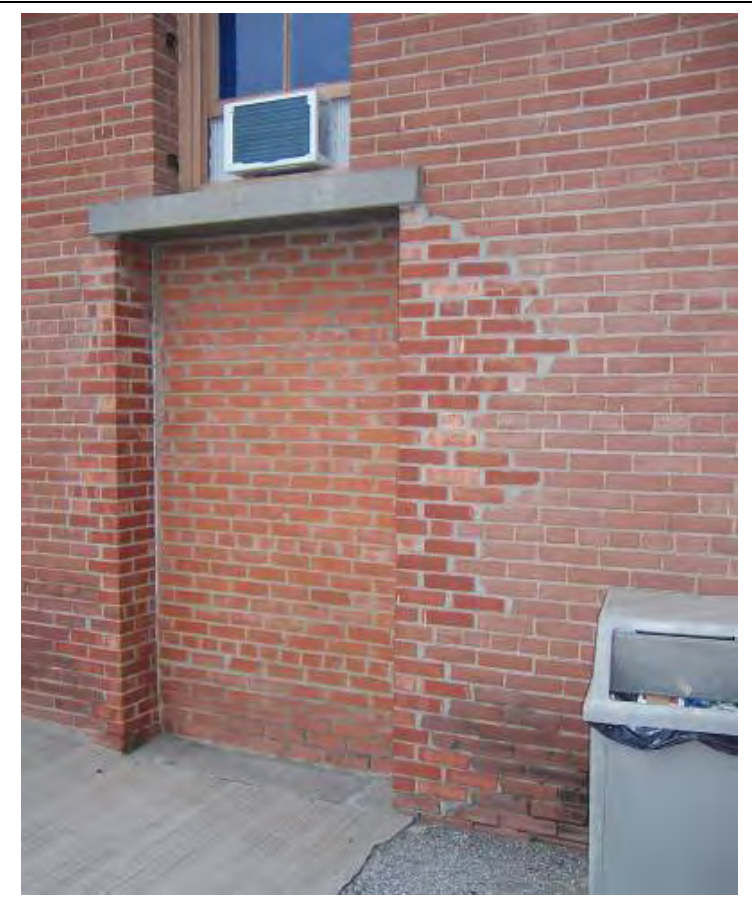

Building 55 - This is an appropriate infill of a door opening since it is recessed and exhibits similar shadows of the original opening. However, the brick type and mortar mixture used around the opening are not appropriate to the building type. 


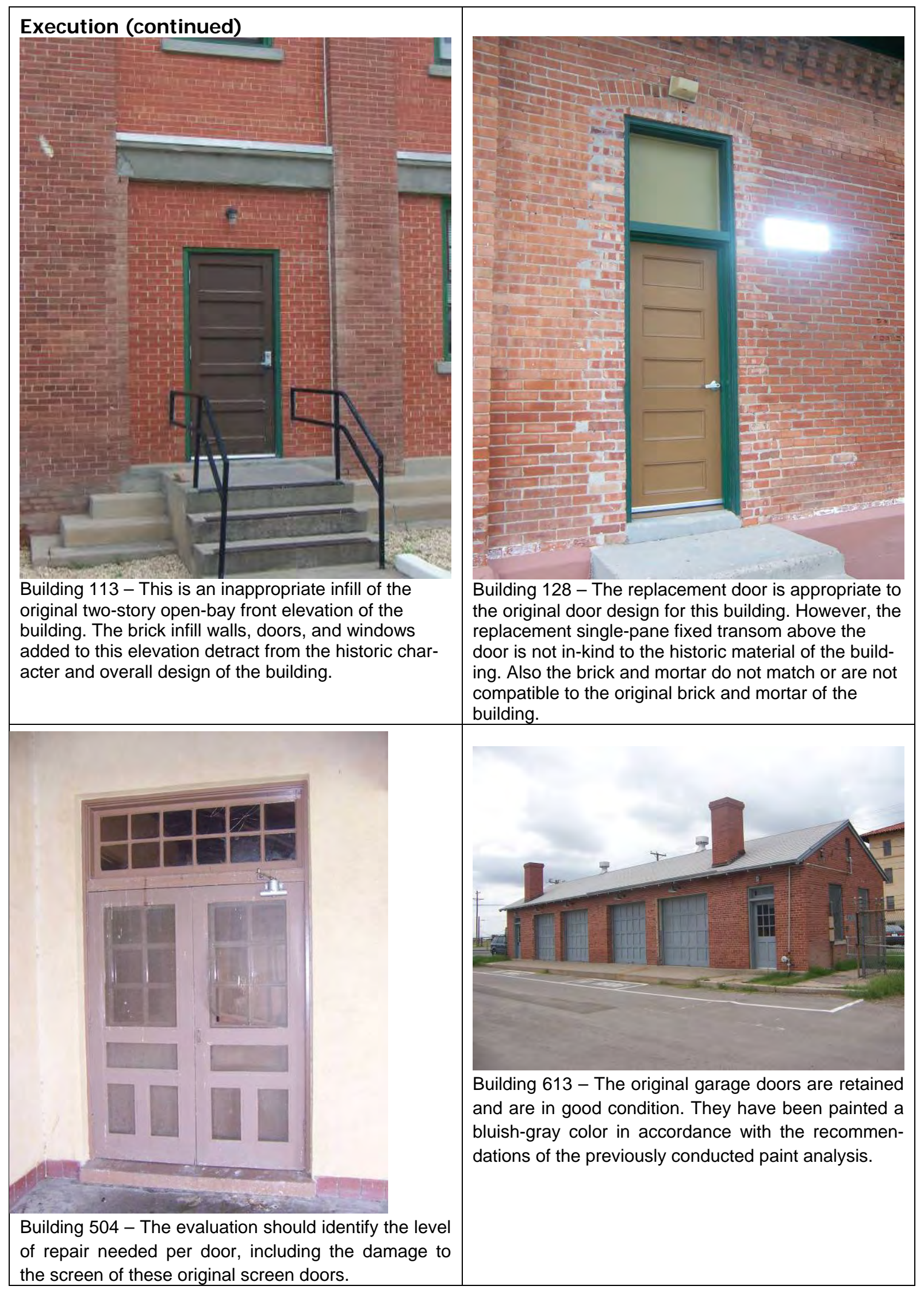




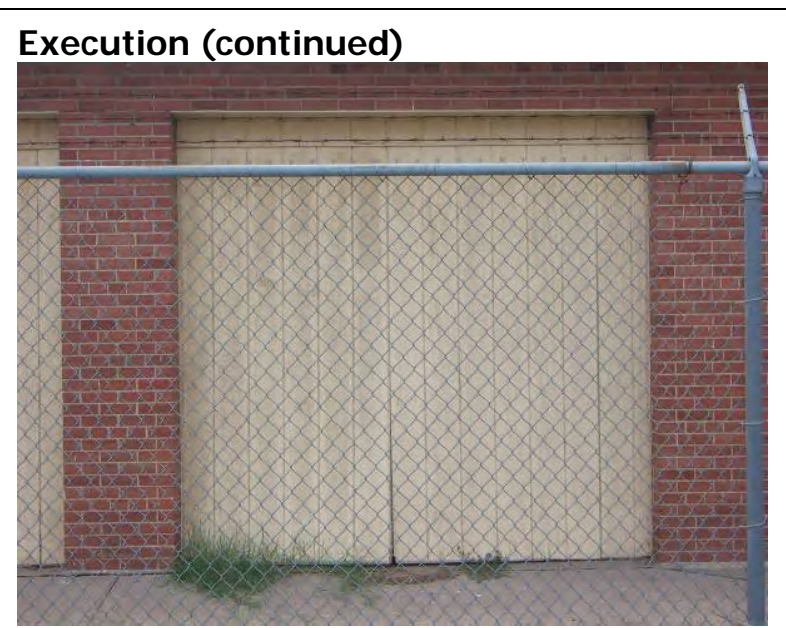

Building 612 - This is an appropriate infill for the original garage door opening. However, the paint color of the infill is not appropriate. It should match that of the existing original garage doors, bluish-gray, like those located on Building 613 (see photo above).

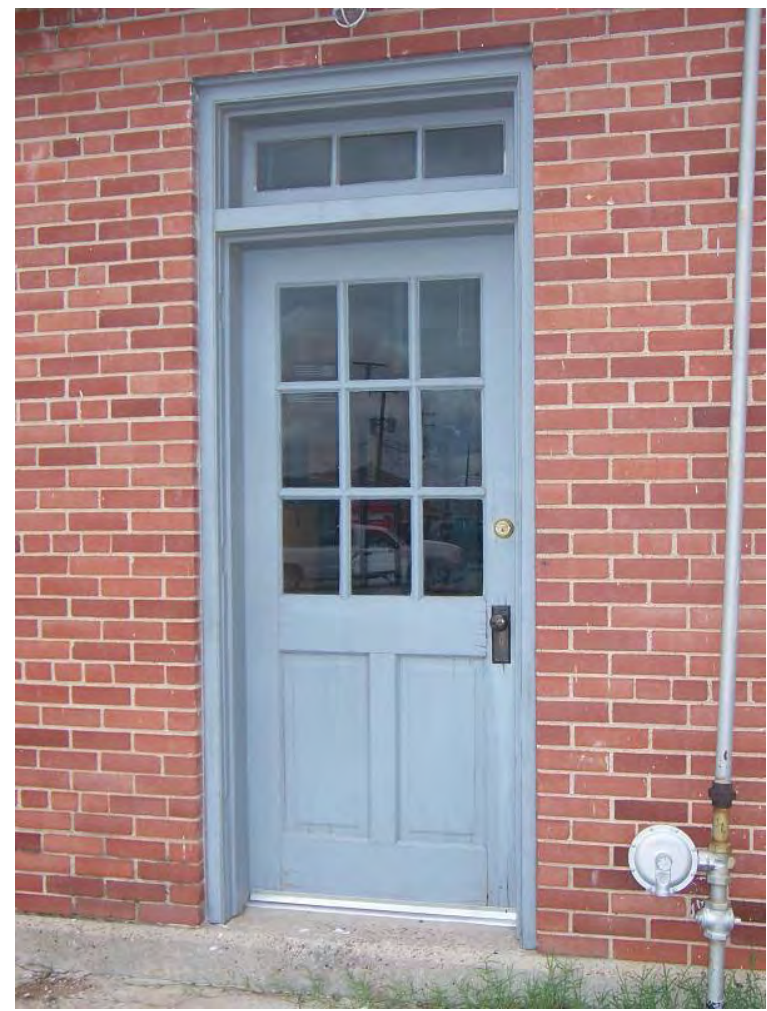

Building 613 - Original wood pane door with divided lights, original hardware, original door frame, and original transom.

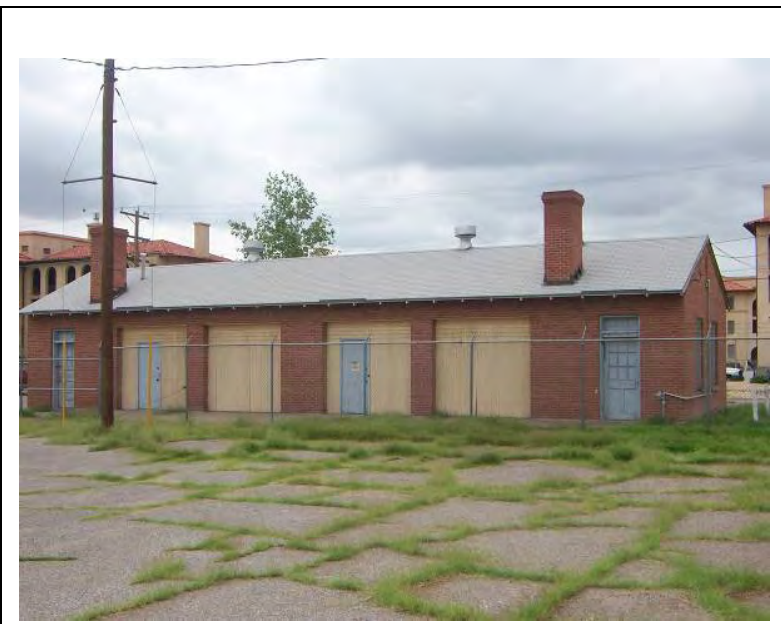

Building 612 - The overall spacing of the garage door bays are intact and the openings have been modified appropriately. However, the wood planks that fill the openings should be painted the same color, bluishgray, like the single entry doors that are placed within the infilled bays. This would give the overall elevation the same uniformed appearance as the original building, like Building 613 (see photo above).

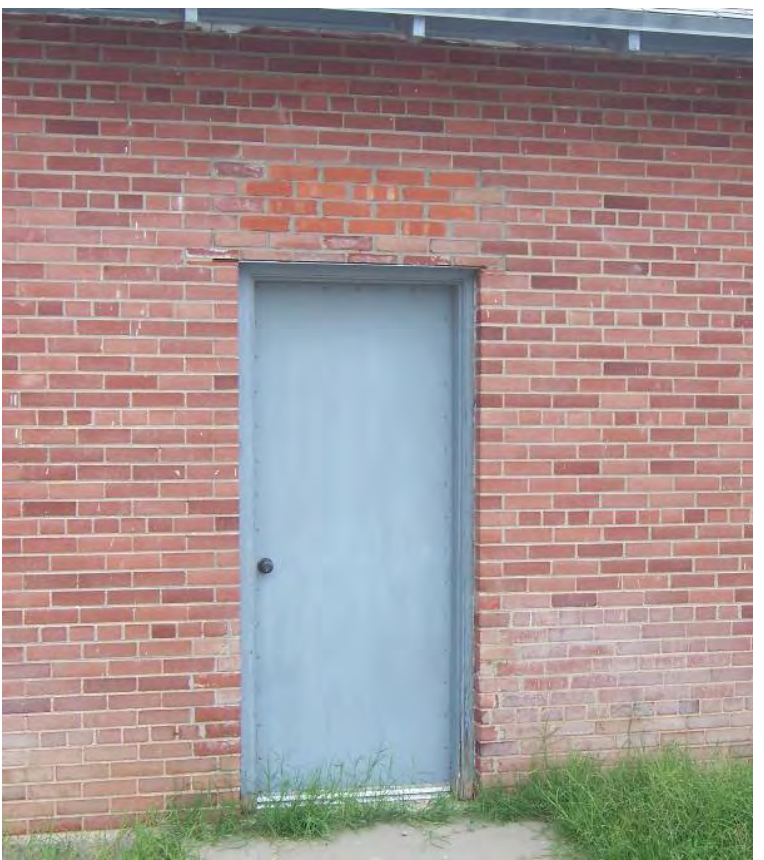

Building 613 - This is an inappropriate door replacement. The new door should be in-kind to the original panel and divided-light door found on the right side of Building 613 elevation (see photo to the left). Also the transom opening has been inappropriately filled in with brick. 


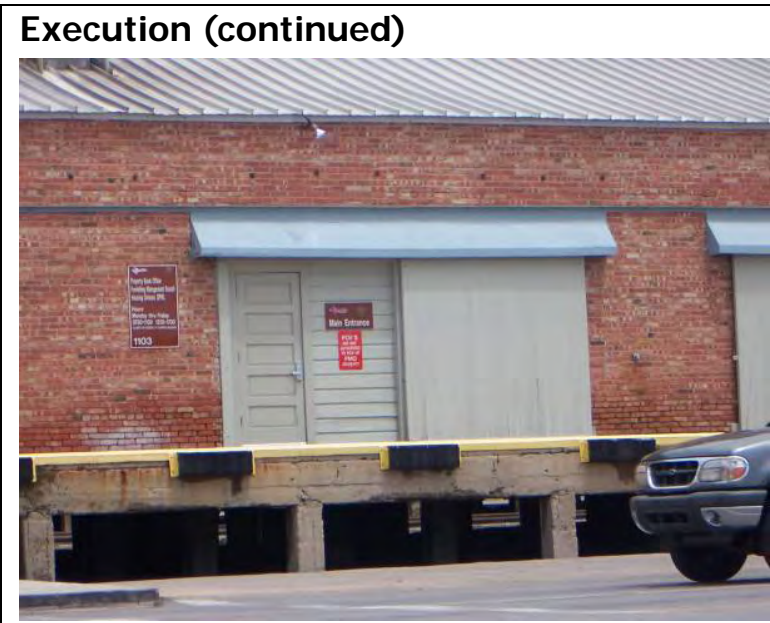

Building 1103 - This is an appropriate modification of the original wood sliding door opening. The original wood sliding door is still intact and the modification of the infill single entry door and wood plank siding is painted the same color as the sliding door to make it appear uniform.

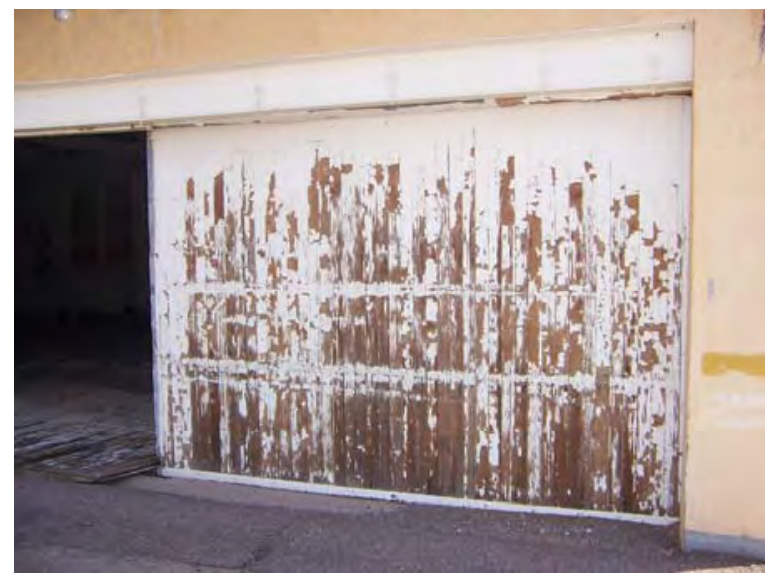

Building 7139 - The paint on this wood sliding door needs to be removed to the next sound layer and the door repainted to protect and preserve the material.

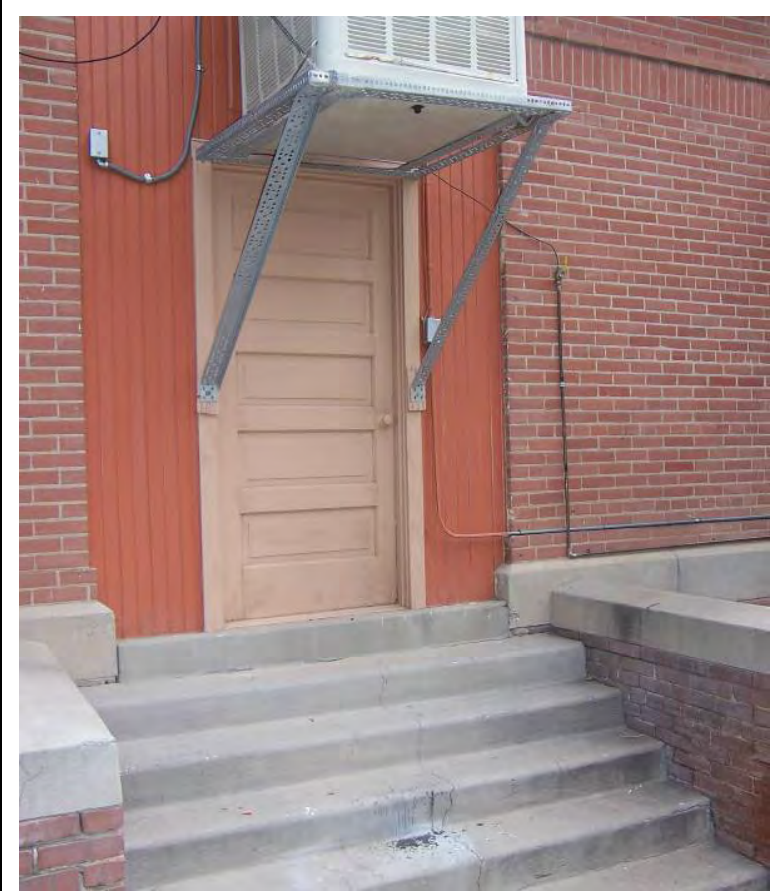

Building 55 - This is a poor example of door modification because of the location of the evaporative cooler. Not only is the cooler dripping water onto the concrete steps but it is probably letting water infiltrate the wood elements of the door.

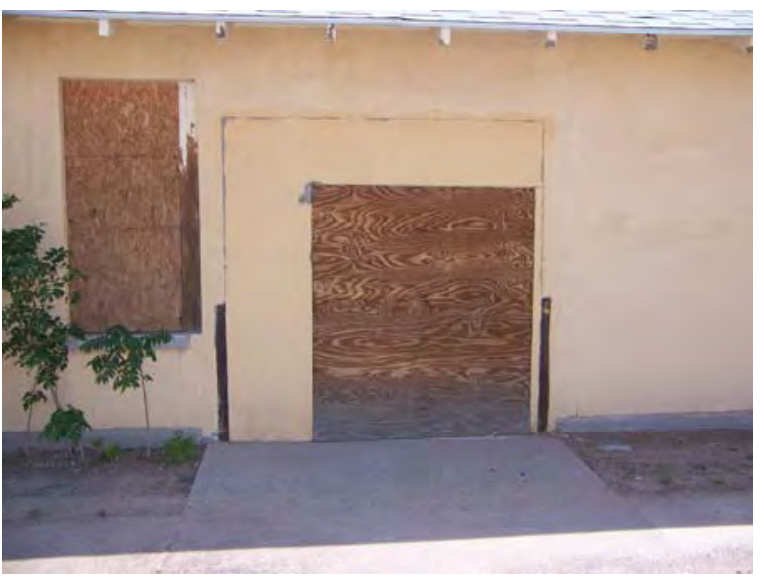

Building 7139 - This is an example of a poor door modification. 


\section{Notes}

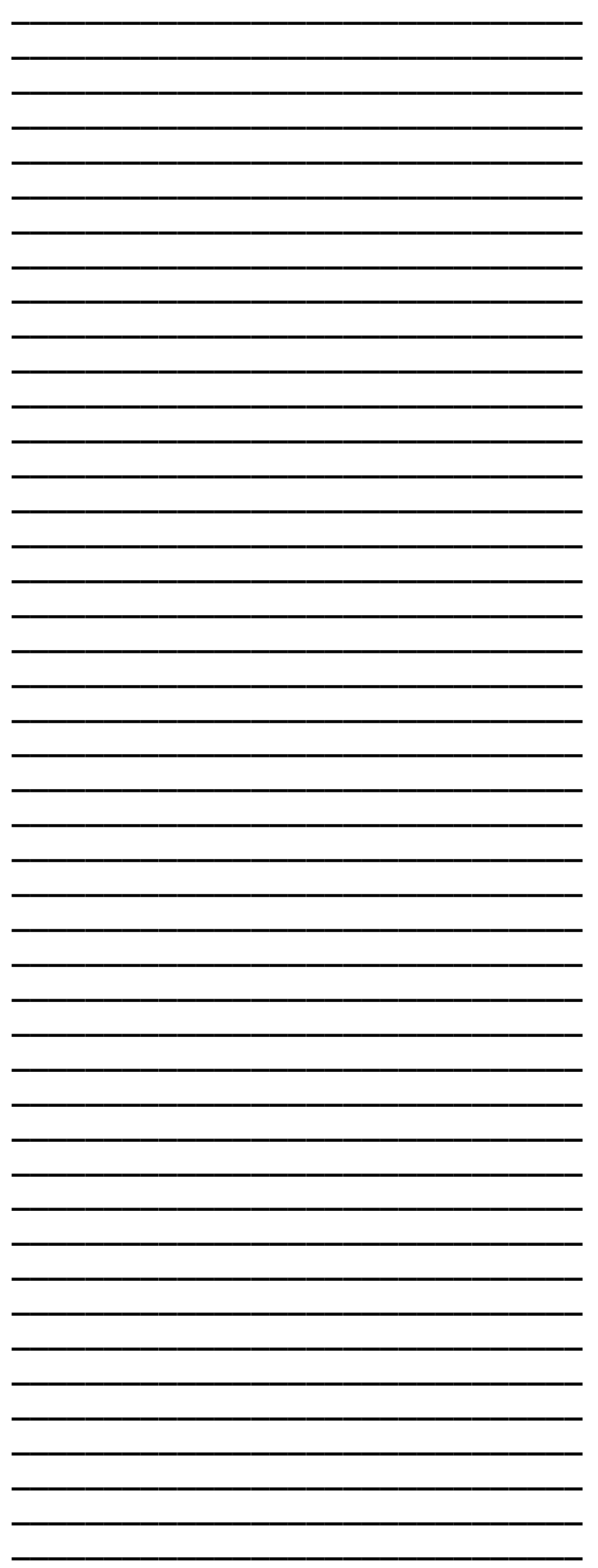




\section{Doors: Metal}

Rolled steel doors are most exclusively found in masonry or concrete buildings. Original doors shall be retained unless they are damaged beyond reasonable repair. The frame and trim shall be retained, or replicated, when damaged beyond repair. If a door must be replaced, the new door shall replicate the original door (if known) in size, proportion, material, shape, glazing pattern, and number of panels, including the use of true-divided lights. If the design of the original door is unknown, staff will work with the applicant to help determine a compatible replacement door.

When a prominent historic door is too deteriorated, or the existing door is not historic, it may make sense to re-use a similar exterior door from a less prominent location such as side or rear entrance.

Routine maintenance of metal doors include paint removal, cleaning, removing rust, repair of weather stripping, and repainting.

Rusting, or corrosion is the most frequent and easily recognizable form of metal deterioration. This process can take place at significantly different rates depending on the material composition, protective treatments applied, and severity of exposure. The presence of any rust on a metal element should alert the observer to the presence of a problem.

\section{Inspection}

- $\quad$ Are the doors historic?

- If the door being replaced is not historic, note features of any other doors that are historic.

- $\quad$ Note materials and their condition at door jambs, sill, and head.

- $\quad$ Does the door match other doors used for similar purposes on the building?

\section{Evaluation}

- If the door is historic can it be repaired?

- If the door is not aesthetically appropriate, will replacing the hardware be sufficient or will the entire door need to be replaced?

\section{Execution}

- Doors that are inappropriate aesthetically should be replaced with doors that match the original door in design and material as closely as possible.

- Use appropriate door hardware.

- Reuse historic doors and door frames.

\section{Further Readings}

GSA has developed technical procedures to be used in specialized historic preservation work, as well as general evaluation, maintenance and repair of older building materials. For more detailed descriptions of repair procedures for metal door maintenance refer to the following, which can be found at http://w3.gsa.gov/web/p/hptp.nsf

- Guidelines for Rehabilitating Historic Buildings: Metals

- $\quad$ Stripping and Repainting Metal Doors 


\section{Inspection}

\section{Recommended...}

- Identifying the material of the door, door frame, and hardware.

- $\quad$ Noting any original design characteristics per door.

- $\quad$ Identifying, retaining, and preserving doors — and their functional and decorative features - that are important in defining the overall historic character of the building.

- $\quad$ Conducting an in-depth survey of the conditions of existing doors early in rehabilitation planning so that repair and upgrading methods and possible replacement options can be fully explored.

- $\quad$ Protecting and maintaining the metal and architectural metal of which the door, door frame, and surrounds are made through appropriate surface treatments such as cleaning, rust removal, limited paint removal, and reapplication of protective coatings.

- Inspecting the work for any serious defects or conditions that would interfere or prevent a satisfactory application of protective coatings such as paints.

Not Recommended...

- $\quad$ Failing to provide adequate protection of material on a cyclical basis so that deterioration of the door material is accelerated.

- $\quad$ Failing to undertake adequate measures to assure protection of historic doors.

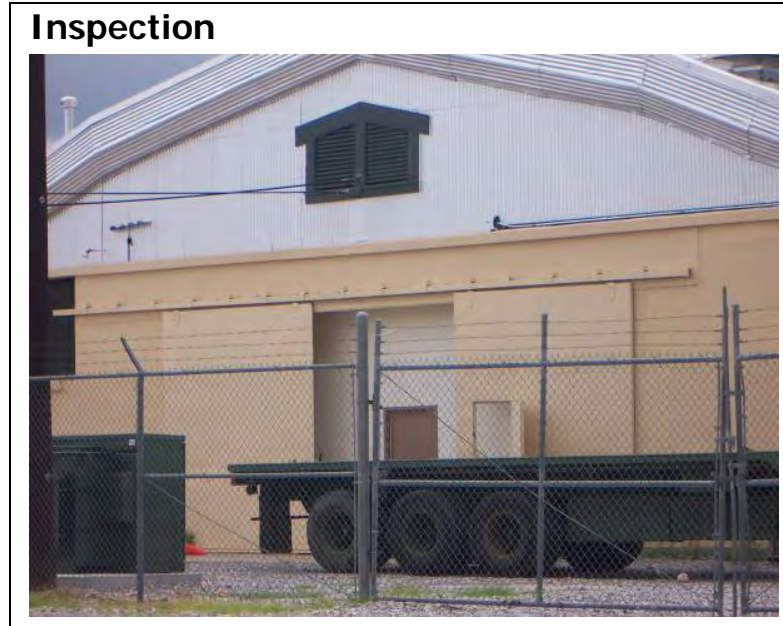

Building 757 - Identify the material of the door, door frame, hardware, and door mechanisms.

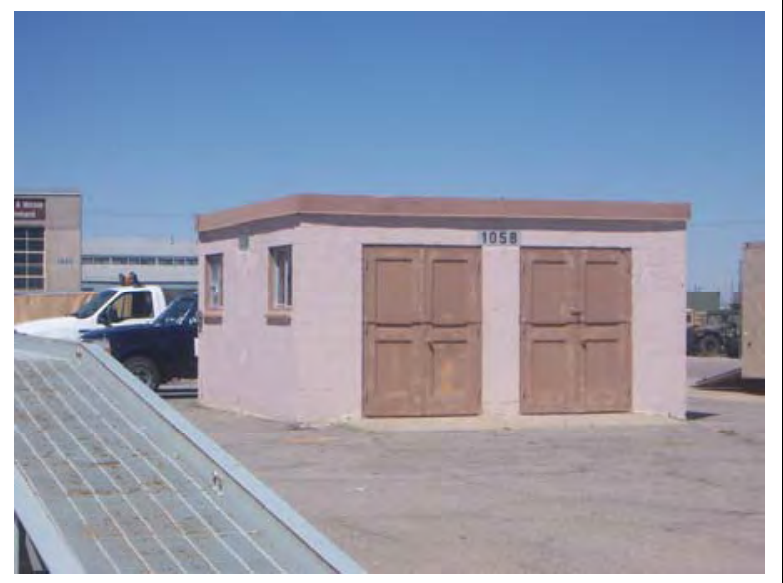

Building 1058 - It is recommended to protect and maintain the metal which comprise the door, door frame, and surrounds through appropriate surface treatments such as cleaning, rust removal, and reapplication of protective coatings.

\section{Evaluation}

The following is a checklist of items to be covered when evaluating the condition of a metal door:

- $\quad$ The presence and the degree of corrosion: Test for the presence of corrosion because it is the controlling factor in metal repair. (Note: Corrosion and the maintenance of metals are discussed in the metal section of the report.) 
- $\quad$ Condition of the paint: Cleaning, priming, and painting measures protect metals from further deterioration brought on by the environment and human induced problems.

- $\quad$ Presence and condition of hardware, screws, bolts, and hinges: Inspect and evaluate the condition of the original hardware and note what remains intact and what has been replaced.

- $\quad$ Condition of masonry and concrete surround: Note any damage to the surround. The frames should be inspected regularly to ensure proper fit and therefore prevent any damage that may occur as a result of deterioration.

Recommended...

- $\quad$ Evaluating the overall condition of materials to determine whether more than protection and maintenance are required, i.e., if repairs to doors and door features will be required.

Not Recommended...

- $\quad$ Removing or radically changing doors that are important in defining the historic character of the building so that, as a result, the character is diminished.

- Changing the number, location, or size through cutting new openings, blocking-in doors, and installing replacement doors that do not fit the historic opening.

- $\quad$ Obscuring historic door trim with metal or other material.

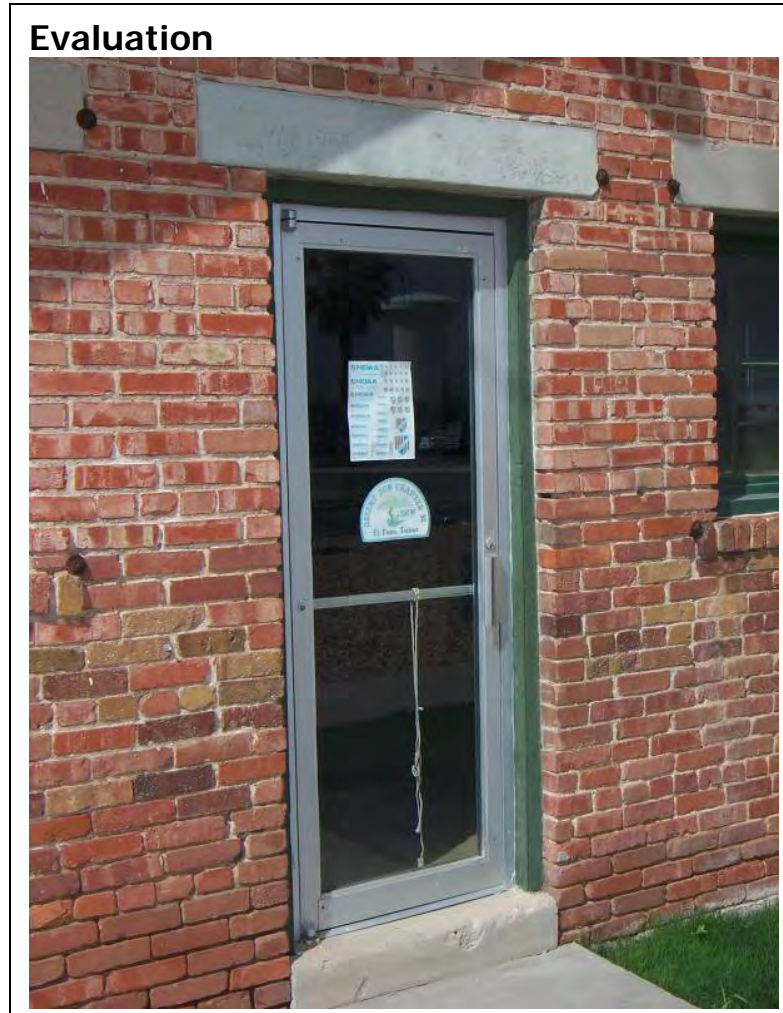

Building 442 - The bright aluminum and plate glass door replacement is inappropriate and does not match the existing wood door style on the building. However, the original wood door frame is still intact.

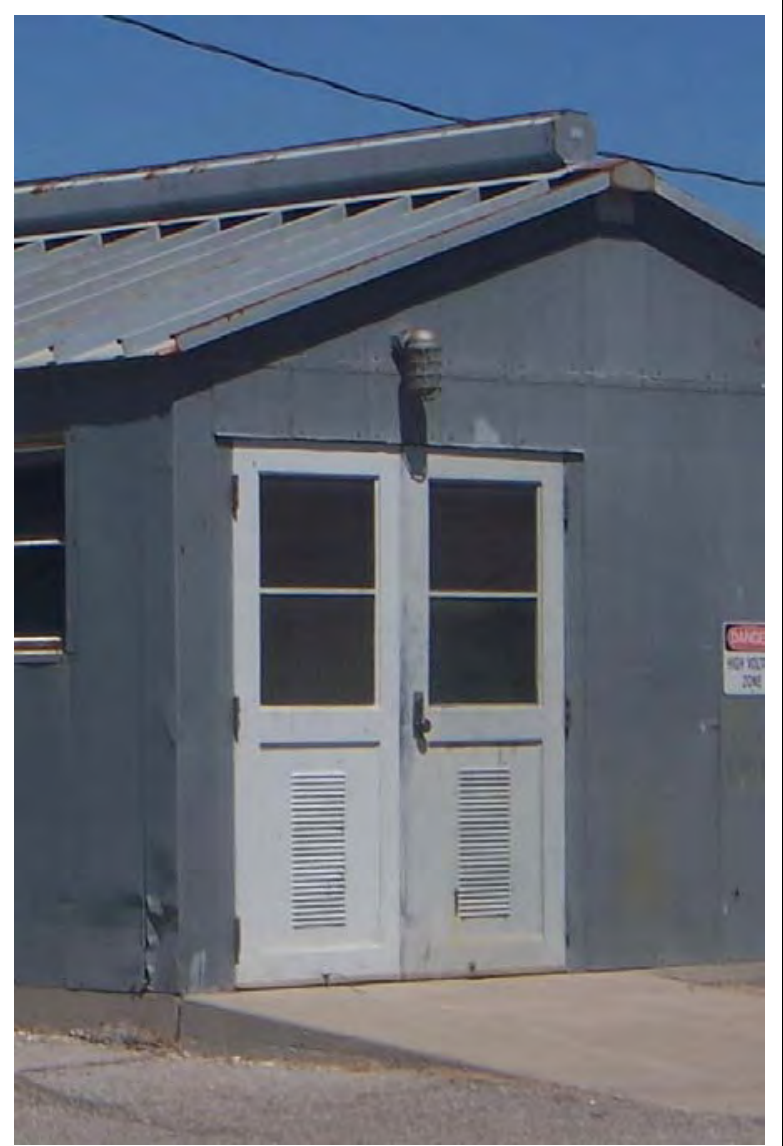

Building 742 - The evaluation of original metal doors should include a test for the presence of corrosion, overall condition of the paint, and the presence and condition of hardware. Note where original hardware is intact. 


\section{Execution}

- If doors will be repainted in the historic colors, do an analysis to determine the original colors before beginning to remove paint.

- $\quad$ Remove excessive or deteriorated paint to the next sound layer.

- $\quad$ Strip the paint using an appropriate method, such as a hand-scraping, or chemical or sandblasting. Both treatments require removal of the glass.

- While repairing paint surfaces, protect adjacent materials such as glass and masonry.

- $\quad$ Correct any conditions, including poor design, which permit water to come in contact with the metal or to puddle near the base of the door or the threshold, which would accelerate the deterioration of the metal elements.

- $\quad$ Check glazing putty for cracked, loose, or missing sections around divided lights.

\section{Repair}

Recommended...

- $\quad$ Repainting all steel section with two coats of finish paint compatible with the primer from the same manufacturer.

- $\quad$ Priming exposed metal with rust-inhibiting primer.

- Immediately repairing gaps in sealant joints between the door frame and walls of the structure that might let moisture into the metal.

- If the corrosion of the metal is light, removing the rust, flaking, and excessive paint.

- $\quad$ Repairing glazing putty where necessary.

- $\quad$ Repairing door frames by patching, splicing, consolidating, or otherwise reinforcing. Such repair may also include replacement in-kind—or with compatible substitute material—of those parts that are either extensively deteriorated or are missing when there are surviving prototypes.

Not Recommended...

- $\quad$ Stripping doors of historic material.

- $\quad$ Failing to reuse serviceable door hardware such as brass hinges, handles, and locks.

\section{Replace}

Recommended...

- $\quad$ Replacing in-kind an entire door that is too deteriorated to repair using the same design details such as number of divided lights, panels, and hardware. If using the same kind of material is not technically or economically feasible when replacing doors deteriorated beyond repair; then a compatible substitute material may be considered.

- $\quad$ Replace missing screws or fasteners.

- $\quad$ Any steel replacement door or parts of doors to be installed should be hot-dipped galvanized.

- Hallway doors that are proposed to be filled in with walls should be left in place, if visually and reasonable feasible, with a wall constructed behind it so as to leave the original door on the hallway side. 
Not Recommended...

- $\quad$ Replacing windows solely because of peeling paint, broken glass, and high air filtration. These conditions, in themselves, are not indications that doors are beyond repair.

- $\quad$ Retrofitting or replacing doors rather than maintaining the door, frame, and glazing.

- $\quad$ Replacing an entire door when repair of materials and limited replacement of deteriorated or missing parts are appropriate.

- $\quad$ Using substitute material for the replacement part that does not convey the visual appearance of the surviving parts of the door or that is physically or chemically incompatible.

- $\quad$ Removing a character-defining door that is unrepairable and blocking it in, or replacing it with a new door that does not convey the same visual appearance.

- $\quad$ Replacement doors should be considered only as a last resort. If at all possible repair the deteriorated elements appropriately.

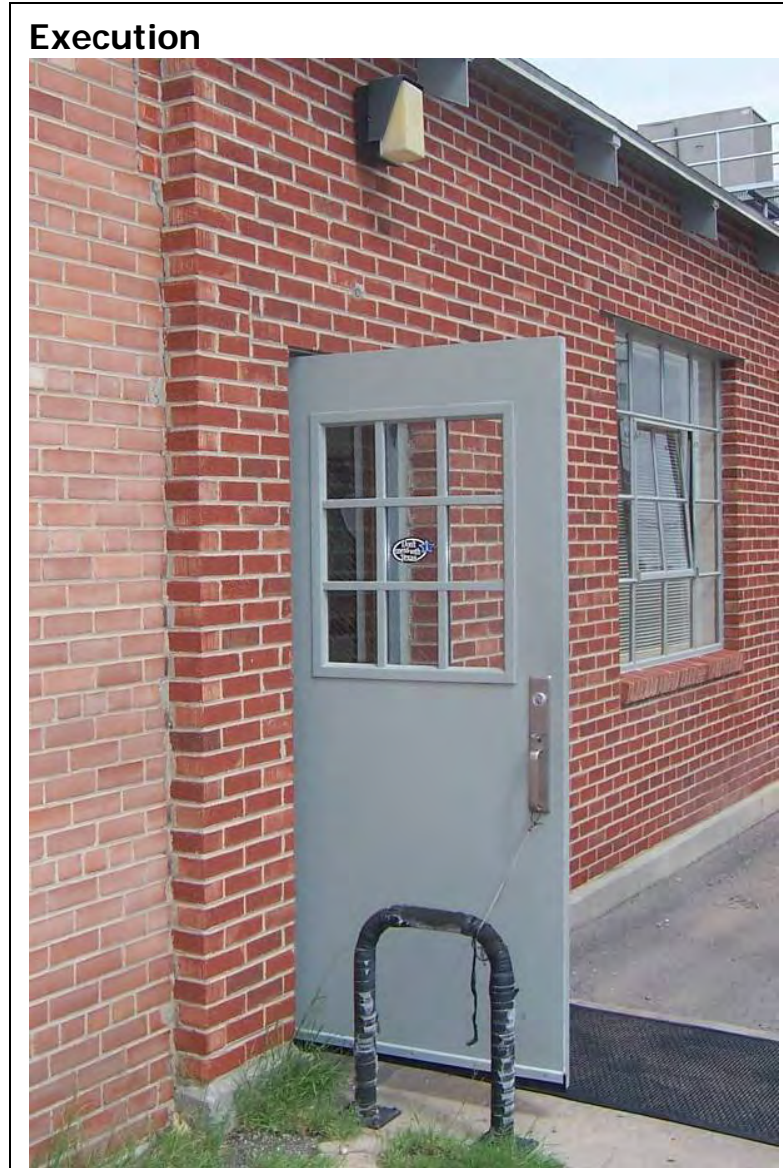

Building 622 - Although this is not an original door, it is an appropriate retrofit into the opening. It somewhat mimics the original wood door with divided-lights. However, it is missing the paneled detail at the bottom portion of the door.

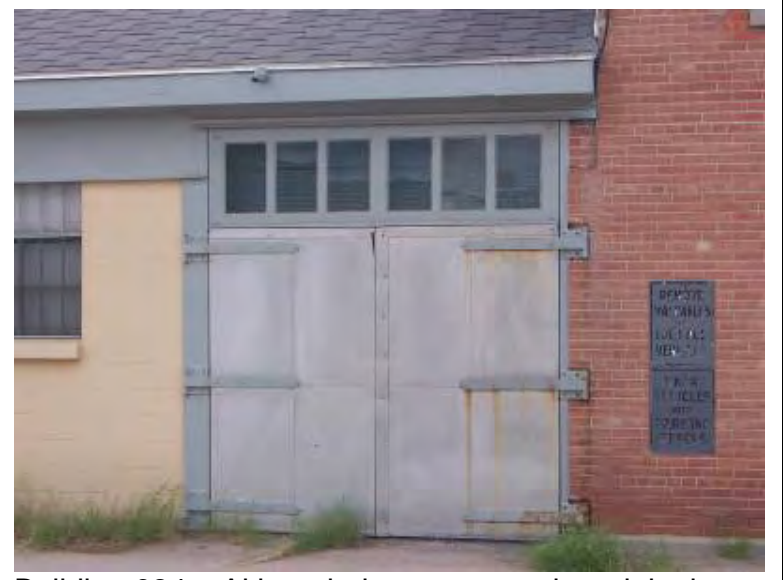

Building 624 - Although these are not the original stable doors, they do date back to the period of significance when the building was converted to classrooms in the 1950s. The transom windows are original to the 1950 s construction. 


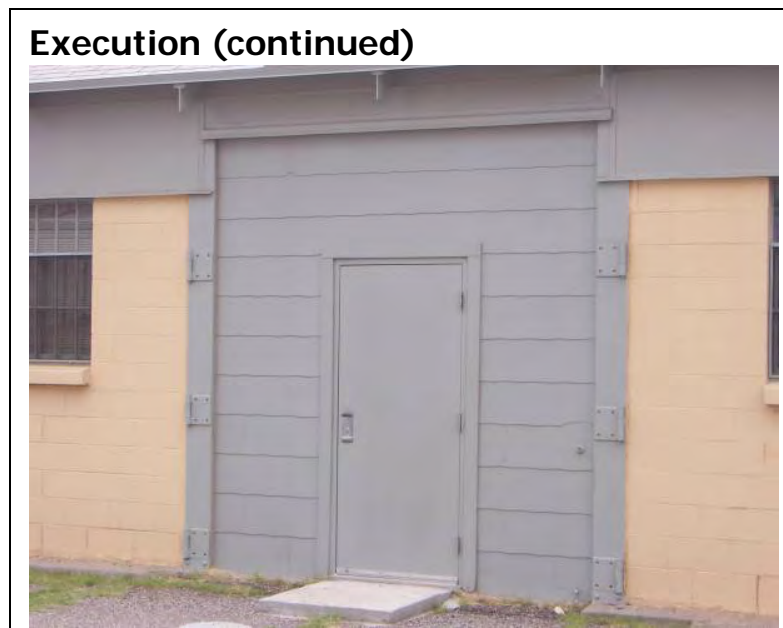

Building 620 - This is an appropriate infill even though the original transom has been removed above the door opening. It mimics the metal doors found on Building 624, which is of the same construction period and design (see photo above).

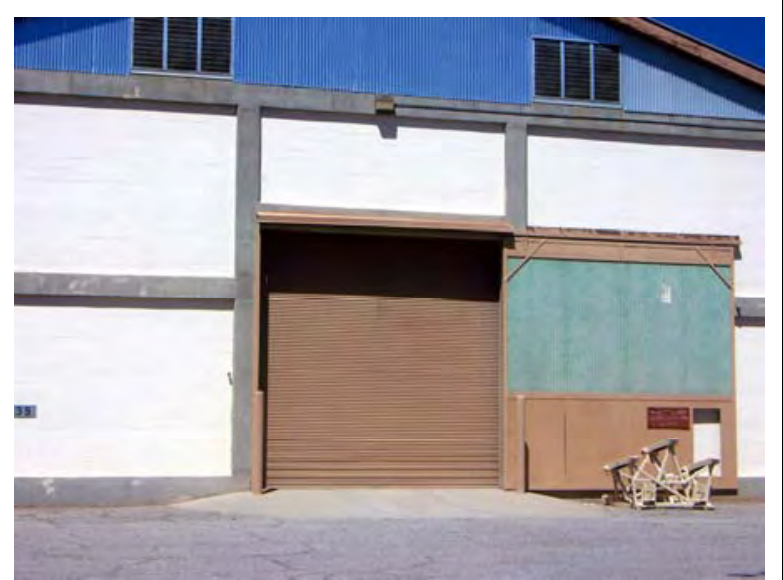

Building 739 - The metal roll-up door is an appropriate retrofit for the door opening on the concrete block building. Notice the original sliding metal door and door mechanism are still intact even if they are not operable. 
Notes

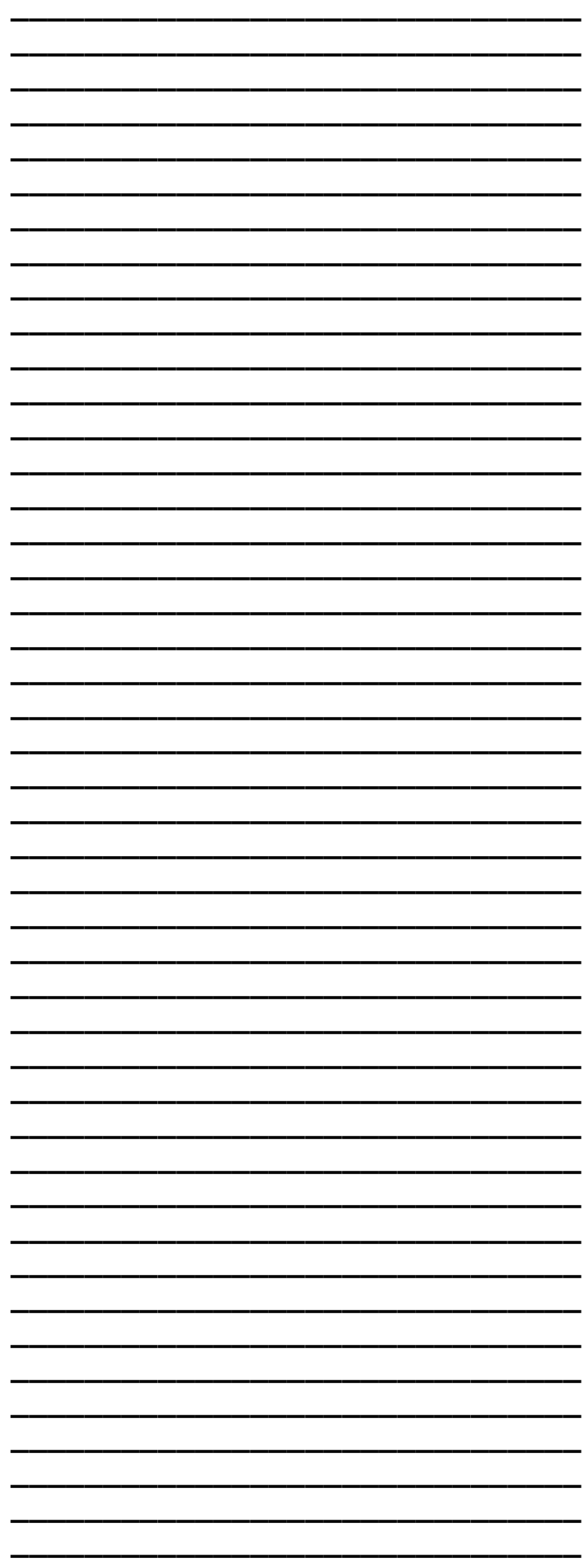




\section{Maintenance Guides for Windows}

\section{Windows: Overview}

Original windows are important features on historic buildings. Their spacing contributes to the visual rhythm of the facade, while providing insight into interior spaces and the uses of the building. Their design, craftsmanship, and materials contribute to a property's historic value. Because there are so many design choices such as number, location, size, muntin profile, and arrangement of panels on the windows, these architectural elements are key indicators of the historical style and date of construction. Historic materials for windows include wood and metal (most often, steel). Wood is easily worked for design effects, including the addition of decorative trim for window surrounds. Most of the historic windows were made from old growth wood, and have a natural resistance to weather and insect decay. Metal windows were originally made to imitate wood windows. The inherent strength of the material, however, permitted larger windows with thin muntins and frames.

Window types include double-hung, singlehung, casement, horizontal sliding, projected out or awning, hopper, and fixed. Frame materials are plastic, aluminum, steel, wood, and metal-clad wood (steel and aluminum).

The glazing compound or putty around glass panels in older windows should be examined carefully since this is often the most vulnerable part of the window and its repair is time consuming. Examine glazing tapes or strips around glass panels in steel and aluminum windows for signs of deterioration such as hardened sealant or poor fit. Check metal sashes for weep holes that have been blocked by paint, sealant, or dirt. Weep holes are usually easy to clean.

Window weather stripping is generally of three types; metal, foam plastic, or plastic stripping. Check each type for fit. Check metal for dents, bends, or straightness. Check foam plastic for resiliency. Check plastic stripping for brittleness and cracks. Make sure that weather stripping is held in place.

\section{Maintenance/ Management Guidelines for Windows}

- Original windows are important features on historic buildings. Their design, craftsmanship, and materials contribute to a building's historic value. The replacement of windows is often proposed because of the condition or poor functioning. However, peeling paint, broken glass, stuck sashes, and high air infiltration are no indications that windows are beyond their useful lives. The glazing compound or putty around glass panels in older windows should be examined since this is often the most vulnerable part of the window. Windows that are repaired and properly maintained will have greatly extended service lives while contributing to the historic character of the building. Window maintenance should start with a survey that records the condition of every window in the building, identifying which ones are original.

- According to The Secretary of the Interior's Standards for Rehabilitation, the proper procedure is to respect the significance of the original materials and features, repair and retain wherever possible, and replace them only when absolutely necessary.

- The following recommendations for care of the historic site are to be thoroughly read and understood before a treatment is specified. The Secretary of the Interior's Standards for Rehabilitation should also be consulted to determine the appropriateness of any treatment.

Full documentation can be found at http://www.cr.nps.gov/hps/tps/tax/rhb/stand.htm

Construction Documents and Specifications for Rehabilitation and Replacement of Historic Windows, Fort Bliss Manual

Fort Bliss National Historic District Exterior Paint Analysis, Fort Bliss Manual 
Check windows that are not protected from the weather for presence of essential flashing at the head. Storm windows should be checked for operation, weather-tightness, overall condition, and fit. Check the condition of the screens and glass inserts.

Also, windows are frequently the subject of anti-terrorism or force protection improvement projects and several viable alternatives to replacement are available.

\section{Maintenance}

Window maintenance should start with a survey that records the condition of every window in the building, identifying which ones are original. Window schedules should be prepared, listing all parts of each window unit. Perform simple maintenance first, repair as needed, replace damaged or missing parts in-kind, and replace the entire unit in-kind only if it cannot be repaired. Maintaining protective paint coatings is important to prevent decay of wood and rolled steel windows. The exterior of the windows should be checked periodically. Appropriate surface treatments such as cleaning, rust removal, limited paint removal, and reapplication of protective coating systems are necessary.

The replacement of windows is often proposed because of the condition or poor functioning. However, peeling paint, broken glass, stuck sashes, damaged hardware, and high air infiltration are no indication that windows are beyond their useful lives. These concerns can be addressed through repair and repainting, and replacement is not recommended. Windows that are repaired and properly maintained will have greatly extended service lives while contributing to the historic character of the building. When energy conservation is a concern, weatherization and/or the addition of storm doors will reduce heating and cooling costs, while helping to preserve the original materials and the paint finish.

\section{Identify, Retain, and Preserve}

Recommended...

- $\quad$ Identifying, retaining, and preserving windows - and their functional and decorative features - that are important in defining the overall historic character of the building. Such features can include frames, sash, muntins, glazing, heads, hoodmolds, and interior and exterior shutters and blinds.

- $\quad$ Conducting an in-depth survey of the conditions of existing doors early in rehabilitation planning so that repair and upgrading methods and possible replacement options can be fully explored.

Not Recommended...

- $\quad$ Removing or radically changing windows that are important in defining the historic character of the building so that, as a result, the character is diminished.

- $\quad$ Changing the number, location, size, or glazing pattern of windows, through cutting new openings, blocking-in windows, and installing replacement windows that do not fit the historic opening.

- $\quad$ Obscuring historic window trim with metal or other material.

- $\quad$ Stripping windows of historic material such as wood, cast iron, and bronze.

- $\quad$ Replacing windows solely because of peeling paint, broken glass, stuck sash, and high air filtration. These conditions, in themselves, are no indication that windows are beyond repair.

- Installation of security grills unless historically used or mission driven. If mission driven, then the design of the new grills needs to be compatible with the building. 


\section{Protect and Maintain}

Recommended...

- Protecting and maintaining the wood and architectural metal of which the window frame, sash, muntins, and surrounds are made through appropriate surface treatments such as cleaning, rust removal, limited paint removal, and reapplication of protective coatings.

- $\quad$ Evaluating the overall condition of materials to determine whether more than protection and maintenance are required, i.e., if repairs to windows and window features will be required.

Not Recommended...

- $\quad$ Failing to provide adequate protection of material on a cyclical basis so that deterioration of the window material is accelerated.

- $\quad$ Retrofitting or replacing window rather than maintaining the sash, frame, and glazing.

- $\quad$ Failing to undertake adequate measures to assure protection of historic windows.

\section{Repair}

Recommended...

- $\quad$ Repairing window frames and sashes by patching, splicing, consolidating, or otherwise reinforcing. Such repair may also include replacement in-kind—or with compatible substitute material—of those parts that are either extensively deteriorated or are missing when there are surviving prototypes.

Not Recommended...

- $\quad$ Replacing an entire window when repair of materials and limited replacement of deteriorated or missing parts are appropriate.

- $\quad$ Failing to reuse serviceable window hardware such as brass sash lifts and sash locks.

- $\quad$ Using substitute material for the replacement part that does not convey the visual appearance of the surviving parts of the window or that is physically or chemically incompatible.

\section{Replace}

Recommended...

- $\quad$ Replacing in-kind and entire window that is too deteriorated to repair using the same design details such as number of divided lights, panels, and hardware. If using the same kind of material is not technically or economically feasible when replacing windows deteriorated beyond repair; then a compatible substitute material may be considered.

Not Recommended...

- $\quad$ Removing a character-defining window that is unrepairable and blocking it in, or replacing it with a new window that does not convey the same visual appearance. 


\section{Good Example of Windows}

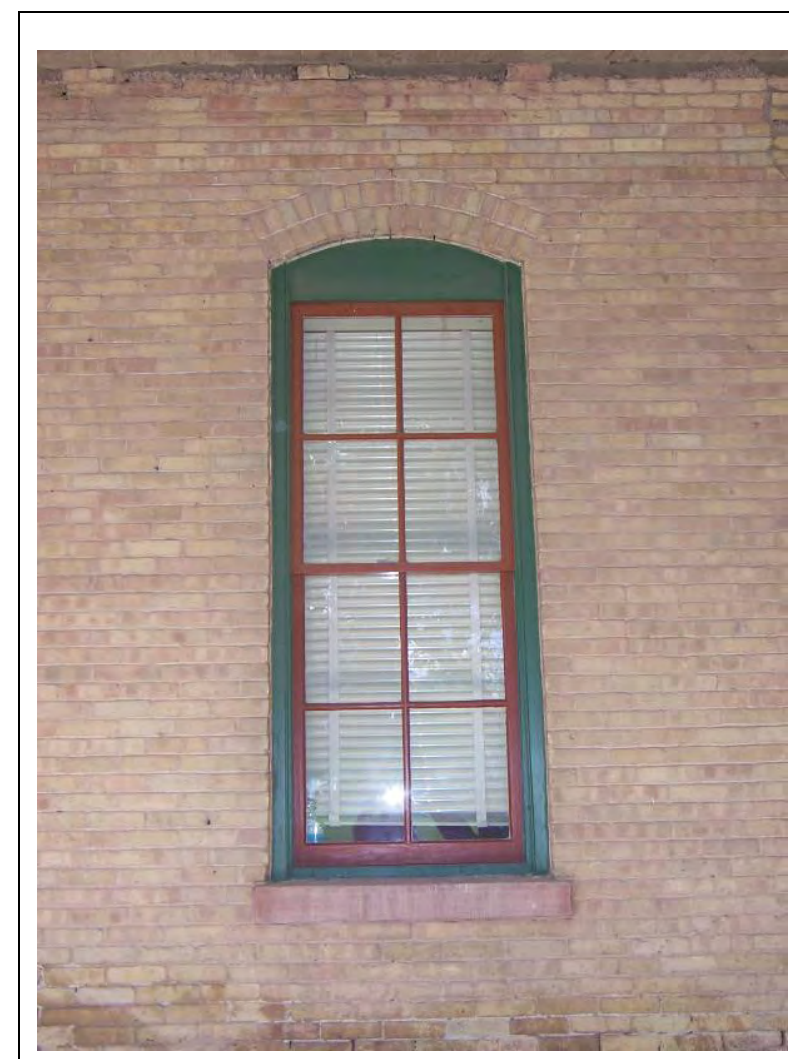

Building 13 - Original wood double-hung window with an arched opening.

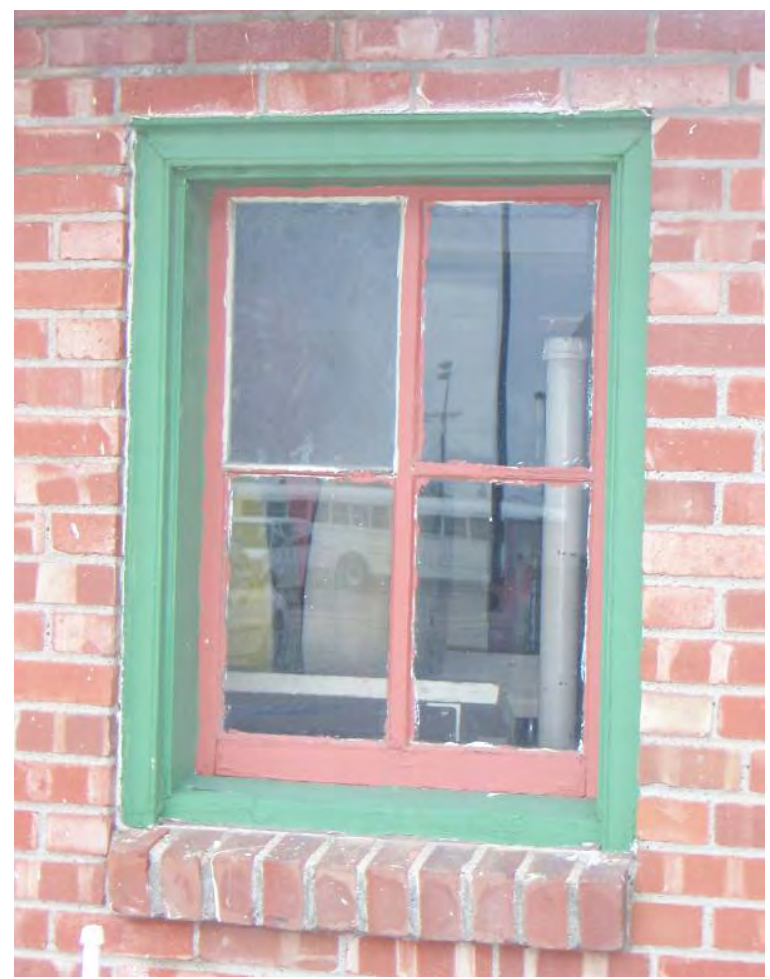

Building 54 - Divided-light fixed wood window that needs a little repair on the muntins.

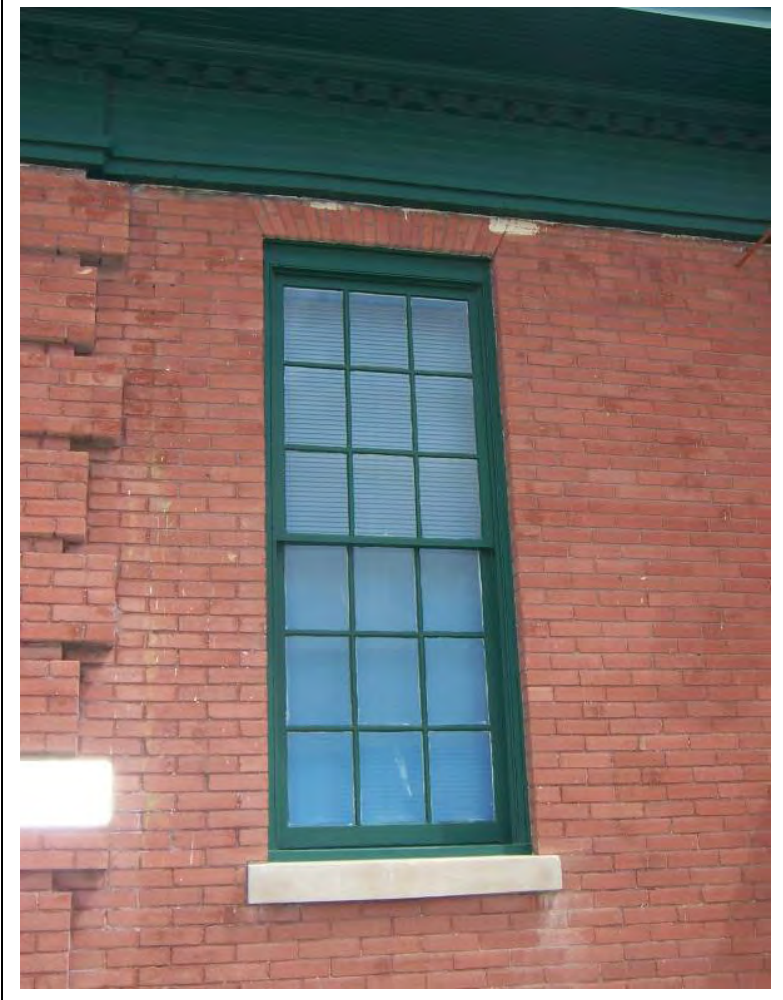

Building 51 - Another example of an original wood double-hung window.

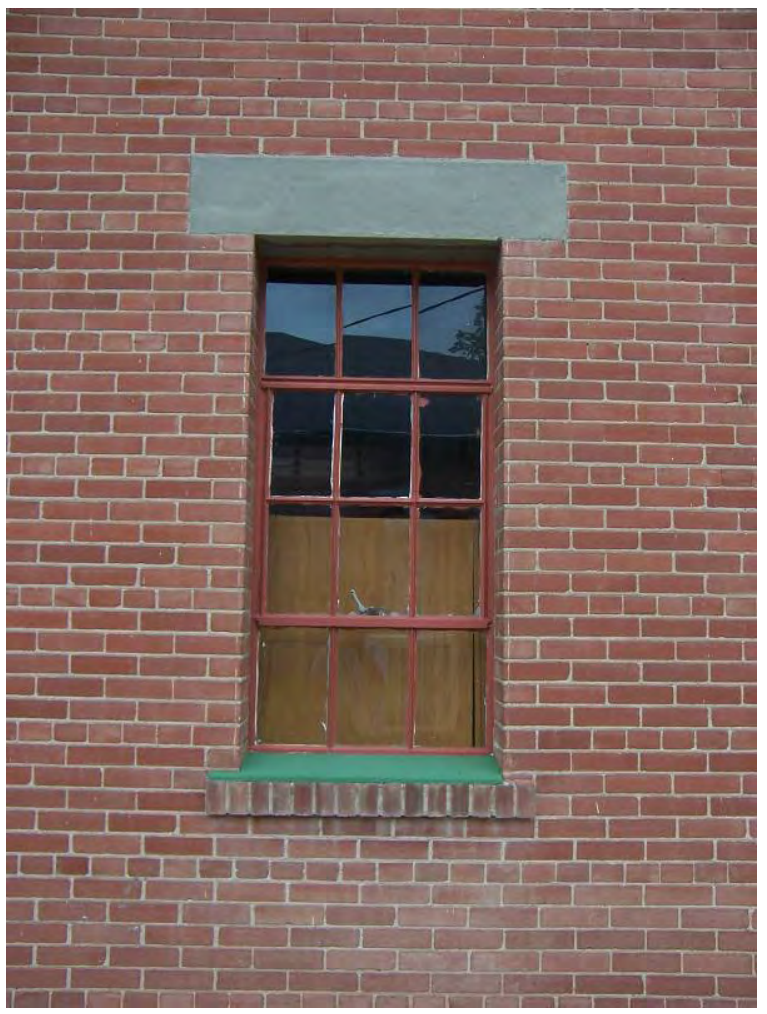

Building 54 - Metal divided-light awning window. 


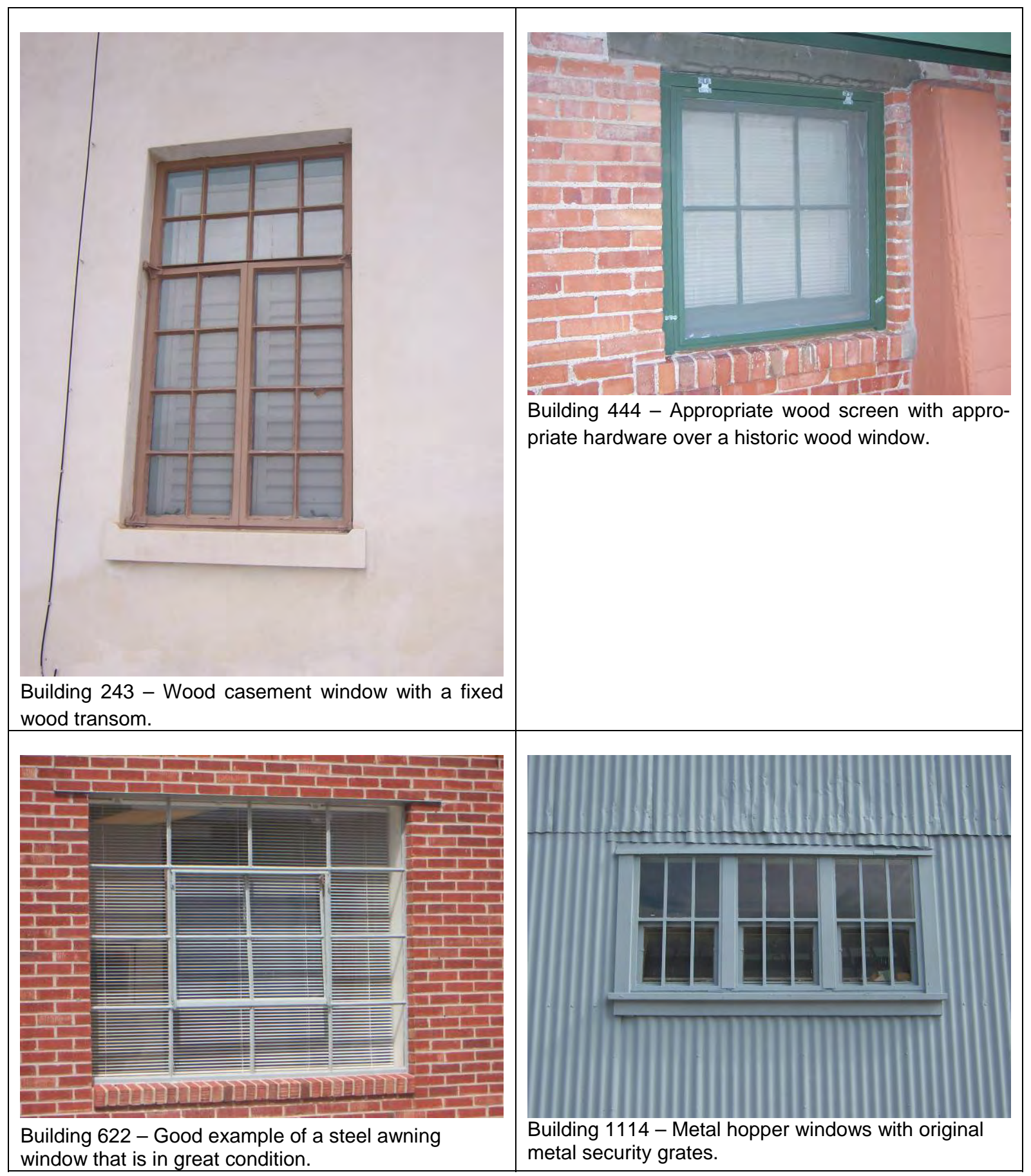




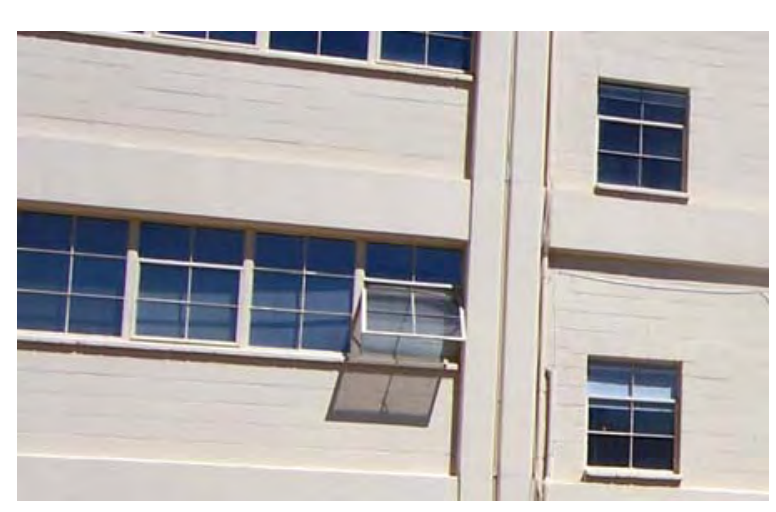

Building 1002 - Original six-pane steel awning windows on a concrete block building.

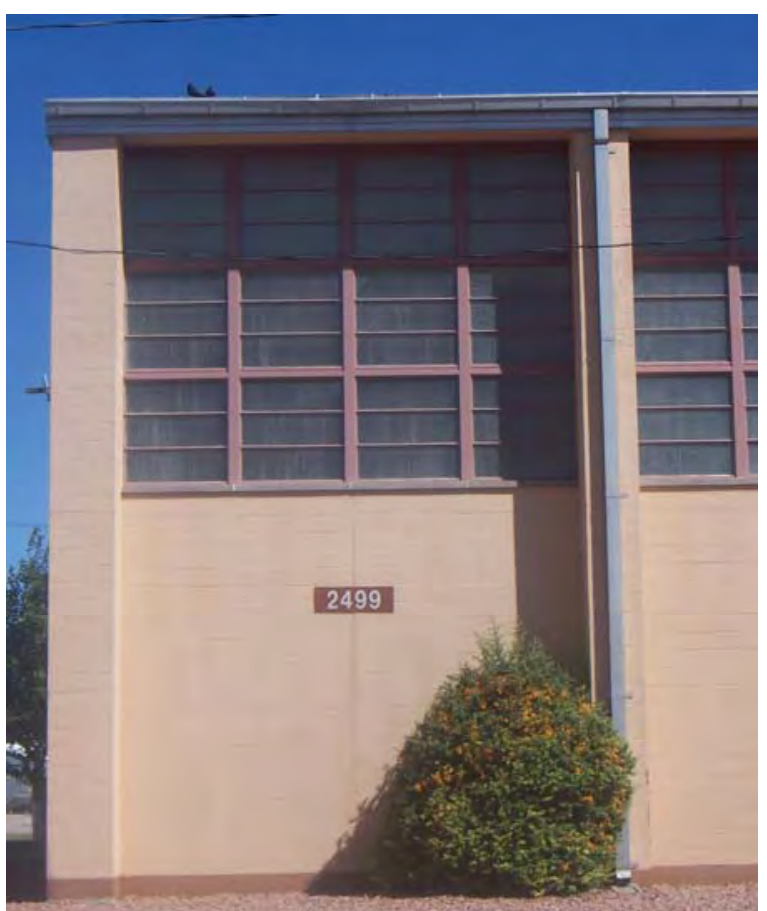

Building 2499 - Example of multi-pane steel industrial windows on a concrete block building

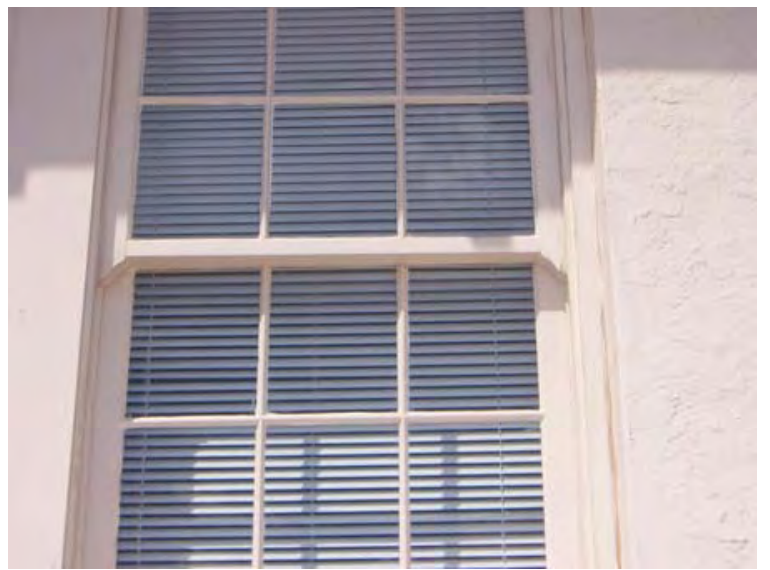

Building 7167 - Original wood double-hung window. 


\section{Windows: Wood}

Original windows shall be retained unless they are damaged beyond reasonable repair. If windows are beyond repair due to rot, dry rot or substantial insect damage and must be replaced, the replacement shall be manufactured to the exact size of the original window opening, duplicating the pane pattern exactly. The frame and trim shall be retained, or replicated, when damaged beyond repair. For replacement windows, either true divided light (the single-pane of glass within a wood frame) or simulated true-divided light (where the wood frame is glued over a thermal glass "sandwich" and cannot be removed) glazing is recommended. The simulated true-divided light sash replicates the historic appearance with accurate shadow lines provided by the depth and molding profile of the sash muntins. Inserted or removable grills do not replicate these characteristics of the original windows and shall not be used.

Wood is the preferred material for replacement of wood windows. Historic shutters shall not be removed. Shutters are generally recommended only if originally used on the building, which is often documented with historic photographs. Replacement shutters shall match historic shutters in size, design, material, color, method of installation, and operation.

When a prominent historic window is too deteriorated, or the existing window is not historic, it may make sense to re-use a similar exterior window from a less prominent location such as side or rear entrance.

Problems with wood windows include:

- $\quad$ termite infestation,

- $\quad$ water infiltration,

- $\quad$ misalignment and difficulty in opening or closing due to uneven settlement of the wood frame and building, and/or

- $\quad$ peeling paint and putty.

In most cases, except for where misalignment is due to uneven settlement of the building, the damage can be easily repaired. Generally the actions necessary to

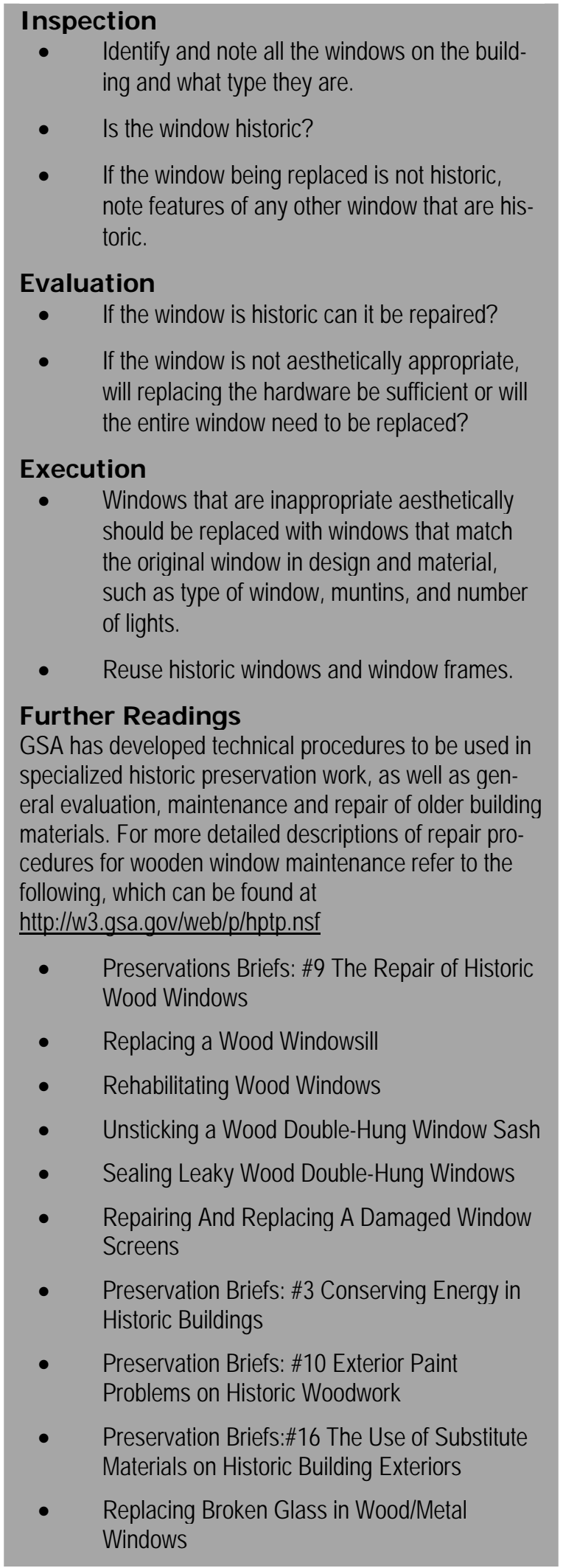

\section{nspection} ing and what type they are.

Is the window historic?

If the window being replaced is not historic, note features of any other window that are historic.

- If the window is historic can it be repaired?

If the window is not aesthetically appropriate, will replacing the hardware be sufficient or will the entire window need to be replaced?

\section{xecution}

should be replaced with windows that match the original window in design and material, such as type of window, muntins, and number

.

\section{Further} eral evaluation, maintenance and repair of older building materials. For more detailed descriptions of repair procedures for wooden window maintenance refer to the following, which can be found at htp://w3.gsa.gov/web/p/hptp.ns

- $\quad$ Preservations Briefs: \#9 The Repair of Historic Wood Windows

- $\quad$ Replacing a Wood Windowsil

- $\quad$ Rehabilitating Wood Windows

- Unsticking a Wood Double-Hung Window Sash

- $\quad$ Sealing Leaky Wood Double-Hung Windows

Repairing And Replacing A Damaged Window Screens Historic Buildings

Preservation Briefs: \#10 Exterior Pain

Preservation Briefs:\#16 The Use of Substitute Paterials on Historic Building Exteriors Windows 
return a window to "like new" condition will fall into three broad categories:

- $\quad$ Routine maintenance: paint removal, cleaning, repair of weather stripping, repainting, and adding wood consolidant where deteriorated and epoxy filler or sections of wood are cracked or missing.

- $\quad$ Structural stabilization: dry the wood, treat decayed areas with fungicide, waterproof with two or three applications of boiled linseed oil, fill cracks and holes with putty or wood filler, and paint the surface.

- $\quad$ Replacement or refurbishment of parts: including hardware.

\section{Inspection}

Recommended...

- Identifying, retaining, and preserving windows - and their functional and decorative features - that are important in defining the overall historic character of the building. Such features can include frames, sash, muntins, glazing, heads, hoodmolds, and interior and exterior shutters and blinds.

- $\quad$ Conducting an in-depth survey of the conditions of existing windows early in rehabilitation planning so that repair and upgrading methods and possible replacement options can fully explored.

- $\quad$ Protecting and maintaining the wood and architectural metal of which the window frame, sash, muntins, and surrounds are made through appropriate surface treatments such as cleaning, rust removal, limited paint removal, and reapplication of protective coatings.

Not Recommended...

- $\quad$ Failing to provide adequate protection of material on a cyclical basis so that deterioration of the window material is accelerated.

- $\quad$ Failing to undertake adequate measures to assure protection of historic windows. 

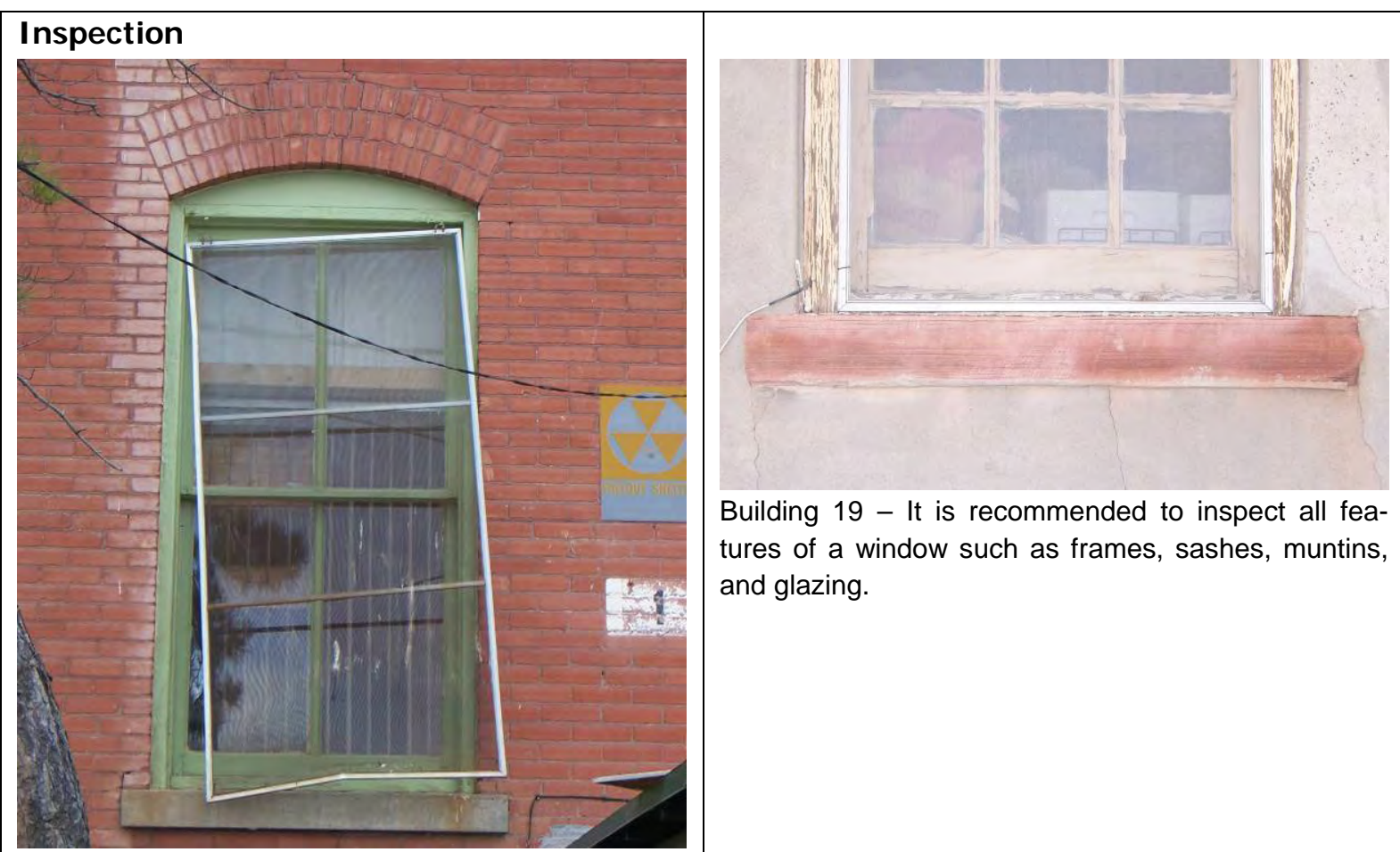

Building 19 - It is recommended to inspect all features of a window such as frames, sashes, muntins, and glazing.

Building 1 - The aluminum frame screen is inappropriate for this wood window type. It should be removed and replaced with an appropriate wood screen.

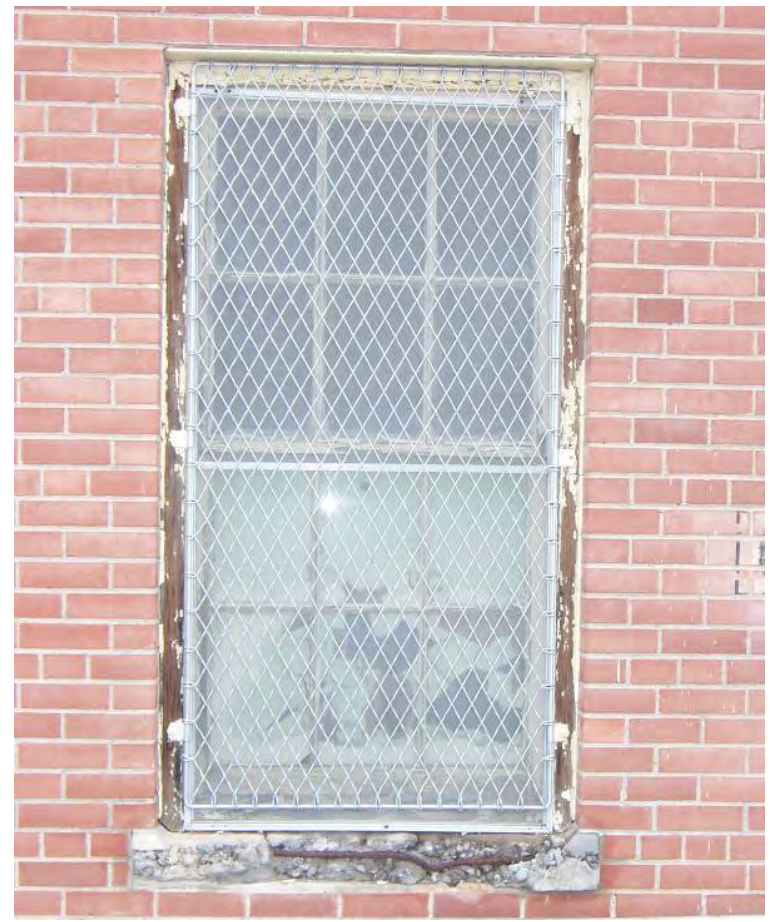

Building 612 - An inspection of all windows will find the appropriate treatments to damaged historic windows. If damaged beyond repair, the replacement window shall be manufactured to the original window in design and material. 


\section{Evaluation}

The following is a checklist of items to be covered when evaluating the condition of a wood window:

- Condition of the paint: One clue to the areas suffering from excessive moisture is the condition of the paint; therefore, each window should be examined for areas of paint failure. Paint blistering, cracking, flaking, and peeling usually indicate points of water penetration, moisture saturation, and potential deterioration. Failure of the paint should NOT, however, be mistakenly interpreted as a sign that the wood is unrepairable.

- $\quad$ Condition of the frame and sill: Poor design of the exterior windowsill is a frequent problem. Window deterioration usually begins on horizontal surfaces and at joints where water collects, causing the wood to become saturated.

- $\quad$ Condition of the window: Cracks or any signs of wood swelling and splitting are serious problems.

- $\quad$ Glazing problems: Inspect and evaluate the divided lights in windows.

- $\quad$ Hardware: Check hardware frequently for signs of disrepair.

- $\quad$ Operational soundness: Examine each window for operational soundness beginning with the lower parts of the frame. Stiffness in operation of the window can weaken the joints, causing movement and slight separation. This process makes the joints vulnerable to water, which is readily absorbed in the end-grain of the wood.

Recommended...

- $\quad$ Evaluating the overall condition of materials to determine whether more than protection and maintenance are required, i.e., if repairs to windows and window features will be required.

Not Recommended...

- $\quad$ Removing or radically changing windows that are important in defining the historic character of the building so that, as a result, the character is diminished.

- $\quad$ Changing the number, location, size, or muntin pattern through cutting new openings, blocking-in windows, and installing replacement windows that do not fit the historic opening.

- $\quad$ Obscuring historic window trim with metal or other material. 


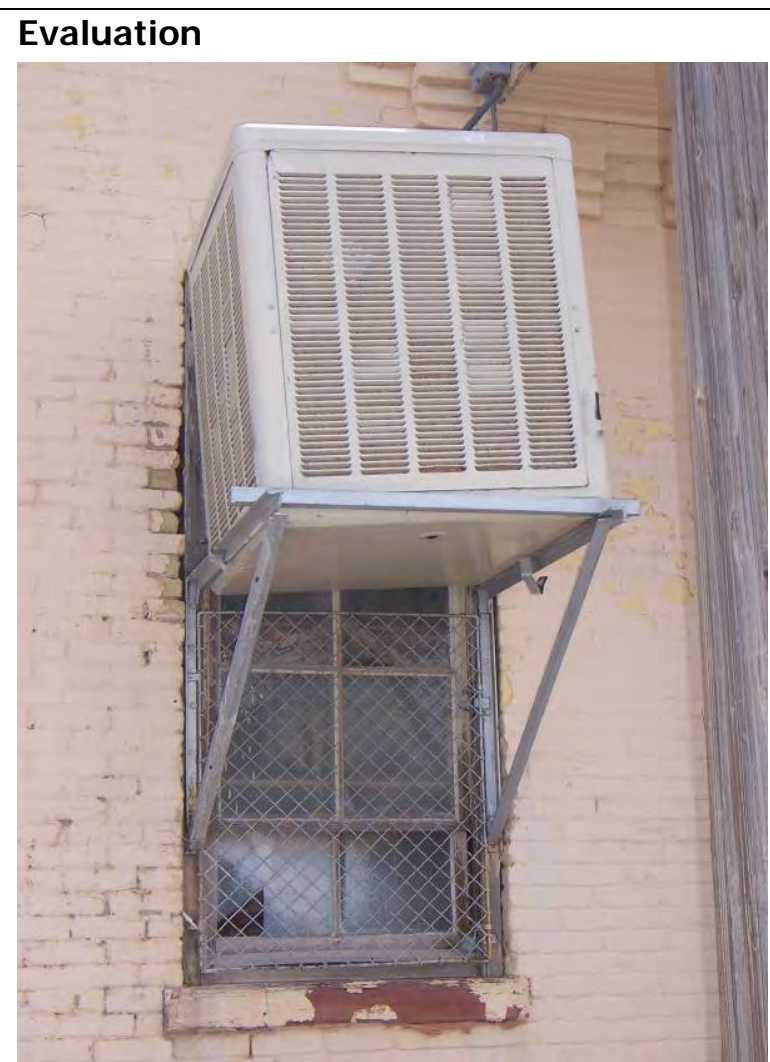

Building 21 - This is a poor example of a window modification because of the evaporation cooler placement. The cooler needs to be removed and the overall condition of the window needs to be evaluated and the proper repairs need to be done.

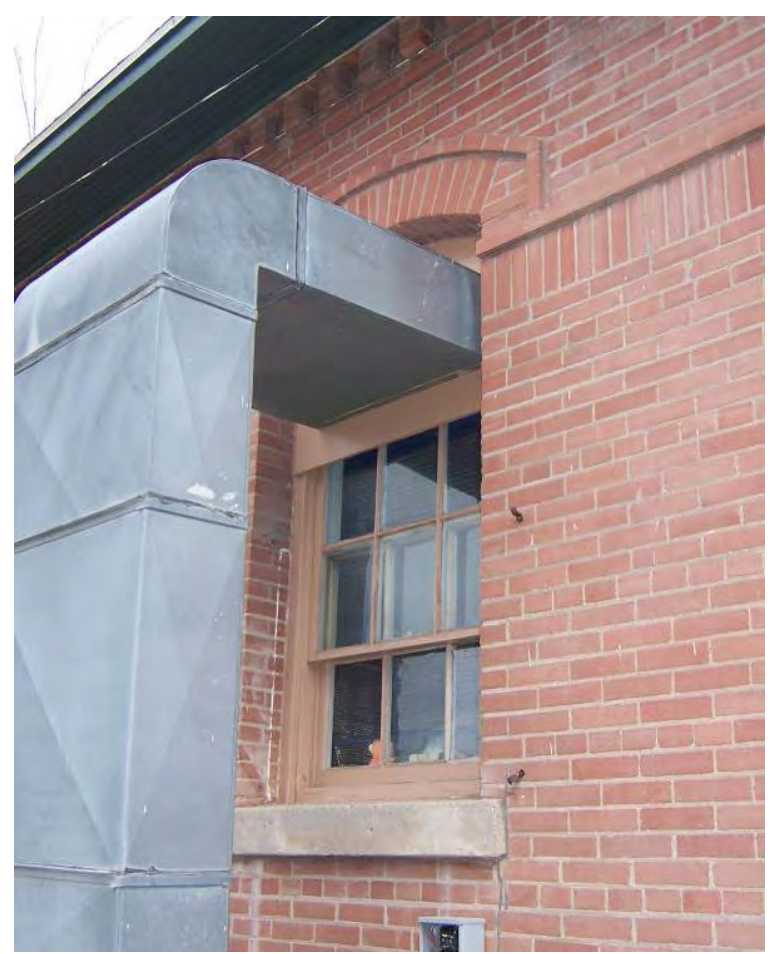

Building 55 - Another poor example of mechanical system placement within a windowsash.

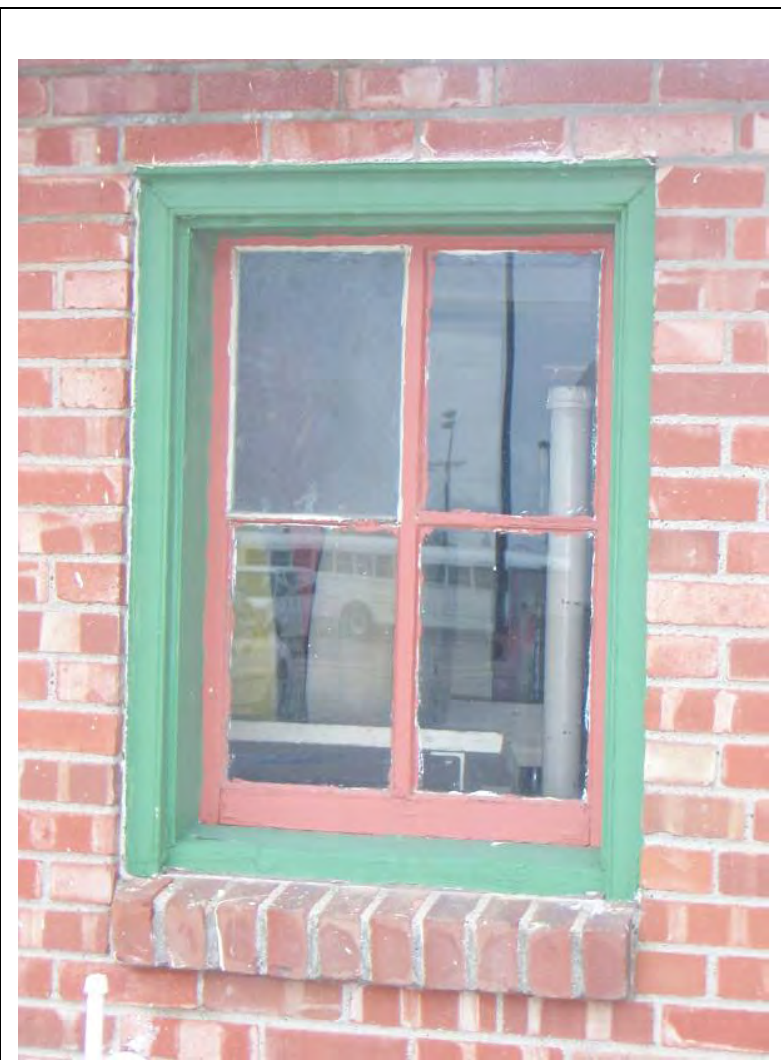

Building 54 - Evaluate the condition of the glazing. Inspect and evaluate the divided lights in the window and the muntins.

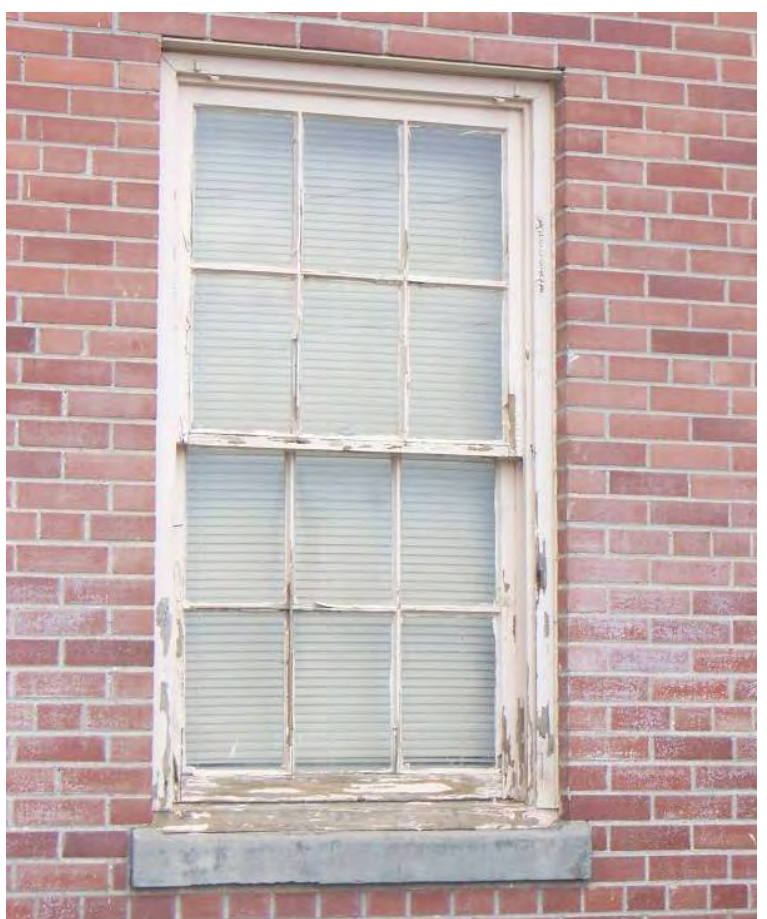

Building 628 - Evaluated the condition of the paint. If windows need to be repainted, do so in accordance with the paint analysis. 


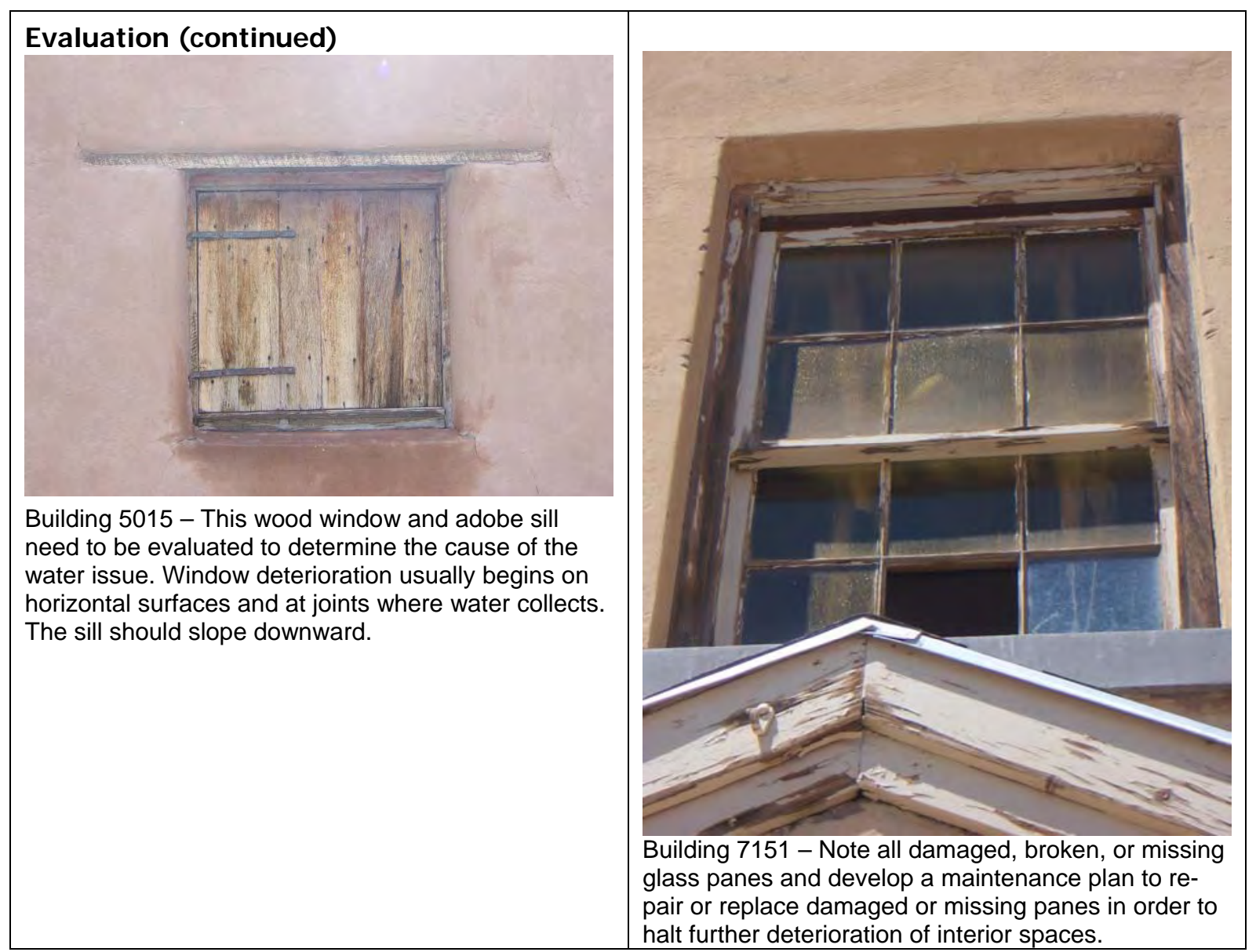

\section{Execution}

- If windows will be repainted in the historic colors, do so in accordance with the paint analysis, or conduct such an analysis to determine the original colors before beginning to remove paint.

- $\quad$ Remove excessive or deteriorated paint as needed to the next sound layer.

- $\quad$ Strip the paint using an appropriate method. Avoid the use of mechanical abrasive scraping techniques that may damage the wood and its profiles.

- $\quad$ Use care not to damage the profile of the moldings with scraping.

- $\quad$ Sand carefully so as not to blunt the edges of the moldings.

- If using a heat gun, either remove the divided lights in the window or protect them from sudden temperature changes with gypsum board covered with aluminum foil.

- $\quad$ Correct any conditions, including poor design, which permit water to come in contact with the wood or to puddle on the sill.

- $\quad$ Prime dried-out wood with linseed oil before repainting.

- $\quad$ Caulk gaps between joints and seams.

- $\quad$ Check glazing putty for cracked, loose, or missing sections around divided lights. 


\section{Repair}

Recommended...

- $\quad$ Repairing defective windowsills to permit positive drainage. The sill should be sloped downward away from the building.

- Immediately repairing gaps in sealant joints between the window frame and walls of the structure that might let moisture into the wood.

- If too deteriorated, repair or replace decayed wood using epoxies or by slicing new wood.

- $\quad$ Repairing glazing putty where necessary.

- $\quad$ Re-glazing broken or missing lights.

- $\quad$ Repairing window frames and sashes by patching, splicing, consolidating, or otherwise reinforcing. Such repair may also include replacement in-kind—or with compatible substitute material—of those parts that are either extensively deteriorated or are missing when there are surviving prototypes.

Not Recommended...

- $\quad$ Stripping windows of historic material such as wood, cast iron, and bronze.

- $\quad$ Failing to reuse serviceable window hardware such as brass sash lifts and sash locks.

\section{Replace}

Recommended...

- $\quad$ Replacing in-kind an entire window that is too deteriorated to repair using the same design details such as number of divided lights, panels, and hardware. If using the same kind of material is not technically or economically feasible when replacing windows deteriorated beyond repair; then a compatible substitute material may be considered.

- $\quad$ Replacing existing aluminum frame screens with wood framed screens (where appropriate) during window rehab projects.

Not Recommended...

- $\quad$ Replacing windows solely because of peeling paint, broken glass, and high air filtration. These conditions, in themselves, are no indication that windows are beyond repair.

- $\quad$ Retrofitting or replacing windows rather than maintaining the window, sash, muntins, frame, and glazing.

- $\quad$ Replacing an entire window when repair of materials and limited replacement of deteriorated or missing parts are appropriate.

- $\quad$ Using substitute material for the replacement part that does not convey the visual appearance of the surviving parts of the window or that is physically or chemically incompatible.

- $\quad$ Removing a character-defining window that is unrepairable and blocking it in, or replacing it with a new window that does not convey the same visual appearance. 


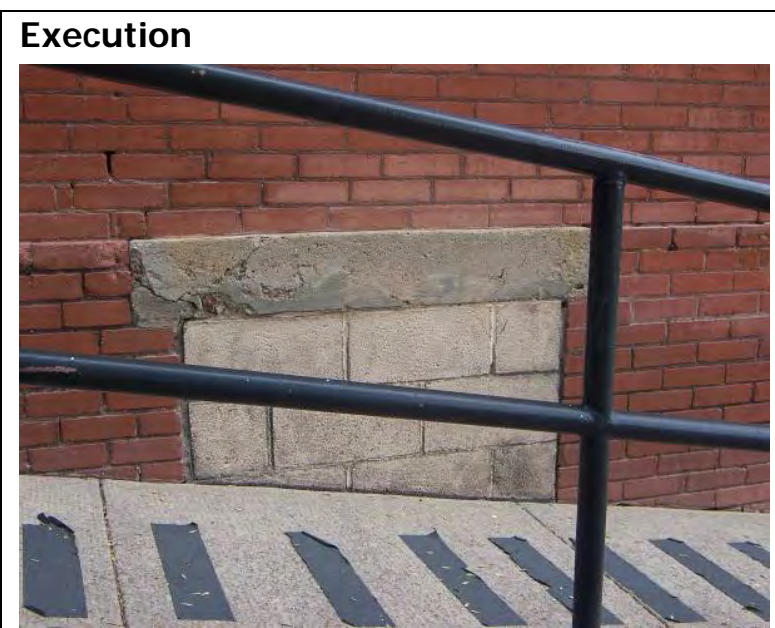

Building 1 - An ADA access ramp blocks the inappropriate concrete block infill of a window opening.

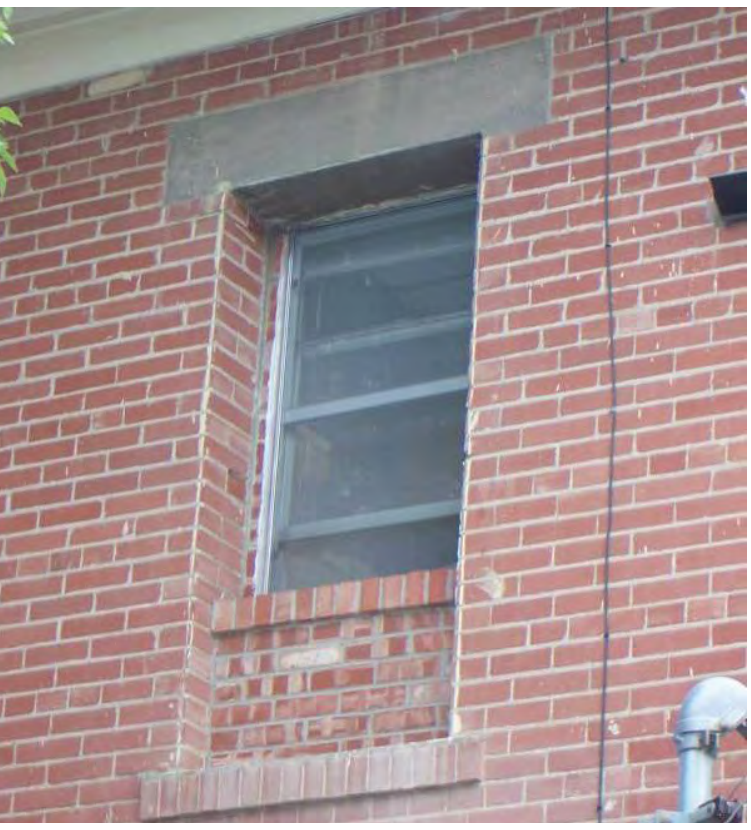

Building 54 - Poor example of window replacement. It is not recommended to modify a window opening as shown above. The replacement window should be in-kind to the original

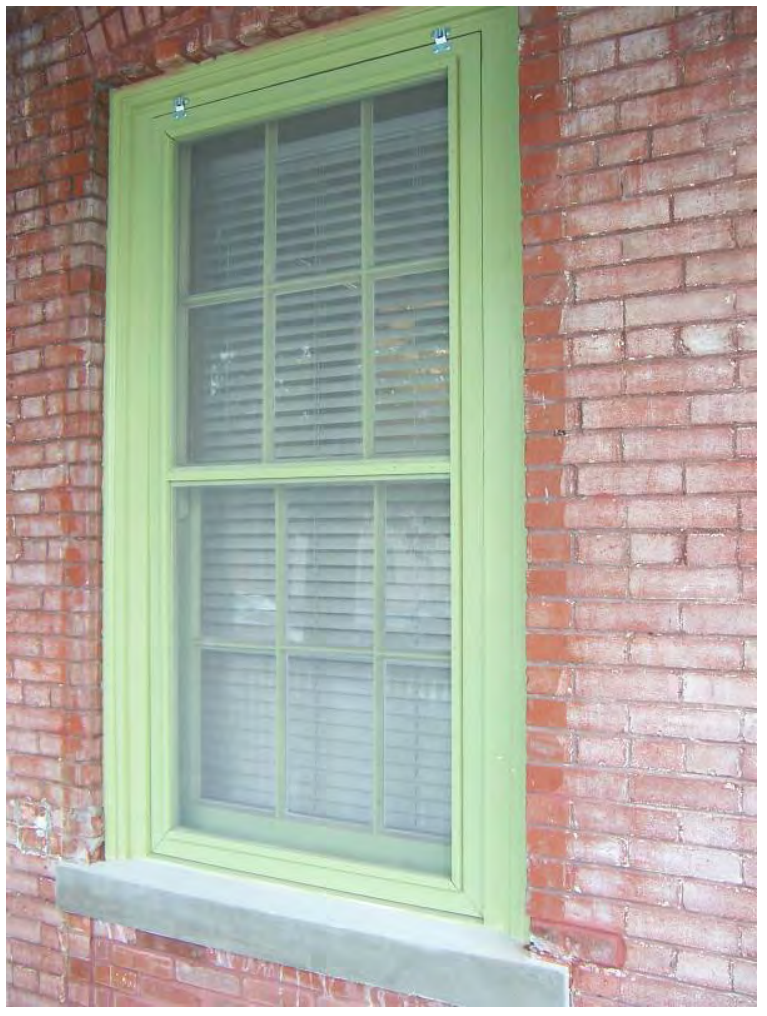

Building 4 - A good example of a replacement wood double-hung window and wood screen with appropriate hardware. The window was replaced in-kind to the original window.

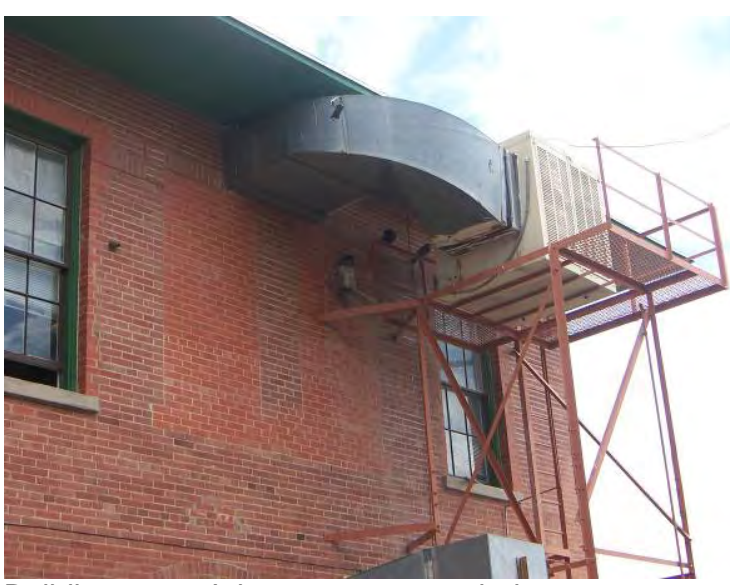

Building 113 - It is not recommended to remove character-defining windows and fill in the openings. 


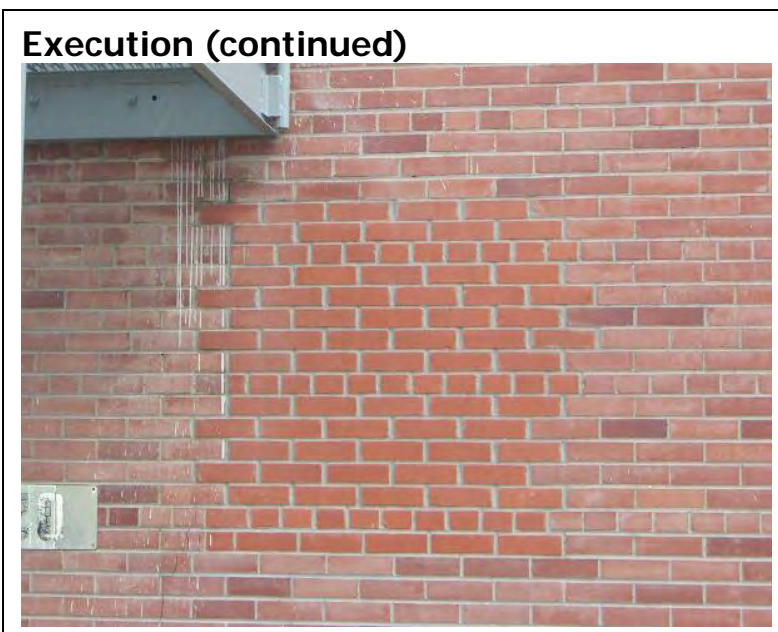

Building 620 - This infill is inappropriate. It does not meet standards. The infill should not convey the illusion that a window was never there.

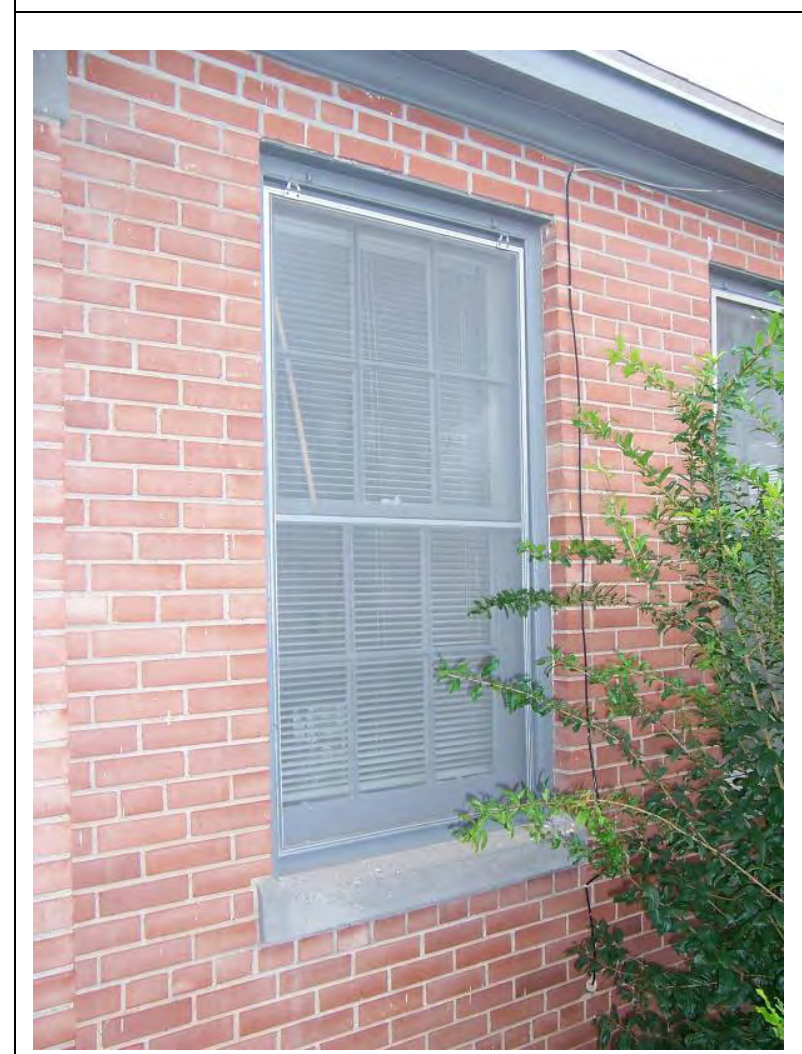

Building 629 - Inappropriate screen. The aluminum screen should be removed and replaced with a wood screen where appropriate.

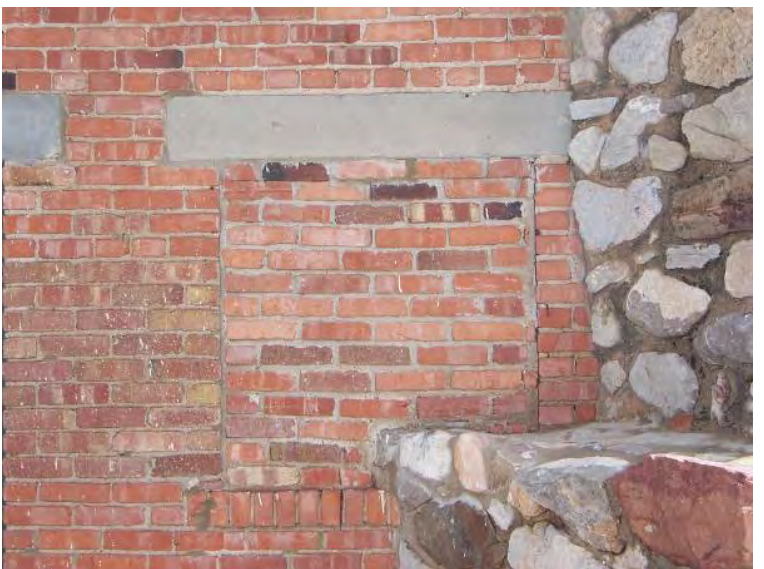

Building 624 - The brick is a proper infill material to use here; however, the brick should not be flush with the exterior wall. The infill should be set within the opening.

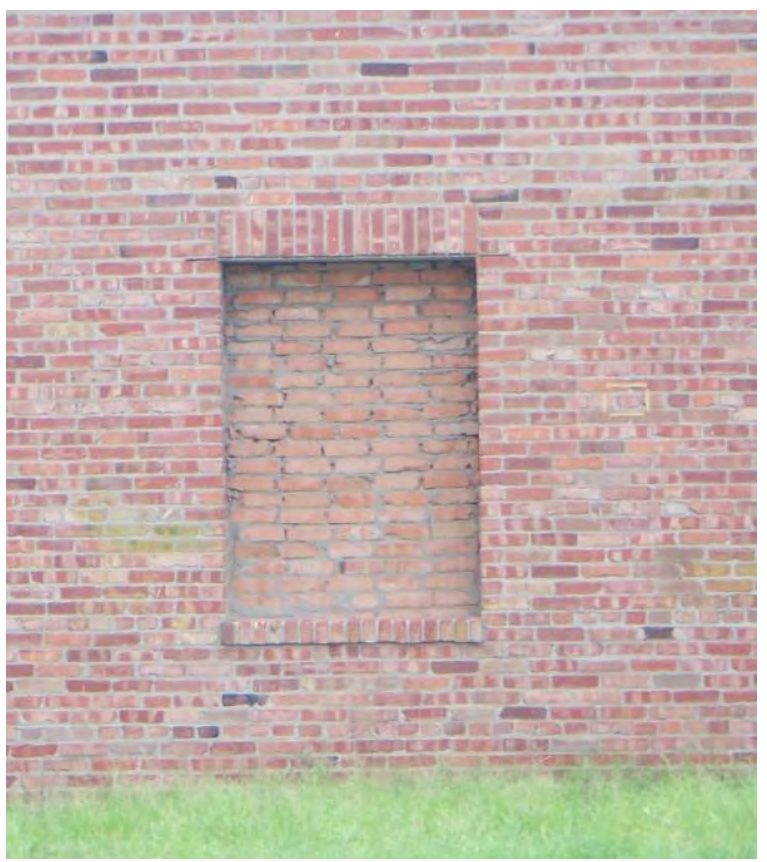

Building 730 - This is an appropriate infill for the original window opening since it is recessed and exhibits similar shadows of the original opening. 


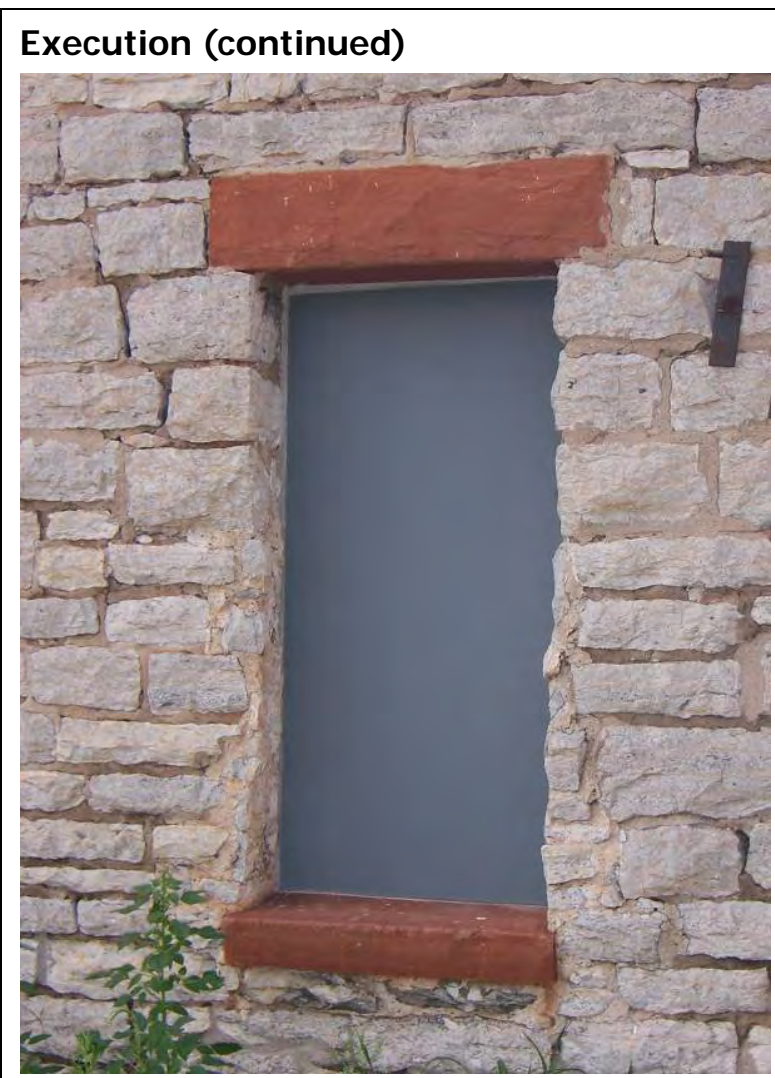

Building 2011 - Although this filled in window opening meets the standards, more appropriate materials could be used for the infill.

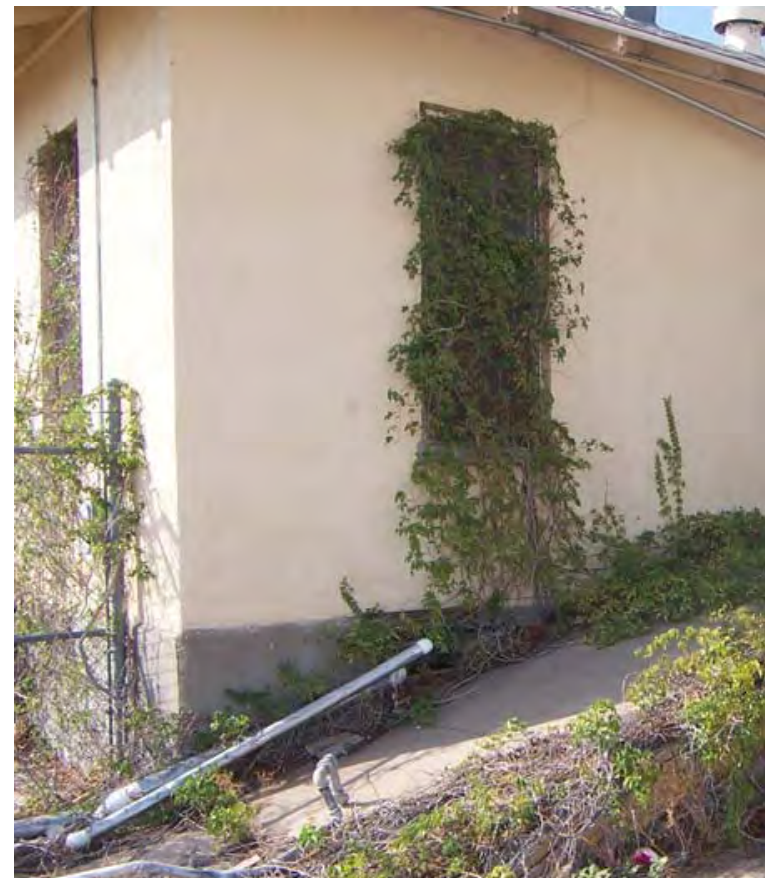

Building 7136 - The vegetation needs to be completely removed from the wood window in order to protect and preserve it.
Building 7115 - Do not remove any character-defining features of the window such as decorative grates. 
Notes

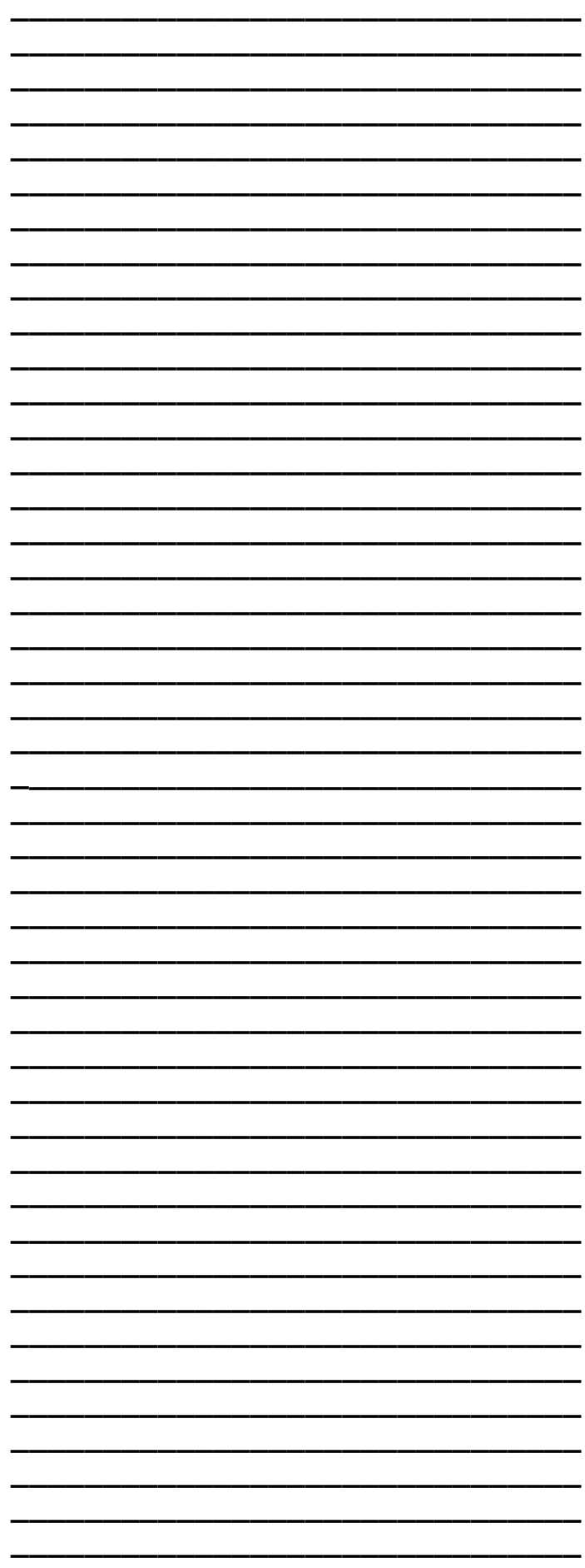




\section{Windows: Metal}

Rolled steel windows are most exclusively found in masonry or concrete buildings. Original windows shall be retained unless they are damaged beyond reasonable repair. The frame and trim shall be retained, or replicated, when damaged beyond repair. If a window must be replaced due to corrosion, the new window shall replicate the original window (if known) in size, proportion, material, shape, glazing pattern, and number of lights, including the use of true-divided lights. If the design of the original window is unknown, staff will work with the applicant to help determine a compatible replacement window.

When a prominent historic window is too deteriorated, or the existing window is not historic, it may make sense to re-use a similar exterior window from a less prominent location such as side or rear entrance.

Rusting or corrosion is the most frequent and easily recognizable form of metal deterioration. This process can take place at significantly different rates depending on the material composition, protective treatments applied, and severity of exposure. The presence of any rust on a metal element should alert the observer to the presence of a problem.

Many other factors can affect both corrosion and the rate of corrosion. Corrosion rates can also be accelerated where the detailing of the metal provides pockets which can collect and hold moisture and corrosive agents. Preventive maintenance plans should consider detailing, such as crevices and recessed areas, in establishing routine inspection techniques and frequency of inspection.

Routine maintenance of metal windows include paint removal, cleaning, removing rust, repair of weather stripping, repainting, and checking hardware for working operation (or replacing in-kind).

\section{Inspection}

- Identify and note all of the windows on the building and what type they are.

- Is the window historic?

- If the window being replaced is not historic, note features of any other window that are historic.

\section{Evaluation}

- If the window is historic can it be repaired?

- If the window is not aesthetically appropriate, will replacing the hardware be sufficient or will the entire window need to be replaced?

\section{Execution}

- Windows that are inappropriate aesthetically should be replaced with windows that match the original window in design and material, such as type of window, muntins, and number of lights.

- $\quad$ Reuse historic windows and window frames.

\section{Further Readings}

GSA has developed technical procedures to be used in specialized historic preservation work, as well as general evaluation, maintenance and repair of older building materials. For more detailed descriptions of repair procedures for metal window maintenance refer to the following, which can be found at http://w3.gsa.gov/web/p/hptp.nsf

- $\quad$ Guidelines for Rehabilitating Historic Buildings: Architectural Metals Hung Windows

- $\quad$ Cleaning and Painting Steel Windows

- Replacing Broken Glass in Wood and Metal Windows
- Installing Weatherstripping on Metal Double- 


\section{Inspection}

Recommended...

- $\quad$ Identifying the material of the window, window frame, and hardware.

- Identifying, retaining, and preserving windows - and their functional and decorative features - that are important in defining the overall historic character of the building. Such features can include frames, sash, muntins, glazing, heads, hoodmolds, and interior and exterior shutters and blinds.

- $\quad$ Conducting an in-depth survey of the conditions of existing windows early in rehabilitation planning so that repair and upgrading methods and possible replacement options can fully explored.

- $\quad$ Protecting and maintaining the metal and architectural metal of which the window, sash, window frame, and glass are made through appropriate surface treatments such as cleaning, rust removal, limited paint removal, and reapplication of protective coatings.

Not Recommended...

- $\quad$ Failing to provide adequate protection of material on a cyclical basis so that deterioration of the window material is accelerated.

- $\quad$ Failing to undertake adequate measures to assure protection of historic windows.

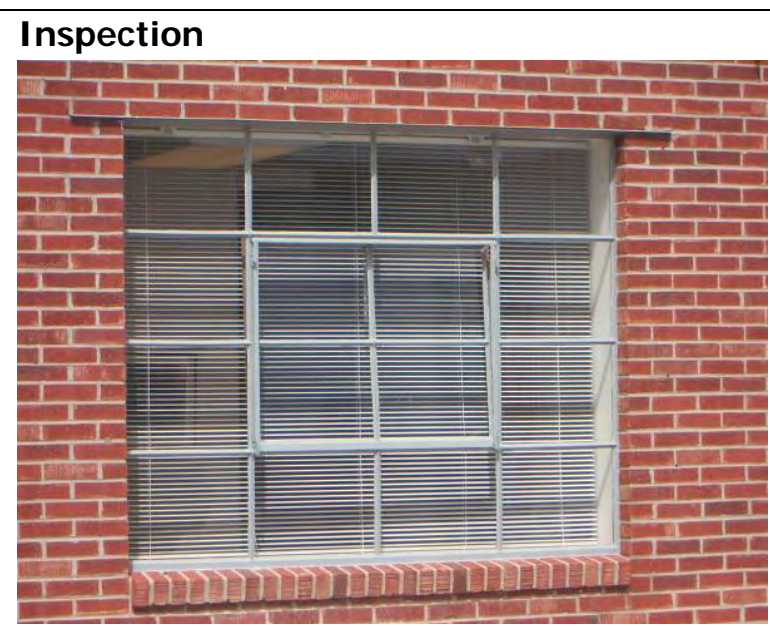

Building 622 - Conduct an in-depth survey of the condition of existing metal windows.

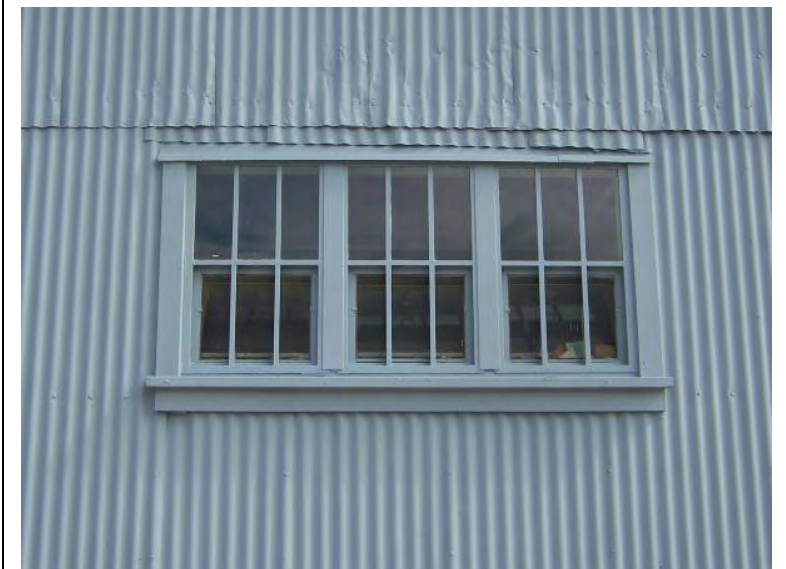

Building 1114 - It is required to protect and maintain the metal and architectural metal of which the window, sash, frame, and glass are made through appropriate window treatments. 


\section{Evaluation}

The following is a checklist of items to be covered when evaluating the condition of a metal window:

- $\quad$ The presence and the degree of corrosion: Test for the presence of corrosion because it is the controlling factor in metal repair. (Note: Corrosion and the maintenance of metals are discussed in the metal section of the report.)

- $\quad$ Condition of the paint: Cleaning, priming, and painting measures protect metals from further deterioration brought on by the environment and human-induced problems.

- $\quad$ Presence and condition of hardware, screws, bolts, and hinges: Inspect and evaluate the condition of the original hardware and note what remains intact and what has been replaced.

- $\quad$ Condition of masonry and concrete surround: Note any damage to the surround. The frames should be inspected regularly to ensure proper fit and therefore prevent any damage that may occur as a result of deterioration.

- Inspect how many layers of paint the sashes have where they meet the frames to ensure the windows operate and close properly. In some cases, too many layers of paint alter the operation of the window and do not allow the window to operate correctly.

Recommended...

- $\quad$ Evaluating the overall condition of materials to determine whether more than protection and maintenance are required, i.e., if repairs to windows and window features will be required.

Not Recommended...

- $\quad$ Removing or radically changing windows which are important in defining the historic character of the building so that, as a result, the character is diminished.

- Changing the number, location, or size, through cutting new openings, blocking-in windows, and installing replacement windows that do not fit the historic opening. 


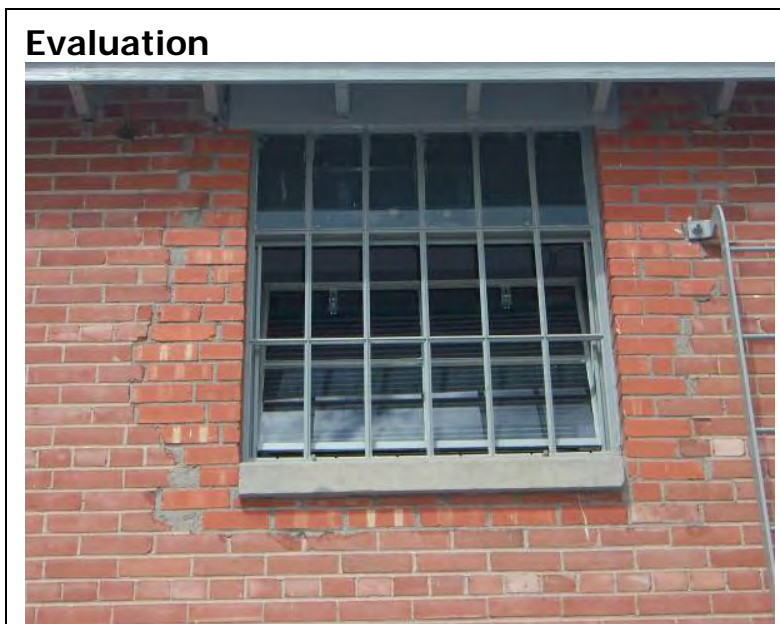

Building 624 - Evaluate the condition of the metal hopper window and determine if the metal security grate is original to the window design.

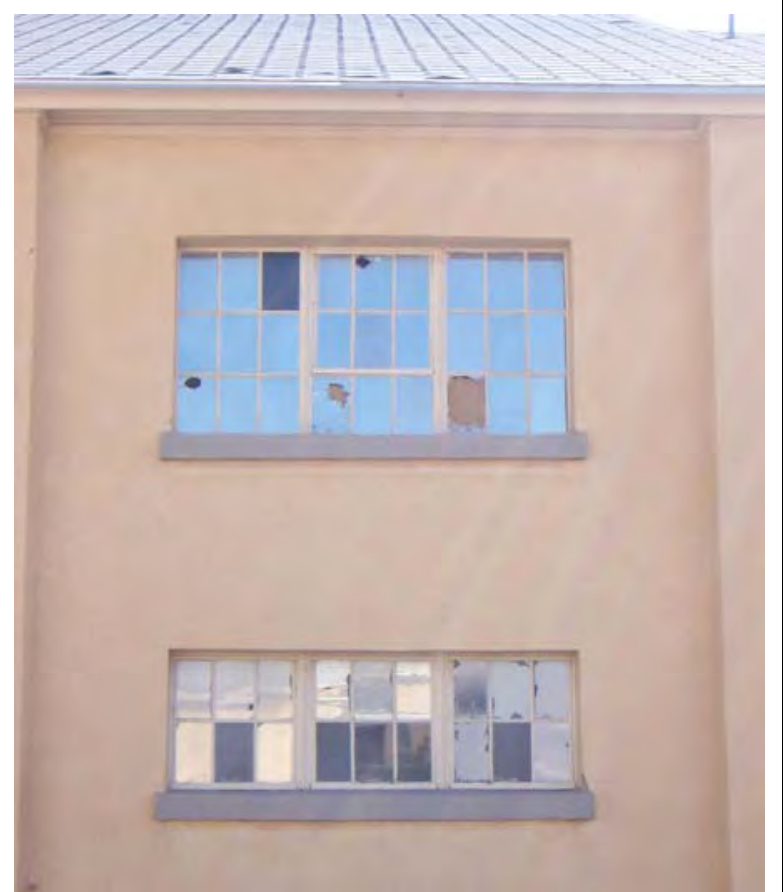

Building 7155 - Note all damaged, broken, or missing glass panes from windows. Develop a maintenance program to repair or replace the damaged or missing panes in order to prevent further deterioration of the interior of the building. 


\section{Execution}

- If windows will be repainted in the historic colors, do an analysis to determine the original colors before beginning to remove paint.

- $\quad$ Remove excessive or deteriorated paint as needed to the next sound layer.

- $\quad$ Strip the paint using an appropriate method, such as a hand-scraping, chemical or sandblasting. All treatments require removal of the glass.

- While repairing paint surfaces, protect adjacent materials such as glass and masonry.

- $\quad$ Correct any conditions, including poor design, which permit water to come in contact with the metal or to puddle on the sill, which could accelerate the deterioration of the metal elements.

- $\quad$ Check glazing putty for cracked, loose, or missing sections around glass.

\section{Repair}

Recommended...

- $\quad$ Repainting all steel section with two coats of finish paint compatible with the primer from the same manufacturer.

- $\quad$ Priming exposed metal with rust inhibiting primer.

- Immediately repairing gaps in sealant joints between the window frame and walls of the structure that might let moisture into the metal.

- If the corrosion of the metal is light, removing the rust, flaking, and excessive paint.

- $\quad$ Repairing glazing putty where necessary.

- $\quad$ Repairing window frames and sashes by patching, splicing, consolidating, or otherwise reinforcing. Such repair may also include replacement in-kind—or with compatible substitute material—of those parts that are either extensively deteriorated or are missing when there are surviving prototypes.

Not Recommended...

- $\quad$ Stripping windows of historic material.

- $\quad$ Failing to reuse serviceable window hardware such as brass sash lifts and sash locks.

\section{Replace}

Recommended...

- $\quad$ Replacing in-kind an entire window that is too deteriorated to repair using the same design details such as number of divided lights, panels, and hardware. If using the same kind of material is not technically or economically feasible when replacing windows deteriorated beyond repair; then a compatible substitute material may be considered.

- $\quad$ Hot-dipped galvanizing any steel replacement window or parts of windows to be installed.

- $\quad$ Replacing missing screws or fasteners.

- Considering replacement windows only as a last resort. If at all possible repair the deteriorated elements appropriately.

Not Recommended...

- $\quad$ Replacing windows solely because of peeling paint, broken glass, and high air filtration. These conditions, in themselves, are no indication that windows are beyond repair. 
- $\quad$ Retrofitting or replacing windows rather than maintaining the window, sash, muntins, and glazing.

- $\quad$ Replacing an entire window when repair of materials and limited replacement of deteriorated or missing parts are appropriate.

- $\quad$ Using substitute material for the replacement part that does not convey the visual appearance of the surviving parts of the window or that is physically or chemically incompatible.

- $\quad$ Removing a character-defining window that is unrepairable and blocking it in, or replacing it with a new window that does not convey the same visual appearance

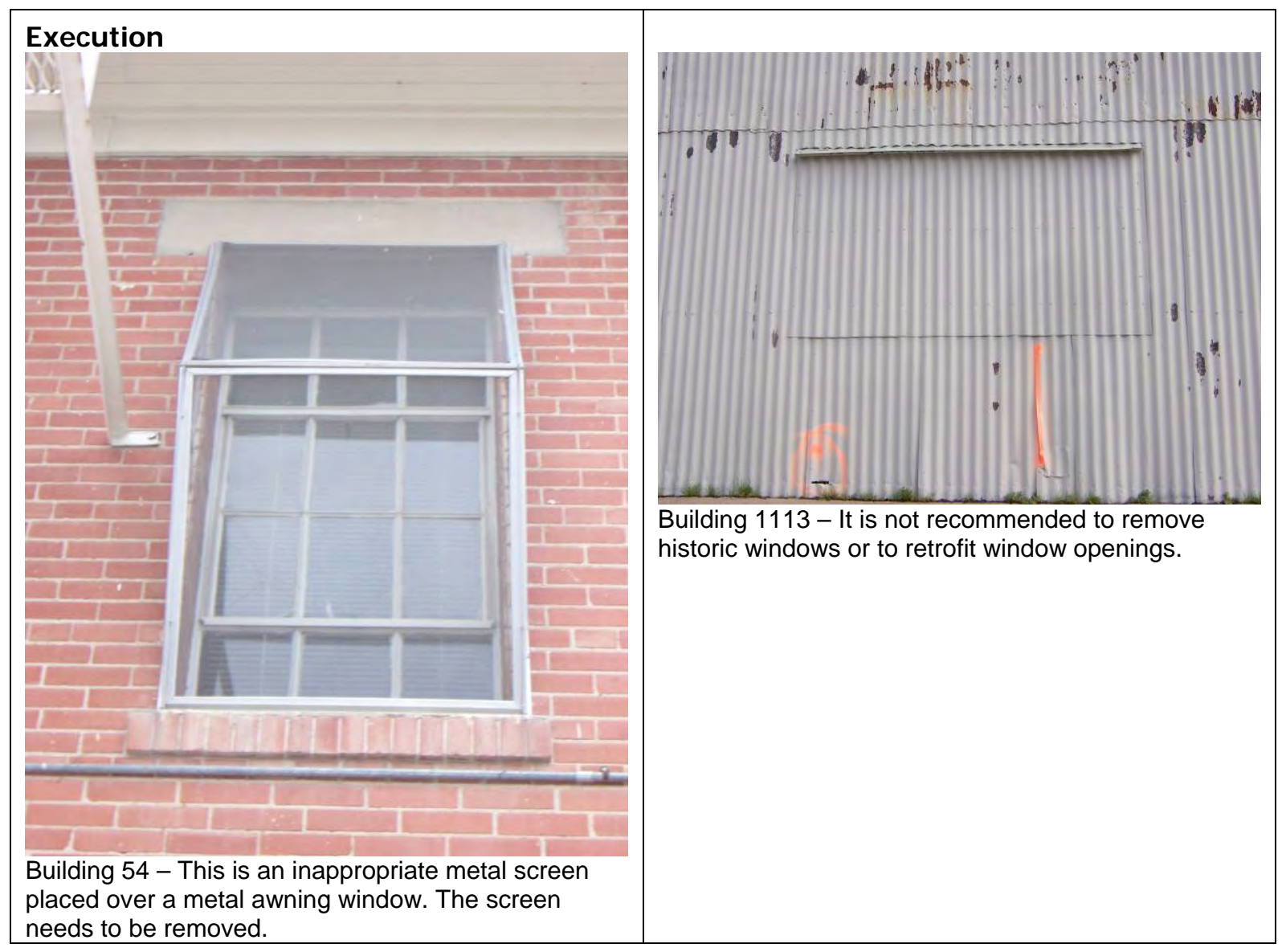




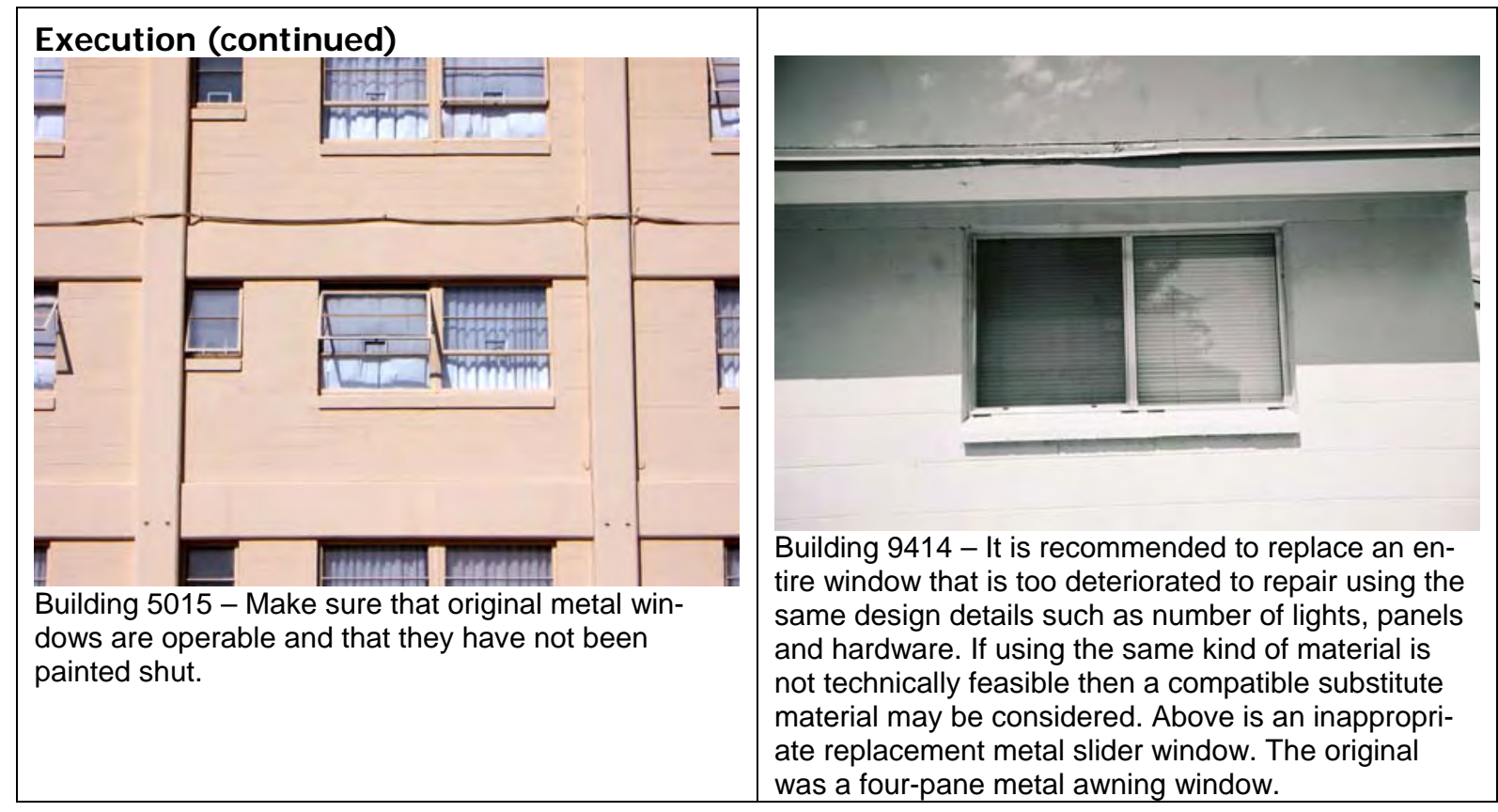


Notes

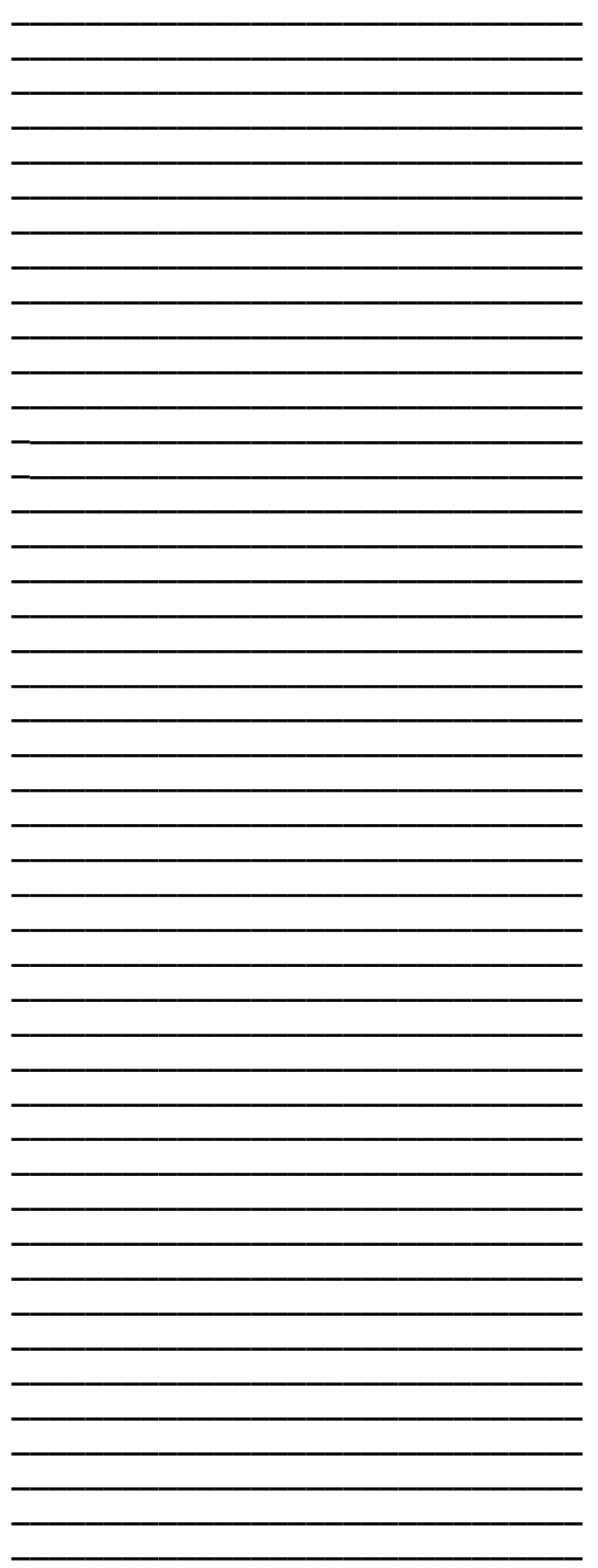




\section{Maintenance Guides for Hardware}

\section{Hardware: Overview}

Door and window hardware is a significant character-defining feature in historic buildings. Hardware includes knob, knob and lock plates, locks, pull handles, and hinges. The hardware for most DoD buildings is typically very simple and usually is steel, stainless steel, brass, or bronze.

All historic hardware should be retained and reused. Where missing, replacement hardware should match the material and design of the original hardware as closely as possible.

The first item that needs to be done is to identify all of the hardware on both the interior and exterior of a building. Their identification needs to take place together with an evaluation of their condition early in project planning. Note whether the hardware is historic to the building or if it has been replaced.

In some cases, older locksets can have their locking mechanism disabled and remain as part of the door hardware as a passage set knob accompanied by a new compatible deadbolt.

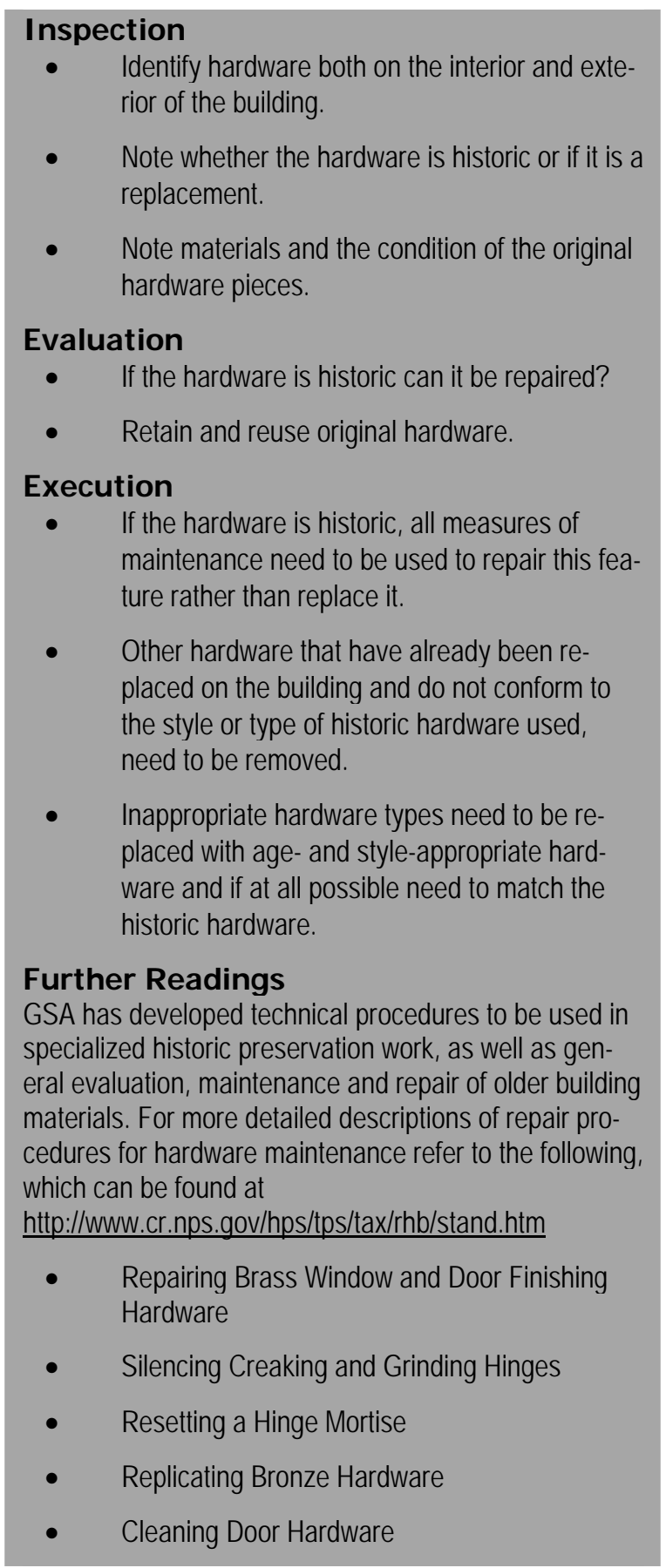




\section{Knobs/Handles and Knob Plates}

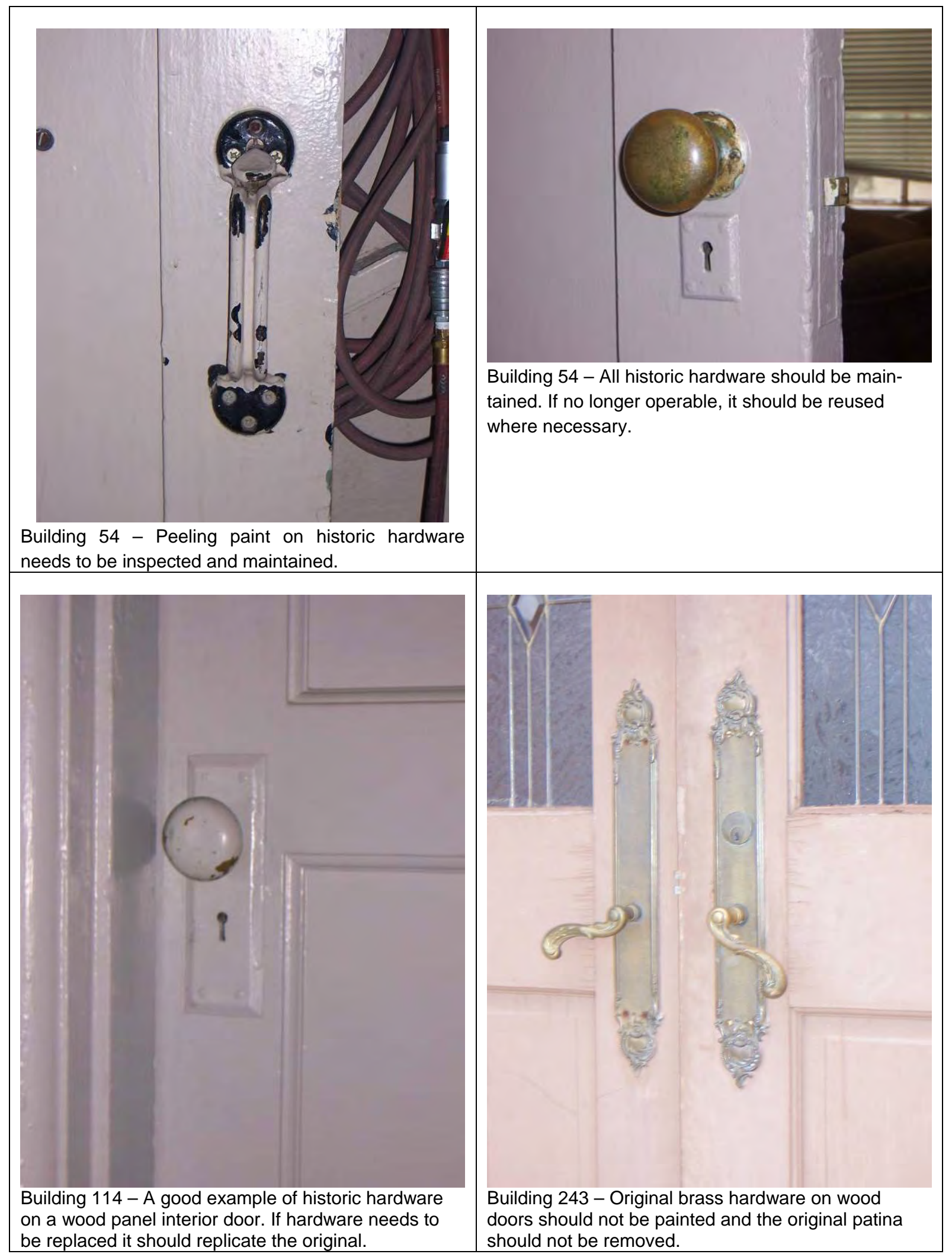




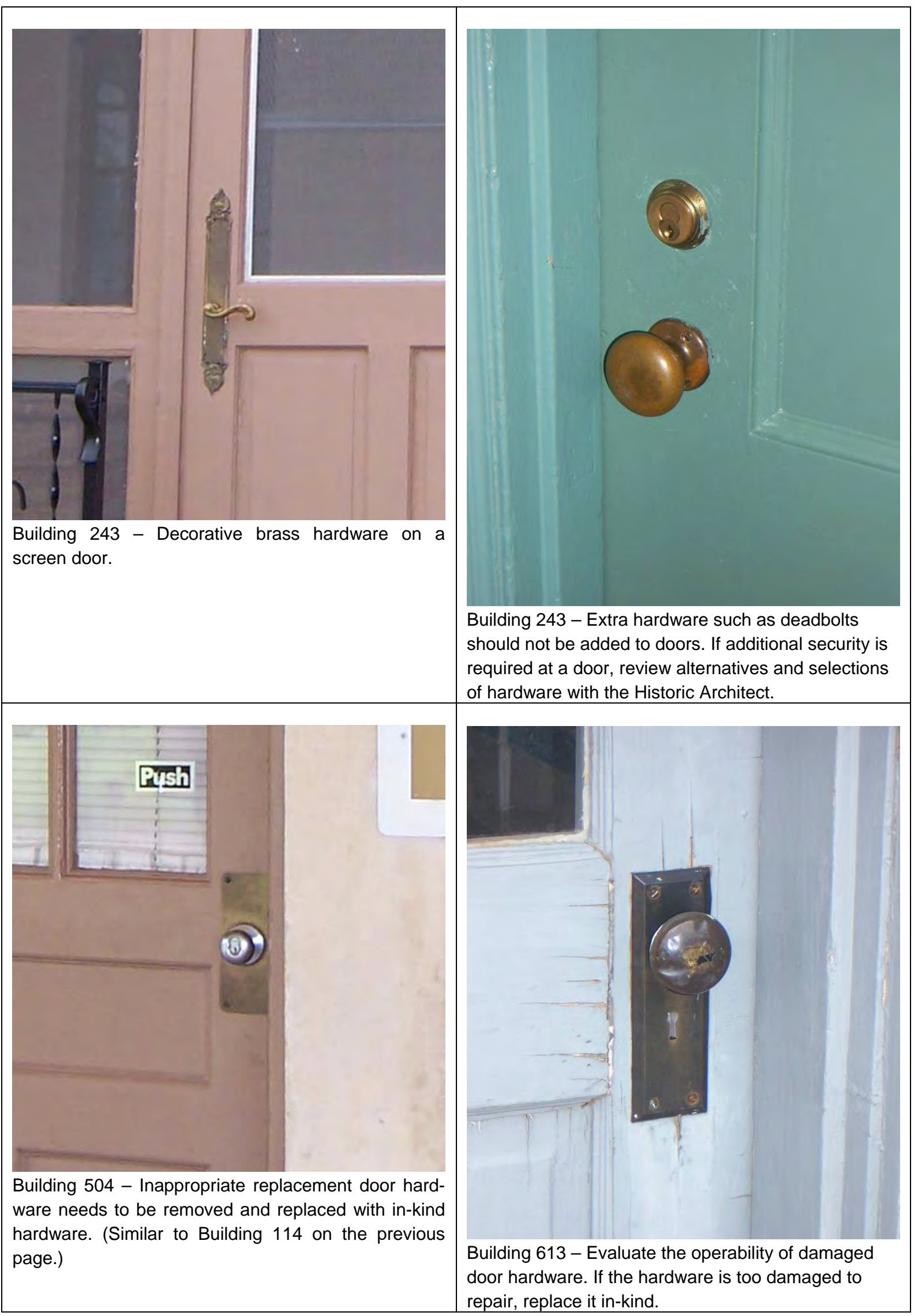




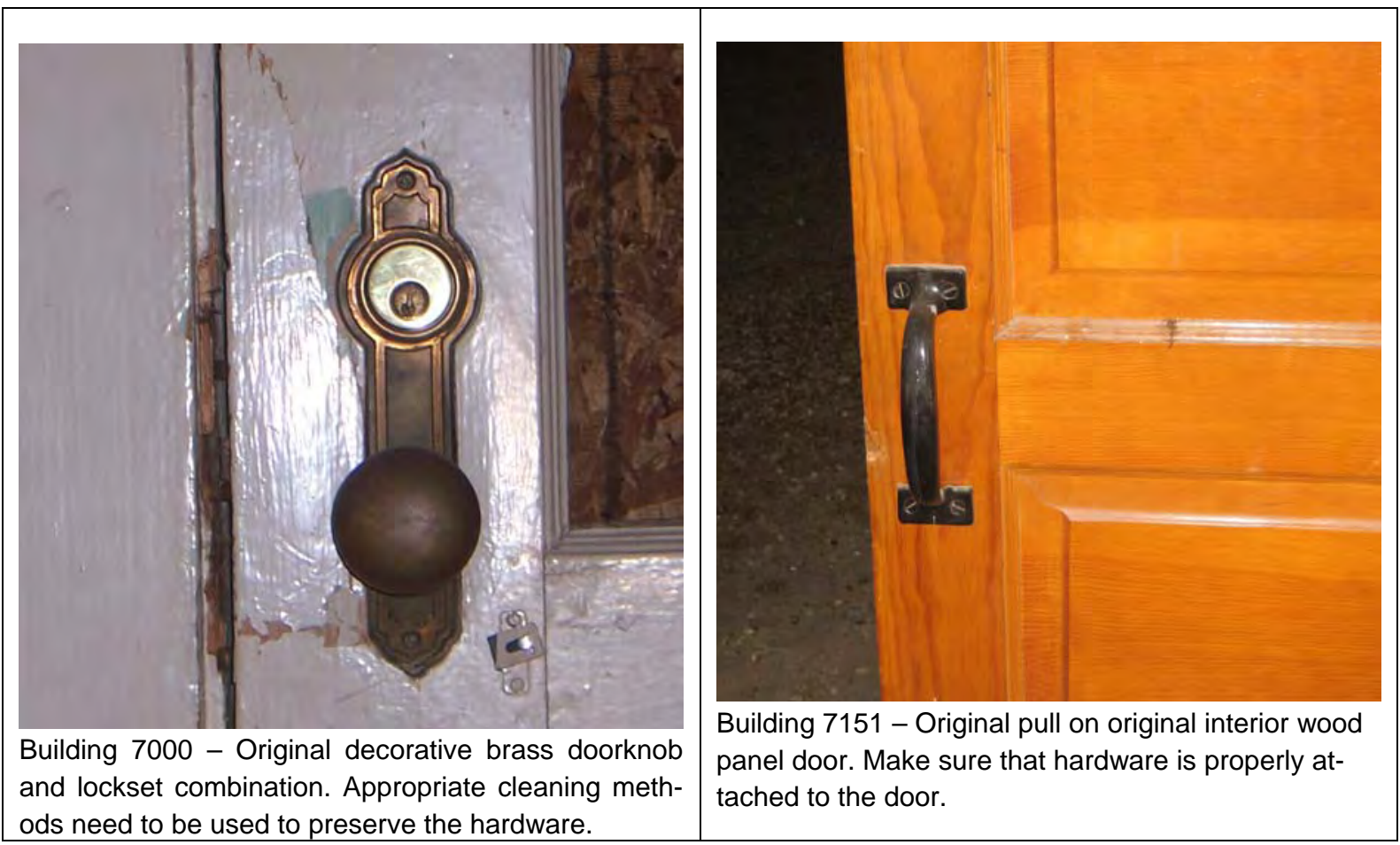

\section{Latches/Locks}

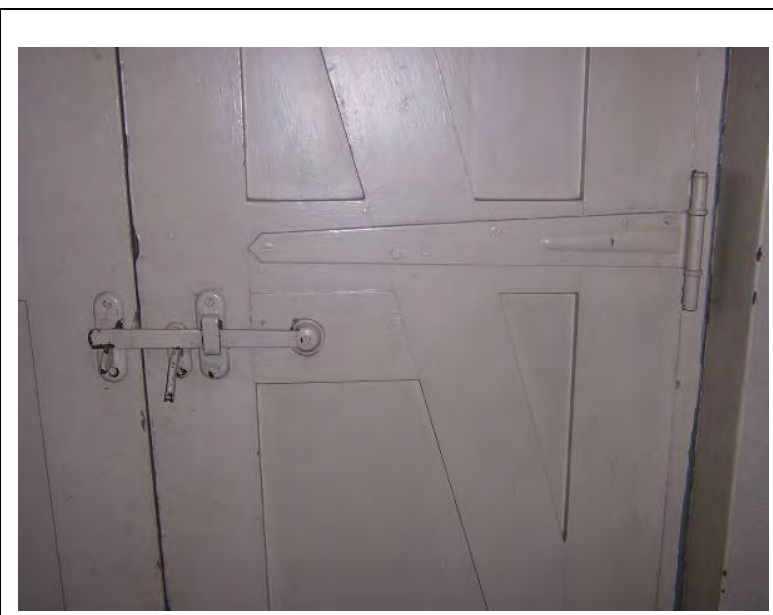

Building 54 - Original latch. Make sure that latch is not painted shut and is still operable.

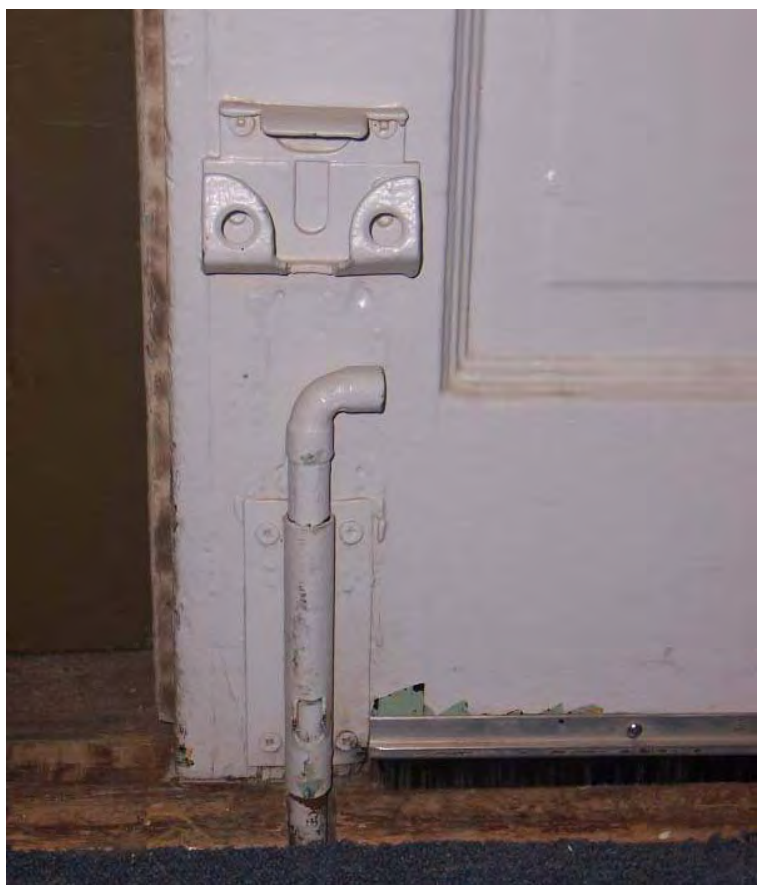

Building 114 - Original lock located at the bottom of the door. 

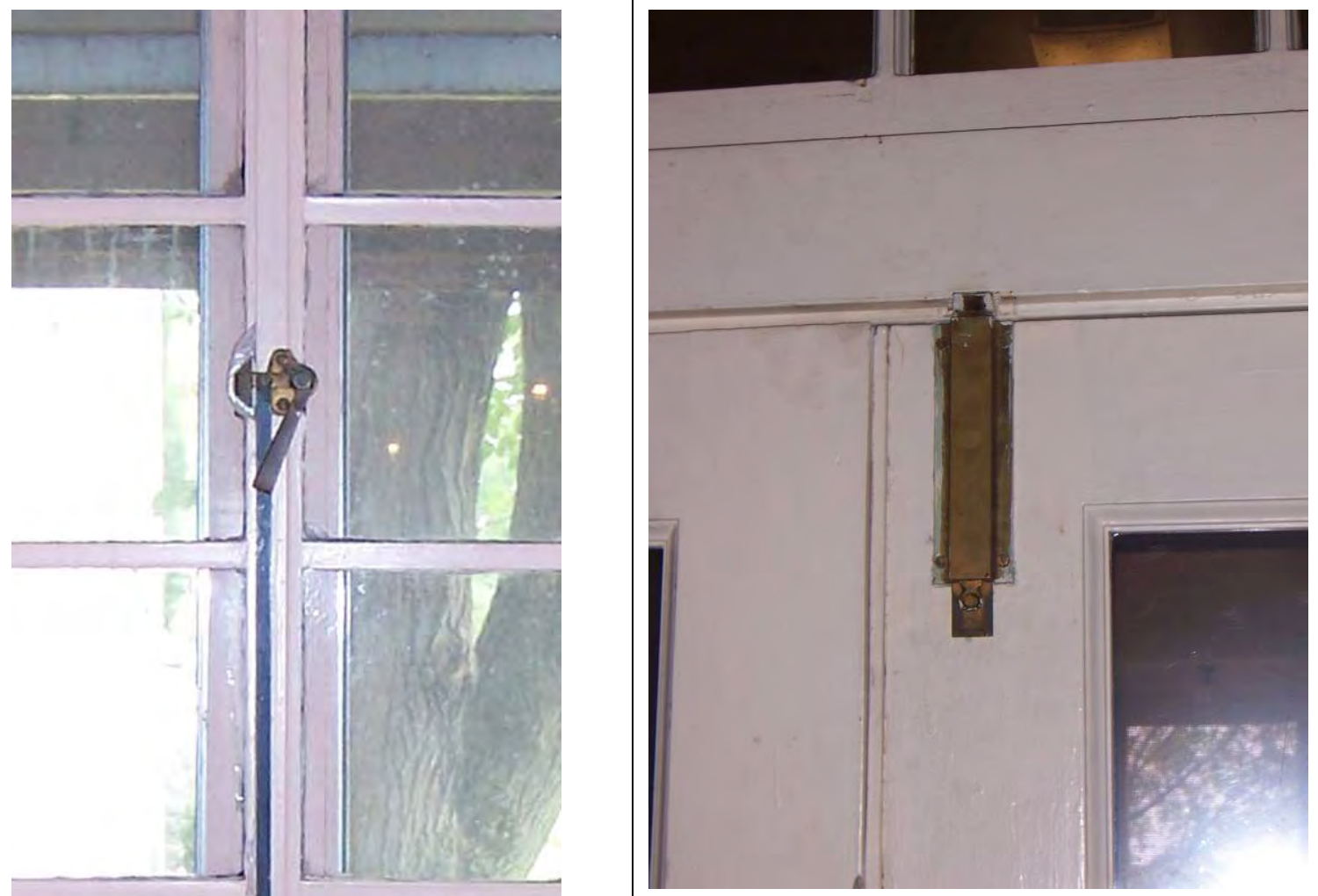

Building 504 - Latch located at the top of the interior French doors. 


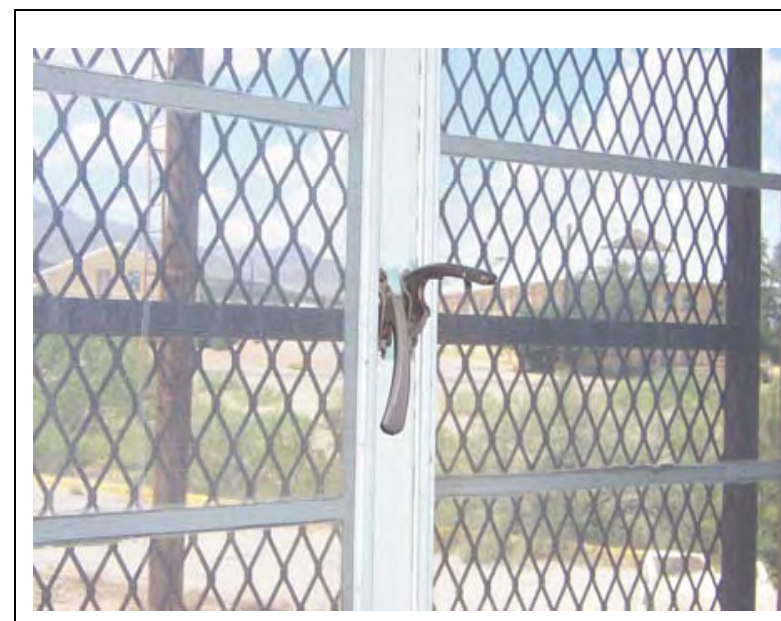

Building 7124 - Original locks on steel casement windows.

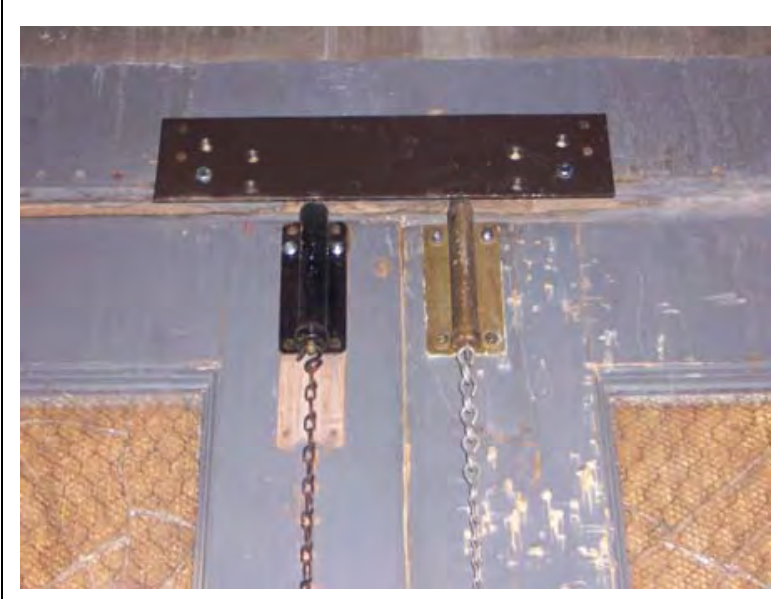

Building 7133 - Locks on original wood hinge doors

\section{Hinges}

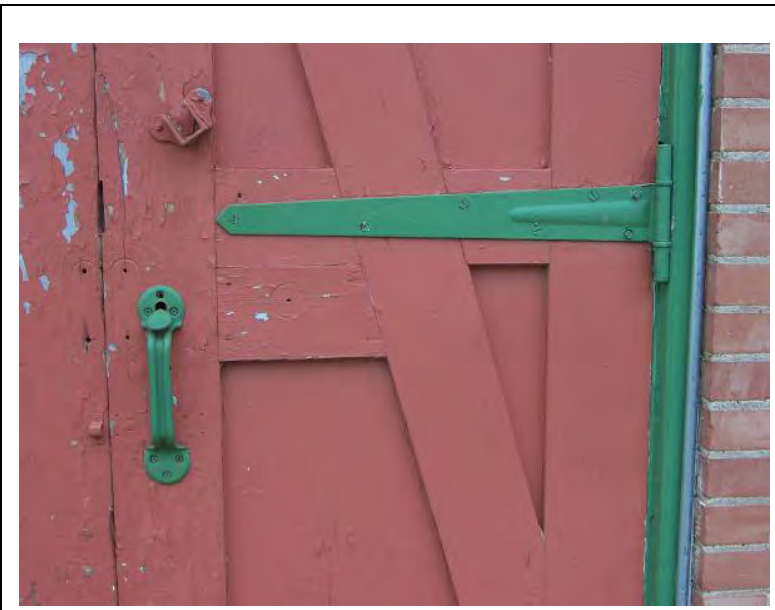

Building 54 - Painted metal hinge on a wood door. Make sure not to add too many layers of paint on the metal elements. Too much paint might make the elements inoperable and make the door stick.
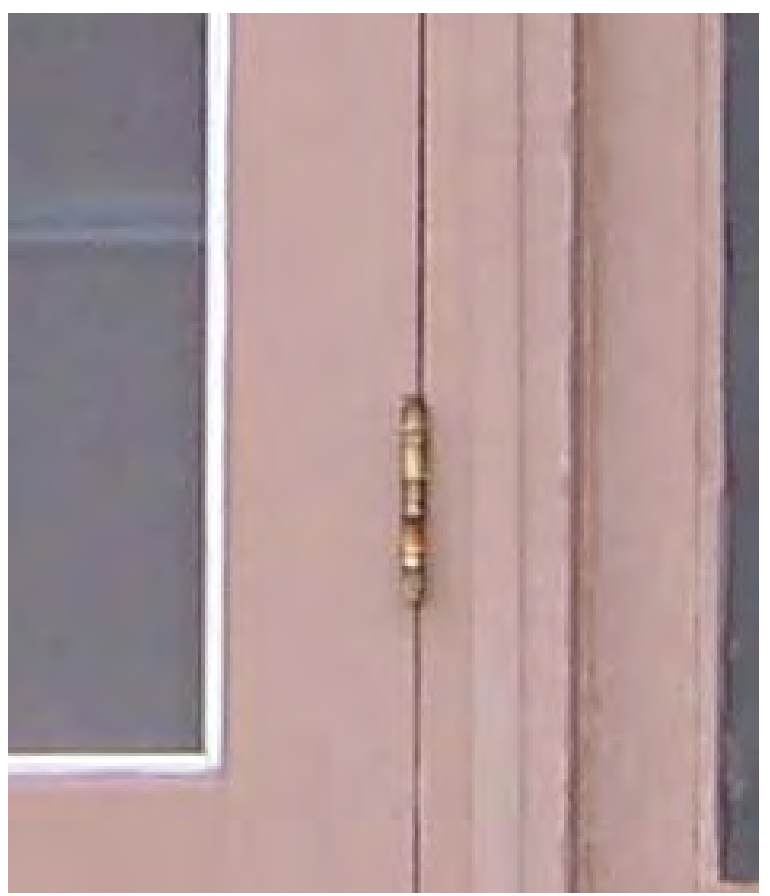

Building 243 - Brass hinges should not be painted. Keep hinges lubricated so that they function properly. 


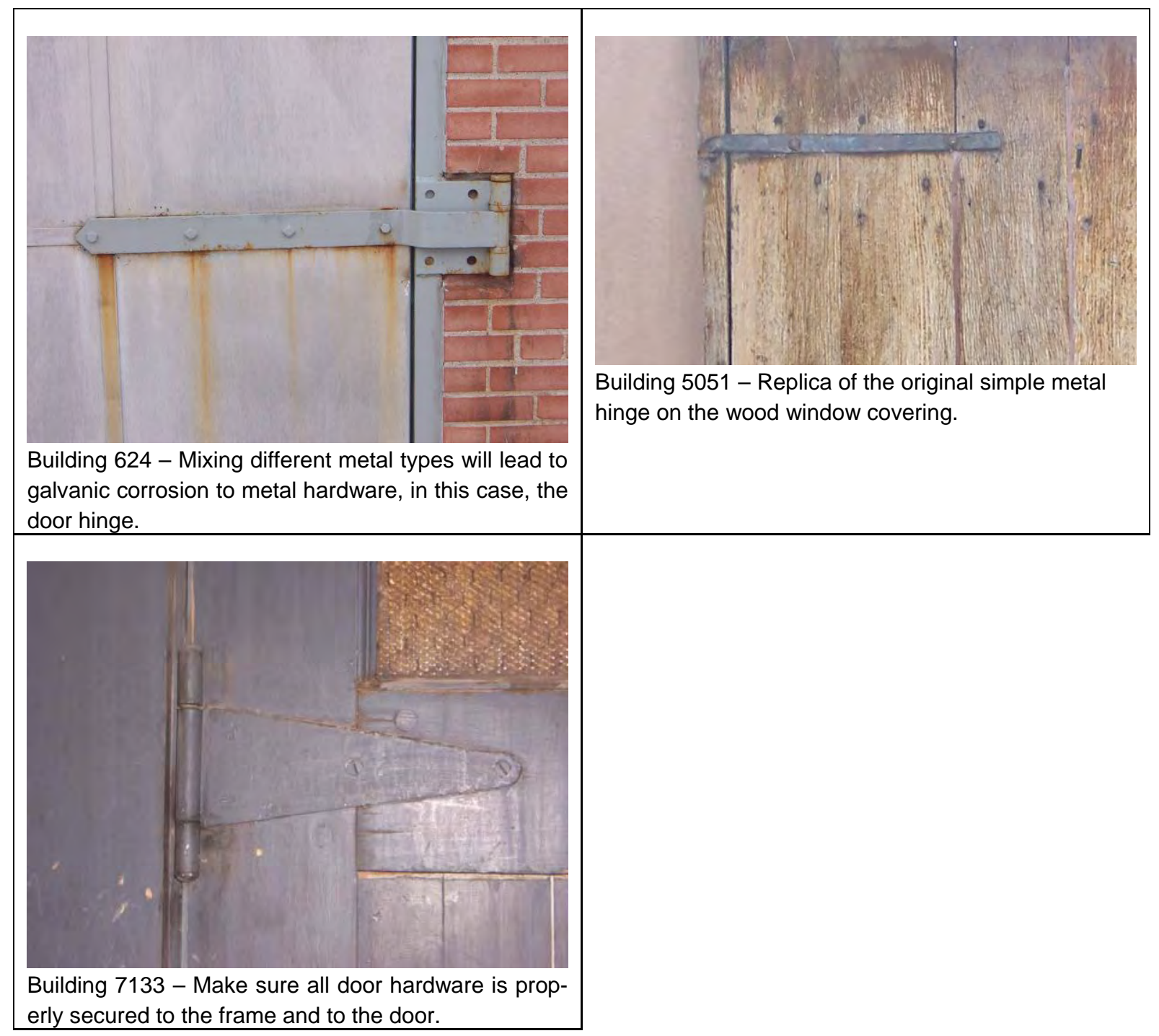

\section{Repair}

It is highly recommended that the damaged historic hardware be repaired rather than replaced.

Historic hardware should be maintained as follows:

- When doors and windows stick, stress on the hardware can result in damage. If overpainting is the cause, remove paint as appropriate to eliminate sticking.

- Brass and bronze hardware should not be painted. Remove paint that has been applied. Clean original hardware with appropriate (no-acidic) materials, and regularly lubricate locks and hinges. Do not lacquer historic brass and bronze hardware. If plating of original hardware is worn, replate rather than replace the hardware.

- If removal of hardware is required for cleaning or refurbishing, care should be taken to avoid damage to screws, parts, and finishes. Keep all parts of each hardware set together in individual identified containers.

- Removing paint from hardware is easily done by boiling hardware in a pot of water with some trisodium phosphate (TSP). Then the paint will scrape off easily. 


\section{Replace}

- Replace non-historic hardware to match the original whenever possible to conform to the character of the building. Care should be taken to ensure that new "period" hardware is similar in style and era to the architectural style of the building.

- Extra hardware, such as deadbolts or surfaces bolts, should not be added to doors. This not only changes the historic appearance but also damages the original materials of the door. If additional security is required at a particular door or window, review alternatives and selection of hardware with the Historical Architect.

The following are a few examples of inappropriate and appropriate types of hardware found on some of the Fort Bliss historic buildings. After all of the hardware has been identified as historic or replacement, the inappropriate hardware replacements need to be removed and appropriate style and age hardware needs to be installed.

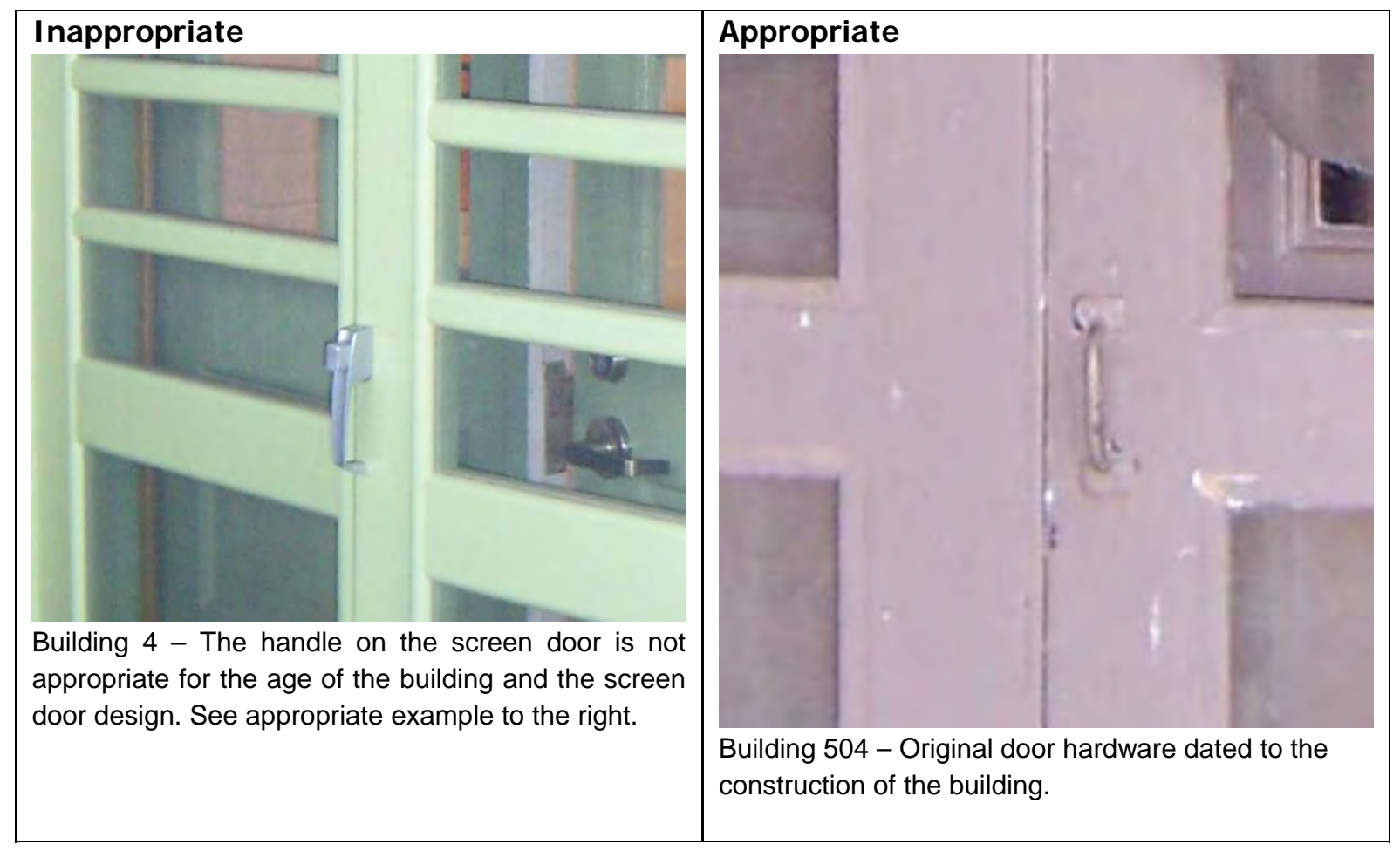




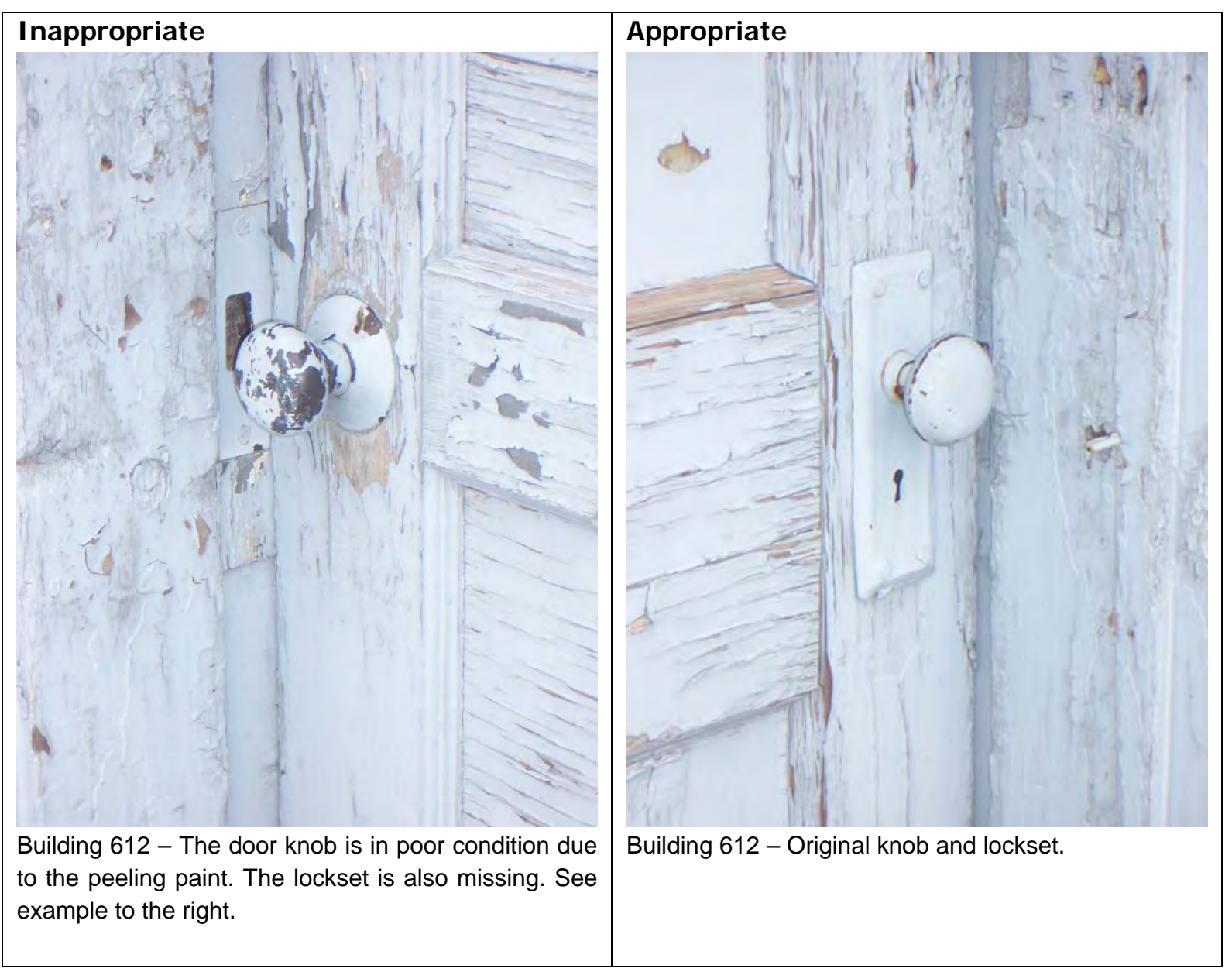




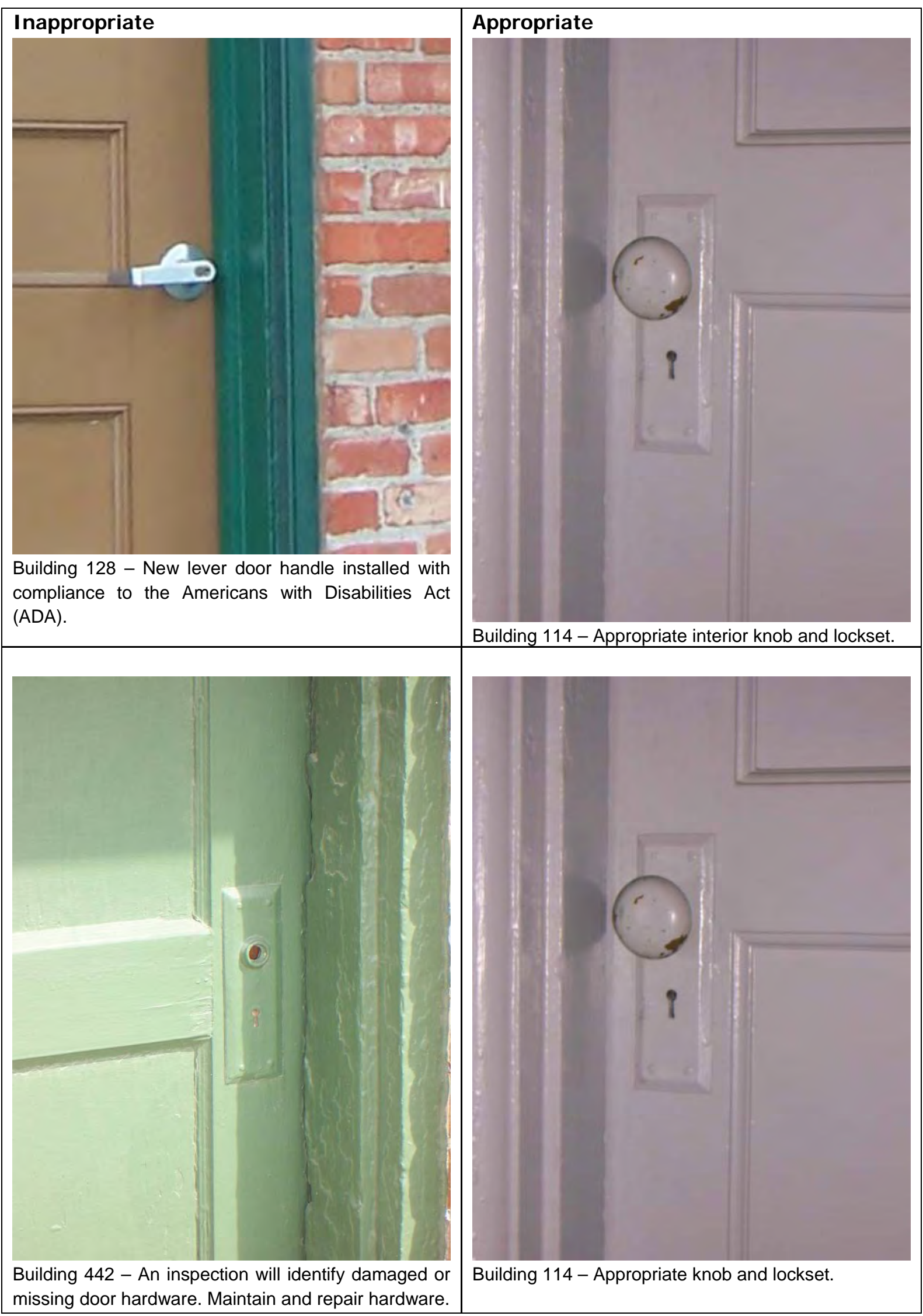




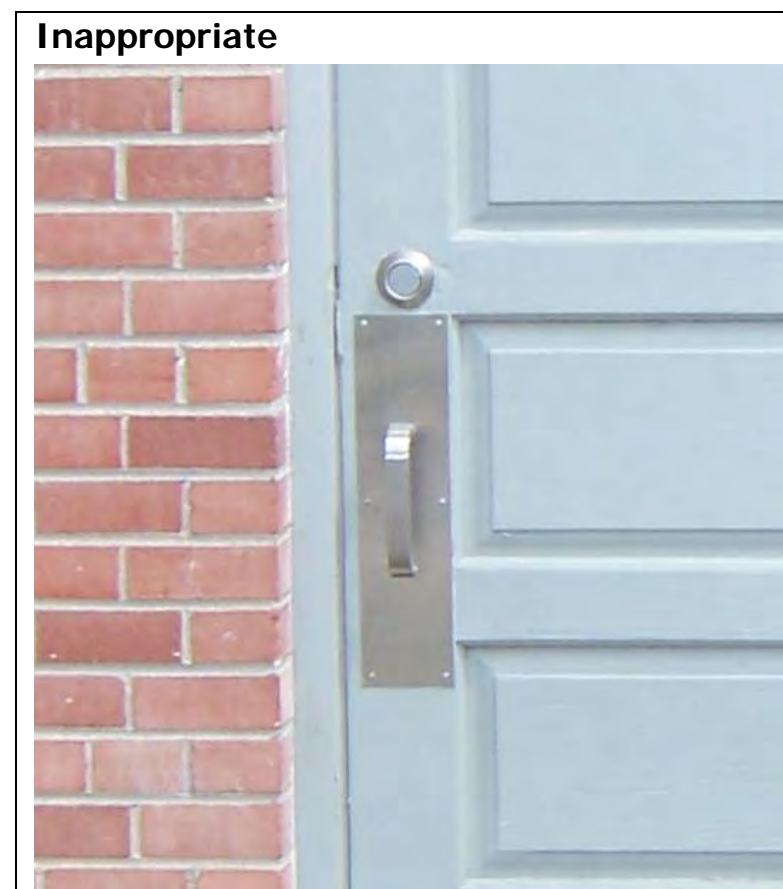

Building 620 - Use historically appropriate replacement door hardware. If the building needs to be retrofitted for ADA purposes, choose in-kind hardware. Here for example, the pull is acceptable but the plate is too large and inappropriate.

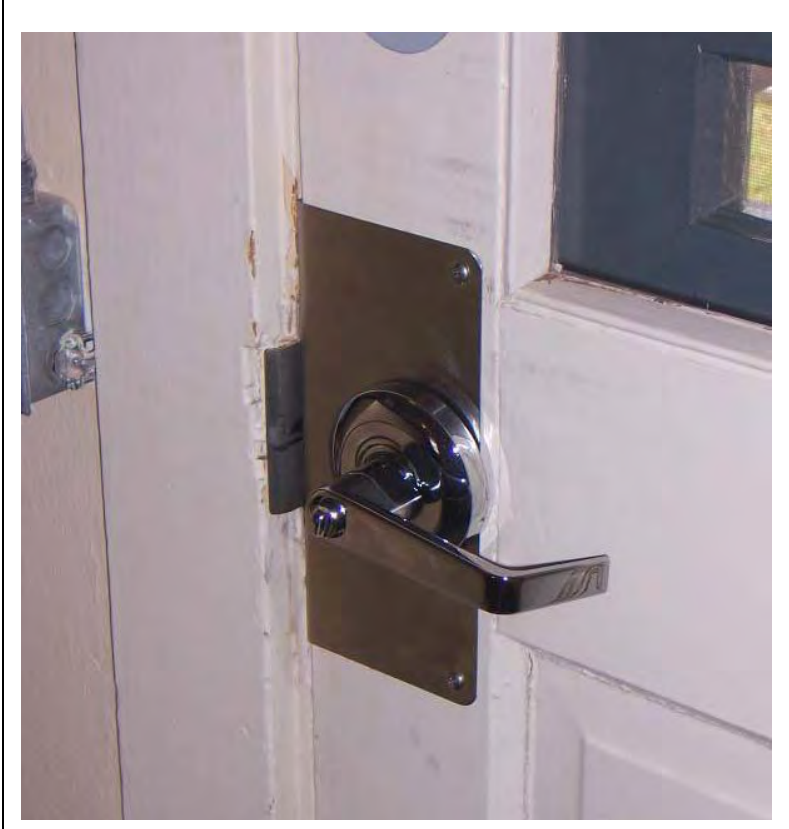

Building 629 - New lever door handle installed with compliance to the Americans with Disabilities Act (ADA). If the building needs to be retrofitted for ADA purposes, choose in-kind hardware replacements. Here for example, the handle is acceptable but the plate is too large and inappropriate.

\section{Appropriate}

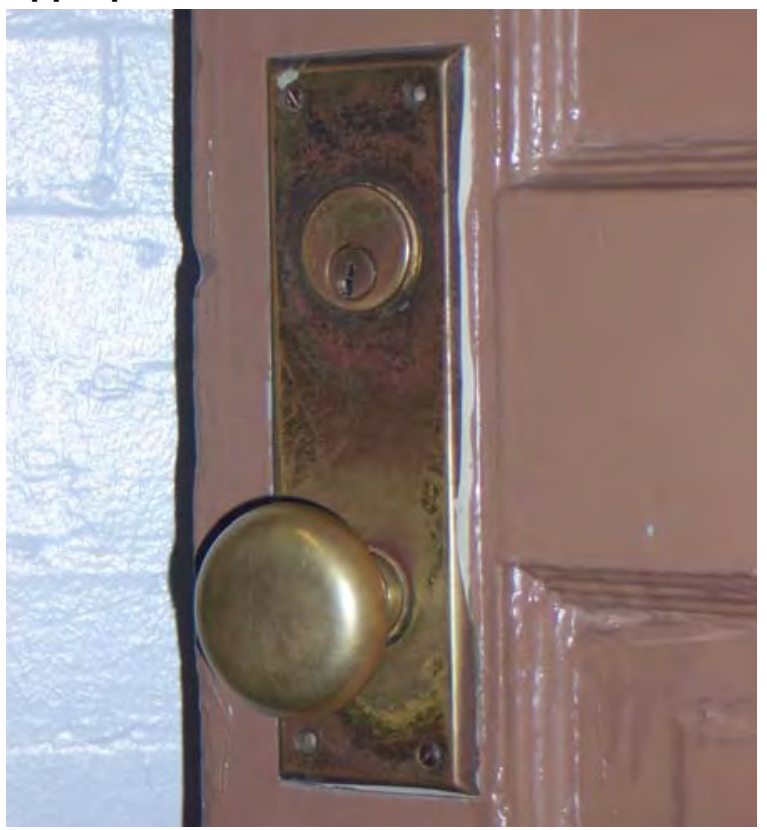

Building 114 - Older locksets can have their locking mechanism disabled and remain as part of the door hardware as a passage set knob accompanied by a new compatible deadbolt.
Building 629 - Original door hardware with knob and keyhole; however, the paint needs to be removed from the metal. 
Historic hardware is not only limited to doors and windows but can also be found on interior features such as historic cabinets. The following two photographs are examples of original hardware found on a group of kitchen cabinets.

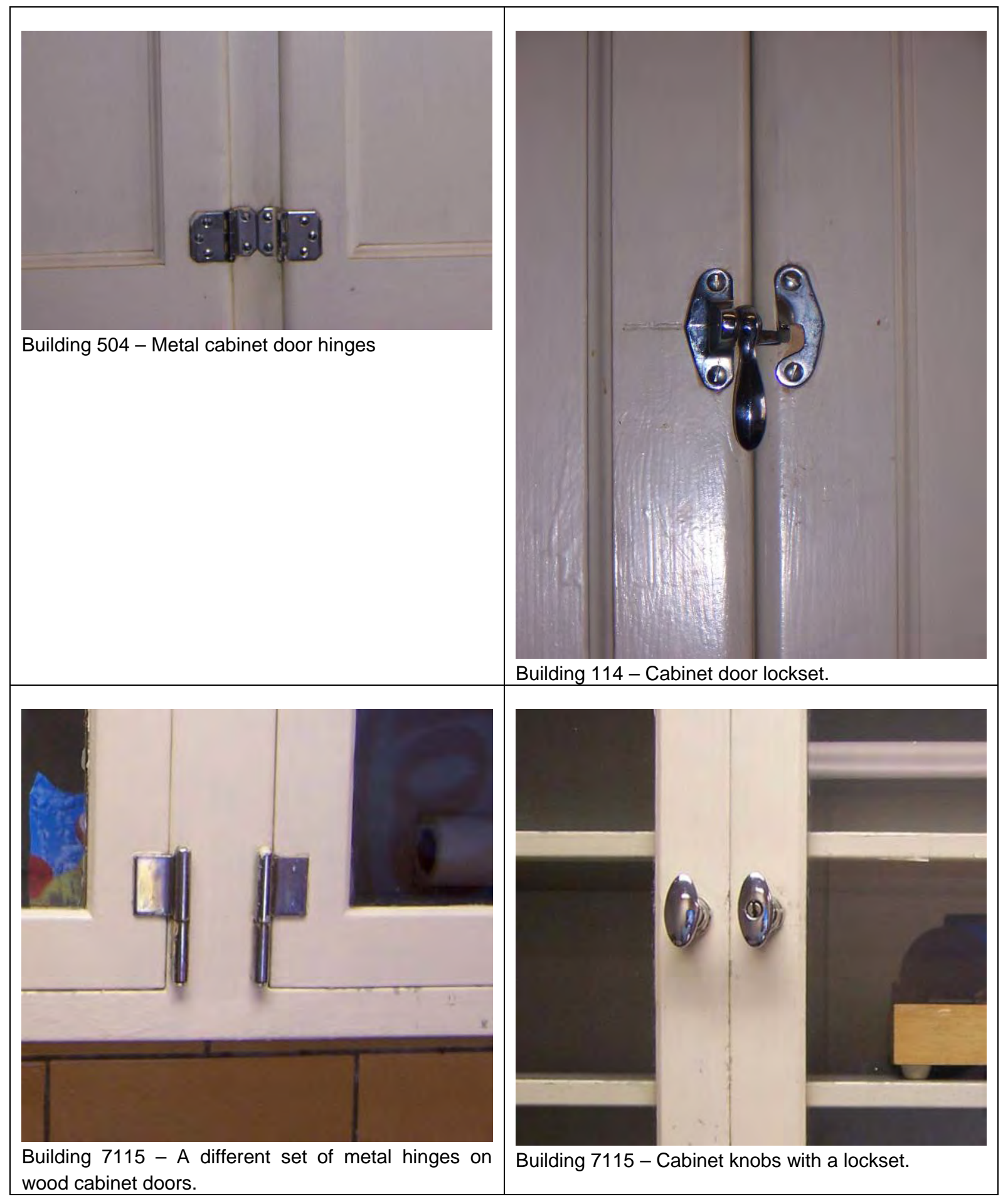


Notes

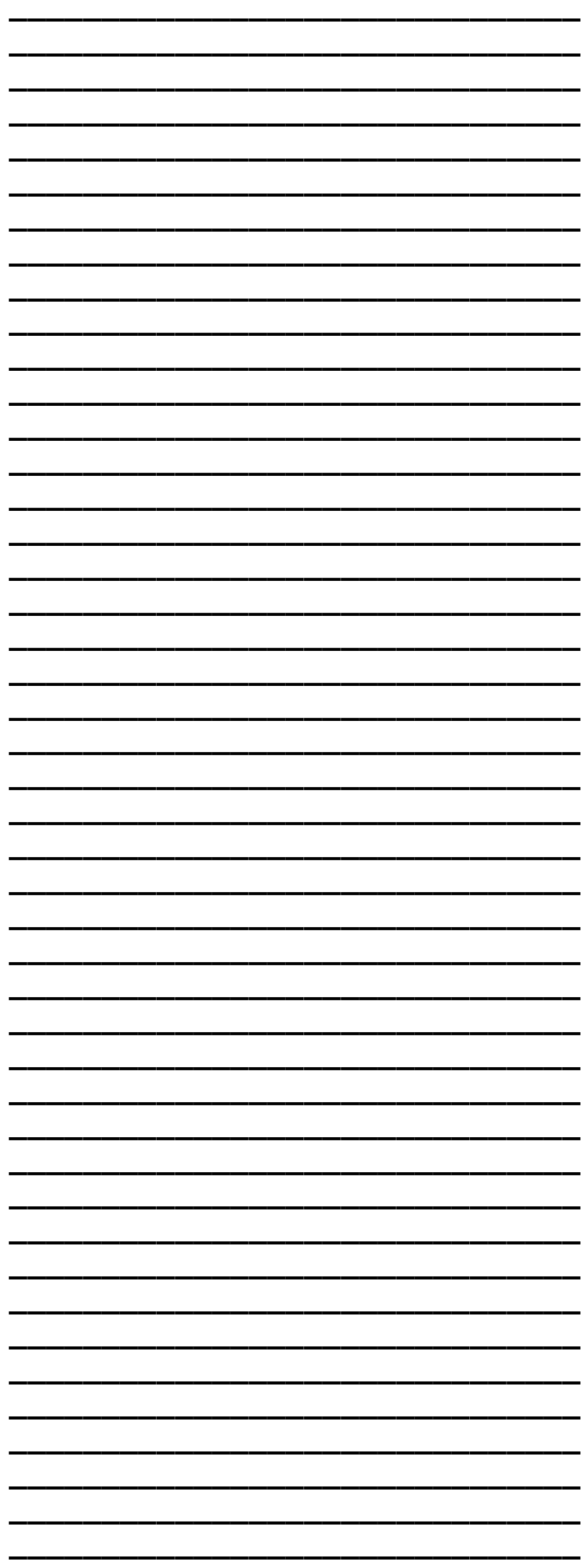




\section{Maintenance Guides for Metal}

\section{Metal: Overview}

Iron is a dark grey metal and is the major constituent of a range of materials including wrought iron, cast iron, carbonized iron (carbon steel) and steel, each of which has its own unique properties. Its uses have since grown to include items for domestic use to architectural building components. The presence of iron in a feature may be detected with a magnet.

Characteristics of wrought iron include:

- $\quad$ Soft

- $\quad$ Ductile

- Magnetic

- $\quad$ Strong - high elasticity and tensile strength

- $\quad$ Malleable - can be heated and reheated and worked into various shapes. Note: Wrought iron becomes stronger the more it is worked.

- $\quad$ Suitable for members in tension or compression.

Typical uses of wrought iron include:

- $\quad$ Fences, gates, and railings,

- Balconies,

- $\quad$ Porches,

- $\quad$ Canopies,

- Roof cresting,

- Hardware,

- $\quad$ Iron cramps (i.e., to secure masonry veneer building frames).

\section{Maintenance/ Management Guidelines} for Metal

- Some type of coating should probably be considered an integral feature of wrought iron service. Inspection should include a visual examination of all surfaces to determine if a coating exists. Failure of a coating should also be identified and corrected. The early stages of pitting and corrosion in metal elements should be monitored regularly. All water damage should be noted and remedied at its earliest possible stages. As soon as rehabilitation or restoration has been completed, some program of continuing maintenance should be initiated. Many of the maintenance and repair techniques, particularly those relating to cleaning and painting, are potentially dangerous and should be carried out only by experienced and qualified professionals.

- According to The Secretary of the Interior's Standards for Rehabilitation, the proper procedure is to respect the significance of the original materials and features, repair and retain wherever possible, and replace them only when absolutely necessary.

- The following recommendations for care of the historic site are to be thoroughly read and understood before a treatment is specified. The Secretary of the Interior's Standards for Rehabilitation should also be consulted to determine the appropriateness of any treatment.

Full documentation can be found at http://www.cr.nps.gov/hps/tps/tax/rhb/stand.htm

Problems may be classified into two broad categories: 1) Natural or inherent problems based on the characteristics of the material and the conditions of the exposure, and 2) Vandalism and human-induced problems.

\section{Natural or Inherent Problems}

Chemical corrosion can attack decorative and structural wrought iron features in several ways:

- Uniform attack: Corrosion attacks the metal surface evenly.

- Pitting: Attacks the metal surface in select areas. 
- Rust: Probably the most common form of chemical corrosion of wrought iron. It occurs when unprotected metal is exposed to oxygen in the atmosphere in the presence of moisture. Moisture can be in the form of normal humidity, rain, dew, or condensation.

- Galvanic corrosion: Galvanic corrosion occurs when two dissimilar metals are in contact with one another and an electrolyte, such as rainwater, condensation, dew, or fog is present. In the case of wrought iron, direct contact with copper or zinc will cause galvanic corrosion.

\section{Vandalism or Human-Induced Problems}

Mechanical or physical deterioration includes:

- Fatigue: Failure of metal that has been repeatedly stressed beyond its elastic limit.

- Heat: Usually in the form of fire will cause wrought iron features to become plastic, distort, and fail.

- Distortion: Permanent deformation or failure may occur when a metal is overloaded beyond its yield point because of increased live or dead loads, thermal stresses, or structural modification altering stress regime.

\section{Identify, Retain, and Preserve}

Recommended...

- Identifying, retaining, and preserving architectural metal features such as columns, capitals, window hoods, or stairways that are important in defining the overall historic character of the building; and their finishes and colors.

Not Recommended...

- Removing or radically changing architectural metal features that are important in defining the overall historic character of the building so that, as a result, the character is diminished.

- Removing a major portion of the historic architectural metal from a facade instead of repairing or replacing only the deteriorated metal, then reconstructing the facade with new material in order to create a uniform or "improved" appearance.

- Radically changing the type of finish or its historical color or accent scheme.

\section{Protect and Maintain}

Recommended...

- Protecting and maintaining architectural metals from corrosion by providing proper drainage so that water does not stand on flat, horizontal surfaces or accumulate in curved, decorative features.

- Cleaning architectural metals, when necessary, to remove corrosion prior to repainting or applying other appropriate protective coatings.

- Identifying the particular type of metal prior to any cleaning procedure and then testing to assure that the gentlest cleaning method possible is selected or determining that cleaning is inappropriate for the particular metal.

- Cleaning soft metals such as lead, tin, copper, terneplate, and zinc with appropriate chemical methods because their finishes can be easily abraded by blasting methods.

- $\quad$ Using the gentlest cleaning methods for cast iron, wrought iron, and steel—hard metals -in order to remove paint buildup and corrosion. If hand-scraping and wire brushing 
have proven ineffective, low-pressure dry grit blasting may be used as long as it does not abrade or damage the surface.

- Applying appropriate paint or other coating systems after cleaning in order to decrease the corrosion rate of metals or alloys.

- Repainting with colors that are appropriate to the historic building or district.

- Applying an appropriate protective coating.

- Evaluating the overall condition of the architectural metals to determine whether more than protection and maintenance are required, that is, if repairs to features will be necessary.

Not Recommended...

- Failing to identify, evaluate, and treat the causes of corrosion, such as moisture from leaking roofs or gutters.

- Placing incompatible metals together without providing a reliable separation material. Such incompatibility can result in galvanic corrosion of the less noble metal, e.g., copper will corrode cast iron, steel, tin, and aluminum.

- Exposing metals that were intended to be protected from the environment.

- Applying paint or other coatings to metals such as copper, bronze, or stainless steel that were meant to be exposed.

- Using cleaning methods that alter or damage the historic color, texture, and finish of the metal; or cleaning when it is inappropriate for the metal.

- Removing the patina of historic metal. The patina may be a protective coating on some metals, such as bronze or copper, as well as a significant historic finish.

- Cleaning soft metals such as lead, tin, copper, terneplate, and zinc with grit blasting which will abrade the surface of the metal.

- Failing to use gentler methods prior to abrasively cleaning cast iron, wrought iron, or steel or using high-pressure grit blasting.

- Failing to reapply protective coating systems to metals or alloys that require them after cleaning so that accelerated corrosion occurs.

- Using new colors that are inappropriate to the historic building or district.

- Failing to assess pedestrian use or new access patterns so that architectural metal features are subject to damage by use or inappropriate maintenance such as salting adjacent sidewalks.

- Failing to undertake adequate measures to assure the preservation of architectural metal features.

\section{Repair}

Recommended...

- Repairing architectural metal features by patching, splicing, or otherwise reinforcing the metal following recognized preservation methods. Repairs may also include the limited replacement in-kind — or with a compatible substitute material—of those extensively deteriorated or missing parts of features when there are surviving prototypes such as porch balusters, column capitals or bases; or porch cresting. 
Not Recommended...

- Replacing an entire architectural metal feature such as a column or a balustrade when repair of the metal and limited replacement of deteriorated or missing parts are appropriate.

- Using a substitute material for the replacement part that does not convey the visual appearance of the surviving parts of the architectural metal feature or that is physically or chemically incompatible.

\section{Replace}

Recommended...

- Replacing in-kind an entire architectural metal feature that is too deteriorated to repair-if the overall form and detailing are still evident—using the physical evidence to guide the new work. Examples could include cast iron porch steps or steel sash windows. If using the same kind of material is not technically or economically feasible, then a compatible substitute material may be considered.

Not Recommended...

- Removing an architectural metal feature that is unrepairable and not replacing it; or replacing it with a new architectural metal feature that does not convey the same visual appearance.

\section{Good Examples of Wrought I ron}

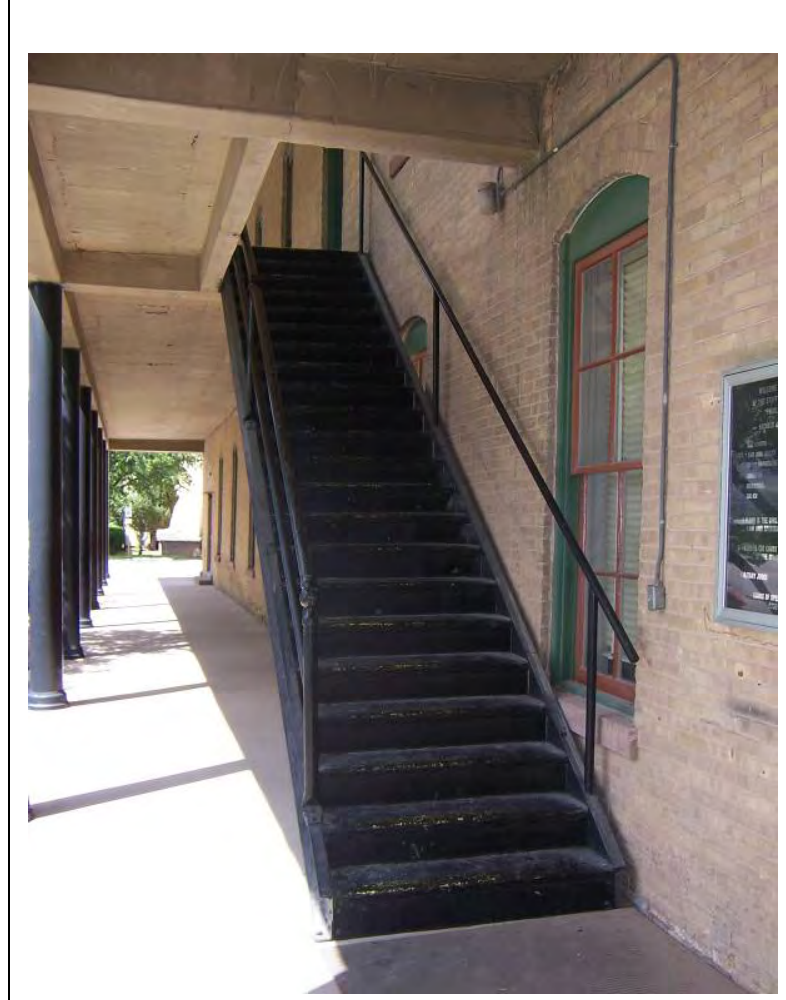

Building 13 - The metal stairs are original to the construction of the building and are an integral part of the overall design. They should not be removed.

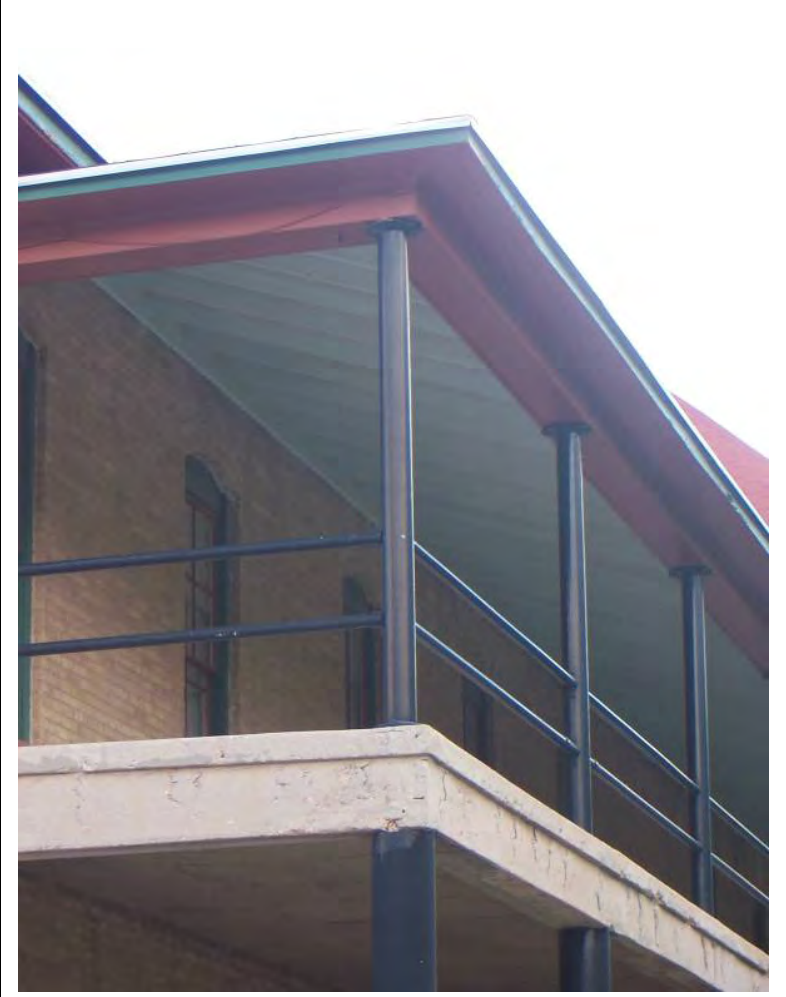

Building 13 - The metal columns and railings are in great condition. These elements in combination to the openness of the two-story balcony are integral features to the overall design of the building. They should be checked regularly for damage or maintenance requirements. 

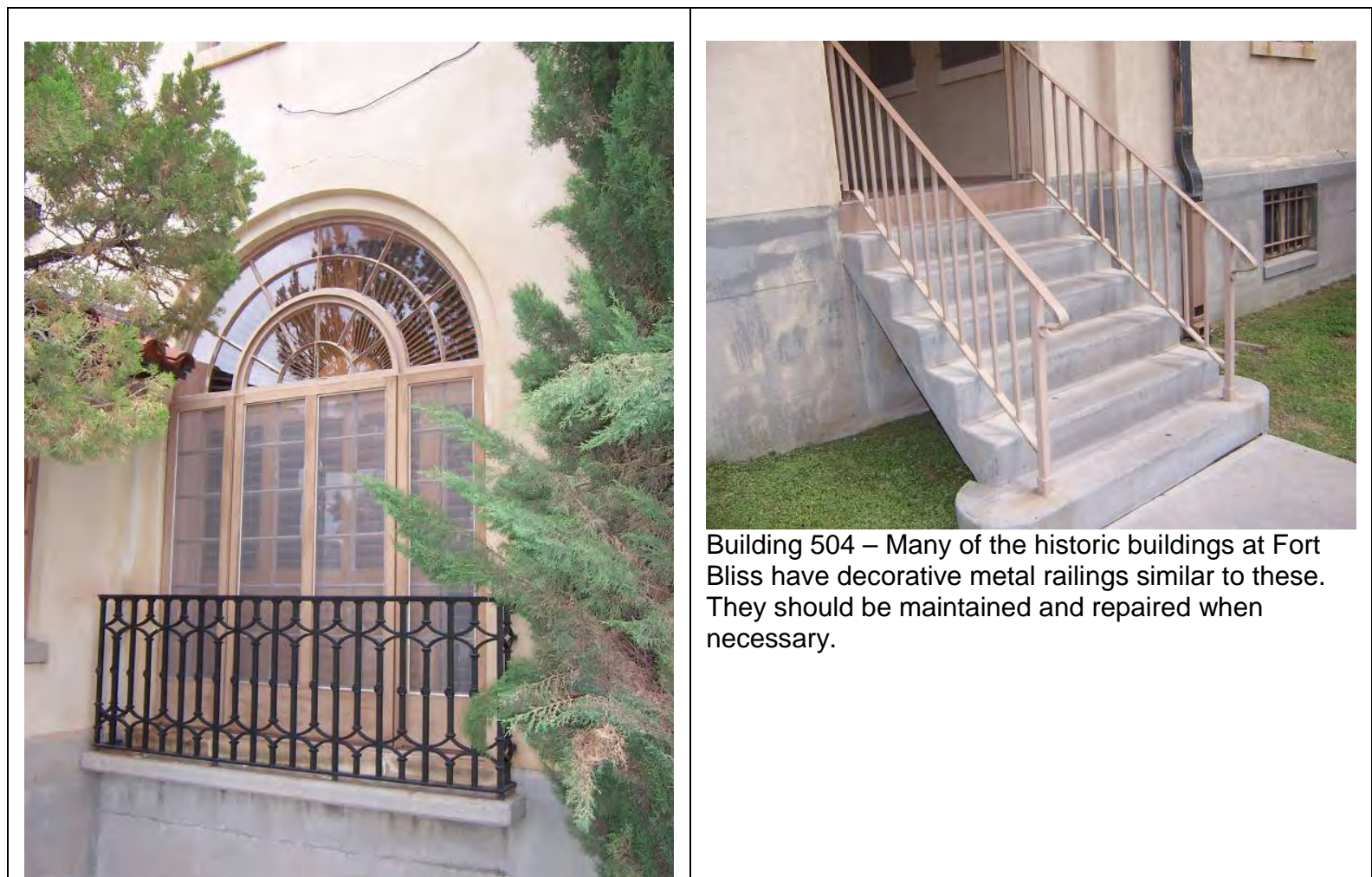

Building 504 - Many of the historic buildings at Fort Bliss have decorative metal railings similar to these. They should be maintained and repaired when necessary.

Building 243 - Good example of metal detail work used as an architectural feature. 


\section{Metal: Rusting}

Rusting, or oxidation, is the most frequent and easily recognizable form of wrought iron deterioration. This process can take place at significantly different rates depending on the material composition, protective treatments applied, and severity of exposure. The presence of any rust on a wrought iron element should alert the observer to the presence of a serious problem.

Rusting is such a common problem that it is easily recognizable. It is loosely bound and the outer layers will usually come off when rubbed by hand or brushed against. It is not a deposit on the surface.

\section{Causes}

The probability of rust occurring is generally dependent upon two factors:

- $\quad$ the degree of protection (usually a protective coating) provided to keep the moisture from contact with the metal, and

- $\quad$ the degree of moisture present in the air.

Many other factors can affect both corrosion and the rate of corrosion. Corrosion rates can also be accelerated where the detailing of the wrought iron provides pockets which can collect and hold moisture and corrosive agents. Preventive maintenance plans should consider detailing, such as crevices and recessed areas, in establishing routine inspection techniques and frequency of inspection.

\section{Inspection}

- $\quad$ Remove surface dirt and grime and look for signs of damage and wear.

- Identify areas where rust or corrosion is present on metal elements.

\section{Evaluation}

- Determine level of treatment necessary to repair severely damaged metal.

- Determine if the metal element needs to be replaced if too deteriorated to repair.

\section{Execution}

- $\quad$ Repair the source of the damage before repair proceeds.

- Remove light corrosion and grime.

- Clean metal and reapply protective coating.

- Replace in-kind to the historic materials.

\section{Further Readings}

GSA has developed technical procedures to be used in specialized historic preservation work, as well as general evaluation, maintenance and repair of older building materials. For more detailed descriptions of repair procedures for rusting metals refer to the following, which can be found at http://w3.gsa.gov/web/p/hptp.nsf

- Guidelines for Rehabilitating Historic Buildings: Architectural Metals 


\section{Inspection}

Recommended...

- Removing surface dirt and grime and looking for signs of damage and wear.

- Identifying areas where rust or corrosion is present on metal elements.

- Protecting and maintaining architectural metals from corrosion by providing proper drainage so that water does not stand on flat, horizontal surfaces or accumulate in curved, decorative features.

- Identifying the particular type of metal prior to any cleaning procedure and then testing to assure that the gentlest cleaning method possible is selected or determining that cleaning is inappropriate for the particular metal.

Not Recommended...

- Failing to identify, evaluate, and treat the causes of corrosion, such as moisture from leaking roofs or gutters.

- Failing to undertake adequate measures to assure the preservation of architectural metal features.

- Failing to assess pedestrian use or new access patterns so that architectural metal features are subject to damage by use or inappropriate maintenance such as salting adjacent sidewalks.

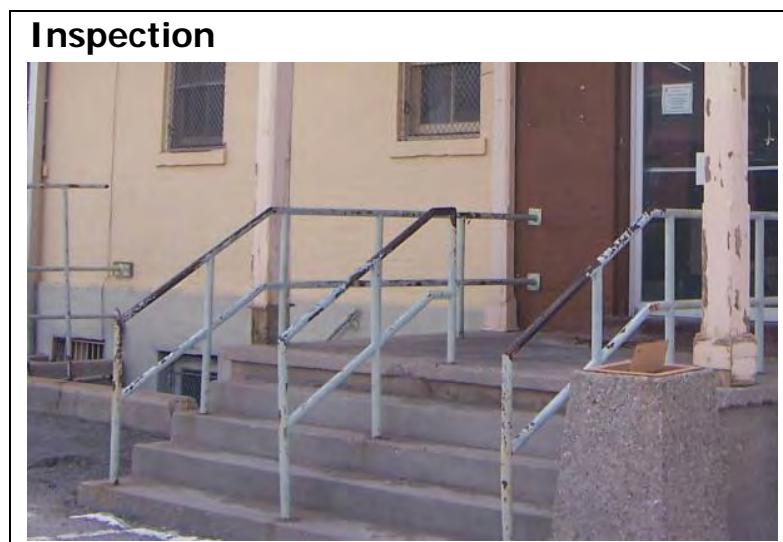

Building 21 - Even though these metal handrails are not original to the building they should be maintained if not replaced with the appropriate handrail design. A periodic inspection of the metal handrails show signs of wear on the painted rails where heavily used.

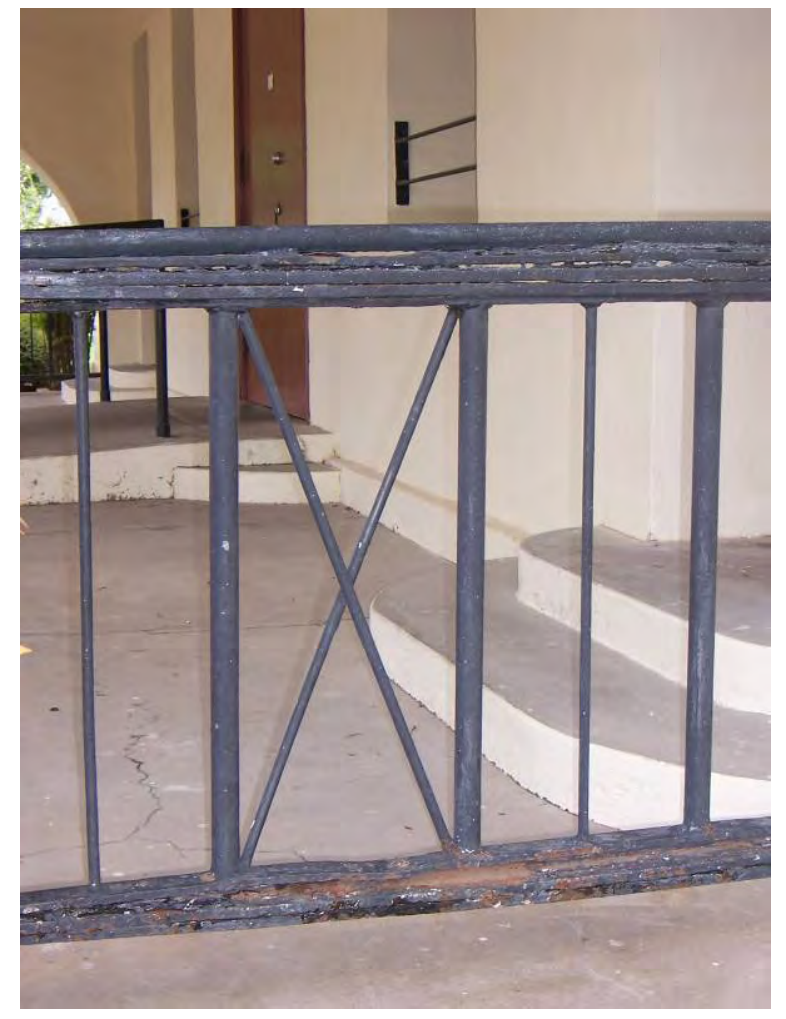

Building 315 - Inspect the overall condition and stability of metal elements. In this case, the metal is showing signs of severe deterioration. 


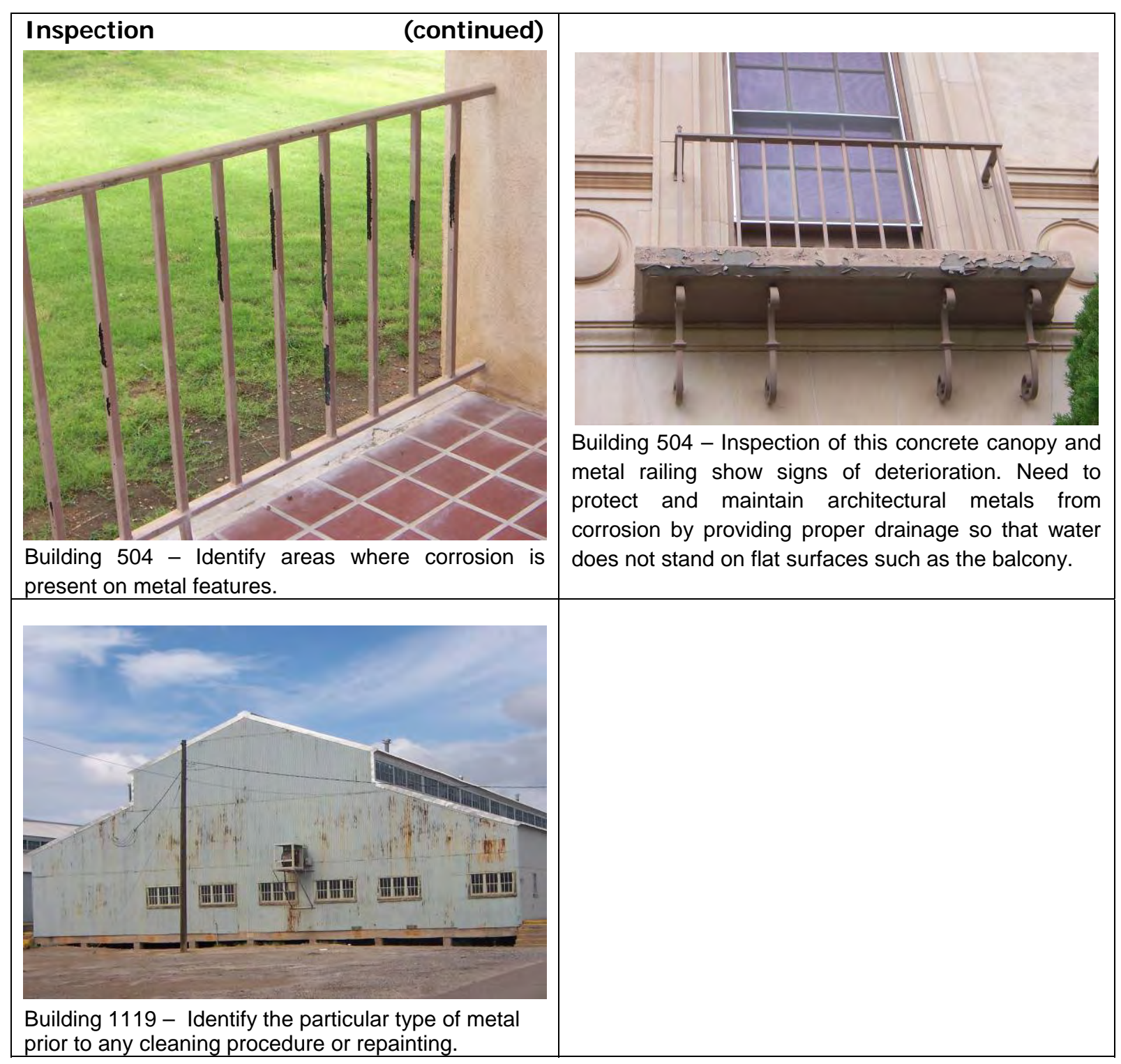




\section{Evaluation}

Recommended...

- Determining level of treatment necessary to repair severely damaged metal.

- Determining if the metal element needs to be replaced if too deteriorated to repair.

- Evaluating the overall condition of architectural metals to determine whether more than protection and maintenance are required, that is, if repairs to features will be necessary.

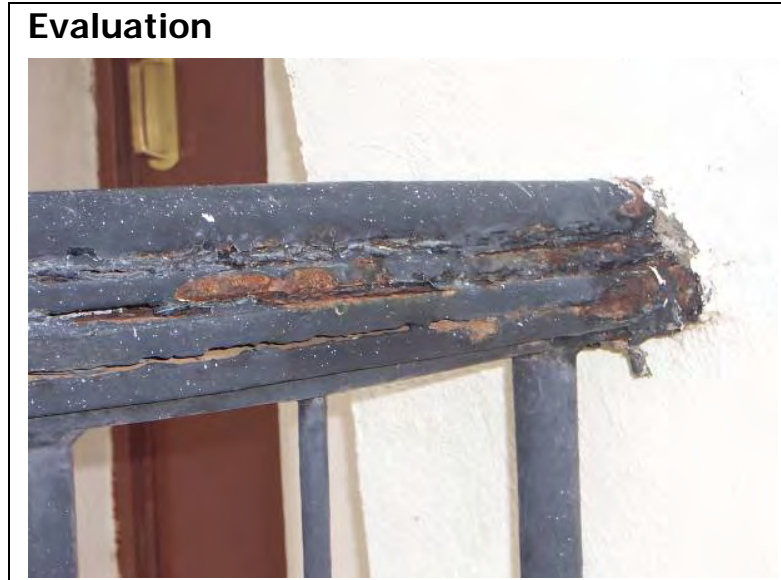

Building 315 - Failing to undertake adequate measures to assure the preservation of architectural metal features is not recommended.

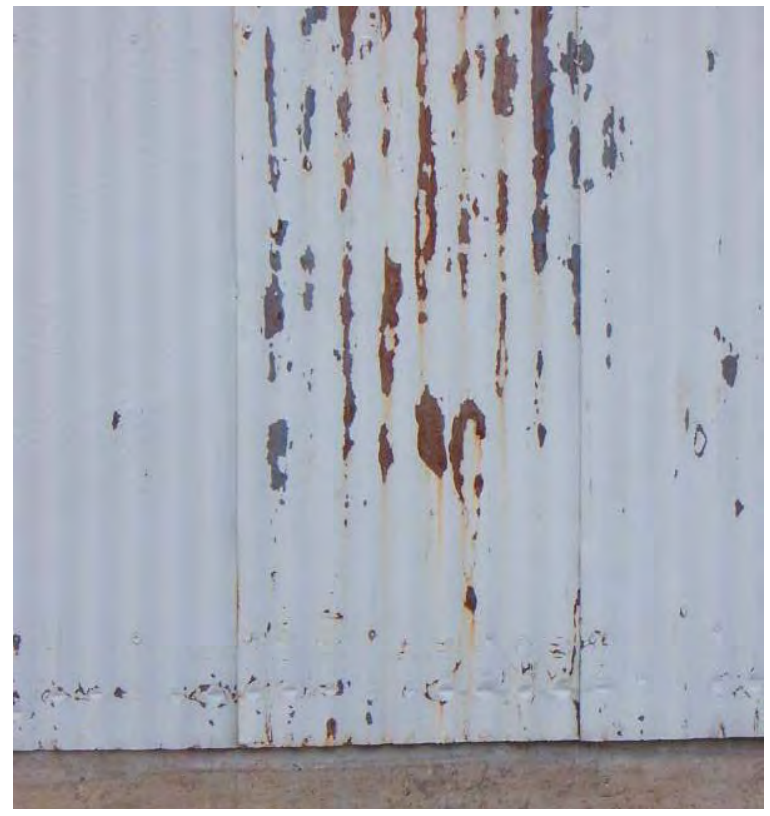

Building 1113 - Evaluate the overall condition of the metal to determine whether more than protection and maintenance are required.

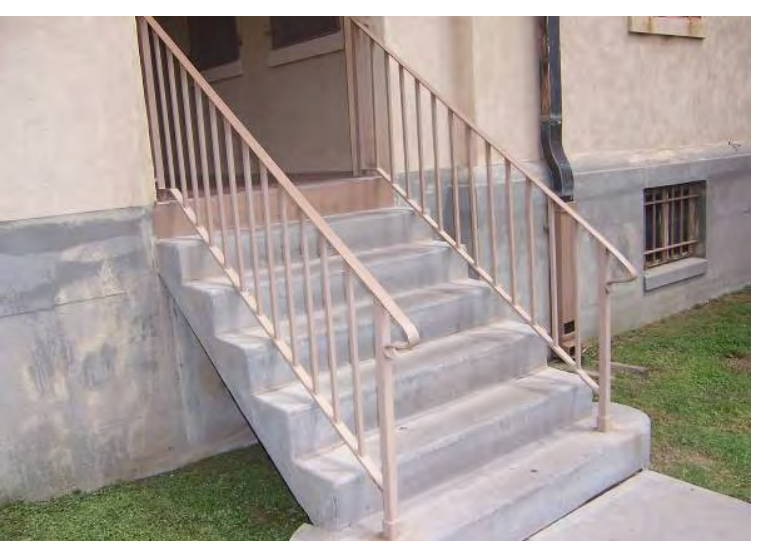

Building 504 - Determine if the metal feature can be repaired or if it needs to be replaced in-kind. 


\section{Repair}

Recommended...

- Repairing architectural metal features by patching, splicing, or otherwise reinforcing the metal following recognized preservation methods. Repairs may also include the limited replacement in-kind —or with a compatible substitute material —of those extensively deteriorated or missing parts of features when there are surviving prototypes such as porch balusters, column capitals or bases, or porch cresting.

- Cleaning architectural metals, when necessary, to remove corrosion prior to repainting or applying other appropriate protective coatings.

- Using the gentlest cleaning methods for cast iron, wrought iron, and steel—hard metalsin order to remove paint buildup and corrosion. If hand-scraping and wire brushing have proven ineffective, low-pressure dry grit blasting may be used as long as it does not abrade or damage the surface.

- Applying appropriate paint or other coating systems after cleaning in order to decrease the corrosion rate of metals.

- Repainting with colors that are appropriate to the historic building or district.

- Applying an appropriate protective coating.

Not Recommended...

- Replacing an entire architectural metal feature such as a column or a balustrade when repair of the metal and limited replacement of deteriorated or missing parts are appropriate.

- Using a substitute material for the replacement part that does not convey the visual appearance of the surviving parts of the architectural metal feature or that is physically or chemically incompatible.

- Placing incompatible metals together without providing a reliable separation material. Such incompatibility can result in galvanic corrosion of the less noble metal, e.g., copper will corrode cast iron, steel, tin, and aluminum.

- Exposing metals which were intended to be protected from the environment.

- Failing to use gentler methods prior to abrasively cleaning cast iron, wrought iron, or steel or using high-pressure grit blasting.

- Failing to reapply protective coating systems to metals or alloys that require them after cleaning so that accelerated corrosion occurs

\section{Replace}

Recommended...

- Replacing in-kind an entire architectural metal feature that is too deteriorated to repair-if the overall form and detailing are still evident—using the physical evidence to guide the new work.

Not Recommended...

- Removing an architectural metal feature that is unrepairable and not replacing it; or replacing it with a new architectural metal feature that does not convey the same visual appearance. 


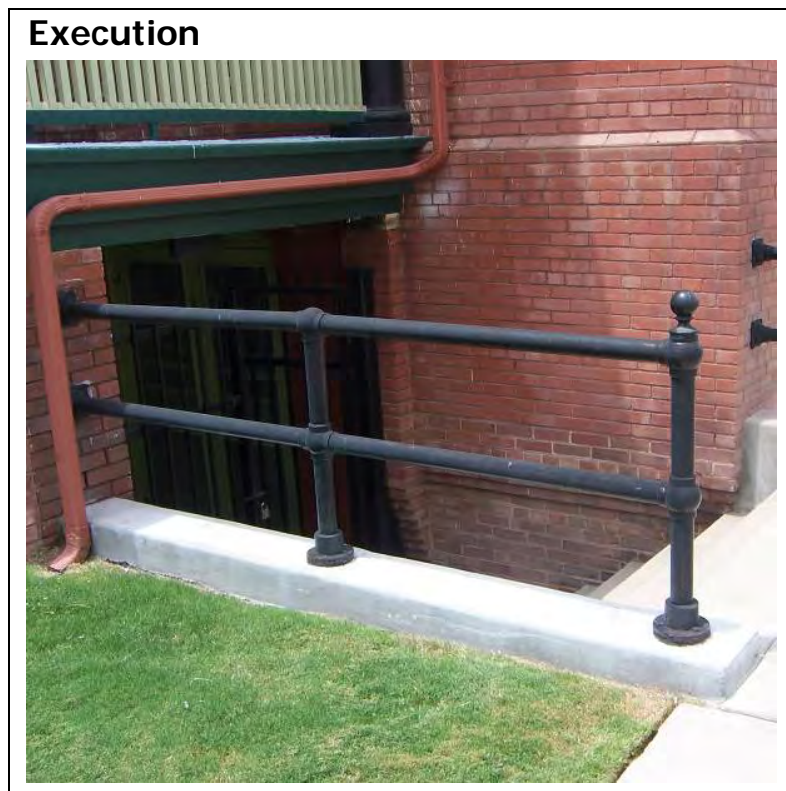

Building 4 - This metal handrail is a good example of replacement in-kind to the original metal feature.

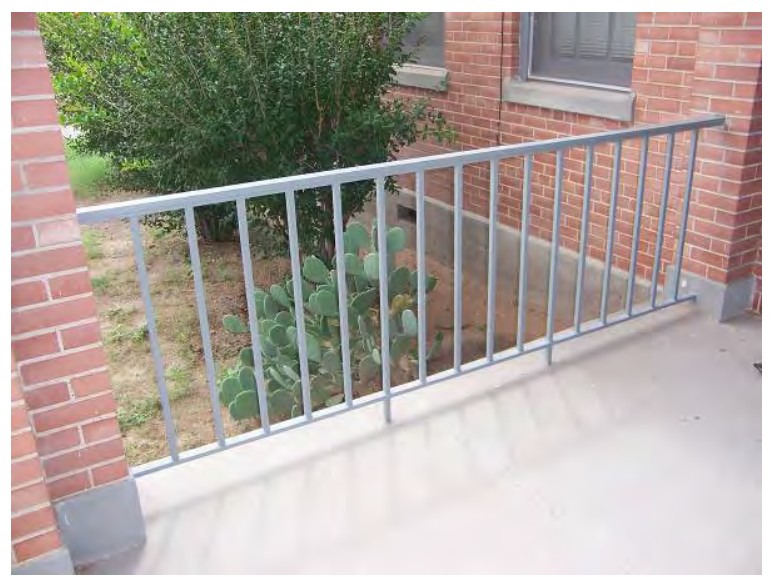

Building 629 - Clean architectural metals when necessary, to remove corrosion prior to repainting or applying other appropriate protective coatings.

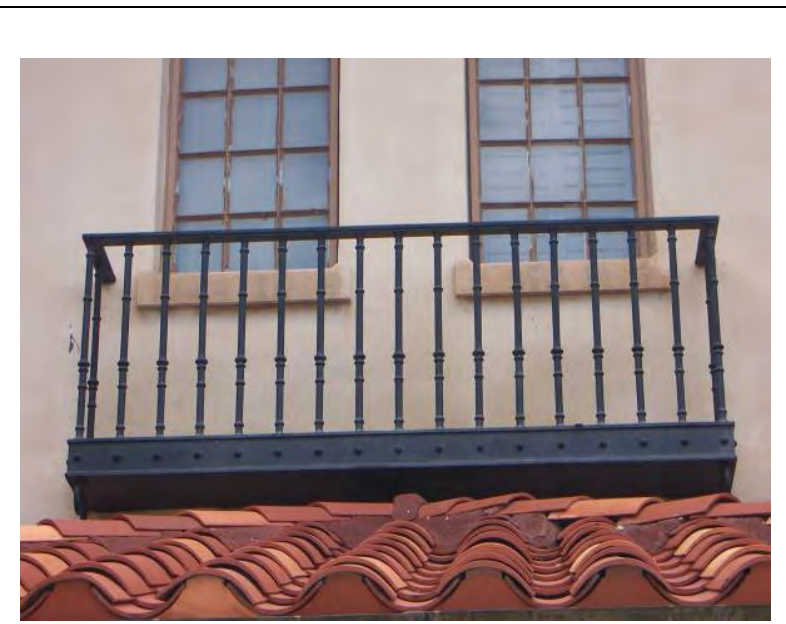

Building 243 - By providing proper drainage of water from the metal balcony, the preservation of the metal features will be maintained. 
Notes

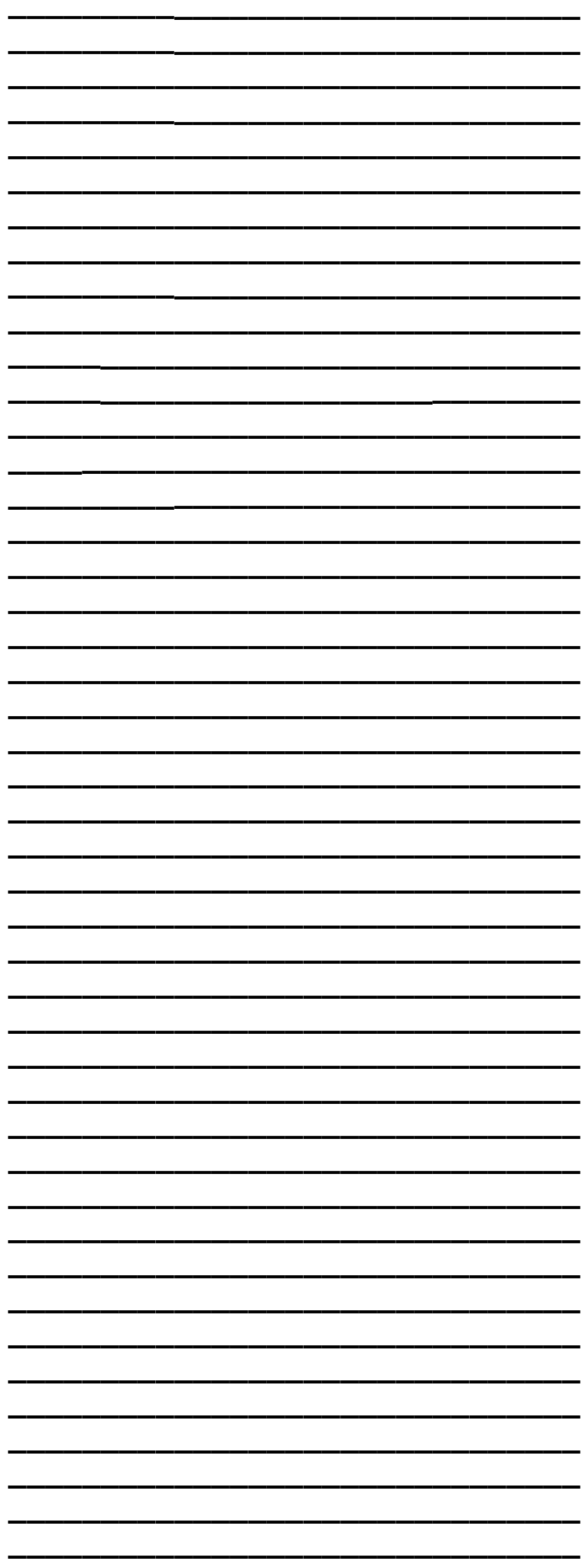




\section{Metal: Protective Coatings}

Barrier coatings are the most commonly used protective mechanism for wrought iron and steel. Some type of coating (such as wax, paint, or metallic coating) should probably be considered an integral feature of wrought iron service. The absence of such a coating or a failure in an existing coating should be corrected. Inspection should include a visual examination of all surfaces to determine if a coating exists, a fact which may be very apparent for opaque paints and coatings but substantially less apparent for clear lacquers, waxes, or oils. Surfaces having the appearance of raw metal should be carefully examined for signs of rusting. Absence of a coating should be considered a major problem and corrective action should be undertaken.

Failure of a coating should also be identified and corrected. Coatings can wear away, crack, flake, blister, or peel away, indicating that the coating has failed and is no longer protecting the wrought iron from moisture. Failed coatings can, in fact, trap moisture beneath the film and accelerate corrosion at certain points on the surface. Check for small chips in the coating surface and peeling of the coating surfaces. Inspection of the surface should include a careful check for all of the types of coating failures. A record should be made of any coating failures observed so that corrective action can be taken.

Many of the maintenance and repair techniques, particularly those relating to cleaning and painting, are potentially dangerous and should be carried out only by experienced and qualified professionals using protective equipment suitable to the task.

\section{Procedures for Cleaning and Paint Removal}

When there is extensive failure of the protective coating and/or when heavy corrosion exists, the rust and most or all of the paint must be removed to prepare the surfaces for new protective coatings. Before selecting a process, test panels should be prepared on the iron to be cleaned to determine the relative effectiveness of various techniques. There are a number of techniques that can be used to remove paint and corrosion from wrought iron, which include:

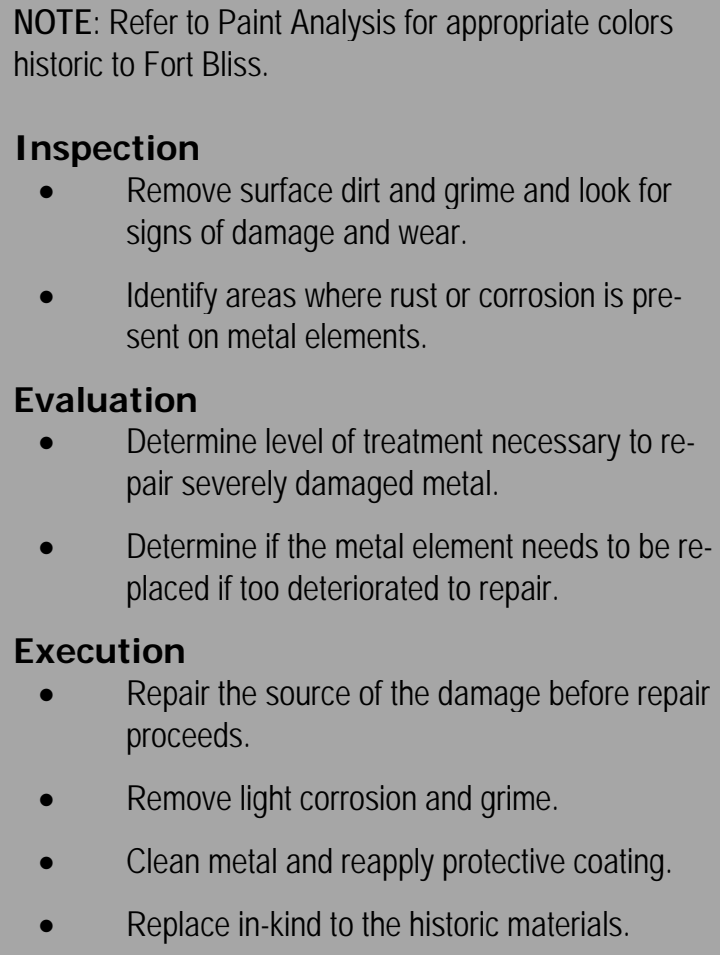

- Identify areas where rust or corrosion is present on metal elements.

\section{Evaluation}

- Determine level of treatment necessary to repair severely damaged metal.

- Determine if the metal element needs to be replaced if too deteriorated to repair.

\section{Execution}

- $\quad$ Repair the source of the damage before repair proceeds.

- Remove light corrosion and grime.

- Clean metal and reapply protective coating.

- $\quad$ Replace in-kind to the historic materials.

\section{Further Readings}

GSA has developed technical procedures to be used in specialized historic preservation work, as well as general evaluation, maintenance and repair of older building materials. For more detailed descriptions of repair procedures for protective coatings refer to the following, which can be found at http://w3.gsa.gov/web/p/hptp.nsf

- Guidelines for Rehabilitating Historic Buildings: Architectural Metals

- Cleaning/Removing Paint from Wrought Iron, Cast Iron, and steel Using Mechanical/Abrasive Methods

- Primers and Paints for Wrought Iron, Cast Iron, and Steel

- Applying a Sacrificial Coating to Wrought Iron, Cast Iron, and Steel

- Dangers of Abrasive Cleaning To Historic Buildings 
- Hand-scraping, chipping, and wire brushing - the most common and least expensive methods for removing paint and light rust from iron. However, they do not remove all corrosion or paint as effectively as other methods.

- $\quad$ Low-pressure grit blasting - commonly called abrasive cleaning. It is often the most effective approach to removing excessive paint build-up or substantial corrosion.

- $\quad$ Air-abrasive paint removal - while air-abrasive cleaning (commonly known as sandblasting) is destructive for softer building materials; iron, a hard material with a natural uneven surface, will not be noticeably damaged by its careful use. Do not use airabrasive cleaning methods in the following situations: 1) On thin sections or fine, intricate details of wrought iron features. 2) On features for which the original surface texture is an integral part of the design.

NOTE: Remove only as much paint and rust each day as can be primed that same day. Bare iron will begin to rust again within a matter of hours. It should not be allowed to sit unprotected overnight.

Thorough surface preparation is necessary for the adhesion of new protective coatings. All loose, flaking, and deteriorated paint must be removed from the iron, as well as dirt. For paint to adhere properly, the metal surfaces must be absolutely dry before painting. Poorly prepared surfaces will cause the failure of even the best paints.

\section{Inspection}

Recommended...

- Removing surface dirt and grime and looking for signs of damage and wear.

- Identifying areas where rust or corrosion is present on metal elements.

Not Recommended...

- $\quad$ Failing to undertake adequate measures to assure the preservation of architectural metal features. 


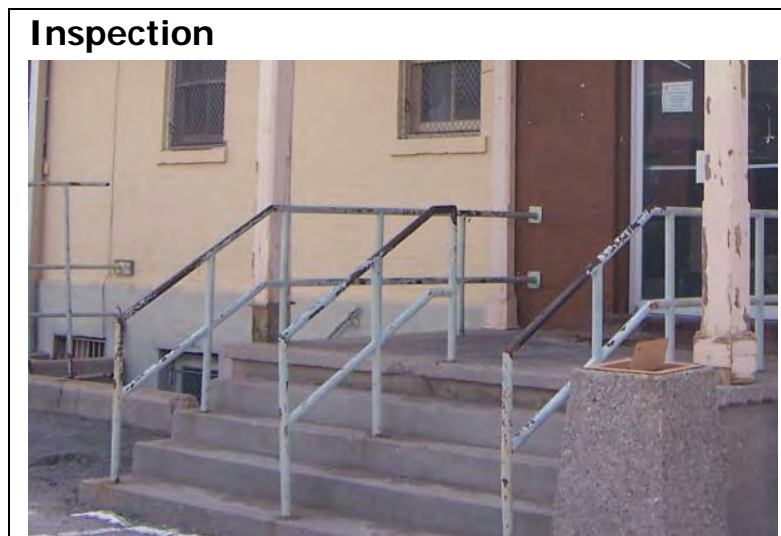

Building 21 - A periodic inspection identifies areas of rust, corrosion, or protective coating failures.

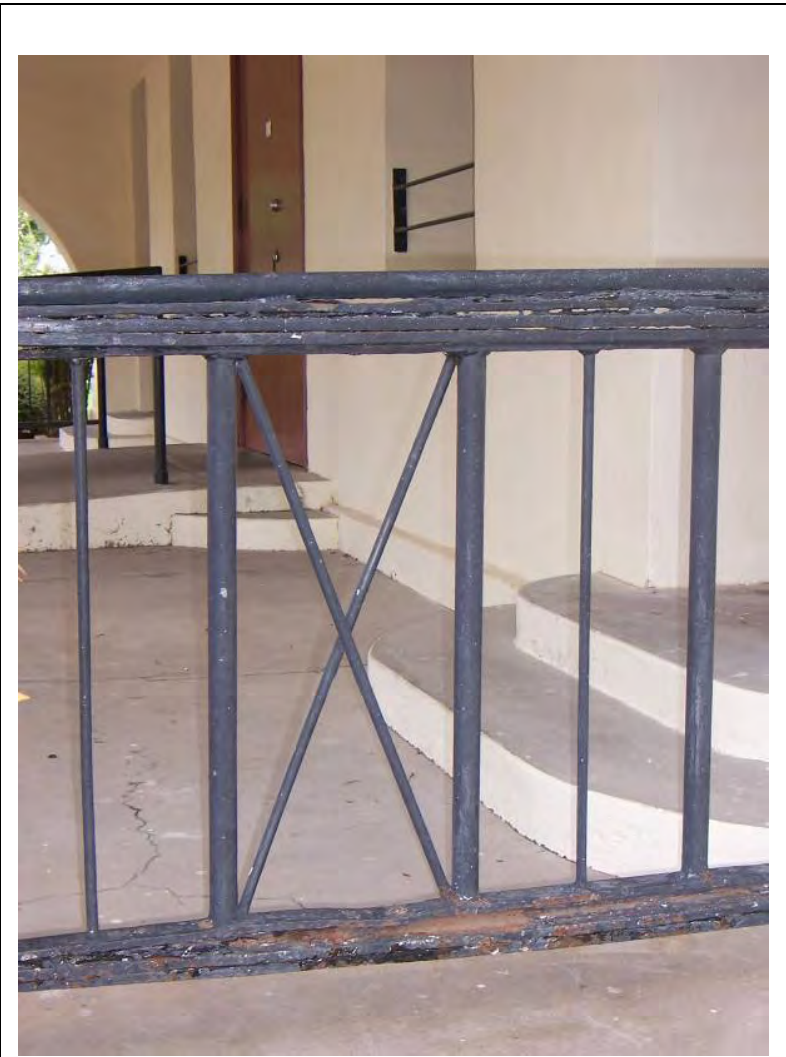

Building 315 - Surfaces of raw metal should be examined for signs of rusting. Provide an appropriate protective coating.

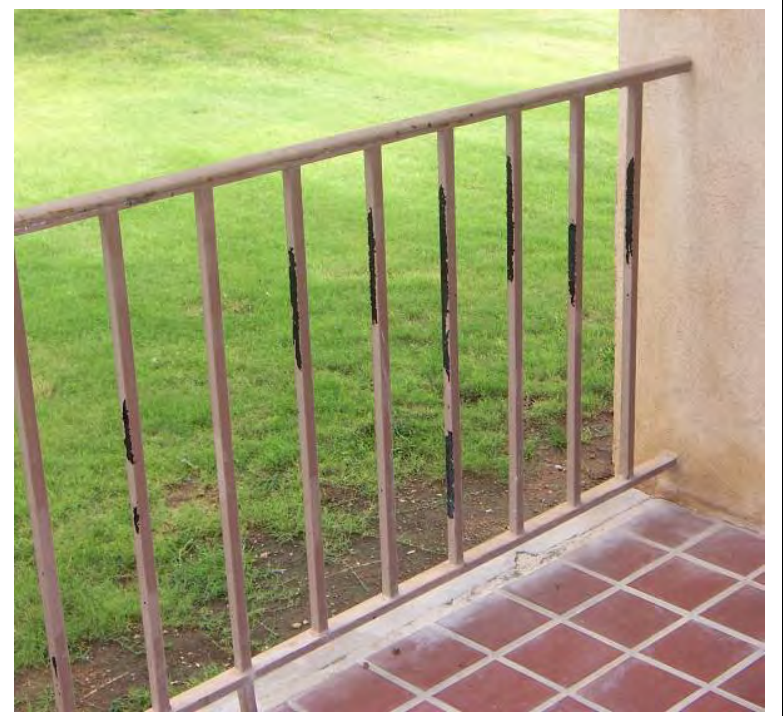

Building 504 - An inspection of metal features reveals light deterioration of the paint/protective coating, which should be cleaned and repainted after cause of damage is identified. 


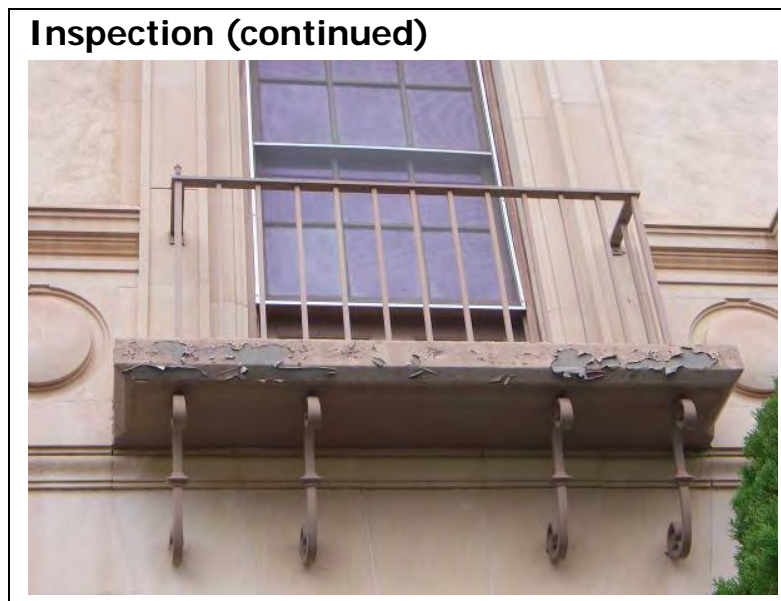

Building 504 - Check for chips in the coating surface and peeling of paint. Here the paint peeling on the concrete balcony may be caused by standing water. Look at the connection between the metal and the concrete.

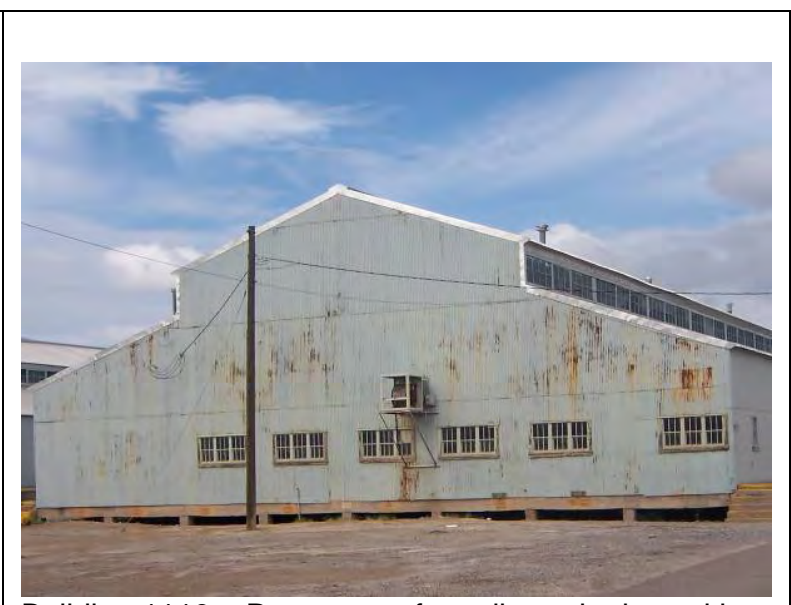

Building 1119 - Remove surface dirt and grime with proper cleaning techniques before repainting.

\section{Evaluation}

Recommended...

- Determining level of treatment necessary to repair severely damaged metal.

- Determining if the metal element needs to be replaced if too deteriorated to repair.

- Evaluating the overall condition of the architectural metals to determine whether more than protection and maintenance are required, that is, if repairs to features will be necessary.

Not Recommended...

- Ignoring signs of deterioration in paint or protective coatings on metal elements. 


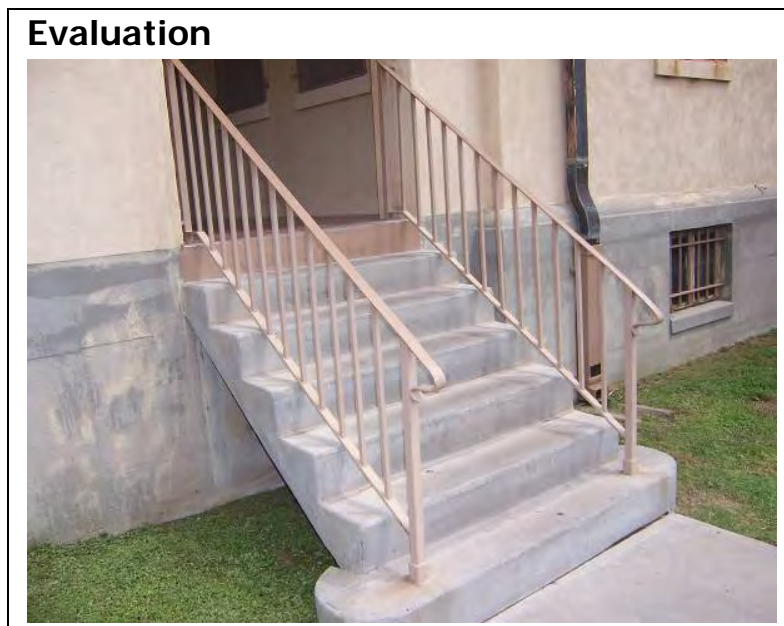

Building 504 - Evaluate and identify the particular metal type before cleaning or reapplying paint or a protective coating.

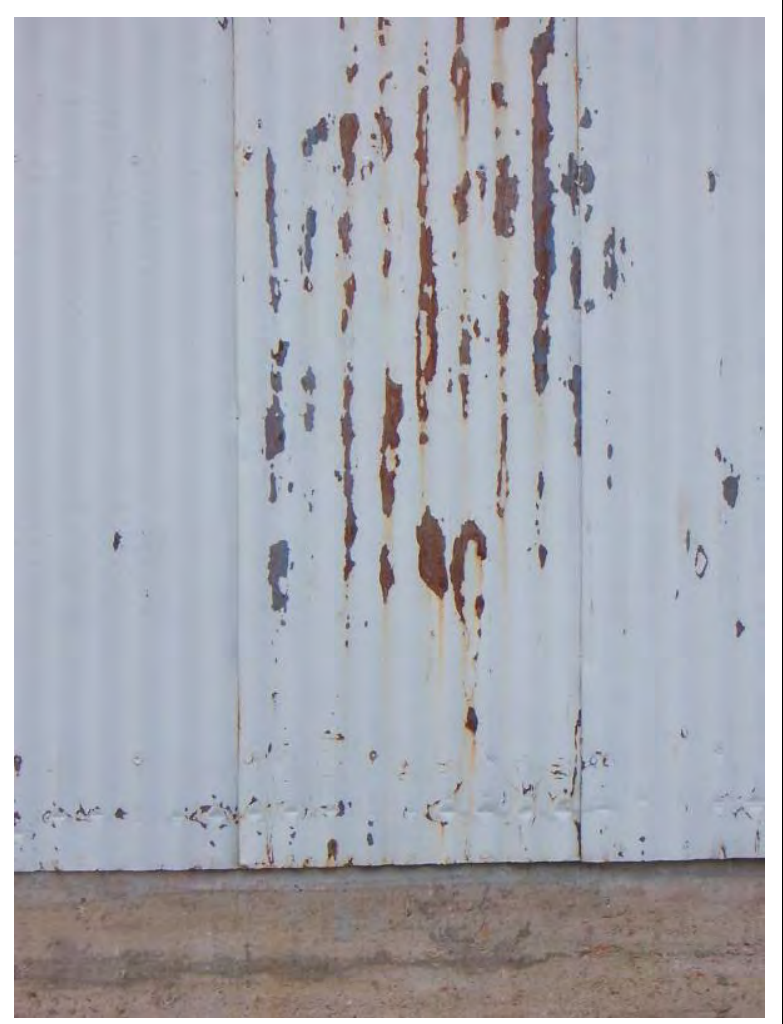

Building 1113 - Determine the cause for the chipping paint and rust and prescribe the proper procedure for repair of the metal element.

\section{Execution}

Recommended...

- Repairing the source of the damage before repair proceeds.

- Clean metal and reapply protective coating.

\section{Repair}

Recommended...

- Cleaning architectural metals, when necessary, to remove corrosion prior to repainting or applying other appropriate protective coatings.

- Identifying the particular type of metal prior to any cleaning procedure and then testing to assure that the gentlest cleaning method possible is selected or determining that cleaning is inappropriate for the particular metal.

- Using the gentlest cleaning methods for cast iron, wrought iron, and steel—hard metalsin order to remove paint buildup and corrosion. If hand-scraping and wire brushing have proven ineffective, low-pressure dry grit blasting may be used as long as it does not abrade or damage the surface.

- Applying appropriate paint or other coating systems after cleaning in order to decrease the corrosion rate of metals.

- Repainting with colors that are appropriate to the historic building or district. 
- Applying an appropriate protective coating.

Not Recommended...

- Exposing metals that were intended to be protected from the environment.

- Removing the patina of historic metal. The patina may be a protective coating on some metals, such as bronze or copper, as well as a significant historic finish.

- Failing to use gentler methods prior to abrasively cleaning cast iron, wrought iron, or steel or using high-pressure grit blasting.

- Failing to reapply protective coating systems to metals or alloys that require them after cleaning so that accelerated corrosion occurs.

- Using new colors that are inappropriate to the historic building or district.

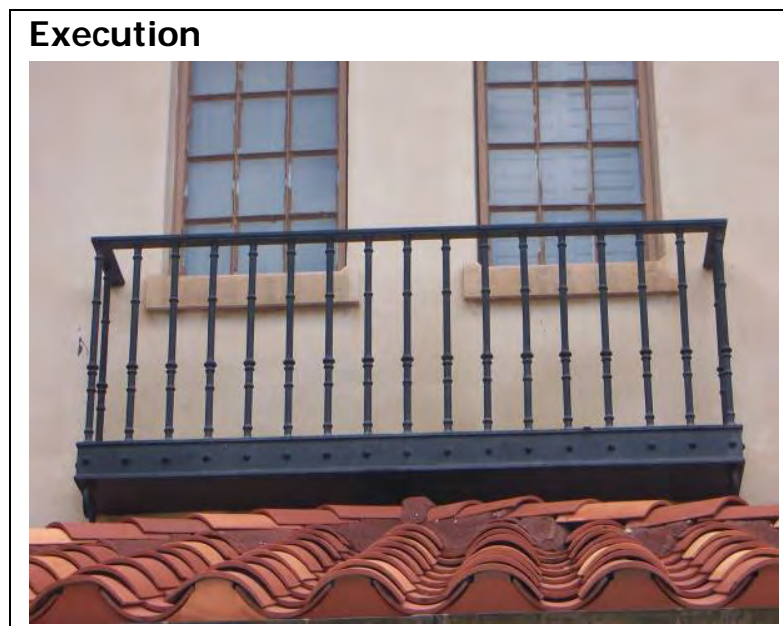

Building 243 - Make sure that water is not allowed to stand on metal elements such as the metal balcony.

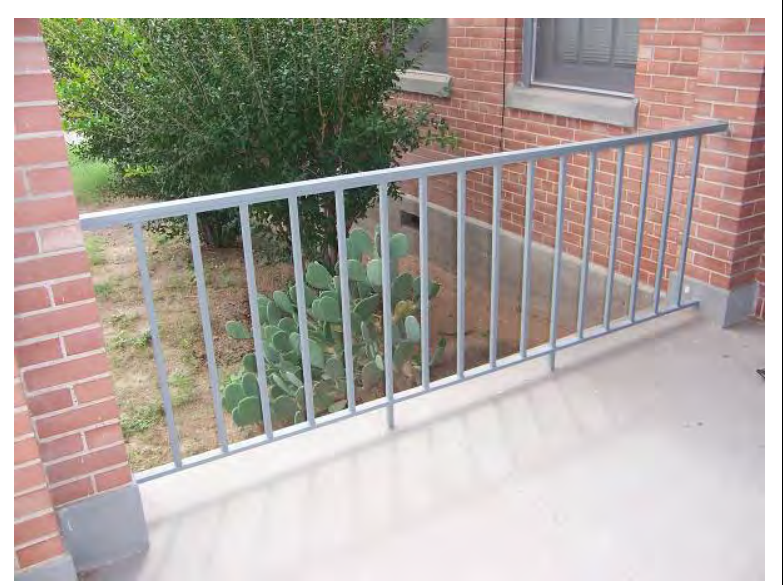

Building 629 - It is recommended to repaint with colors that are appropriate to the historic building or district. Consult the paint analysis. 
Notes

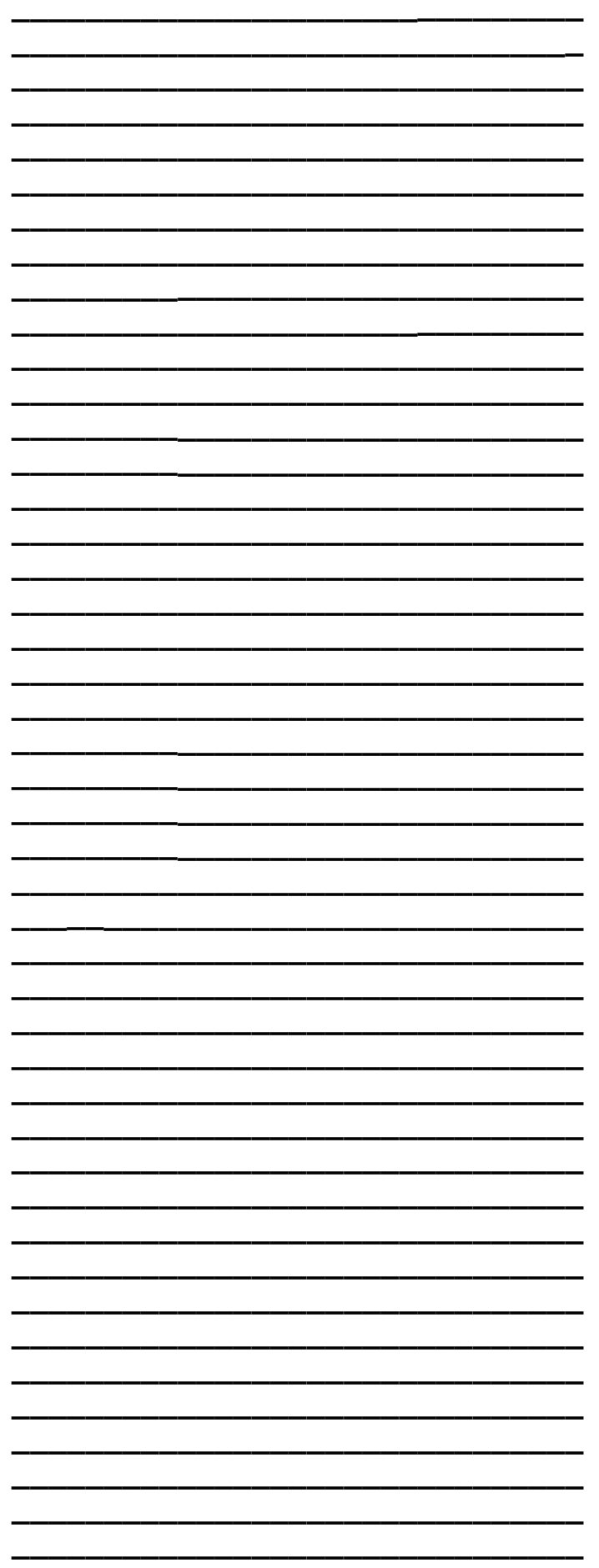




\section{Maintenance Guides for Interior Spaces and Finishes}

\section{Interior Spaces and Finishes: Overview}

The interiors of historic buildings are complex systems of spaces, features, finishes, and materials. Rehabilitation seeks to balance respect for historic buildings with recognition of modern needs. The interior of a building, including the arrangement and sequence of spaces, built-in features, and applied finishes are important in defining the building's character.

Identifying and retaining original floor plans and features, such as floors, baseboards, columns, sills, paneling, fireplaces, mantels, stairways, cornices, fixtures, and finishes, including wallpaper, paint, and plaster, is crucial to preserving the historic interior. Each piece, even the seemingly mundane, is part of a larger whole. Removal or alteration of interior spaces, features, and finishes results in the incremental loss of irreplaceable historic materials and feeling. When cleaning, the gentlest methods and products should be used. Removing or stripping historic finishes, such as paints and varnishes, is not recommended.

Damaged features should be repaired rather than replaced. If a historic architectural feature must be replaced, the replacement should be of similar design and materials as the original. If the original design is not known, use compatible new design. New features should complement not obscure character-defining features.

The following is a checklist that will help guide the Fort Bliss staff in the rehabilitation of historic interiors. It is a general preservation approach to guide construction work.

\section{Identify and Evaluate the Importance of Interior Elements Prior to Rehabilitation}

- Research the building's history.

- Identify interior elements.

- Assessing alterations and deterioration.

- Drawing up plans and executing work.
Maintenance/ Management Guidelines for I nterior Finishes

- The interior of a building is important in defining the building's character. Identifying and retaining original floor plan and features is crucial to preserving the historic interior. Damaged features should be repaired rather than replaced.

- According to The Secretary of the Interior's Standards for Rehabilitation, the proper procedure is to respect the significance of the original materials and features, repair and retain wherever possible, and replace them only when absolutely necessary.

- The following recommendations for care of the historic site are to be thoroughly read and understood before a treatment is specified. The Secretary of the Interior's Standards for Rehabilitation should also be consulted to determine the appropriateness of any treatment.

Full documentation can be found at http://www.cr.nps.gov/hps/tps/tax/rhb/stand.htm

Construction Documents \& Specifications: Preservation \& Rehabilitation of Historic Interior Finishes, Fort Bliss Manual 


\section{Recommended Approaches for Rehabilitating Historic Interiors}

- Retain and preserve floor plans and interior spaces that are important in the overall historic character of the building.

- Avoid subdividing spaces that are characteristically of a building type or style or that are directly associated with specific persons or patterns of events.

- Avoid making new cuts in floors and ceilings where such cuts would change the character-defining spaces and the historic configuration of such spaces.

- Avoid installing dropped ceiling below ornamental ceilings or in rooms where the ceilings are part of the building's character.

- Retain and preserve interior features and finishes that are important in defining the overall historic character of the building.

- Retain stairs in their historic configuration and location.

- Retain and preserve visible features of early mechanical systems that are important in defining the overall historic character of the building, such as radiators, vents, grilles, plumbing fixtures, switch plates, and light fixtures.

- Do not "fur out" perimeter walls for insulation purposes. This requires unnecessary removal of window trim and can change the room's proportion.

- Do not remove paint and plaster from traditionally finished surfaces to expose masonry and wood work.

- Do not use destructive methods-propane and butane torches or sandblasting techniques to remove paint or other coatings from historic features.

- Do not use harsh and abrasive cleaning.
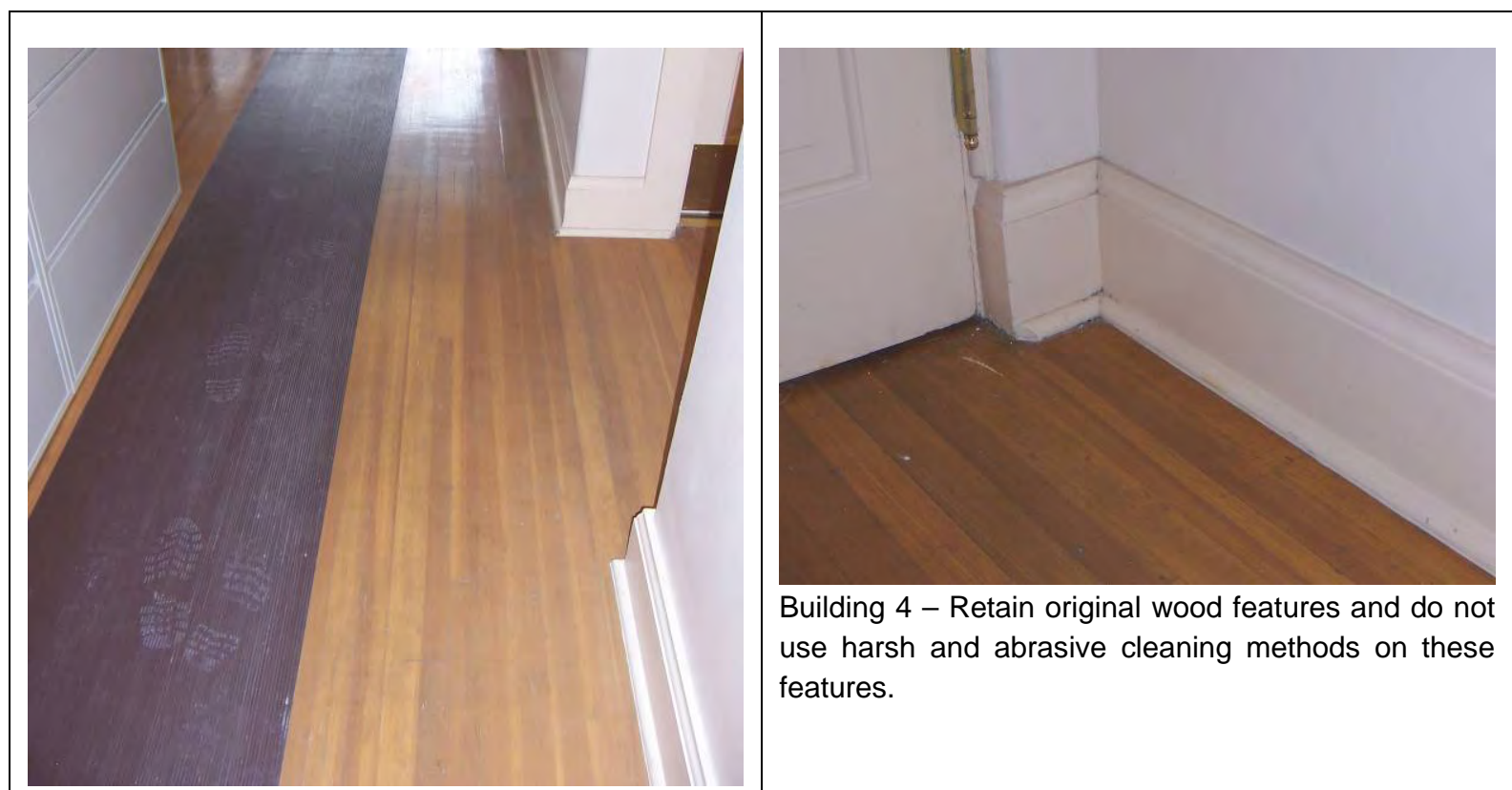

Building 4 - Retain original wood features and do not use harsh and abrasive cleaning methods on these features.

Building 4 - The hallway runner helps preserve interior features like the wood floor. 


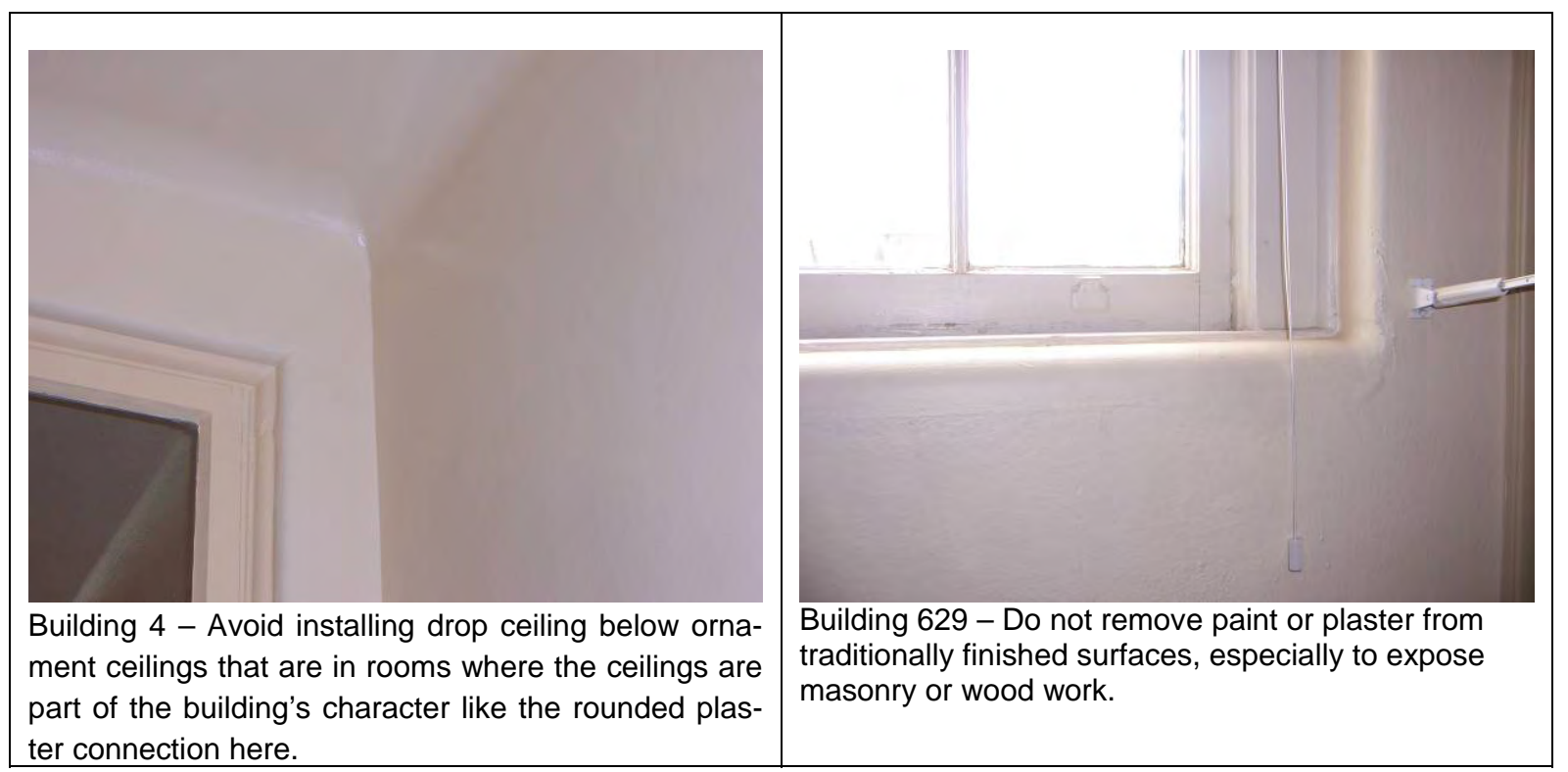




\section{Interior Finishes: Wood}

Wood floors, built-in cabinetry, stairs, and railings, and millwork have particular value as character-defining elements. Evaluate the overall condition of the wood features to determine whether protection and maintenance are sufficient, or if repair is necessary.

Original wood elements should be inspected for signs of damage and deterioration such as rot, drying, splitting, termites, warping, or other damage. These symptoms should be documented and addressed in regular maintenance inspections.

\section{Identify, Retain, and Preserve}

Recommended...

- Identifying, retaining, and preserving architectural historic interior wood features such as baseboards, door millwork, window millwork, mantels, floors, cabinetry, and portant in defining the overall historic character of the building; and their finishes and colors. Identification is also critical to differentiate between hardwoods and softwoods prior to work. Each type of wood has unique properties and thus requires different treatments.

Not Recommended...

- Removing or radically changing architectural historic interior wood, which is important in defining the overall historic character of the building so that, as a result, the character is diminished. stairs, and/or railings that are im-

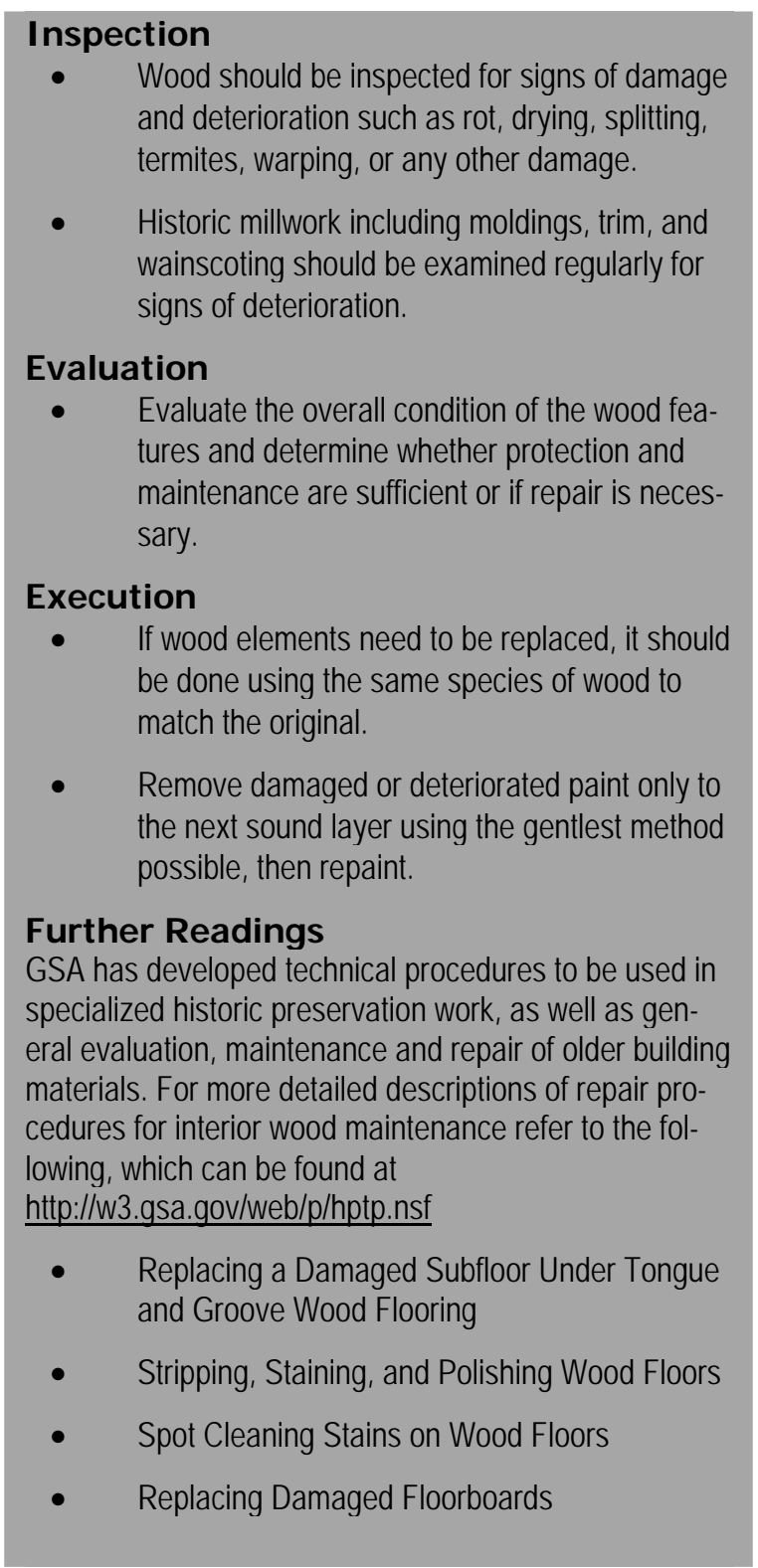

Inspection and deterioration such as rot, drying, splitting, termites, warping, or any other damage. wainscoting signs of deterioration.

valuation tures and determine whether protection and maintenance are sufficient or if repair is necessary.

xecution be done using the same species of wood to match the original. the next sound layer using the gentlest method possible, then repaint.

\section{Further Readings}

GSA has developed technical procedures to be used in specialized historic preservation work, as well as general evaluation, maintenance and repair of older building materials. For more detailed descriptions of repair procedures for interior wood maintenance refer to the following, which can be found at .

Radically changing the type of finish or its historic color or accent scheme.

\section{Protect and Maintain}

Recommended...

- Removing damaged or deteriorated paint only to the next sound layer using the gentlest means possible (hand-scraper, wire brush, or sandpaper), then repaint. Stripping methods including hot air guns, heat plates, and chemical or dip stripping should be used with great care, and only as a supplement to hand-scraping, brushing, and sanding.

- Applying specification-approved primer and paint following proper surface preparation and product instructions. 
- Inspecting regularly for wood that is excessively or continually moist and for evidence of insect infestation and fungal rot.

- Addressing evidence of moisture infiltration and infestation as soon as possible.

- Using only hot-dipped, zinc-coated nails, bolts, and hardware for use on treated wood.

- Countersinking and puttying all new, exposed nails and screws according to general specifications.

Not Recommended...

- Replacing, rebuilding, or altering any original wood features that could be preserved or consolidated.

- Introducing new or non-specific brands of paint, colors, or methods of application.

- Failing to identify, evaluate, and treat the causes of wood deterioration, including insect or fungus infestation.

- Using chemical preservatives (such as creosote) which can change the appearance of wood features.

- Using destructive paint removal methods such as propane or butane torches, sandblasting, or waterblasting. These methods can irreversibly damage historic woodwork.

- Using thermal devices improperly when removing paint so that historic woodwork is scorched or damaged.

- Failing to neutralize wood thoroughly after using chemicals so the new paint does not adhere.

- Allowing detachable wood features, like doors, to soak too long in a caustic solution so that the wood grain is raised and the surface roughened.

- Installing new decorative wood trim intended to simulate older wood trim when decorative wood trim was not part of the historic building design.

\section{Repair}

Recommended...

- Filling moderate-sized holes and check cracks with putty or epoxy filler. Repair should be applied as per general specifications.

- Repairing fragile original wood using well-tested consolidants when appropriate. Repairs should be physically, visually, and chemically compatible and identifiable upon close inspection.

Not Recommended...

- Removing or replacing original wood that could be stabilized and conserved, or repaired with limited replacement of deteriorated or missing parts.

- Using substitute materials that are physically, visually, or chemically incompatible with the original materials.

- Painting previously unpainted wood surfaces (shellac or varnish).

\section{Replace}

Recommended...

- Replacing deteriorated or damaged wood by carefully patching, piecing-in, or otherwise reinforcing the wood using recognized preservation methods. Replacement work should be permanently dated in an unobtrusive location. 
Not Recommended...

- Removing an original wood feature that is repairable. Removing an original wood feature that is unrepairable and not replacing it, or failing to label the new work.

\section{Wood Floors}

Wood floors, built-in cabinetry, stairs, railings, and trim have particular value as characterdefining elements. A wood floor surface can be either a series of connected planks or parquet (small wood pieces arranged in decorative patterns). The wood used is either plain sawn or quarter sawn. Plank flooring, the more common type, is assembled by joining: butt joint, tongue and groove, shiplap, doweled, or splice. Wood floors are usually secured to the under structure by countersinking nails, blind-nailing, or screwing and plugging. This following is a list of preservation methods for wood floors.

- Use shade or awning to control direct sunlight on interior wood finish to prevent ultraviolet damage.

- Maintain wood floors by cleaning and waxing regularly. Do not wax wood floors with a polyurethane finish, as they become slippery since wax is not absorbed into the grain.

- Protect wood floors during maintenance and repair operations.

- Refinish the floors. The objectives of wood refinishing and cleaning are to give wood surfaces a smooth, uniform appearance consistent with the original design intent, and to preserve the inherent patina. Splotches, streaks, runs, or any other kind of spotty appearance shall not be accepted. Too aggressive cleaning or sanding shall NOT be accepted.

- Spot clean stains on wood floors.

- Apply stain to wood floor to obtain a finish to match the original.

- Apply floor sealer (two coats) in accordance with manufacturer's printed instructions, including machine buffing with steel wool as recommended by the manufacturer.

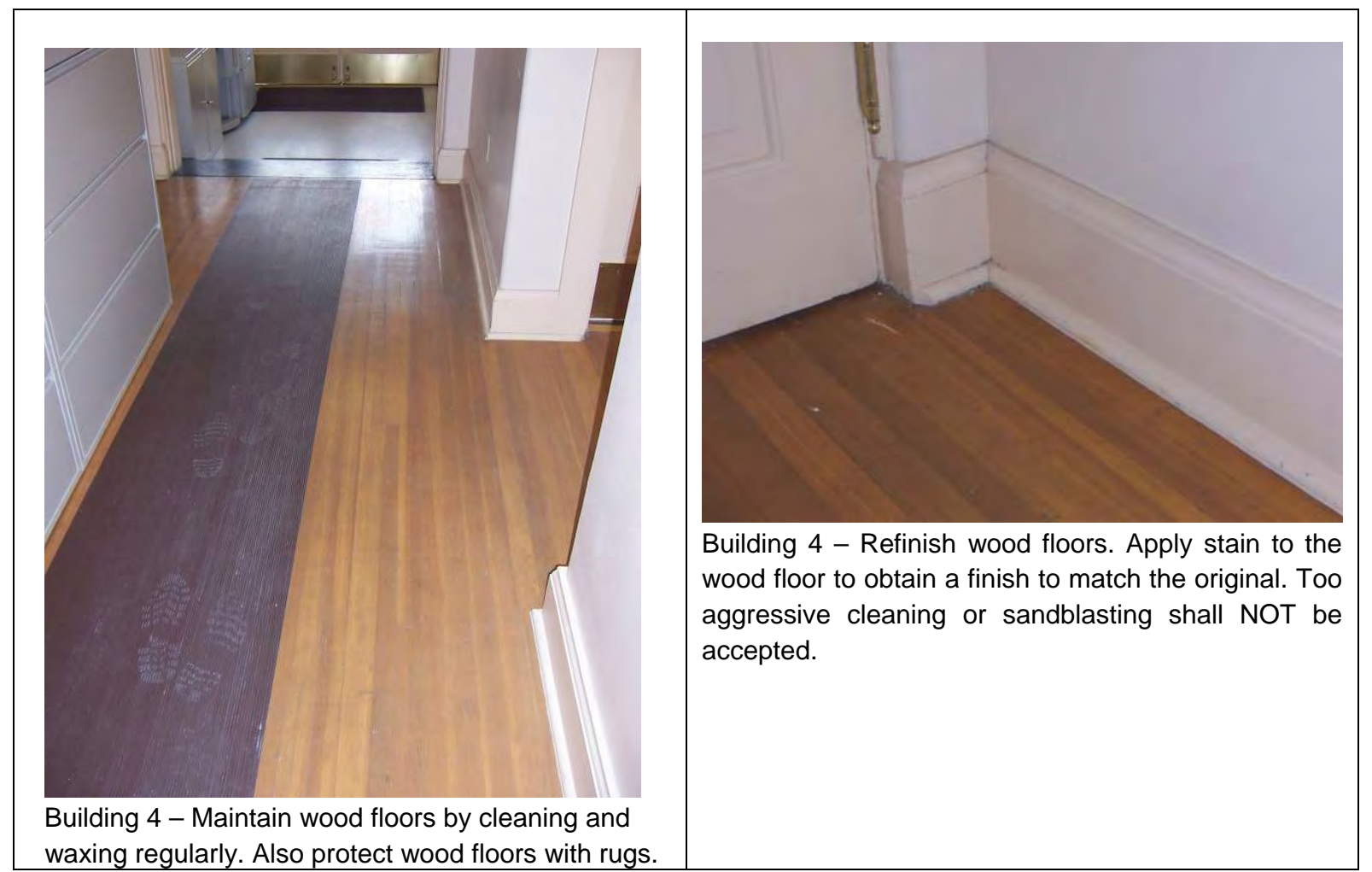




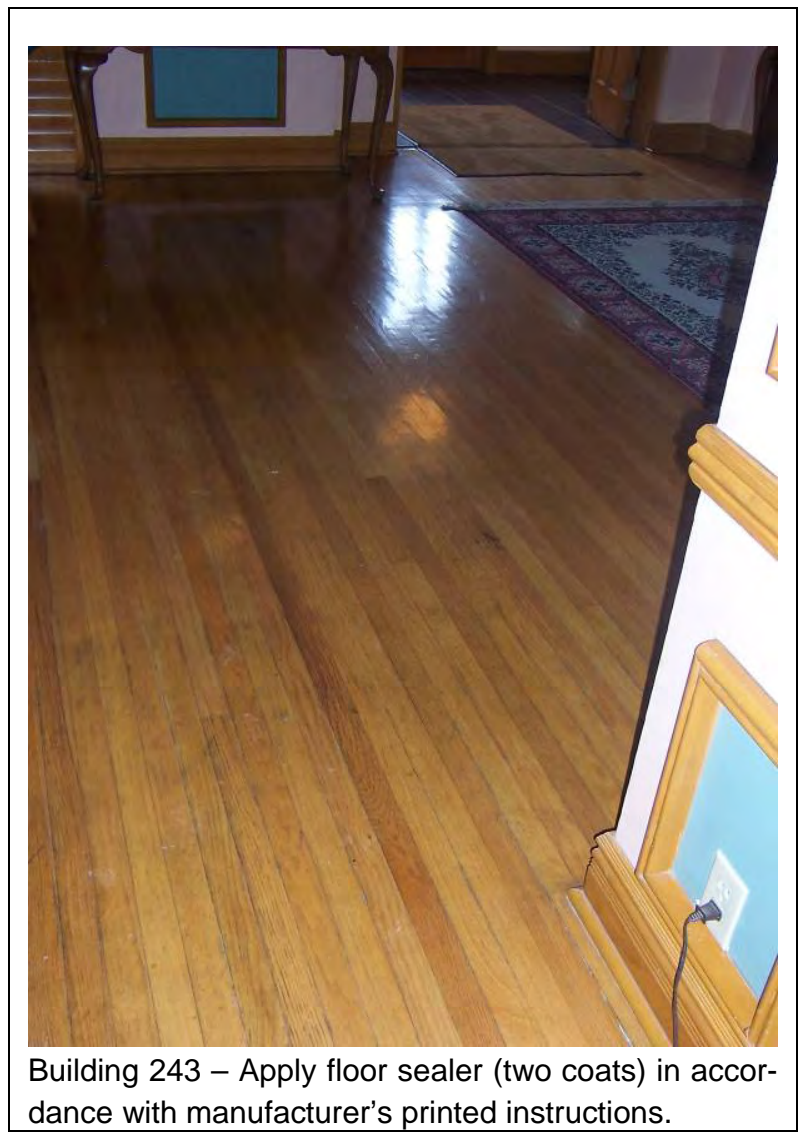

\section{Millwork}

Historic millwork, which includes moldings, trim, and wainscoting, should be examined regularly for signs of deterioration or damage. Historic millwork is an important character-defining feature of historic buildings and should not be replaced unless damaged beyond repair. The replaced sections should accurately match the profile of the original millwork.

- Limit paint removal. Generally, interior wood features should be stripped only if it is necessary to make elements such as windows operable, to expose lost detail due to overpainting, or to remove lead-containing paint.

- A historic paint analysis will be necessary to find the original color of the trim.

- Repaint wood trim and walls with colors that are appropriate to the historic building based on historic paint layers analysis.

- Retain wood trim. It should be saved and restored whenever possible; however, if replacement is necessary, the pieces should be spliced. If entire sections need to be replaced, replacement pieces should match the historic trim pieces. 


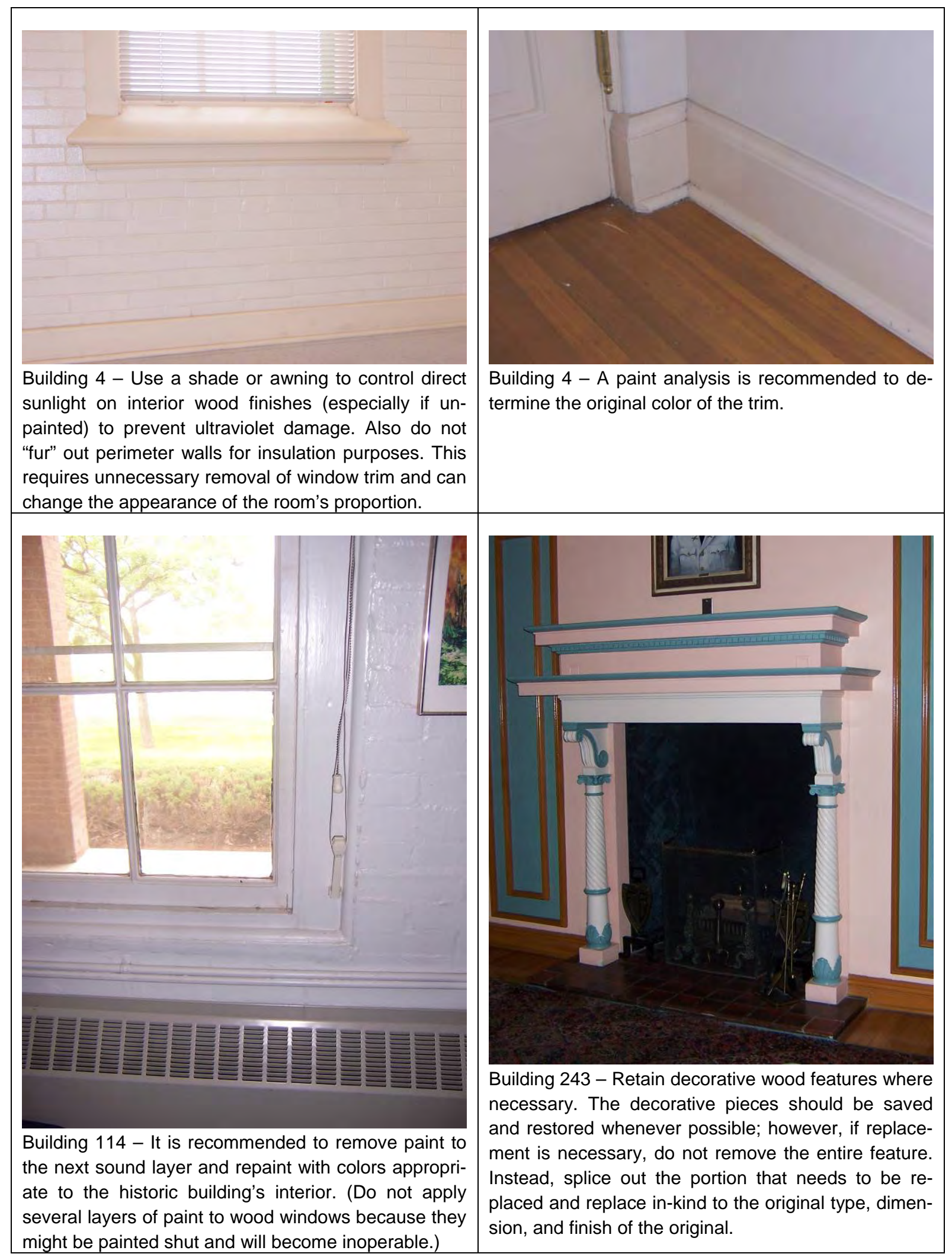




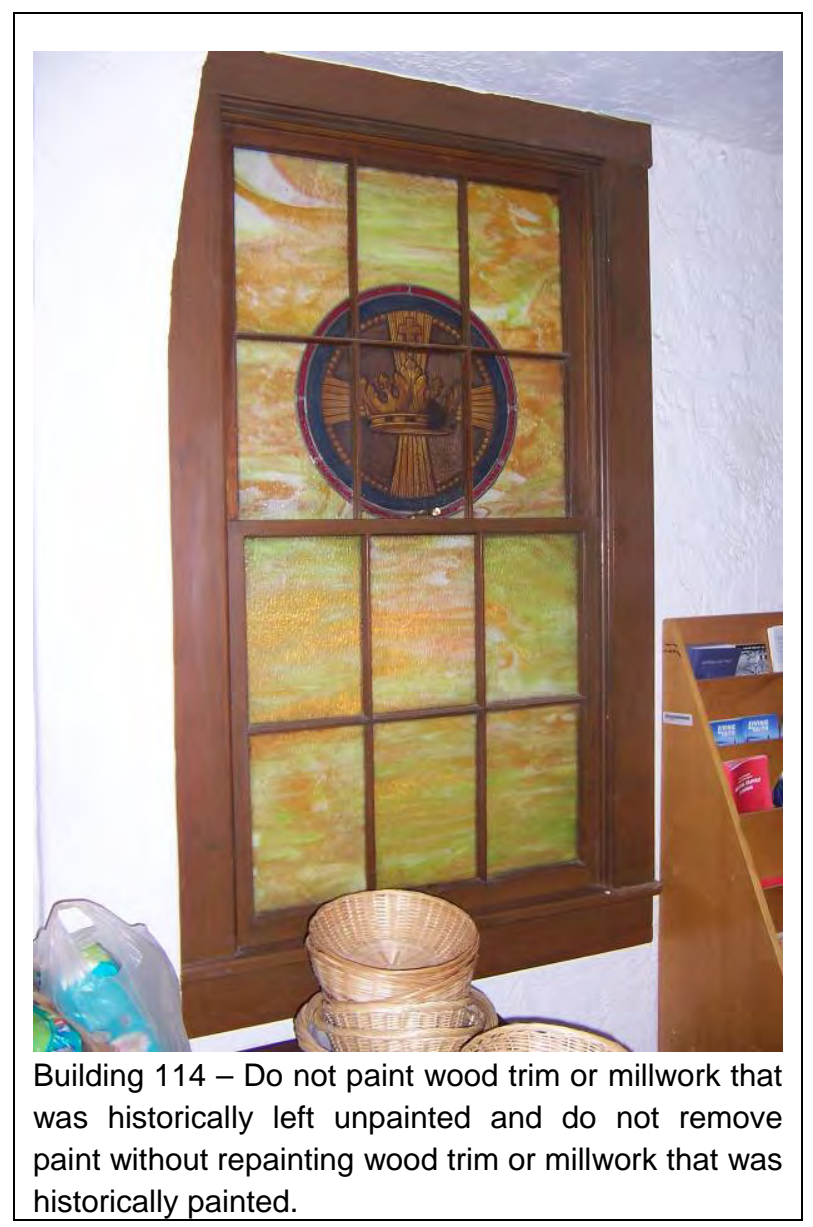


Notes

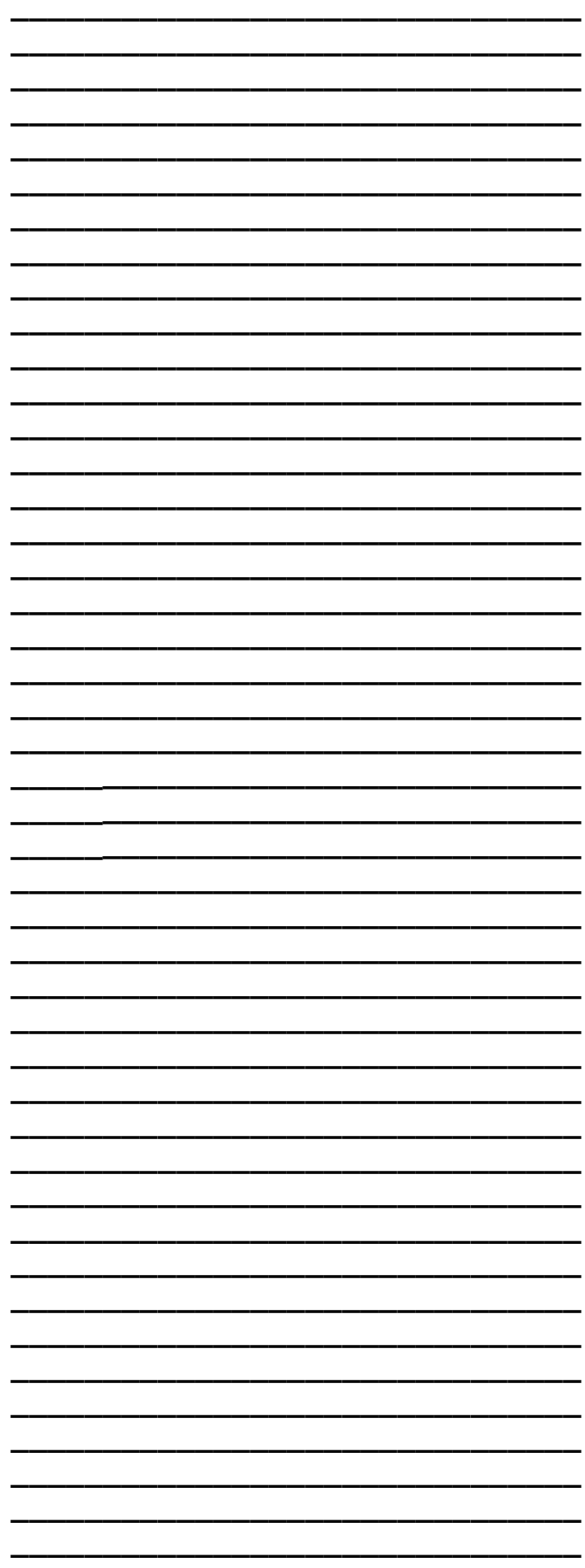




\section{Interior Finishes: Plaster}

Plaster is used on a wall and ceiling finish in the interior of many historic buildings.

Three-coat plaster is strong and durable. It resists fire and reduces sound transmission. Replacing plaster is expensive.

There are two types of plaster: lime and gypsum. Lime was used until the late $19^{\text {th }}$ century, but its disadvantages of a difficult application process and long drying time gave way to a new plastering material, gypsum. Gypsum begins to cure as soon as it is mixed with water and it sets in minutes.

However, gypsum plaster is more susceptible to water damage.

Lath provides a means of holding the plaster in place. There are three types of lath: wood, metal, and masonry.

\section{Problems}

When plaster dries, it is a relatively rigid material that should last indefinitely. However, there are conditions that cause plaster to crack, effloresce, separate, or become detached from its lath frame work.

- Structural Problems: Overload stresses within a wall acting on the building as a whole can create stress cracks. Appearing as diagonal lines in a wall, stress cracks usually start at a door or window frame, but they appear anywhere in a wall at seemingly random points. Overloading and structural movement (especially when combined with rusted nails or poor quality plaster) can cause plaster to detach from the lath. The plaster loses its key. When the mechanical bond with the lath is broken, plaster becomes loose or bowed. If repairs are not made, especially to ceilings, gravity will simply cause chunks of plaster to fall to the floor.

- Poor Workmanship: The proper proportioning and mixing of materials are vital to the quality of the plaster job. A bad mix can cause problems that appear years later in a plaster wall. Incompatible basecoats and finish coats, improper plaster application, too much retardant, and inadequate plaster thickness are all issues regarding poor workmanship of plaster.

- Improper Curing: Proper temperature and air circulation during curing are key factors in a durable plaster job.

\section{Inspection \\ - Inspect for cracks in the plaster. \\ - Identify the root of the problem causing dam- age to the plaster. \\ Evaluation \\ - If removing paint, a paint sample should be conducted. \\ - $\quad$ Check and test for lead-based paints. \\ - If the plaster is beyond repair, decide whether to plaster over the old lath or install new lath and build-up new plaster layers over it. \\ Execution \\ - $\quad$ Once the root problem is diagnosed, appropri- ate patching should take place. \\ - $\quad$ Remove old chipped plaster and replace with new plaster fill that matches the historic color. \\ - Mild cleaning techniques should be used for in- terior plaster.}

\section{Further Readings}

GSA has developed technical procedures to be used in specialized historic preservation work, as well as general evaluation, maintenance and repair of older building materials. For more detailed descriptions of repair procedures for plaster refer to the following, which can be found at http://w3.gsa.gov/web/p/hptp.nsf

- $\quad$ Preservation Briefs: \#21 Repairing Historic Flat Plaster - Walls and Ceilings

- $\quad$ Cleaning and Stripping Paint from Plaster Surfaces

- $\quad$ Concealing Water Stains on Plaster Surfaces

- $\quad$ Patching Hairline Cracks in Plaster

- Patching Small Chips and Cracks in Plaster 
- Moisture: Plaster applied to a masonry wall is vulnerable to water damage if the wall is constantly wet. When salts from the masonry substrate come in contact with water, they migrate to the surface of the plaster, appearing as dry bubbles or efflorescence. The source of the moisture must be eliminated before replastering the damaged area. Moisture problems occur for several reasons; interior plumbing, roof leaks, gutter and downspout leaks, and dampness around building foundation.

\section{Cleaning}

Mild cleaning techniques should be used for interior plaster. Minor build-up of dust and dirt can be removed with brushes and a vacuum. A rinse of mild detergent and water may also be used, but the plaster should not remain wet for extended periods of time. Major stains can be removed by applying a temporary, porous, absorptive surface treatment.

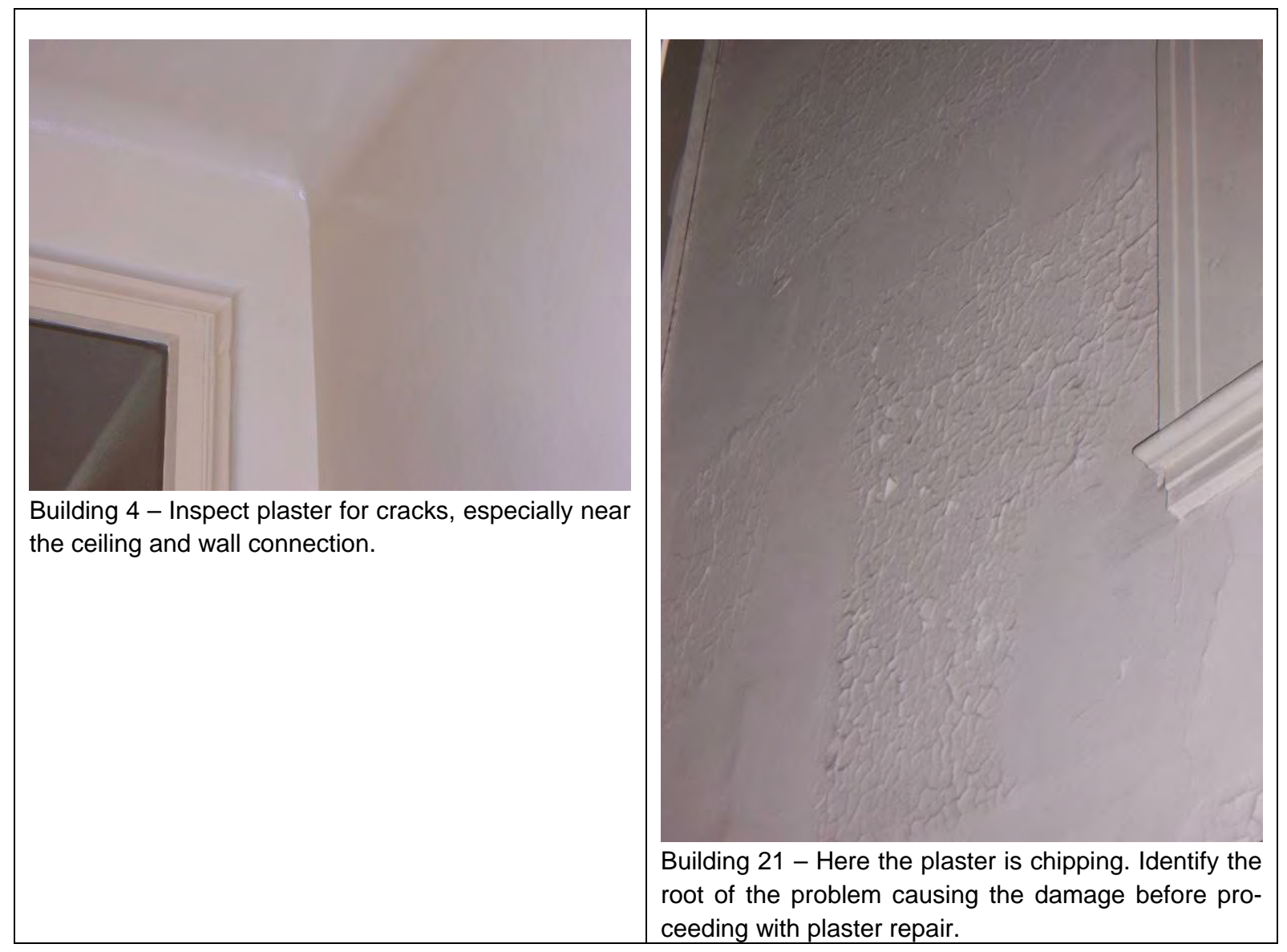




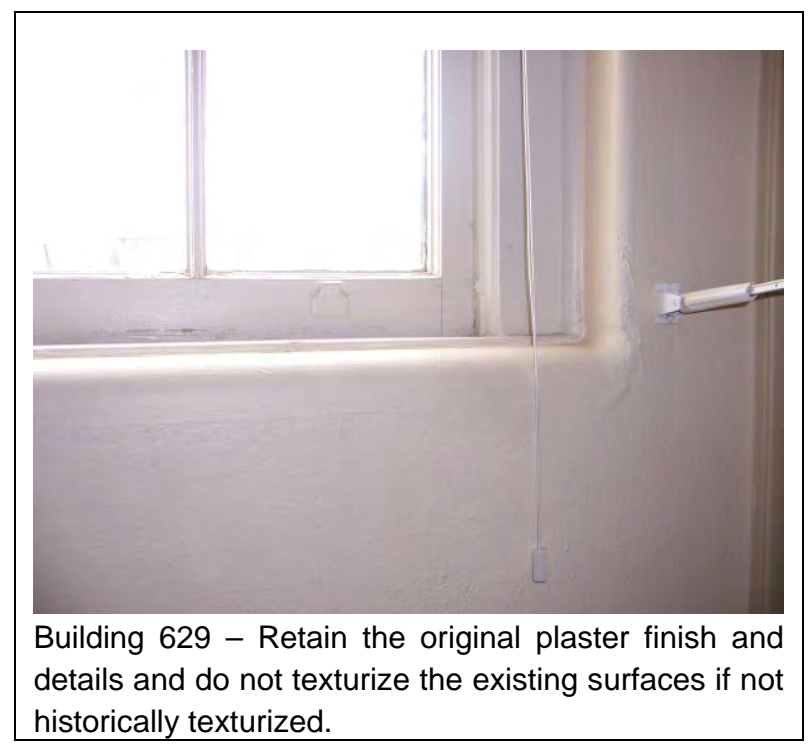

\section{Repair}

Many of the problems that cause plaster to fail are not easily remedied. If major structural problems are found to be the source of the plaster problem the structural problem should be corrected. Some repairs can be made by removing only small sections of plaster to gain access. Cosmetic damage from minor building movement, holes, or bowed areas can be repaired without the need for wholesale demolition. However, it may be necessary to remove deteriorated plaster caused by rising damp in order for masonry walls to dry out. Repairs made to a wet base will fail again. Repairing plaster often requires the help of a professional plasterer.

- Hairline cracks are not a serious cause for concern as long as the underlying plaster is in good condition. To repair, widen the crack slightly with a sharp, pointed tool and fill the crack. If the crack is a little larger, bridge the gap with tape. For delaminated areas, paint a liquid plaster-bonding agent onto the area and then replaster with a new finish coat.

- For small holes (less than 4 inches in diameter) that involve loss of the finish coats, the repair is made in two applications. First, a layer of basecoat plaster is troweled in place and scraped back below the level of the existing plaster. When the base coat has set but not dried, more plaster is applied to create a smooth, level surface. One-coat patching is not generally recommended by plasterers because it tends to produce concave surfaces that show up when the work is painted.

- For larger holes where all three coats of plaster are damaged or missing down to the lath, clean out the old plaster down to the lath layer. Repair the lath and then build up the plaster finish.

- Retain the original plaster finishes and do not texturize the existing surfaces.

- The key to a successful paint job is proper drying of the plaster. To allow proper drying time, check with the The Secretary of the Interior Standards guidelines on plaster repair and replacement. 


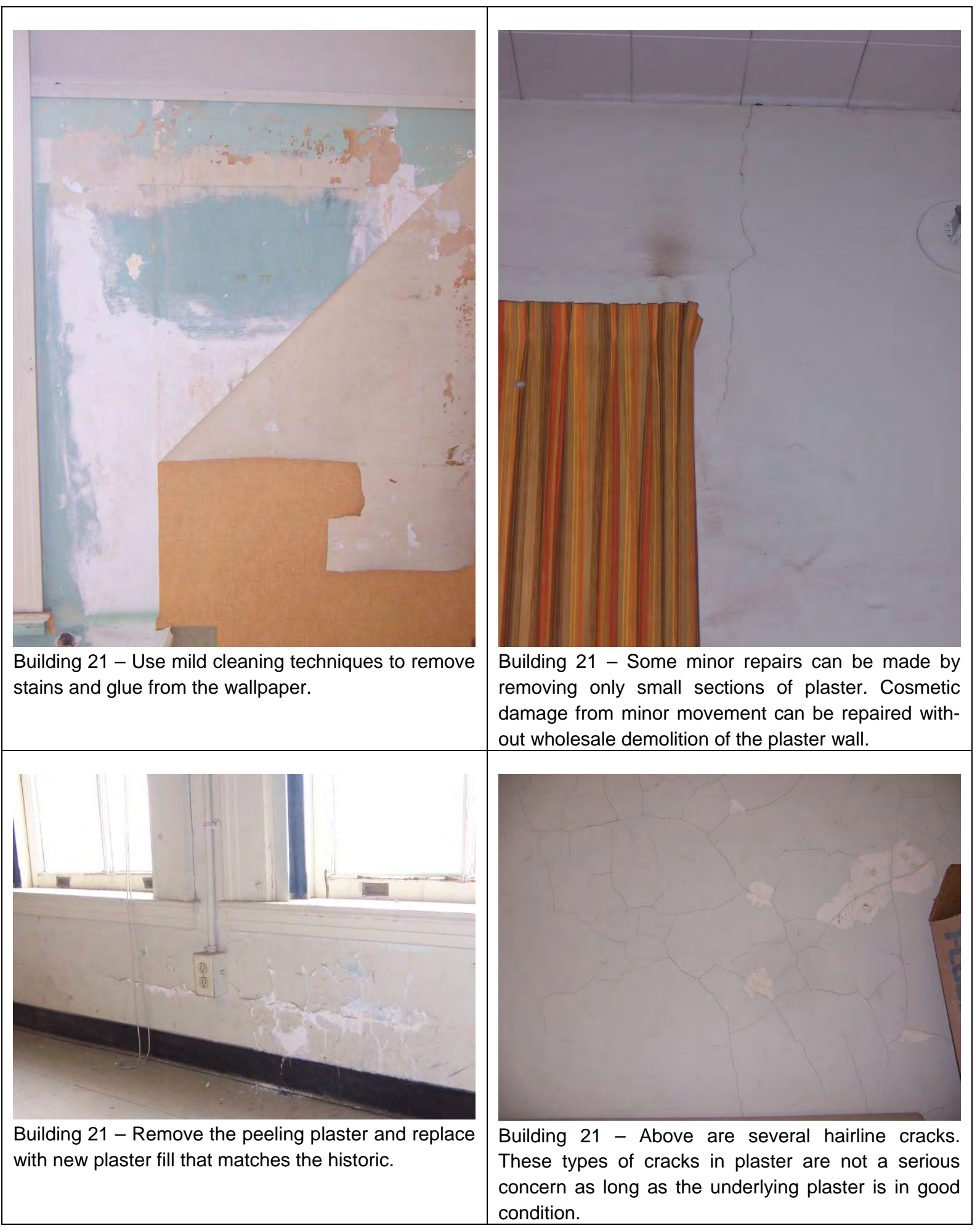




\section{Replace}

Partial or complete removal may be necessary if plaster is badly damaged, particularly if the damage is caused by long-term moisture problems. When the damaged plaster has been removed, the owner must decide whether to replaster over the existing lath or use a different system. This decision should be based in part on the thickness of the original plaster and the condition of the original lath.

Recommended...

- Replaster old wood lath.

- Replaster over new metal lath.

- Replaster over new rock lath.

Not Recommended...

- Replacing a damaged plaster wall or ceiling with drywall or other non-original materials.

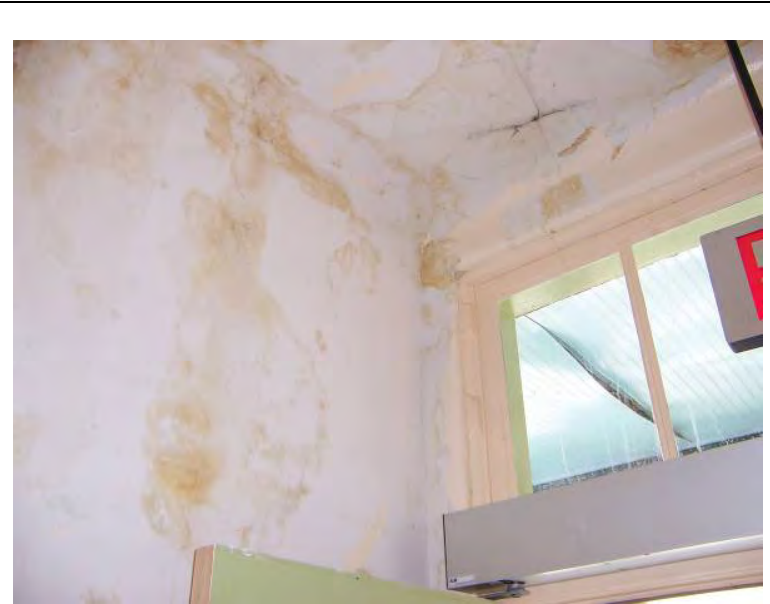

Building 4 - Partial or complete removal of plaster may be necessary; however, it is not recommended to replace a damaged plaster wall or ceiling with drywall. Fix the root cause of the problem before proceeding. 
Notes

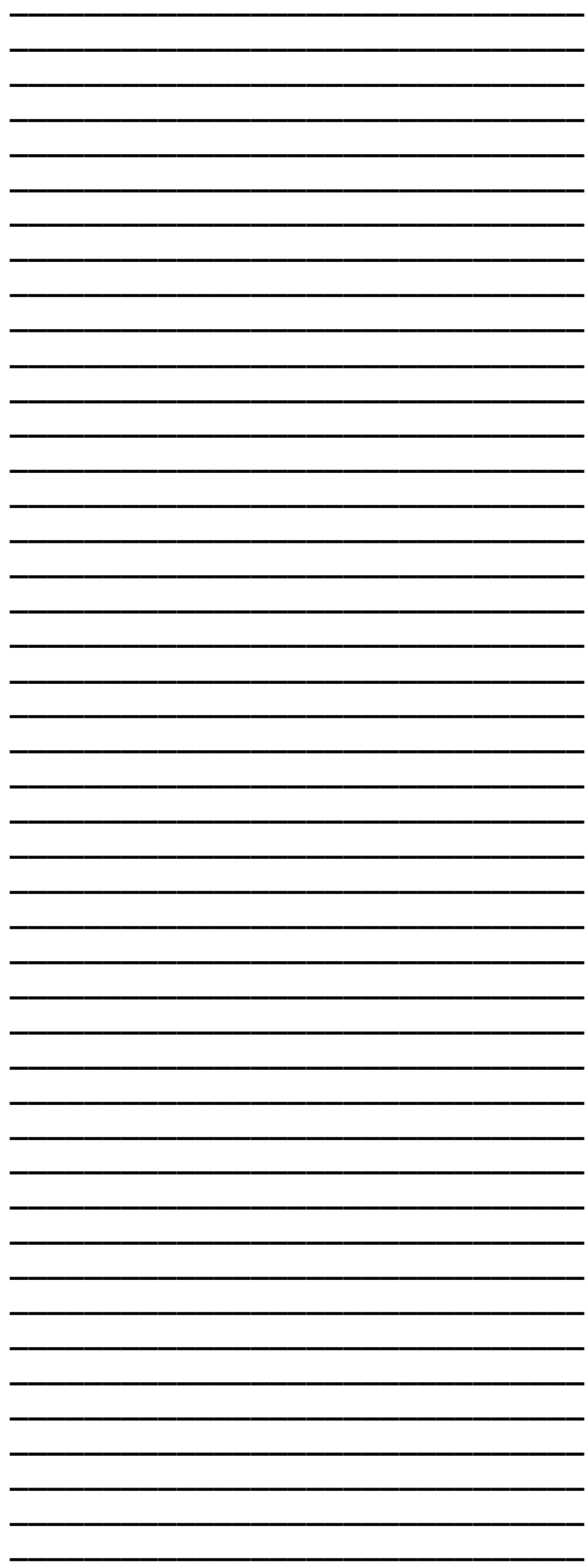




\section{Maintenance Guides for Mechanical and Electrical Systems}

\section{Mechanical and Electrical Systems: Overview}

The visible decorative features of historic mechanical systems such as grilles, radiators, lighting fixtures, and ornamental switch plates may contribute to the overall historic character of the building and should be retained and repaired, whenever possible.

Their identification needs to take place together with an evaluation of their condition early in project planning.

\section{Identify, Retain, and Preserve}

Recommended...

- Identifying, retaining, and preserving visible features of early mechanical systems that are important in defining the overall historic character of the building. This may include radiators, vents, fans, grilles, plumbing fixtures, switch plates and lights.

Not Recommended...

- Removing or radically changing features of mechanical systems that are important in defining the overall historic character of a building so that, as a result, the character is diminished.

\section{Protect and Maintain}

Recommended...

- Protecting and maintaining mechanical, plumbing, and electrical systems and their features through cyclical cleaning and other appropriate measures.

- Preventing accelerated deterioration of mechanical systems by providing adequate ventilation of attics, crawl spaces, and cellars so that moisture problems are avoided.

- Improving the energy efficiency of existing mechanical systems to help reduce the need for elaborate new equipment. Consideration should be given to installing storm windows, insulating attic and crawl spaces, or adding awnings, if appropriate. 
Not Recommended...

- Failing to provide adequate protection of materials on a cyclical basis so that deterioration of mechanical systems results.

- Enclosing mechanical systems in areas that are not adequately ventilated so that deterioration of the system results.

- Installing unnecessary air conditioning or climate control systems, which can add excessive moisture to the building. This additional moisture can either condense inside, damaging interior surfaces, or pass through interior walls to the exterior, potentially damaging adjacent materials as it migrates.

\section{Repair}

Recommended...

- Repairing mechanical systems by augmenting or upgrading system parts, such as installing new pipes and ducts, rewiring, or adding new compressors or boilers.

- Replacing portions of components to ensure the original element is preserved (e.g., replacing porcelain sockets in light fixtures in lieu of replacing the entire light fixture).

Not Recommended...

- Replacing a mechanical system or its functional parts when it could be repaired and retained.

\section{Replace}

Recommended...

- Replace in-kind — or with compatible substitute material — those visible features of mechanical systems that are either extensively deteriorated or are prototypes such as ceiling fans, switch plates, radiators, grilles, or plumbing fixtures.

Not Recommended...

- Installing a replacement feature that does not convey the same visual effect as the original feature.

- Installing a new mechanical system so that character-defining structural or interior features are radically changed, damaged, or destroyed.

- Concealing mechanical equipment in walls or ceilings in a manner that requires the removal of historic building material.

- Installing a "dropped” acoustical ceiling to hide mechanical equipment when this destroys the proportions of character-defining interior spaces.

- Cutting through features such as masonry walls in order to install air-conditioning units.

- Radically changing the appearance of the historic building or damaging or destroying windows by installing heating/air-conditioning units in historic window frames. 


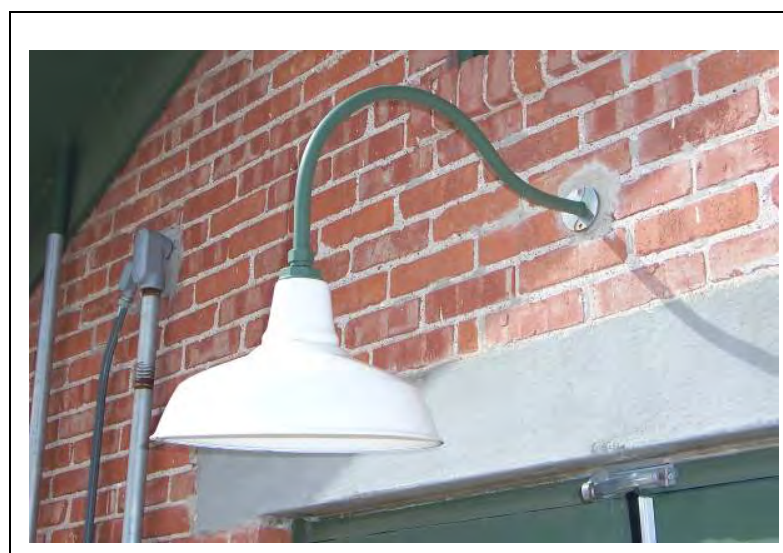

Building 13 - Age-appropriate replacement light fixture.

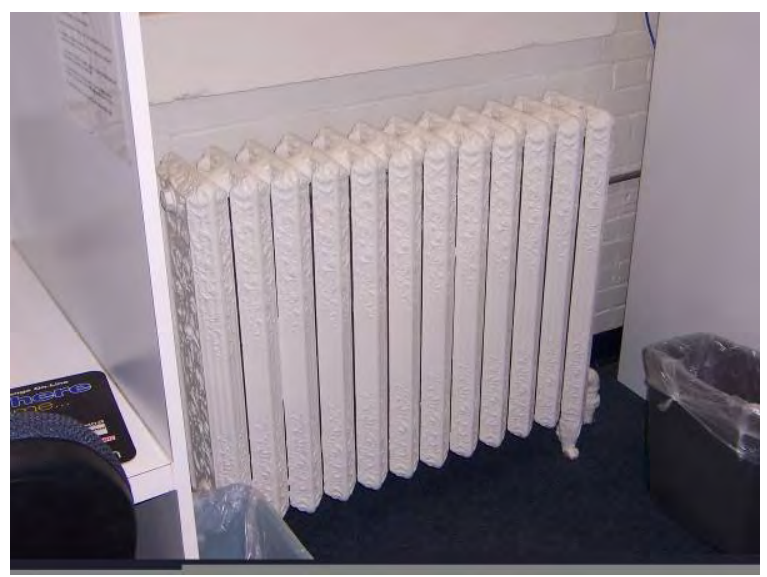

Building 55 - Original radiator; efforts should be made to maintain original radiators. If the radiator is no longer the source of heat, disconnect and leave in place.

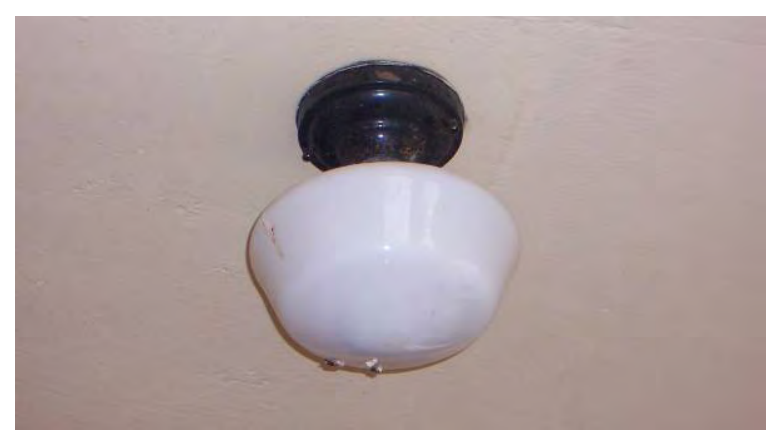

Building 515 - Original globe light fixture. Replacements should be in-kind to this style for interior light fixtures.

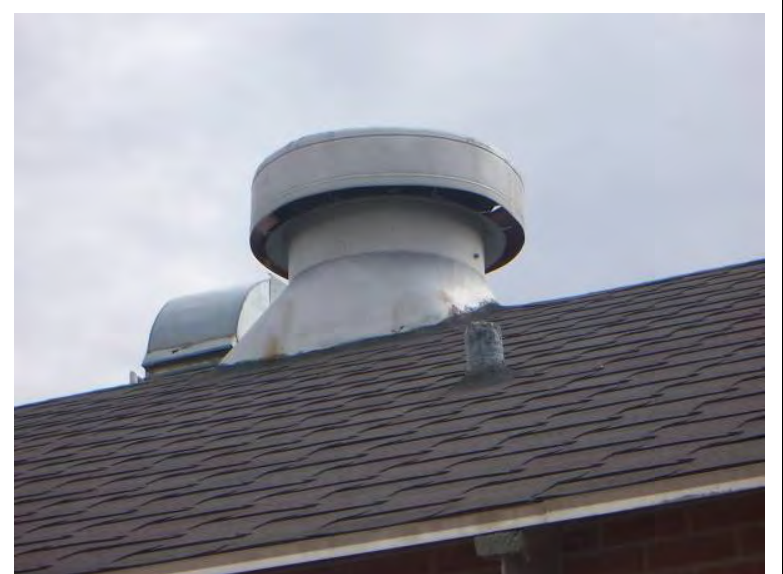

Building 624 - Original metal roof ventilator. Regular inspection and maintenance should be done on all roof/ventilation equipment. 


\section{Mechanical Systems: Lighting}

Identifying all of the light fixtures on both the interior and exterior of a building needs to be done first. Their identification needs to take place together with an evaluation of their condition early in project planning. Note whether each light fixture is historic to the building or if it has been replaced.

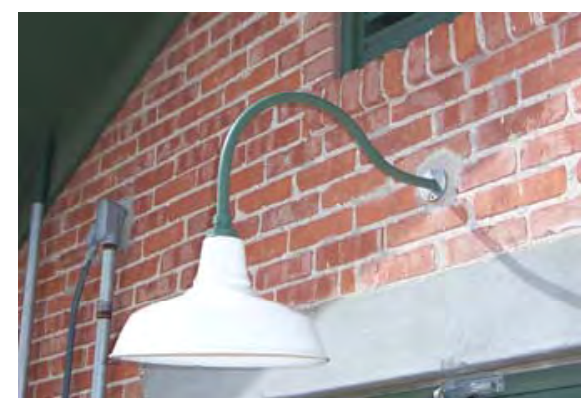

Building 613 - Good example of replacement exterior light fixture.

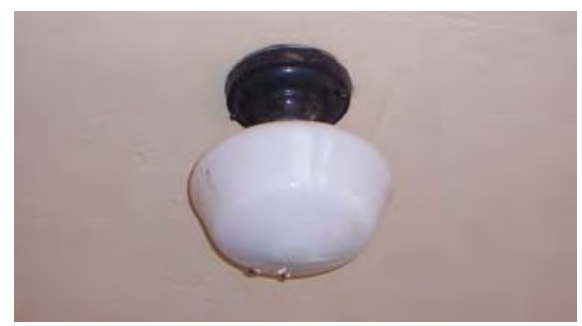

Building 515 - Good example of interior light fixture.

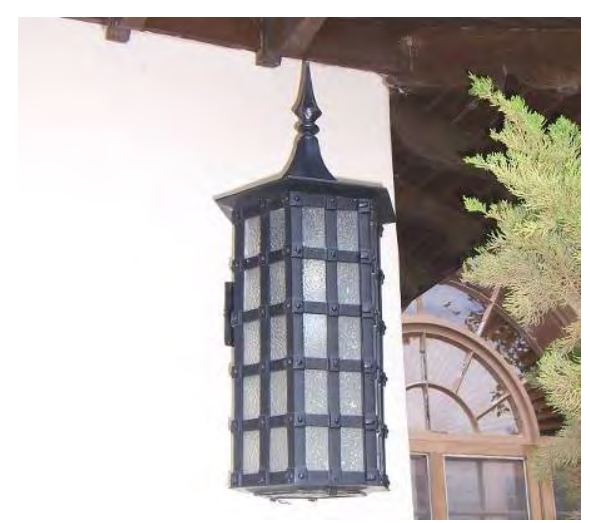

Building 243 - Good example of a decorative exterior light fixture.

\section{Inspection}

- Identify the light fixtures both on the interior and exterior of the building.

- Note whether each light fixture is historic or if it is a replacement.

- Note materials and the condition of each light fixture.

\section{Evaluation}

- If the light fixture is historic can it be repaired?

\section{Execution}

- If the light fixture is historic all measures of maintenance need to be used to repair this feature rather than replace it.

- $\quad$ Other light fixtures that have already been replaced on the building and do not conform to the style or type of historic light fixture used, need to be removed.

- Inappropriate light fixture types need to be replaced with age and style appropriate light fixture and if at all possible need to match the historic light fixture.

\section{Further Readings}

GSA has developed technical procedures to be used in specialized historic preservation work, as well as general evaluation, maintenance and repair of older building materials. For more detailed descriptions of repair procedures for lighting systems refer to the following, which can be found at http://w3.gsa.gov/web/p/hptp.nsf

- Guidelines for Rehabilitating Historic Buildings: Mechanical Systems

- Historical Mechanical Systems

- $\quad$ Construction Documents \& Specifications: Preservation \& Rehabilitation of Historic Lighting, Fort Bliss Manual 


\section{Repair}

It is highly recommended that the damaged historic light fixture be repaired rather than replaced.

\section{Replace}

Replace non-historic light fixtures to match the original whenever possible to conform to the character of the building. Care should be taken to ensure that new "period" light fixtures are similar in style and era to the architectural style of the building. There is a tendency to overstep this concept and choose light fixtures that may not be in the vocabulary of the architecture, installing an "old" looking fixture that is inappropriate to the actual period of the building. It is usually better and safer to be more conservative by choosing an understated modern piece that "disappears" into its environment. The following are a few examples of inappropriate and appropriate types of light fixtures found on some of Fort Bliss historic buildings. After all of the light fixtures have been identified as historic or replacement, the inappropriate light fixture replacements need to be removed and appropriate style and age fixtures need to be installed.

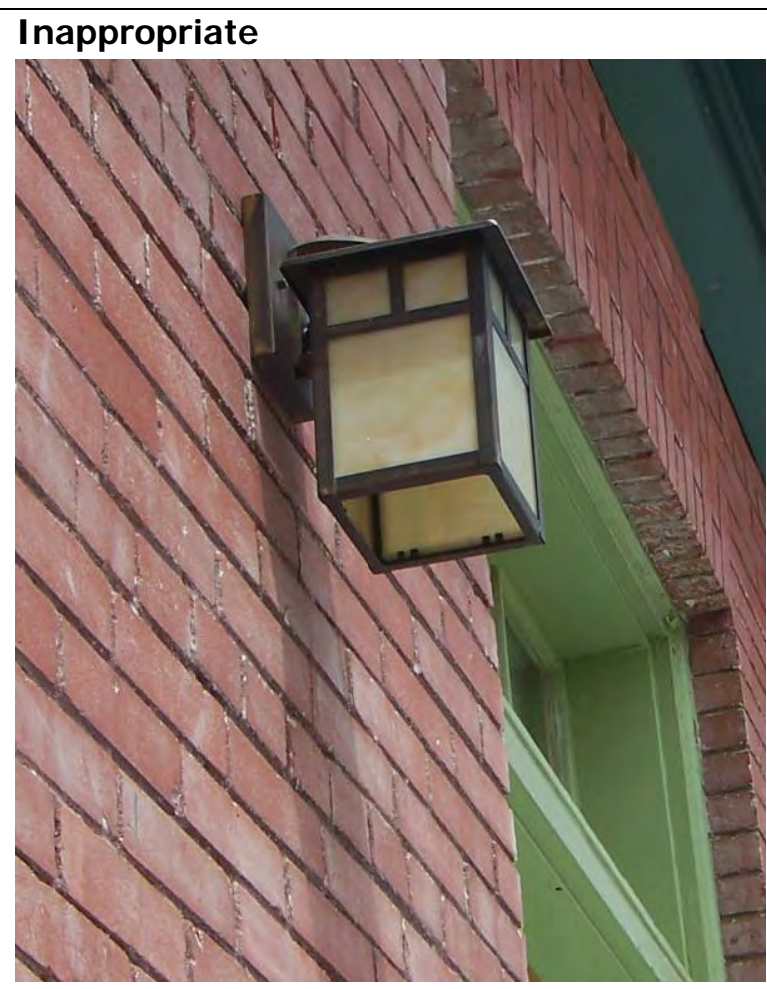

Building 4 - This craftsman-style light fixture is an inappropriate replacement. This type of light fixture needs to be replaced with a type of light more age appropriate to the building. A compatible replacement type would be similar in style to the light fixture located to the right, on a smaller scale.

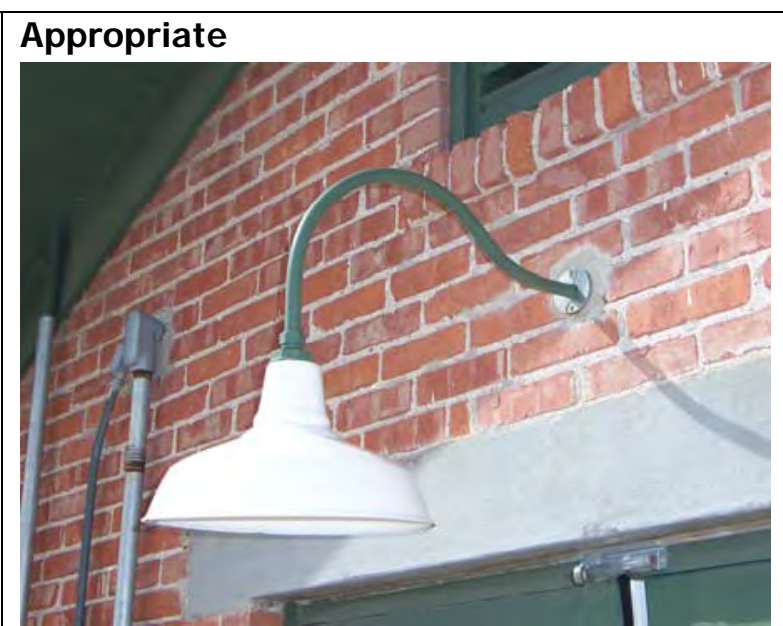

Building 444 - This simple metal light fixture with a porcelain shade is more of an age-appropriate replacement for brick buildings. 


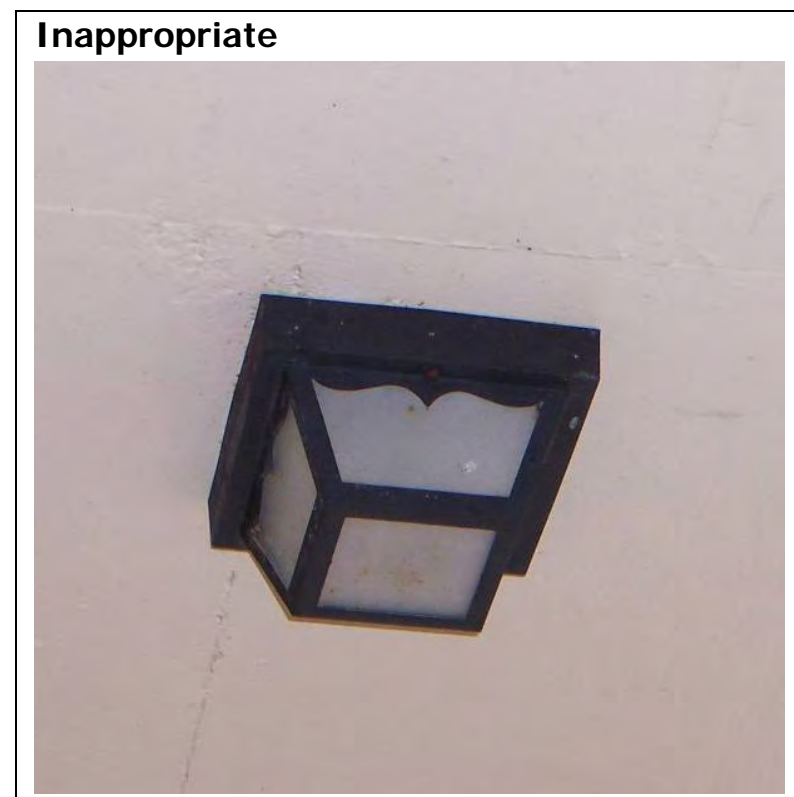

Building 504 - This light fixture is inappropriate. It is not an appropriate type of mounted ceiling light fixture for the historic buildings at Fort Bliss. This type of fixture should be removed and replaced with a fixture similar to the historic fixture located to the right.

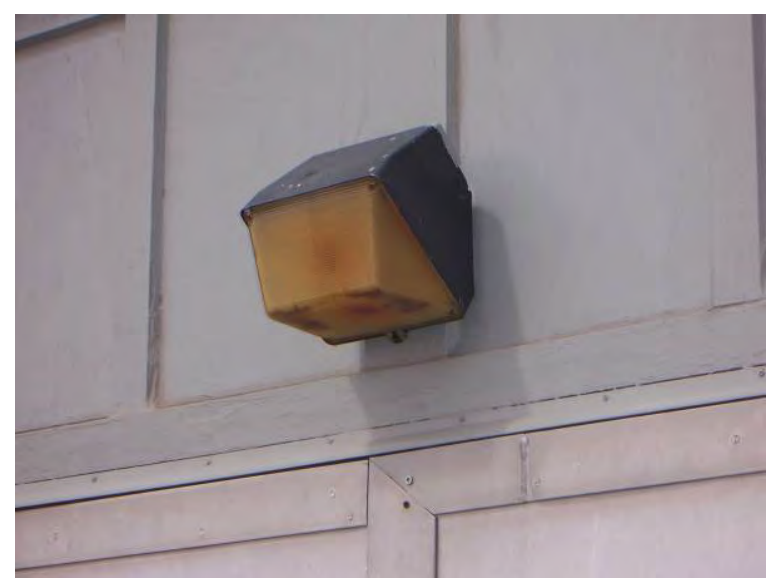

Building 624 - This light fixture is inappropriate and needs to be replaced.

\section{Appropriate}

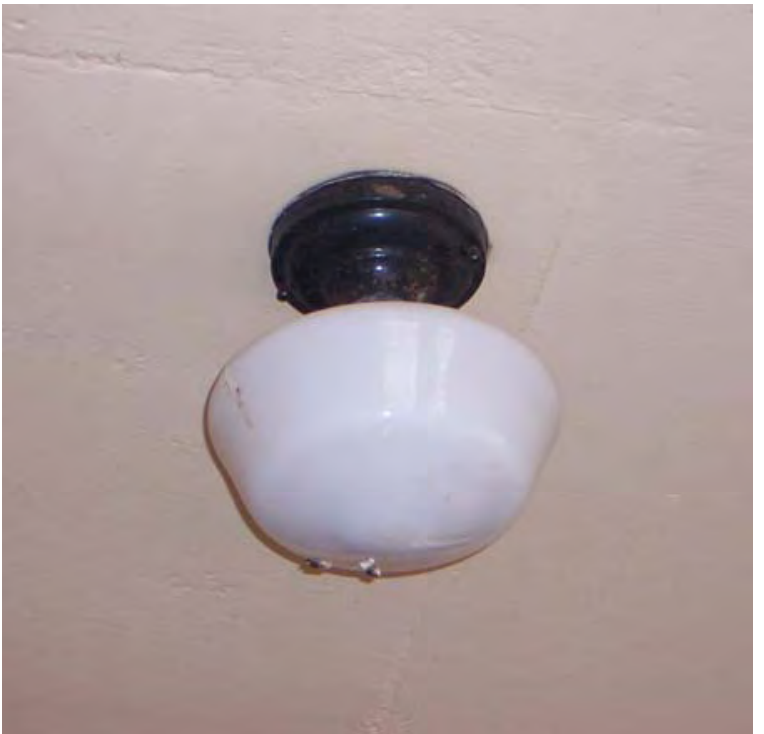

Building 515 - This mounted metal base and white globe historic light fixture is an appropriate example of what to follow when replacing a damaged or inappropriate light fixture.

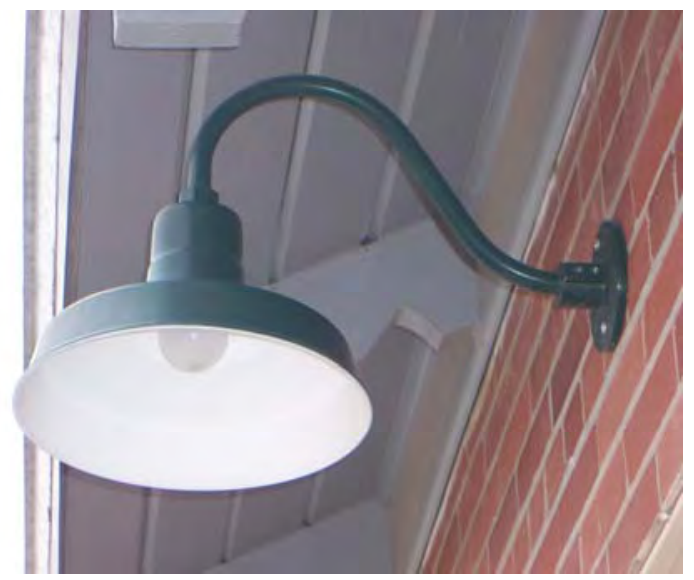

Building 613 - Although this is a replacement light fixture, it conforms to the style and is an age appropriate replacement. 


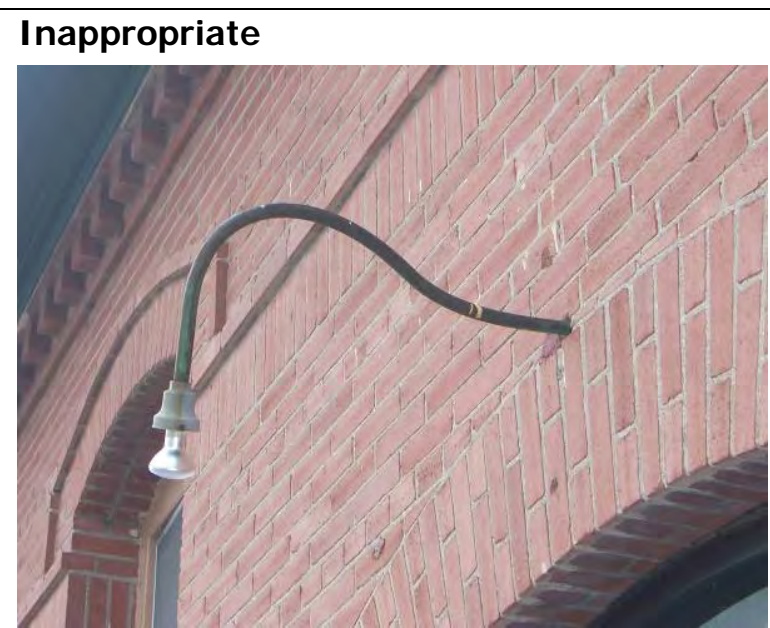

Building 55 - Original light fixture, but it is missing the original shade. Needs to be repaired with a shade like the one found on Building 613 .

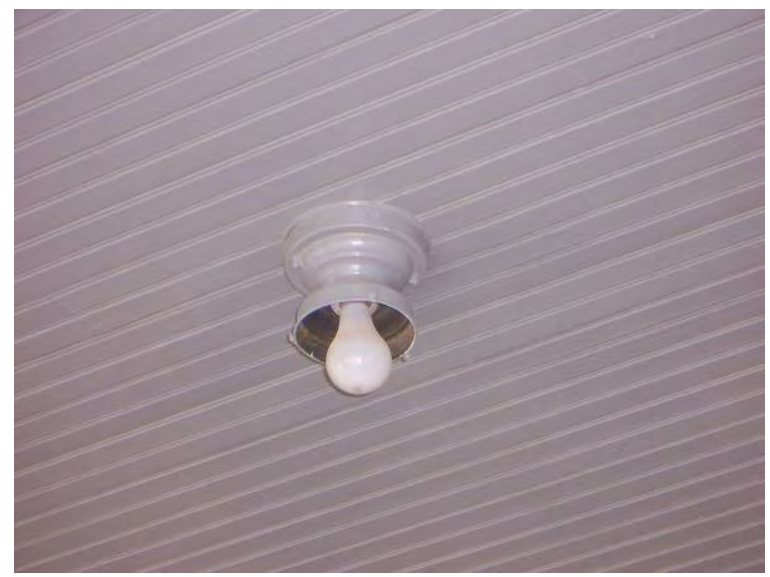

Building 629 - Original light fixture that is missing the globe. Needs to be repaired with an appropriate globe replacement similar to the one on Building 512.

\section{Appropriate}

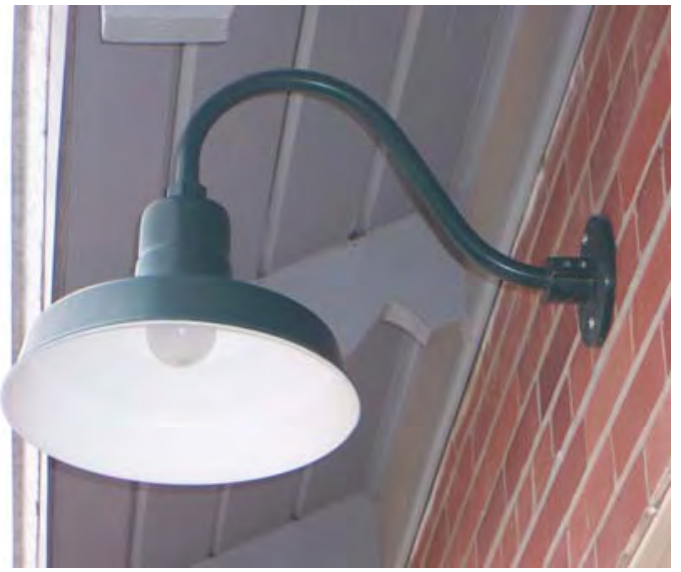

Building 613 - Although this is a replacement light fixture, it conforms to the style and is an age appropriate replacement.

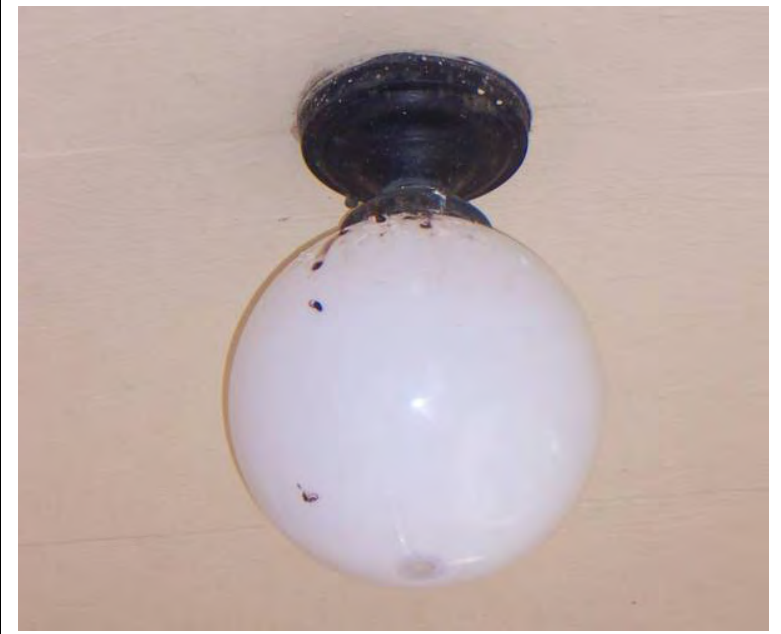

Building 512 - Good example of globe light fixture. 
The following two photographs are examples of replacement interior light fixtures. They are not original to the building; however, they are not completely inappropriate replacement fixtures. There should be some reference to the historical intent when evaluating the type and condition of the light fixtures and the course of direction.

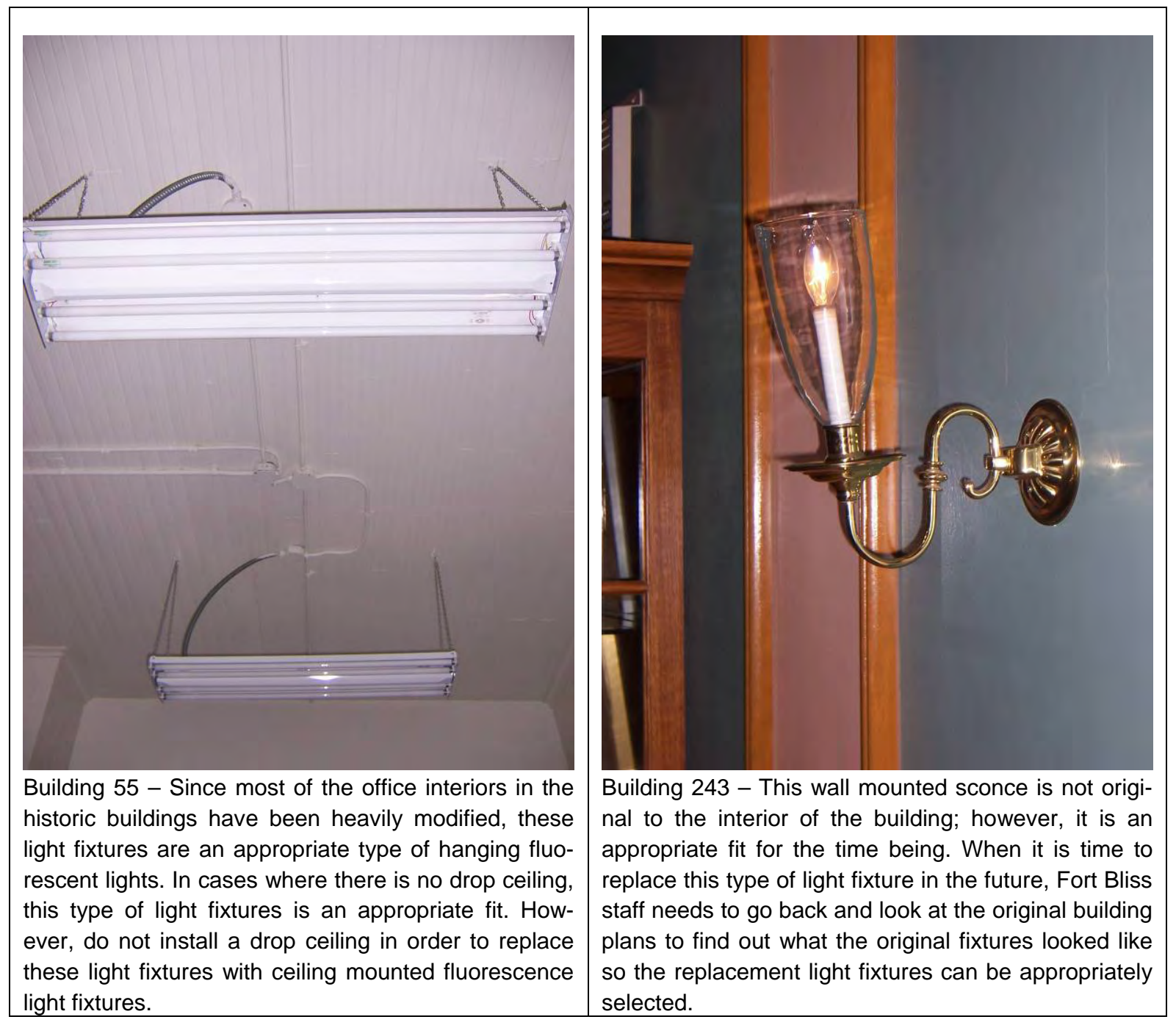


Notes

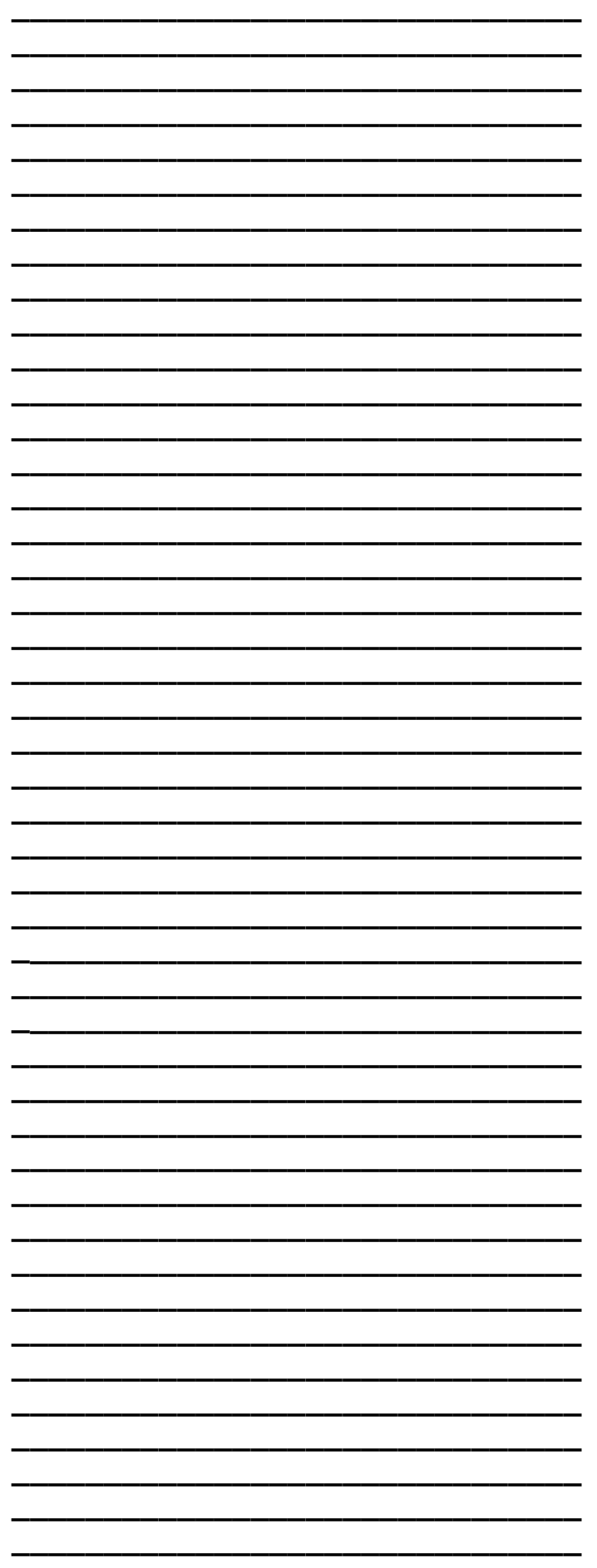


Groman, J ennifer and Susie Payne, Historic Resources Team, Conservation Division, Directorate of Environment, Fort Bliss. "The Fort Bliss Landscape Handbook for Historic Residences." Prepared for the Directorate of Environment, Fort Bliss, Texas, 2002.

"The Waterproofing Manual." Prepared for the Directorate of Environment- Conservation Division, Fort Bliss, Texas, 2004.

"The Adobe Manual." Prepared for the Directorate of Environment- Conservation Division, Fort Bliss, Texas, 2004. 


\section{REPORT DOCUMENTATION PAGE}

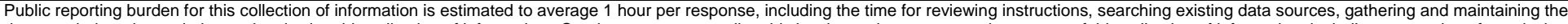

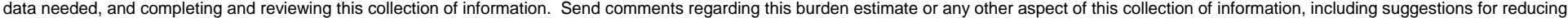

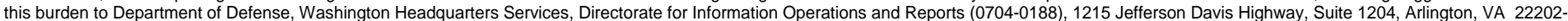

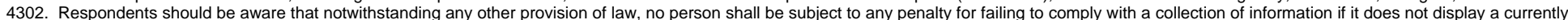
valid OMB control number. PLEASE DO NOT RETURN YOUR FORM TO THE ABOVE ADDRESS.
1. REPORT DATE (DD-MM-YYYY)
May 2008
2. REPORT TYPE
Final

Final

4. TITLE AND SUBTITLE

Fort Bliss Standards for the Treatment of Historic Buildings:

An Illustrated Maintenance and Repair Manual

DATES COVERED (From - To)

5a. CONTRACT NUMBER

5b. GRANT NUMBER

5c. PROGRAM ELEMENT NUMBER

6. AUTHOR(S)

Sunny Stone, Adam Smith, and Ryan Murphy

\section{5d. PROJECT NUMBER}

5e. TASK NUMBER

5f. WORK UNIT NUMBER

8. PERFORMING ORGANIZATION REPORT NUMBER

7. PERFORMING ORGANIZATION NAME(S) AND ADDRESS(ES)
U.S. Army Engineer Research and Development Center (ERDC)

Construction Engineering Research Laboratory (CERL)

ERDC/CERL SR-08-6

PO Box 9005

Champaign, IL 61826-9005

\section{SPONSORING I MONITORING AGENCY NAME(S) AND ADDRESS(ES)}

US Army Garrison Fort Bliss

10. SPONSOR/MONITOR'S ACRONYM(S)

ATZC-DOE-C

Directorate of Environment

Conservation Division

Bldg. 624 Pleasonton Rd.

11. SPONSOR/MONITOR'S REPORT

Fort Bliss, Texas 79916 NUMBER(S)

\section{DISTRIBUTION I AVAILABILITY STATEMENT}

Approved for public release; distribution is unlimited.

\section{SUPPLEMENTARY NOTES}

Copies are available from the National Technical Information Service, 5285 Port Royal Road, Springfield, VA 22161.

\section{ABSTRACT}

This report satisfies Section 110 of the National Historic Preservation Act (NHPA) of 1966 as amended and will help the Fort Bliss Cultural Resources Office and Directorate of Public Works in managing their historic building.

All buildings, especially historic ones, require regular planned maintenance and repair. The most notable cause of historic building element failure and/or decay is not due to the fact that the historic building is old, but rather is caused by an incorrect or inappropriate repair and/or basic neglect of the historic building fabric.

Maintaining historic buildings and keeping a log of completed repairs and maintenance can help in:

- $\quad$ Reducing the cost of maintenance in the long run

- Increasing the life of the building and its elements

- $\quad$ The efficient use of the building and its elements

- $\quad$ Safety and security

- $\quad$ Compliance with Federal and DoD historic preservation regulations.

\section{SUBJECT TERMS}

Fort Bliss, TX

historic preservation
National Register of Historic Places (NRHP) historic buildings cultural resources management maintenance

\section{SECURITY CLASSIFICATION OF:}

\section{a. REPORT}

Unclassified

\section{b. ABSTRACT}

Unclassified c. THIS PAGE

Unclassified

17

17. LIMITATION
OF ABSTRACT
SAR

NSN 7540-01-280-5500

\begin{tabular}{l|} 
OF. NUMBER \\
OF PAGES \\
\cline { 2 - 2 } \\
309
\end{tabular}

19a. NAME OF RESPONSIBLE PERSON

19b. TELEPHONE NUMBER (include area code) 